\title{
The MARine Biogeochemistry of Dissolved ANd Colloidal Iron
}

\author{
By \\ Jessica Nicole Fitzsimmons \\ B.A., Boston University, 2008 \\ Submitted in partial fulfillment of the requirements for the degree of \\ Doctor of Philosophy \\ at the \\ MASSACHUSETTS INSTITUTE OF TECHNOLOGY \\ and the \\ WOODS HOLE OCEANOGRAPHIC INSTITUTION
}

September 2013

(C) 2013 Jessica N. Fitzsimmons

All rights reserved.

The author hereby grants to MIT and WHOI permission to reproduce and to distribute publicly paper and electronic copies of this thesis document in whole or in part in any medium now known or hereafter created.

Author:

Jessica N. Fitzsimmons

Joint Program in Chemical Oceanography

Massachusetts Institute of Technology and Woods Hole Oceanographic Institution

August 22nd, 2013

Certified by:

Edward A. Boyle

Professor of Ocean Geochemistry, MIT

Thesis Supervisor

Accepted by:

Elizabeth B. Kujawinski

Associate Scientist in Marine Chemistry \& Geochemistry, WHOI

Chair, Joint Committee for Chemical Oceanography 


\title{
The Marine Biogeochemistry of Dissolved and Colloidal Iron
}

\author{
By \\ Jessica Nicole Fitzsimmons \\ Submitted to the MIT/WHOI Joint Program in Oceanography in August, 2013, in partial \\ fulfillment of the requirements for the degrees of Doctor of Philosophy
}

\begin{abstract}
Iron is a redox active trace metal micronutrient essential for primary production and nitrogen acquisition in the open ocean. Dissolved iron ( $\mathrm{dFe})$ has extremely low concentrations in marine waters that can drive phytoplankton to Fe limitation, effectively linking the $\mathrm{Fe}$ and carbon cycles. Understanding the marine biogeochemical cycling and composition of $\mathrm{dFe}$ was the focus of this thesis, with an emphasis on the role of the size partitioning of $\mathrm{dFe}(<0.2 \mu \mathrm{m})$ into soluble $(\mathrm{sFe}<0.02 \mu \mathrm{m})$ and colloidal

$(0.02 \mu \mathrm{m}<\mathrm{cFe}<0.2 \mu \mathrm{m})$ size fractions. This was accomplished through the measurement of the $\mathrm{dFe}$ distribution and size partitioning along basin-scale transects experiencing a range of biogeochemical influences.

$\mathrm{dFe}$ provenance was investigated in the tropical North Atlantic and South Pacific Oceans. In the North Atlantic, elevated $\mathrm{dFe}(>1 \mathrm{nmol} / \mathrm{kg})$ concentrations coincident with the oxygen minimum zone were determined to be caused by remineralization of a high $\mathrm{Fe}: \mathrm{C}$ organic material (vertical flux), instead of a laterally advected low oxygen-high $\mathrm{dFe}$ plume from the African margin. In the South Pacific Ocean, dFe maxima near $2000 \mathrm{~m}$ were determined by comparison with dissolved manganese and ${ }^{3} \mathrm{He}$ to be caused by hydrothermal venting. The location of these stations hundreds to thousands of kilometers from the nearest vents confirms the "leaky vent" hypothesis that enough $\mathrm{dFe}$ escapes precipitation at the vent site to contribute significantly to abyssal $\mathrm{dFe}$ inventories.

The size partitioning of $\mathrm{dFe}$ was also investigated in order to trace the role of $\mathrm{dFe}$ composition on its cycling. First, the two most commonly utilized methods of sFe filtration were compared: cross flow filtration (CFF) and Anopore filtration. Both were found to be robust $\mathrm{sFe}$ collection methods, and sFe filtrate through $\mathrm{CFF}(10 \mathrm{kDa})$ was found to be only $74 \pm 21 \%$ of the sFe through Anopore $(0.02 \mu \mathrm{m})$ filters at 28 locations, a function of both pore size differences and the natural variability in distribution of $10 \mathrm{kDa}-$ $0.02 \mu \mathrm{m}$ colloids. In the North Atlantic, a colloidal-dominated partitioning was observed in the surface ocean underlying the North African dust plume, in and downstream of the TAG hydrothermal system, and along the western Atlantic margin. However, cFe was depleted or absent at the deep chlorophyll maximum. A summary model of dFe size partitioning in the North Atlantic open ocean is presented in conclusion, hypothesizing that a constant $\mathrm{dFe}$ exchange between soluble and colloidal pools modulates the constant partitioning of nearly $50 \% \mathrm{dFe}$ into the colloidal phase throughout the subsurface North Atlantic Ocean, while sFe and cFe cycle independently in the upper ocean.
\end{abstract}

Thesis supervisor: Edward A. Boyle, Professor of Ocean Geochemistry, MIT 


\section{Acknowledgements}

First and foremost, I would like to thank my advisor, Ed, for his guidance and support for this thesis project. Ed allowed me independence in my science, which I never knew I wanted but now I know I could never live without. He provided me with endless support and incredible opportunities: as long as I could back-up my ideas with sound reasoning, he acted as if he didn't know the word "no." I was so lucky to travel internationally not only on six research cruises but also to many conferences worldwide. Ed was eternally optimistic, and when he had to criticize or remind me to relax, he always did it gently, which I appreciated so much.

I also thank my committee, who not only provided me professional advice and mentorship but also gave me incredible inspiration. I realize that students in other disciplines have anxiety over their thesis committee meetings, but I was always excited for mine. I knew that I would leave that room more invigorated about my science than when I entered. My committee improved the quality and direction of my work so much, and to them I am very grateful.

I am also very grateful to the numerous collaborators and field teams who made this journey so much fun. I thank the U.S. GEOTRACES family, to whom I owe much of my training in trace metal sampling and analysis and cruise leadership, and especially Pete, Randie, Sara, Kaitlin, Chris, Katharina, and Geo for the endless laughter. I was also lucky enough to be a part of the C-MORE family, who provided me with luxurious cruise opportunities and the freedom to explore in detail things I might not have had time for on other cruises. This was a particularly rewarding learning experience.

I also owe a HUGE thanks to the Boyle lab and Joint Program. Rick, Jong-Mi, Ruifeng, Yolanda, Gonzalo, Rene, Abigail, and Simone - I was so lucky to develop a special friendship with each of you, and while you all taught me something about science, more importantly you taught me how to be a better me, both personally and professionally. Thanks so much for picking me up on my lowest days and reminding me how great research can be! Special thanks also to my Joint Program friends, especially Meagan, Emily, Britta, and Evan, and to my MIT buddies Sara, Anthony, and Oscar - you all made grad school a fun place to be. Also to the JP Academic Programs Office and the E25 Administrative Assistants (especially Julia, Meg, and Mary) - you gals were incredible. Not only were you there each and every time I had a stupid bureaucratic question, but you were always good for a pick-me-up. You are the ladies who make things happen, and I would have been lost with you.

Finally, I thank my parents, Nick and Jade, Dana, the 3rd Floor Girls (Irina, Erin, Sarah, Smita, and Julia), Alli, and most importantly, my husband. What do I thank you for? EVERYTHING. For the daily laughter, love, care, support, and fun times. You all reminded me to breathe when I was down, shook me when I was crazy, danced with me when I needed a smile, and floated with me when I was sky high. To my parents: you always told me that I could do anything if I worked hard enough, and you were by my side every step of this journey with all the love and support you could muster. Thank you, and I love you guys so much. And to my huband: I would never have made it through this journey without you, nor would I have wanted to. You are my rock, my everything, and I can't wait for our next adventure. I love you.

Funding for this research was provided by an MIT Presidential Fellowship, an NSF Graduate Research Fellowship (\# 0645960), a fellowship from the Martin Family Society of Fellows for Sustainability, several NSF Chemical Oceanography grants (OCE-0751409, OCE-07020278, OCE0926204, and OCE-0926197), and the Center for Microbial Oceanograhy: Research and Education (NSF OIA \#EF-0424599). 


\section{Table of Contents}

Chapter 1: Introduction $\quad 13$

1.1 Dissolved Fe composition and biogeochemistry 14

$\begin{array}{ll}\text { 1.2 Marine colloid chemistry } & 19\end{array}$

$\begin{array}{ll}1.3 \text { The bioavailability of colloidal Fe } & 22\end{array}$

1.4 Marine colloidal Fe distributions and biogeochemistry 23

1.5 Dissertation outline and chapter descriptions 26

$\begin{array}{ll}\text { References for Chapter } 1 & 30\end{array}$

Chapter 2: An intercalibration between the GEOTRACES GO-FLO and the MITESS/Vanes sampling systems for dissolved iron concentration analyses (and a closer look at adsorption effects)

2.1 Introduction $\quad 40$

2.2 Methods $\quad 42$

2.2.1 Cleaning procedures $\quad 42$

2.2.2 Sample collection $\quad 43$

2.2.3 Adsorption experiment 43

2.2.4 Headspace experiment 44

$2.2 .5 \mathrm{dFe}$ analyses $\quad 44$

2.3 Assessment $\quad 45$

2.3.1 Adsorption experiment $\quad 46$

2.3.2 Headspace - $\mathrm{CO}_{2}$ loss experiment 49

2.4 Discussion $\quad 50$

2.5 Comments and Recommendations $\quad 52$

References for Chapter 2

Chapter 3: Dissolved iron in the tropical North Atlantic Ocean 55

3.1 Introduction $\quad 56$

$\begin{array}{ll}3.2 \text { Methods } & 57\end{array}$

3.2.1 Seawater sampling $\quad 57$

3.2.2 Nutrient measurements $\quad 57$

$\begin{array}{ll}3.2 .3 \mathrm{dFe} \text { measurement } & 57\end{array}$

3.2.4 Dissolved manganese measurement 58

$\begin{array}{ll}3.3 \text { Results and Discussion } & 58\end{array}$

3.3.1 Surface dFe distribution $\quad 58$

3.3.2 Water column dFe distribution $\quad 59$

3.3.2.1 Regional circulation of the tropical North Atlantic 59

3.3.2.2 Upper $1000 \mathrm{~m}$ dFe distribution $\quad 60$

3.3.2.3 Station 13 full water column $\mathrm{dFe}$ distribution $\quad 61$

3.3.3 dFe provenance in the tropical North Atlantic OMZ 64

3.3.4 Effects of future deoxygenation on $\mathrm{dFe}$ in the tropical North Atlantic OMZ 66

3.4. Conclusions 66 
$\begin{array}{ll}\text { References for Chapter } 3 & 67\end{array}$

Supplementary Material 3A: 1-D Fe model including scavenging 69

Supplementary Material 3B: Data from Chapter $3 \quad 74$

Chapter 4: Distal transport of dissolved hydrothermal iron in the deep South Pacific Ocean

4.1 Introduction, Results, and Discussion $\quad 80$

$\begin{array}{ll}\text { 4.2 Methods } & 86\end{array}$

$\begin{array}{lr}\text { References for Chapter } 4 & 89\end{array}$

Supplementary Material for Chapter $4 \quad 95$

Chapter 5: Assessment and comparison of Anopore ${ }^{\mathrm{TM}}$ and cross flow filtration methods for the determination of dissolved iron size fractionation $\begin{array}{ll}\text { into soluble/colloidal phases in seawater } & \mathbf{1 0 7}\end{array}$

$\begin{array}{ll}5.1 \text { Introduction } & 111\end{array}$

$\begin{array}{ll}5.2 \text { Methods } & 113\end{array}$

5.2.1 Anopore $^{\mathrm{TM}}$ filtration $\quad 113$

5.2.2 Cross flow filtration (ultrafiltration) $\quad 114$

$\begin{array}{ll}\text { 5.2.3 Sample collection } & 116\end{array}$

$\begin{array}{ll}5.2 .4 \mathrm{Fe} \text { analyses } & 117\end{array}$

$\begin{array}{ll}5.3 \text { Assessment } & 118\end{array}$

$\begin{array}{ll}\text { 5.3.1 } \text { Anopore }^{\mathrm{TM}} \text { filtration } & 118\end{array}$

$\begin{array}{ll}\text { 5.3.2 Cross flow filtration (ultrafiltration) } & 121\end{array}$

5.3.3 Comparison of Anopore filtration with CFF 125

5.4 Discussion

5.5 Conclusions and recommendations 131

$\begin{array}{ll}\text { References for Chapter } 5 & 134\end{array}$

Chapter 6: Both soluble and colloidal iron phases control dissolved iron variability in the tropical North Atlantic Ocean 145

$\begin{array}{lr}6.1 \text { Introduction } & 149\end{array}$

6.2 Sampling \& Analysis Methodology 151

6.3 Results \& Discussion 152

6.3.1 Surface distribution $\quad 152$

6.3.2 Water column profiles $\quad 155$

6.3.2.1 Euphotic zone $\quad 155$

6.3.2.2 Upper $1000 \mathrm{~m} \quad 157$

6.3.2.3 Deep ocean 159

6.3.3 Controls on dissolved Fe variability $\quad 160$

$\begin{array}{ll}6.4 \text { Conclusions } & 164\end{array}$

$\begin{array}{ll}\text { References for Chapter } 6 & 165\end{array}$

$\begin{array}{ll}\text { Supplemental Data from Chapter 6 } & 174\end{array}$ 
Chapter 7: Partitioning of dissolved iron into soluble and colloidal phases along the U.S. GEOTRACES North Atlantic Zonal transect 177

$\begin{array}{lc}7.1 \text { Introduction } & 178\end{array}$

$\begin{array}{lr}7.2 \text { Methods } & 180\end{array}$

$\begin{array}{ll}7.3 \text { Results \& Discussion } & 182\end{array}$

7.3.1 dFe size partitioning from the major Fe sources 183

7.3.1.1 Aerosol deposition: the surface ocean 183

7.3.1.2 Eastern margin: Mauritanian oxygen minimum zone187

7.3.1.3 Western boundary (Line W) 188

7.3.1.4 TAG hydrothermal system 191

7.3.2 dFe size partitioning due to internal ocean dFe cycling 193

7.3.2.1 Deep chlorophyll maximum 194

7.3.2.2 Remineralization $\quad 197$

7.3.2.3 Deep ocean 199

7.3.3 Consensus on dFe partitioning in the North Atlantic 201

$\begin{array}{ll}7.4 \text { Conclusions } & 206\end{array}$

$\begin{array}{ll}\text { References for Chapter } 7 & 208\end{array}$

Appendix I: Dissolved iron distribution, size partitioning, and stable isotopes in the Southeast Pacific Ocean

References for Appendix I

Appendix II: Iron chemistry at the TAG hydrothermal field $\mathbf{2 4 3}$

$\begin{array}{ll}\text { Introduction } & 243\end{array}$

$\begin{array}{ll}\text { Methods } & 244\end{array}$

$\begin{array}{ll}\text { Results and Discussion } & 245\end{array}$

References for Appendix II 251

Appendix III: Size partitioned dissolved iron isotopes and ligands in the $\begin{array}{ll}\text { North Atlantic Ocean } & 253\end{array}$

Introduction $\quad 253$

Site selection and methodology $\quad 255$

$\begin{array}{ll}\text { Results and Discussion } & 257\end{array}$

Size partitioning of Fe-binding ligands $\quad 258$

Size fractionated dissolved Fe isotopes $\quad 261$

$\begin{array}{ll}\text { Referneces for Appendix III } & 267\end{array}$

Appendix IV: Temporal variability of dissolved iron at Station ALOHA 271

$\begin{array}{ll}\text { References for Appendix IV } & 275\end{array}$ 


\section{List of Figures}

\section{Chapter 1}

$\begin{array}{ll}\text { Figure 1. The marine Fe cycle } & 15\end{array}$

Figure 2. Summary of the size partitioning of Fe into soluble, colloidal, and particulate size fractions

\section{Chapter 2}

Figure 1. Sampling devices used in the intercalibration 41

Figure 2. Experimental design flowchart 44

Figure 3. dFe profile intercalibration using MITESS/Vanes and GEOTRACES GO-FLO bottles at the SAFe station 46

Figure 4. Kinetics of adsorption to bottle walls results 48

Figure 5. Headspace Experiment results $\quad 49$

\section{Chapter 3}

Figure 1. Tropical North Atlantic cruise transect $\quad 57$

Figure 2. Surface water dFe distribution and literature review 58

Figure 3. 3-D visualization of the dFe distribution 60

Figure 4. Temperature-salinity diagram for the cruise transect 61

Figure 5. 2-D visualization of the dFe distribution 62

Figure 6. dFe distribution near the Cape Verde Islands 63

Figure 7. Profile of dFe, dMn, phosphate, and dissolved oxygen (Station 13) 63

Figure 8. dFe-AOU correlation across the transect 63

Figure 9. dMn distribution 64

Figure 10. Non-dimensionalized results of the dFe-dissolved oxygen model 65

Figure 11. dFe as a function of dissolved oxygen along the cruise transect 66

Figure S1. Modeled vs. measured dissolved oxygen concentrations at $500 \mathrm{~m} \quad 70$

Figure S2. Modeleled vs. measured dFe at 500m (no scavenging) 71

Figure S3. Modeled vs. measured dFe at 500m (with scavenging) 72

\section{Chapter 4}

Figure 1. $\mathrm{dFe},{ }^{3} \mathrm{He}$, and dMn profiles at three Pacific Ocean stations 92

Figure 2. Size partitioning of dFe into soluble and colloidal phases 93

Figure 3. Distal hydrothermal $\mathrm{dFe}^{\beta} \mathrm{He}$ ratios $\quad 94$

Figure S1. Map of South Pacific station locations 95

Figure S2. Fe-AOU relationships in the South Pacific 97

\section{Chapter 5}

Figure 1. Station locations and filter type of all published dFe size partitioning studies in the global ocean 
Figure 2. Anopore ${ }^{\mathrm{TM}}$ and cross flow filtration geometries $\quad 140$

Figure 3. Results from the Anopore ${ }^{\mathrm{TM}}$ clog experiment 141

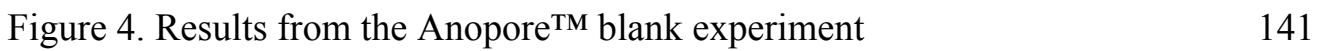

Figure 5. Cross flow filtration mass balances (by volume and flow rate) 142

Figure 6. Soluble Fe comparison using CFF and Anopore ${ }^{\mathrm{TM}}$ filtration 142

Figure 7. Soluble $\mathrm{Fe}$ comparison using $\mathrm{CFF}$ and Anopore $^{\mathrm{TM}}$ filtration at TENATSO

\section{Chapter 6}

Figure 1. Tropical North Atlantic cruise track with size partitioning stations indicated

Figure 2. dFe size partitioning in the surface ocean by longitude 170

Figure 3. Euphotic zone dFe size partitioning in the subtropical gyre and OMZ 170

Figure 4. dFe size partitioning to $1000 \mathrm{~m}$ in the tropical North Atlantic 171

Figure $5 . \mathrm{dFe}$ and $\mathrm{sFe}$ concentrations at $500 \mathrm{~m}$ depth by oxygen concentration 172

Figure 6. Full depth profile of dFe size partitioning at Station 13 and comparison to the size partitioning profile of Bergquist et al. (2007) 173

$\begin{array}{ll}\text { Figure 7. dFe-sFe-cFe partitioning plots } & 174\end{array}$

\section{Chapter 7}

Figure 1. GEOTRACES North Atlantic Zonal Transect station map 214

Figure 2. Distributions of dFe, $\mathrm{sFe}, \mathrm{cFe}$, and \%cFe across GEOTRACES NAZT 215

Figure 3. Surface dFe size partitioning and Fe(II) concentrations 216

Figure 4. Mauritanian OMZ transect distributions of dFe, $\mathrm{sFe}, \mathrm{cFe}$, and \%cFe 217

Figure 5. dFe size partitioning comparison of $\mathrm{CFF}$ and Anopore ${ }^{\mathrm{TM}}$ filtration at TENATSO

Figure 6. dFe size partitioning and Fe(II) at Station 14, northwest of TAG 219

Figure 7. dFe size partitioning at the deep chlorophyll maximum 220

Figure 8. dFe, sFe, and cFe relationships with AOU 221

Figure 9. Full depth profiles of dFe size partitioning 222

Figure 10. dFe-sFe-cFe partitioning plots 223

Figure 11. Proposed model of dFe size partitioning in the North Atlantic 225

\section{Appendix I}

$\begin{array}{ll}\text { Figure 1. Map of BiG RAPA station locations } & 230\end{array}$

Figure 2. Salinity and water mass distribution along BiG RAPA 231

Figure 3. Hydrography and nutrient distribution along BiG RAPA 232

Figure 4. dFe distribution in the upper 400m of BiG RAPA 233

Figure 5. Surface dFe distribution and size partitioning 234

Figure 6. Station 1 OMZ Fe chemistry and hydrography 235

Figure 7. dFe distribution in the upper 1000m of BiG RAPA 236

Figure 8. dFe relationships with oxygen and AOU 236 
Figure 9. dFe isotopes at Stations 1, 4, and 7 along BiG RAPA

\section{Appendix II}

Figure 1. TAG transmissometry, dFe, and dMn data 248

Figure 2. Fe chemistry at TAG as a function of dMn (dilution proxy) 249

Figure 3. Fe physico-chemical speciation at TAG 250

\section{Appendix III}

Figure 1. The size partitioning of $\mathrm{dFe}$ and dFe-binding ligands 264

Figure 2. Measured sFe/dFe vs. modeled sFe/dFe 265

Figure 3. Hydrography, dFe size partitioning, and dFe isotope partitioning 266

\section{Appendix IV}

Figure 1. Surface dFe concentration time-series at Station ALOHA 272

Figure 2. Euphotic zone profile of dFe at Station ALOHA 273

Figure 3. $\mathrm{dFe}$ isotopic composition in intermediate waters of Station ALOHA 274 


\section{List of Tables}

\section{Chapter 2}

Table 1. MITES/Vanes vs. GO-FLO dFe intercalibration results 45

$\begin{array}{ll}\text { Table 2. Adsorption kinetics results } & 47\end{array}$

Table 3. Estimated contribution of bottle adsorption during the Headspace

Experiment

\section{Chapter 3}

Table 1. Summary of Fe:C ratios and pre-formed dFe 64

Table S1. Measured data and estimated constant used in the model 73

$\begin{array}{ll}\text { Table SB. Chapter } 3 \text { data summary } & 74\end{array}$

\section{Chapter 4}

$\begin{array}{ll}\text { Table S1. Chapter } 4 \text { data summary } & 102\end{array}$

\section{Chapter 5}

Table 1. Effect of cFe calculation equation on dFe partitioning 138

Table 2. Summary recommendations for Anopore vs. CFF usage 138

\section{Chapter 6}

$\begin{array}{ll}\text { Table S1. Chapter } 6 \text { data summary } & 175\end{array}$

\section{Chapter 7}

Table 1. Analytical merits of dFe and sFe methodology 226

Table 2. dFe:C, sFe:C and pre-formed Fe summary 227

\section{Appendix III}

Table 1. Surface $\mathrm{dFe}, \mathrm{sFe}$, and $\mathrm{cFe}$ concentrations and isotopes 


\section{Chapter 1}

\section{Introduction}

Iron $(\mathrm{Fe})$ is an essential micronutrient for marine phytoplankton, required for enzymes involved in nitrogen assimilation, remineralization, and the photosynthetic apparatus (MOREL et al., 2003). Though it is the fourth most abundant element in the Earth's crust, Fe has very low (picomolar to nanomolar) concentrations in the ocean because of its low solubility in oxygenated waters. This has led to model estimates that nearly $40 \%$ of surface ocean phytoplankton growth is limited by Fe (MOORE and BRAUCHER, 2008; MOORE et al., 2002). As a result, marine Fe concentrations directly impact global climate by modulating the productivity of the phytoplankton that fix carbon dioxide and sequester carbon into the abyssal oceans. It is therefore imperative to study and understand the chemical form, bioavailability, and cycling of Fe in ocean in order to understand how external sources and sinks and internal cycling of Fe may affect the ocean ecosystem and global climate.

Over the last three decades, the chemical oceanography community has made great strides in the exploration of marine Fe distributions and cycling. Before this, marine Fe data were plagued by contamination acquired during both sample collection and analysis, since ubiquitous dust and the ships/equipment used to sample seawater can all be Fe rich. These contamination problems were overcome with the use of non-metal sampling bottles and hydrowires at sea, and HEPA-filters were added to trace metal laboratories to produce a clean working environment during analysis. While these efforts allowed for the first high-quality marine Fe datasets, our exploration of marine $\mathrm{dFe}$ was still prohibitively data-poor, since only single profiles offering limited global applicability were produced by the time-consuming early trace metal analytical methods (BRULAND and RUE, 2001). Over the last 20 years with the advancements in inductivelycoupled plasma mass spectrometry (ICP-MS) detection limits and precision (BILLER and 
Bruland, 2012; LAGERSTROM et al., 2013; LeE et al., 2011; Wu and Boyle, 1998) and the development of automated flow-injection methods for both Fe extraction (MILNE et al., 2010) and Fe detection (MEAsures et al., 1995; OBATA et al., 1993), Fe measurements in seawater today are relatively routine, require less sample volume, and have high-throughput capacity. The accuracy and precision of marine Fe data are at their zenith as a result of the development of appropriate standard reference materials by the SAFe and GEOTRACES intercalibration projects (JOHNSON et al., 2007). Even sample collection is less spatially limited with the success of the international GEOTRACES program, which seeks to map the global distribution of marine trace elements and isotopes and identify the processes that regulate those distributions.

In this thesis, sampling was focused on state-of-the-art, basin-scale transects and high-throughput Fe analysis using ICP-MS in order to explore marine $\mathrm{dFe}$ biogeochemistry. Three dFe transects were acquired: the OC449-2 tropical North Atlantic transect (Chapter 3 and 6), the BiG RAPA Southeast Pacific transect (Chapter 4 and Appendix I), and the GEOTRACES North Atlantic Zonal transect (Chapter 7 and Appendices II and III). Opportunistic sampling, methods development, and experiments were also conducted at Station ALOHA and the SAFe station on the GEOTRACES Pacific Intercalibration cruise (Chpater 2, 5, and Appendix IV). This thesis aimed to identify $\mathrm{dFe}$ sources along the three cruise transects, as well as explore the composition and cycling of $\mathrm{dFe}$ through the use of the size partitioning of $\mathrm{dFe}$ into soluble and colloidal fractions. These topics are introduced in this section, first providing a review of marine $\mathrm{dFe}$ biogeochemistry and composition, followed by a discussion of marine colloids and colloidal Fe biogeochemistry. Finally, the aims and results of each of the chapters in this thesis are outlined.

\subsection{Dissolved Fe composition and biogeochemistry}

The exploration of the marine $\mathrm{dFe}$ cycle was motivated by the development of the Fe hypothesis, which posited that in multiple regions of the global ocean called highnutrient, low-chlorophyll zones (HNLC zones), macronutrient (nitrate, phosphate) 
concentrations are high but chlorophyll concentrations are low because Fe limits primary production (MARTIN, 1990; MARTIN and FITZWATER, 1988; MARTIN et al., 1990). Since Martin's Fe hypothesis, fertilization experiments where Fe was added to large swaths of HNLC ocean resulted in massive phytoplankton blooms, confirming that $\mathrm{Fe}$ is indeed the micronutrient limiting primary production in HNLC waters (reviewed in BOYD et al., 2007). Fe research since has revealed a very complex biogeochemistry, involving multiple sources, aggregation and scavenging, redox chemistry, photochemistry, biological utilization and remineralization, sorption onto particles, organic complexation, a wide size distribution including soluble and colloidal phases, and a low solubility (Figure 1). dFe is classified as a "hybrid-type" element (BRULAND and LOHAN, 2003) because it experiences both nutrient-type processes (biological uptake in the euphotic

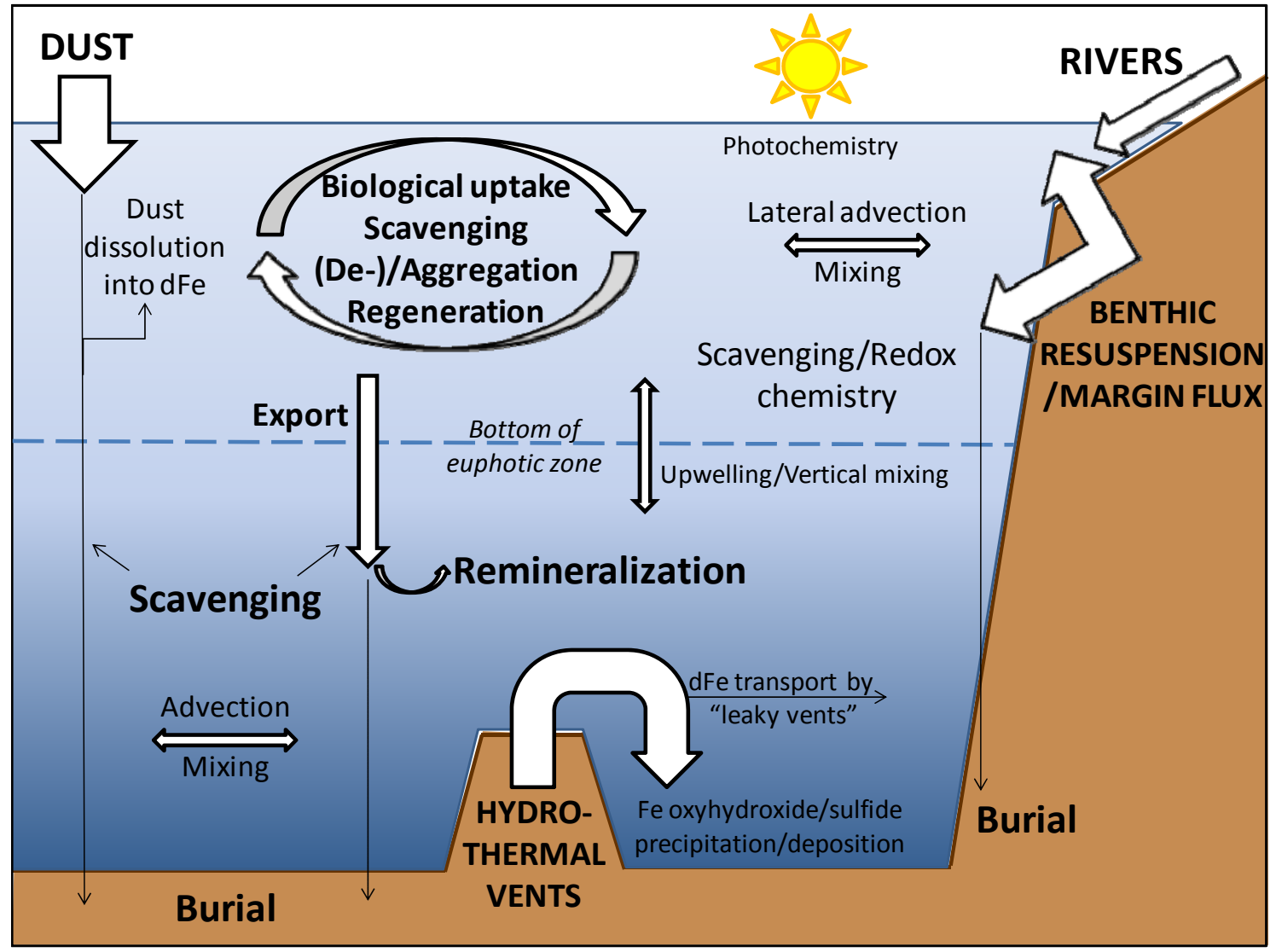

Figure 1: The marine Fe cycle 
zone and remineralization with depth) and scavenging-type processes with a short residence time that results in no buildup of Fe along thermohaline circulation. Fe(II) is the more soluble of the two oxidation states of Fe and is thought to be the most biologically available Fe phase (MOREL et al., 2008; SALMON et al., 2006; SHAKED et al., 2005); however, $\mathrm{Fe}(\mathrm{III})$ is the thermodynamically favored oxidation state in oxygenated waters, and thus most marine $\mathrm{Fe}$ is $\mathrm{Fe}(\mathrm{III})$. Fe(III) has a very low solubility in seawater $(<0.1 \mathrm{nmol} / \mathrm{kg}$ at $\mathrm{pH} 8)$, which leads to significant Fe scavenging and precipitation to particulate phases (KumA et al., 1996; LiU and Millero, 1999; LiU and Millero, 2002). Thus, marine residence times of $\mathrm{dFe}$ are as short as 6-62 days in the dust-rich surface North Atlantic Ocean (CROOT et al., 2004; JICKELLS, 1999) and are longer at 70-270 years in the deep ocean (BERGQUIST and Boyle, 2006; BRULAND et al., 1994).

Fe sources to the ocean include atmospheric dust fluxes, rivers, continental margin fluxes, and hydrothermal vents (Figure 1). While rivers are relatively insignificant Fe inputs to the global ocean because of estuarine flocculation (BOYLE et al., 1977), atmospheric dust inputs are traditionally considered the most significant Fe input (DUCE and TindALE, 1991; JiCKELLS et al., 2005; MAHOwALD et al., 2005). In the last decade, however, several studies have shown that continental margin fluxes of Fe can be important in some regions (ELROD et al., 2004; LAM and BISHOP, 2008), potentially rivaling aerosol sources in those areas (MOORE and BRAUCHER, 2008). In fact, I investigate a dust vs. continental margin Fe source in the tropical North Atlantic in Chapter 3. The final source of Fe to the ocean is hydrothermal vents, which release millimolar concentrations of $\mathrm{Fe}$ into the ocean (six orders of magnitude greater than in deep ocean seawater) at high flow rates. Despite these high concentrations, however, vented Fe was long thought to precipitate quantitatively near the vent site and thus was not believed to contribute significantly to marine dFe budgets (GERMAN et al., 1991). Recently, the "leaky vent" hypothesis has suggested that some hydrothermal-dFe does escape the vent site to contribute significantly to the ocean dFe inventory (TONER et al., 2012), and I explore whether hydrothermal vents can impact distal dFe concentrations in the abyssal ocean in Chapter 4. 
The major sink of Fe from the ocean is scavenging to the particulate phase. Several metal loss mechanisms are encompassed by the term "scavenging," including adsorption/surface complexation to particulate species, precipitation into particles, as well as aggregation into successively larger particles. Even biological uptake of dFe into cells of particulate size could be encompassed by scavenging, since it moves Fe from the dissolved to the particulate phase. Scavenging processes can be abiotic, biological, associated with Fe inputs such as dust and continental margin fluxes, and even induced by redox processes in oxygen minimum zones, margin sediments, near hydrothermal vents, and during photochemical processing in the surface ocean. It is this scavenging that prevents $\mathrm{dFe}$ from accumulating higher concentrations along thermohaline circulation (BRULAND et al., 1994).

However, we've known since the earliest high-quality marine Fe datasets that $\mathrm{dFe}$ can significantly exceed its Fe(III) solubility of $\sim 0.1 \mathrm{nmol} / \mathrm{kg}$, so how is marine $\mathrm{dFe}$ kept from being scavenged? Using competitive ligand exchange adsorptive cathodic stripping voltammetry (CLE-ACSV), it was shown that seawater contains ubiquitous organic compounds with a very high affinity to bind Fe (RUE and BRULAND, 1995; VAN DEN BERG, 1995; WU and LUTHER, 1995). The concentrations of these Fe-binding ligands are usually in excess of dFe concentrations (BUCK and BRULAND, 2007), and assuming equilibrium between the electrochemically characterized ligand pool and $\mathrm{dFe}$, it can be calculated that $>99.9 \%$ of marine $\mathrm{dFe}$ is organically bound. This organic chelation not only buffers $\mathrm{dFe}$ concentrations above Fe(III) mineral solubility, but it also allows for $\mathrm{dFe}$ to be much more available to the phytoplankton that compete for the short $\mathrm{dFe}$ supply.

Because Fe-binding ligands are only a small fraction of the seemingly countless different organic compounds in seawater, it has thus far been analytically impossible to separate and identify the chemical composition of the specific ligands that bind dFe. Early studies demonstrating elevated strong-ligand concentrations near the surface ocean where microorganisms are abundant, as well as the similar binding constants of marine Fe ligands with known bacterially-produced Fe-ligands called siderophores, lent to 
hypotheses that marine $\mathrm{dFe}$ was bound by biologically produced siderophores and/or biological degradation products such as porphyrins (RUE and BRULAND, 1995). Using laboratory cultures of marine organisms, several biologically produced siderophores have been isolated (ITO and ButLeR, 2005; MARTINEZ and ButLER, 2007; MARTINEZ et al., 2003; MARTINEZ et al., 2000; TRICK, 1989; TRICK et al., 1983a; TRICK et al., 1983b); the hydroxamate, catecholate, and carboxylate functional groups are common to these siderophores and are thought to be responsible for chelating the Fe. Only hydroxamate siderophores have been isolated from natural seawater, and these have been found at (sub-) picomolar concentrations comprising only $0.5-5 \%$ of total dFe pools (MAWJI et al., 2008; MAWJ et al., 2011; VeLASQUEZ et al., 2011). Analytical methods pursuing the chemical composition of these ligands is developing rapidly (GLEDHILL and BUCK, 2012a), with advancements in high-pressure liquid chromotagraphy coupled to ICP-MS (BOITEAU et al., 2013), high-resolution mass spectrometry (VELASQUEZ et al., 2011), and flow-field flow fractionation coupled to ICP-MS (STOLPE et al., 2010; STOLPE and HASSELOV, 2010).

One discovery, however, changed our perception of marine $\mathrm{dFe}$ composition from a siderophore-focused composition to a more varied composition: $\mathrm{dFe}$ has a dynamic size distribution ranging from truly dissolved "soluble" Fe complexes (sFe typically less than $0.02 \mu \mathrm{m}$ ) to very small particulate "colloidal" Fe complexes (cFe between $0.02 \mu \mathrm{m}$ and $0.2 \mu \mathrm{m}$, WU et al., 2001). Bacterially-produced siderophores discovered to date are small chemicals that should easily fall into the soluble size fraction, so the significant presence of "colloidal" species (as much as $90 \%$ in some regions) indicated that dFe complexation must be more diverse than previously thought. Recently, it has been hypothesized that much of this $\mathrm{cFe}$ is bound to less well-defined organic compounds persisting in the "ligand soup" of the open ocean (HUNTER and BOYD, 2007), with humic-like substances (BATCHELLI et al., 2010; LAGLERA et al., 2011) and exopolymeric saccharides (EPS, HASSLER et al., 2011a; HASSLER et al., 2011b) as likely candidates. Inorganic Fe (nanoparticles) may also contribute to this $\mathrm{cFe}$ pool, as shown in hydrothermal fluids 
(YUCEL et al., 2011) and in Southern Ocean surface waters underlying the Patagonian dust plume (VON DER HEYDEN et al., 2012).

It is the cycling of colloidal Fe that is the focus of this dissertation. Due to their larger size, cFe might be expected to cycle differently than truly dissolved (soluble) $\mathrm{Fe}$ species. Scavenging models have shown theoretically (HONEYMAN and SANTSCHI, 1989) and experimentally (HONEYMAN and SANTSCHI, 1991) that Fe colloids are an important intermediary between the dissolved and particulate phases (Figure 2). However, there is still much we do not understand about the role colloidal Fe plays in dFe biogeochemistry, ranging from fundamental questions about Fe colloids such as their composition, distribution, and partitioning, to more advanced questions of their cycling, including their rates of coagulation and relative bioavailability. I review below what has been learned about colloidal Fe thus far.

\subsection{Marine colloid chemistry}

Colloids are a group of compounds defined operationally by their size; they are collected by sequential filtrations with an upper size limit of 0.2-0.4 $\mu \mathrm{m}$ and a lower size limit of 1-10 kDa or $0.02 \mu \mathrm{m}$ (GUO and SANTSCHI, 1997). More important than their operational definition, however, colloids have a theoretical definition. Colloids exist between the dissolved and sinking particulate fractions; their lower limit is described as the smallest dimension at which a compound is separated from the surrounding media (composing a surface, usually $\sim 1 \mathrm{~nm}$ ), while their upper limit marks the size at which gravity becomes the principal force acting on the compound (WELLS, 2002). Thus, colloids are non-sinking particles found operationally in the "dissolved" fraction. It is this "theoretical" difference between soluble and colloidal phases that defines their variable biogeochemistries.

Early studies using ultra-centrifugation and transmission electron microscopy (TEM) suggested that marine colloids are mostly composed of organic, not inorganic, material (ISAO et al., 1990; Wells, 2002; Wells and GoldBerg, 1991; 1992). Some inorganic crystalline material composed largely of $\mathrm{Fe}$ is present in the colloidal class in 
estuarine and coastal waters, but inorganic colloids are rare in open ocean waters (WELLS, 2002). An exception to this, however, is the report of colloidal-sized magnetite in surface waters of the Southern Ocean underlying the Patagonian dust plume (VON DER HEYDEN et al., 2012), indicating that there may be select regions where nanoparticulate $\mathrm{cFe}$ (defined in this dissertation as colloidal-sized Fe of inorganic composition) might be prevalent, even in the open ocean. Colloids are chemically heterogeneous and can be enriched in trace elements such as Fe and Al (Wells and GoldBerg, 1991). Colloids are also physically heterogeneous, comprised of smaller $2-5 \mathrm{~nm}$ sized granules that are joined together (WELLS and GOLDBERG, 1992), which has led to the conclusion that the major source of colloids to the ocean is in situ production by aggregation and coagulation of smaller material. Sediment resuspension (GuO et al., 1996), delivery by estuaries (BENNER et al., 1992), hydrothermal vents (SANDS et al., 2012), and atmospheric dust inputs (AgUiLAR-IsLAS et al., 2010) are also colloidal inputs to the ocean. Photochemical oxidation, disaggregation to the dissolved phase, and biological degradation are all sinks of colloids from the ocean, although progressive aggregation of colloids into larger particles is thought to be the major output (WELLS and GOLDBERG, 1994).

In 1989, HONEYMAN and SANTSCHI developed a theoretical model by which solutes are transferred from the dissolved to the sinking particle fraction via colloidal intermediaries (Figure 2). They named this model the "colloidal pumping" hypothesis, whereby metals first bind to colloids in a rapid equilibrium step, and then the colloids aggregate into larger particles via a slower, rate-limiting step until they eventually sink out of the system as particulate species. This model brought colloids to the forefront of marine geochemical research, since scavenging and burial in marine sediments is the dominant output for many metals in the oceans (LI, 1981). The colloidal pumping model was verified by the reproduction of the slow scavenging rates observed for Th isotopes in the ocean (BACON and ANDERSON, 1982), which could not be explained by the physicochemical theories prevalent at the time; colloidal pumping was also confirmed by its ability to explain the counterintuitive "particle-concentration effect" (ANDERSON, 2007). 


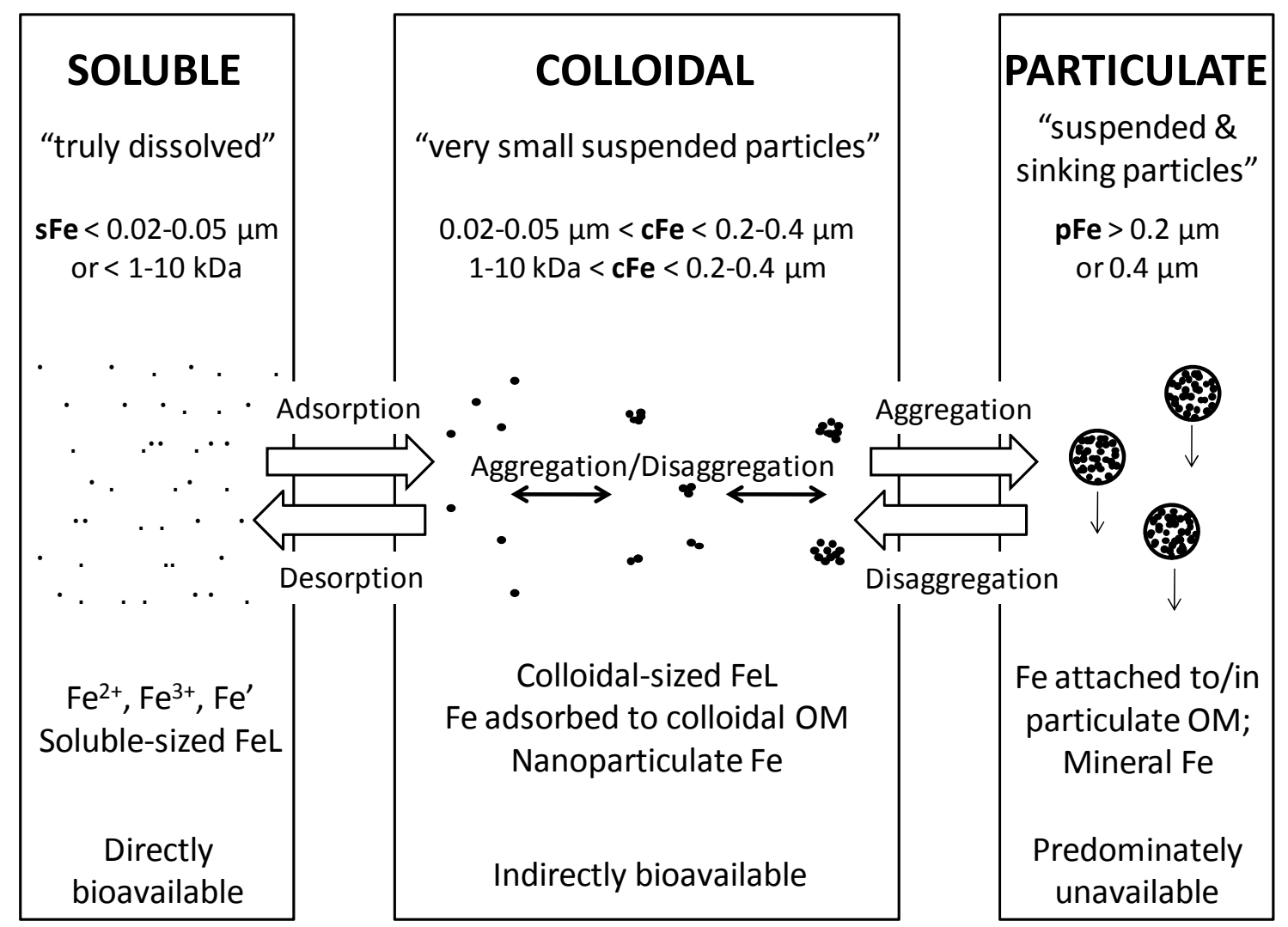

Figure 2: The size partitioning of Fe into soluble, colloidal, and particulate size fractions. $\mathrm{sFe}$ and cFe combine to make dFe. From top to bottom, this figure summarizes the "theoretical" definitions of these size fractions, their operational size definitions based on filtration, the proposed mechanisms that relate these size fractions (HONEYMAN and SANTSCHI, 1989), the potential chemical composition of these fractions, and their relative bioavailabilities.

Laboratory tests finally proved the "colloidal pumping" hypothesis using radio-labeled metals (HONEYMAN and SANTSCHI, 1991; StORDAL et al., 1996; Wen et al., 1997), and colloid turnover rates with respect to aggregation were estimated using colloidal ${ }^{234} \mathrm{Th}$ to be on the order of 10 days in the ocean (MORAN and BUESSELER, 1992).

Although marine colloids are primarily organic, they are very important to marine inorganic biogeochemistry because of their chemical proclivity to scavenge other metals, leading to a significant output of metals from the surface ocean. Metal interactions with colloidal organic matter are characterized by ligand association reactions where the positively charged metals associate with electronegative or negatively charged functional groups on the organic colloid. In estuarine and coastal waters, a significant portion of 
dissolved bioactive metals exist in the colloidal fraction: $\sim 70-100 \%$ of $\mathrm{Fe}, \sim 65-90 \%$ of $\mathrm{Cu}$, up to $\sim 75 \%$ of $\mathrm{Ni}$ and $\mathrm{Cd}$, and $5-32 \%$ of Co (WELLS, 2002, and references therein; WEN et al., 1996). Zn and Mn, in contrast, are predominantly soluble. There are far fewer studies of colloidal metals in open ocean waters (GREENAMOYER and MORAN, 1996; GUO et al., 2000), except for colloidal Fe which has been studied most significantly and will be discussed more explicitly in section 1.4 below.

\subsection{The bioavailability of colloidal Fe}

The bioavailability of colloidal Fe is a question of utmost importance in motivating future studies of marine Fe colloid distributions and cycling. If Fe colloids do make up a majority of the variable dissolved Fe fraction in the global ocean (BERGQUIST et al., 2007) but this fraction is only moderately bioavailable (CHEN et al., 2003; WANG and DEI, 2003), then current models linking dissolved Fe distributions and nutrient limitation may be overestimating the bioavailability of Fe (LEFEVRE and WATSON, 1999; MOORE et al., 2009; MoORE et al., 2002), and more of the surface ocean may be Fe limited than presently believed.

Early studies suggested that cell-adsorbed colloidal ferric hydroxides were available for direct uptake by diatoms (GOLDBERG, 1952; HARVEY, 1937; HAYWARD, 1968). However, this idea was disproven when pulse-chase experiments using radiolabeled Fe showed that Fe was principally transported into the cell from solution, not from the adsorbed fraction (ANDERSON and MOREL, 1982). Even inorganic colloids as small as 6-50 Fe atoms per colloid were not available for direct uptake by diatoms (RICH and MOREL, 1990). Only mixotrophic flagellates have been shown to be capable of direct ingestion of Fe colloids (small bacteria and inorganic Fe colloids) by phagotrophy (Maranger et al., 1998; Nodwell and Price, 2001).

It is now understood, however, that dissolved Fe, including the colloidal fraction, is mostly bound to organic compounds. Following this, studies of Fe bioavailability quickly expanded to show that certain species preferred specific Fe-ligand complexes over others (HASSLER and SCHOEMANN, 2009; MALDONADO and PRICE, 1999; SORIA- 
DENGG and HORSTMANN, 1995; WELLS, 1999). In general, eukaryotes prefer porphyrinlike complexes, while prokarytoes prefer siderophore complexes, in accordance with their Fe uptake mechanisms (HUTCHINS et al., 1999). Incubations using natural colloidal Fe assemblages, which are composed of an undetermined amount of organic and inorganic material, demonstrated that phytoplankton can in fact access the natural colloidal Fe fraction, although they prefer the soluble fraction and take it up much faster (CHEN and WANG, 2001). These results indicate that colloidal Fe may need to dissociate from the colloid via cell surface reduction or photoreduction before it can be taken up, although it is still indirectly bioavailable (Figure 2). In follow-up studies, diatoms were shown to prefer coastal and oceanic colloidal Fe over estuarine colloidal Fe (CHEN et al., 2003), while cyanobacteria were shown to prefer estuarine and oceanic colloidal Fe over coastal colloidal Fe (WANG and DEI, 2003). On the contrary, during studies specifically investigating the bioavailability of colloidal Fe bound to exopolymeric saccharides (EPS), Fe-EPS was found to be highly available, preferred even over some soluble-sized Fe-siderophore complexes (HASSLER et al., 2011). Thus, it appears that colloidal Fe bioavailability is quite complex, varying with both species and colloid composition, both of which change significantly over the global ocean.

\subsection{Marine colloidal Fe distributions and biogeochemistry}

The distributions of soluble and colloidal Fe are important to constrain because these distributions determine 1) whether an element is available for biological uptake, and 2) whether Fe is likely to remain dissolved or be moved to the particle phase that is exported from the system (i.e. the residence time of $\mathrm{dFe}$ ). There have been very limited studies of colloidal Fe distributions (shown in map view in Chapter 5, Figure 1), and most of these existing studies contain single profiles of dFe partitioning; there is an extreme dearth of colloidal Fe studies along transects, which have the potential to provide us much more information about factors controlling the observed partitioning. In general, the dissolved Fe size fraction $(\mathrm{dFe})$ is defined as the amount of $\mathrm{Fe}$ passing through a 0.2 or $0.4 \mu \mathrm{m}$ filter, and the soluble Fe fraction $(\mathrm{sFe})$ is defined as the amount of Fe passing 
through a $0.02 \mu \mathrm{m}$ filter or collected in the permeate of a $1-10 \mathrm{kDa}$ cross flow filtration (CFF) apparatus. The colloidal Fe class $(\mathrm{cFe})$ is calculated as $\mathrm{cFe}=\mathrm{dFe}-\mathrm{sFe}$. Here I review by depth the patterns of $\mathrm{dFe}$ size partitioning and resulting theories of $\mathrm{cFe}$ biogoechemical cycling discovered up until the writing of this thesis. A note of caution: in addition to the biogeochemical mechanisms described, some of the variability in $\mathrm{dFe}$ partitioning discussed below can be attributed to differences in the filter pore sizes used in each of the studies; however, given the relative deficiency of size fractionated $\mathrm{dFe}$ data globally and the complete absence of an intercalibration of filter types, a global comparison of all current data remains useful as an introduction to colloidal Fe biogeochemistry.

Surface concentrations of colloidal Fe range were nearly negligible $(0-0.1 \mathrm{nM})$ in the Southern Ocean (BOYE et al., 2010; CHEVER et al., 2010), North Pacific (NISHIOKA et al., 2001), and subtropical South Atlantic (BERGQUIST et al., 2007), while colloidal Fe concentrations were as high as $0.4-0.7 \mathrm{nM}$ in the North Atlantic . WELLS (2003) noted a pattern between colloidal loading and sFe filtration mechanism, and he suggested that these regional differences might simply be an artifact of the sFe filtration methods used (Anopore filtration providing high colloidal Fe, CFF providing low colloidal Fe). However, this geographic pattern also matches a range of dust fluxes to the surface ocean, with higher dust deposition in the North Atlantic underlying the North African dust plume, and much lower dust deposition in the Southern Ocean, subarctic North Pacific, and subtropical South Atlantic (MAHOWALD et al., 2005); this might suggest that dust deposits colloidal Fe into the surface ocean. A study by USSHER et al. (2010) supports this theory by reporting a complete range in surface $\% \mathrm{cFe}(=\mathrm{cFe} / \mathrm{dFe})$ between $0 \%$ and $72 \%$, where higher $\% \mathrm{cFe}$ corresponded with higher dissolved aluminum (Al) concentrations, a proxy for dust deposition (Figure 4, KRAMER et al., 2004; MEASURES and VINK, 2000). BERGQUIST et al. (2007) found similar spatial variation in \%cFe (between $0 \%$ and 66\%) in a north-south transect in the western North Atlantic, again with highest $\% \mathrm{cFe}$ coincident with high dissolved Al. This led to their hypothesis that dust releases Fe preferentially into the colloidal fraction. 
Directly below the cFe surface maximum, BERGQUIST et al. (2007) reported that in the mixed layer $(30-70 \mathrm{~m}) \mathrm{cFe}$ decreased to negligible concentrations at all Atlantic stations examined. This pattern was also observed in the western (WU et al., 2001) and eastern (USSHER et al., 2010) North Atlantic and in the subarctic Northeast Pacific (NiSHIOKA et al., 2001). It was hypothesized that the drop in colloidal Fe is caused by either downward mixing of a transient dust deposition event with water of lower cFe below or colloidal Fe removal by aggregation or biological uptake (BERGQUIST et al., 2007).

At intermediate depths, the contribution of cFe to total $\mathrm{dFe}$ is spatially variable (compare $20 \% \mathrm{cFe}$ in the Southern Ocean with $88 \% \mathrm{cFe}$ in the Northeast Atlantic, Chever et al., 2010; THuroczy et al., 2010). NiSHIOKA et al. (2001) also found temporal variation in nutricline $\mathrm{dFe}$ partitioning at a single station over several years. In this depth range, remineralization has the potential to release Fe into the soluble or colloidal size fraction, depending on the size of the organic compound to which the released Fe is bound and to what extent ligand exchange occurs upon release. Furthermore, colloidal aggregation and subsequent particle sinking in this depth range could serve to significantly reduce the $\% \mathrm{cFe}$ present in the $\mathrm{dFe}$ fraction. Therefore, depending on the biological, chemical, and physical characteristics of the nutricline, dissolved Fe partitioning might change quite dramatically. BERGQUIST et al. (2007) found that \%cFe was highest at the station with the most severe oxygen minimum, leading them to hypothesize that remineralization releases Fe preferentially into the colloidal size fraction. In contrast, BOYE et al. (2010) suggested that remineralization releases Fe into both soluble and colloidal phases.

Very few studies have examined dissolved Fe partitioning in deep waters. The first investigation showed that $\mathrm{dFe}$ in both the North Atlantic and North Pacific abyssal oceans was 30-70\% colloidal Fe (WU et al., 2001), and deepwater values in most studies since then have fit that description (BERGQUIST et al., 2007; BOYE et al., 2010; CHEVER et al., 2010; ThuroczY et al., 2010). North Atlantic Deep Water (NADW) sFe was measured to be $0.3-0.4 \mathrm{nM}$ by Wu et al. (2001), and using the cFe decrease between the 
North and South Atlantic NADW, cFe was calculated to have a scavenging residence time of 140 years (BERGQUIST et al., 2007). The abyssal ocean, however, is still relatively unexplored for dFe size partitioning.

BERGQUIST et al. (2007) summarized dFe partitioning in the North Atlantic by showing that the variability in dissolved Fe concentrations with depth is dominated by variation in colloidal $\mathrm{Fe}$; soluble $\mathrm{Fe}$, in contrast, maintains a nutrient-like profile with a near-constant concentration below remineralization depths (Figure 5). Much more global data is required to determine the global applicability of this $\mathrm{dFe}$ partitioning pattern, yet the potential impacts of independently cycling sFe and cFe pools are immense. For instance, where we believe Fe to be replete for biouptake because of high $\mathrm{dFe}$ concentrations, Fe may actually be limiting if the $\mathrm{dFe}$ is dominated by relatively unavailable cFe. Moreover, where we believe Fe to be dissolved and stable, it might actually have a very short residence time if the fraction is dominated by scavengingprone $\mathrm{cFe}$.

\subsection{Dissertation outline and chapter descriptions}

The primary objective of this dissertation was to explore the biogeochemical cycling and composition of dFe through both an assessment of the sources and sinks controlling dFe distributions worldwide as well as an examination of the composition and cycling of dFe resulting from its size partitioning into soluble and colloidal fractions. The field data for this thesis are concentrated in Chapters 3 and 6 for the tropical North Atlantic, Chapter 4 and Appendix I for the eastern South Pacific, and Chapter 7 and Appendices II and III for the subtropical North Atlantic. Chapters 2 and 5 shift the research focus toward intercalibration and experimental constraints on sample collection and processing methodology.

Chapter 2 (FITZSIMMONS and BOYLE, 2012) contains dFe data comparing the two methods of seawater sample collection used throughout this dissertation: the MITESS/Vanes system (BELL et al., 2002) and the U.S. GEOTRACES GO-FLO rosette system (CUTTER and BRULAND, 2012). This intercalibration proved that the two sampling 
systems produce identically uncontaminated samples for $\mathrm{dFe}$ and can be used interchangeably. Also in this chapter, the kinetics of dFe adsorption to bottle walls is constrained, which is important for studies of $\mathrm{dFe}$ size partitioning because of the double filtration required: seawater filtered for $\mathrm{dFe}(0.2$ or $0.4 \mu \mathrm{m}$ size cutoff) must sit in a holding bottle before $\mathrm{sFe}$ filtration, during which time $\mathrm{dFe}$ can adsorb to bottle walls and bias the resulting dFe partitioning. Sorption kinetics were discovered to be dependent on the time in the holding bottle as well as the bottle's size/volume.

In Chapter 3, the $\mathrm{dFe}$ distribution along a 27 -station transect in the tropical North Atlantic is reported and modeled (FITZSIMMONS et al., 2013). dFe was found to have enhanced concentrations $>1 \mathrm{nmol} / \mathrm{kg}$ near 500m depth coincident with the oxygen minimum zone (OMZ) near the Cape Verde Islands. While this dFe enhancement might be interpreted as arising from lateral transport of African margin $\mathrm{dFe}$, constant $\mathrm{Fe} / \mathrm{AOU}$ ratios across the transect and along all depths sampled indicated instead that this elevated $\mathrm{dFe}$ arose from the remineralization of high $\mathrm{Fe}: \mathrm{C}$ organic material.

Chapter 4 contains an evaluation of the distal impact of hydrothermal venting on the dFe distribution and dFe size partitioning of the abyssal South Pacific Ocean. Three stations located hundreds to thousands of kilometers from the nearest known vent sites exhibited dFe concentration anomalies at $2000 \mathrm{~m}$ depth (between $0.4-1.0 \mathrm{nmol} / \mathrm{kg}$ above background $\mathrm{dFe}$ concentrations), and dissolved manganese and ${ }^{3} \mathrm{He}$ maxima at coincident depths verify that this $\mathrm{dFe}$ enrichment is hydrothermally derived. This distal transport confirms the "leaky vent" hypothesis in the South Pacific Ocean, which posits that instead of all Fe being precipitated near the vent site, some hydrothermal $\mathrm{Fe}$ is retained in the dissolved phase and is transported sufficiently far from the vent site to contribute significantly to the global dFe budget.

Chapter 5 is the first chapter that focuses exclusively on dFe size partitioning into soluble and colloidal phases. It contains an evaluation and comparison of the two most commonly used methods for collecting size fractionated dFe samples: cross flow filtration (CFF; 10kDa pore size) and Anopore ${ }^{\mathrm{TM}}$ filtration ( $0.02 \mu \mathrm{m}$ pore size). Both methods were found to be robust for the collection of sFe samples, and the advantages 
and disadvantages of each are reviewed. Moreover, the first comparison of these two filtration systems on identical seawater samples demonstrated that sFe filtered using CFF was only $74 \pm 21 \%$ that collected with Anopore filtration, a difference attributed to both a smaller effective pore size in the CFF system as well as a natural variability in the $10 \mathrm{kDa}$ $-0.02 \mu \mathrm{m}$ size fraction with location and depth.

Chapter 6 is a follow-up to Chapter 3, containing the dFe size partitioning results from seven stations along the tropical North Atlantic cruise transect. dFe partitioning patterns are described as a function of depth, including the preferential partitioning of dust-derived surface $\mathrm{dFe}$ into the colloidal size fraction and the disappearance of $\mathrm{cFe}$ at the deep chlorophyll maximum. The overall partitioning observed in these stations surprisingly reflected that both $\mathrm{sFe}$ and $\mathrm{cFe}$ contribute to dFe variability, opposing the previous hypothesis that North Atlantic $\mathrm{dFe}$ variability is controlled by a dynamic colloidal phase alone (BERGQUIST et al., 2007).

The final chapter, Chapter 7, includes a report of the dFe partitioning along the U.S. GEOTRACES North Atlantic Zonal Transect, which with 28 stations sampled at 2537 depths each is the highest spatial and depth resolution of $\mathrm{dFe}$ size fractionation sampled to date. The partitioning resulting from the four major $\mathrm{dFe}$ inputs to the North Atlantic (dust, hydrothermal vents, the western continental margin, and the eastern OMZ) are discussed, as well as the partitioning in the deep chlorophyll maximum, remineralization depths, and the abyssal ocean. To conclude, a model is presented that explains how both $\mathrm{sFe}$ and $\mathrm{cFe}$ might cycle synchronously below the deep chlorophyll maximum in the North Atlantic, with a "remineralization-driven" partitioning controlling the observed $\mathrm{dFe}$ size fractionation away from external $\mathrm{dFe}$ sources.

The four appendices contain reports of additional projects not complete at the time of writing this dissertation. Appendix I includes a discussion of the $\mathrm{dFe}$ biogeochemistry in the upper $1000 \mathrm{~m}$ of the eastern South Pacific Ocean (same transect as Chapter 4), encompassing the most oligotrophic of all global subtropical gyres as well as one of the most productive oxygen minimum zones in the global ocean. Appendix II contains an analysis of the Fe chemistry (dissolved, soluble, colloidal, particulate, and 
Fe(II)) in the TAG hydrothermal plume collected during the U.S. GEOTRACES North Atlantic cruise. Appendix III includes size fractionated Fe-ligand and dFe isotope data collected on the U.S. GEOTRACES North Atlantic cruise. Surprisingly, most ligands detected were soluble, despite the partitioning of most of the dFe into the colloidal phase, and the surface ocean soluble Fe isotopes were isotopically enriched compared to $\mathrm{dFe}$ isotopes, supporting the hypothesis that the two size fractions cycle independently in the upper ocean. Finally, Appendix IV contains a time-series of surface dFe at the oligotrophic Station ALOHA north of Oahu where we hope to record the influence of Loihi hydrothermal vents, seasonal trends of biological population composition and productivity, and changes in the physical circulation near Hawai'i on the temporal variability of dFe. 


\section{References for Chapter 1}

Aguilar-Islas, A. M., Wu, J., Rember, R., Johansen, A. M., and Shank, L. M., 2010. Dissolution of aerosol-derived iron in seawater: Leach solution chemistry, aerosol type, and colloidal iron fraction. Marine Chemistry 120, 25-33.

Anderson, M. A. and Morel, F. M. M., 1982. The influence of aqueous iron chemistry on the uptake of iron by the coastal diatom Thalassiosira weisflogii. Limnology and Oceanography 27, 789-813.

Anderson, R. F., 2007. Chemical Tracers of Particle Transport. In: Turekian, K. K. and Holland, H. D. Eds.), Treatise on Geochemistry. Elsevier Science Ltd., Cambridge, UK.

Bacon, M. P. and Anderson, R. F., 1982. Distribution of thorium isotopes between dissolved and particulate forms in the deep-sea. Journal of Geophysical Research Oceans and Atmospheres 87, 2045-2056.

Batchelli, S., Muller, F. L. L., Chang, K. C., and Lee, C. L., 2010. Evidence for Strong but Dynamic Iron-Humic Colloidal Associations in Humic-Rich Coastal Waters. Environmental Science \& Technology 44, 8485-8490.

Bell, J., Betts, J., and Boyle, E., 2002. MITESS: a moored in situ trace element serial sampler for deep-sea moorings. Deep-Sea Research Part I-Oceanographic Research Papers 49, 2103-2118.

Benner, R., Chin-Leo, C., Gardner, W., Eadie, B., and Cotner, J., 1992. The fates and effects of riverine and shelf-derived DOM on Mississippi River Plume/gulf shelf processes, Nutrient Enhanced Coastal Ocean Productivity, NECOP workshop Proceedings, October 1991, TAMU-SG-92-109. Texas A\&M University Sea Grant Program, College Station, TX.

Bergquist, B. A. and Boyle, E. A., 2006. Dissolved iron in the tropical and subtropical Atlantic Ocean. Global Biogeochemical Cycles 20, 14.

Bergquist, B. A., Wu, J., and Boyle, E. A., 2007. Variability in oceanic dissolved iron is dominated by the colloidal fraction. Geochimica et Cosmochimica Acta 71, 2960-2974.

Biller, D. V. and Bruland, K. W., 2012. Analysis of Mn, Fe, Co, Ni, Cu, Zn, Cd, and Pb in seawater using the Nobias-chelate PA1 resin and magnetic sector inductively coupled plasma mass spectrometry (ICP-MS). Marine Chemistry 130-131, 12-20.

Boiteau, R. M., Fitzsimmons, J. N., Repeta, D. J., and Boyle, E. A., 2013. Detection of Iron Ligands in Seawater and Marine Cyanobacteria Cultures by High-Performance Liquid Chromatography-Inductively Coupled Plasma-Mass Spectrometry. Analytical Chemistry 85, 4357-4362.

Boyd, P. W., Jickells, T., Law, C. S., Blain, S., Boyle, E. A., Buesseler, K. O., Coale, K. H., Cullen, J. J., de Baar, H. J. W., Follows, M., Harvey, M., Lancelot, C., Levasseur, M., Owens, N. P. J., Pollard, R., Rivkin, R. B., Sarmiento, J., Schoemann, V., Smetacek, V., Takeda, S., Tsuda, A., Turner, S., and Watson, A. J., 2007. Mesoscale iron enrichment experiments 1993-2005: Synthesis and future directions. Science 315, 612-617.

Boye, M., Nishioka, J., Croot, P., Laan, P., Timmermans, K. R., Strass, V. H., Takeda, S., and de 
Baar, H. J. W., 2010. Significant portion of dissolved organic Fe complexes in fact is Fe colloids. Marine Chemistry 122, 20-27.

Boyle, E. A., Edmond, J. M., and Sholkovitz, E. R., 1977. The mechanism of iron removal in estuaries. Geochimica et Cosmochimica Acta 41, 1313-1324.

Bruland, K. W. and Lohan, M. C., 2003. Controls of Trace Metals in Seawater. In: Turekian, K. K. and Holland, H. D. Eds.), Treatise On Geochemistry. Elsevier Science Ltd., Cambridge, United Kingdom.

Bruland, K. W., Orians, K. J., and Cowen, J. P., 1994. Reactive trace metals in the stratified central North Pacific. Geochimica et Cosmochimica Acta 58, 3171-3182.

Bruland, K. W. and Rue, E. L., 2001. Analytical Methods for the Determination of Concentrations and Speciation of Iron. In: Turner, D. R. and Hunter, K. A. Eds.), The Biogeochemistry of Iron in Seawater. John Wiley \& Sons Ltd.

Buck, K. N. and Bruland, K. W., 2007. The physicochemical speciation of dissolved iron in the Bering Sea, Alaska. Limnology and Oceanography 52, 1800-1808.

Chen, M., Dei, R. C. H., Wang, W.-X., and Guo, L., 2003. Marine diatom uptake of iron bound with natural colloids of different origins. Marine Chemistry 81, 177-189.

Chen, M. and Wang, W. X., 2001. Bioavailability of natural colloid-bound iron to marine plankton: Influences of colloidal size and aging. Limnology and Oceanography 46, 19561967.

Chever, F., Bucciarelli, E., Sarthou, G., Speich, S., Arhan, M., Penven, P., and Tagliabue, A., 2010. Physical speciation of iron in the Atlantic sector of the Southern Ocean along a transect from the subtropical domain to the Weddell Sea Gyre. J. Geophys. Res. 115, C10059.

Croot, P. L., Streu, P., and Baker, A. R., 2004. Short residence time for iron in surface seawater impacted by atmospheric dry deposition from Saharan dust events. Geophysical Research Letters 31, L23S08.

Cutter, G. A. and Bruland, K. W., 2012. Rapid and noncontaminating sampling system for trace elements in a global ocean surveys. Limnology \& Oceanography: Methods 10, 425-436.

Duce, R. A. and Tindale, N. W., 1991. Atmospheric transport of iron and its deposition in the ocean. Limnology and Oceanography 36, 1715-1726.

Elrod, V. A., Berelson, W. M., Coale, K. H., and Johnson, K. S., 2004. The flux of iron from continental shelf sediments: a missing source for global budgets. Geophysical Research Letters 31, L12307.

Fitzsimmons, J. N. and Boyle, E. A., 2012. An intercalibration between the GEOTRACES GOFLO and the MITESS/Vanes sampling systems for dissolved iron concentration analyses (and a closer look at adsorption effects). Limnology \& Oceanography: Methods 10, 437 450 .

Fitzsimmons, J. N., Zhang, R., and Boyle, E. A., 2013. Dissolved iron in the tropical North Atlantic oxygen minimum zone. Marine Chemistry 154, 87-99.

German, C. R., Campbell, A. C., and Edmond, J. M., 1991. Hydrothermal scavenging at the MidAtlantic Ridge: Modification of trace element dissolved fluxes. Earth and Planetary Science Letters 107, 101-114. 
Gledhill, M. and Buck, K. N., 2012. The organic complexation of iron in the marine environment: a review. Frontiers in Microbiology 3, 69.

Goldberg, E. D., 1952. Iron assimilation by marine diatoms. Biological Bulletin 102, 243-248.

Greenamoyer, J. M. and Moran, S. B., 1996. Evaluation of an Osmonics spiral-wound cross-flow filtration system for sub-um sampling of $\mathrm{Cd}, \mathrm{Cu}$ and $\mathrm{Ni}$ in seawater. Marine Chemistry 55, 153-163.

Guo, L. and Santschi, P. H., 1997. Composition and cycling of colloids in marine environments. Rev. Geophys. 35, 17-40.

Guo, L., Santschi, P. H., and Warnken, K. W., 2000. Trace metal composition of colloidal organic material in marine environments. Marine Chemistry 70, 257-275.

Guo, L. D., Santschi, P. H., Cifuentes, L. A., Trumbore, S., and Southon, J., 1996. Cycling of high molecular weight dissolved organic matter in the Middle Atlantic Bight as revealed by carbon isotopic (13C and 14C) signatures. Limnology and Oceanography 41.

Harvey, H. W., 1937. The supply of iron to diatoms. Journal of the Marine Biological Association of the United Kingdom 22, 205-217.

Hassler, C. S., Alasonati, E., Mancuso Nichols, C. A., and Slaveykova, V. I., 2011 a. Exopolysaccharides produced by bacteria isolated from the pelagic Southern Ocean: Role in Fe binding, chemical reactivity, and bioavailability. Marine Chemistry 123, 88-98.

Hassler, C. S. and Schoemann, V., 2009. Bioavailability of organically bound Fe to model phytoplankton of the Southern Ocean. Biogeosciences 6, 2281-2296.

Hassler, C. S., Schoemann, V., Nichols, C. M., Butler, E. C. V., and Boyd, P. W., 2011 b. Saccharides enhance iron bioavailability to Southern Ocean phytoplankton. Proceedings of the National Academy of Sciences 108, 1076-1081.

Hayward, J., 1968. Studies on the growth of Phaeodactylum tricornutum .3. Effect of iron on growth. Journal of the Marine Biological Association of the United Kingdom 48, 295 302.

Honeyman, B. D. and Santschi, P. H., 1989. A Brownian-pumping model for oceanic trace metal scavenging: Evidence from Th isotopes. Journal of Marine Research 47, 951-992.

Honeyman, B. D. and Santschi, P. H., 1991. Coupling adsorption and particle aggregation: Laboratory studies of "Colloidal pumping" using ${ }^{59} \mathrm{Fe}$-labeled hematite. Environmental Science \& Technology 25, 1739-1747.

Hunter, K. A. and Boyd, P. W., 2007. Iron-binding ligands and their role in the ocean biogeochemistry of iron. Environmental Chemistry 4, 221-232.

Hutchins, D. A., Witter, A. E., Butler, A., and Luther III., G. W., 1999. Competition among marine phytoplankton for different chelated iron species. Nature 400, 858-861.

Isao, K., Hara, S., Terauchi, K., and Kogure, K., 1990. Role of sub-micrometre particles in the ocean. Nature 345, 242-244.

Ito, Y. and Butler, A., 2005. Structure of synechobactins, new siderophores of the marine cyanobacterium Synechococcus sp PCC 7002. Limnology \& Oceanography 50, 19181923.

Jickells, T. D., 1999. The inputs of dust derived elements to the Sargasso Sea; a synthesis. Marine Chemistry 68, 5-14. 
Jickells, T. D., An, Z. S., Andersen, K. K., Baker, A. R., Bergametti, G., Brooks, N., Cao, J. J., Boyd, P. W., Duce, R. A., Hunter, K. A., Kawahata, H., Kubilay, N., laRoche, J., Liss, P. S., Mahowald, N., Prospero, J. M., Ridgwell, A. J., Tegen, I., and Torres, R., 2005. Global iron connections between desert dust, ocean biogeochemistry, and climate. Science 308, 67-71.

Johnson, K. S., Boyle, E. A., Bruland, K. W., Coale, K., Measures, C., Moffett, J., Aguilar-Islas, A., Barbeau, K., Bergquist, B., Bowie, A., Buck, K., Cai, Y., Chase, Z., J. Cullen, Doi, T., Elrod, V., Fitzwater, S., Gordon, M., King, A., Laan, P., Laglera-Baquer, L., Landing, W., Lohan, M., Mendez, J., Milne, A., Obata, H., Ossiander, L., Plant, J., Sarthou, G., Sedwick, P., Smith, G. J., Sohst, B., Tanner, S., Berg, S. V. D., and Wu, J., 2007. Developing standards for dissolved iron in seawater. EOS Transactions America Geophysical Union 88, 131-132.

Kramer, J., Laan, P., Sarthou, G., Timmermans, K. R., and de Baar, H. J. W., 2004. Distribution of dissolved aluminium in the high atmospheric input region of the subtropical waters of the North Atlantic Ocean. Marine Chemistry 88, 85-101.

Kuma, K., Nishioka, J., and Matsunaga, K., 1996. Controls on iron(III) hydroxide solubility in seawater: The influence of $\mathrm{pH}$ and natural organic chelators. Limnology and Oceanography 41, 396-407.

Lagerstrom, M. E., Field, M. P., Seguret, M., Fischer, L., Hann, S., and Sherrell, R. M., 2013. Automated on-line flow-injection ICP-MS determination of trace metals (Mn, Fe, Co, Ni, $\mathrm{Cu}$ and $\mathrm{Zn}$ ) in open ocean seawater: Application to the GEOTRACES program. Marine Chemistry 155, 71-80.

Laglera, L. M., Battaglia, G., and van den Berg, C. M. G., 2011. Effect of humic substances on the iron speciation in natural waters by CLE/CSV. Marine Chemistry 127, 134-143.

Lam, P. J. and Bishop, J. K. B., 2008. The continental margin is a key source of iron to the HNLC North Pacific Ocean. Geophysical Research Letters 35, L07608.

Lee, J.-M., Boyle, E. A., Echegoyen-Sanz, Y., Fitzsimmons, J. N., Zhang, R., and Kayser, R. A., 2011. Analysis of trace metals $(\mathrm{Cu}, \mathrm{Cd}, \mathrm{Pb}$, and $\mathrm{Fe})$ in seawater using single batch Nitrilotriacetate resin extraction and isotope dilution inductively coupled plasma mass spectrometry. Analytica Chimica Acta 686, 93-101.

Lefevre, N. and Watson, A. J., 1999. Modeling the geochemical cycle of iron and its impact on atmospheric $\mathrm{CO}_{2}$ concentrations. Global Biogeochemical Cycles 13, 727-736.

Li, Y.-H., 1981. Ultimate removal mechanisms of elements from the ocean. Geochimica et Cosmochimica Acta 45, 1159-1164.

Liu, X. and Millero, F. J., 1999. The solubility of iron hydroxide in sodium chloride solutions. Geochimica et Cosmochimica Acta 63, 3487-3497.

Liu, X. and Millero, F. J., 2002. The solubility of iron in seawater. Marine Chemistry 77, 43-54.

Mahowald, N., Baker, A. R., Bergametti, G., Brooks, N., Duce, R. A., Jickells, T., Kubilay, N., Prospero, J. M., and Tegen, I., 2005. Atmospheric global dust cycle and iron inputs to the ocean. Global Biogeochemical Cycles 19, GB4025.

Maldonado, M. T. and Price, N. M., 1999. Utilization of iron bound to strong organic ligands by 
plankton communities in the subarctic Pacific Ocean. Deep Sea Research Part II: Topical Studies in Oceanography 46, 2447-2473.

Maranger, R., Bird, D. F., and Price, N. M., 1998. Iron acquisition by photosynthetic marine phytoplankton from ingested bacteria. Nature 396, 248-251.

Martin, J. H., 1990. Glacial-interglacial CO2 change: The iron hypothesis. Paleoceanography 5, $1-13$.

Martin, J. H. and Fitzwater, S. E., 1988. Iron deficiency limits phytoplankton growth in the northeast Pacific subarctic. Nature 331, 341-343.

Martin, J. H., Gordon, R. M., and Fitzwater, S. E., 1990. Iron in Antarctic waters. Nature 345, 156-158.

Martinez, J. S. and Butler, A., 2007. Marine amphiphilic siderophores: marinobactin structure, uptake, and microbial partitioning. Journal of Inorganic Biochemistry 101, 1692-1698.

Martinez, J. S., Carter-Franklin, J. N., Mann, E. L., Martin, J. D., Haygood, M. G., and Butler, A., 2003. Structure and membrane affinity of a suite of amphiphilic siderophores produced by a marine bacterium. Proceedings of the National Academy of Sciences 2003, 37543759.

Martinez, J. S., Zhang, G. P., Holt, P. D., Jung, H.-T., Carrano, C. J., Haygood, M. G., and Butler, A., 2000. Self-assembling amphiphilic siderophores from marine bacteria. Science 287, $1245-1247$.

Mawji, E., Gledhill, M., Milton, J. A., Tarran, G. A., Ussher, S., Thompson, A., Wolff, G. A., Worsfold, P. J., and Achterberg, E. P., 2008. Hydroxamate siderophores: occurrence and importance in the Atlantic Ocean. Environmental Science and Technology 42, 86758680 .

Mawji, E., Gledhill, M., Milton, J. A., Zubkov, M. V., Thompson, A., Wolff, G. A., and Achterberg, E. P., 2011. Production of siderophore type chelates in Atlantic Ocean water enriched with different carbon and nitrogen sources. Marine Chemistry 124, 90-99.

Measures, C. I. and Vink, S., 2000. On the use of dissolved aluminum in surface waters to estimate dust deposition to the ocean. Global Biogeochem. Cycles 14, 317-327.

Measures, C. I., Yuan, J., and Resing, J. A., 1995. Determination of iron in seawater by flow injection-analysis using in-line preconcentration and spectrophotometric detection. Marine Chemistry 50, 3-12.

Milne, A., Landing, W., Bizimis, M., and Morton, P., 2010. Determination of Mn, Fe, Co, Ni, Cu, $\mathrm{Zn}, \mathrm{Cd}$ and $\mathrm{Pb}$ in seawater using high resolution magnetic sector inductively coupled mass spectrometry (HR-ICP-MS). Analytica Chimica Acta 665, 200-207.

Moore, C. M., Mills, M. M., Achterberg, E. P., Geider, R. J., LaRoche, J., Lucas, M. I., McDonagh, E. L., Pan, X., Poulton, A. J., Rijkenberg, M. J. A., Suggett, D. J., Ussher, S. J., and Woodward, E. M. S., 2009. Large-scale distribution of Atlantic nitrogen fixation controlled by iron availability. Nature Geosci 2, 867-871.

Moore, J. K. and Braucher, O., 2008. Sedimentary and mineral dust sources of dissolved iron to the world ocean. Biogeosciences 5, 631-656.

Moore, J. K., Doney, S. C., Glover, D. M., and Fung, I. Y., 2002. Iron cycling and nutrient- 
limitation patterns in surface waters of the World Ocean. Deep Sea Research Part II: Topical Studies in Oceanography 49, 463-507.

Moran, S. B. and Buesseler, K. O., 1992. Short residence time of colloids in theupper ocean estimated from ${ }^{238} \mathrm{U}_{-}{ }^{234} \mathrm{Th}$ disequilibria. Nature 359, 221-223.

Morel, F. M. M., Kustka, A. B., and Shaked, Y., 2008. The role of unchelated Fe in the iron nutrition of phytoplankton. Limnology and Oceanography 53, 400-404.

Morel, F. M. M., Milligan, A. J., and Saito, M. A., 2003. Marine Bioinorganic Chemistry: The Role of Trace Metals in the Oceanic Cycles of Major Nutrients. In: Turekian, K. K. and Holland, H. D. Eds.), Treatise On Geochemistry. Elsevier Science Ltd., Cambridge, United Kingdom.

Nishioka, J., Takeda, S., Wong, C. S., and Johnson, W. K., 2001. Size-fractionated iron concentrations in the northeast Pacific Ocean: distribution of soluble and small colloidal iron. Marine Chemistry 74, 157-179.

Nodwell, L. M. and Price, N. M., 2001. Direct use of inorganic colloidal iron by marine mixotrophic phytoplankton. Limnology and Oceanography 46, 765-777.

Obata, H., Karatani, H., and Nakayama, E., 1993. Automated determination of iron in seawater by chelating resin concentration and chemiluminescence. Analytical Chemistry 65, 15241528 .

Rich, H. W. and Morel, F. M. M., 1990. Availability of well-defined iron colloids to the marine diatom Thalassiosira weissflogii. Limnology and Oceanography 35, 652-662.

Rue, E. L. and Bruland, K. W., 1995. Complexation of iron(III) by natural organic ligands in the Central North Pacific as determined by a new competitive ligand equilibration/adsorptive cathodic stripping voltammetric method. Marine Chemistry 50, 117-138.

Salmon, T. P., Rose, A. L., Neilan, B. A., and Waite, T. D., 2006. The FeL model of iron acquisition: Nondissociative reduction of ferric complexes in the marine environment. Limnology and Oceanography 51, 1744-1754.

Sands, C. M., Connelly, D. P., Statham, P. J., and German, C. R., 2012. Size fractionation of trace metals in the Edmond hydrothermal plume, Central Indian Ocean. Earth and Planetary Science Letters 319-320, 15-22.

Shaked, Y., Kustka, A. B., and Morel, F. M. M., 2005. A general kinetic model for iron acquisition by eukaryotic phytoplankton. Limnology and Oceanography 50, 872-882.

Soria-Dengg, S. and Horstmann, U., 1995. Ferrioxamines B and E as iron sources for the marine diatom Phaeodactylum tricornutum. Marine Ecology Progress Series 127, 269-277.

Stolpe, B., Guo, L., Shiller, A. M., and Hassellöv, M., 2010. Size and composition of colloidal organic matter and trace elements in the Mississippi River, Pearl River and the northern Gulf of Mexico, as characterized by flow field-flow fractionation. Marine Chemistry 118, 119-128.

Stolpe, B. and Hassellov, M., 2010. Nanofibrils and other colloidal biopolymers binding trace elements in coastal seawater: Significance for variations in element size distributions. Limnology \& Oceanography 55, 187-202.

Stordal, M. C., Santschi, P. H., and Gill, G. A., 1996. Colloidal pumping: Evidence for the 
coagulation process using natural colloids tagged with ${ }^{203} \mathrm{Hg}$. Environmental Science \& Technology 30, 3335-3340.

Thuróczy, C. E., Gerringa, L. J. A., Klunder, M. B., Middag, R., Laan, P., Timmermans, K. R., and de Baar, H. J. W., 2010. Speciation of Fe in the Eastern North Atlantic Ocean. Deep Sea Research Part I: Oceanographic Research Papers 57, 1444-1453.

Toner, B. M., Marcus, M. A., Edwards, K. J., Rouxel, O., and German, C. R., 2012. Measuring the form of iron in hydrothermal plume particles. Oceanography 25, 209-212.

Trick, C. G., 1989. Hydroxamate-siderophore production and utilization by marine eubacteria. Current Microbiology 18, 375.

Trick, C. G., Andersen, R. J., Gillam, A., and Harrison, P. J., 1983a. Prorocentrin: an extracellular siderophore produced by the marine dinoflagellate Prorocentrum minimum. Science $\mathbf{2 1 9}$, 306.

Trick, C. G., Andersen, R. J., Price, N. M., Gillam, A., and Harrison, P. J., 1983b. Examination of hydroxamate-siderophore production by neritic eukaryotic marine phytoplankton. Marine Biology 75, 9.

Ussher, S. J., Achterberg, E. P., Sarthou, G., Laan, P., de Baar, H. J. W., and Worsfold, P. J., 2010. Distribution of size fractionated dissolved iron in the Canary Basin. Marine Environmental Research 70, 46-55.

van den Berg, C. M. G., 1995. Evidence for organic complexation of iron in seawater. Marine Chemistry 50, 139-157.

Velasquez, I., Nunn, B. L., Ibisanmi, E., Goodlet, D. R., Hunter, K. A., and Sander, S. G., 2011. Detection of hydroxamate siderophores in coastal and sub-Antarctic waters off the South Eastern coast of New Zealand. Marine Chemistry 126, 97-107.

von der Heyden, B. P., Roychoudhury, A. N., Mtshali, T. N., Tyliszczak, T., and Myneni, S. C. B., 2012. Chemically and Geographically Distinct Solid-Phase Iron Pools in the Southern Ocean. Science 338, 1199-1201.

Wang, W. X. and Dei, R. C. H., 2003. Bioavailability of iron complexed with organic colloids to the cyanobacteria Synechococcus and Trichodesmium. Aquatic Microbial Ecology 33, 247-259.

Wells, M. L., 1999. Manipulating iron availability in nearshore waters. Limnology and Oceanography 44, 1002-1008.

Wells, M. L., 2002. Marine Colloids and Trace Metals. In: Dennis, A. H. and Carlson, C. A. Eds.), Biogeochemistry of Marine Dissolved Organic Matter. Academic Press, San Diego.

Wells, M. L., 2003. The level of iron enrichment required to initiate diatom blooms in HNLC waters. Marine Chemistry 82, 101-114.

Wells, M. L. and Goldberg, E. D., 1991. Occurrence of small colloids in sea water. Nature 353, 342-344.

Wells, M. L. and Goldberg, E. D., 1992. Marine submicron particles. Marine Chemistry 40, 5-18.

Wells, M. L. and Goldberg, E. D., 1994. The distribution of colloids in the North Atlantic and Southern Oceans. Limnology and Oceanography 39, 286-302.

Wen, L.-S., Santschi, P. H., and Tang, D., 1997. Interactions between radioactively labeled 
colloids and natural particles: Evidence for colloidal pumping. Geochimica et Cosmochimica Acta 61, 2867-2878.

Wen, L.-S., Stordal, M. C., Tang, D., Gill, G. A., and Santschi, P. H., 1996. An ultraclean crossflow ultrafiltration technique for the study of trace metal phase speciation in seawater. Marine Chemistry 55, 129-152.

Wu, J. and Boyle, E. A., 1998. Determination of iron in seawater by high-resolution isotope dilution inductively coupled plasma mass spectrometry after $\mathrm{Mg}(\mathrm{OH}) 2$ coprecipitation. Analytica Chimica Acta 367, 183-191.

Wu, J., Boyle, E. A., Sunda, W. G., and Wen, L., 2001. Soluble and colloidal iron in the oligotrophic North Atlantic and North Pacific. Science 293, 847-849.

$\mathrm{Wu}, \mathrm{J}$. and Luther, G. W., 1995. Complexation of Fe(III) by natural organic ligands in the Northwest Atlantic Ocean by a competitive ligand equilibration method and a kinetic approach. Marine Chemistry 50, 159-177.

Wu, J. F. and Luther, G. W., 1996. Spatial and temporal distribution of iron in the surface water of the northwestern Atlantic Ocean. Geochimica et Cosmochimica Acta 60, 2729-2741.

Yucel, M., Gartman, A., Chan, C. S., and Luther, G. W., 2011. Hydrothermal vents as a kinetically stable source of iron-sulphide-bearing nanoparticles to the ocean. Nature Geoscience 4, 367-371. 


\title{
Chapter 2
}

\section{An intercalibration between the GEOTRACES GO- FLO and the MITESS/Vanes sampling systems for dissolved iron concentration analyses (and a closer look at adsorption effects)}

Reprinted with permission of Limnology \& Oceanography: Methods (ASLO). Copyright 2013 by the Association for the Sciences of Limnology and Oceanography, Inc.

Fitzsimmons, J.N. and Boyle, E.A. 2012. An intercalibration between the GEOTRACES GO-FLO and the MITESS/Vanes sampling systems for dissolved iron concentration analyses (and a closer look at adsorption effects). Limnology \& Oceanography: Methods 10: 437-450. Published 7 April 2012.

\begin{abstract}
An intercalibration of dissolved iron ( $\mathrm{dFe}$ ) concentrations was conducted from samples collected on the GEOTRACES Pacific Intercalibration cruise using two different sampling devices: the GEOTRACES GO-FLO rosette system and MITESS/Vane samplers. At each depth, the dFe concentrations were identical within analytical error, except at $500 \mathrm{~m}$ where contamination in one bottle is suspected. $\mathrm{dFe}$ adsorption kinetics to bottle walls was also investigated. Over $29 \mathrm{~h}, 18 \%$ of the $\mathrm{dFe}$ adsorbed to the walls of $1 \mathrm{~L}$ bottles, whereas over $15 \mathrm{~h}, 19 \%$ adsorbed to the walls of $250 \mathrm{~mL}$ bottles, suggesting a relationship between $\mathrm{dFe}$ adsorption and sample bottle surface area to volume ratio. Contrary to expectations that refrigeration would slow adsorption, cold $250 \mathrm{~mL}$ bottles demonstrated a $29 \% \mathrm{dFe}$ loss over $15 \mathrm{~h}$ compared to $19 \%$ loss at room temperature. Finally, we tested the hypothesis that the decreasing dFe observed in successive sub sampled bottles from the (unacidified) SAFe D1 tank was due not only to adsorption but also to $\mathrm{pH}$-dependent $\mathrm{Fe}$ solubility changes resulting from carbon dioxide outgassing to the headspace of the 500L SAFe D1 tank. Filtered, low-pH seawater collected at $1000 \mathrm{~m}$ in the North Pacific was placed into bottles with variable headspace for $15-17 \mathrm{~h}$. The $\mathrm{pH}$ rose with increasing headspace, demonstrating that carbon dioxide outgassed, and $\mathrm{dFe}$ decreased in magnitude similar to the SAFe D1 sample. Fe size fractionation results did not conclusively reveal an Fe loss mechanism, but estimates of wall adsorption predicted from our adsorption experiments suggest that the decrease in dFe was more than can be expected by simple adsorption.
\end{abstract}




\title{
LIMNOLOGY
}

and

\section{An intercalibration between the GEOTRACES GO-FLO and the MITESS/Vanes sampling systems for dissolved iron concentration analyses (and a closer look at adsorption effects)}

\author{
Jessica N. Fitzsimmons* and Edward A. Boyle \\ Massachusetts Institute of Technology, E25-615, 45 Carleton Street, Cambridge, MA 02142
}

\begin{abstract}
An intercalibration of dissolved iron ( $\mathrm{dFe}$ ) concentrations was conducted from samples collected on the GEOTRACES Pacific Intercalibration cruise using two different sampling devices: the GEOTRACES GO-FLO rosette system and MITESS/Vane samplers. At each depth, the dFe concentrations were identical within analytical error, except at $500 \mathrm{~m}$ where contamination in one bottle is suspected. dFe adsorption kinetics to bottle walls was also investigated. Over $29 \mathrm{~h}, 18 \%$ of the dFe adsorbed to the walls of $1 \mathrm{~L}$ bottles, whereas over $15 \mathrm{~h}, 19 \%$ adsorbed to the walls of $250 \mathrm{~mL}$ bottles, suggesting a relationship between dFe adsorption and sample bottle surface area to volume ratio. Contrary to expectations that refrigeration would slow adsorption, cold $250 \mathrm{~mL}$ bottles demonstrated a $29 \%$ dFe loss over $15 \mathrm{~h}$ compared to $19 \%$ loss at room temperature. Finally, we tested the hypothesis that the decreasing dFe observed in successive sub-sampled bottles from the (unacidified) SAFe D1 tank was due not only to adsorption but also to $\mathrm{pH}$-dependent Fe solubility changes resulting from carbon dioxide outgassing to the headspace of the 500L SAFe D1 tank. Filtered, low-pH seawater collected at $1000 \mathrm{~m}$ in the North Pacific was placed into bottles with variable headspace for $15-17 \mathrm{~h}$. The $\mathrm{pH}$ rose with increasing headspace, demonstrating that carbon dioxide outgassed, and dFe decreased in magnitude similar to the SAFe D1 sample. Fe size fractionation results did not conclusively reveal an Fe loss mechanism, but estimates of wall adsorption predicted from our adsorption experiments suggest that the decrease in dFe was more than can be expected by simple adsorption.
\end{abstract}

With John Martin's discovery that iron could be a limiting nutrient in phytoplankton growth (Martin and Fitzwater 1988), marine trace metal biogeochemistry has evolved, with more fieldwork devoted to obtaining trace metal samples, more groups participating in trace metal investigations, and increasing inclusion of trace metal parameters in marine models of nutrient and climate cycles. In 2003, the international GEOTRACES program was founded, which aimed to establish global trace element distributions and quantify the fluxes and

*Corresponding author: E-mail: jessfitz@mit.edu

Acknowledgments

We thank the GEOTRACES Pacific Intercalibration cruise trace metal sampling team for sampling the GO-FLOs and providing assistance deploying the Vane samplers. Many thanks also to the HOT-231 team for integrating the Vane samplers into their larger scientific commitments, and especially Craig Nosse, Susan Curless, Matt Church, and Dave Karl, for the opportunity to participate in the cruise. We also thank Bridget Bergquist for her thoughts on the headspace experiment from the SAFe cruise. Finally, we thank the officers and crew of the R/V Knorr and the R/V Kilo Moana for successful cruise experiences. This work was supported by a National Science Foundation Graduate Research Fellowship (NSF Award \#0645960), NSF OCE-0751409, and NSF-OIA Award \#EF-0424599.

DOI 10.4319/lom.2012.10.437 processes that affect these distributions under variable hydrographic and biogeochemical regimes. The positive international response to this program and the monetary commitment for cruises made by so many countries is a testament to the maturation of the trace metal field.

As interest in trace metal biogeochemistry has grown, the technology associated with collecting uncontaminated seawater samples and analyzing low metal concentrations in seawater's complex matrix has developed as well. However, in response to the limited calibration of the now numerous sample collection, handling, and analytical methods used in the community, an intercalibration committee was established from the inception of the GEOTRACES program to lead and oversee these comparison efforts. The power of an international collaboration is the ability to share the manpower and monetary responsibility for collecting and analyzing globally, but the comparison is only as strong as the many methods can intercalibrate.

Depending on the measurement and metal of interest, there are many points at which analytical and sampling offsets can occur: precleaning (filters, bottles), sample collection (samplers, hydrowire), sample treatment (filtration, handling, acidification), sample processing (leaching, pre-concentra- 
tion), and sample analysis (detection method). Specifically for dissolved trace metal concentration analyses, there are two primary methodological points at which disagreement between labs is likely to occur: during sample collection or during sample analysis. In the case of sample collection, complicating factors may be related to 1) true natural differences in the fraction of metal collected (i.e., filters with different pore sizes collect dissimilar fractions of metal, acidification to different $\mathrm{pH}$ labilizes different metal fractions, etc.) or 2) procedural divergences during sample collection that alter the dissolved metal concentration. For example, some sampling devices may contaminate the dissolved metal fraction if they are not properly cleaned or handled, and certain kinds of subsampling bottles may result in adsorption of trace metals before measurement of the dissolved fraction, while other kinds do not. Only a shipboard intercalibration where multiple sample collection systems are used to collect seawater at the same time, location, and depth and are then measured using identical analytical methods can prove that two sample collection systems produce the same result. In contrast, when comparing laboratory analytical methods, standard reference materials (SRMs) can be used to ensure the viability of a given method. The effort to produce low-concentration, saltwater standard reference materials was significantly advanced during the SAFe cruise of 2004, which resulted in a $1000 \mathrm{~L}$ surface sample (SAFe S1) and a $500 \mathrm{~L}$ sample from $1000 \mathrm{~m}$ (SAFe D2) that were sub-sampled and distributed globally as SRMs (Johnson et al. 2007). The use of one or both of these standards to validate analytical methods is becoming the norm in the trace metal community.

Historically, several facets of shipboard sample collection have been thought to contribute to metal contamination of the seawater sample including the metal hydrowire, the ship's metal "aura" (Schaule and Patterson 1981), metal from internal springs of Niskin samplers, metal messengers, surface water "slicks" that contaminate samplers deployed in an "open" position, and metal carousel frames. Two sampling systems that have overcome these problems during the past decades are external/rubber spring bottle-based systems and MITESS sampler-based systems (Bell et al. 2002; Bruland et al. 1979). MITESS (Moored In-situ Trace Element Sampler System) is an autonomous sampler whose exterior is made entirely of metal-free ultra-high molecular weight polyethylene and contains an internal electronics board and motor that are used to pre-program the sampler to open and close a sample bottle at a designated time (Fig. 1a, Bell et al. 2002). A precleaned plastic bottle filled with slightly acidified distilled water is loaded into the sampler, which is sent to depth closed. The sampler then opens and closes electronically at depth to collect a sample. MITESS samplers can be deployed either in the "Vane" mode (Fig. 1b) or on a mooring apparatus. In the "Vane" mode, the MITESS sampler is loaded into a weathervane-type structure made of PVC and polycarbonate that orients the sampler upstream of the contaminating hydrowire; each MITESS sampler collects seawater from an individual depth. In the MITESS mooring apparatus, twelve MITESS sampling units

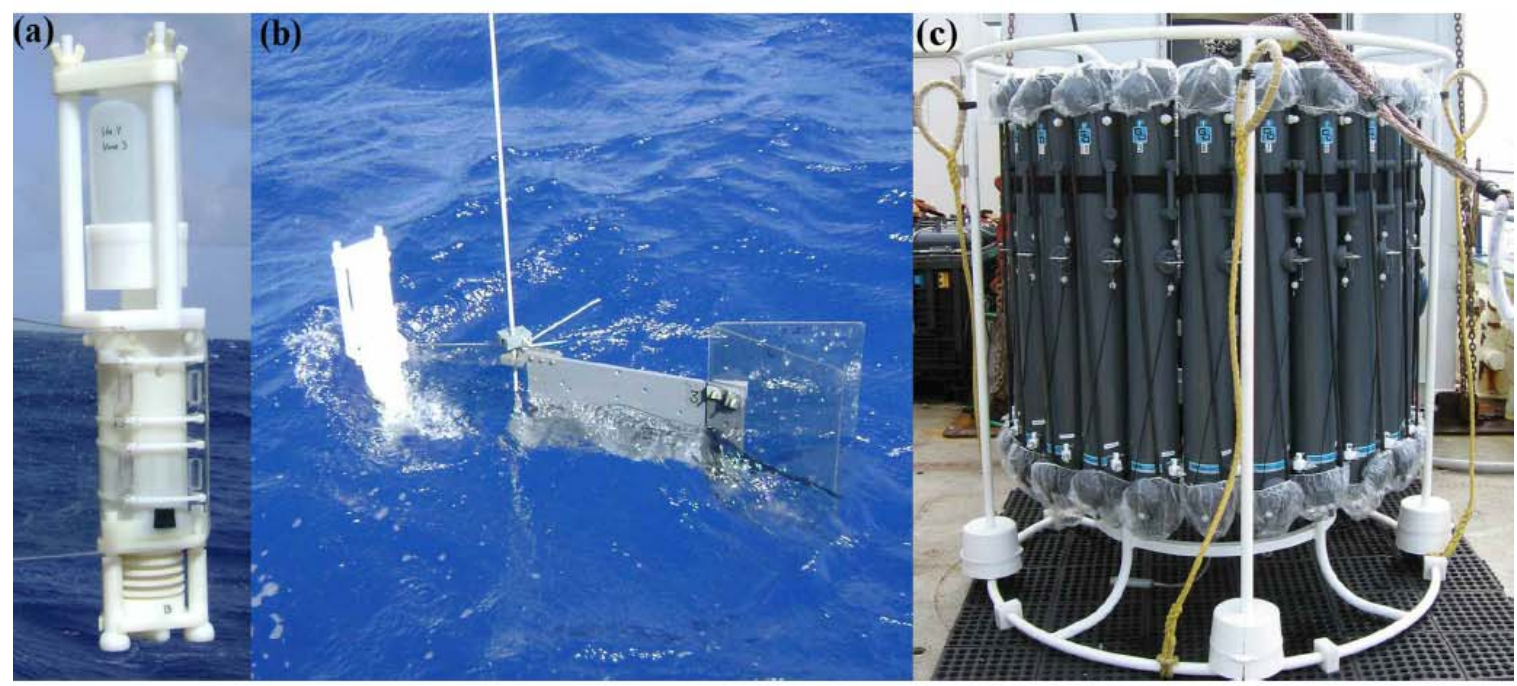

Fig. 1. Sampling devices used in this study's intercalibration. (a) The MITESS unit, externally made of plastic, autonomously opens and closes a precleaned sampling bottle at depth. (b) The MITESS unit can be mounted on a Vane apparatus, which orients the MITESS sampling unit upstream of the hydrowire and Vane body to eliminate potential contamination by the wire. (c) The U.S. GEOTRACES carousel, loaded with $24 \times 12$ L GO-FLO bottles mounted on an epoxy-coated aluminum rosette. Shower caps are used to protect the bottles from contamination on deck and are removed at deployment. 
are housed in a single structure but can open/close individually; although this structure was designed for moorings, it can also be used on a hydrowire to collect samples in vertical profiles (see Bell et al. 2002 for more detailed information).

General Oceanics also manufactures two external-spring sampling bottles that can be used to collected uncontaminated seawater samples: the GO-FLO bottle and the Niskin-X bottle. Either bottle can be deployed individually on a nonmetallic hydrowire or in groups on an epoxy-coated or titanium rosette (Bruland et al. 1979; De Baar et al. 2008; Kuma et al. 2003; Takata et al. 2004). Teflon-encased messengers are used to trip the bottles, or they are tripped electronically via CTD programming or conducting cable (De Baar et al. 2008; Measures et al. 2008). The samplers can be deployed in the "closed" positions to avoid contamination from the ship's "aura" and the surface microlayer, or they can be deployed open and successfully rinse out on their way to depth before they are tripped (Measures et al. 2008).

There are advantages and disadvantages to each of these sampling systems. In the case of the external spring bottles, oftentimes the bottles are open on deck and sent down open, which can contaminate for extremely contamination-prone elements such as $\mathrm{Fe}$ and $\mathrm{Zn}$ if proper care is not observed. The MITESS sample bottles are sealed closed on deck and during deployment, eliminating handling contamination, and the sampling bottle is an acid-cleaned bottle (typically HDPE, but FEP fluorocarbon, polymethylpentene [PMP] and other materials have also been used). However, the MITESS/Vanes units do not easily accommodate in-line sample filtration systems (such as capsule filters), and they have a smaller sample collection volume (0.5-2 L) than GO-FLO and Niskin-X bottles. Moreover, some people have voiced concern that metals might adsorb to the MITESS-sampling bottle before the seawater is filtered and sub-sampled, which could cause the samples to underrepresent the true seawater metal concentration. An unpublished comparison of GO-FLO and MITESS lead $(\mathrm{Pb})$ data at SAFe (2004) and on the U.S. GEOTRACES Atlantic Intercalibration cruise (2008) did not show any differences between sampling systems (Boyle unpub. data), but similar dFe data have not yet been reported.

In this article, we report a comparison of dissolved $\mathrm{Fe}(\mathrm{dFe})$ concentration from samples collected using the U.S. GEOTRACES GO-FLO system (Fig. 1c) and MITESS Vanes. These samples were taken in 2009 at the SAFe station on the U.S. GEOTRACES Pacific Intercalibration (IC2) cruise and were analyzed together by identical protocols. Further, an experiment assessing iron adsorption inside HDPE bottles over time is included. This experiment has implications not only for samples collected using MITESS/Vanes but for all plastic sampling bottles where samples are left unacidified for more than 2-3 $\mathrm{h}$ before analysis or are analyzed using short post-acidification times.

Finally, to expand on the adsorption experiments, we also conducted an experiment on a Hawaii Ocean Time Series cruise (HOT-231) that explored the differential effects of adsorption and $\mathrm{pH}$ changes resulting from carbon dioxide $\left(\mathrm{CO}_{2}\right)$ loss into the head space, which may account for the decreasing dFe observed in the 2004 SAFe D1 SRM (Johnson et al. 2007). On the SAFe cruise, the SAFe D1 seawater sample, collected at $1000 \mathrm{~m}$, was not acidified inside its $500 \mathrm{~L}$ collection tank. Instead, each $500 \mathrm{~mL}$ aliquot was acidified individually after it was sub-sampled from the tank and resulted in consistently decreasing dFe concentrations from 0.9 to $0.7 \mathrm{nM}$ with increasing aliquot number. Johnson et al. (2007) explained this pattern by suggesting that dissolved Fe might have adsorbed to the tank walls during sub-sampling, decreasing the dissolved Fe concentration in samples collected later. An alternate hypothesis is that as the headspace inside the 500-L tank increased, $\mathrm{CO}_{2}$ outgassed from the low-pH $1000 \mathrm{~m}$ seawater sample, increasing the $\mathrm{pH}$ of the seawater inside the tank and changing the speciation and/or solubility of the dFe. As $\mathrm{pH}$ increases, Fe becomes less soluble and would be more likely to form colloids or particles that could aggregate or settle out some of the previously dissolved Fe. The experiment discussed in this article tests this headspace-pH-Fe speciation hypothesis.

\section{Methods}

Cleaning procedures

All water used at sea and in the laboratory was first purified by a general MIT-building deionized water system. It was then passed through a second Barnstead ultrapure deionizing cartridge in our laboratory, and finally distilled in a Corning glass/vycor still. This water was checked for blanks and found to contain negligible $\mathrm{Fe}$ (well below analytical detection limit). Trace metal grade hydrochloric acid $(\mathrm{HCl})$ and nitric acid $\left(\mathrm{HNO}_{3}\right)$ were prepared by redistilling reagent-grade acid four times in a Vycor still. Trace metal work was conducted inside ISO 5 (formerly known as Class 100) flow benches at sea and in the laboratory (unless otherwise indicated), and sample bottles were handled using polyethylene gloves.

All plastic bottles used in this study were HDPE widemouth bottles (with polypropylene caps) that were first immersed open in a reagent grade $2 \mathrm{~N} \mathrm{HCl}$ bath to clean the caps, threads, and exterior and were then rinsed at least five times with pure water. The insides of the bottles were then leached overnight at $60^{\circ} \mathrm{C}$ in $10 \%$ reagent grade $\mathrm{HCl}$, rinsed again at least five times with pure water, and finally leached overnight at $60^{\circ} \mathrm{C}$ in $0.06 \mathrm{~N}$ trace metal grade $\mathrm{HCl}$. The bottles were stored inside plastic ziploc bags until used. $0.4 \mu \mathrm{m}$ Nuclepore $^{\mathrm{TM}}$ polycarbonate track-etched (PCTE) filters and $0.2 \mu \mathrm{m}$ Supor membrane filters were precleaned in the laboratory by soaking in $10 \%$ trace metal grade $\mathrm{HCl}$ overnight in a $60^{\circ} \mathrm{C}$ oven and then rinsed at least five times with clean water one day, then five times again the next day. Whatman Anodisc ${ }^{\mathrm{TM}}$ $0.02 \mu \mathrm{m}$ alumina filters used to collect soluble $\mathrm{Fe}$ (sFe) samples, in contrast, were only rinsed on the ship immediately before use because they decompose in the weeks following 
acid rinsing. $0.2 \mu \mathrm{m}$ Pall Acropak-200 ${ }^{\mathrm{TM}}$ Supor ${ }^{\circledR}$ capsule filters were precleaned by flushing $5 \mathrm{~L}$ filtered surface seawater through the filter and were stored full in the refrigerator until use. Sample collection

Samples for the GEOTRACES GO-FLO and MITESS/Vanes intercalibration were collected on the GEOTRACES IC2 cruise in May 2009 aboard the R/V Knorr at the SAFe station, $30.0^{\circ} \mathrm{N}$ and $140.0^{\circ} \mathrm{W}$. GO-FLO samples were collected as a part of the GEOTRACES Pacific Baseline and were split into two casts: a deep cast on 18 May from $700-4500 \mathrm{~m}$, and a shallow cast (25$600 \mathrm{~m}$ ) in the early hours of 20 May. These samples were collected following guidelines described by Cutter et al. (2010) in the GEOTRACES Intercalibration "Cookbook," but specific details are given below. 24 GO-FLO bottles were mounted onto a Seabird polyurethane powder-coated aluminum rosette (Fig. 1c). The bottles were deployed in the "open" position on a Kevlar conducting cable, but to reduce contamination on deck, the bottles were kept covered on both ends with shower caps until deployment. GO-FLO bottles were first brought to the deepest depth and then tripped on ascent at $1-3 \mathrm{~m} / \mathrm{min}$. Upon reaching deck, shower caps were immediately replaced, and each bottle was moved into the positive-pressure HEPAfiltered air GEOTRACES clean van and mounted onto plastic wall racks. The bottles were pressurized to $\sim 0.4 \mathrm{~atm}$ with HEPA filtered air to enable timely filtration through capsule filers (see Cutter et al. 2010). An 8-cm long piece of acid-cleaned 3/8-inch Bev-a-Line 4 tubing was inserted into the spigot of the GO-FLO. After salinity and nutrient samples were taken, a precleaned $0.2 \mu \mathrm{m}$ Acropak-200 Supor capsule filter was attached to the Bev-a-Line tubing to collect filtered sub-samples after filter rinsing with at least $500 \mathrm{~mL}$ of each seawater sample. Two Acropak filters were used per 24-bottle cast. Subsampling bottles used in this intercalibration were $30 \mathrm{~mL}$ HDPE bottles, rinsed three times each with $\sim 10 \%$ of the bottle volume before filling to the shoulder.

MITESS Vane samples were taken on three different casts on the GEOTRACES IC 2 cruise at the same SAFe station as the GO-FLO samples: $3000 \mathrm{~m}$ on 14 May, $1000-2500 \mathrm{~m}$ and 4000 $\mathrm{m}$ on 15 May, and $25-850 \mathrm{~m}$ and $3500 \mathrm{~m}$ on 18 May. On each cast, the MITESS units were loaded with a $1 \mathrm{~L}$ bottle filled with $\sim 0.001 \mathrm{M}$ trace metal grade $\mathrm{HCl}$ (Fig. 1a), and they were deployed on a Kevlar hydrowire. Vanes were pre-programmed to reach depth before opening, and the bottles remained open for 10-12 min for adequate flushing with seawater before closing. Once on deck, the sealed sample bottles were immediately placed into plastic bags using polyethylene gloves and were not opened until inside an ISO 5 flow bench.

Inside the flow bench, $0.4 \mu \mathrm{m}$ Nuclepore PCTE filters or Whatman Anodisc $0.02 \mu \mathrm{m}$ alumina filters were mounted on a Teflon filtration rig inside the flow bench, and the filters were rinsed with $>100 \mathrm{~mL} 0.06 \mathrm{~N}$ trace metal grade $\mathrm{HCl}$, then $>100$ $\mathrm{mL}$ clean water, and finally $>50 \mathrm{~mL}$ sample. Samples were then vacuum filtered $(0.5 \mathrm{~atm})$ directly into $30 \mathrm{~mL}$ HDPE sample storage bottles after a single bottle rinse. Two to three replicates from each filter type were filtered into separate $30 \mathrm{~mL}$ bottles with the bottle sequence noted. The last replicate filtered was the first sample analyzed, as it had seen the most filter rinsing before collection; contaminating Fe from the filter or filter housing is most likely to be washed out by the time the last sample is filtered, making it the least likely to be contaminated. Filtration of all Vane samples were completed within $3 \mathrm{~h}$ of samples reaching deck on this cruise. The Vanes and GO-FLO samples were all acidified to $\mathrm{pH} 2$ from the same batch $6 \mathrm{~N}$ trace metal grade $\mathrm{HCl}$ by adding $60 \mu \mathrm{L}$ acid to every $30 \mathrm{~mL}$ sample.

\section{Adsorption experiment}

Adsorption of iron onto HDPE bottles of two sizes was tested in this study: $1 \mathrm{~L}$ bottles and $250 \mathrm{~mL}$ bottles. First, on the GEOTRACES IC2 cruise, adsorption was measured in $1 \mathrm{~L}$ bottles. On 11 May 2009, four Vanes were stacked $\sim 1 \mathrm{~m}$ apart on a Kevlar hydrowire and deployed to collect samples at $\sim 1000 \mathrm{~m}$ depth. One of these $1 \mathrm{~L}$ samples was filtered immediately through a $0.4 \mu \mathrm{m}$ Nuclepore filter and an Anodisc 0.02 $\mu \mathrm{m}$ filter as described above. The other three Vanes samples sat untouched in the back of a flow bench for $6 \mathrm{~h}, 12 \mathrm{~h}$, and $29 \mathrm{~h}$ before filtration. Note that a Vane sample, when tripped, has no headspace bubble at all, as seawater completely fills the bottle.

The adsorption experiment was repeated in $250 \mathrm{~mL}$ HDPE bottles on a Hawaii Ocean Time Series cruise (HOT-231, $22^{\circ}$ $45^{\prime} \mathrm{N}, 158^{\circ} 0.0^{\prime} \mathrm{W}$ ) in April 2011, and the procedure is outlined in a flowchart in Fig. 2a. On this cruise, the same sampling procedures were used as described above, except that a $1.5 \mathrm{~L}$ HDPE bottle was loaded into the Vane for sampling instead of the $1 \mathrm{~L}$ bottles used on the GEOTRACES IC2 cruise, and a metal hydrowire was used instead of Kevlar. The use of a metal hydrowire would not contaminate the sample collected, as the Vanes are designed to orient the all-plastic MITESS sampling unit upstream of both the hydrowire and the Vane body itself so that the sampler constantly sees fresh, uncontaminated seawater (Bell et al. 2002). Eight Vanes were stacked on the metal hydrowire ( $1.2 \mathrm{~m}$ apart) and programmed to collect a sample at $\sim 1000 \mathrm{~m}$. Immediately after the Vanes were recovered, five $250 \mathrm{~mL}$ bottles were rinsed inside the flow bench once each with homogenized sample water from a single $1.5 \mathrm{~L}$ Vane bottle and filled to minimize the air bubble inside. Two of these $250 \mathrm{~mL}$ bottles were placed in a plastic bag inside the refrigerator, while the other two were placed inside a plastic bag at room temperature inside a dark box. The remaining $250 \mathrm{~mL}$ sample was filtered immediately using the same filter rig and filtration procedures as on the GEOTRACES IC2 cruise. After 2 $\mathrm{h}$ and $40 \mathrm{~min}$, one refrigerated and one room temperature 250 $\mathrm{mL}$ bottle were filtered, and finally this process was repeated after $15 \mathrm{~h}$ and $40 \mathrm{~min}$ for the remaining two $250 \mathrm{~mL}$ bottles. Filtration order was kept consistent with the $0.02 \mu \mathrm{m}$ filtration completed first, and the cold bottle always filtered before the room temperature bottle. These samples were finally acidified to $\mathrm{pH} 2$ with trace metal grade $\mathrm{HCl}$. 
(a)

\section{Adsorption Experiment (HOT-231)}

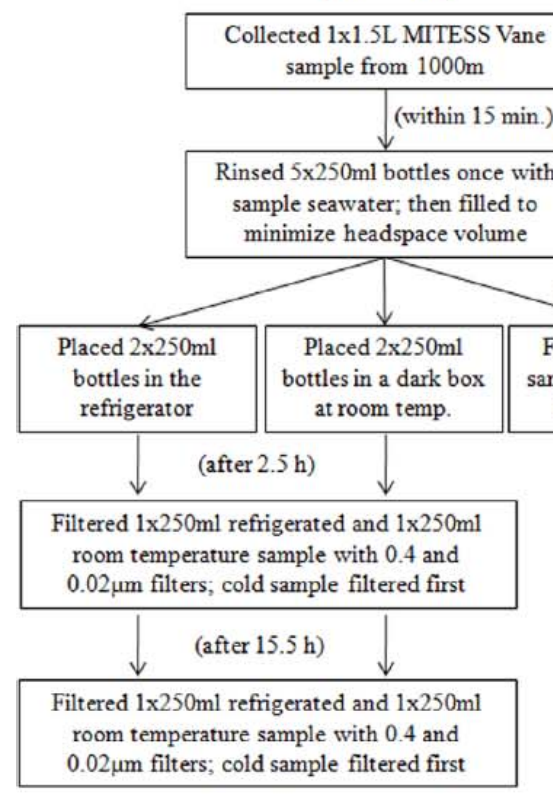

(b)

\section{Headspace Experiment (HOT-231)}

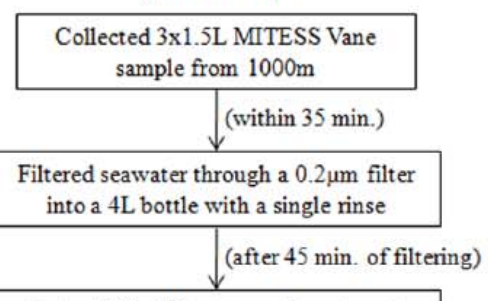

mmediately)

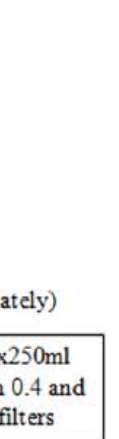

eadspace Experiment bottles (one rinse prior to filling)

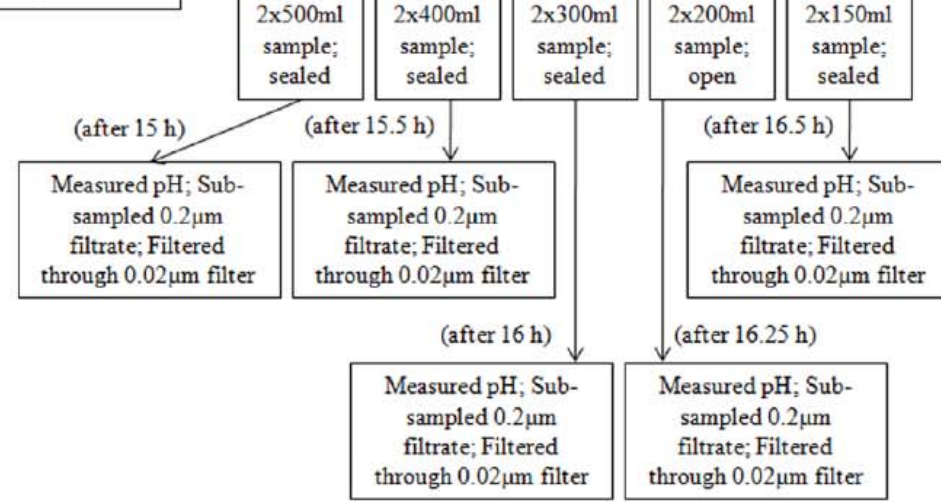

Fig. 2. Flowchart representing the methodological steps and timings of (a) the Adsorption Experiment on the HOT-231 cruise and (b) the Headspace Experiment. The $0.4 \mu \mathrm{m}$ filters were Nuclepore filters, the $0.2 \mu \mathrm{m}$ filters were Supor Acropak capsule filters, and the $0.02 \mu \mathrm{m}$ filters were Anodisc filters.

Headspace experiment

The Headspace Experiment procedure is outlined in a flowchart in Fig. 2b. On the HOT-231 cruise in April 2011, eight Vanes were deployed to $1000 \mathrm{~m}$ depth, as stated above. A half hour after the samplers reached the deck, $4 \mathrm{~L}$ unfiltered seawater from three of the eight Vanes were filtered on the filter rig through a $0.2 \mu \mathrm{m}$ Supor membrane filter into a clean bottle; this served to homogenize the seawater from the three Vanes. This homogenized, filtered seawater was then poured into ten $500 \mathrm{~mL}$ bottles with one of five variable sample volumes after a single rinse each: two replicates of $500 \mathrm{~mL}$ sample, two replicates of $400 \mathrm{~mL}$ sample, two replicates of $300 \mathrm{~mL}$ sample, two replicates of $200 \mathrm{~mL}$ sample, and two replicates of $150 \mathrm{~mL}$ sample. The $200 \mathrm{~mL}$ samples were left uncapped in the rear of the flow bench to establish an "infinite headspace" open system, whereas the other eight bottles were capped tightly and then packed into Ziploc bags for $\sim 15 \mathrm{~h}$. After $\sim 15$ $\mathrm{h}$, the $\mathrm{pH}$ of each sample was recorded, followed by sub-sampling in order of decreasing sample volume. The $\mathrm{pH}$ was mea- sured using a VWR ${ }^{\circledast}$ SympHony ${ }^{\circledR}$ Handheld $\mathrm{pH}$ meter, and the $\mathrm{pH}$ is reported using the National Bureau of Standards (NBS) scale (Bates 1973; Millero et al. 1993). Then two sub-samples were collected: first, a dFe sub-sample was poured into a clean $30 \mathrm{~mL}$ bottle after a single rinse (recall that the seawater in this experiment had been previously filtered using the $0.2 \mu \mathrm{m}$ Supor membrane), and then a sFe sub-sample was collected by passing some sample through a $0.02 \mu \mathrm{m}$ filter using the aforementioned Anodisc protocol. By the end of the sample processing, $16.5 \mathrm{~h}$ had passed since the experiment was begun. Because the sample volumes poured into each headspace experiment $500 \mathrm{~mL}$ bottle were only approximated by eye, a permanent marker was used to mark the height of sample volume in each bottle; after the experiment was completed, these bottles were refilled to the marked line, and the true sample volume of each was quantified using a graduated cylinder. dFe analyses

Samples were analyzed via isotope-dilution ICP-MS using an ${ }^{54} \mathrm{Fe}$ spike and batch preconcentration with nitrilotriacetate 
resin (Lee et al. 2011). Over relevant dissolved Fe analyses for the samples mentioned herein, procedure blanks ranged from 0.021-0.091 nM. Surface seawater collected on the SAFe cruise averaged $0.086 \pm 0.039 \mathrm{nM}(1 \mathrm{SD}, n=25)$; note that this is not the official SAFe S1 SRM but a large volume surface sample collected on the same cruise that is used as an internal lab standard in the Boyle lab (Lee et al. 2011). Comprehensive lab analyses of the SAFe D2 standard for dFe using the Lee et al. (2011) method averaged $0.95 \pm 0.05 \mathrm{nmol} / \mathrm{kg}(1 \mathrm{SD}, n=38$ ) for SAFe D2 bottle 33 and $0.89 \pm 0.03 \mathrm{nmol} / \mathrm{kg}(1 \mathrm{SD}, n=22)$ for SAFe D2 bottle 446 ; this agrees well with the consensus value for this standard of $0.90 \pm 0.02 \mathrm{nmol} / \mathrm{kg}$.

\section{Assessment}

Our intercalibration was designed to identify differences in dFe concentrations arising from the use of various sampling devices (MITESS/Vanes and GEOTRACES GO-FLO bottles), while keeping all other factors constant. Thus, intercalibration samples were collected on the same GEOTRACES IC2 cruise at the same SAFe station. The shallowest Vanes samples, which had the highest probability of variable dFe concentrations over short temporal scales (unpredictable contributions by eddies, dust inputs, and biological activity), were sampled within $2 \mathrm{~d}$ of the GO-FLO samples to reduce the chances that natural dFe variation would spoil the upper $500 \mathrm{~m}$ intercalibration. Filtrates were collected in identical bottles that were precleaned together, and samples were acidified together. In the laboratory, they were analyzed by the same analytical method on the same day. Only two variables remained: sampling method (the variable of interest) and filtration method, which posed a significant risk of complicating the intercalibration. GO-FLO samples were filtered through Acropak 0.2 $\mu \mathrm{m}$ capsule filters under $\sim 0.4 \mathrm{~atm}$ pressure, while Vanes sam- ples were filtered on a filter rig through Nuclepore $0.4 \mu \mathrm{m}$ membrane filters under $0.5 \mathrm{~atm}$ vacuum pressure. A difference of up to $0.3 \mathrm{nM}$ has been reported between $0.2 \mu \mathrm{m}$ and $0.4 \mu \mathrm{m}$ Nuclepore filtrates in samples from the continental shelf $(\mathrm{Wu}$ and Luther 1994).

The results of this intercalibration are shown numerically in Table 1 and graphically in Fig. 3. The dFe concentrations collected using these two methods are identical at each depth within the reported error, except at $500 \mathrm{~m}$. Given the consistency of the results between the two samplers at all other depths, we suspect that the $500 \mathrm{~m}$ Vane sample is contaminated. This positive intercalibration suggests that GO-FLO bottles and MITESS samplers can be used interchangeably to collect trace metal-clean samples at sea. This dFe intercalibration confirms that MITESS samplers adequately flush with seawater in the 10-12 min they are open at depth (which had been shown previously for MITESS samplers using salinity, Bell et al. 2002). Furthermore, the consistent but low dFe concentrations measured for both GO-FLO and MITESS samples at $25 \mathrm{~m}$ suggests that there is no apparent "interface effect" or "surface slick" contamination when GO-FLO bottles are deployed open.

One concern that has been expressed about MITESS samplers is whether the metal concentrations in MITESS sub-samples will be lower than natural concentrations as a result of metal adsorption to the bottle walls (because they collect seawater in a non-conditioned, acid-cleaned bottle). This concern stems from the fact that acid-washing activates plastic adsorption sites (Batley and Gardner 1977). However, the MITESS samplers must be filled with distilled water during deployment in order for the solution inside the bottle to be fully replaced with seawater during sample collection (by buoyancy driven exchange). There is opportunity for even more metal adsorption to bottle walls if long wait times are tolerated

Table 1. Numerical results of the intercalibration between MITESS Vanes and GO-FLO samplers at the SAFe station on the GEOTRACES IC2 cruise. Dissolved Fe concentration is shown in $\mathrm{nM}$ for each sampler, and the external reproducibility is reported as one standard deviation (1SD). The number of replicate analyses for each sample is shown as " $n$." When only one replicate analysis is reported, the long-term external reproducibility of the analytical method $(0.05 \mathrm{nM})$ determined using the SAFe D2 standard is assigned as the error. Samples suspected of contamination are designated in parentheses.

\begin{tabular}{|c|c|c|c|c|c|c|}
\hline \multirow[b]{2}{*}{ Depth (m) } & \multicolumn{3}{|c|}{ Vanes $^{*}$} & \multicolumn{3}{|c|}{ GO-FLO ${ }^{\dagger}$} \\
\hline & $\mathrm{Fe}(\mathrm{nM})$ & 1SD (nM) & $n$ & $\mathrm{Fe}(\mathrm{nM})$ & 1SD (nM) & $n$ \\
\hline 25 & 0.15 & 0.03 & 3 & 0.13 & 0.01 & 3 \\
\hline $100^{*} / 110^{\dagger}$ & 0.07 & 0.04 & 2 & 0.08 & 0.01 & 2 \\
\hline 250 & 0.19 & 0.04 & 3 & 0.25 & 0.02 & 3 \\
\hline 500 & $(1.14)$ & 0.04 & 2 & 0.59 & 0.01 & 3 \\
\hline 700 & 0.87 & 0.01 & 2 & 0.86 & 0.05 & 3 \\
\hline 850 & 0.82 & 0.01 & 2 & 0.83 & 0.03 & 2 \\
\hline 1000 & 0.75 & 0.00 & 2 & 0.77 & 0.01 & 2 \\
\hline 1500 & 0.65 & 0.02 & 2 & 0.65 & 0.02 & 3 \\
\hline 2500 & 0.63 & 0.02 & 2 & 0.61 & 0.00 & 3 \\
\hline 3000 & 0.50 & 0.01 & 3 & 0.54 & 0.00 & 3 \\
\hline 3500 & 0.50 & 0.02 & 2 & 0.50 & 0.01 & 3 \\
\hline 4000 & 0.56 & 0.05 & 1 & 0.57 & 0.01 & 2 \\
\hline
\end{tabular}




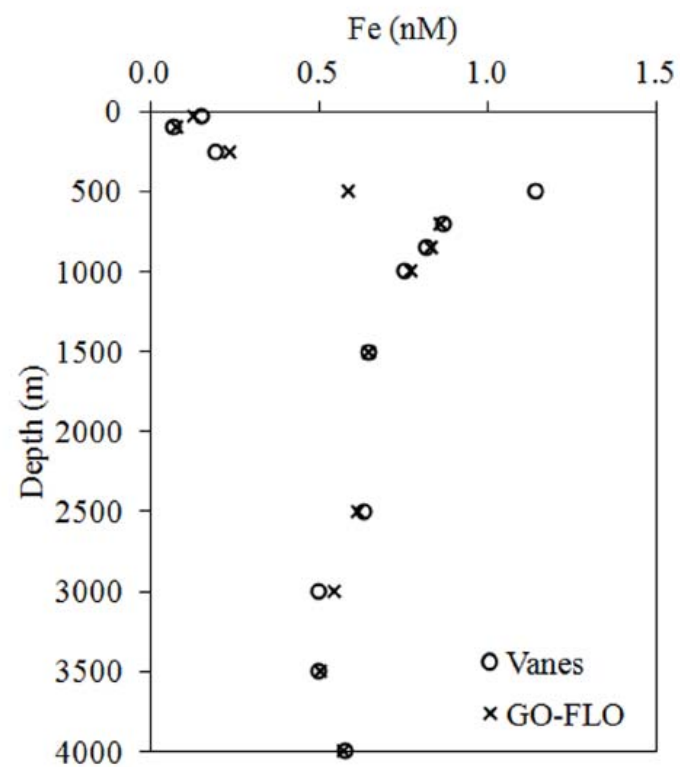

Fig. 3. Comparison of dFe profiles obtained using the MITESS Vanes and GO-FLO sampling systems on the GEOTRACES Pacific Intercalibration cruise. MITESS samples were filtered through $0.4 \mu \mathrm{m}$ Nuclepore membrane filters, while GO-FLO samples were filtered through Acropak Supor $0.2 \mu \mathrm{m}$ capsule filters. The dFe values for the two sampling systems agree within error for all depths except $500 \mathrm{~m}$, where the Vanes sample is suspected to be contaminated.

between seawater sampling and filtration. However, our intercalibration results indicate that there is no systematic difference between samples collected using Vanes and GO-FLO bottles, regardless of the slower off-line filtration used for MITESS samples. Perhaps the long flushing time at depth for MITESS samples may effectively "condition" the bottle walls against adsorption. Regardless, filtration within 3-4 h of sampling is too short a time for enough adsorption to occur that it is distinguishable beyond analytical error across sampling systems.

It is moderately surprising that the dFe concentration from these two sampler types was so consistent despite the different filter types and pore sizes used $(0.4 \mu \mathrm{m}$ Nuclepore membrane and $0.2 \mu \mathrm{m}$ Acropak capsule). In the western North Atlantic $\mathrm{Wu}$ and Luther (1994) measured a significant difference between the dFe of 0.2 and $0.4 \mu \mathrm{m}$ Nuclepore filtrates and defined this difference as the colloidal Fe (cFe) fraction in their study. They report a consistent cFe concentration between 10 $500 \mathrm{~m}$ that contributes $20 \%$ to $45 \%$ of the $<0.4 \mu \mathrm{m}$ Fe fraction; below $750 \mathrm{~m}$, the cFe drops to negligible values. In our intercalibration, there were only four samples analyzed between $10-500 \mathrm{~m}$, and they were identical within error for the two sampling methods used. The difference between 0.2 and $0.4 \mu \mathrm{m}$ filtrates in Wu and Luther's North Atlantic study could be related to a Saharan dust or coastal sedimentary component of suspended colloidal material, neither of which would be expected in the open ocean North Pacific site of this study. Because the size distribution of oceanic Fe species is not well understood, it is impossible to say whether the observed consistency between 0.2 and $0.4 \mu \mathrm{m}$ Fe filtrates in this study is common for samples from other open ocean regions; this warrants further study.

Adsorption experiment

Although adsorption of Fe to the MITESS bottle walls does not appear to occur over the $3 \mathrm{~h}$ it took to filter the intercalibration samples from the GEOTRACES cruise, it is expected that adsorption of metals to the bottle walls would occur over longer time periods. Previous studies of $\mathrm{Fe}$ adsorption using ${ }^{55} \mathrm{Fe}$ additions have shown that $\mathrm{dFe}$ does adsorb to bottle walls with increasing adsorption as a function of bottle material: polycarbonate $\sim$ polyethylene $<$ HDPE $\sim$ polytetrafluoroethylene (PTFE) polymethylmethacrylate (PMMA) < quartz (Fischer et al. 2007). Most significantly, even in the bottles with least adsorption, $50 \%$ of the dFe adsorbed over $70 \mathrm{~h}$, so the potential for adsorption of natural Fe from seawater to bottle walls during sample handling is great.

Ion exchange is the accepted cation adsorption mechanism on organic surfaces, and it is thought that this ion exchange occurs at a charged double layer on the polymer surface (Benes and Smetana 1969). Hydroxide ions compose the inner charged layer after they are sorbed directly to the plastic surface via van der Waals forces or hydrogen bonds. The negative hydroxide charge is balanced by cations from the solution that compose the outer charged layer. It is well established experimentally that adsorption occurs much more frequently to hydrolyzed metals than to free cations (James and Healy 1972a; Starik et al. 1963); this can be explained thermodynamically. Free energy is required to displace the cation's secondary solvation sheath (the primary solvation shell is retained during adsorption), but free energy is also released during coulombic attraction of the metal to the hydroxide surface (James and Healy 1972b). As the average ionic charge of a metal complex decreases, these energies change so that more energy is released during coulombic attraction than is needed to remove the secondary solvation layer, favoring adsorption in hydrolyzed metal complexes with lower oxidation states than in free cations with higher oxidation states.

In seawater, the Fe adsorption story is further complicated as a result of the presence of organic ligands and colloidal Fe aggregates; these compounds may be differentially attracted to the plastic surface. This attraction is difficult to predict theoretically because of the dearth of information available on the chemical structures of these compounds in natural seawater. Whether the natural organic ligand is charged would change the Fe complex's attraction to the plastic surface, as would its size. Furthermore, it is possible that the organic Fe ligand itself might be attracted to the plastic 
either by charge-charge attraction, hydrogen bonding, or van der Waals forces, depending on its structure. A preliminary experiment assessing ${ }^{55} \mathrm{Fe}$ adsorption to polycarbonate bottles indicated that $\mathrm{Fe}^{\prime}$, the sum of the inorganic species of $\mathrm{Fe}(\mathrm{III})$ not complexed by organic ligands, is the only natural dFe class that adsorbs to bottle walls, since in undersaturated solutions where $\mathrm{Fe}$ is bound by the organic ligand desferrioxamine B (DFB), no adsorption was observed over $24 \mathrm{~h}$ (Schlosser and Croot 2008).

The adsorption potential of dFe colloids are even more unclear because of their uncertain organic or inorganic composition. Based on his transmission electron microscopy and coincident energy dispersive spectroscopy studies of samples from across the global ocean, Wells (2002) posits that colloidal Fe in the open ocean is bound by natural dissolved organic matter; it is not inorganically bound. This may be an important distinction because inorganic colloids have been found to be significantly adsorbed by plastic regardless of charge (Benes and Smetana 1969). In summary, it is much more difficult to predict Fe adsorption equilibrium in natural waters, such as seawater, than in lab-based experiments in distilled water, and adsorption kinetics under all conditions are poorly constrained.

In the adsorption experiments completed in this study, we aimed to describe Fe adsorption kinetics in oceanographically relevant terms without the use of added ${ }^{55} \mathrm{Fe}$. Radio-Fe changes the speciation and size distribution of dFe upon addition, making it difficult to extrapolate adsorption results to natural samples. We define dissolved $\mathrm{Fe}(\mathrm{dFe})$ as the $\mathrm{Fe}$ passing through a 0.2 or $0.4 \mu \mathrm{m}$ filter, soluble $\mathrm{Fe}(\mathrm{sFe})$ as the Fe passing through a $0.02 \mu \mathrm{m}$ filter, and colloidal $\mathrm{Fe}(\mathrm{cFe})$ as the calculated difference between $\mathrm{dFe}$ and sFe. Unfiltered and unacidified seawater samples were kept in HDPE bottles for variable amounts of time, after which they were filtered for $\mathrm{dFe}$ and $\mathrm{sFe}$ and acidified. This experiment was undertaken both on the GEOTRACES IC2 cruise at SAFe and on the HOT231 cruise at Station ALOHA, and all experiments were completed on water from $1000 \mathrm{~m}$, a depth which has been shown to have high dFe concentrations in the Pacific Ocean. The adsorption results from both of these experiments are shown numerically in Table 2 and graphically as a function of time in Fig. 4, demonstrating at both sites that significant adsorption occurs for both dFe and sFe.

On the GEOTRACES cruise, four Vanes were tripped at 1000 $\mathrm{m}$ at the SAFe station, and these samples were allowed to adsorb to the four $1 \mathrm{~L}$ HDPE bottles in which they were collected for up to $40 \mathrm{~h}$ (Fig. 4a). Initial homogeneity of these four samples is assumed, as each of the Vanes was only a meter apart; homogeneity was not explicitly monitored because we did not want to introduce air bubbles into the bottles for fear that a miniature "Headspace Experiment" (see below) would complicate our adsorption results. As the results in Fig. 4a indicate, $18 \%$ of the dFe was adsorbed to the $1 \mathrm{~L}$ bottles after $29 \mathrm{~h}$ for a final reduction in dFe of $0.18 \mathrm{nM}$. These results were corroborated in the replicate adsorption experiment on HOT-231 (Fig. 4b), where unfiltered water from $1000 \mathrm{~m}$ was immediately transferred to $250 \mathrm{~mL}$ HDPE bottles with minimal headspace after sampling with the Vanes. In the HOT-231 experiment, dFe decreased $19 \%$ after $15.5 \mathrm{~h}$. It is important to note that adsorption in the HOT cruise samples occurred despite an initial rinse of all bottles with sample before filling; thus, it is not likely that quick bottle rinses change the adsorption characteristics of the bottle surface. Furthermore, the increased adsorption rate (approximately doubled) for the HOT cruise samples can be attributed to the increased surface area to volume ratio (SA:V, Table 2) in the $250 \mathrm{~mL}$ bottles used on HOT as compared to the $1 \mathrm{~L}$ bottles on GEOTRACES. These results are consistent with a relationship between adsorption rate and $S A: V$, as would be expected for a surface-active process. SA:V correlations with adsorption rate are not unprecedented in the literature: previous studies of PMMA have demonstrated this relationship by increasing the number of small pieces of PMMA plastic (with a known surface area) in contact with a known volume of solution to produce a correlation between amount of ${ }^{55} \mathrm{Fe}$ adsorbed and PMMA surface area (Fischer et al. 2007).

Table 2. Adsorption experiment results. All concentrations are expressed in $\mathrm{nM}$, and the parenthetical values are the percentage Fe decreased from the initial concentration. " $\mathrm{C}$ " indicates samples kept cold in a refrigerator, and " $\mathrm{W}$ " indicates samples maintained warm at room temperature.

\begin{tabular}{|c|c|c|c|c|}
\hline & \multicolumn{2}{|c|}{$\begin{array}{c}\text { GEOTRACES Pacific Intercalibration Cruise } \\
1 \text { L bottles } \\
\text { SA:V ratio }=0.576 \mathrm{~cm}^{-1}\end{array}$} & \multicolumn{2}{|c|}{$\begin{array}{c}\text { HOT-231 Cruise } \\
250 \mathrm{~mL} \text { bottles } \\
\text { SA:V ratio }=0.902 \mathrm{~cm}^{-1}\end{array}$} \\
\hline & $\mathrm{dFe}$ & $\mathrm{sFe}$ & $\mathrm{dFe}$ & $\mathrm{sFe}$ \\
\hline Initial & $0.94(0 \%)$ & - & $1.08(0 \%)$ & $0.70(0 \%)$ \\
\hline $2.5 \mathrm{~h}$ & - & - & $\begin{array}{l}\text { C: } 0.90(17 \%) \\
\text { W: } 0.97(10 \%)\end{array}$ & $\begin{array}{c}\text { C: } 0.66(7 \%) \\
\text { W: } 0.73(-4 \%)\end{array}$ \\
\hline $6 \mathrm{~h}$ & $0.85(9 \%)$ & 0.65 & - & - \\
\hline $13.3 \mathrm{~h}$ & $0.80(15 \%)$ & 0.46 & - & - \\
\hline $15.5 \mathrm{~h}$ & - & - & $\begin{array}{l}\text { C: } 0.77(29 \%) \\
\text { W: } 0.88(19 \%)\end{array}$ & $\begin{array}{l}\text { C: } 0.56(20 \%) \\
W: 0.44(43 \%)\end{array}$ \\
\hline $29 \mathrm{~h}$ & $0.76(18 \%)$ & 0.51 & & \\
\hline
\end{tabular}



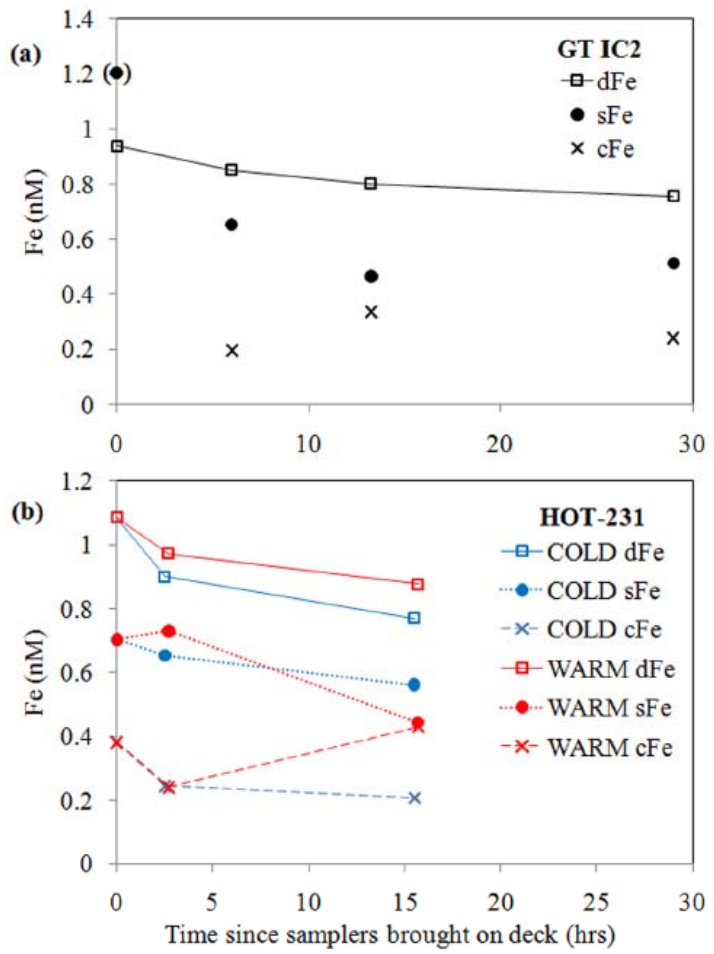

Fig. 4. Adsorption Experiment: Fe concentrations after unfiltered seawater was left unacidified in HDPE bottles for variable amounts of time. (a) Samples are taken from $1000 \mathrm{~m}$ at the SAFe site on the GEOTRACES IC2 cruise. The water was left in $1 \mathrm{~L}$ bottles before it was filtered with $0.4 \mu \mathrm{m}$ Nuclepore ( $\mathrm{dFe}$ ) and $0.02 \mu \mathrm{m}$ Anodisc filters (sFe). The sFe in parenthesis was filtered using a cracked filter and thus does not reflect the true sFe concentration. (b) Samples are taken from $1000 \mathrm{~m}$ at Station ALOHA on the HOT-231 cruise. The seawater was kept in $250 \mathrm{~mL}$ bottles in a refrigerator (COLD) and a dark box at room temperature (WARM) before it was filtered with $0.2 \mu \mathrm{m}$ Supor filters (dFe) and $0.02 \mu \mathrm{m}$ Anodisc filters (sFe). $\mathrm{cFe}$ is calculated as the difference between $\mathrm{dFe}$ and $\mathrm{sFe}$.

On both the HOT and GEOTRACES IC2 cruises, adsorption was evident on timescales as short as a few hours, which suggests that sub-sampling should be completed as soon as possible after sampling. For Vanes samples, sub-sampling cannot occur much faster than $\sim 3 \mathrm{~h}$ after sampling, yet $10 \%$ adsorption is observed in $250 \mathrm{~mL}$ bottles within $2.5 \mathrm{~h}$. Fortunately, Vanes sample bottles hold a large volume sample (1-2 L) and thus maintain a much lower SA:V ratio than the $250 \mathrm{~mL}$ bottles that demonstrate rapid adsorption kinetics. Consistent with the SA:V relationship to adsorption proposed by the 250 $\mathrm{mL}$ and $1 \mathrm{~L}$ bottle data, the $1 \mathrm{~L}$ Vanes bottles should accrue much less adsorption over the $3 \mathrm{~h}$ that it takes to sub-sample, and thus no dFe adsorption to bottle walls was observed in the earlier intercalibration between $1 \mathrm{~L}$ Vanes samplers and GOFLO samples.

Descriptions of adsorption by dFe analyses alone are not sufficient to determine whether soluble or colloidal Fe contribute most significantly to the adsorption of Fe onto plastic bottle walls. This additional detail was investigated on both cruises by examining the size fractionation of Fe in the adsorbing solution, and the results are indicated in Fig. 4. On the GEOTRACES IC2 cruise (Fig. 4a), the initial timepoint sFe sample was unfortunately contaminated by a cracked Anodisc filter $(\mathrm{sFe}>\mathrm{dFe})$. The next two timepoints, however, indicate a decrease in sFe from 0.65 to $0.49 \pm 0.03 \mathrm{nM}$. This decrease does suggest that sFe participates in adsorption to bottle walls, but given only three datapoints and the unrelenting risk of contamination, we repeated the experiment on the HOT-231 cruise. The comparable room temperature data in Fig. $4 \mathrm{~b}$ from the HOT cruise indicates a much clearer pattern. No significant adsorption of soluble Fe occurred over the first $3 \mathrm{~h}$, with sFe averaging $0.72 \mathrm{nM}$ during this time. By $15 \mathrm{~h}$, sFe dropped to $0.44 \mathrm{nM}$, an almost $40 \%$ decrease. The independent adsorption experiment bottles left in the refrigerator (temperature results discussed below) corroborate this drop of sFe, with a decrease of $20 \%(0.14 \mathrm{nM})$ of the sFe over the same $15 \mathrm{~h}$. These results suggest that soluble Fe does contribute significantly to the dFe adsorption. Colloidal Fe (equal to dFe - sFe), on the other hand, did not demonstrate a clear adsorption trend on either cruise and actually increased concentration at room temperature on both cruises. The cFe increase may indicate that sFe is aggregating instead of being adsorbed.

Finally, trace metal oceanographers often put sample bottles in a dark refrigerator after they are collected but before they are filtered, acidified, or analyzed to slow or stop any biological or chemical reactions that might change the metal concentration of the sample. This hypothesis was tested explicitly for bottle wall adsorption on the HOT cruise by comparing the dFe from $250 \mathrm{~mL}$ adsorption experiment bottles placed in a refrigerator against identical bottles kept at room temperature. The results are shown in Fig. 4b and demonstrate that the seawater kept cold actually adsorbed more dFe ( $29 \%$ over $15 \mathrm{~h})$ than the seawater maintained at room temperature ( $19 \%$ over $15 \mathrm{~h})$, and the pattern had already presented after only $2.5 \mathrm{~h}$ of adsorption time ( $17 \%$ adsorbed cold versus $10 \%$ adsorbed warm). Although it might be expected that at low temperatures adsorption kinetics would slow, these results suggest that adsorption may instead be under thermodynamic control. Adsorption is an exothermic process (Bartell et al. 1951), and thus it is expected that equilibrium adsorption would be increased at low temperatures. In the refrigerated samples, all size fractions of $\mathrm{Fe}$ demonstrate progressive losses, indicating that adsorption is the dominant process changing the metal concentration of the seawater sample at cold temperatures. On the other hand, in the room temperature samples the sFe and cFe did not demonstrate clear patterns, suggesting that aggregation to form colloids might also contribute to metal dynam- 
ics within the sample over time. It is possible, then, that dFe aggregation reactions are temperature-dependent; this warrants further exploration.

Headspace- $\mathrm{CO}_{2}$ loss experiment

In the spirit of examining trends of Fe loss, we undertook another experiment on the HOT cruise to investigate whether adsorption was the only mechanism causing the decrease in dFe concentration of successive SAFe D1 aliquots with time (Johnson et al. 2007). In a $500 \mathrm{~L}$ tank such as the one used on the 2004 SAFe cruise, the sample SA:V ratio would be expected to be quite small, and thus much less adsorption would be likely to occur than in the small volume bottles explored in this study. We specifically tested an alternate hypothesis that the dFe decrease occurred because of dFe aggregation and/or precipitation as a result of $\mathrm{pH}$ increases caused by $\mathrm{CO}_{2}$ outgassed into the increasing headspace of the SAFe D1 $500 \mathrm{~L}$ tank. This outgassing and possible change in Fe solubility would only occur in regions where the seawater $\mathrm{pH}$ is very low and the iron concentration is very high, such as at $1000 \mathrm{~m}$ depth in the North Pacific at SAFe (in 2004) and at HOT in the study presented here. To complete the experiment on the HOT cruise, we sub-sampled aliquots of filtered but unacidifed seawater from $1000 \mathrm{~m}$ into $500 \mathrm{~mL}$ bottles with headspaces ranging from $50 \mathrm{~mL}$ to open systems. These samples were kept in their bottles for $15-17 \mathrm{~h}$, during which time it was expected that the $\mathrm{CO}_{2}$ outgassing within the bottle, $\mathrm{pH}$ change, and possible Fe speciation/solubility changes would occur. After this time, each sample was monitored for $\mathrm{pH}$, sub-sampled, and filtered for sFe.

First, we had to establish that $\mathrm{CO}_{2}$ did outgas from the seawater. Given that the seawater was maintained in a $500 \mathrm{~mL}$ bottle under still conditions (besides the vibration and roll of the ship), it would be expected that $\mathrm{CO}_{2}$ exchange with the headspace air would occur by molecular diffusion, the most significant flux occurring in the bottles with the greatest headspace (most thermodynamic drive). We can assess this exchange by calculating the change in $\mathrm{pH}$ between the initial seawater sample and the same seawater sample after equilibration in a closed system consisting of defined liquid and air volumes. According to GLODAP (Key et al. 2004), 1000 m SAFe seawater has a DIC of $\sim 2361 \mu \mathrm{mol} / \mathrm{kg}$ and an alkalinity of $\sim 2372 \mu \mathrm{eq} / \mathrm{kg} ; 1000 \mathrm{~m}$ HOT seawater has a DIC of $\sim 2339$ $\mu \mathrm{mol} / \mathrm{kg}$ and an alkalinity of $\sim 2371 \mu \mathrm{eq} / \mathrm{kg}$. We assume the air space in our ventilated flow bench aboard the ship has a $\mathrm{p}_{\mathrm{CO} 2}$ of $385 \mathrm{ppmV}$. Using the equilibrium constants for seawater recommended by Millero (1995), these compositions imply that upon equilibration with the atmosphere the initial $\mathrm{pH}$ of 7.36 for SAFe should rise to 8.07 , and the initial $\mathrm{pH}$ of 7.42 for HOT $1000 \mathrm{~m}$ water would rise to $\mathrm{pH} 8.07$. As can be seen in Fig. 5a, the $\mathrm{pH}$ did increase with headspace volume from a $\mathrm{pH}$ of 7.6 to a $\mathrm{pH}$ in excess of 8.0 when the bottle was left uncapped, demonstrating that $\mathrm{CO}_{2}$ outgassing did occur and proceeded as expected by equilibrium. The offset between the predicted HOT sample $\mathrm{pH}$ and the lowest measured $\mathrm{pH}$ (sam-
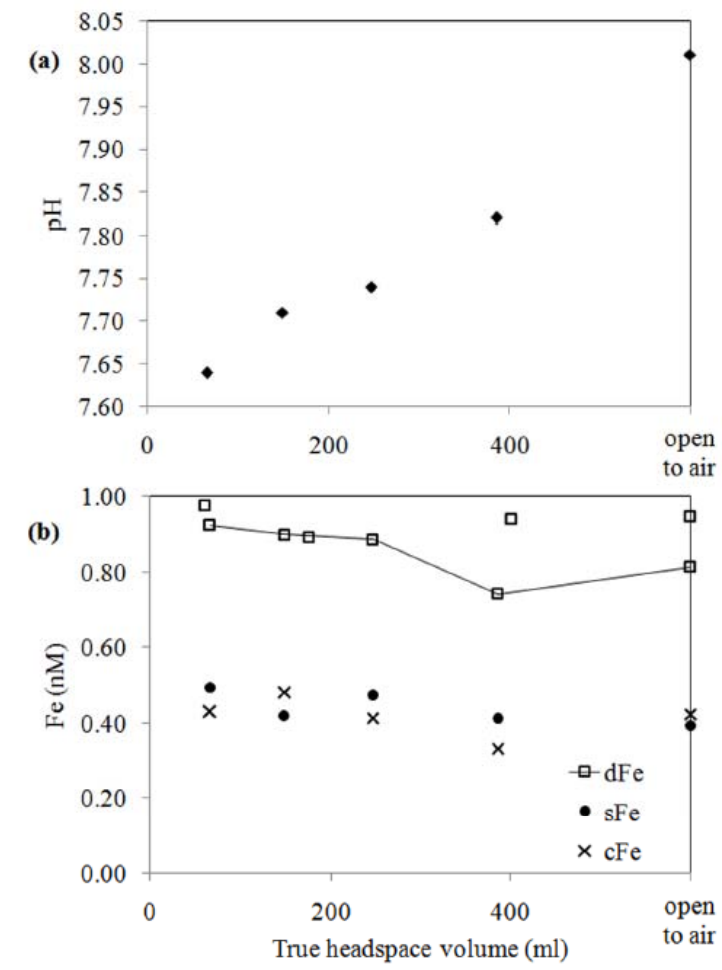

Fig. 5. Headspace Experiment results after $15-17 \mathrm{~h}$ time in $500 \mathrm{~mL}$ bottles with variable headspace. Samples were collected at the HOT station at $1000 \mathrm{~m}$, filtered using a $0.2 \mu \mathrm{m}$ Supor membrane filter, and homogenized (unacidified) before being placed into the $500 \mathrm{~mL}$ bottles. (a) Seawater $\mathrm{pH}$ increased with increasing headspace, indicating that carbon dioxide successfully outgassed from the seawater into the headspace. (b) Fe size fractions as a function of headspace volume. All dFe samples are shown (except a $2.2 \mathrm{nM}$ sample at $300 \mathrm{~mL}$ headspace, which was contaminated), yet the dFe trendline excludes samples suspected of contamination. sFe and $\mathrm{CFe}$ are only shown for the samples indicated in the dFe trendline.

ple with the least headspace) can be attributed to initial outgassing during sample processing and experiment setup, as well as outgassing during the experiment into the $65 \mathrm{~mL}$ headspace for the $500 \mathrm{~mL}$ sample.

In the $\mathrm{pH}$ range 7.3 to 8.1 , inorganic $\mathrm{Fe}$ speciation is defined by the chemical transformation of $\mathrm{Fe}(\mathrm{OH})_{2}{ }^{+}$into dissolved $\mathrm{Fe}(\mathrm{OH})_{3}{ }^{\circ}$, which becomes the dominant species around $\mathrm{pH}$ 7.5. Liu and Millero (2002) measured the Fe solubility as a function of $\mathrm{pH}$ in two seawater samples with different natural ligand concentrations, and the results demonstrate decreases in $\mathrm{dFe}$ of $0.1-0.2 \mathrm{nM}$ over this $\mathrm{pH}$ range that would result from Fe speciation changes. They are also careful to note the possible contribution of colloids (Liu and Millero 1999): over time, dissolved $\mathrm{Fe}(\mathrm{OH})_{3}{ }^{\circ}$ equilibrates with colloidal $\mathrm{Fe}(\mathrm{OH})_{3}$, which 
can aggregate and precipitate if present. Thus, not only are Fe speciation changes happening over this $\mathrm{pH}$ range, but changes in the colloidal behavior of dFe also occur. In fact, the point of zero charge of $\mathrm{Fe}(\mathrm{OH})_{3}$ is 7.5 (Cornell et al. 1989), indicating the $\mathrm{pH}$ at which an $\mathrm{Fe}(\mathrm{OH})_{3}$ solid surface is neutrally charged; at this $\mathrm{pH}, \mathrm{Fe}(\mathrm{OH})_{3}{ }^{\circ}$ species experience maximal attraction to any $\mathrm{Fe}(\mathrm{OH})_{3}$ colloids present via van der Waals forces, and aggregation is optimized. Thus, over the $\mathrm{pH}$ range that the SAFe D1 seawater tank experienced during outgassing, not only did Fe solubility changes occur that could have resulted in dFe precipitation, but aggregation of $\mathrm{Fe}(\mathrm{OH})_{3}$ species was favored and might have led to precipitation of amorphous minerals on the tank walls or even settling/aggregation of particles in the bottom of the SAFe tank.

The headspace experiment results from the HOT cruise are shown in Fig. 5b. This experiment was performed in duplicate, and it appears that a few of the replicate headspace bottles suffered from contamination despite being rinsed once before filling. When the suspected contaminated samples are excluded, however, a decreasing trend for dFe with increasing headspace is apparent (indicated by the line). The reduction in dFe from the $50 \mathrm{~mL}$ headspace sample to the $390 \mathrm{~mL}$ headspace sample was a significant $0.18 \mathrm{nM}$ drop, very close to the $\sim 0.2 \mathrm{nM}$ decrease observed in the SAFe D1 sub-samples. This indicated to us that a significant dFe removal mechanism was operating in our headspace experiment samples that may reflect changes in the $\mathrm{pH}$ of the seawater sample.

To investigate whether precipitation or colloidal aggregation mechanisms might be operating, the Fe size fractionation was measured, and the results are shown in Fig. 5b. Colloidal Fe shows no significant variation with headspace. sFe similarly demonstrates no reliable trend. Our results thus do not conclusively prove a single Fe loss chemical transformation, and future studies would be required to reveal the acting mechanism.

To complicate matters, it was impossible to complete this headspace experiment without also completing an adsorption experiment because the seawater was maintained unacidified for 15-17 h. Adsorption was, in fact, the hypothesized explanation given by Johnson et al. (2007) for the dFe loss in the SAFe D1 tank, and as our adsorption experiment results show, a $15 \%$ adsorption of dFe would be predicted over the time these samples were kept unacidified (assuming the kinetics of a $1 \mathrm{~L}$ bottle). If the SAFe D1 tank adsorption kinetics were the same as our observations for $1 \mathrm{~L}$ bottles (which seems unlikely because of the large difference in SA:V ratio between $1 \mathrm{~L}$ bottles and the 500 L SAFe D1 tank), at the maximal 15\% adsorption rate over $15 \mathrm{~h}$, only 0.13 of the $0.20 \mathrm{nM}$ drop in the SAFe D1 dFe could be explained by adsorption in the absence of headspace effects, indicating that another Fe removal mechanism was also in operation. However, it is important to remember that this $15 \%$ adsorption is based on a surface area to volume ratio for $1 \mathrm{~L}$ bottles that is much greater than that of the 500 L SAFe D1 tank, so this is an upper limit on the contribution of adsorption to the dFe loss.
On the HOT cruise, the adsorption experiment samples were collected at the same time and nominal depth as the headspace experiment samples and can be used for comparison. To be clear, the adsorption experiment samples were filtered using a $0.4 \mu \mathrm{m}$ membrane filter, not the $0.2 \mu \mathrm{m}$ filter used for the headspace experiment, although our intercalibration results at SAFe indicate no difference between $0.2 \mu \mathrm{m}$ and $0.4 \mu \mathrm{m} \mathrm{dFe}$ at 1000 $\mathrm{m}$ in the North Pacific. Since we observed a change in the adsorption rate with sample surface area to volume ratio (SA:V) in the adsorption experiment, and we would expect a change in the $\mathrm{SA}: \mathrm{V}$ ratio for each of the variable headspace samples, we calculated how much dFe loss could be attributed to adsorption (in the absence of headspace) for each of the headspace bottles based on their SA:V ratio. The results are shown in Table 3 and indicate that if the initial dFe concentration in the adsorption experiment $(1.08 \mathrm{nM})$ is assumed to be the same as the initial dFe concentration in the headspace experiment, adsorption can only fully explain the dFe loss in the samples with low headspace. The samples with the largest headspace, in contrast, show a much greater loss of dFe than is predicted by adsorption alone, indicating that another dFe removal mechanism is operating. Because these samples with large headspace volume demonstrated the greatest $\mathrm{pH}$ increases, a mechanism of Fe solubility and/or speciation change is implicated.

In summary, although our experiment could not resolve the mechanism of dFe loss, our results do suggest that for low$\mathrm{pH}$, high dFe samples such as the SAFe D1 tank sample, outgassing of $\mathrm{CO}_{2}$ and the resulting $\mathrm{pH}$ increase causes a change in Fe solubility and/or speciation that leads to a loss of dFe to particles or large colloids that settle out or nucleate on the walls of the container. This chemical transformation is separate from normal metal adsorption to the bottle walls and is specific to the aquatic chemistry of seawater and natural dFe, not the chemistry of the bottle or container. We recommend that when sampling waters suspected of having a low $\mathrm{pH}$ and high dFe concentration that every effort be made to minimize the headspace in the bottle and process the sample as quickly as possible to prevent $\mathrm{CO}_{2}$ loss. This may include sampling GO-FLO bottles with the lowest $\mathrm{pH}$ first, so as to minimize the time they sit pressurized.

\section{Discussion}

Our intercalibration results suggest that GO-FLO and MITESS Vane samplers can be used interchangeably to collect uncontaminated seawater samples for dFe analysis. This will become especially important for the GEOTRACES program when metal distributions from transects sampled using GOFLO rosette systems are compared with published profiles collected using Vane samplers. For instance, several profiles in the western Atlantic Ocean collected using Vane profiles (Bergquist and Boyle 2006; Bergquist et al. 2007) intersect with the U.S. North Atlantic east-west transect and the Dutch north-south Atlantic transect, and now they can be compared without hesitation (besides filter type, which warrants future 
Table 3. Estimated contribution of adsorption (in the absence of headspace) to the decrease of dFe in the headspace experiment over $15 \mathrm{~h}$. The adsorption experiment $250 \mathrm{~mL}$ and $1 \mathrm{~L}$ data used to obtain an adsorption/SA:V relationship are shown at the top. Surface areas are calculated assuming the bottle is a perfect cylinder (height is taken at the base of the neck), and therefore, represent slight overestimations because the bottles are curved at the bottom and the shoulder. The $\%$ dFe expected to remain in the $500 \mathrm{~mL}$ headspace bottles are calculated using a linear extrapolation as a function of surface area:volume (SA:V) ratio of the measured adsorption experiment values shown.

\begin{tabular}{|c|c|c|c|c|c|c|c|}
\hline $\begin{array}{l}\text { Bottle } \\
\text { size } \\
(\mathrm{mL}) \\
\end{array}$ & $\begin{array}{c}\text { Headspace } \\
\text { volume } \\
(\mathrm{mL})\end{array}$ & $\begin{array}{c}\text { Sample } \\
\text { volume } \\
(\mathrm{mL})\end{array}$ & $\begin{array}{c}\text { Surface } \\
\text { area } \\
\left(\mathrm{cm}^{2}\right)\end{array}$ & $\begin{array}{l}\mathrm{SA}: \mathrm{V} \\
\text { ratio } \\
\left(\mathrm{cm}^{-1}\right)\end{array}$ & $\begin{array}{l}\% \mathrm{dFe} \\
\text { expected to } \\
\text { remain }\end{array}$ & $\begin{array}{c}\text { Measured } \\
\text { dFe } \\
(\mathrm{nM})\end{array}$ & $\begin{array}{c}\text { Measured \% } \\
\text { dFe remaining } \\
\left(1.08 \mathrm{nM}^{*}\right)\end{array}$ \\
\hline 250 & 0 & 280 & 224.1 & 0.800 & $80.7 \%$ & & \\
\hline 1000 & 0 & 1055 & 589.0 & 0.558 & $85.2 \%$ & & \\
\hline 500 & 50 & 500 & 324.4 & 0.648 & $83.5 \%$ & 0.92 & $85.5 \%$ \\
\hline 500 & 150 & 400 & 267.2 & 0.668 & $83.2 \%$ & 0.90 & $83.3 \%$ \\
\hline 500 & 250 & 300 & 210.0 & 0.700 & $82.6 \%$ & 0.89 & $82.1 \%$ \\
\hline 500 & Infinite & 170 & 135.7 & 0.798 & $80.8 \%$ & 0.81 & $75.3 \%$ \\
\hline 500 & 400 & 150 & 124.2 & 0.828 & $80.2 \%$ & 0.74 & $68.7 \%$ \\
\hline
\end{tabular}

'The measured \% dFe remaining is calculated assuming an initial sample dFe concentration of $1.08 \mathrm{nM}$, as measured in the adsorption experiment initial timepoint sample.

study). Nonetheless, there are advantages and disadvantages for each sampler. GO-FLO samplers collect higher volume samples than the Vanes and can accommodate faster-flowing in-line capsule filtration, whereas the Vanes must be filtered using an external filtration apparatus, which increases chances of contamination. In addition, Vanes have an inherently larger manpower requirement, as they must be built from their pieces at the start of a cruise and maintained in working order throughout. GO-FLO samplers, however, cannot be deployed on a metal hydrowire without contamination, as the Vane samples collected at HOT in this study could. There is also a major cost differential between these two systems: the GEOTRACES GO-FLO system (including winch, rosette, cable, and clean van) is purchased and shipped at a much higher cost than the Vanes, which can be broken down and shipped in small boxes.

Our adsorption experiment results demonstrate that adsorption does occur inside acid-cleaned HDPE bottles, even when they are pre-rinsed, but that if samples are filtered within a few hours of collection the adsorption is insignificant compared to the uncertainty in the dFe analytical measurement. It appears that soluble and colloidal Fe are both adsorbed and that there is a relationship between surface area to volume ratio and adsorption rate, as would be expected. However, because the seawater samples used in these experiments were unfiltered, we cannot preclude that natural biological reactions or particle adsorption might also contribute to the changes in dFe concentration with time that we have attributed to bottle wall adsorption.

The adsorption effects demonstrated herein do not only apply to HDPE bottles collected using Vane samplers. These adsorption effects would also apply to samples that remain unacidified in other types of bottles for long periods of time before analysis. Samples analyzed at sea by spectrophotomet- ric or chemiluminescent methods, for example, should be analyzed quickly after sample collection to prevent metal adsorption to the walls, or a significant amount of time should be provided for redissolution of dissolved metals from the bottles walls, especially because these samples are frequently collected in small bottles with large SA:V ratios and thus suffer the largest adsorption effect. Similarly, samples analyzed for metal speciation are frequently frozen at sea, and it is not clear that adsorption is prevented before freezing. In fact, the effect of freezing samples at sea for future analyses has been studied for dFe, and there is a marked difference between Fe solubility measurements of frozen and fresh samples due to a variable "grow-in" period of dFe during melting (Schlosser et al. 2011). Even Teflon-coated GO-FLO and Niskin-X bottles suffer adsorption effects, although perhaps to a lesser extent given the lower SA:V ratio of these large-volume samplers.

Finally, the headspace experiment suggests that the SAFe D1 $1000 \mathrm{~m}$ sample exhibited not only Fe adsorption to the walls of the $500 \mathrm{~L}$ tank, as suggested by Johnson et al. (2007), but also $\mathrm{pH}$ related changes in Fe solubility and speciation that caused $\mathrm{Fe}$ to precipitate or Fe colloids to aggregate and settle out. Although sample $\mathrm{pH}$ was not measured on the SAFe cruise in 2004, thermodynamics calculations indicate that the SAFe D1 seawater likely increased from a $\mathrm{pH}$ of $\sim 7.35$ to a $\mathrm{pH}$ in excess of 8.0 during the sub-sampling of the unacidified tank sample as a result of $\mathrm{CO}_{2}$ outgassing to the headspace. Fe adsorption alone, as measured in our adsorption experiment in the absence of headspace, was not sufficient to explain the drop in dFe that occurred inside this large tank; in fact, the adsorption would be minimized in a tank with such a large surface area to sample volume ratio. Thus, pH-dependent Fe speciation/solubility changes are implicated as a cause for the observed dFe losses. 


\section{Comments and recommendations}

The consistency of dFe concentrations collected using Vanes and GO-FLO samplers is encouraging, although the effects of the chosen filter type might be significant in the upper $500 \mathrm{~m}$. Since much existing dFe data have been generated using $0.4 \mu \mathrm{m}$ Nuclepore filters while future data will likely be published with the $0.2 \mu \mathrm{m}$ capsule filters recommended for use on GEOTRACES cruises, we recommend that more studies be completed constraining the geographic variability of this $0.2-0.4 \mu \mathrm{m}$ Fe fraction. These types of intercalibration efforts are beginning to be undertaken (De Jong et al. 2000; Ken Bruland pers. comm.). Moreover, when using a new filter type, it would be best to intercalibrate it with filters used more commonly so as to best integrate the new data into the established literature.

The results of the adsorption experiment constrained $\mathrm{dFe}$ adsorption kinetics in HDPE bottles and the relationship between bottle surface area to volume ratio and adsorption rate. However, the translation of these rates to other bottle types is not clear. Bruland et al. (1979) state that no adsorption of copper, nickel, zinc, or cadmium occurred to the Tefloncoated walls of GO-FLO bottles when left for $2 \mathrm{~h}$ before subsampling. Similarly, no adsorption occurs in our $1 \mathrm{~L} \mathrm{HDPE}$ bottles from the MITESS units in $2 \mathrm{~h}$ either, yet the sampling of GO-FLO bottles can require many hours on cruises with a large number of sub-sample bottles and limited personnel. We recommend that adsorption tests be completed on all bottle types, especially those with small volumes, whenever long wait times are encountered. Furthermore, when extended delays are expected before sample processing, we recommend keeping the bottles at room temperature where exothermic adsorption reactions are less likely to occur. However, since surprising colloidal dynamics occurred in the samples kept at room temperature, further study is warranted on the potential temperature-dependence of colloidal Fe aggregation.

Finally, the results of our headspace experiment suggest that low $\mathrm{pH}$, high dFe samples will outgas $\mathrm{CO}_{2}$, increase $\mathrm{pH}$, and experience Fe solubility changes if sufficient headspace and time are allowed. We recommend that to collect unbiased $\mathrm{dFe}$ samples, headspaces over low $\mathrm{pH}$, high dFe samples should be avoided, and sampling of the lowest $\mathrm{pH}$ samples should be completed first and as quickly as possible. This includes many deep ocean samples, especially in the North Pacific where $\mathrm{pH}$ is particularly low after accumulated remineralization along thermohaline circulation. The warming of these cold, deep samples as they are brought up through warm shallow waters and into the warm atmosphere only serves to further the potential $\mathrm{CO}_{2}$ outgassing, since gases are less soluble in warm water than in cold water. This headspace effect also has significant implications for GO-FLO samplers pressurized with air and especially those pressurized with nitrogen, which would suffer more outgassing as a result of the negligible partial pressure of $\mathrm{CO}_{2}$ in the pure nitrogen headspace.
Seawater sub-samples collected for dFe measurements at sea by flow injection or chemiluminescent methods should be filled to the top to minimize headspace or should be analyzed soon after sampling to avoid dFe losses.

\section{References}

Bartell, F. E., T. L. Thomas, and Y. Fu. 1951. Thermodynamics of adsorption from solutions. IV. Temperature dependence of adsorption. J. Phys. Chem. 55:1456-1462 [doi:10.1021/ j150492a005].

Bates, R. G. 1973. Determination of $\mathrm{pH}$, theory and practice, 2nd ed. Wiley.

Batley, G. E., and D. Gardner. 1977. Sampling and storage of natural waters for trace metal analysis. Water Res. 11:745756 [doi:10.1016/0043-1354(77)90042-2].

Bell, J., J. Betts, and E. Boyle. 2002. MITESS: a moored in situ trace element serial sampler for deep-sea moorings. DeepSea Res. I 49:2103-2118 [doi:10.1016/S0967-0637(02) 00126-7].

Benes, P., and J. Smetana. 1969. Radiochemical study of the sorption of trace elements. IV. Adsorption of iron on polyethylene and its state in aqueous solutions. Collection of Czechoslovak Chemical Communications 34:1360-1374.

Bergquist, B. A., and E. A. Boyle. 2006. Dissolved iron in the tropical and subtropical Atlantic Ocean. Glob. Biogeochem. Cycle 20:14 [doi:10.1029/2005GB002505].

, J. Wu, and E. A. Boyle. 2007. Variability in oceanic dissolved iron is dominated by the colloidal fraction. Geochim. Cosmochim. Acta 71:2960-2974 [doi:10.1016/ j.gca.2007.03.013].

Bruland, K. W., R. P. Franks, G. A. Knauer, and J. H. Martin. 1979. Sampling and analytical methods for the determination of copper, cadmium, zinc, and nickel at the nanogram per liter level in sea water. Anal. Chim. Acta 105:233-245 [doi:10.1016/S0003-2670(01)83754-5].

Cornell, R. M., R. Giovanoli, and W. Schneider. 1989. Review of the hydrolysis of iron(III) and the crystallization of amorphous iron(III) hydroxide hydrate. J. Chem. Technol. Biotechnol. 46:115-134 [doi:10.1002/jctb.280460204].

Cutter, G., and others. 2010. Sampling and Sample-handling Protocols for GEOTRACES Cruises. Version 1.0. http://www.geotraces.org/science/intercalibration.

De Baar, H. J. W., and others. 2008. Titan: A new facility for ultraclean sampling of trace elements and isotopes in the deep oceans in the international Geotraces program. Mar. Chem. 111:4-21 [doi:10.1016/j.marchem.2007.07.009].

De Jong, J. T. M., M. Boye, V. F. Schoemann, R. F. Nolting, and H. J. W. De Baar. 2000. Shipboard techniques based on flow injection analysis for measuring dissolved $\mathrm{Fe}, \mathrm{Mn}$ and $\mathrm{Al}$ in seawater. J. Environ. Monitor. 2:496-502 [doi:10.1039/ b002762f].

Fischer, A. C., J. J. Kroon, T. G. Verburg, T. Teunissen, and H. T. Wolterbeek. 2007. On the relevance of iron adsorption to container materials in small-volume experiments on iron 
marine chemistry: 55Fe-aided assessment of capacity, affinity and kinetics. Mar. Chem. 107:533-546 [doi:10.1016/ j.marchem.2007.08.004].

James, R. O., and T. W. Healy. 1972a. Adsorption of hydrolyzable metal ions at the oxide-water interface. I. Co(II) adsorption on $\mathrm{SiO} 2$ and $\mathrm{TiO} 2$ as model systems. J. Colloid Interface Sci. 40:42-52 [doi:10.1016/0021-9797(72)90172-5]. - and $-1972 \mathrm{~b}$. Adsorption of hydrolyzable metal ions at the oxide-water interface. III. A thermodynamic model of adsorption. J. Colloid Interface Sci. 40:65-81 [doi:10.1016/0021-9797(72)90174-9].

Johnson, K. S., and others. 2007. Developing standards for dissolved iron in seawater. EOS Trans. AGU 88:131-132 [doi:10.1029/2007EO110003].

Key, R. M., and others. 2004. A global ocean carbon climatology: Results from Global Data Analysis Project (GLODAP). Global Biogeochem. Cycles 18:GB231 [doi:10.1029/2004 GB002247].

Kuma, K., Y. Isoda, and S. Nakabayashi. 2003. Control on dissolved iron concentrations in deep waters in the western North Pacific: Iron(III) hydroxide solubility. J. Geophys. Res. 108:3289 [doi:10.1029/2002JC001481].

Lee, J.-M., E. A. Boyle, Y. Echegoyen-Sanz, J. N. Fitzsimmons, R. Zhang, and R. A. Kayser. 2011. Analysis of trace metals $(\mathrm{Cu}, \mathrm{Cd}, \mathrm{Pb}$, and $\mathrm{Fe})$ in seawater using single batch Nitrilotriacetate resin extraction and isotope dilution inductively coupled plasma mass spectrometry. Anal. Chim. Acta 686:93-101 [doi:10.1016/j.aca.2010.11.052].

Liu, X., and F. J. Millero. 1999. The solubility of iron hydroxide in sodium chloride solutions. Geochim. Cosmochim. Acta 63:3487-3497 [doi:10.1016/S0016-7037(99)00270-7].

— and - 2002. The solubility of iron in seawater. Mar. Chem. 77:43-54 [doi:10.1016/S0304-4203(01)00074-3].

Martin, J. H., and S. E. Fitzwater. 1988. Iron deficiency limits phytoplankton growth in the north-east Pacific subarctic. Nature 331:341-343 [doi:10.1038/331341a0].

Measures, C. I., W. M. Landing, M. T. Brown, and C. S. Buck. 2008. A commercially available rosette system for trace metal-clean sampling. Limnol. Oceanogr. Methods 6:384394 [doi:10.4319/lom.2008.6.384].

Millero, F. J. 1995. Thermodynamics of the carbon dioxide system in the oceans. Geochim. Cosmochim. Acta 59:661-677 [doi:10.1016/0016-7037(94)00354-O].

[ , and others. 1993. The use of buffers to measure the $\mathrm{pH}$ of seawater. Mar. Chem. 44:143-152 [doi:10.1016/03044203(93)90199-X].

Schaule, B. K., and C. C. Patterson. 1981. Lead concentrations in the northeast Pacific: evidence for global anthropogenic perturbations. Earth Planet. Sci. Lett. 54:97-116 [doi:10.1016/0012-821X(81)90072-8].

Schlosser, C., and P. L. Croot. 2008. Application of cross-flow filtration for determining the solubility of iron species in open ocean seawater. Limnol. Oceanogr. Methods 6:630642 [doi:10.4319/lom.2008.6.630].

, C. L. De La Rocha, and P. L. Croot. 2011. Effects of iron surface adsorption and sample handling on iron solubility measurements. Mar. Chem. 127:48-55 [doi:10.1016/ j.marchem.2011.07.008].

Starik, I. E., V. N. Scebetkobskij, and I. A. Skulskij. 1963. The absorption of radioactive isotopes on polymer adsorbents that are not ion-exchangers III. Radiokhimiya 4:393-398.

Takata, H., and others. 2004. Spatial variability of iron in the surface water of the northwestern North Pacific Ocean. Mar. Chem. 86:139-157 [doi:10.1016/j.marchem.2003. 12.007].

Wells, M. L. 2002. Marine colloids and trace metals, p. 367404. In A. H. Dennis and C. A. Carlson [eds.], Biogeochemistry of marine dissolved organic matter. Academic Press.

Wu, J., and G. W. Luther. 1994. Size-fractionated iron concentrations in the water column of the western North Atlantic Ocean. Limnol. Oceanogr. 39:1119-1129 [doi:10.4319/ 1o.1994.39.5.1119].
Submitted 26 July 2011 Revised 13 March 2012 Accepted 7 April 2012 


\title{
Chapter 3
}

\section{Dissolved iron in the tropical North Atlantic Ocean}

\author{
Reprinted with permission of Marine Chemistry.
}

Fitzsimmons, J.N., Zhang, R., and Boyle, E.A. 2013. Dissolved iron in the tropical North Atlantic Ocean. Marine Chemistry 154: 87-99.

\begin{abstract}
Seawater from 27 stations was sampled in a zig-zag transect across the tropical North Atlantic from Barbados to the Cape Verde Islands, $7-20^{\circ} \mathrm{N}$ and $21-58^{\circ} \mathrm{W}$. Under the Northwest African dust plume, surface dissolved $\mathrm{Fe}(\mathrm{dFe})$ was elevated, averaging $0.55 \pm$ $0.29 \mathrm{nmol} / \mathrm{kg}$ (1SD), but showed a wide range from 0.12 to $1.31 \mathrm{nmol} / \mathrm{kg}$ with no clear longitudinal or latitudinal gradients. A subsurface dFe maximum in excess of $1 \mathrm{nmol} / \mathrm{kg}$ was evident coincident with the oxygen minimum zone. Our goal was to determine whether this maximum occurred as a result of remineralization of high $\mathrm{Fe}: \mathrm{C}$ organic material formed in the dust-laden (Fe-rich) surface ocean or as a result of lateral mixing of a coastal $\mathrm{Fe}$ signal from the African margin. We found that $\mathrm{dFe}$ is directly related to apparent oxygen utilization (AOU)with the same slope across all depths sampled, which implies a remineralization source throughout the water column. A continental margin $\mathrm{dFe}$ supply was discounted because a modeled margin Fe source should cause curvature in the Fe-AOU relationship that was not observed. We also did not see a significant dissolved manganese $(\mathrm{dMn})$ plume emanating from the margin. Regenerated Fe:C ratios calculated from the dFe:AOU relationships ranged from 9.6 to $12.4 \mu \mathrm{mol} \mathrm{Fe} / \mathrm{mol} \mathrm{C}$, which is much higher than ratios found in HNLC and dust-poor regions. Deep waters measured at one station in the eastern tropical North Atlantic reflected typical NADW concentrations until $4000 \mathrm{~m}$, where the $\mathrm{dFe}$ increased to $0.82 \mathrm{nmol} / \mathrm{kg}$ in four discrete samples down to $5000 \mathrm{~m}$. We propose that this increase in $\mathrm{dFe}$ may reflect $\mathrm{dFe}$ inputs to deep waters as they traverse the Mid-Atlantic Ridge and enter the eastern basin.
\end{abstract}




\title{
Dissolved iron in the tropical North Atlantic Ocean
}

\author{
Jessica N. Fitzsimmons ${ }^{a, *}$, Ruifeng Zhang ${ }^{b, 1}$, Edward A. Boyle ${ }^{c, 2}$ \\ a MIT/WHOI Joint Program in Chemical Oceanography, MIT E25-615, 45 Carleton St, Cambridge, MA 02142, USA \\ b State Key Laboratory for Estuarine \& Coastal Research, East China Normal University, 3663 North Zhongshan Road, Shanghai 200062, China \\ c Massachusetts Institute of Technology, MIT E25-619, 45 Carleton St, Cambridge, MA 02142, USA
}

\section{A R T I C L E I N F O}

\section{Article history:}

Received 26 December 2012

Received in revised form 6 May 2013

Accepted 6 May 2013

Available online 23 May 2013

Keywords:

Dissolved iron

Oxygen minimum zon

Trace metals

Tropical North Atlantic

Biogeochemistry

GEOTRACES

\begin{abstract}
A B S T R A C T
Seawater from 27 stations was sampled in a zig-zag transect across the tropical North Atlantic from Barbados to the Cape Verde Islands, $7-20^{\circ} \mathrm{N}$ and $21-58^{\circ} \mathrm{W}$. Under the Northwest African dust plume, surface dissolved Fe (dFe) was elevated, averaging $0.55 \pm 0.29 \mathrm{nmol} / \mathrm{kg}$ (1SD), but showed a wide range from 0.12 to $1.31 \mathrm{nmol} / \mathrm{kg}$ with no clear longitudinal or latitudinal gradients. A subsurface dFe maximum in excess of $1 \mathrm{nmol} / \mathrm{kg}$ was evident coincident with the oxygen minimum zone. Our goal was to determine whether this maximum occurred as a result of remineralization of high $\mathrm{Fe}: \mathrm{C}$ org anic material formed in the dust-laden (Fe-rich) surface ocean or as a result of lateral mixing of a coastal Fe signal from the African margin. We found that dFe is directly related to apparent oxygen utilization (AOU) with the same slope across all depths sampled, which implies a remineralization source throughout the water column. A continental margin dFe supply was discounted because a modeled margin Fe source should cause curvature in the Fe-AOU relationship that was not observed. We also did not see a significant dissolved manganese $(\mathrm{dMn})$ plume emanating from the margin. Regenerated Fe:C ratios calculated from the $\mathrm{dFe}: \mathrm{AOU}$ relationships ranged from 9.6 to $12.4 \mu \mathrm{mol} \mathrm{Fe} / \mathrm{mol} \mathrm{C}$, which is much higher than ratios found in HNLC and dust-poor regions. Deep waters measured at one station in the eastern tropical North Atlantic reflected typical NADW concentrations until $4000 \mathrm{~m}$, where the $\mathrm{dFe}$ increased to $0.82 \mathrm{nmol} / \mathrm{kg}$ in four discrete samples down to $5000 \mathrm{~m}$. We propose that this increase in $\mathrm{dFe}$ may reflect dFe inputs to deep waters as they traverse the Mid-Atlantic Ridge and enter the eastern basin.
\end{abstract}

(c) 2013 Elsevier B.V. All rights reserved.

\section{Introduction}

Dissolved iron ( $\mathrm{dFe}$ ) is a marine micronutrient essential for proteins in the photosynthetic apparatus as well as pathways responsible for the conversion between fixed nitrogen species (Morel et al., 2003). Models of nutrient limitation for photosynthesis and nitrogen fixation suggest that more than $40 \%$ of surface ocean primary production is limited by Fe (Moore and Braucher, 2008; Moore et al., 2002). The accuracy of these models, however, is limited by how well marine nutrient distributions are known, and measurements of micronutrient dFe are still relatively scarce in many regions of the ocean.

The tropical North Atlantic Ocean is an especially important area to study the distribution and cycling of dFe for several reasons. First, an extensive oxygen minimum zone ( $\mathrm{OMZ}$ ) extends westward from the northem African coast with oxygen concentrations as low as $40-60 \mu \mathrm{mol} / \mathrm{kg}$. This OMZ forms because coastal upwelling promotes oxygen consumption via respiration in the thermocline (Karstensen et al., 2008), while at the same time, physical replenishment of the biologically utilized oxygen

\footnotetext{
* Corresponding author. Tel.: +1617324 0283.

E-mail addresses: jessfitz@mit.edu (J.N. Fitzsimmons), rfzhang@sklec.ecnu.edu.cn (R. Zhang), eaboyle@mit.edu (E.A. Boyle).

Tel.: +862162233890

Tel.: + 16172533388 .
}

0304-4203/\$ - see front matter $\odot 2013$ Elsevier B.V. All rights reserved http://dx.doi.org/10.1016/j.marchem.2013.05.009 by circulation is minimized because this region lies in an under-ventilated "shadow zone" (Luyten et al., 1983). While these suboxic oxygen concentrations are not low enough to favor the stability of soluble $\mathrm{Fe}(\mathrm{II})$, this region is still an important OMZ in which to juxtapose Fe cycling with OMZs that do favor $\mathrm{Fe}$ (II) formation such as the subtropical Southeastem Pacific OMZ (Blain et al., 2008), the Peru upwelling region (Bruland et al., 2005), and the Arabian Sea OMZ (Moffett et al., 2007). The tropical North Atlantic has also been shown to be the OMZ that has expanded and intensified the most in the last fifty years (Stramma et al., 2008b), with a measured deoxygenation rate of $0.5 \mu \mathrm{mol} / \mathrm{kg} / \mathrm{year}$ (Stramma et al., 2009), providing cause for a thorough investigation of Fe distributions in order to predict how further intensification of the OMZ might change future Fe and carbon cycling there. Finally, and arguably most importantly, the tropical North Atlantic receives some of the highest rates of dust deposition in the world, as the trade winds blow dust from northwest Africa over the tropical North Atlantic (Gao et al., 2001). Since $3.5 \%$ of African dust is composed of Fe (Zhu et al., 1997), dissolved Fe (dFe) concentrations in the tropical North Atlantic are likely to be higher than other oceanic regions (Jickells et al., 2005). Thus, the tropical North Atlantic is an ideal location in which to investigate how atmospherically derived $\mathrm{Fe}$ is translated into oceanic dFe.

Only three studies have reported dFe profiles in the tropical North Atlantic Ocean. Rijkenberg et al. (2012) recently investigated dFe concentrations near the Cape Verde Islands, and Bergquist and Boyle 
(2006a) reported in the western tropical North Atlantic a dFe maximum of $1.2 \mathrm{nmol} / \mathrm{kg}$ at $500 \mathrm{~m}$, coincident with the oxygen minimum, at $10^{\circ} \mathrm{N}, 45^{\circ} \mathrm{W}$. Similarly, a north-south transect of dFe along $20-29^{\circ} \mathrm{W}$ was reported by Measures et al. (2008) who observed a dFe maximum from 4 to $19^{\circ} \mathrm{N}$ in excess of $1.5 \mathrm{nM}$, again coincident with the oxygen minimum. Although it is expected that dFe should be elevated in surface waters underlying the North African dust plume and that this signal would be transferred to the $\mathrm{OMZ}$ via particle sinking and remineralization, these high dFe concentrations imply Fe: $\mathrm{C}$ ratios three times what is considered typical of oceanic organic matter (Sunda, 1997). These dFe maxima in excess of $1 \mathrm{nmol} / \mathrm{kg}$ are surprising considering that minimum dissolved oxygen concentrations reach only $50-100 \mu \mathrm{mol} / \mathrm{kg}$, making it unlikely that $\mathrm{Fe}$ (II) contributes significantly to the dFe maximum. Two possible hypotheses for the enrichment of dFe in this region are: 1) remineralization in the oxygen minimum zone of high $\mathrm{Fe}: \mathrm{C}$ organic matter formed in the Fe-rich (dust-laden) surface ocean, or 2) lateral mixing of a dFe plume released from reducing sediments along the African margin. Several recent studies have suggested that continentally-derived Fe fluxes to the open ocean may be as significant as dust fluxes (Elrod et al., 2004), and particulate shelf Fe has been found hundreds of kilometers from shore (Lam et al., 2006). In this paper, we describe the spatial variability of dFe in the tropical North Atlantic from 6 to $20^{\circ} \mathrm{N}$ and from 52 to $22^{\circ} \mathrm{W}$ to evaluate which of these two aforementioned hypotheses contributes most significantly to the $\mathrm{dFe}$ maximum in this region

\section{Methods}

\subsection{Seawater sampling}

In August 2008, trace metal clean seawater samples were collected from 27 stations in the tropical North Atlantic Ocean aboard the $R / V$ Oceanus (OC 449-2), which traveled from Bridgetown, Barbados, to Mindelo Sao Vicente, Cape Verde Islands, along the cruise track shown in Fig 1. The northernmost stations are situated on the edge of the subtropical gyre (upper ocean salinity $>37$ ) and thus experience more oligotrophic conditions (pycnoclines depressed to $400 \mathrm{~m}$, chlorophyll max at $\sim 130 \mathrm{~m}$ ) than the rest of the stations that lie in the equatorial region (upper ocean salinity <37) and experience shallower pycnoclines of $150-200 \mathrm{~m}$ and maximum chlorophyll concentrations at $40-90 \mathrm{~m}$ depth. The main characteristic of the tropical North Atlantic region is its broad oxygen minimum (Fig. 1), with minimum oxygen concentrations reaching as low as $48 \mu \mathrm{mol} / \mathrm{kg}$ at $500 \mathrm{~m}$ depth.
A rosette of $24 \times 8 \mathrm{~L}$ Niskin bottles with a Seabird CTD were used to make the hydrographic measurements on the cruise. At each depth, three unfiltered seawater samples were collected for nutrient analysis in $30 \mathrm{~mL}$ vials after three rinses each. An unfiltered seawater sample for dissolved oxygen analysis was also collected in a $125 \mathrm{~mL}$ Erlenmeyer flask through a tube that filled the flask from the bottom until it overflowed at least twice its volume, at which point the tube was removed and the flask was immediately stoppered to minimize bubbles; all efforts were made to reduce bubbles in the tube and in the sample during sample collection.

The uncontaminated seawater samples reported in this study were collected using the weathervane version of the Moored In situ Trace Element Serial Samplers (MITESS) (Bell et al., 2002) following the techniques described in Fitzsimmons and Boyle (2012). Each MITESS module, made entirely of ultrahigh molecular weight polyethylene, opens and closes an acid-cleaned 1 L HDPE bottle while underwater in order to minimize contamination by the ship and eliminate sample handling effects on the ship's deck. Near-surface samples $(\sim 7 \mathrm{~m})$ were collected using the "ATE" (Automated Trace Element) sampler, a single MITESS unit deployed manually off the side of the ship, using a plastic-coated line. All deeper samples were collected using MITESS Vanes attached to a metal hydrowire; the metal wire does not contaminate the seawater sample because the plastic vane rotates freely around the hydrowire, orienting the sampling bottle upstream of the metal wire. Samples were $0.5 \mathrm{~atm}$ vacuumfiltered through $0.4 \mu \mathrm{m}$ Nuclepore ${ }^{\mathrm{TM}}$ filters on a Teflon filter holder directly into acid-cleaned $30 \mathrm{~mL}$ HDPE sub-sampling bottles after rinsing once with $\sim 10 \mathrm{~mL}$ of filtered sample. All filtrates were acidified on the ship to $\mathrm{pH}$ 2. MITESS Vane sample collection has been found to produce dFe concentrations indistinguishable from those collected by the U.S GEOTRACES GO-FLO carousel system (Fitzsimmons and Boyle, 2012).

\subsection{Nutrient measurements}

Oxygen measurements were made at sea by the classical Winkler procedure as modified by Strickland and Parsons (1968). Reactive phosphorus analyses were also made at sea using the colorimetric detection of the phosphomolybdate complex as described by Murphy and Riley (1962) using a Shimadzu UV-120-02 spectrophotometer.

\section{3. dFe measurement}

Samples were analyzed for dFe at least three months after acidification in triplicate $(1.5 \mathrm{~mL}$ each) via isotope dilution inductively coupled plasma mass spectrometry (ID-ICP-MS) on a hexapole collision cell

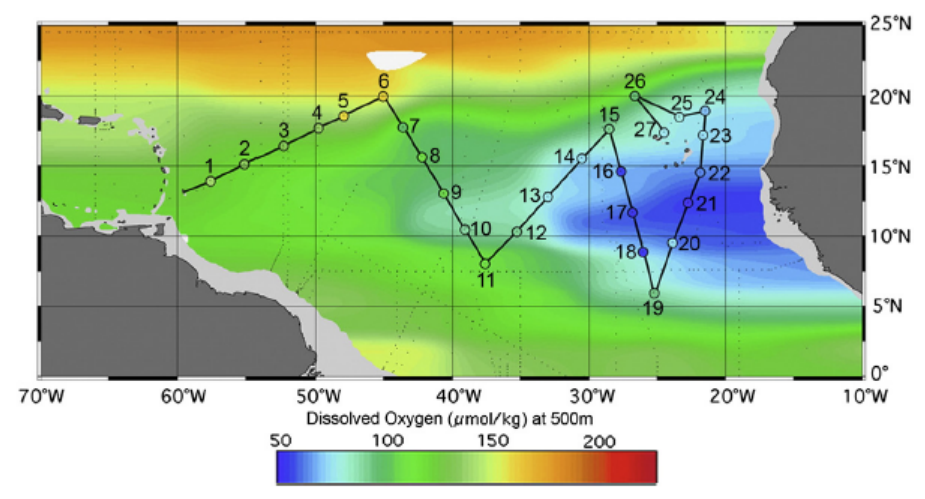

Fig. 1. The sampling transect with station numbers identified. Profiles were taken to $1000 \mathrm{~m}$ at all stations except Station 13 , where a full depth profile to $\sim 5000 \mathrm{~m}$ was taken; Station 13 represents the deepest part of the transect, located in the abyssal plain east of the Mid-Atlantic Ridge. Color contours indicate the distribution of dissolved oxygen at $500 \mathrm{~m}$ taken from the eWOCE dataset (small dots). Colors inside the station dots indicate the dissolved oxygen concentrations at $500 \mathrm{~m}$ measured on our cruise. (For interpretation of the references to color in this figure legend, the reader is referred to the web version of this article.) 
IsoProbe using an ${ }^{54} \mathrm{Fe}$ spike and batch pre-concentration with nitrilotriacetate (NTA) resin (Lee et al., 2011). During the period of these analyses, procedural blanks averaged $0.18 \mathrm{nM}$, most of which came from the NTA resin, and these blanks were very reproducible during a single analytical session (1SD of procedure blanks ranged from 0.005 $0.05 \mathrm{nmol} / \mathrm{kg}$ resulting in an average detection limit of $0.08 \mathrm{nmol} / \mathrm{kg}$ ) Surface seawater collected on the SAFe cruise (not SAFe $S$ standard reference material but water collected at the same station, used as a Boyle lab internal standard) averaged $0.10 \pm 0.04 \mathrm{nmol} / \mathrm{kg}(1 \mathrm{SD}, \mathrm{n}=20)$. Comprehensive lab analyses of SAFe D2 standard for dFe during the period of these analyses averaged $0.95 \pm 0.047 \mathrm{nmol} / \mathrm{kg}$ (Bottle 33, 1SD $\mathrm{n}=38$ ) and $0.90 \pm 0.02 \mathrm{nmol} / \mathrm{kg}$ (Bottle 446, $1 \mathrm{SD}, \mathrm{n}=10$ ), which agrees well with the current consensus value of $0.933 \pm 0.023 \mathrm{nmol} / \mathrm{kg}$ (May 2013; www.geotraces.org/science/intercalibration).

\subsection{Dissolved manganese measurement}

Samples were pre-concentrated for dissolved manganese (dMn) by a modified version of the Milne et al. (2010) automated offline method followed by analysis for dMn concentration using quadrupole ICP-MS and standard addition calibrations. $12 \mathrm{~mL}$ filtered and acidified samples were aliquoted into acid cleaned $50 \mathrm{~mL}$ Corning centrifuge tubes (orange cap). 60,120, and $180 \mu \mathrm{L}$ of $100 \mathrm{nM}$ Mn standard were added to SAFe surface water in order to generate standard curves throughout the run; this allowed for final Mn standard concentrations of 0.5 1.0 , and $1.5 \mathrm{nM}$, respectively. The $\mathrm{pH}$ of each sample was brought to $6.0 \pm 0.2$ with ammonium acetate buffer $(\mathrm{pH} 8.9)$ before being pumped through the extraction system. The extraction was run identically to that described by Milne et al. (2010), except that the microcolumn was filled with Nobias PA-1 resin (Sohrin et al., 2008). After elution through the Nobias column in $1.0 \mathrm{~mL}$ of $1 \mathrm{M} 4 \times$ Vycor $@$ distilled nitric acid, extracted samples were analyzed for $\mathrm{dMn}$ by ICP-MS on a VG/Fisons PQ2 +. The SAFe D1 standard reference material water was found to have a dMn concentration of $0.42 \pm 0.004 \mathrm{nmol} / \mathrm{kg}$ $(\mathrm{n}=3 ; \pm 1 \mathrm{SD}$ of replicate analyses), falling on the high side of the SAFe D2 consensus range of $0.35 \pm 0.06 \mathrm{nmol} / \mathrm{kg}$ but within the range of the ICPMS-analyzed "high" subset of samples of $0.39 \pm$ $0.05 \mathrm{nmol} / \mathrm{kg}$. dMn procedure blanks were less than $0.01 \mathrm{nmol} / \mathrm{kg}$.

\section{Results and discussion}

\subsection{Surface dFe distribution}

The distribution of surface dFe concentrations from our transect and five others from this region is shown in Fig. 2 (Bergquist et al., 2007; Croot et al., 2004b; Measures et al., 2008; Moore et al., 2009; Sarthou et al., 2003). Three surface currents dominate circulation in the stations sampled in this study. First, the Canary Current flows at $10-15 \mathrm{~cm} / \mathrm{s}$ from north to south along the northwest African coast out to $30^{\circ} \mathrm{W}$ between 10 and $30^{\circ} \mathrm{N}$ (Zhou et al., 2000). As a result of the trade winds, the Canary Current turns west into the North Equatorial Current between 7 and $20^{\circ} \mathrm{N}$, forming the southern boundary of the North Atlantic subtropical gyre (Bourles et al., 1999). Finally, as the trade winds move north in the late summer, the seasonal North Equatorial Countercurrent forms between 3 and $10^{\circ} \mathrm{N}$, flowing from west to east and balancing the flow of water moving westward in the North and South Equatorial currents (Richardson and Reverdin, 1987). Thus, most of the surface water in our study traveled from the northeast to the southwest, except for the water south of $\sim 10^{\circ} \mathrm{N}$ (Stations 10-12 and 18-20), which likely came from the west.
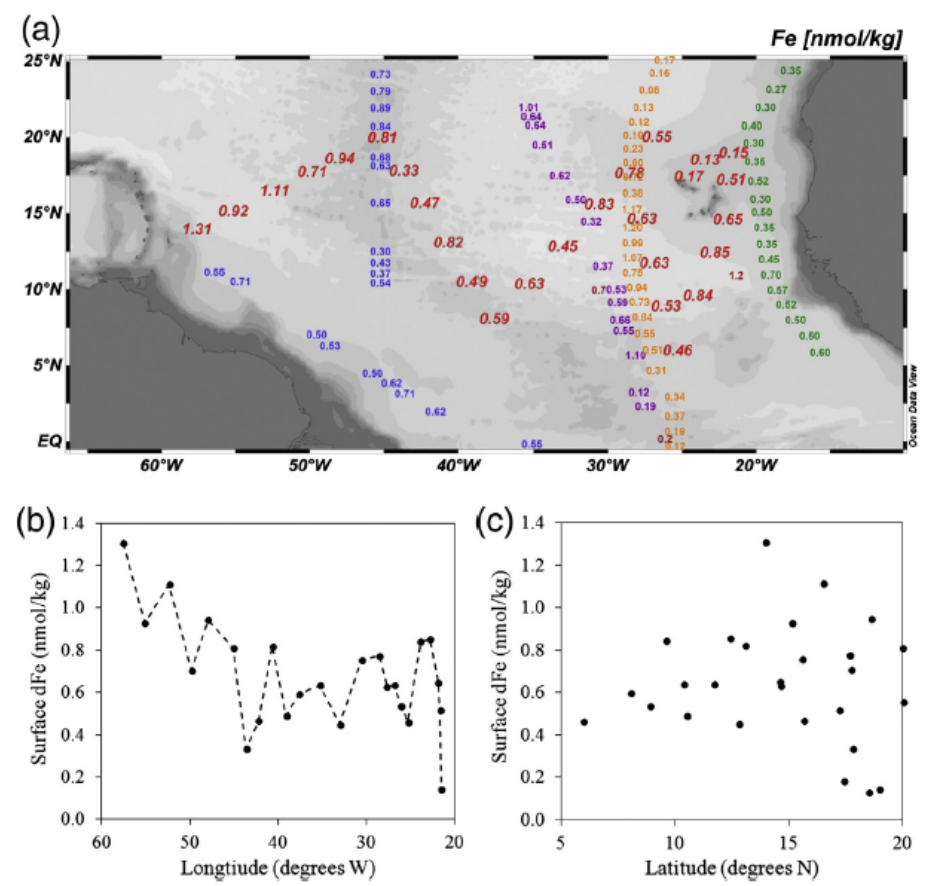

Fig. 2. The surface water dFe distribution as a function of (a) geographic location, (b) longitude, and (c) latitude. In (a), new measurements (OC449-2) are shown larger and italicized in red. Blue samples $\left(45^{\circ} \mathrm{W}\right.$ and near South American coast) are from Bergquist et al. (2007), purple samples (25-35 $\mathrm{W}$ ) from Moore et al. (2009), single-decimal place magenta samples are from Croot et al. (2004b), orange samples $\left(28^{\circ} \mathrm{W}\right.$ ) are from Measures et al. (2008), and green samples (nearest African coast) are from Sarthou et al. (2003). In (b), the surface dFe from northerly Stations 25-27 is removed for clarity. (For interpretation of the references to color in this figure legend, the reader is referred to the web version of this article.) 
In the OC449-2 stations, the highest surface dFe concentration was found at the western-most station (Station $1,1.35 \mathrm{nmol} / \mathrm{kg}$ ). This sample had a low salinity of 33.56 and an elevated silicate concentration of $2.3 \mu \mathrm{mol} / \mathrm{kg}$, indicating that this water was part of an Amazon eddy (Steven and Brooks, 1972). Typically, freshwater from the Amazon River flows into the North Brazil Current, which joins the North Equatorial Counter Current or the Guyana Current, depending on the season; however, seasonally the North Brazil current pinches off eddies that travel northwestward into the Caribbean Sea (Hellweger and Gordon, 2002). Despite Fe removal during flocculation in estuaries (Boyle et al., 1977), dFe concentrations as high as $1.2 \mathrm{nmol} / \mathrm{kg}$ have been detected in an Amazon eddy (Bergquist and Boyle, 2006b). Thus, the high $\mathrm{dFe}$ in the waters of Station 1 and perhaps Station 2 can be attributed to Amazon River sources. In contrast, the lowest dFe concentrations were found in the northeastern section of the transect near the Cape Verde Islands at Stations 24, 25, and 27, averaging $0.15 \mathrm{nmol} / \mathrm{kg}$. This matches the average surface $\mathrm{dFe}$ concentrations of $0.13 \pm 0.07 \mathrm{nmol} / \mathrm{kg}$ observed in the same Cape Verde region earlier in 2008 (Rijkenberg et al., 2012). The lower temperatures associated with these surface samples $\left(25-26{ }^{\circ} \mathrm{C}\right.$ in contrast to nearby stations' $27-28^{\circ} \mathrm{C}$ ) suggest that upwelling was occurring at these stations, and upwelled nutrients likely stimulated biological productivity that removed $\mathrm{dFe}$ from surface waters. Surface nutrients such as nitrate $(0.0-0.1 \mu \mathrm{mol} / \mathrm{kg})$ and phosphate $(0.13-0.19 \mu \mathrm{mol} / \mathrm{kg})$ were also depressed at these stations despite the cooler temperatures, supporting the inference of biological depletion of $\mathrm{dFe}$ and macronutrients.

The Northwest African dust plume carries particles from the Sahara and Sahel desert regions over the Atlantic Ocean (Husar et al., 1997), where partial dissolution of dust is likely to release large amounts of $\mathrm{Fe}$ into the dissolved phase upon deposition in the surface ocean (Jickells et al., 2005). The trajectory of North African desert dust, however, varies seasonally due to a latitudinal migration of the Intertropical Convergence Zone (Chiapello et al., 1995; Prospero et al., 1981). In the summer, African dust is transported above the trade winds in the Saharan Air Layer (1.5-6 km altitude), which carries dust across the Atlantic to the Caribbean and southeast United States (Chiapello et al., 1995). Accordingly, Barbados sees higher mineral dust fluxes in the summer than in the winter (Prospero and Carlson, 1972; Prospero et al., 1981). Near the Cape Verde Islands, however, mineral dust fluxes are five times higher in winter months, peaking in January (Chiapello et al., 1995). This occurs because in the winter, dust is restricted to the shallow trade wind layer, depositing most of the winter dust in the eastem tropical Atlantic basin (Chiapello et al., 1995).

Following this reasoning, we would not have been surprised to find an east-west gradient in surface dFe during our summer sampling, assuming that the residence time of dFe is sufficiently short to maintain a seasonal signal (a recent estimate of upper ocean Fe residence time in this region is 6-62 days; Croot et al., 2004b). As can be seen in Fig. $2 b$, a decreasing west-east dFe trend is apparent in the western part of the transect (four-fold decrease in dFe concentrations from $1.31 \mathrm{nmol} / \mathrm{kg}$ at Station 1 to $0.33 \mathrm{nmol} / \mathrm{kg}$ by Station 7), although much of this trend is driven not by dust deposition but by the elevated surface dFe at Stations 1-2 from the Amazon River plume. Ignoring the Amazon influenced stations, there is still elevated dFe in Stations 3-5 that decreases to the east, which could indicate increased dust deposition in the western basin as compared to the middle and eastem basins (three-fold decrease from $1.11 \mathrm{nmol} / \mathrm{kg}$ at Station 3 to $0.33 \mathrm{nmol} / \mathrm{kg}$ by Station 7), fulfilling the seasonal dust deposition patterns described above. As Fig. 2c shows, there is also no clear dependence of surface $\mathrm{dFe}$ with latitude within the narrow range of $8-20^{\circ} \mathrm{N}$, while several other North Atlantic studies found maximum dFe within this same range compared to stations further north and south (Bergquist and Boyle, 2006a; Measures et al., 2008; Sarthou et al., 2003). We believe that our "zig-zag" transect obscures clear latitudinal or longitudinal features in surface dFe, as this transect weaves in and out of both biogeochemical gradients and dust deposition zones.
However, as can be seen in Fig. 2, our surface dFe data fits well within published values in the region. 72 out of the 128 surface water samples (56\%) shown in this map have dFe concentrations greater than or equal to $0.4 \mathrm{nmol} / \mathrm{kg}$ (average $0.55 \pm 0.29,1 \mathrm{SD}$ ), which is significantly higher than values reported in the northeastern Pacific Ocean (Brown et al., 2005; Bruland et al., 1994; Johnson et al., 2003; Keith Johnson et al., 2005; Martin et al., 1989; Takata et al., 2006), Southern Ocean (Croot et al., 2004a; Klunder et al., 2011; Martin et al., 1990; Sedwick et al., 1997; Sohrin et al., 2000), and subarctic North Atlantic (Laës et al., 2003; Martin et al., 1993; Thuróczy et al., 2010). It should not be controversial to suggest that the majority of this enrichment is due to partial dissolution of $\mathrm{Fe}$ from extensive aerosol deposition in this region from African dust (Jickells et al., 2005 and references therein; Mahowald et al., 2005).

\subsection{Water column dFe distribution}

Fig. 3 (Schlitzer, 2012) shows the three-dimensional dFe water column distribution in the upper $1000 \mathrm{~m}$ along the occupied transect as a section folded along the cruise track (excluding the northeasternmost stations 23-27 shown in Fig. 6). Most strikingly, the dFe distribution changes dramatically at $\sim 42^{\circ} \mathrm{W}$ (Station 8 ), effectively separating the transect into east and west regions. In the western region (Stations 18 ), there is a strong dFe minimum at $125 \mathrm{~m}$ that stretches as deep as $500 \mathrm{~m}$. In contrast, in the eastern region (Stations 9-22) there is a strong dFe maximum centered at $500 \mathrm{~m}$ that coincides with the oxygen minimum. These contrasting pattems define the dFe distribution in the tropical North Atlantic and occur because of changes in physical circulation and resulting biogeochemical cycling in these two areas.

\subsubsection{Regional circulation of the tropical North Atlantic}

The circulation of the tropical North Atlantic can be described using temperature-salinity relationships (Fig. 4). Because this region encompasses the convergence of multiple water masses, it is an important site of mixing for waters from both the northern and southern hemispheres (Stramma and Schott, 1999). From the surface to $200 \mathrm{~m}$ depth, circulation is driven by Tropical Surface Water currents, formed predominantly in the North Atlantic (discussed in Section 3.1). Below $200 \mathrm{~m}$, the seawater is composed of North Atlantic and South Atlantic Central Waters until the $27.1 \mathrm{~kg} / \mathrm{m}^{3}$ isopycnal $(\sim 500 \mathrm{~m})$, where cold low-salinity Antarctic Intermediate Waters (AAIW) begin to dominate. Deeper than $1200 \mathrm{~m}$, southward-flowing North Atlantic Deep Water (NADW) and northward-flowing Antarctic Bottom Waters (AABW) are the chief water masses. For the rest of this paper, dFe will be shown as a function of depth instead of potential density for ease of understanding, as the potential density contours are relatively flat (Fig. 5a).

In the Central Water Layer of the tropical North Atlantic, two water masses dominate: the North Atlantic Central Water (NACW) and the South Atlantic Central Water (SACW). Both exhibit nearly linear temperature-salinity (T-S) relationships (Fig. 4) and are found along the isopycnals $25.8<\sigma_{\theta}<27.1$ (Fig. 5a). NACW is saltier and warmer than SACW, and the majority of NACW is composed of either Madeira Mode Water, which subducts northwest of Madeira, or $18^{\circ}$ Mode Water, which subducts in the Sargasso Sea (Siedler et al., 1987; Worthington, 1959). The fresher and colder SACW contains predominantly Indian Ocean Central Water that is transferred to the Atlantic and then into the tropics by the Benguela Current (Stramma et al., 2005). NACW and SACW meet along the Cape Verde Frontal Zone (CVFZ), located as far north as $20^{\circ} \mathrm{N}$ near the African coast but along $15^{\circ} \mathrm{N}$ over the central and western North Atlantic (Tomczak and Godfrey, 2003). Because NACW and SACW occupy overlapping density ranges, the two water masses mix freely along their common isopycnal in the CVFZ, which serves to complicate the origin of the pre-formed dFe signal at these depths (see Section 3.3). 


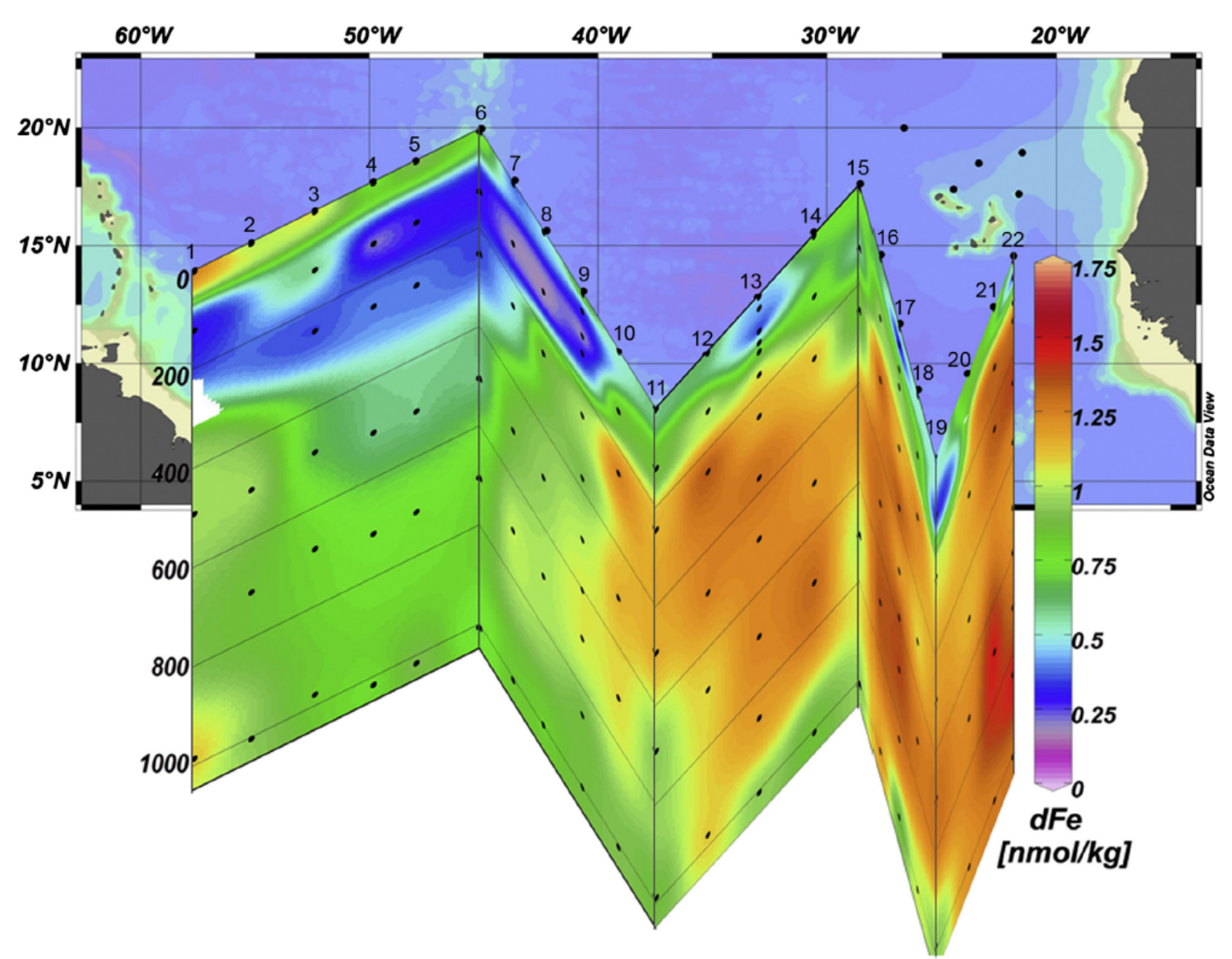

Fig. 3. OC449-2 dFe distribution in the upper $1000 \mathrm{~m}$ of the tropical North Atlantic Ocean. Sample locations are indicated as dots at the mapped station positions, and the vertical profiles extend below that. Station numbers are indicated at the top. Note that the northeastern Stations $23-27$ cannot be shown in this section because of graphical limitations: they are shown in Fig. 7.

As can be seen in Fig. 5b, the oxygen minimum straddles the $\sigma_{\theta}=$ $27.1 \mathrm{~kg} / \mathrm{m}^{3}$ boundary between Central Waters and AAIW at $400-450 \mathrm{~m}$ depth. AAIW originates in the southern hemisphere under welloxygenated conditions and advects oxygen northward, ventilating the tropical North Atlantic OMZ from below (Stramma et al., 2008a). The OMZ is maintained by a general westward flow of low oxygen, upwelled waters from along the African coast. It is further strengthened in a counterclockwise circulating area of water south of the Cape Verde Islands called the Guinea Dome. The general westward spread of low oxygen waters at $500 \mathrm{~m}$ from 6 to $17^{\circ} \mathrm{N}$ is interrupted by narrow zonal jets of eastward flowing water that form the main ventilation source of the OMZ (Brandt et al., 2008; Stramma et al., 2005, 2008a).

In the western part of the section (Stations 1-8), the isopycnals are spaced farther apart (deeper pycnoclines), which suggests that these stations lie closer to the center of the subtropical gyre (Fig. 5a). Central Waters pervade as deep as $500 \mathrm{~m}$, indicated by the depressed $\sigma_{\theta}=$ $27.1 \mathrm{~kg} / \mathrm{m}^{3}$ boundary. Subtropical gyre waters are also much better oxygenated than in the eastern basin (Fig. 5b).

3.2.2. Upper $1000 \mathrm{~m}$ dFe distribution

In the western basin subtropical gyre sites (Stations 1-8), dFe surface maxima are underlain by broad minima in the pycnocline down to $250 \mathrm{~m}$ depth. Minimum dFe concentrations were often seen at $125 \mathrm{~m}$, which is close to the $100-130 \mathrm{~m}$ chlorophyll maxima at these stations (as designated by a maximum in the CTD fluorescence trace), indicating that biological uptake within the euphotic zone and/or scavenging was drawing down dFe between the sea surface and these depths. Summer dFe minima of $0.15-0.30 \mathrm{nmol} / \mathrm{kg}$ at $125 \mathrm{~m}$ measured in this study were a bit lower than the winter dFe minimum of $0.35 \mathrm{nmol} / \mathrm{kg}$ measured by Bergquist and Boyle (2006a) at $30^{\circ} \mathrm{N}, 45^{\circ} \mathrm{W}$, which could be caused by seasonal changes in biomass or simply reflect a difference between sampling locations. Furthermore, since our $125 \mathrm{~m}$ samples were close to the chlorophyll maximum and probably coincide with the dFe minimum, we estimated the depletion between the surface mixed layer sample and the $\mathrm{dFe}$ minimum at $125 \mathrm{~m}$. For Stations 3-6, this difference averaged $0.63 \mathrm{nmol} / \mathrm{kg}$, which is much higher than the $0.35 \mathrm{nmol} / \mathrm{kg}$ difference measured in the stratified North Pacific (Bruland et al., 1994) and also higher than the $0.2-0.3 \mathrm{nmol} / \mathrm{kg}$ difference measured by Bergquist and Boyle (2006a) farther north in the same subtropical gyre as OC449-2. This comparison indicates that not only does this region exhibit remarkably high surface dFe concentrations because of enhanced dust deposition in the summer, but it also supports a significant dFe sink below the surface that draws down almost all of the surface $\mathrm{dFe}$. This sink can be attributed either to high rates of biological activity in the upper thermocline that take up and/or scavenge much of the 


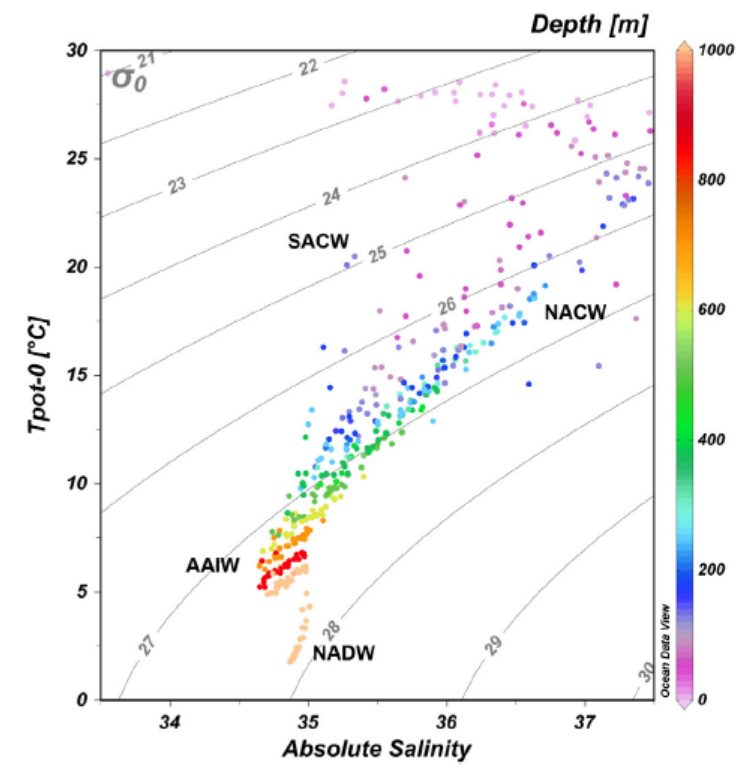

Fig. 4. Temperature-salinity diagram for OC449-2 with water masses indicated. NACW is North Atlantic Central Water, SACW is South Atlantic Central Water, AAIW is Antarctic Intermediate Water, and NADW is North Atlantic Deep Water. Potential density contours are shown in gray.

atmospherically deposited $\mathrm{Fe}$ and/or to successive colloidal aggregation of dust-derived dFe that creates sinking particles following dust deposition (Aguilar-Islas et al., 2010; Bergquist et al., 2007).

The $\mathrm{dFe}$ minimum in NACW gradually increases to a maximum in AAIW in the western basin. The AAIW at $~ 700 \mathrm{~m}$ has relatively uniform dFe at Stations 2-6, with an average concentration of $0.79 \pm 0.01 \mathrm{nmol} / \mathrm{kg}$. This is much higher than the $0.38 \mathrm{nmol} / \mathrm{kg}$ dFe reported by Bergquist and Boyle(2006a) for South Atlantic AAIW at $24.5^{\circ} \mathrm{S}$. They calculate a regenerated $\mathrm{Fe}: \mathrm{C}$ ratio of only $5.4 \mu \mathrm{mol} / \mathrm{mol}$ at their South Atlantic site, while in this study we calculated a regenerated Fe:C ratio of $10-11 \mu \mathrm{mol} / \mathrm{mol}$ (discussed in Section 3.3). We attribute these differences to changes in $\mathrm{Fe}: \mathrm{C}$ ratios in the microbial populations living in surface waters of these regions and consequent remineralization between the North and South Atlantic AAIW (see below).

In the eastern basin, the subsurface dFe distribution is very different than in the western subtropical gyre. Most stations did not have sufficient resolution to sample the dFe minimum, since the chlorophyll maximum in the eastern basin was on the order of 40-80 m deep. However, stations sampled with higher resolution (Stations 9, 13, 17, and 22) again show a surface dFe maximum followed by a minimum in the deep chlorophyll maximum. The surface mixed layer to dFe minimum difference for these stations was $0.3-0.7 \mathrm{nmol} / \mathrm{kg}$, which is the same as the 0.4-0.6 nM range reported by Measures et al. (2008) nearby, again demonstrating the extreme drawdown of dFe in the shallow waters of the euphotic zone.

The defining characteristic of the eastern tropical North Atlantic subsurface dFe distribution is a broad dFe maximum that begins above $250 \mathrm{~m}$ and continues through the upper $1000 \mathrm{~m}$. This dFe maximum is in excess of $1 \mathrm{nmol} / \mathrm{kg}$ at all stations east of Station 9 , reaching maxima of $1.4-1.5 \mathrm{nmol} / \mathrm{kg}$. This is in the same range as that observed by Measures et al. (2008) in their north-south transect along $25-30^{\circ} \mathrm{W}$ but is higher than the $1.2 \mathrm{nmol} / \mathrm{kg}$ maximum observed by Bergquist and Boyle (2006a) about $1250 \mathrm{~km}$ to the west. The core of the dFe maximum stretches as far north as $15^{\circ} \mathrm{N}$, with
Station 15 at $17.6^{\circ} \mathrm{N}$ lying just north of the maximum, and as far south as was sampled, $6^{\circ} \mathrm{N}$. Measures et al. also saw an extension of the dFe maximum as far north as $18^{\circ} \mathrm{N}$ and as far south as $6^{\circ} \mathrm{N}$ on their June 2003 cruise. Not surprisingly, the geographic extent of this dFe maximum appears to be stable over the five years between Measures et al. and our sampling efforts.

Finally, dFe in the upper $1000 \mathrm{~m}$ of Stations 19-27 in the region closest to the Cape Verde Islands is shown in Fig. 6. As Fig. 6a shows, elevated $\mathrm{dFe}$ up to $1.6 \mathrm{nmol} / \mathrm{kg}$ is observed closest to the African coast, some of the highest concentrations measured in the entire transect. This might be thought to indicate a margin source of dFe; however, upwelling is also strongest near the coast, so productivity and downward regenerated fluxes are also higher. Station 19 lies at $6^{\circ} \mathrm{N}$, the lowest latitude sampled, and exhibits a broad dFe minimum to $125 \mathrm{~m}$, deeper than most of the other eastern Atlantic stations. This could be due either to water origin, as this southern station receives low dFe water from the west carried by the North Equatorial Counter Current, or to lower Fe input from dust at low latitude. The northernmost Station 26 at $20^{\circ} \mathrm{N}$ similarly shows a deep $\mathrm{dFe}$ minimum to $125 \mathrm{~m}$; this feature, however, occurs because this northernmost station lies on the edge of the subtropical gyre (upper ocean salinity $>37$ ) and thus shows gyre-like dFe profiles similar to western basin gyre Stations 4-7. Station 23 also has generally lower dFe concentrations than Stations 22 and 24 nearby. The patchiness of the dFe distribution near the Cape Verde Islands (Fig. 6c) can be explained by a combination of the complex banded zonal currents in this region (Brandt et al., 2008; Stramma et al., 2008a) and the fact that upwelling occurs locally and seasonally along the African coastline, which places a fine-scale control on potential biological uptake of Fe between Mauritania and the Cape Verde Islands.

Fig. $6 b$ and $c$ shows zonal transections of dFe as a function of longitude. At $17.3^{\circ} \mathrm{N}$ (Fig. 6b), no significant offshore decrease in $\mathrm{dFe}$ is observed; in fact, dFe concentrations at the more western Station 27 are higher at most depths than at Station 23. In contrast, at $19^{\circ} \mathrm{N}$ (Fig. $6 \mathrm{c}$ ), which is farther away from the complexities of the Cape Verde Islands, dFe concentrations successively decrease offshore for an overall drop in dFe of $0.9 \mathrm{nmol} / \mathrm{kg}$ at $125 \mathrm{~m}$ and $\sim 0.35 \mathrm{nmol} / \mathrm{kg}$ at the other depths. This may suggest that $\mathrm{dFe}$ is locally introduced at the African margin and is then diluted and mixed and/or scavenged going offshore, although it is important to note that the CVFZ straddles Stations 25-26, with NACW feeding the westernmost Station 26 and SACW feeding Stations 24-25, resulting in the potential for different pre-formed dFe at Station 26.

\subsubsection{Station 13 full water column dFe distribution}

A full water column profile was collected at Station 13, the deepest part of the eastern tropical North Atlantic basin sampled $\left(12.8^{\circ} \mathrm{N}\right.$, $33.0^{\circ} \mathrm{W}$, Fig. 7). dFe reaches a maximum of $1.3 \mathrm{nmol} / \mathrm{kg}$ in the $375-700 \mathrm{~m}$ depth range, coincident with the $70 \mu \mathrm{mol} / \mathrm{kg}$ oxygen minimum. The dFe and dissolved oxygen profiles mirror each other as observed further east by Bergquist and Boyle (2006a) at $10^{\circ} \mathrm{N}$, $45^{\circ} \mathrm{W}$, where they measured a dFe maximum of $1.2 \mathrm{nmol} / \mathrm{kg}$ and a coincident oxygen minimum of $\sim 100 \mu \mathrm{mol} / \mathrm{kg}$. These tropical North Atlantic dFe maxima between 1 and $1.5 \mathrm{nmol} / \mathrm{kg}$ in the tropical North Atlantic have low concentrations compared to the maxima in suboxic waters of the tropical Southeast Pacific near Chile, where off-shelf $\mathrm{dFe}$ concentrations reached up to $3.39 \mathrm{nM}$ (Blain et al., 2008), and near Peru, where deep shelf concentrations exceed $50 \mathrm{nM}$ (Bruland et al., 2005). In both of these cases, $\mathrm{Fe}$ (II) was stabilized by the hypoxic dissolved oxygen concentrations, low $\mathrm{pH}$, and cold water, so it is likely that $\mathrm{Fe}$ (II) contributed significantly to the measured dFe. In contrast, in the tropical North Atlantic OMZ, oxygen concentrations of at least $50 \mu \mathrm{mol} / \mathrm{kg}$, higher $\mathrm{pH}$, and warmer waters favor rapid oxidation of any $\mathrm{Fe}$ (II) species present, and thus the dFe is likely to be composed predominately of $\mathrm{Fe}$ (III) and overall dFe concentrations are lower. dFe concentrations are maintained above the $<0.2 \mathrm{nmol} / \mathrm{kg}$ 


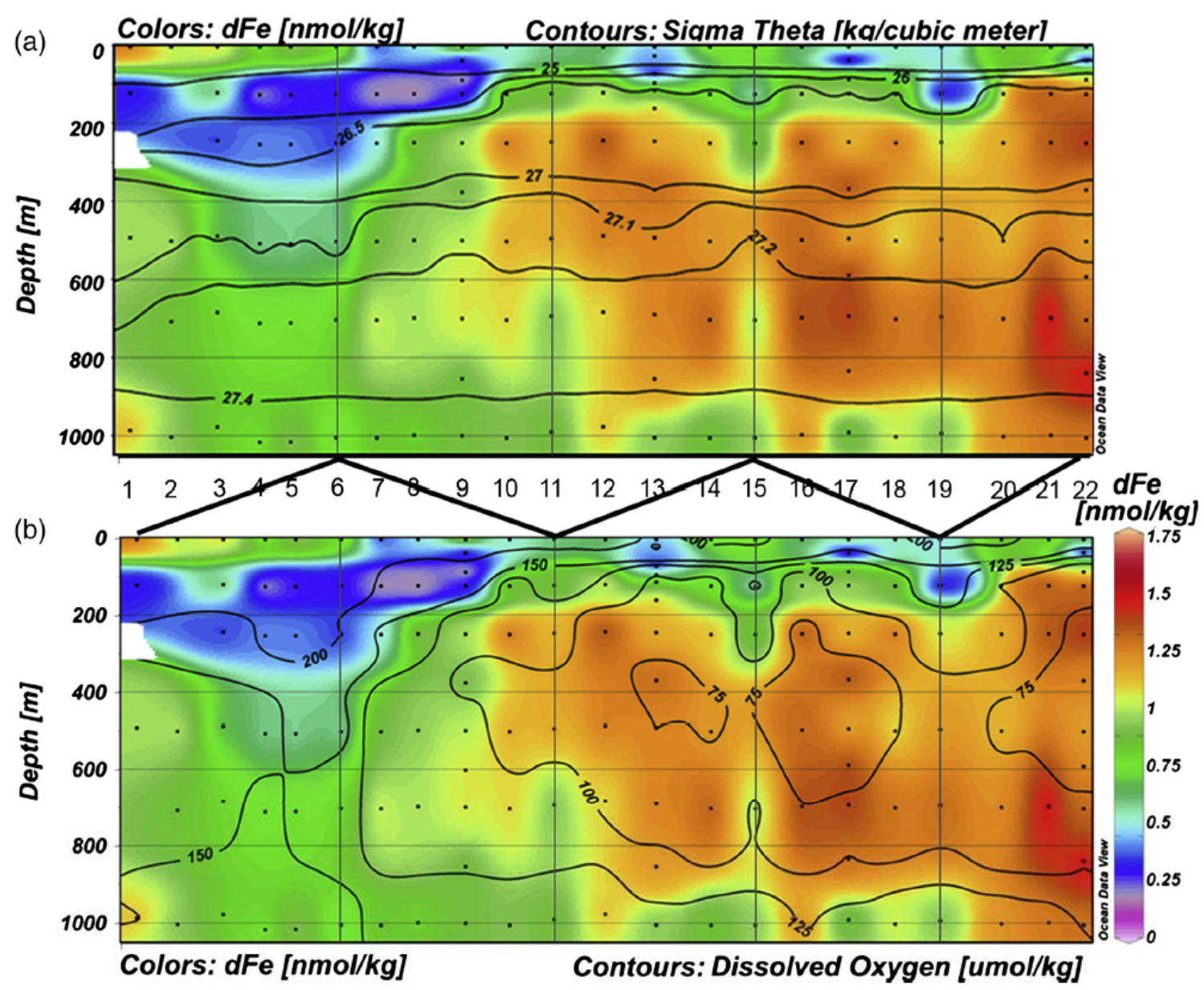

Fig. 5. dFe distribution for Stations 1-22 with (a) sigma theta density contours and (b) dissolved oxygen contours. The zig-zag line in the middle indicates the shape of the sampling transect, and for reference vertical lines are shown corresponding to the folds in Fig. 3. Station numbers are indicated in the center of the diagram.

inorganic Fe(III) solubility determined by Liu and Millero (2002) because organic ligand complex marine dFe (Rue and Bruland, 1995; van den Berg, 1995; Wu and Luther, 1995); organic ligands have been found to be in excess of dissolved Fe in all studies in the tropical and sub-tropical North Atlantic (Boye et al., 2006; Cullen et al., 2006; Gerringa et al., 2006; Gledhill and van den Berg, 1994; Rijkenberg et al., 2008).

In addition, a closer examination of Fig. 7 shows that although the phosphate and oxygen profiles are mirror images, the dFe profile has a different shape than the phosphate profile. Below the dFe max at the OMZ, dFe reaches minimum values by $1250 \mathrm{~m}$, while phosphate continues to decrease until at least $1750 \mathrm{~m}$. This may be caused by any of the following three processes: Fe is remineralized shallower than phosphate (Fe:P remineralization ratios change with depth), scavenging of dFe increases in the transition between AAIW and $\mathrm{NADW}$, or preformed $\mathrm{dFe}$ and phosphorus diverge in the depth range in question. Because it has been shown that Antarctic surface waters run out of dFe before phosphate and nitrate (Coale et al., 2005), it would make sense that surface waters sinking from that zone as AAIW would have significant pre-formed phosphate but little pre-formed dFe, so we suggest that is the most likely cause of this feature.
Deepwater was sampled at Station 13, and measurements of potential temperature $\left(1.8-4{ }^{\circ} \mathrm{C}\right)$ and salinity (>34.9) suggest that in the depth range $1500-4000 \mathrm{~m}$ the dominant water mass was NADW (McCartney, 1992; Tomczak and Godfrey, 2003). Through this depth range, dFe was found to have an average concentration of $0.72 \pm 0.03 \mathrm{nmol} / \mathrm{kg}$ (1SD) over five sampled depths. This is identical to that measured in NADW at $10^{\circ} \mathrm{N} 45^{\circ} \mathrm{W}$ by Bergquist and Boyle (2006a), at $46^{\circ} \mathrm{N} 8^{\circ} \mathrm{W}$ by Laës et al. (2003) in the northeast Atlantic, and at $33^{\circ} 40^{\prime} \mathrm{N} 57^{\circ} 40^{\prime} \mathrm{W}$ by Wu et al. (2001) near Bermuda.

Between 3800 and $5000 \mathrm{~m}$, the measured dFe concentration at Station 13 increases to $0.82 \pm 0.01 \mathrm{nmol} / \mathrm{kg}$ (1SD) over four sampled depths. Water at these depths is thought to be composed of a mixture of NADW and AABW (Mantyla and Reid, 1983). AABW transits north from the Southern Ocean along the western Atlantic basin and finally crosses the Mid-Atlantic Ridge into the eastern North Atlantic through the Vema Fracture Zone near $10^{\circ} \mathrm{N}$ (McCartney et al., 1991), mixing with NADW along the way. In the western South Atlantic at $24.5^{\circ} \mathrm{S}, \mathrm{AABW}$ (identified by silica in excess of $100 \mu \mathrm{mol} / \mathrm{kg}$ ) contained dFe of only $0.42 \mathrm{nmol} / \mathrm{kg}$ (Bergquist and Boyle, 2006a). If the Station 13 deep water was a mixture of NADW containing $\mathrm{dFe}$ of $0.73 \mathrm{nmol} / \mathrm{kg}$ and AABW containing $0.42 \mathrm{nmol} / \mathrm{kg}$, it should contain less Fe than the $0.82 \mathrm{nmol} / \mathrm{kg}$ we observe in the eastern basin bottom water. In fact, 

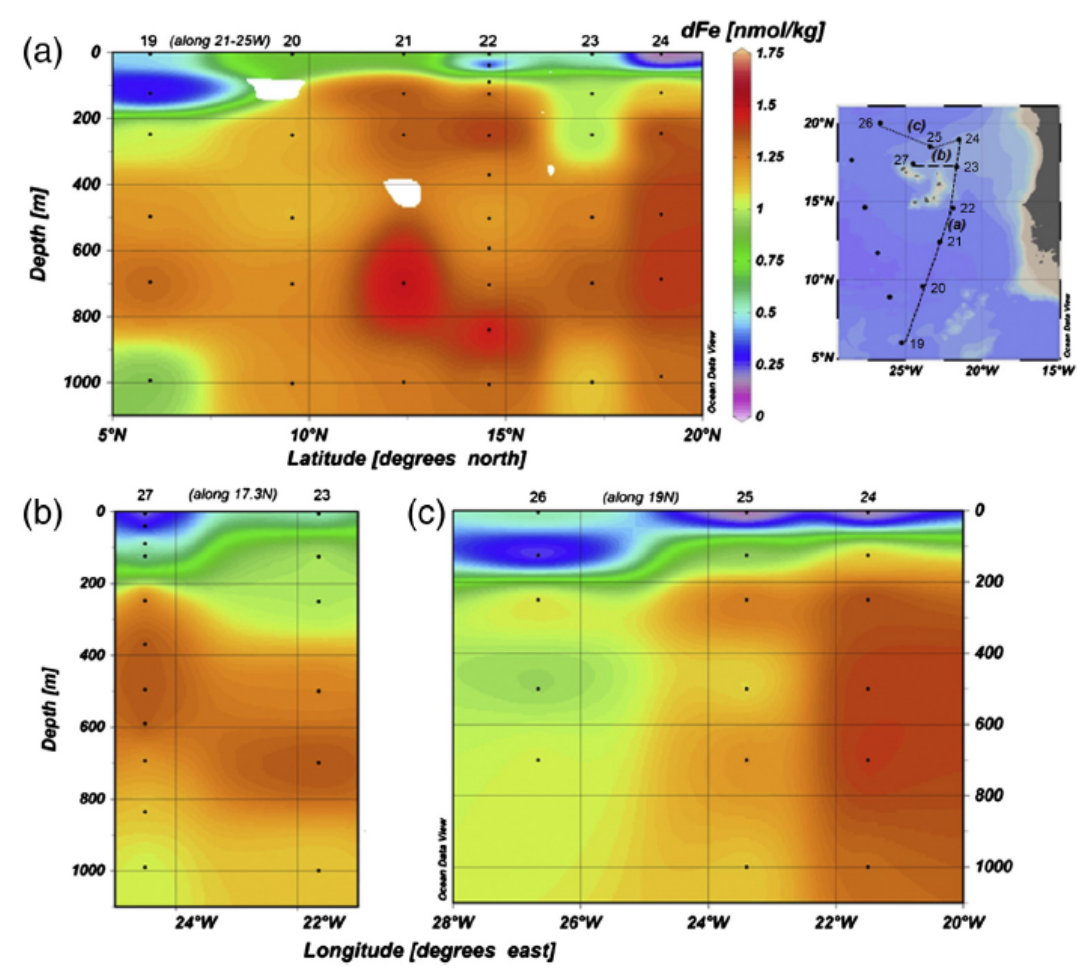

Fig. 6. dFe distribution in the upper $1000 \mathrm{~m}$ at (a) Stations 19-24 as a function of latitude, (b) Stations 23 and 27 as a function of longitude, and (c) Stations 26 as a function of longitude. Station numbers and intersecting latitude or longitude line are indicated at the top of each plot, and the geographic location of each transect is shown on the map in the upper right.

Rijkenberg et al. (2012) found that waters in this depth range near the Canary Islands $\left(27.5^{\circ} \mathrm{N}, 21^{\circ} \mathrm{W}\right)$ had an Fe concentration of $0.31 \mathrm{nmol} / \mathrm{kg}$. Nonetheless, we believe that the deepest OC449-2 Station $130.82 \pm$ $0.01 \mathrm{nmol} / \mathrm{kg} \mathrm{dFe}$ measurements are accurate and uncontaminated since the enhanced $\mathrm{dFe}$ is reproducible over four discretely sampled depths ranging over more than $1000 \mathrm{~m}$ of the water column.

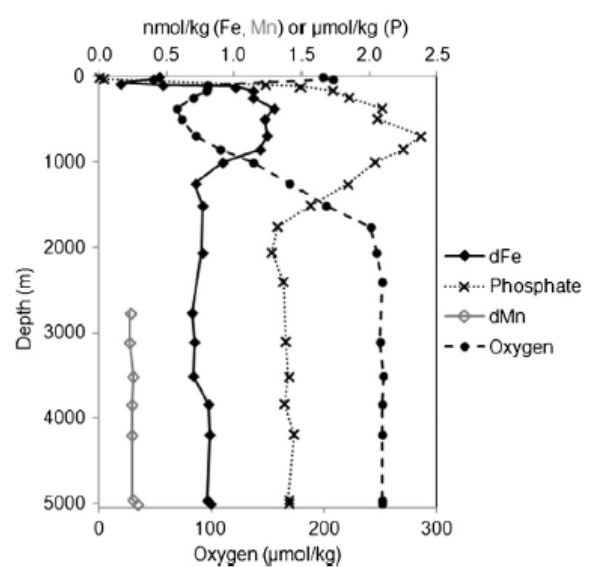

Fig. 7. Profiles of dFe, dMn, phosphate, dissolved oxygen from Station 13 at $12.8^{\circ} \mathrm{N}$, $33.0^{\circ} \mathrm{W}$ in the eastern tropical North Atlantic Ocean.
We suggest that the increased dFe in the deepest samples of the eastem basin may be due to the acquisition of hydrothermally-influenced dFe during transit through the Vema Fracture Zone. Copper-iron sulfide deposits were found in the Vema Fracture Zone years ago (Bonatti et al., 1976), indicating a hydrothermal influence in this region. While no hydrothermal venting is believed to occur in the fracture zone itself, these deposits were thought to have been carried from the adjacent Mid-Atlantic Ridge (MAR) rift valley, which cuts perpendicular through the fracture zone. Klinkhammer et al. (1985) found indirect evidence of hydrothermal venting at the intersection of the MAR and the Vema

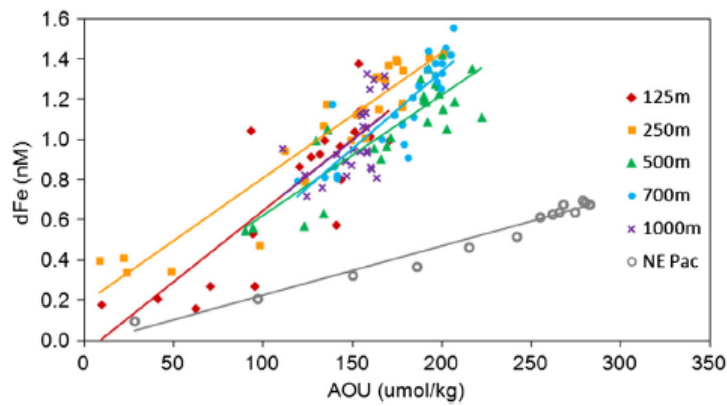

Fig. 8. dFe as a function of AOU at all stations. The "NE Pac" data is taken from Ocean Station Papa on the VERTEX VII cruise (Martin et al., 1989). 
Table

Summary of Fe:C ratios and pre-formed dFe.

\begin{tabular}{llrrrl}
\hline $\begin{array}{l}\text { Depth } \\
\mathrm{m}\end{array}$ & Sigma-theta & $\mathrm{r}^{2}$ & \multicolumn{1}{l}{$\begin{array}{l}\mathrm{Fe}: \mathrm{C} \\
\mu \mathrm{mol} / \mathrm{mol}^{\mathrm{a}}\end{array}$} & $\begin{array}{l}\mathrm{C}: \mathrm{Fe} \\
\mathrm{mol} / \mathrm{mol}^{\mathrm{a}}\end{array}$ & $\begin{array}{l}\text { Pre-formed dFe } \\
\mathrm{nmol} / \mathrm{kg}^{\mathrm{ba}}\end{array}$ \\
\hline 125 & 26.25 & 0.70 & $11.3 \pm 1.8$ & $88,000 \pm 14,000$ & \\
250 & 26.8 & 0.89 & $10.0 \pm 0.7$ & $100,000 \pm 7500$ & $0.19 \pm 0.07$ \\
500 & 27.2 & 0.74 & $9.6 \pm 1.2$ & $104,000 \pm 13,000$ & \\
700 & 27.32 & 0.74 & $12.4 \pm 1.5$ & $81,000 \pm 10,000$ & \\
1000 & 27.5 & 0.30 & $11.2 \pm 3.6$ & $90,000 \pm 28,500$ & \\
All depths & & 0.74 & $9.8 \pm 0.5$ & $101,600 \pm 5000$ & \\
NE Pacific & & 0.97 & $3.9 \pm 0.2$ & $254,000 \pm 12,500$ & \\
\hline
\end{tabular}

a Errors shown are 1 standard error.

${ }^{\text {b }}$ Values are only shown if significantly different from zero.

c Northeast Pacific values from Ocean Station Papa (Martin et al., 1989).

Fracture Zone by the measurement of enhanced $\mathrm{Mn}$ to $2.0 \mathrm{nM}$ in the rift valley $\left(11.02^{\circ} \mathrm{N}, 44.66^{\circ} \mathrm{W}\right)$. Direct evidence of active venting at this intersection was finally recorded recently via hydrological anomalies (Beltenev et al., 2009), providing a clear potential Fe source to the Vema Fracture Zone.

We made dMn measurements on deep waters from Station 13 in order to test this hydrothermal hypothesis, since Mn is heavily enriched along with Fe in hydrothermal fluids (Edmond et al., 1979) and is seen to emanate from hydrothermal vents into the deep ocean (Middag et al., 2011a,2011b; Noble et al., 2012). The dMn measurements from our Station 13 deepwater samples are shown in Fig 7. NADW (2750$3500 \mathrm{~m}) \mathrm{dMn}$ averaged $0.24 \pm 0.01 \mathrm{nmol} / \mathrm{kg}(\mathrm{n}=3)$, while in the deepest waters $\mathrm{dMn}$ averaged $0.26 \pm 0.02 \mathrm{nmol} / \mathrm{kg}$. Thus, while the $A A B W$-affected waters do have a higher average dMn concentration, they are not significantly different from the shallower NADW waters, and Mn cannot be used to conclusively prove the presence of hydrothermal influence. However, with a potential hydrothermal dFe input of only $0.1 \mathrm{nmol} / \mathrm{kg}$ (indicating significant metal dilution/scavenging from the vent source), it is not clear that any hydrothermal $\mathrm{dMn}$ input would have been detectable. $\mathrm{dMn}$ has a much shorter estimated residence time with respect to scavenging in the deep ocean (20-40 years) compared to dFe (70-140 years, Bruland et al., 1994), and this residence time pattern was corroborated by modeled residence times in hydrothermally influenced samples from the Arctic Ocean where dMn residence times were 7-12 times shorter than those of dFe (Klunder et al., 2012). Thus, even if the $\mathrm{dFe}$ increase was a result of hydrothermal venting, the coincident $\mathrm{dMn}$ signal may have been scavenged away by the time it reached our Station 13 location ( 1200 km). Additional measurements of dFe in this AABW-NADW mixture east of the Mid-Atlantic Ridge are required to see whether an enhanced dFe signature is reproducible over time and can be tied to transit through the Vema Fracture Zone.

\section{3. dFe provenance in the tropical North Atlantic $O M Z$}

One of the goals of this study was to determine the provenance of the elevated dFe concentrations coincident with the $\mathrm{OMZ}$ in the eastern tropical North Atlantic. This pattern was observed not only in this study but also by Bergquist and Boyle (2006a), Measures et al. (2008), and Rijkenberg et al. (2012). dFe concentrations in all of these studies were in excess of $1 \mathrm{nmol} / \mathrm{kg}$ and imply $\mathrm{Fe}: \mathrm{C}$ ratios greater than $10 \mu \mathrm{mol} / \mathrm{mol}$, about three times those seen in the Northeast Pacific (Martin et al., 1989). Does this high dFe occur as a result of Fe deposition by atmospheric dust, followed by remineralization of enriched Fe:C organic material at depth, or instead as a result of the horizonta mixing of a dFe plume with low oxygen waters from reducing sediments along the African coast?

Although it is difficult to prove that this is the only valid interpretation of the dFe distribution, we can show that the dFe distribution in the upper $1000 \mathrm{~m}$ of the tropical North Atlantic is consistent with a simple fixed (and enriched) dFe:AOU remineralization ratio. dFe distributions were compared to apparent oxygen utilization (AOU), and the resulting relationship is shown in Fig. 8 (statistics in Table 1). All of the depths sampled in the upper $1000 \mathrm{~m}$ demonstrate a near constant slope between dFe and AOU (Table 1), which would be expected if remineralization from fixed "Redfield" material was controlling the dFe: AOU relationship. At all depths except $250 \mathrm{~m}$, the intercept is not significantly different than zero. At $250 \mathrm{~m}$, there is a significant non-zero positive intercept signifying pre-formed dFe from source waters at this depth.

We used the observed AOU:dFe relationship to infer Fe:C ratios, applying a C:AOU ratio of 1.6 typical of marine phytoplankton (Martin et al., 1987). The Fe:C for this ocean section ranges from 9.6-12.4 $\mu \mathrm{mol} / \mathrm{mol}$ (Table 1), which agrees with the Fe:C ratio of

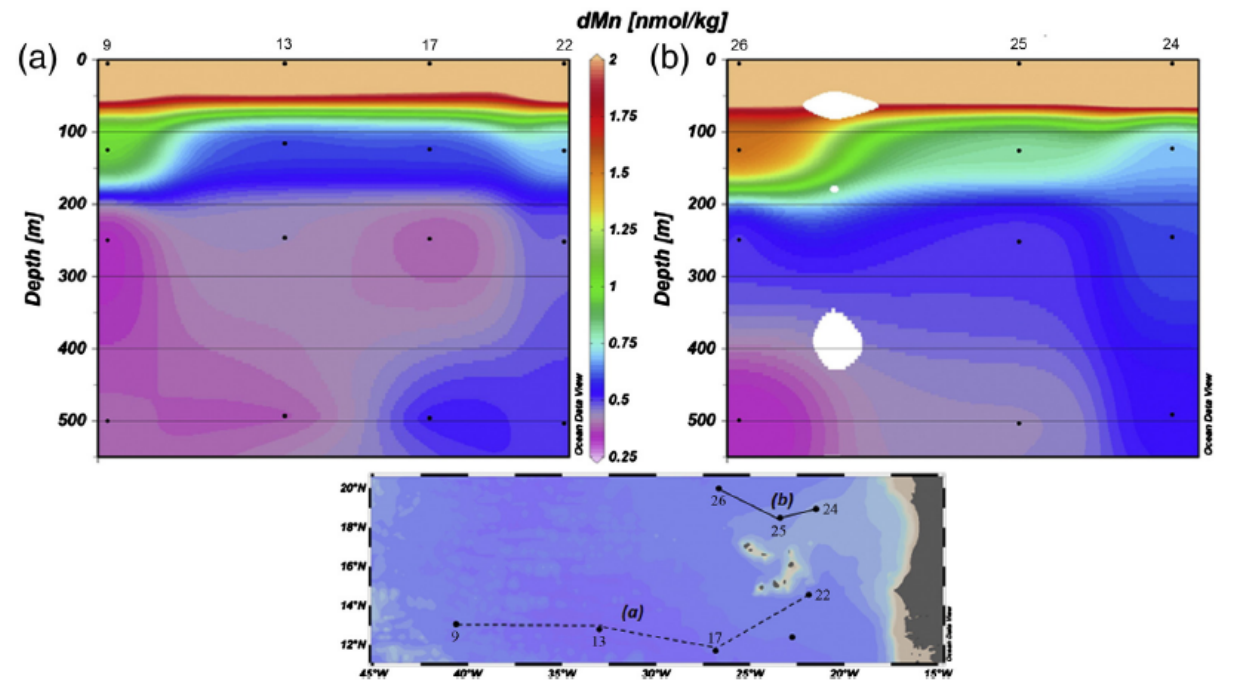

Fig. 9. Dissolved Mn distribution in the eastern tropical North Atlantic. 
$11 \mu \mathrm{mol} / \mathrm{mol}$ estimated by Bergquist and Boyle (2006a) for their vertical profile at $10^{\circ} \mathrm{N}, 45^{\circ} \mathrm{W}$. In contrast, these ratios are $2.5-3$ times higher than the ratios observed in the Northeast Pacific (Sunda, 1997) a known Fe-limited, high-nutrient low-chlorophyll (HNLC) region (Martin et al., 1989). The enriched Fe:C in the tropical North Atlantic could indicate a difference in the cellular Fe requirements for the organisms living in Fe-replete conditions under the Saharan dust plume compared to those in HNLC regions. However, while phytoplankton in Fe-limited regions have adapted to low Fe conditions by using smaller cell sizes and growing more slowly than their coastal counterparts, an Fe: $C$ ratio $\geq 10 \mu \mathrm{mol} / \mathrm{mol}$ is well above what is required for minimum growth of most open ocean species (Sunda and Huntsman, 1995). The enriched $\mathrm{Fe}: \mathrm{C}$ ratios observed could, thus, also reflect the occurrence of "luxury uptake," the storage of Fe in the cell (at a high $\mathrm{Fe}: \mathrm{C}$ ratio) for future use when Fe is less available from the environment (Sund and Huntsman, 1995). Differentiating Fe luxury uptake from the variable Fe:C requirements of phytoplankton was impossible because the identity of surface populations was not known. However, even if we did have this information, because the $\mathrm{OMZ} \mathrm{Fe:C} \mathrm{signature} \mathrm{only} \mathrm{re-}$ flects the Fe:C ratio of the sinking fraction (presumably only the largest cells) and the scavenging effect on this ratio at depth is unclear, it would be difficult to prove the presence of luxury uptake by this method.

While our $\mathrm{dFe}-\mathrm{AOU}$ relationship suggests that the main source of Fe enrichment in the $\mathrm{OMZ}$ is the remineralization of high $\mathrm{Fe}: \mathrm{C}$ particulate material, the hypothesis that $\mathrm{dFe}$ is released from coastal reducing sediments is not yet excluded. One way to search for a margin Fe source is to examine the distribution of $\mathrm{dMn}$, which is often released along with Fe from reducing sediments. As can be seen in the dMn distribution in Fig. 9, there is an offshore decrease in $\mathrm{dMn}$ at $500 \mathrm{~m}$ in both transects measured. While this could be construed as a delivery of $\mathrm{dMn}$ from coastal reducing sediments, it could just as easily be explained by the oxygen distribution at $500 \mathrm{~m}$ across these same stations (increasing offshore from 68 to $96 \mu \mathrm{mol} / \mathrm{kg}$ in the northern transect and from 48 to $105 \mu \mathrm{mol} / \mathrm{kg}$ in the southern transect). It is well understood that dMn at depth is maintained by a balance of inputs by remineralization and losses by scavenging (Johnson et al., 1992, 1996); however, at low oxygen concentrations, the scavenging rate constant is reduced, contributing to an apparent $\mathrm{dMn}$ increase/maximum in low oxygen waters that can easily be misconstrued as a margin flux if the OMZ is coastal. Furthermore, it is important to note that $\mathrm{dMn}$ concentrations in the $\mathrm{OMZ}$ of the tropical North Atlantic are at minimum concentrations of $\sim 0.35-0.55 \mathrm{nmol} / \mathrm{kg}$, not a maximum as observed for dFe. Following Measures et al. (2008), we offer this as evidence that the high dFe is not the result of inputs from reduced coastal sediments. However, we note that if the residence time of $\mathrm{dMn}$ in the thermocline is much less than that of Fe (as estimated for deep waters in Bruland et al., 1994), this condusion might not be airtight. In this event, dMn may not be an ideal proxy for continental dissolved metal sources, and other proxies such as Fe isotopes, where depleted $\delta^{56} \mathrm{Fe}$ signatures have been observed in the reduced pore waters of reducing sediments and adjacent coastal regions (John et al., 2012; Severmann et al., 2006), might be more definitive.

Another way of searching for an influence of dFe released from coastal reducing sediments is to match observed data to modeled data in the presence and absence of a coastal Fe flux. We have constructed a simple one-dimensional steady-state isopycnal model that considers oxygen consumption, iron regeneration, and continental margin $\mathrm{Fe}$ fluxes. We base this model on the Brandt et al. (2008) suggestion that in the North Atlantic tropical oxygen minimum zone "the oxygen decrease from $35^{\circ} \mathrm{W}$ to $10^{\circ} \mathrm{W}$ within the oxygen tongue is mainly balanced by lateral eddy diffusivity and oxygen consumption." Our model is a one dimensional east-west ( $x, L=$ total length) isothermal, isopycnal model with constant horizontal diffusivity $\left(\kappa_{H}\right)$. We assume that the oxygen consumption rate in this domain is constant $\left(J_{\mathrm{O}_{2}}\right)$ and matched with "Redfield Ratio" $\mathrm{Fe} / \mathrm{O}_{2}$ for iron remineralization $\left(\mathrm{R}_{\mathrm{Fe}} \mathrm{O}_{2}\right)$. On the western margin, we fix oxygen $\left(\mathrm{O}_{2}\right.$ (west)) and iron (Fe(west)) at their observed concentrations, and at the eastern boundary we specify an iron flux from the sediments $\left(S_{\mathrm{Fe}}\right)$ with no significant loss of oxygen. The equations for this model are:

$0=\frac{\partial \mathrm{O}_{2}(x)}{\partial t}=K_{H} \frac{\partial^{2} \mathrm{O}_{2}(x)}{\partial x^{2}}-J_{\mathrm{O}_{2}}$

$0=\frac{\partial \mathrm{Fe}(x)}{\partial t}=K_{H} \frac{\partial^{2} \mathrm{Fe}(x)}{\partial x^{2}}+R_{\mathrm{Fe}} J_{\mathrm{O}_{2}}$

with Eq. (2) having an Fe flux ( $\left.S_{\mathrm{Fe}}\right)$ at the eastern margin.

Reflecting on the solution to these differential equations, the oxygen concentration must be curvilinear vs. $x$ because the western margin supplies all of the oxygen depleted across the entire basin:

$\int_{0}^{L} J_{\mathrm{O}_{2}} d x=\left.K_{H} \frac{d \mathrm{O}_{2}}{d x}\right|_{x=0}$

and hence must have a high slope, whereas in the middle of the domain, the flux is half as high, so $d_{\mathrm{O}_{2}} / d x$ is half of that at the western boundary (and similarly the slope is zero at the eastern boundary).
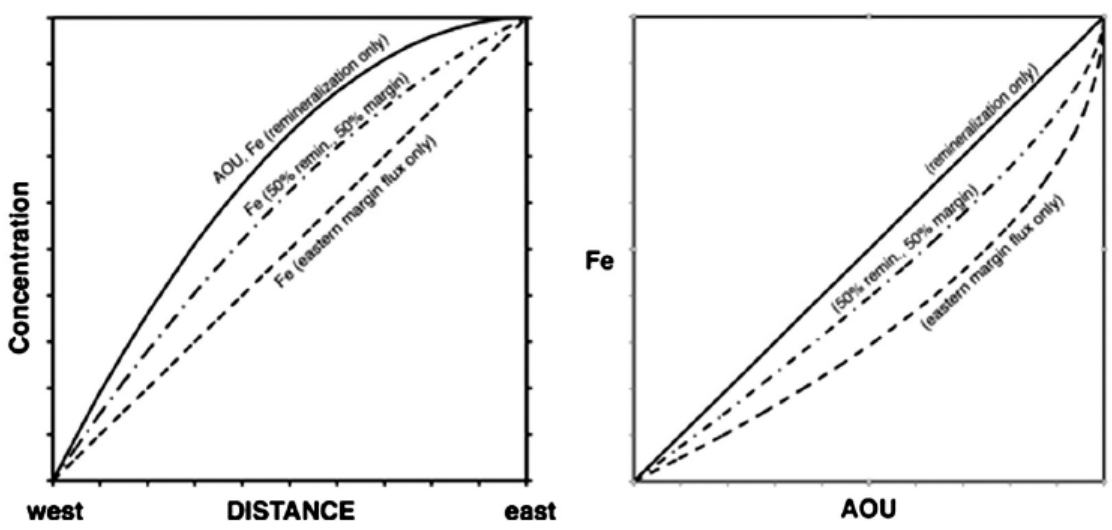

Fig. 10. Non-dimensionalized plots of tropical North Atlantic OMZ dFe-oxygen model solutions. 


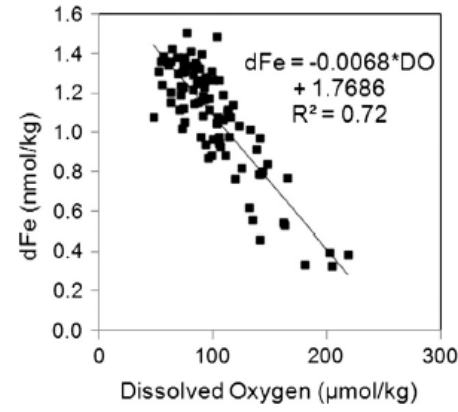

Fig. 11. dFe as a function of dissolved oxygen concentration for all stations sampled along the $\mathrm{OMZ}$ between the depths of $250-850 \mathrm{~m}$.

Furthermore, since all of the sedimentary Fe flux is introduced at the eastern margin $(x=L)$, this flux is constant and diffusive across the basin towards the east:

$S_{\mathrm{Fe}}=K_{H} \frac{d \mathrm{Fe}(L)}{d x}$

and Fe increases linearly from west to east. Subject to the specified boundary conditions, the solutions to these equations are:

$\mathrm{O}_{2}(x)=\mathrm{O}_{2}$ (west) $+\frac{J_{\mathrm{O}_{2}}}{2 K_{H}} x^{2}-\frac{J_{\mathrm{O}_{2}}}{K_{H}} L x$

$\mathrm{Fe}(x)=\mathrm{Fe}($ west $)-\frac{R_{\mathrm{Fe}} J_{\mathrm{O}_{2}}}{2 K_{H}} x^{2}+\frac{R_{\mathrm{Fe}} J_{\mathrm{O}_{2}}}{K_{H}} L x+\frac{S_{\mathrm{Fe}}}{K_{H}} x$.

Fig. 10 illustrates dimensionless solutions to these equations. In order to constrain which Fe inputs are most important in the tropica North Atlantic, the modeled Fe concentration results as a function of AOU can be compared to observations in Fig. 8. The prime outcome is that a significant eastern continental margin flux leads to curvature in the Fe-AOU relationship that is not observed in the data of Fig. 8; note here that we also considered an Fe steady state that included scavenging as a dFe sink, and scavenging was found to exacerbate, not compensate for, the curvature in the Fe-AOU relationship (see Supplementary Material A for the scavenging model). Thus, a mechanism of dFe delivery at depth via remineralization is favored over a laterally mixed margin source.

3.4. Effects of future deoxygenation on dFe in the tropical North Atlantic $\mathrm{OMZ}$

As stated in Section 3.2.2, the dFe maximum in the tropical North Atlantic OMZ is stable in location and magnitude between 2003 when sampled by Measures et al. (2008) and 2008 when sampled for this study. This temporal stability occurs despite the reported average deoxygenation rate of $0.5 \mu \mathrm{mol} / \mathrm{kg} /$ year over the last decades in the tropical North Atlantic OMZ (Stramma et al., 2009). In fact, this deoxygenation is the fastest of any OMZ in the world (Stramma et al., 2008b). From our measurements, dFe and dissolved oxygen (DO) are linearly correlated (Fig. 11); this relationship is a simple reflection of the fixed dFe:AOU relationship, along with largely invariant initial oxygen concentrations. Using this relationship and the measured drop in DO of $2.5 \mu \mathrm{mol} / \mathrm{kg}$ over the 5 years between the two cruises, an increase of only $0.024 \mathrm{nmol} / \mathrm{kg}$ Fe would be predicted, which is near the precision of our dFe measurement and certainly could not be distinguished between two sampling and measurement systems over 5 years. Thus, even if deoxygenation did occur at $0.5 \mu \mathrm{mol} / \mathrm{kg} / \mathrm{year}$ over the five years between the two studies with a consequent increase in dFe defined by Fig. 11, it would not have been analytically distinguishable between these data sets.

If future deoxygenation of the tropical North Atlantic OMZ was to alter the local dFe inventory, the deoxygenation would have to be driven by a change in export production and oxygen utilization during remineralization rather than changes in initial oxygen concentration. Model simulations of future climate change suggest that global thermodines will physically deoxygenate when upstream waters warm and oxygen becomes less soluble (Matear and Hirst, 2003). However, biological factors related to changes in export production and remineralization at depth are also important, especially in OMZs. In the open ocean, future export production is predicted to decrease as primary production drops in surface waters due to complete nutrient consumption when oceans stratify from warming and decreased circulation (Bopp et al., 2001; Matear and Hirst, 2003). This would decrease oxygen utilization at depth and perhaps result in future increases in oxygenation of these thermoclines. In OMZs, however, where ventilation is minimal and local upwelling frequently occurs nearby, models predict that export production might increase, despite ocean stratification and warming (Matear and Hirst, 2003), which would cause further deoxygenation of the OMZ. Only if this change in export production were the cause of the $\mathrm{OMZ}$ deoxygenation would the dFe inventory in the tropical North Atlantic $\mathrm{OMZ}$ increase (assuming constant $\mathrm{Fe}: \mathrm{C}$ and dust deposition of Fe). Clearly, more work is needed to investigate the causes for the tropical North Atlantic OMZ deoxygenation, especially since the identity of the operating mechanism may have a direct impact on the future inventories of important nutrients such as $\mathrm{dFe}$.

\section{Conclusions}

While it is not surprising that dFe is enriched in surface waters of the tropical North Atlantic underlying the Saharan dust plume, in the underlying oxygen minimum waters $\mathrm{dFe}$ is near $1.5 \mathrm{nmol} / \mathrm{kg}$. Constant dFe:AOU relationships across all depths sampled in the upper $1000 \mathrm{~m}$ suggest that biological regeneration is a more consistent explanation for this enrichment than sedimentary diagenetic dFe mixed out from the African margin; the lack of significant dMn in the OMZ and the results of our simplified one-dimensional $\mathrm{Fe}$ model are consistent with the argument against continental margin release of $\mathrm{dFe}$. Estimated $\mathrm{Fe}: \mathrm{C}$ ratios were three times higher underlying the NW African dust plume than those measured in HNLC zones of the Northeast and equatorial Pacific. This enrichment of biotic Fe in high-Fe environments has implications for suggested ocean Fe fertilization concepts, since it would imply that high levels of Fe enrichment might be relatively ineffective as a means of removing carbon from the surface ocean.

\section{Acknowledgments}

We thank Jong-Mi Lee and Takamitsu Ito for measuring nutrients and dissolved oxygen on the cruise as well as Richard Kayser for his efforts in maintaining and deploying the MITESS units. We would also like to thank Phoebe Lam for her help at sea and useful discussions as well as Nicholas Fitzsimmons for aid with the modeling. Excellent marine support was offered by the officers and crew of the $R / V$ Oceanus. Finally, we thank Reiner Schlitzer and his group for sharing the Ocean Data View graphics program and Eric Achterberg, Maeve Lohan, and Chris Measures for their comments on this manuscript. J.N. Fitzsimmons was funded by a National Science Foundation Graduate Research Fellowship (NSF Award \#0645960), and this work was funded by NSF OCE-07020278 and the Center for Microbial Oceanography: Research and Education (NSF-OIA Award \#EF-0424599). 


\section{Appendix A. Supplementary data}

Supplementary data to this article can be found online at http:// dx.doi.org/10.1016/j.marchem.2013.05.009. Supplementary Material A contains the one-dimensional Fe model that includes a scavenging term. Supplementary Material B tabulates the data for all stations of this study.

\section{References}

Aguilar-Islas, A.M., Wu, J., Rember, R., Johansen, A.M., Shank, L.M., 2010. Dissolution of aerosol-derived iron in seawater: leach solution chemistry, aerosol type, and colloidal iron fraction. Mar. Chem. $120(1-4), 25-33$.

Bell, J., Betts, J., Boyle, E., 2002. MITESS: a moored in situ trace element serial sampler for deep-sea moorings. Deep-Sea Res. I Oceanogr. Res. Pap. 49 (11), 2103-2118.

Beltenev, V., et al., 2009. New data about hydrothermal fields on the Mid-Atlantic Ridge between $11^{\circ}-14^{\circ} \mathrm{N}$ : 32 nd Cruise of R/V Professor Logatchev. InterRidge News, 18 13-17.

Bergquist, B.A., Boyle, E.A., 2006a. Dissolved iron in the tropical and subtropical Atlantic Ocean. Global Biogeochem. Cycles 20 (1), 14.

Bergquist, B.A., Boyle, E.A., 2006b. Iron isotopes in the Amazon River system: weathering and transport signatures. Earth Planet. Sci. Lett. 248 (1-2), 54-68.

Bergquist, BA., Wu, J., Boyle, E.A., 2007. Variability in oceanic dissolved iron is dominated by the colloidal fraction. Geochim. Cosmochim Acta 71 (12), 2960-2974

Blain, S., Bonnet, S., Guieu, C., 2008. Dissolved iron distribution in the tropical and sub tropical South Eastern Pacific. Biogeosciences 5 (1), 269-280.

Bonatti, E., Guerstein-Honnorez, B.-M., Honnorez, J., 1976. Copper-iron sulfide mineralizations from the Equatorial Mid-Atlantic Ridge. Econ. Geol. 71, 1515-1525.

Bopp, L, et al., 2001. Potential impact of climate change on marine export production. Global Biogeochem. Cycles 15 (1), 81-99.

Bourles, B., R.L, M., Johns, E., Wilson, W.D., Leaman, K.D., 1999. Upper layer currents in the western tropical North Atlantic. J. Geophys. Res. 104, 1361-1375.

Boye, M., et al., 2006. The chemical speciation of iron in the north-east Atlantic Ocean. Deep Sea Research Part I. Oceanographic Research Papers, 53. 4, pp. 667-683.

Boyle, E.A., Edmond, J.M., Sholkovitz, ER., 1977. The mechanism of iron removal in estuaries. Geochim. Cosmochim. Acta 41, 1313-1324.

Brandt, P., et al, 2008. Oxygen tongues and zonal currents in the equatorial Atlantic J. Geophys. Res. 113, C04012.

Brown, M.T., Landing, W.M., Measures, C.I., 2005. Dissolved and particulate Fe in the western and central North Pacific: results from the 2002 IOC cruise. Geochem. Geophys. Geosyst. 6 (10), Q10001.

Bruland, KW., Orians, K.J., Cowen, J.P., 1994. Reactive trace metals in the stratified central North Pacific. Geochim. Cosmochim. Acta 58 (15), 3171-3182.

Bruland, K.W., Rue, E.L., Smith, G.J., DiTullio, G.R., 2005. Iron, macronutrients and diatom blooms in the Peru upwelling regime: brown and blue waters of Peru. Mar. Chem. 93, 81-103. Chiapello, I., et al, 1995. An additional low layer transport of Sahelian and Saharan dust
over the North-Eastern Tropical Atlantic. Geophys. Res. Lett. 22 (23), 3191-3194.

Coale, K.H. Gordon, R.M. Wang Z, 2005. The distribution and behavior of the dissolved and particulate iron and zinc in the Ross Sea and Antarctic Circumpolar Current along 70 W. Deep-Sea Res. I 52, 295-318.

Croot, P.L, Andersson, K., Ozturk, M., Turner, D.R., 2004a. The distribution and specification of iron along 6 degrees E in the Southern Ocean. Deep-Sea Res. II Top. Stud. Oceanogr. 51 (22-24), 2857-2879.

Croot, P.L., Streu, P. Baker, A.R., 2004b. Short residence time for iron in surface seawate impacted by atmospheric dry deposition from Saharan dust events. Geophys. Res. Lett. 31 (23), L23508.

Cullen, J.T., Bergquist, BA., Moffett, J.W., 2006. Thermodynamic characterization of the partitioning of iron between soluble and colloidal species in the Atlantic Ocean. Mar. Chem. 98 (2-4), 295-303.

Edmond, J.M., et al, 1979. Ridge crest hydrothermal activity and the balances of the major and minor elements in the ocean: the Galapagos data. Earth Planet. Sci. Lett. 46, 1-18.

Elrod, VA., Berelson, W.M., Coale, K.H., Johnson, KS., 2004. The flux of iron from continental shelf sediments: a missing source for global budgets. Geophys. Res. Lett. 31, L12307.

Fitzsimmons, J.N., Boyle, E.A., 2012. An intercalibration between the GEOTRACES GO-FLO and the MITESS/Vanes sampling systems for dissolved iron concentration analyses (and a closer look at adsorption effects). Limnol. Oceanogr. Methods 10, 437-450.

Gao, Y, Kaufman, Y.J., Tanre, D., Kolber, D., Falkowski, P.G., 2001. Seasonal distribution of aeolian iron fluxes to the global ocean. Geophys. Res. Lett. 28, 29-32

Gerringa, LJ.A., Veldhuis, M.J.W., Timmermans, K.R., Sarthou, G., de Baar, H.J.W., 2006. Co-variance of dissolved Fe-binding ligands with phytoplankton characteristics in the Canary Basin. Mar. Chem. 102 (3-4), 276-290.

Gledhill, M., van den Berg, C.M.G., 1994. Determination of complexation of iron(III) with natural organic ligands in seawater using cathodic stripping voltammetry. Mar. Chem. 47, 41-54

Hellweger, F.L, Gordon, A.L., 2002. Tracing Amazon River water into the Caribbean Sea. J. Mar. Res. 60 (4), 537-549.

Husar, R.B., Prospero, J.M., Stowe, L.L., 1997. Characterization of tropospheric aerosols over the oceans with the NOAA advanced very high resolution radiometer optical

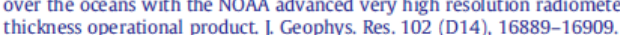

Jickells, T.D., et al., 2005. Global iron connections between desert dust, ocean biogeochemistry, and climate. Science 308 (5718), 67-71.
John, S.G., Mendez, J., Moffett, J., Adkins, J., 2012. The flux of iron and iron isotopes from San Pedro Basin sediments. Geochim. Cosmochim. Acta 93, 14-29.

Johnson, J.K., Miller, L.A., Sutherland, N.E., Wong. C.S., 2005. Iron transport by mesoscale Haida eddies in the Gulf of Alaska. Deep-Sea Res. II Top. Stud. Oceanogr. 52 (7-8), 933-953.

Johnson, KS., et al, 1992. Manganese flux from continental margin sediments in a transect through the oxygen minimum. Science $257,1242-1245$.

Johnson, K.S., Coale, K.H., Berelson, W.M., Gordon, R.M., 1996. On the formation of the manganese maximum in the oxygen minimum. Geochim. Cosmochim. Acta 60 (8), 1291-1299.

Johnson, KS., et al., 2003. Surface ocean-lower atmosphere interactions in the Northeast Pacific Ocean Gyre: aerosols, iron, and the ecosystem response. Global Biogeochem. Cycles 17 (2), 1063.

Karstensen, J., Stramma, L., Visbeck, M., 2008. Oxygen minimum zones in the eastern tropical Atlantic and Pacific oceans. Prog. Oceanogr. 77, 331-350.

Klinkhammer, G., Rona, P., Greaves, M. Elderfield, H., 1985. Hydrothermal manganese plumes in the Mid-Atlantic Ridge rift valley. Nature 314 (6013), 727-731.

Klunder, M.B. Laan, P. Middag, R., De Baar, H.J.W., van Ooijen, J.C., 2011. Dissolved iron in the Southern Ocean (Atlantic sector). Deep-Sea Res. II Top. Stud. Oceanogr. 58 (25-26), 2678-2694.

Klunder, M.B., Laan, P., Middag, R., de Baar, H.J.W., Bakker, K., 2012. Dissolved iron in the Arctic Ocean: important role of hydrothermal sources, shelf input and scavenging removal. J. Geophys. Res. 117 (C4), C04014

Laës, A., et al., 2003. Deep dissolved iron profiles in the eastern North Atlantic in relation to water masses. Geophys. Res. Lett. 30 (17), 1902

Lam, P.J. et al., 2006. Wintertime phytoplankton bloom in the subarctic Pacific supported by continental margin iron. Global Biogeochem. Cycles 20, GB1006.

Lee, J.-M., et al., 2011. Analysis of trace metals (Cu, Cd, Pb, and Fe) in seawater using single batch nitrilotriacetate resin extraction and isotope dilution inductively coupled plasma mass spectrometry. Anal. Chim. Acta 686, 93-101.

Liu, X., Millero, F.J. 2002. The solubility of iron in seawater. Mar. Chem. 77, 43-54.

Luyten, J.R., Pedlosky. J., Stommel, H., 1983. The ventilated thermocline.J. Phys. Oceanogr. $13,292-309$.

Mahowald N, et al, 2005. Atmospheric global dust cycle and iron inputs to the ocean. Global Biogeochem. Cycles 19, GB4025.

Mantyla, A.W., Reid, J.L., 1983. Abyssal characteristics of the World Ocean waters, Deep-Sea Res. 30 (8A), 805-833.

Martin, J.H., Knauer, G.A., Karl, D.M., Broenkow, W.W., 1987. VERTEX: carbon cycling in the northeast Pacific. Deep-Sea Res.Part A Oceanogr. Res. Pap. 34 (2), 267-285.

Martin, J.H., Goron, R.M., Fitzwater, S., Broenkow, W.W., 1989. VERTEX: phytoplankton/ iron studies in the Gulf of Alaska. Deep-Sea Res. 36 (5), 649-680.

Martin, J.H., Gordon, R.M., Fitzwater, S.E., 1990. Iron in Antarctic waters. Nature 345, $156-158$.

Martin, J.H., Fitzwater, S.E., Michael Gordon, R., Hunter, C.N., Tanner, S.J., 1993. Iron, primary production and carbon-nitrogen flux studies during the JGOFS North Atlantic bloom experiment. Deep-Sea Res. II Top. Stud. Oceanogr. 40 (1-2), 115-134.

Matear, R.J., Hirst, A.C., 2003. Long-term changes in dissolved oxygen concentrations in the ocean caused by protracted global warming. Global Biogeochem. Cycles 17 (4), 1125.

McCartney, M.S., 1992. Recirculating components to the deep boundary current of the northern North Atlantic. Prog. Oceanogr. 29, 283-383.

McCartney, M.S. Bennett, S.L., Woodgate-Jones, M.E., 1991. Eastward flow through the Mid-Atlantic Ridge at 11 degrees $\mathrm{N}$ and its influence on the abyss of the Eastern Basin. J. Phys. Oceanogr. 21, 1089-1121.

Measures, C.I., Landing, W.M., Brown, M.T., Buck, C.S., 2008. High-resolution Al and Fe data from the Atlantic Ocean CLIVAR- $\mathrm{CO}_{2}$ repeat hydrography A16N transect: extensive linkages between atmospheric dust and upper ocean geochemistry. Global Biogeochem. Cycles 22, GB1005.

Middag, R. de Baar, H.J.W., Laan, P., Cai, P.H., van Ooijen, J.C., 2011a. Dissolved manganese in the Atlantic sector of the Southern Ocean. Deep-Sea Res. II Top. Stud. Oceanogr. 58, 2661-2677.

Middag, R., de Baar, H.J.W., Laan, P., Klunder, M.B., 2011b. Fluvial and hydrothermal input of manganese into the Arctic Ocean. Geochim. Cosmochim. Acta 75 (9), 2393-2408.

Milne, A., Landing, W., Bizimis, M., Morton, P., 2010. Determination of Mn, Fe, Co, Ni, $\mathrm{Cu}, \mathrm{Zn}, \mathrm{Cd}$ and $\mathrm{Pb}$ in seawater using high resolution magnetic sector inductively coupled mass spectrometry (HR-ICP-MS). Anal. Chim. Acta 665 (2), 200-207.

Moffett, J.W., Goepfert, T.., Naqvi, S.W.A., 2007. Reduced iron associated with secondary nitrite maxima in the Arabian Sea. Deep-Sea Res. I Oceanogr. Res. Pap. 54 (8), 1341-1349.

Moore, J.K., Braucher, 0. 2008. Sedimentary and mineral dust sources of dissolved iron to the world ocean. Biogeosciences 5, 631-656.

Moore, J.K., Doney, S.C., Glover, D.M., Fung, I.Y., 2002. Iron cycling and nutrientlimitation pattems in surface waters of the World Ocean. Deep-Sea Res. II Top. Stud. Dceanogr. 49 (1-3), 463-507.

Moore, C.M., et al., 2009. Large-scale distribution of Atlantic nitrogen fixation controlled by iron availability. Nat. Geosci. 2 (12), 867-871.

Morel, F.M.M., Milligan, A.J., Saito, M.A., 2003. Marine bioinorganic chemistry: the role of trace metals in the oceanic cycles of major nutrients. In: Turekian, K.K., Holland, H.D. (Eds.), Treatise on Geochemistry. Elsevier Science Ltd., Cambridge, United Kingdom, pp. 113-143.

Murphy.J., Riley. J.P., 1962. A modified single solution method for the determination of phosphate in natural waters. Anal. Chim. Acta 27, 31-36.

Noble, A.E., et al, 2012. Basin-scale inputs of cobalt, iron, and manganese from the BenguelaAngola front to the South Atlantic Ocean. Limnol. Oceanogr. 57 (4), 989-1010.

Prospero, J.M., Carlson, T.N., 1972. Vertical and areal distribution of Saharan dust over the Western Equatorial North Atlantic Ocean. J. Geophys. Res. 77, 5255-5265. 
Prospero, JM. Glaccum, R.A., Nees, R.T, 1981. Atmospheric transport of soil dust from Africa to South America. Nature 289, 570-572.

Richardson, P. Reverdin, G 1987. Seasonal gycle of velocity in the Atlantic North Equatorial Countercurrent as measured by surface drifters, current meters, an ship drifts. J. Geophys. Res. 92, 3691-3708.

Rijkenberg, M.J.A., et al., 2008. Changes in iron speciation following a Saharan dust event in the tropical North Atlantic Ocean. Mar. Chem. $110(1-2), 56-67$.

Rijkenberg, M.J.A., et al., 2012. Fluxes and distribution of dissolved iron in the eastern (sub-) tropical North Atlantic Ocean. Global Biogeochem. Cycles 26 (3), GB3004.

Rue, E.L., Bruland, KW., 1995. Complexation of iron(III) by natural organic ligands in the Central North Pacific as determined by a new competitive ligand equilibration/ adsorptive cathodic stripping voltammetric method. Mar. Chem. 50 (1-4), 117-138.

Sarthou, G., et al., 2003. Atmospheric iron deposition and sea-surface dissolved iron concentrations in the eastern Atlantic Ocean. Deep-Sea Res. I Oceanogr. Res. Pap. $50(10-11), 1339-1352$

Schlitzer, R., 2012. Ocean Data View. http://odv.awi,de

Sedwick, P.N., Edwards, P.R., Mackey, D.J., Griffiths, F.B., Parslow, J.S., 1997, Iron and manganese in surface waters of the Australian subantarctic region. Deep-Sea Res. manganese in surface waters of the Austrit.
I Oceanogr. Res. Pap. 44 (7), 1239-1253.

Severmann, S. Johnson, C.M., Beard, B.L, McManus, J. 2006. The effect of early diagenesis on the $\mathrm{Fe}$ isotope compositions of porewaters and authigenic minerals in esis on the Fe isotope compositions of porewaters and authigenic miner.
continental margin sediments. Geochim. Cosmochim. Acta 70, 2006-2022.

Siedler, G., Kuhl, A., Zenk, W., 1987. The Madeira Mode Water. J. Phys. Oceanogr. 17 $1561-1570$.

Sohrin, Y., et al., 2000. The distribution of Fe in the Australian sector of the Southern Ocean. Deep-Sea Res, I Oceanogr. Res. Pap. 47 (1), 55-84.

Sohrin, Y., et al., 2008. Multielemental determination of GEOTRACES key trace metals in seawater by ICPMS after preconcentration using an ethylenediaminetriacetic acid chelating resin. Anal. Chem. 80 (16), 6267-6273.

Steven, D.M., Brooks, A.L., 1972. Identification of Amazon River water at Barbados, W. Indies, by salinity and silicate measurements. Mar. Biol. 14, 345-348.

Stramma, L., Schott, F., 1999. The mean flow field of the tropical Atlantic Ocean. DeepSea Res. II 46, 279-303.

Stramma, L., Hüttl, S., Schafstall, J., 2005. Water masses and currents in the upper tropical northeast Atlantic off northwest Africa J. Geophys, Res, 110 (C12), C12006.
Stramma, L, et al., 2008a. Oxygen minimum zones in the North Atlantic south and east of the Cape Verde Islands. J. Geophys. Res. 113, C04014.

Stramma, L., Johnson, G.C. Sprintall, J., Mohrholz, V., 2008b. Expanding oxygenminimum zones in the tropical oceans. Science 320, 655-658.

Stramma, L., Visbeck, M., Brandt, P., Tanhua, T., Wallace, D., 2009. Deoxygenation in the oxygen minimum zone of the eastern tropical North Atlantic. Geophys. Res. Lett. 36 (20), L20607.

Strickland, J.D.H., Parsons, T.R., 1968. A Practical Handbook of Seawater Analysis. Bulletin of the Fisheries Research Board of Canada, Ottawa 167

Sunda, W.G., 1997. Control of dissolved iron concentrations in the world ocean, a comment. Mar. Chem. 57 (3-4), 169-172.

Sunda, W.G., Huntsman, S.A., 1995. Iron uptake and growth limitation in oceanic and coastal phytoplankton. Mar. Chem. 50 (1-4), 189-206.

Takata, H., et al, 2006. Comparing the vertical distribution of iron in the eastern and western North Pacific Ocean. Geophys. Res. Lett. 33 (2), L02613.

. C. Sea Res. I Oceanogr. Res. Pap. 57 (11), 1444-1453.

Tomczak, M., Godfrey, J.S., 2003. Regional Oceanography: An Introduction (Published online, $390 \mathrm{pp}$.).

van den Berg CMC. 1995. Evidence for organic complexation of iron in seawater. Mar. Chem. 50 (1-4), 139-157,

1959. The $18^{\circ}$ water in the Sargasso Sea. Deep-Sea Res. 5, 297-305.

Wu, J., Luther, G.W., 1995. Complexation of $\mathrm{Fe}$ (III) by natural organic ligands in the Northwest Atlantic Ocean by a competitive ligand equilibration method and kinetic approach. Mar. Chem. 50 (1-4), 159-177.

Wu, J., Boyle, E.A., Sunda, W.G., Wen, L, 2001. Soluble and colloidal iron in the oligotrophic North Atlantic and North Pacific. Science 293, 847-849.

Zhou, M., Paduan, J.M., Niiler, P.P., 2000. Surface currents in the Canary Basin from drifter observations. J. Geophys. Res. 105, 21893-21911.

Zhu, X.R., Prospero, J.M., Millero, F.J., 1997. Diel variability of soluble Fe(II) and soluble total Fe in North African dust in the trade winds at Barbados. J. Geophys. Res. 102 (D17), 21297-21305. 


\section{Supplementary Material A: 1-D Fe model including scavenging}

The steady state equations discussed in the paper were:

$$
\begin{aligned}
& O_{2}(x)=O_{2}(\text { west })+\frac{J_{O_{2}}}{2 \kappa_{H}} x^{2}-\frac{J_{O_{2}}}{\kappa_{H}} L x \\
& F e(x)_{\text {noscav }}=F e(\text { west })-\frac{R_{F e} J_{O_{2}}}{2 \kappa_{H}} x^{2}+\frac{R_{F e} J_{O_{2}}}{\kappa_{H}} L x+\frac{S_{F e}}{\kappa_{H}} x
\end{aligned}
$$

Equation 6 does not include a scavenging component, and since we do not know the relative scavenging contribution to the Fe steady state in the tropical North Atlantic, we added a scavenging term to the model in order to be ensure that any curvature in the Fe-AOU relationship contributed by an eastern continental margin flux was not removed via scavenging to create the linear Fe-AOU relationship observed:

$$
0=\frac{\partial F e(x)}{\partial t}=\kappa_{H} \frac{\partial^{2} F e(x)}{\partial x^{2}}-\lambda F e(x)+R_{F e} J_{O 2}
$$

Using the same boundary conditions used to solve Equations 1-2, the solution to this equation was:

$$
F e(x)_{s c a v}=A \exp \left(\sqrt{\frac{\lambda}{\kappa_{H}}} x\right)+B \exp \left(-\sqrt{\frac{\lambda}{\kappa_{H}}} x\right)+\frac{R_{F e} J_{O 2}}{\lambda}
$$

where A and B are constants ( $\lambda$ must be positive, and the differential must be solved only from 0 to $\mathrm{L}$ ):

$$
A=F e(\text { west })-\frac{R_{F e} J_{O 2}}{\lambda}-B
$$

$$
B=\frac{\kappa_{H} \sqrt{\frac{\lambda}{\kappa_{H}}}\left(F e(\text { west })-\frac{R_{F e} J_{O 2}}{\lambda}\right) \exp \left(\sqrt{\frac{\lambda}{\kappa_{H}}} L\right)-S_{F e}}{\kappa_{H} \sqrt{\frac{\lambda}{\kappa_{H}}}\left[\exp \left(\sqrt{\frac{\lambda}{\kappa_{H}}} L\right)+\exp \left(-\sqrt{\frac{\lambda}{\kappa_{H}}} L\right)\right]}
$$

In order to evaluate the scavenging contribution at various eastern margin $\mathrm{Fe}$ inputs, we estimated the constants in these equations by fitting the modeled data to the observed data. To develop a database of observed data, we first calculated the distance L from Station $1\left(15^{\circ} \mathrm{N}, 57.58^{\circ} \mathrm{W}\right)$ to the Mauritanian coast $\left(15^{\circ} \mathrm{N}, 17.5^{\circ} \mathrm{W}\right)$ as $\sim 4300 \mathrm{~km}$, and then we solved for the distance (x) at each station using its longitude along an assumed $15^{\circ} \mathrm{N}$ latitude. We also included the measured dissolved oxygen, $\mathrm{dFe}$, and $\mathrm{AOU}$ at $500 \mathrm{~m}$ for each of these stations in the database (Table S1).

First, we assumed that the horizontal diffusivity $\left(\kappa_{\mathrm{H}}\right)$ was equal to $1000 \mathrm{~m}^{2} / \mathrm{s}$, as measured by an $\mathrm{SF}_{6}$ tracer experiment in this region (Ledwell et al. 1998). Then, assuming $\mathrm{O}_{2}$ (west) was the highest oxygen value measured (Station $6=163.1 \mu \mathrm{mol} / \mathrm{kg}$ ), and using a seawater density of $1025 \mathrm{~kg} / \mathrm{m}^{3}$, we 
used the oxygen steady state equation (5) to determine a value of $\mathrm{J}$ where the modeled data best fit the measured data. The best fit J value was $330 \mu \mathrm{mol} / \mathrm{m}^{3} / \mathrm{y}$ (Figure S1).

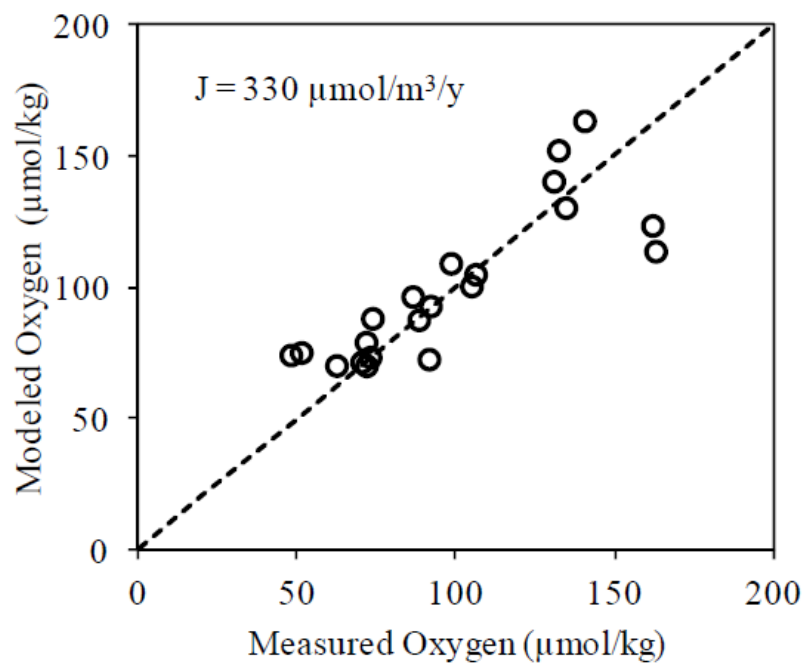

Figure S1: Measured and modeled oxygen concentrations at $500 \mathrm{~m}$ across the Tropical North Atlantic. The dotted line is a $1: 1$ relationship, and the best fit was found using a oxygen consumption rate (J) of $330 \mu \mathrm{mol} / \mathrm{m}^{3} / \mathrm{y}$.

Next, the Fe steady state equation 6 (in the absence of scavenging) was used to generate model $\mathrm{Fe}(\mathrm{x})$ data that could be compared to the measured dFe data across the transect. At an eastern margin flux $\left(\mathrm{S}_{\mathrm{Fe}}\right)$ of zero, the best fit of the modeled data to the observations (Figure S2, a-b) occurred at a Redfield ratio of Fe to oxygen $\left(\mathrm{R}_{\mathrm{Fe}}\right)$ of $0.0072 \mathrm{nmol} \mathrm{Fe} / \mu \mathrm{mol} \mathrm{O}$, which matches the $\mathrm{Fe}: \mathrm{C}$ of $11 \mathrm{umol} \mathrm{Fe} / \mathrm{mol} \mathrm{C}$ established in this paper $\left(0.0069 \mathrm{nmol} \mathrm{Fe} / \mu \mathrm{mol} \mathrm{O} \mathrm{O}_{2}\right)$ assuming an $\mathrm{O}_{2}: \mathrm{C}$ ratio of $1.6\left(170 \mathrm{O}_{2}: 106 \mathrm{C}\right.$;

Anderson and Sarmiento 1994). The modeled $\mathrm{Fe}(\mathrm{x})$ data was relatively insensitive to changes in $\mathrm{S}_{\mathrm{Fe}}$ up to a flux of $\sim 10^{6} \mathrm{nmol} \mathrm{Fe} / \mathrm{m}^{2} / \mathrm{y}$, above which the Redfield ratio could be decreased to make the modeled and measured $\mathrm{Fe}$ data match again (albeit to biologically inconsistent ratios of $0.16 \mu \mathrm{mol} \mathrm{Fe} / \mathrm{mol} \mathrm{C}$ ), yet the Fe-AOU relationship acquires a curve that was not supported by the data (Figure S2, c-d). At $\mathrm{S}_{\mathrm{Fe}}$ above $10^{7} \mathrm{nmol} \mathrm{Fe} / \mathrm{m}^{2} / \mathrm{y}$, it was difficult to match the modeled and measured $\mathrm{dFe}$ data. This is the major result of the model in the main body of this text.

However, we wondered whether adding a scavenging output of $\mathrm{dFe}$ in the model could erase the curvature in the Fe-AOU relationship contributed by an eastern continental margin flux, leaving the linear Fe-AOU relationship observed. Thus, we varied the $\mathrm{S}_{\mathrm{Fe}}$ flux and the $\lambda$ scavenging rate at a constant $\mathrm{R}_{\mathrm{Fe}}$ of $0.0072 \mathrm{nmol} \mathrm{Fe} / \mu \mathrm{mol} \mathrm{O} \mathrm{O}_{2}$. At low $\mathrm{S}_{\mathrm{Fe}}$ flux $\left(\leq 10^{6} \mathrm{nmol} / \mathrm{m}^{2} / \mathrm{y}\right)$, the scavenging rate needed to match the observed dFe data was very low $(0.001 / \mathrm{y})$ and indicated a system where mixing dominated the Fe distribution. At the $\mathrm{S}_{\mathrm{Fe}}$ flux of $10^{7} \mathrm{nmol} \mathrm{Fe} / \mathrm{m}^{2} / \mathrm{y}$ where the no-scavenging Fe model could no longer match the observed $\mathrm{dFe}$ data, a scavenging rate of $0.003 / \mathrm{y}$ was needed to match the modeled and 

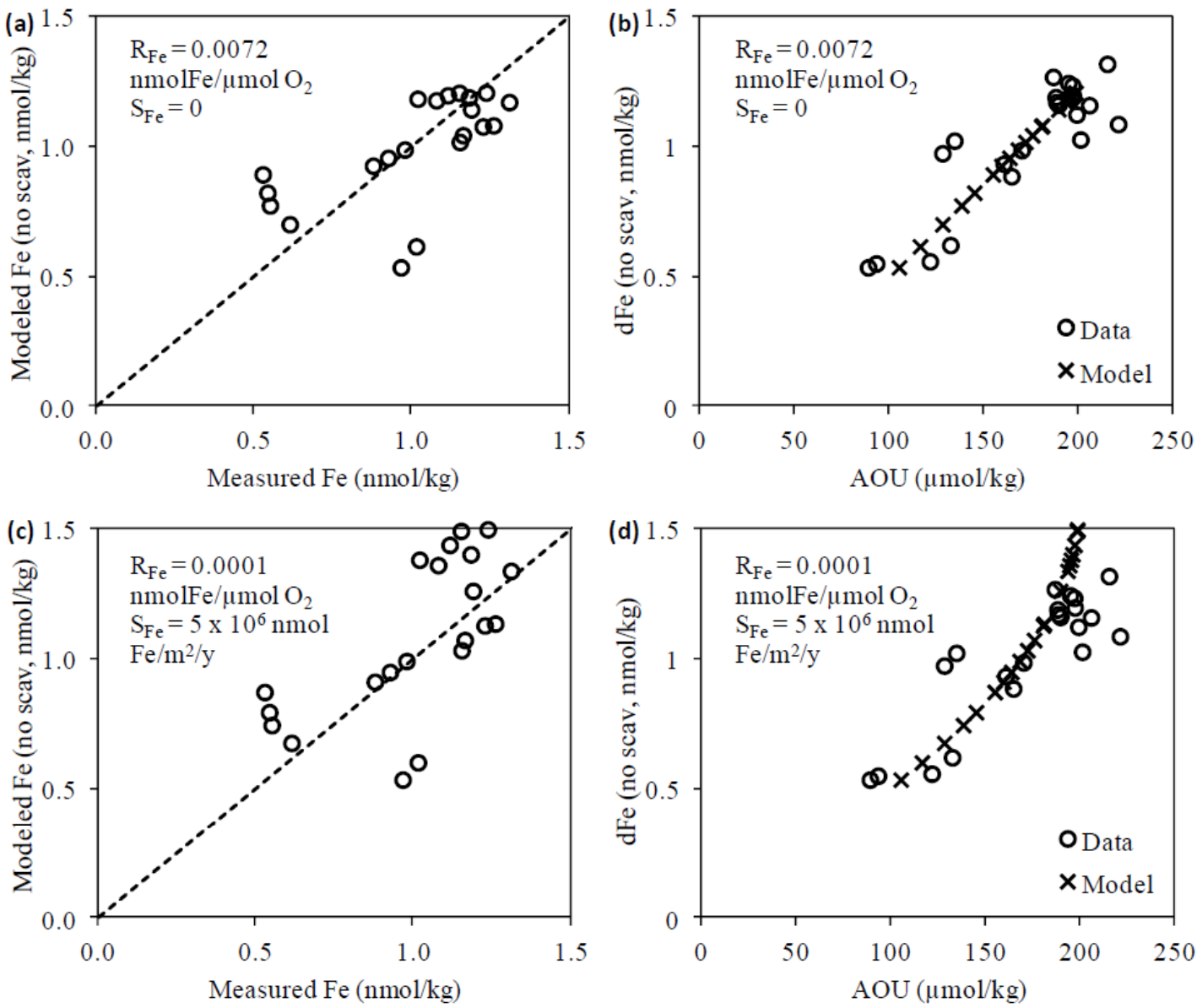

Figure S2: Output of the $\mathrm{Fe}(\mathrm{x})$ model (no scavenging, equation 6) compared to the measured dFe data $(\mathrm{a}, \mathrm{c})$ at various Redfield Fe: $\mathrm{O}_{2}$ ratios and eastem margin Fe fluxes. The dotted line is the 1:1 ratio between measured and modeled data. While the model can be made to fit the Fe data reasonably well, the modeled Fe/AOU relationship really only matches the observed regression in the presence of low (or no) eastern margin flux.

measured $\mathrm{dFe}$ data (Figure S3, a-b), yet the scavenging could not remove the curvature in the Fe-AOU relationship. This pattern was exacerbated at higher $\mathrm{S}_{\mathrm{Fe}}$ fluxes $\left(10^{8} \mathrm{nmol} \mathrm{Fe} / \mathrm{m}^{2} / \mathrm{y}\right)$ where only a narrow range of scavenging rates caused the modeled $\mathrm{Fe}(\mathrm{x})$ data to approach measured data (Figure S3, c-f), but the match between modeled and observed $\mathrm{dFe}$ was quite poor. In these cases, the Fe-AOU relationship had significant curvature that did not even fall within the range of measured data.

Thus, assuming the model and estimated constants approximate natural conditions, there could not have been a significant eastern margin Fe flux because a curved Fe-AOU regression would have resulted. Even enhanced scavenging could not remove the curving effect of the eastern margin flux on the Fe-AOU relationship. Only remineralization produced the observed linear Fe-AOU correlation. 

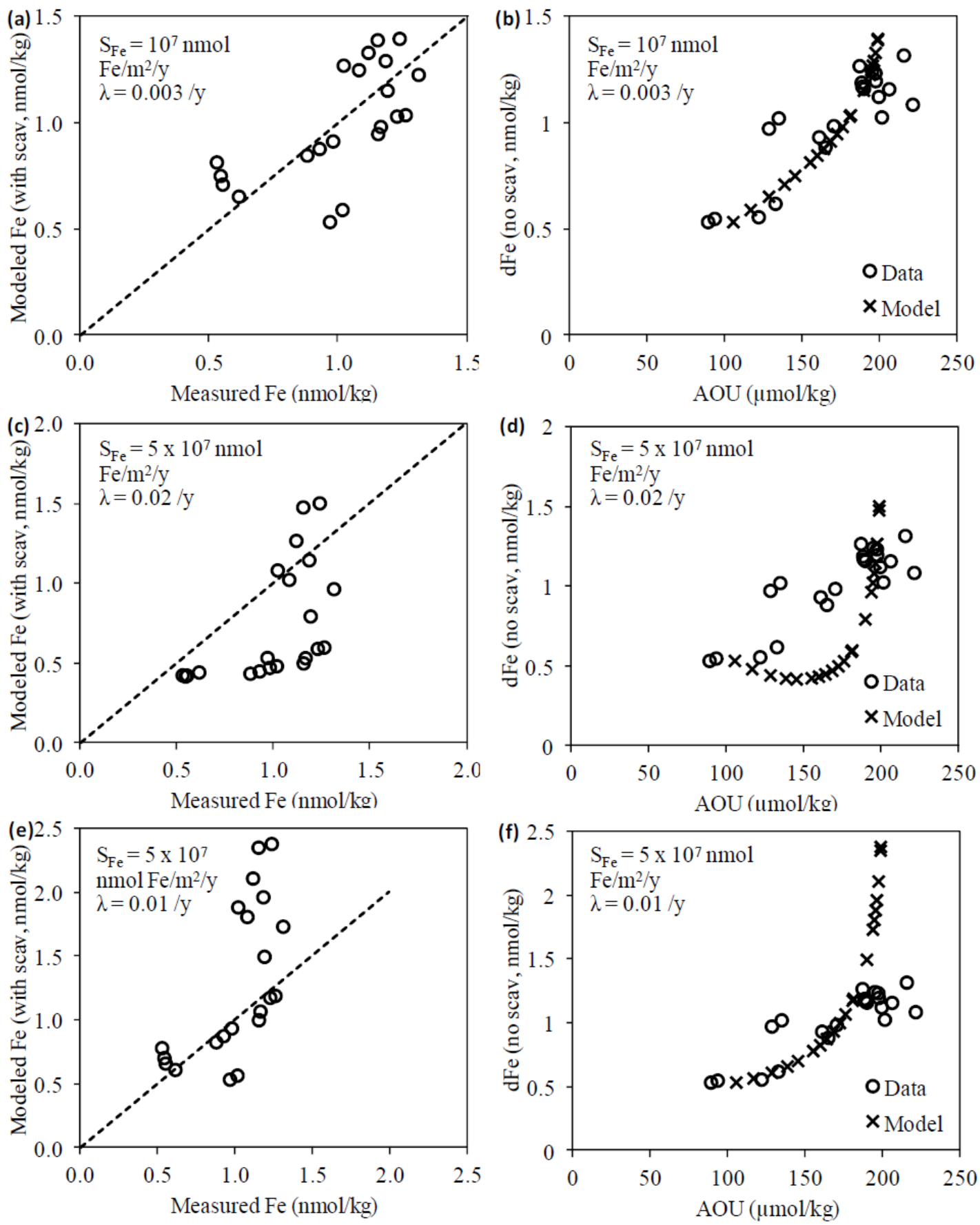

Figure S3: Output of the $\mathrm{Fe}(\mathrm{x})$ model (with scavenging, equations 8-10) compared to the measured dFe data (a, c, e) at various eastern margin Fe fluxes and scavenging rates. The dotted line is the 1:1 ratio between measured and modeled data. While the modeled Fe-AOU correlation matches the observed relationship fairly well at low scavenging ratios where mixing dominates the dFe distribution (b), scavenging serves to worsen the curvature in the Fe-AOU regression (instead of improve it), and thus a significant eastem margin Fe flux could not result in the linear Fe-AOU relationship observed in the tropical North Atlantic. 
Table S1: Measured data from $500 \mathrm{~m}$ depth used in the modeling efforts.

\begin{tabular}{|c|c|c|c|c|c|c|}
\hline Sta. & $\begin{array}{c}\text { Longitude } \\
\left({ }^{\circ} \mathbf{W}\right)\end{array}$ & $\mathbf{x}(\mathbf{m})$ & $\begin{array}{c}\text { Observed } \\
\mathrm{O}_{2} \\
(\mu \mathrm{mol} / \mathrm{kg})\end{array}$ & $\begin{array}{c}\text { Observed } \\
\text { AOU } \\
(\mu \mathrm{mol} / \mathrm{kg})\end{array}$ & $\begin{array}{c}\text { Observed } \\
\text { dFe } \\
(\mu \mathrm{mol} / \mathrm{kg})\end{array}$ & \\
\hline 1 & 57.58 & 0 & 140.7 & 128.9 & 0.970 & \\
\hline 2 & 55.13 & 263000 & 132.5 & 135.2 & 1.018 & Estimated Constants \\
\hline 3 & 52.35 & 561000 & 131.0 & 133.1 & 0.617 & \\
\hline 4 & 49.81 & 834000 & 134.8 & 122.3 & 0.554 & - $\mathrm{L}=4300 \mathrm{~km}=4,300,000 \mathrm{~m}$ \\
\hline 5 & 47.96 & 1032000 & 162.1 & 93.8 & 0.546 & $1000 \mathrm{~m}^{2} / \mathrm{s}=31536 \mathrm{y}$ \\
\hline 6 & 45.08 & 1341000 & 163.1 & 89.6 & 0.531 & \\
\hline 7 & 43.62 & 1498000 & 98.6 & 165.4 & 0.882 & $10^{10} \mathrm{~m}^{2} / \mathrm{y}$ \\
\hline 8 & 42.22 & 1648000 & 106.4 & 161.4 & 0.930 & $\mathrm{I}=330 \mu \mathrm{mol} / \mathrm{m}^{3} / \mathrm{v}$ \\
\hline 9 & 40.63 & 1818000 & 105.1 & 170.8 & 0.982 & $\bullet \mathrm{J}=330 \mu \mathrm{mol} / \mathrm{m} / \mathrm{y}$ \\
\hline 10 & 39.10 & 1983000 & 86.6 & 190.3 & 1.157 & - $\mathrm{R}_{\mathrm{Fe}}=0.0072 \mathrm{nmol} \mathrm{Fe} /$ \\
\hline 11 & 37.63 & 2141000 & 92.2 & 189.2 & 1.167 & \\
\hline 12 & 35.27 & 2394000 & 88.5 & 187.5 & 1.264 & $\mu \mathrm{mol} \mathrm{O}_{2}$ \\
\hline 13 & 33.02 & 2365000 & 73.9 & 197.7 & 1.230 & \\
\hline 14 & 30.55 & 2899000 & 71.9 & 197.9 & 1.193 & \\
\hline 16 & 27.67 & 3208000 & 51.5 & 216.1 & 1.314 & \\
\hline 17 & 26.84 & 3297000 & 48.2 & 221.9 & 1.082 & \\
\hline 18 & 26.05 & 3381000 & 73.2 & 201.9 & 1.023 & \\
\hline 19 & 25.27 & 3465000 & 91.7 & 188.8 & 1.186 & \\
\hline 20 & 23.90 & 3611000 & 70.5 & 199.9 & 1.119 & \\
\hline 22 & 21.88 & 3828000 & 62.6 & 206.6 & 1.155 & \\
\hline 23 & 21.65 & 3852000 & 72.0 & 195.5 & 1.240 & \\
\hline
\end{tabular}

\section{References}

Anderson, L. A., and J. L. Sarmiento. 1994. Redfield ratios of remineralization determined by nutrient data analysis. Global Biogeochemical Cycles 8: 65-80.

Ledwell, J. R., A. J. Watson, and C. S. Law. 1998. Mixing of a tracer in the pycnocline. J. Geophys. Res.Oceans 103: 21499-21529. 
Supplementary Information B

\begin{tabular}{|c|c|c|c|c|c|c|c|c|c|c|c|}
\hline Station & Date & $\begin{array}{l}\text { Lat } \\
\left({ }^{\circ} \mathrm{N}\right)\end{array}$ & $\begin{array}{l}\text { Lon } \\
\left({ }^{\circ} \mathrm{W}\right)\end{array}$ & $\begin{array}{l}\text { Depth } \\
\text { (m) }\end{array}$ & $\begin{array}{c}\mathrm{dFe} \\
(\mathrm{nmol} / \mathrm{kg})\end{array}$ & $1 \mathrm{SD}$ & $\mathrm{n}$ & $\begin{array}{c}\mathrm{dMn} \\
(\mathrm{nmol} / \mathrm{kg})\end{array}$ & $\begin{array}{c}\text { CTD } \\
\text { Depth (m) }\end{array}$ & $\begin{array}{c}\mathrm{O}_{2} \\
(\mu \mathrm{mol} / \mathrm{kg})\end{array}$ & $\begin{array}{c}\mathrm{PO}_{4}^{3-} \\
(\mu \mathrm{mol} / \mathrm{kg})\end{array}$ \\
\hline \multirow[t]{4}{*}{1} & $8 / 7 / 08$ & 13.945 & 57.581 & 10 & 1.35 & 0.05 & 2 & & 5 & 228.2 & 0.06 \\
\hline & & & & 123 & 0.28 & 0.05 & 3 & & 125 & 213.3 & 0.09 \\
\hline & & & & 494 & 1.00 & 0.03 & 2 & & 500 & 140.7 & \\
\hline & & & & 987 & 1.18 & 0.01 & 4 & & 1003 & 173.2 & 2.04 \\
\hline \multirow[t]{4}{*}{2} & $8 / 8 / 08$ & 15.129 & 55.129 & 10 & 0.95 & 0.01 & 2 & & 5 & 229.3 & 0.10 \\
\hline & & & & 502 & 1.05 & 0.03 & 5 & & 501 & 132.5 & \\
\hline & & & & 708 & 0.87 & 0.01 & 3 & & 700 & 147.7 & 2.14 \\
\hline & & & & 1004 & 0.93 & 0.00 & 5 & & 1002 & 163.9 & 2.11 \\
\hline \multirow[t]{6}{*}{3} & $8 / 9 / 08$ & 16.485 & 52.350 & 10 & 1.14 & 0.02 & 2 & & 5 & 223.6 & 0.04 \\
\hline & & & & 122 & 0.64 & 0.02 & 2 & & 125 & 231.1 & 0.00 \\
\hline & & & & 245 & 0.35 & 0.01 & 4 & & 250 & 180.7 & 0.55 \\
\hline & & & & 489 & 0.64 & 0.02 & 2 & & 500 & 131.0 & 1.63 \\
\hline & & & & 685 & 0.83 & 0.04 & 2 & & 699 & 143.3 & 2.09 \\
\hline & & & & 978 & 0.83 & 0.01 & 2 & & 1001 & 172.5 & 2.03 \\
\hline \multirow[t]{6}{*}{4} & $8 / 10 / 08$ & 17.714 & 49.808 & 10 & 0.73 & 0.05 & 3 & & 5 & 232.5 & 0.06 \\
\hline & & & & 127 & 0.16 & 0.04 & 2 & & 126 & 234.0 & 0.10 \\
\hline & & & & 254 & 0.41 & 0.03 & 4 & & 249 & 202.5 & 0.53 \\
\hline & & & & 509 & 0.57 & 0.01 & 3 & & 501 & 134.8 & \\
\hline & & & & 712 & 0.80 & 0.06 & 2 & & 699 & 165.2 & 2.44 \\
\hline & & & & 1017 & 0.76 & 0.02 & 3 & & 1001 & 162.6 & 2.52 \\
\hline \multirow[t]{6}{*}{5} & $8 / 11 / 08$ & 18.590 & 47.956 & 10 & 0.97 & 0.02 & 3 & & 8 & 227.6 & 0.02 \\
\hline & & & & 127 & 0.29 & 0.04 & 2 & & 124 & 236.4 & 0.03 \\
\hline & & & & 254 & 0.40 & 0.03 & 2 & & 251 & 218.5 & \\
\hline & & & & 508 & 0.56 & 0.02 & 2 & & 497 & 162.1 & 1.50 \\
\hline & & & & 711 & 0.81 & 0.02 & 3 & & 699 & 140.5 & 2.48 \\
\hline & & & & 1016 & 0.96 & 0.03 & 2 & & 1001 & 184.2 & 2.34 \\
\hline \multirow[t]{6}{*}{6} & $8 / 12 / 08$ & 19.962 & 45.081 & 10 & 0.83 & 0.01 & 4 & & 5 & 232.9 & 0.18 \\
\hline & & & & 127 & 0.30 & 0.01 & 2 & & 126 & 225.6 & 0.05 \\
\hline & & & & 251 & 0.34 & 0.01 & 3 & & 249 & 203.8 & 0.45 \\
\hline & & & & 502 & 0.55 & 0.01 & 2 & & 500 & 163.1 & 1.52 \\
\hline & & & & 703 & 0.81 & 0.01 & 3 & & 700 & 141.9 & 2.16 \\
\hline & & & & 1005 & 0.72 & 0.00 & 2 & & 1001 & 167.4 & 2.37 \\
\hline \multirow[t]{6}{*}{7} & $8 / 13 / 08$ & 17.778 & 43.621 & 10 & 0.34 & 0.02 & 2 & & 5 & 216.7 & 0.01 \\
\hline & & & & 126 & 0.18 & 0.02 & 2 & & 125 & 198.4 & 0.00 \\
\hline & & & & 252 & 0.47 & 0.02 & 2 & & 249 & 140.8 & 0.89 \\
\hline & & & & 503 & 0.91 & 0.05 & 2 & & 500 & 98.6 & 1.83 \\
\hline & & & & 704 & 1.08 & 0.02 & 5 & & 699 & 102.9 & 2.12 \\
\hline & & & & 1006 & 0.87 & 0.02 & 2 & & 1002 & 134.0 & 2.11 \\
\hline \multirow[t]{6}{*}{8} & $8 / 14 / 08$ & 15.649 & 42.225 & 10 & 0.48 & 0.01 & 3 & & 5 & 210.1 & 0.01 \\
\hline & & & & 125 & 0.16 & 0.04 & 2 & & 124 & 174.3 & 0.18 \\
\hline & & & & 250 & 0.94 & 0.05 & 2 & & 250 & 138.4 & 1.16 \\
\hline & & & & 500 & 0.96 & 0.02 & 2 & & 500 & 106.4 & 2.05 \\
\hline & & & & 700 & 1.01 & 0.03 & 3 & & 701 & 114.2 & 2.34 \\
\hline & & & & 999 & 0.82 & 0.00 & 2 & & 1002 & 144.4 & 2.26 \\
\hline \multirow[t]{11}{*}{9} & $8 / 15 / 08$ & 13.069 & 40.635 & 10 & 0.84 & 0.02 & 4 & 2.53 & 5 & 208.4 & 0.03 \\
\hline & & & & 40 & 0.25 & 0.02 & 2 & & 58 & 207.1 & 0.02 \\
\hline & & & & 90 & 0.13 & 0.01 & 3 & & 91 & 204.6 & 0.04 \\
\hline & & & & 125 & 0.27 & 0.00 & 3 & 0.96 & 125 & 146.8 & 0.54 \\
\hline & & & & 250 & 1.00 & 0.04 & 2 & 0.33 & 250 & 99.4 & 1.41 \\
\hline & & & & 377 & 0.90 & 0.01 & 3 & & 376 & 95.7 & 1.86 \\
\hline & & & & 500 & 1.01 & 0.02 & 2 & 0.38 & 500 & 105.1 & 2.07 \\
\hline & & & & 603 & 1.10 & 0.06 & 6 & & 599 & 108.5 & 2.24 \\
\hline & & & & 700 & 1.11 & 0.02 & 6 & & 700 & 114.9 & 2.31 \\
\hline & & & & 854 & 0.84 & 0.02 & 4 & & 851 & 125.3 & 2.31 \\
\hline & & & & 1000 & 0.89 & 0.04 & 4 & & 1004 & 150.9 & 2.13 \\
\hline \multirow[t]{3}{*}{10} & $8 / 16 / 08$ & 10.487 & 39.100 & 10 & 0.50 & 0.01 & 3 & & 5 & 204.3 & 0.01 \\
\hline & & & & 126 & 0.93 & 0.03 & 3 & & 123 & 110.2 & 1.08 \\
\hline & & & & 252 & 1.31 & 0.02 & 4 & & 251 & 100.3 & 1.77 \\
\hline
\end{tabular}




\begin{tabular}{|c|c|c|c|c|c|c|c|c|c|c|c|}
\hline Station & Date & $\begin{array}{l}\text { Lat } \\
\left({ }^{\circ} \mathrm{N}\right)\end{array}$ & $\begin{array}{l}\text { Lon } \\
\left({ }^{\circ} \mathrm{W}\right)\end{array}$ & $\begin{array}{l}\text { Depth } \\
\text { (m) }\end{array}$ & $\begin{array}{c}\mathrm{dFe} \\
(\mathrm{nmol} / \mathrm{kg})\end{array}$ & $1 \mathrm{SD}$ & $\mathrm{n}$ & $\begin{array}{c}\mathrm{dMn} \\
(\mathrm{nmol} / \mathrm{kg})\end{array}$ & $\begin{array}{c}\text { CTD } \\
\text { Depth (m) }\end{array}$ & $\begin{array}{c}\mathrm{O}_{2} \\
(\mu \mathrm{mol} / \mathrm{kg})\end{array}$ & $\begin{array}{c}\mathrm{PO}_{4}^{3-} \\
(\mu \mathrm{mol} / \mathrm{kg})\end{array}$ \\
\hline \multirow[t]{3}{*}{10} & $8 / 16 / 08$ & 10.487 & 39.100 & 503 & 1.19 & 0.02 & 3 & & 500 & 86.6 & 2.15 \\
\hline & & & & 704 & 1.11 & 0.05 & 4 & & 698 & 104.3 & 2.27 \\
\hline & & & & 1006 & 0.94 & 0.02 & 4 & & 1003 & 143.7 & 2.15 \\
\hline \multirow[t]{6}{*}{11} & $8 / 17 / 08$ & 8.042 & 37.629 & 10 & 0.61 & 0.02 & 2 & & 6 & 204.3 & 0.02 \\
\hline & & & & 124 & 0.87 & 0.03 & 2 & & 125 & 134.4 & 1.32 \\
\hline & & & & 248 & 1.15 & 0.03 & 4 & & 250 & 112.5 & 1.83 \\
\hline & & & & 496 & 1.20 & 0.02 & 2 & & 498 & 92.2 & 2.25 \\
\hline & & & & 694 & 0.91 & 0.03 & 3 & & 700 & 110.9 & 2.32 \\
\hline & & & & 991 & 0.87 & 0.03 & 4 & & 1001 & 150.0 & 2.14 \\
\hline \multirow[t]{6}{*}{12} & $8 / 18 / 08$ & 10.348 & 35.274 & 10 & 0.65 & 0.01 & 2 & & 5 & 210.1 & 0.02 \\
\hline & & & & 122 & 1.05 & 0.04 & 4 & & 126 & 125.9 & 1.38 \\
\hline & & & & 244 & 1.39 & 0.04 & 3 & & 250 & 74.1 & 1.73 \\
\hline & & & & 489 & 1.30 & 0.02 & 3 & & 500 & 88.5 & 2.16 \\
\hline & & & & 684 & 1.09 & 0.01 & 5 & & 700 & & 2.30 \\
\hline & & & & 977 & 1.14 & 0.04 & 7 & & 1004 & 143.3 & 2.18 \\
\hline \multirow[t]{24}{*}{13} & $8 / 19 / 08$ & 12.807 & 33.018 & 10 & 0.46 & 0.01 & 4 & 2.55 & 5 & 197.4 & 0.00 \\
\hline & & & & 28 & 0.42 & 0.00 & 2 & & 29 & 207.1 & 0.04 \\
\hline & & & & 74 & 0.16 & 0.03 & 3 & & & & \\
\hline & & & & 97 & 0.49 & 0.00 & 2 & & 105 & 96.8 & 1.24 \\
\hline & & & & 116 & 1.04 & 0.00 & 3 & 0.58 & 124 & 96.4 & 1.49 \\
\hline & & & & 162 & 1.18 & 0.03 & 2 & & 175 & 95.0 & 1.73 \\
\hline & & & & 247 & 1.18 & 0.03 & 2 & 0.43 & 251 & 83.6 & 1.85 \\
\hline & & & & 370 & 1.34 & 0.03 & 4 & & 375 & 69.8 & 2.09 \\
\hline & & & & 493 & 1.27 & 0.02 & 3 & 0.36 & 501 & 73.9 & 2.06 \\
\hline & & & & 690 & 1.29 & 0.03 & 3 & & 699 & 85.5 & 2.38 \\
\hline & & & & 854 & 1.23 & 0.01 & 5 & & 850 & 108.3 & 2.25 \\
\hline & & & & 1005 & 0.95 & 0.02 & 3 & & 1002 & 137.6 & 2.04 \\
\hline & & & & 1256 & 0.73 & 0.05 & 3 & & 1202 & 169.4 & 1.84 \\
\hline & & & & 1508 & 0.79 & 0.01 & 2 & & 1499 & 200.7 & 1.56 \\
\hline & & & & 1759 & 1.22 & 0.01 & 3 & & 1801 & 241.2 & 1.33 \\
\hline & & & & 2057 & 0.79 & 0.04 & 3 & & 2050 & 245.6 & 1.28 \\
\hline & & & & 2408 & 1.56 & 0.06 & 3 & & 2449 & 251.4 & 1.37 \\
\hline & & & & 2759 & 0.71 & 0.01 & 2 & & 2999 & 249.4 & 1.39 \\
\hline & & & & 3111 & 0.73 & 0.03 & 3 & & 3250 & 254.1 & 1.41 \\
\hline & & & & 3512 & 0.72 & 0.02 & 2 & & 3499 & 251.9 & 1.41 \\
\hline & & & & 3833 & 0.83 & 0.02 & 2 & & & & \\
\hline & & & & 4193 & 0.85 & 0.02 & 3 & & 4002 & 251.2 & 1.38 \\
\hline & & & & 4958 & 0.83 & 0.04 & 3 & & 4500 & 251.2 & 1.45 \\
\hline & & & & 5003 & 0.85 & 0.02 & 2 & & 5000 & 250.9 & 1.41 \\
\hline \multirow[t]{6}{*}{14} & $8 / 21 / 08$ & 15.576 & 30.554 & 10 & 0.78 & 0.01 & 4 & & 5 & 202.8 & 0.03 \\
\hline & & & & 126 & 0.80 & 0.02 & 2 & & 125 & 91.3 & 1.13 \\
\hline & & & & 251 & 1.16 & 0.01 & 3 & & 251 & 74.1 & 1.64 \\
\hline & & & & 503 & 1.23 & 0.02 & 2 & & 502 & 71.9 & 1.96 \\
\hline & & & & 704 & 1.38 & 0.04 & 2 & & 700 & 85.8 & 2.07 \\
\hline & & & & 1006 & 0.86 & 0.02 & 2 & & 999 & 132.2 & 1.95 \\
\hline \multirow[t]{5}{*}{15} & $8 / 22 / 08$ & 17.637 & 28.533 & 10 & 0.80 & 0.01 & 2 & & 4 & 203.0 & 0.03 \\
\hline & & & & 126 & 0.53 & 0.00 & 2 & & 125 & 131.9 & 0.77 \\
\hline & & & & 252 & 0.79 & 0.00 & 2 & & 252 & 120.0 & 1.16 \\
\hline & & & & 704 & 0.98 & 0.04 & 2 & & 701 & 105.0 & 2.22 \\
\hline & & & & 1006 & 0.95 & 0.01 & 2 & & 1001 & 141.6 & 2.06 \\
\hline \multirow[t]{6}{*}{16} & $8 / 23 / 08$ & 14.617 & 27.671 & 10 & 0.65 & 0.01 & 2 & & 5 & 197.8 & 0.02 \\
\hline & & & & 125 & 1.00 & 0.08 & 2 & & 125 & 75.3 & 1.53 \\
\hline & & & & 250 & 1.41 & 0.02 & 5 & & 250 & 62.8 & 1.83 \\
\hline & & & & 499 & 1.35 & 0.02 & 3 & & 501 & 51.5 & 2.21 \\
\hline & & & & 698 & 1.42 & -- & 1 & & 701 & 74.5 & 2.37 \\
\hline & & & & 998 & 1.27 & 0.03 & 6 & & 1001 & 123.5 & 2.16 \\
\hline \multirow[t]{4}{*}{17} & $8 / 24 / 08$ & 11.707 & 26.838 & 10 & 0.65 & 0.01 & 2 & 2.20 & 6 & 199.0 & 0.02 \\
\hline & & & & 40 & 0.11 & 0.01 & 3 & & 60 & 131.3 & 0.57 \\
\hline & & & & 88 & 0.91 & 0.05 & 4 & & 90 & 102.5 & 1.46 \\
\hline & & & & 124 & 1.00 & 0.01 & 2 & 0.59 & 125 & 115.1 & 1.52 \\
\hline
\end{tabular}




\begin{tabular}{|c|c|c|c|c|c|c|c|c|c|c|c|}
\hline Station & Date & $\begin{array}{l}\text { Lat } \\
\left({ }^{\circ} \mathrm{N}\right)\end{array}$ & $\begin{array}{l}\text { Lon } \\
\left({ }^{\circ} \mathrm{W}\right)\end{array}$ & $\begin{array}{l}\text { Depth } \\
\text { (m) }\end{array}$ & $\begin{array}{c}\mathrm{dFe} \\
(\mathrm{nmol} / \mathrm{kg})\end{array}$ & $1 \mathrm{SD}$ & $\mathrm{n}$ & $\begin{array}{c}\mathrm{dMn} \\
(\mathrm{nmol} / \mathrm{kg})\end{array}$ & $\begin{array}{c}\text { CTD } \\
\text { Depth (m) }\end{array}$ & $\begin{array}{c}\mathrm{O}_{2} \\
(\mu \mathrm{mol} / \mathrm{kg})\end{array}$ & $\begin{array}{c}\mathrm{PO}_{4}{ }^{3-} \\
(\mu \mathrm{mol} / \mathrm{kg})\end{array}$ \\
\hline \multirow[t]{7}{*}{17} & $8 / 24 / 08$ & 11.707 & 26.838 & 248 & 1.15 & 0.05 & 2 & 0.37 & 251 & 96.4 & 1.83 \\
\hline & & & & 368 & 1.40 & 0.02 & 5 & & 375 & 54.6 & 2.12 \\
\hline & & & & 496 & 1.11 & 0.03 & 6 & 0.53 & 499 & 48.2 & 2.29 \\
\hline & & & & 589 & 1.47 & 0.05 & 6 & & 600 & 64.3 & 2.40 \\
\hline & & & & 694 & 1.46 & 0.03 & 4 & & 699 & 80.7 & 2.37 \\
\hline & & & & 835 & 1.31 & 0.06 & 5 & & 850 & 105.6 & 2.39 \\
\hline & & & & 992 & 0.81 & 0.01 & 2 & & 1002 & 132.8 & 2.27 \\
\hline \multirow[t]{6}{*}{18} & $8 / 25 / 08$ & 8.890 & 26.048 & 10 & 0.55 & 0.03 & 2 & & 6 & 201.4 & 0.02 \\
\hline & & & & 125 & 0.91 & 0.04 & 4 & & 126 & 120.3 & 1.40 \\
\hline & & & & 251 & 1.30 & 0.02 & 3 & & 251 & 92.4 & 1.71 \\
\hline & & & & 501 & 1.05 & 0.07 & 7 & & 502 & 72.3 & 2.32 \\
\hline & & & & 702 & 1.32 & 0.03 & 3 & & 701 & 93.1 & 2.52 \\
\hline & & & & 1003 & 1.07 & 0.05 & 4 & & 1000 & 142.8 & 2.29 \\
\hline \multirow[t]{6}{*}{19} & $8 / 26 / 08$ & 5.963 & 25.268 & 10 & 0.47 & 0.02 & 2 & & 6 & 204.5 & 0.02 \\
\hline & & & & 124 & 0.27 & 0.02 & 2 & & 123 & 139.6 & 1.10 \\
\hline & & & & 249 & 1.07 & 0.03 & 4 & & 251 & 123.2 & 1.59 \\
\hline & & & & 497 & 1.22 & 0.01 & 3 & & 500 & 91.7 & 2.32 \\
\hline & & & & 696 & 1.35 & 0.03 & 4 & & 701 & 99.0 & 2.54 \\
\hline & & & & 994 & 0.93 & 0.02 & 4 & & 1000 & 142.2 & 2.32 \\
\hline \multirow[t]{6}{*}{20} & $8 / 27 / 08$ & 9.571 & 23.896 & 10 & 0.87 & 0.01 & 2 & & 6 & 203.2 & 0.03 \\
\hline & & & & 125 & 1.64 & 0.03 & 2 & & 126 & 98.6 & 1.62 \\
\hline & & & & 250 & 1.18 & 0.01 & 2 & & 249 & 117.2 & 1.76 \\
\hline & & & & 501 & 1.15 & 0.02 & 3 & & 501 & 70.5 & 2.32 \\
\hline & & & & 701 & 1.25 & 0.12 & 2 & & 701 & 82.9 & 2.51 \\
\hline & & & & 1002 & 1.25 & 0.03 & 3 & & 1000 & 133.5 & 2.32 \\
\hline \multirow[t]{5}{*}{21} & $8 / 28 / 08$ & 12.405 & 22.762 & 10 & 0.88 & 0.00 & 2 & 2.56 & 6 & 202.6 & \\
\hline & & & & 125 & 1.38 & 0.03 & 6 & 0.54 & 124 & 95.1 & 1.50 \\
\hline & & & & 250 & 1.37 & 0.02 & 3 & 0.49 & 249 & 88.3 & 1.70 \\
\hline & & & & 699 & 1.56 & 0.03 & 4 & & 701 & 77.1 & 2.32 \\
\hline & & & & 999 & 1.30 & 0.03 & 2 & & 1001 & 133.5 & 2.12 \\
\hline \multirow[t]{11}{*}{22} & $8 / 29 / 08$ & 14.570 & 21.883 & 10 & 0.67 & 0.02 & 3 & 2.72 & 6 & 200.3 & 0.11 \\
\hline & & & & 40 & 0.20 & 0.04 & 2 & & 60 & 123.1 & 0.90 \\
\hline & & & & 89 & 1.09 & 0.03 & 3 & & 91 & 73.0 & 1.49 \\
\hline & & & & 126 & 1.41 & 0.02 & 3 & 0.69 & 126 & 80.7 & 1.58 \\
\hline & & & & 252 & 1.43 & 0.03 & 2 & 0.47 & 250 & 56.2 & 1.84 \\
\hline & & & & 371 & 1.28 & 0.04 & 3 & & 374 & 55.2 & 1.93 \\
\hline & & & & 503 & 1.19 & 0.05 & 6 & 0.50 & 499 & 62.6 & 2.06 \\
\hline & & & & 593 & 1.24 & 0.02 & 3 & & 602 & 63.1 & 2.19 \\
\hline & & & & 704 & 1.33 & 0.04 & 3 & & 700 & 82.2 & 2.25 \\
\hline & & & & 840 & 1.53 & 0.03 & 3 & & 851 & 103.3 & 2.20 \\
\hline & & & & 1006 & 1.32 & 0.03 & 4 & & 1000 & 124.8 & 2.08 \\
\hline \multirow[t]{6}{*}{23} & $8 / 30 / 08$ & 17.192 & 21.654 & 10 & 0.53 & 0.04 & 3 & & 6 & 203.4 & 0.06 \\
\hline & & & & 125 & 1.02 & 0.04 & 2 & & 124 & 75.2 & 7.34 \\
\hline & & & & 250 & 1.01 & 0.04 & 2 & & 252 & 89.5 & 1.37 \\
\hline & & & & 499 & 1.28 & 0.03 & 3 & & 501 & 72.0 & 1.98 \\
\hline & & & & 699 & 1.38 & 0.02 & 2 & & 700 & 81.6 & 2.23 \\
\hline & & & & 999 & 1.13 & 0.05 & 4 & & 1000 & 134.0 & 2.03 \\
\hline \multirow[t]{6}{*}{24} & $8 / 31 / 08$ & 18.952 & 21.496 & 10 & 0.15 & 0.03 & 3 & 3.91 & 6 & 208.4 & 0.17 \\
\hline & & & & 123 & 1.14 & 0.03 & 4 & 0.68 & 124 & 84.8 & 1.25 \\
\hline & & & & 245 & 1.40 & 0.02 & 2 & 0.60 & 251 & 74.7 & 1.57 \\
\hline & & & & 491 & 1.43 & 0.02 & 2 & 0.53 & 500 & 68.5 & 2.14 \\
\hline & & & & 687 & 1.44 & 0.05 & 3 & & 699 & 90.0 & 2.19 \\
\hline & & & & 982 & 1.33 & 0.01 & 6 & & 1000 & 133.3 & 2.03 \\
\hline \multirow[t]{6}{*}{25} & $8 / 31 / 08$ & 18.500 & 23.402 & 10 & 0.13 & 0.03 & 4 & 2.90 & 5 & 204.9 & 0.13 \\
\hline & & & & 126 & 0.97 & 0.03 & 3 & 0.80 & 126 & 88.4 & 1.34 \\
\hline & & & & 252 & 1.31 & 0.02 & 3 & 0.49 & 249 & 86.6 & 1.46 \\
\hline & & & & 503 & 1.09 & 0.02 & 2 & 0.44 & 500 & 75.2 & 1.96 \\
\hline & & & & 704 & 1.27 & 0.01 & 7 & & 701 & 92.8 & 2.14 \\
\hline & & & & 1006 & 1.12 & 0.05 & 4 & & 1001 & 135.7 & 2.02 \\
\hline
\end{tabular}




\begin{tabular}{|c|c|c|c|c|c|c|c|c|c|c|c|}
\hline Station & Date & $\begin{array}{l}\text { Lat } \\
\left({ }^{\circ} \mathrm{N}\right)\end{array}$ & $\begin{array}{l}\text { Lon } \\
\left({ }^{\circ} \mathrm{W}\right)\end{array}$ & $\begin{array}{c}\text { Depth } \\
\text { (m) }\end{array}$ & $\begin{array}{c}\mathrm{dFe} \\
(\mathrm{nmol} / \mathrm{kg})\end{array}$ & $1 \mathrm{SD}$ & $\mathrm{n}$ & $\begin{array}{c}\mathrm{dMn} \\
(\mathrm{nmol} / \mathrm{kg})\end{array}$ & $\begin{array}{c}\text { CTD } \\
\text { Depth (m) }\end{array}$ & $\begin{array}{c}\mathrm{O}_{2} \\
(\mu \mathrm{mol} / \mathrm{kg})\end{array}$ & $\begin{array}{c}\mathrm{PO}_{4}^{3-} \\
(\mu \mathrm{mol} / \mathrm{kg})\end{array}$ \\
\hline \multirow[t]{5}{*}{26} & $9 / 2 / 08$ & 20.002 & 26.668 & 10 & 0.57 & 0.03 & 3 & 2.62 & 4 & 205.0 & 0.05 \\
\hline & & & & 125 & 0.21 & 0.02 & 3 & 1.58 & 125 & 176.7 & 0.33 \\
\hline & & & & 250 & 1.12 & 0.04 & 3 & 0.50 & 250 & 91.1 & 1.32 \\
\hline & & & & 499 & 0.97 & 0.01 & 2 & 0.33 & 501 & 93.8 & 1.72 \\
\hline & & & & 698 & 1.08 & 0.05 & 4 & & 700 & 103.2 & 2.12 \\
\hline \multirow[t]{11}{*}{27} & $9 / 3 / 08$ & 17.401 & 24.509 & 10 & 0.18 & 0.03 & 3 & & 6 & 204.1 & 0.19 \\
\hline & & & & 39 & 0.19 & 0.03 & 2 & & 61 & 126.4 & 0.90 \\
\hline & & & & 88 & 0.63 & 0.00 & 2 & & 90 & 72.4 & 1.42 \\
\hline & & & & 124 & 0.57 & 0.03 & 2 & & 125 & 97.3 & 1.24 \\
\hline & & & & 247 & 1.35 & 0.02 & 2 & & 251 & 72.9 & 1.79 \\
\hline & & & & 368 & 1.38 & 0.03 & 2 & & 374 & 61.1 & 1.90 \\
\hline & & & & 494 & 1.36 & 0.04 & 3 & & 501 & 75.4 & 2.11 \\
\hline & & & & 590 & 1.40 & 0.05 & 4 & & 601 & 84.2 & 2.26 \\
\hline & & & & 693 & 1.21 & 0.02 & 3 & & 700 & 96.3 & 2.20 \\
\hline & & & & 835 & 1.14 & 0.01 & 2 & & 850 & 112.7 & 2.31 \\
\hline & & & & 990 & 1.06 & 0.01 & 4 & & 1000 & 133.4 & 2.12 \\
\hline
\end{tabular}




\title{
Chapter 4
}

\section{Distal transport of dissolved hydrothermal iron in the deep South Pacific Ocean}

\author{
Submitted to Nature Geoscience. \\ Fitzsimmons, J.N., Boyle, E.A., and Jenkins, W.J. in review. Distal transport of dissolved \\ hydrothermal iron in the deep South Pacific Ocean. Nature Communications.
}

\begin{abstract}
Until recently, hydrothermal vents were not considered an important source in marine dissolved $\mathrm{Fe}(\mathrm{dFe})$ budgets because hydrothermal $\mathrm{Fe}$ was believed to precipitate quantitatively at the vent site. Based on recent abyssal dFe data, however, the "leaky vent" hypothesis argues that some hydrothermal Fe survives in the dissolved phase, contributing a significant flux of dFe to the global ocean. We show here the first measurements of dFe from the abyssal Southeast and Southwest Pacific Ocean, where observed correlations of $\mathrm{dFe}$ with primordial ${ }^{3} \mathrm{He}$ support the hypothesis that $\mathrm{dFe}$ enrichments near $2000 \mathrm{~m}$ are hydrothermally-derived. Remarkably this $\mathrm{dFe}$ is transported beyond the local vent site hundreds to thousands of kilometers away, where dFe is still enriched at $1.0-1.5 \mathrm{nmol} / \mathrm{kg}$. The size partitioning of this hydrothermal $\mathrm{dFe}$ into soluble/colloidal phases further indicates that $\mathrm{dFe}$ transformations continue to occur at great distance from the vent source. This study provides observational evidence in support of "leaky vent" models and confirms that hydrothermal vents can have far-field impacts on the global dFe inventory, potentially providing an abyssal dFe source comparable in magnitude to dust-derived remineralization, with disproportionately large impacts on global climate after upwelling into the Fe-limited Southern Ocean.
\end{abstract}




\title{
Distal transport of dissolved hydrothermal iron in the deep South Pacific Ocean
}

\author{
Jessica N. Fitzsimmons ${ }^{1,2} *$, Edward A. Boyle ${ }^{2}$, and William J. Jenkins ${ }^{3}$ \\ ${ }^{1}$ MIT/WHOI Joint Program in Chemical Oceanography, Cambridge, MA 02139 \\ ${ }^{2}$ MIT, Department of Earth, Atmospheric and Planetary Sciences, Cambridge, MA 02139 \\ ${ }^{3}$ Woods Hole Oceanographic Institution, Marine Chemistry and Geochemistry, Woods \\ Hole, MA 02543 \\ *Corresponding author: jessfitz@mit.edu
}

Submitted to Nature Communications on July 15, 2013

\section{Acknowledgements:}

We thank Jong-Mi Lee and Rick Kayser for collecting and filtering samples on the BiG RAPA cruise, as well as Dan Repeta, and Jon Zehr and Joe Montoya, who served as Chief Scientists on the Melville BiG RAPA and KM0703 SPEEDO cruises, respectively. Finally, we thank the officers and crew of the $R / V$ Kilo Moana and the $R / V$ Melville for their efforts on our behalf. This work was funded by a National Science Foundation Graduate Research Fellowship (NSF Award \#0645960) and the Center for Microbial Oceanography: Research and Education (NSF-OIA Award \#EF-0424599). E.A.B.’s participation in the SPEEDO cruise was funded by a Gordon and Betty Moore Foundation grant to Jon Zehr.

\section{Author Contributions:}

J.N.F and E.A.B. designed the sampling strategy and performed the dissolved iron analyses. E.A.B. did the seagoing work on the KM0703 SPEEDO cruise. W.J.J. interpolated He-3 from the WOCE data. J.N.F. drafted the manuscript, and all authors contributed to data analysis, interpretation of results, and editing of the manuscript. 
Until recently, hydrothermal vents were not considered an important source in marine dissolved Fe (dFe) budgets because hydrothermal Fe was believed to precipitate quantitatively at the vent site ${ }^{1}$. Based on recent abyssal dFe data $^{2-7}$, however, the "leaky vent" hypothesis ${ }^{8}$ argues that some hydrothermal Fe survives in the dissolved phase, contributing a significant flux of dFe to the global ocean. We show here the first measurements of dFe from the abyssal Southeast and Southwest Pacific Ocean, where observed correlations of $\mathrm{dFe}$ with primordial ${ }^{3} \mathrm{He}$ support the hypothesis that $\mathrm{dFe}$ enrichments near $2000 \mathrm{~m}$ are hydrothermally-derived. Remarkably this dFe is transported beyond the local vent site hundreds to thousands of kilometers away, where dFe is still enriched at 1.0-1.5 nmol/kg. The size partitioning of this hydrothermal $\mathrm{dFe}$ into soluble/colloidal phases further indicates that dFe transformations continue to occur at great distance from the vent source. This study provides observational evidence in support of "leaky vent" models and confirms that hydrothermal vents can have far-field impacts on the global dFe inventory, potentially providing an abyssal dFe source comparable in magnitude to dust-derived remineralization, ${ }^{9,10}$, with disproportionately large impacts on global climate after upwelling into the Fe-limited Southern Ocean ${ }^{11}$.

Hydrothermal fluids can have Fe concentrations six orders of magnitude greater than typical deep ocean values ${ }^{12}$, so a small fraction of hydrothermal Fe escaping precipitation into Fe sulfides or oxyhydroxides could significantly impact oceanic dFe distributions. Nonetheless, previous marine $\mathrm{dFe}$ models ${ }^{9}$ have neglected this possible source and instead focused on Fe inputs from atmospheric dust and continental margin fluxes. In recent years, however, hotspots of enhanced $\mathrm{dFe}$ concentration have been detected near known vent sites in all of the major oceans ${ }^{2-7}$, demonstrating that hydrothermal vents impact deep ocean dFe concentrations nearby the vent source. What has not been clear is whether this impact is confined locally or whether vent-derived dFe is carried far enough away from the vent source to contribute to the global marine $\mathrm{dFe}$ inventory. Following the early description by Boyle and Jenkins ${ }^{3}$, we address this question by reporting deep ocean $\mathrm{dFe}$ in the South Pacific Ocean, where hydrothermal 
$\mathrm{Fe}$ (II) lifetimes are near their longest in the global ocean because oxygen concentrations are low, having been significantly consumed along thermohaline circulation ${ }^{13}$. Moreover, abyssal southern hemisphere water masses upwell into the Southern Ocean, so enriched dFe from hydrothermal vents in the South Pacific has the potential to fuel increased biological productivity and carbon export in the Fe-limited Southern Ocean ${ }^{11}$, making the South Pacific region we explored an important area to determine the influence of hydrothermal venting on ocean productivity and climate. No measurements of $\mathrm{dFe}$ concentration deeper than $1000 \mathrm{~m}$ in the South Pacific have been reported previously'.

We observed enhanced dFe concentrations $(1.0-1.5 \mathrm{nmol} / \mathrm{kg})$ centered at $\sim 2000 \mathrm{~m}$ at three stations in the South Pacific: KM0703 SPEEDO Station $19\left(20^{\circ} \mathrm{S}, 170^{\circ} \mathrm{W}\right)$ in the western Pacific, and Melville BiG RAPA Stations $4\left(23.5^{\circ} \mathrm{S}, 88.75^{\circ} \mathrm{W}\right)$ and $7\left(26.25^{\circ} \mathrm{S}\right.$, $104^{\circ} \mathrm{W}$ ) in the eastern Pacific (Figure 1; station map is Figure S1). These dFe concentrations are elevated above North Pacific ${ }^{2,14}$ and Atlantic ${ }^{15}$ deep ocean concentrations of $0.4-0.6 \mathrm{nmol} / \mathrm{kg}$ and thus indicate a clear dFe anomaly. The $\mathrm{dFe}$ maxima are not coincident with apparent oxygen utilization (AOU) maxima at 500$1000 \mathrm{~m}$ and thus are not likely caused by the remineralization of Fe from sinking organic material (Fe-AOU correlations shown in Figure S2). Instead, the dFe profiles show striking similarities to profiles of excess ${ }^{3} \mathrm{He}$, which is derived from primordial degassing at hydrothermally active sites ${ }^{16}$. Thus, the associated ${ }^{3} \mathrm{He}$ and $\mathrm{dFe}$ maxima at $2000 \mathrm{~m}$ suggest a hydrothermal Fe source. A concomitant enrichment in dissolved manganese (dMn) at $2000 \mathrm{~m}$ further corroborates the hypothesis of hydrothermal influence, as $\mathrm{Mn}$ is also released from vents at high concentrations ${ }^{12,17}$ but otherwise has low deep ocean concentrations $^{18}$ (Fe/Mn discussed in Supplementary Information). These correlated dFe, $\mathrm{dMn}$, and ${ }^{3} \mathrm{He}$ profiles demonstrate that hydrothermal venting enriches $\mathrm{dFe}$ by $0.4-0.9$ $\mathrm{nmol} / \mathrm{kg}$ above background concentrations in the abyssal South Pacific Ocean, which is even larger than the $0.1-0.5 \mathrm{nmol} / \mathrm{kg}$ enrichments estimated by a recent model of hydrothermal Fe delivery to the deep ocean ${ }^{11}$.

What is truly remarkable about these South Pacific dFe measurements, however, is that they are sampled from locations hundreds to thousands of kilometers from the 
nearest known vent source, and they still demonstrate high dFe concentrations of 1.0-1.5 $\mathrm{nmol} / \mathrm{kg}$. While we cannot constrain exactly which vents contributed to the observed distal dFe maxima, we can compare the station locations to the sites of known hydrothermal venting ${ }^{19}$ in light of deep South Pacific circulation (reviewed in Supplementary Information). Transit times $(t)$ from the vent sites are also estimated, assuming a conservatively slow abyssal South Pacific current speed ${ }^{20}$ of $2 \mathrm{~mm} / \mathrm{s}$, to be compared to typical deep ocean dFe residence times with respect to scavenging of 70-270 years ${ }^{14,21}$. KM0703 SPEEDO Station 19 in the western South Pacific is downstream of EPR hydrothermal vents more than $6000 \mathrm{~km}$ to the east $(t>95 \mathrm{y})$ at 2000-3500 m depth. This station may also be influenced in the 1000-2000 m depth range by Lau Basin vent sources only 600-700 km away ( $t \sim 10 \mathrm{y}$ ). Melville BiG RAPA Stations 4 and 7 in the Southeast Pacific are affected by hydrothermal sources from the west (southern EPR); circulation studies using steric height estimations ${ }^{22}$ have determined that the enhanced abyssal ${ }^{3} \mathrm{He}$ as well as enriched Fe/Mn oxides in sediments of the Peru/Chile Basins are caused by eastward advection ${ }^{16}$ across the EPR south of $20^{\circ} \mathrm{S}$. Thus, an eastward flowing EPR Fe source at $25^{\circ} \mathrm{S}$ would have to travel at least $800 \mathrm{~km}$ to influence Station 7 $(t=12.5 \mathrm{y})$ and over $2400 \mathrm{~km}$ to influence Station $4(t=38 \mathrm{y})$, although we cannot confirm that hydrothermal $\mathrm{dFe}$ at Stations 4 and 7 are derived from the same vent site. Thus, in the South Pacific, hydrothermal Fe is not only maintained in the dissolved phase locally at the vent site, but it is able to escape rapid scavenging and become transported hundreds to thousands of kilometers from the vent site at high $\mathrm{dFe}$ concentrations.

How is this dissolved phase Fe stabilization achieved? Two hypotheses have been proposed, and perhaps both contribute to vent Fe stabilization. First, pyrite nanoparticles between $4-200 \mathrm{~nm}$ have been shown to account for $5-25 \%$ of the dFe in global vent fluids ${ }^{23}$. These colloids would pass through the $0.4 \mu \mathrm{m}$ filter used to operationally define dissolved $\mathrm{Fe}$ in this study, and due to their small size they would sink very slowly, providing a mechanism by which inorganic $\mathrm{dFe}$ might be carried away from vents in the "dissolved" fraction. Alternatively, organic ligands may bind the Fe(III) formed after oxidation of vent-derived Fe(II) upon mixing of vent fluids with oxic seawater ${ }^{24,25}$. This 
organic chelation protects the Fe from precipitation and stabilizes it in the dissolved fraction as $\mathrm{Fe}$ is advected away from the vent site.

To further investigate the mechanism of dFe stabilization, we measured the size partitioning of $\mathrm{dFe}$ between soluble $\mathrm{Fe}(\mathrm{sFe},<0.02 \mu \mathrm{m})$ and colloidal Fe phases $(0.02$ $\mu \mathrm{m}<\mathrm{cFe}<0.4 \mu \mathrm{m} ; \mathrm{cFe}=\mathrm{dFe}-\mathrm{sFe})$. $\mathrm{sFe}$ is considered to be truly dissolved, while $\mathrm{cFe}$ is composed of particles so small that they remain suspended in solution and are circulated and collected along with the dissolved Fe pool; both inorganic and organically-bound $\mathrm{dFe}$ can be present in both size fractions. The results shown in Figure 2 suggest that when hydrothermally-derived $\mathrm{dFe}$ is high (Station 7), colloidal Fe is the major dFe fraction (cFe composes $76 \%$ of $\mathrm{dFe}$ ), while a more diluted/scavenged $\mathrm{dFe}$ signal (Stations 19 and 4) has a more soluble Fe-rich $\mathrm{dFe}$ pool (50\% soluble, 50\% colloidal Fe). Thus, assuming a similarly partitioned Fe source among the three stations studied here, colloidal Fe appears to compose most of the $\mathrm{dFe}$ near the vent site (Station 7) and is transformed into a soluble Fe maximum (Station 4 ) as the dFe is scavenged away. These observations are consistent with the only published near-field Fe size partitioning study, which demonstrated that within $100 \mathrm{~m}$ of a vent site in the Indian Ocean colloidal Fe was the primary dissolved Fe phase ${ }^{26}$.

In the Southeast Pacific, not only does the $\% \mathrm{sFe}$ increase with distance from the vents, but the absolute sFe concentration also increases with distance from the vent, rising from $0.35 \mathrm{nmol} / \mathrm{kg}$ at Melville BiG RAPA Station 7 to a maximum of 0.51 $\mathrm{nmol} / \mathrm{kg}$ at Station 4. This Station $4 \mathrm{sFe}$ concentration and the $0.44 \mathrm{nmol} / \mathrm{kg} \mathrm{sFe}$ at Station 19 are well above background deep water sFe concentrations in the Pacific Ocean of 0.2-0.3 nmol/ $\mathrm{kg}^{27}$ and must have been transferred from the particulate ( $\mathrm{pFe}$ ) or colloidal fraction. This downstream sFe increase leads us to conclude that $\mathrm{Fe}$ transformations between phases occur not only at the local site of hydrothermal venting but continue hundreds to thousands of kilometers from the vent source. The nature of these $\mathrm{pFe}, \mathrm{sFe}$, and $\mathrm{cFe}$ transformations are unknown, but one potential mechanism that could explain the observed pattern is the conversion of Fe from inorganic colloids to truly soluble, organically-bound complexes over time/distance. 
Using the excess ${ }^{3} \mathrm{He}$ concentrations measured on nearby WOCE sections interpolated onto the depths of the measured dFe data (see Supplementary Information for ${ }^{3} \mathrm{He}$ profile station locations), $\mathrm{dFe} /{ }^{3} \mathrm{He}$ ratios were determined; only depths near the hydrothermally-derived dFe maxima were included in the regression calculation (Figure 3 , closed circles). Resulting $\mathrm{dFe} /{ }^{3} \mathrm{He}$ ratios ranged from $0.9-2.7 \times 10^{6} \mathrm{~mol} \mathrm{Fe} / \mathrm{mol}^{3} \mathrm{He}$, much lower than the $2-10 \times 10^{8} \mathrm{~mol} / \mathrm{mol}$ values found in high-temperature vent fluids (both at EPR $19^{\circ} \mathrm{S}$ and in the Western Pacific vents ${ }^{11}$ ). Thus, only $0.02-1.0 \%$ of total vented hydrothermal Fe survives transport hundreds to thousands of kilometers away in the dissolved phase. Even within the three far-field stations of this study, the highest $\mathrm{dFe} /{ }^{3} \mathrm{He}$ ratios were found at the station closest to the vent source, while the lower ratios represent a more distally-persistent, scavenging-affected hydrothermal signal.

It is worth noting that in the Southwest Pacific the ${ }^{3} \mathrm{He}$ and $\mathrm{dFe}$ profiles are nearly identical, while in the Southeast Pacific the ${ }^{3} \mathrm{He}$ remains enriched to the ocean floor but $\mathrm{dFe}$ decreases to background concentrations below $2500-3000 \mathrm{~m}$. An elevated ${ }^{3} \mathrm{He}$ signal in the absence of any Fe enrichment suggests Fe scavenging. The depth range of this dFe${ }^{3} \mathrm{He}$ separation (3000-4000m) is below the typical sill depth of the southern EPR and Chile Ridge (2500-3000m), and thus we hypothesize that the ${ }^{3} \mathrm{He}$ measured below those depths may actually be relic ${ }^{3} \mathrm{He}$ that reached those depths after long circulation times during which hydrothermal dFe was scavenged (deep ocean residence time of dFe is 70270 years $^{14,21}$ ).

The results of this study support a "leaky vent" model of dFe inputs to the abyssal South Pacific Ocean and also demonstrate transport of hydrothermal Fe in the dissolved phase hundreds to thousands of kilometers from the vent source. If the $\mathrm{dFe} /{ }^{3} \mathrm{He}$ ratio of $0.9 \times 10^{6} \mathrm{~mol} / \mathrm{mol}$ is indicative of the amount of vent-derived dFe "persisting" in the deep ocean, using the estimated annual loss rate of ${ }^{3} \mathrm{He}$ from the ocean ${ }^{28}$ of $750 \pm 200 \mathrm{~mol} / \mathrm{y}$ we estimate that the flux of dFe "leaking" from global vents into the deep ocean is $\sim 7 \times 10^{8}$ $\mathrm{mol} / \mathrm{y}$. This value is twice the hydrothermal flux reported based on Fe-binding ligand measurements near the Mid-Atlantic Ridge ${ }^{24}$ and is nearly $3 \%$ of the estimated $2.36 \times 10^{10}$ $\mathrm{mol} / \mathrm{y}$ aerosol inputs of dissolved Fe into the surface ocean ${ }^{9}$. 
While this might seem to be a relatively insignificant marine Fe source compared to dust, we know that abyssal South Pacific waters eventually upwell in the Fe-limited Southern Ocean ${ }^{11}$ where upper ocean productivity plays a significant role in global carbon export ${ }^{29}$. Thus the relatively small percentage of open ocean $\mathrm{dFe}$ contributed by hydrothermal vents calculated here may play a disproportionately large role in global climate by its influence in the Fe-limited Southern Ocean. If this "persistent" hydrothermal $\mathrm{dFe}$ were to reach the surface and fertilize phytoplankton with an Fe:C ratio of $6 \mu \mathrm{mol} \mathrm{Fe} \mathrm{per} \mathrm{mol} \mathrm{carbon} \mathrm{(typical} \mathrm{of} \mathrm{diatoms} \mathrm{in} \mathrm{the} \mathrm{Fe-limited} \mathrm{Southern} \mathrm{Ocean}{ }^{30}$ ), then this $\mathrm{dFe}$ could support $\sim 1 \times 10^{14} \mathrm{~mol} / \mathrm{y}$ of new carbon, which is comparable in magnitude to global new production $\left(4 \times 10^{14} \mathrm{~mol} / \mathrm{y}\right)^{10}$. This estimate, however, has both positive and negative uncertainties. $\mathrm{dFe} /{ }^{3} \mathrm{He}$ ratios vary globally as a function of bedrock geology and ridge spreading rate, and values along the slow-spreading Mid-Atlantic Ridge $^{31}$ are higher by orders of magnitude than those in the Pacific, indicating that the hydrothermally-supported new production may be biased too low. In contrast, this production estimate may be biased high because it assumes full biological availability of the hydrothermal $\mathrm{dFe}$, which may not be true if the $\mathrm{dFe}$ is in inorganic nanoparticulate form $^{32}$, and also assumes that no additional scavenging of the "persistent" hydrothermal $\mathrm{dFe}$ occurs before upwelling to the surface ocean. We know that the residence time of abyssal $\mathrm{dFe}$ with respective to scavenging onto sinking particles is $100-300$ years $^{14,21}$, so scavenging of some of this "persistent" dFe before upwelling is likely. Future research must focus on distal hydrothermal $\mathrm{dFe}$ transformation pathways and scavenging rates in order to constrain the spatial and temporal extent of this aybssal dFe source, and global Fe and climate models that have neglected hydrothermal $\mathrm{Fe}$ inputs require its inclusion in the future.

\section{Methods}

Station 19 in the Southwest Pacific was sampled on the $R / V$ Kilo Moana in April 2007 on the Center for Microbial Oceanography: Research \& Education (C-MORE) SPEEDO cruise, and Stations 4 and 7 in the Southeast Pacific were sampled on the $R / V$ 
Melville in November-December 2010 on the C-MORE BiG RAPA cruise. Trace metaluncontaminated seawater on KM0703 was collected using the MITESS system, which employed both Teflon and HDPE bottles during sample collection (Teflon vs. HDPE indicated in Supplementary Information data table), followed by filtration through $0.4 \mu \mathrm{m}$ Nuclepore filters into HDPE bottles by previously established methods ${ }^{33}$. Soluble Fe samples were subsequently collected after filtration through a $0.02 \mu \mathrm{m}$ Anodisc filter. On the Melville BiG RAPA cruise, seawater was collected using the MITESS/Vanes system employing HDPE bottles, followed by filtration through $0.4 \mu \mathrm{m}$ Nuclepore filters into HDPE bottles ${ }^{33}$. Soluble Fe samples were collected using a cross flow ultrafiltration system in static mode employing a $10 \mathrm{kDa}$ nominal molecular weight cutoff regenerated cellulose filter (Millipore: Pellicon XL, PLCGC) after conditioning with $350 \mathrm{~mL}$ of filtered sample seawater. Detailed methodological descriptions and an intercalibration between the two soluble Fe sample collection methods used in this study have been described previously ${ }^{34}$.

Samples were analyzed in triplicate for their Fe concentration by isotope dilution inductively-coupled plasma mass spectrometry (ID-ICP-MS) on a hexapole collision cell IsoProbe ICP-MS. The ID-ICP-MS method employs an ${ }^{54} \mathrm{Fe}$-spike and batch preconcentration with nitrilotriacetate resin ${ }^{15}$. Procedure blanks for the western Pacific stations were $0.20 \mathrm{nmol} / \mathrm{kg}$, but very stable to $\pm 0.03 \mathrm{nmol} / \mathrm{kg}$ because they derived quantitatively from the constant amount of NTA superflow resin used to pre-concentrate the Fe. Procedure blanks over the six analytical sessions for the Eastern Pacific stations were much lower, ranging from $0.025-0.060 \mathrm{nmol} / \mathrm{kg}$, and the detection limit (three times the standard deviation of the procedure blanks for each analytical session) averaged 0.025 $\mathrm{nmol} / \mathrm{kg}$. Comprehensive lab analyses of SAFe D2 standard for $\mathrm{dFe}$ during the period of these analyses averaged $0.99 \pm 0.03 \mathrm{nmol} / \mathrm{kg}$ (Bottle 242, $\pm 1 \mathrm{SD}, \mathrm{n}=8$ ) and $0.92 \pm 0.01$ $\mathrm{nmol} / \mathrm{kg}$ (Bottle 446, $\pm 1 \mathrm{SD}, \mathrm{n}=8$ ), which agrees well with the current consensus value of $0.933 \pm 0.023 \mathrm{nmol} / \mathrm{kg}$ (May 2013 consensus:www.geotraces.org/science/intercalibration).

Dissolved manganese $(\mathrm{dMn})$ was extracted from filtered seawater by a modified version of an automated flow injection pre-concentration method ${ }^{35}$ followed by $\mathrm{dMn}$ 
concentration analysis using quadrupole ICP-MS and standard addition calibrations. 12 $\mathrm{mL}$ filtered and acidified samples were aliquoted into acid cleaned $50 \mathrm{~mL}$ Corning centrifuge tubes. 60,120 , and $180 \mu \mathrm{L}$ of $100 \mathrm{nM}$ Mn standard were added to SAFe surface water in order to generate standard curves throughout the run; this allowed for final $\mathrm{Mn}$ standard concentrations of $0.5,1.0$, and $1.5 \mathrm{nM}$, respectively. The $\mathrm{pH}$ of each sample was brought to $6.0 \pm 0.2$ with ammonium acetate buffer ( $\mathrm{pH} 8.9$ ) before being pumped through the extraction system. The extraction system was identical to that described by Milne et al., except that the micro-column was filled with Nobias-chelate PA1 resin (ESI). After elution through the column in $1.0 \mathrm{~mL}$ of $1 \mathrm{M}$ distilled nitric acid, extracted samples were analyzed for dMn by ICP-MS on a VG/Fisons PQ2+. The SAFe D1 standard reference seawater was found to have a dMn concentration of $0.352 \pm 0.020$ $\mathrm{nmol} / \mathrm{kg}$ ( $\mathrm{n}=8 ; \pm 1 \mathrm{SD}$ of replicate analyses), agreeing exactly with the SAFe D2 consensus value of $0.35 \pm 0.05 \mathrm{nmol} / \mathrm{kg}$. $\mathrm{dMn}$ procedure blanks were less than 0.01 $\mathrm{nmol} / \mathrm{kg}$.

The excess ${ }^{3} \mathrm{He}$ data were obtained from http://cchdo.ucsd.edu/ (see also the measurement protocols described at http://cchdo.ucsd.edu/manuals/pdf/91_1/jenknew.pdf) and the stations in the vicinity of the $\mathrm{dFe}$ stations (Figure $\mathrm{S} 1$ ) were used to interpolate onto the $\mathrm{dFe}$ station data in the following manner. First, excess ${ }^{3} \mathrm{He}$ was computed using the reported the helium isotope ratio anomaly and helium concentration, correcting for helium solubility isotope fractionation for equilibrium with air, then each ${ }^{3} \mathrm{He}$ station was vertically interpolated onto neutral density surfaces. Next, each isopycnal surface was interpolated to the geographic location of the dFe stations. Finally, the resultant profiles of ${ }^{3} \mathrm{He}$ vs. neutral density were interpolated to the sampling depths of the $\mathrm{dFe}$ profiles. The statistical uncertainties associated with this interpolation were small relative the variance in the $\mathrm{dFe}:{ }^{3} \mathrm{He}$ relationships subsequently derived. 


\section{References for Chapter 4}

1 German, C. R., Campbell, A. C. \& Edmond, J. M. Hydrothermal scavenging at the Mid-Atlantic Ridge: Modification of trace element dissolved fluxes. Earth and Planetary Science Letters 107, 101-114 (1991).

2 Boyle, E. A., Bergquist, B. A., Kayser, R. A. \& Mahowald, N. Iron, manganese, and lead at Hawaii Ocean Time-series station ALOHA: Temporal variability and an intermediate water hydrothermal plume. Geochimica et Cosmochimica Acta 69, 5165-5166, doi:10.1016/j.gca.2005.03.006 (2005).

Boyle, E. A. \& Jenkins, W. K. Hydrothermal iron in the deep western South Pacific. Geochimica et Cosmochimica Acta 72, A107 (2008).

Klunder, M. B., Laan, P., Middag, R., de Baar, H. J. W. \& Bakker, K. Dissolved iron in the Arctic Ocean: Important role of hydrothermal sources, shelf input and scavenging removal. J. Geophys. Res. 117, C04014, doi:10.1029/2011jc007135 (2012).

$5 \quad$ Klunder, M. B., Laan, P., Middag, R., De Baar, H. J. W. \& van Ooijen, J. C. Dissolved iron in the Southern Ocean (Atlantic sector). Deep Sea Research Part II: Topical Studies in Oceanography 58, 2678-2694 (2011).

Nishioka, J., Obata, H. \& Tsumune, D. Evidence of an extensive spread of hydrothermal dissolved iron in the Indian Ocean. Earth and Planetary Science Letters 361, 26-33, doi: http://dx.doi.org/10.1016/j.epsl.2012.11.040 (2013).

Wu, J., Wells, M. L. \& Rember, R. Dissolved iron anomaly in the deep tropicalsubtropical Pacific: Evidence for long-range transport of hydrothermal iron. Geochimica et Cosmochimica Acta 75, 460-468 (2011).

Toner, B. M., Marcus, M. A., Edwards, K. J., Rouxel, O. \& German, C. R. Measuring the form of iron in hydrothermal plume particles. Oceanography 25, 209-212 (2012).

Moore, J. K. \& Braucher, O. Sedimentary and mineral dust sources of dissolved iron to the world ocean. Biogeosciences 5, 631-656 (2008).

Shaffer, G. Biogeochemical cycling in the global ocean 2. New proudction, Redfield ratios, and remineralization in the organic pump. Journal of Geophysical

Research 101, 3723-2745 (1996).

Tagliabue, A. et al. Hydrothermal contribution to the oceanic dissolved iron inventory. Nature Geosci 3, 252-256 (2010).

Von Damm, K. L. et al. Chemistry of submarine hydrothermal solutions at $21^{\circ} \mathrm{N}$, East Pacific Rise. Geochimica et Cosmochimica acta 49, 2197-2220 (1985).

Field, M. P. \& Sherrell, R. M. Dissolved and particulate Fe in a hydrothermal plume at $9^{\circ} 45^{\prime} \mathrm{N}$, East Pacific Rise: Slow Fe (II) oxidation kinetics in Pacific plumes. Geochimica et Cosmochimica Acta 64, 619-628 (2000).

Bruland, K. W., Orians, K. J. \& Cowen, J. P. Reactive trace metals in the 
stratified central North Pacific. Geochimica et Cosmochimica Acta 58, 31713182 (1994).

Lee, J.-M. et al. Analysis of trace metals $(\mathrm{Cu}, \mathrm{Cd}, \mathrm{Pb}$, and $\mathrm{Fe})$ in seawater using single batch Nitrilotriacetate resin extraction and isotope dilution inductively coupled plasma mass spectrometry. Analytica Chimica Acta 686, 93-101 (2011).

Lupton, J. Hydrothermal helium plumes in the Pacific Ocean. J. Geophys. Res. 103, 15853-15868, doi:10.1029/98jc00146 (1998).

Edmond, J. M., Von Damm, K. L., McDuff, R. E. \& Measures, C. I. Chemistry of hot springs on the East Pacific Rise and their effluent dispersal. Nature 297, 187191 (1982).

Martin, J. H., Knauer, G. A. \& Broenkow, W. W. VERTEX: the lateral transport of manganese in the northeast Pacific. Deep Sea Research Part A. Oceanographic Research Papers 32, 1405-1427, doi:http://dx.doi.org/10.1016/0198-0149(85)90056-1 (1985).

Beaulieu, S. E. InterRidge Global Database of Active Submarine Hydrothermal Vent Fields: prepared for InterRidge, Version 2.0, $<$ http://www.interridge.org/IRvents> (2010).

Hautala, S. L. \& Riser, S. C. A nonconservative b-spiral determination of the deep circulation in the Eastern South Pacific. Journal of Physical Oceanography 23, 1975-2000 (1993).

Bergquist, B. A. \& Boyle, E. A. Dissolved iron in the tropical and subtropical Atlantic Ocean. Global Biogeochemical Cycles 20, 14 (2006).

Reid, J. L. On the total geostrophic circulation of the South Pacific Ocean: Flow Patterns, tracers, and transports. Progress in Oceanography 16, 1-61 (1986).

Yucel, M., Gartman, A., Chan, C. S. \& Luther, G. W. Hydrothermal vents as a kinetically stable source of iron-sulphide-bearing nanoparticles to the ocean. Nature Geoscience 4, 367-371 (2011).

Bennett, S. A. et al. The distribution and stabilisation of dissolved Fe in deep-sea hydrothermal plumes. Earth and Planetary Science Letters 270, 157-167 (2008).

Sander, S. G. \& Koschinsky, A. Metal flux from hydrothermal vents increased by organic complexation. Nature Geoscience 4, 145-150 (2011).

Sands, C. M., Connelly, D. P., Statham, P. J. \& German, C. R. Size fractionation of trace metals in the Edmond hydrothermal plume, Central Indian Ocean. Earth and Planetary Science Letters 319-320, 15-22 (2012).

Wu, J., Boyle, E. A., Sunda, W. G. \& Wen, L. Soluble and colloidal iron in the oligotrophic North Atlantic and North Pacific. Science 293, 847-849 (2001).

Craig, H., Clarke, W. B. \& Beg, M. A. Excess 3 He in deep water on the East Pacific Rise. Earth and Planetary Science Letters 26, 125-132 (1975).

Honjo, S., Manganini, S. J., Krishfield, R. A. \& Francois, R. Particulate organic carbon fluxes to the ocean interior and factors controlling the biological pump: A synthesis of global sediment trap programs since 1983. Progress in Oceanography 76, 217-285, (2008). 
Twining, B. S., Baines, S. B. \& Fisher, N. S. Element stoichiometries of individual plankton cells collected during the southern ocean iron experiment (SOFeX). Limnology \& Oceanography 49, 2115-2128 (2004).

Saito, M. A. et al. A South Atlantic hydrothermal iron plume and implications for global iron cycling. Nature Geoscience (in press).

Rich, H. W. \& Morel, F. M. M. Availability of well-defined iron colloids to the marine diatom Thalassiosira weissflogii. Limnology and Oceanography 35, 652-662 (1990).

Fitzsimmons, J. N. \& Boyle, E. A. An intercalibration between the GEOTRACES GO-FLO and the MITESS/Vanes sampling systems for dissolved iron concentration analyses (and a closer look at adsorption effects). Limnology \& Oceanography: Methods 10, 437-450 (2012).

Fitzsimmons, J. N. \& Boyle, E. A. The assessment and intercalibration of Anopore $^{\mathrm{TM}}$ and cross flow filtration methods for the determination of dissolved iron size fractionation into soluble/colloidal phases in seawater. Limnology \& Oceanography: Methods (in review).

Milne, A., Landing, W., Bizimis, M. \& Morton, P. Determination of Mn, Fe, Co, $\mathrm{Ni}, \mathrm{Cu}, \mathrm{Zn}, \mathrm{Cd}$ and $\mathrm{Pb}$ in seawater using high resolution magnetic sector inductively coupled mass spectrometry (HR-ICP-MS). Analytica Chimica Acta 665, 200-207, doi:10.1016/j.aca.2010.03.027 (2010). 
(a) KM0703 Station 19 (Southwest Pacific: $20^{\circ} \mathrm{S}, 170^{\circ} \mathrm{W}$ )

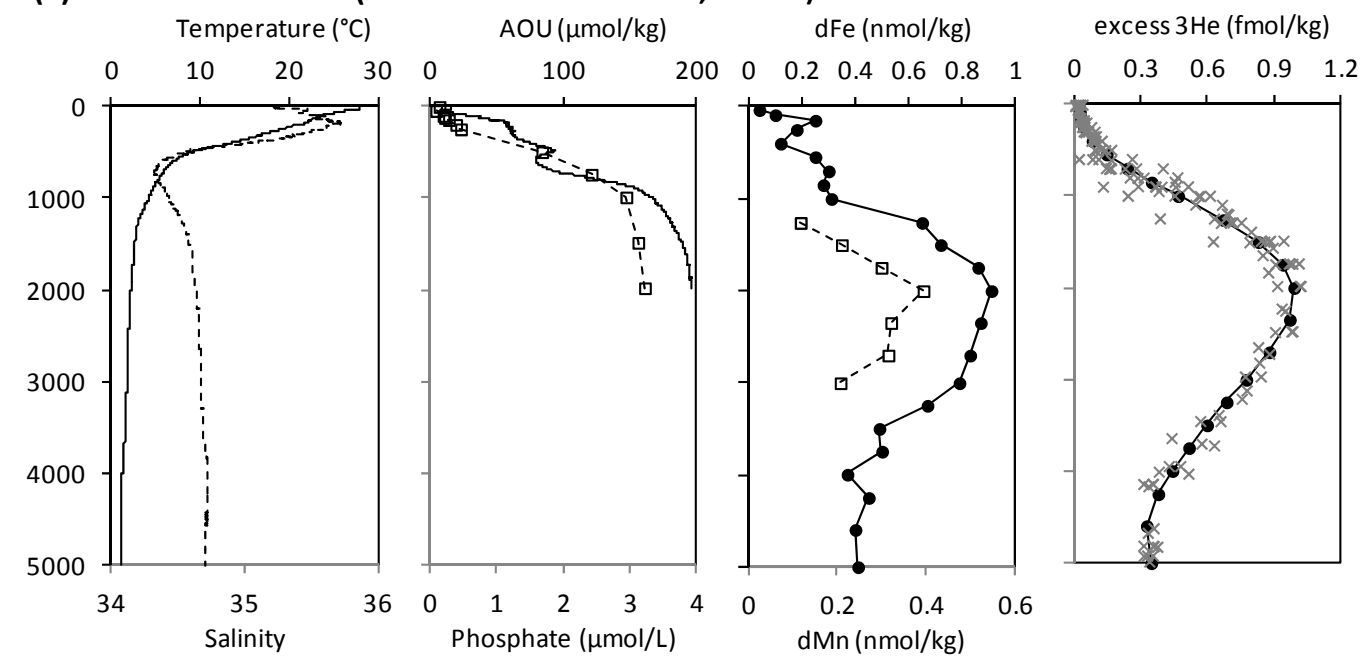

(b) Melville BiG RAPA Station 7 (Southeast Pacific: $26^{\circ} \mathrm{S}, 104^{\circ} \mathrm{W}$ )

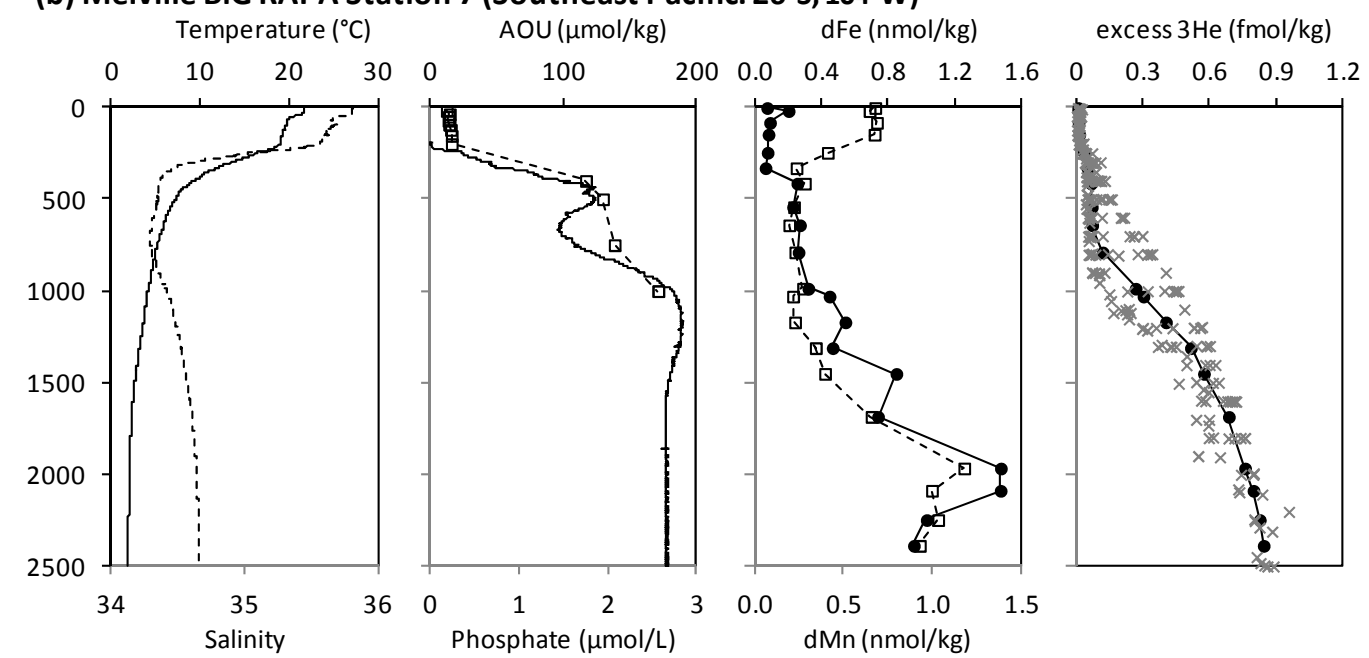

(c) Melville BiG RAPA Station 4 (Southeast Pacific: $23.5^{\circ} \mathrm{S}, 88.5^{\circ} \mathrm{W}$ )

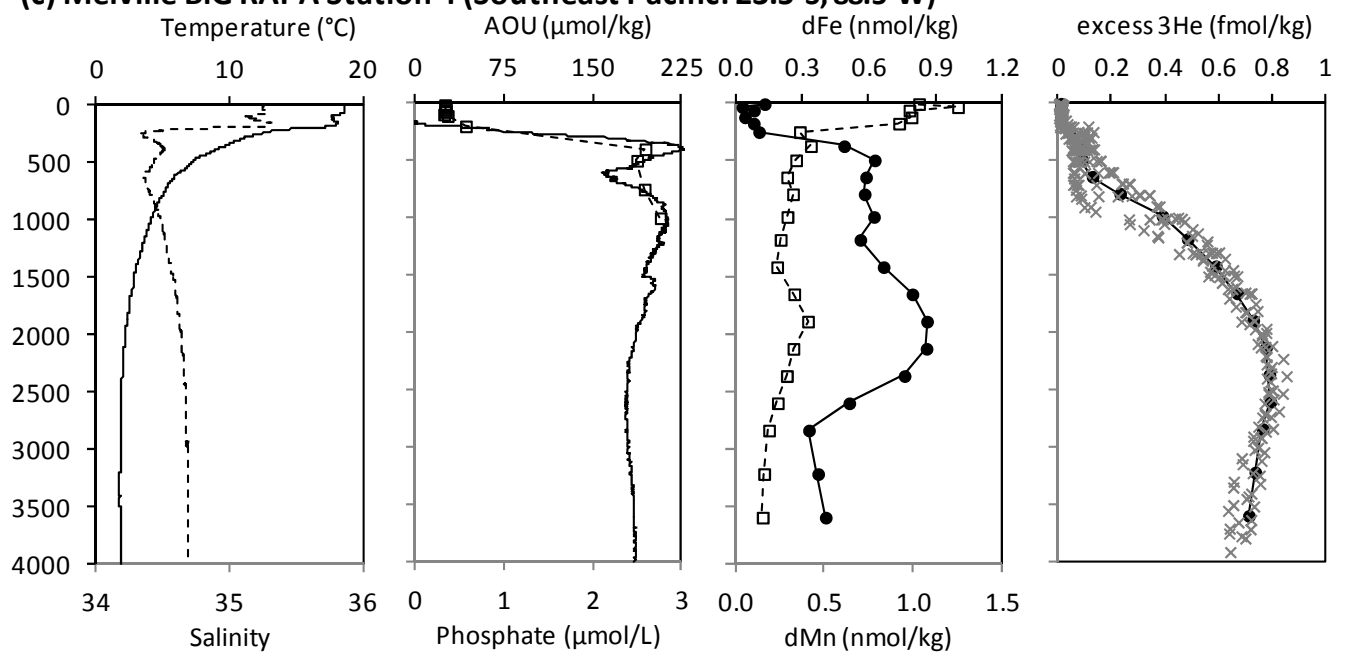


Figure 1: Oceanographic profiles showing a hydrothermal influence on $\mathrm{dFe},{ }^{3} \mathrm{He}$, and $\mathrm{dMn}$ at $2000 \mathrm{~m}$. Relevant profiles taken from (a) SPEEDO-KM0703 Station 19 in the Southwest Pacific, (b) Melville BiG RAPA Station 7 in the Southeast Pacific, and (c) Melville BiG RAPA Station 4 in the Southeast Pacific. Temperature, AOU, and dFe are shown as solid lines, while salinity, phosphate, and $\mathrm{dMn}$ are shown as open circles and dotted lines. The average excess ${ }^{3} \mathrm{He}$ data is shown as a solid line at the depths where dFe measurements were made, while the data used to generate those average values are shown as grey crosses.

(a) KM0703 Sta. 19

$\begin{array}{lll}\text { (b) Big RAPA Sta. } 7 & \text { (c) Big RAPA Sta. } 4\end{array}$

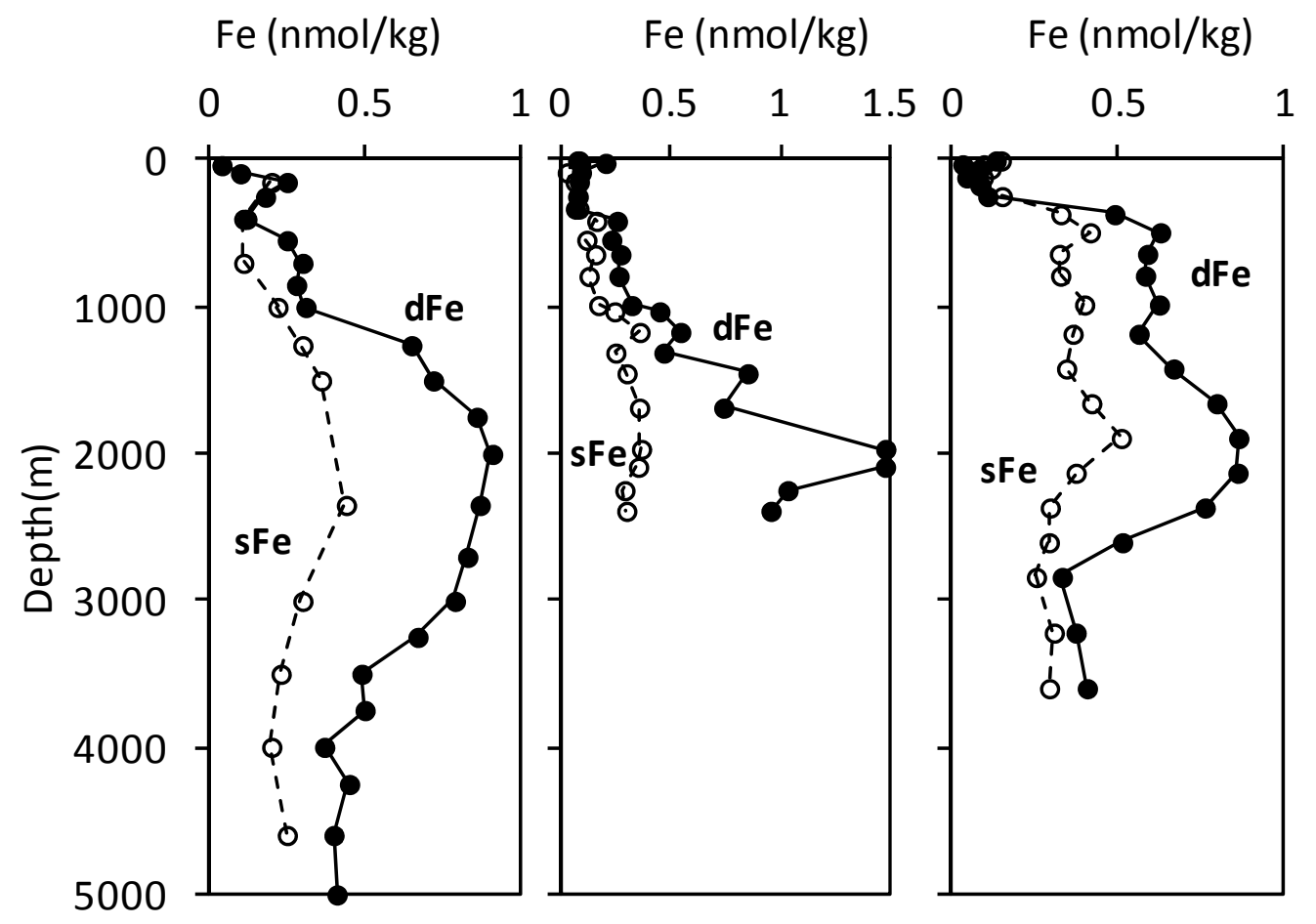

Figure 2: The size partitioning of dFe into soluble and colloidal phases demonstrates continued Fe transformations at great distance from vents. $\mathrm{dFe}$ (closed circles, solid line; $\mathrm{dFe}<0.4 \mu \mathrm{m}$ ) is partitioned into soluble $\mathrm{Fe}$ (open circles, dashed line; $\mathrm{sFe}<0.02 \mu \mathrm{m}$ or $10 \mathrm{kDa}$ ) and colloidal $\mathrm{Fe}$ (the difference between the two lines) fractions at (a) Station 19 in the Southwest Pacific, (b) Station 7 in the Southeast Pacific, and (c) Station 4 in the Southeast Pacific. Note that the Fe concentration scale changes in each of the three panels. 


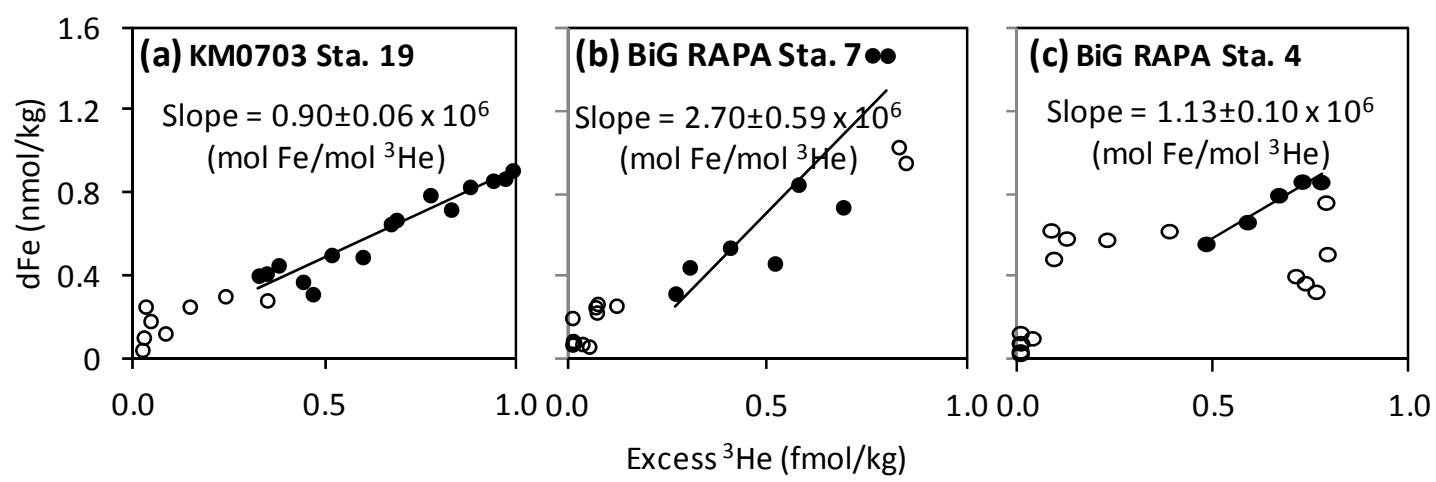

Figure 3: Distal hydrothermal $d F e^{3} \mathrm{He}$ ratios. Station locations are (a) Station 19 in the Southwest Pacific, (b) Station 7 in the Southeast Pacific, and (c) Station 4 in the Southeast Pacific. Data shallower than $1000 \mathrm{~m}$ is excluded from the regression calculation (open circles). Deepest samples at Stations 4 and 7 where dFe appears to have been scavenged while ${ }^{3} \mathrm{He}$ remains elevated are also excluded (open circles). 


\section{Supplementary Material for}

\section{Distal transport of dissolved hydrothermal iron in the deep South Pacific Ocean}

Jessica N. Fitzsimmons*, Edward A. Boyle, and William J. Jenkins

*To whom correspondence should be addressed. Email: jessfitz@mit.edu

\section{This file contains:}

Text (1882 words)

Figure S1 - S2; Figure captions (185 words)

Table S1

24 References

\section{Locations and general circulation of sample stations}

Figure $\mathrm{S} 1$ shows a map of the three stations sampled for dissolved iron (dFe), along with the reference stations used to interpolate profiles of excess ${ }^{3} \mathrm{He}$ at our stations and known sites of hydrothermal venting near the sampling sites (both active and confirmed) ${ }^{1}$.
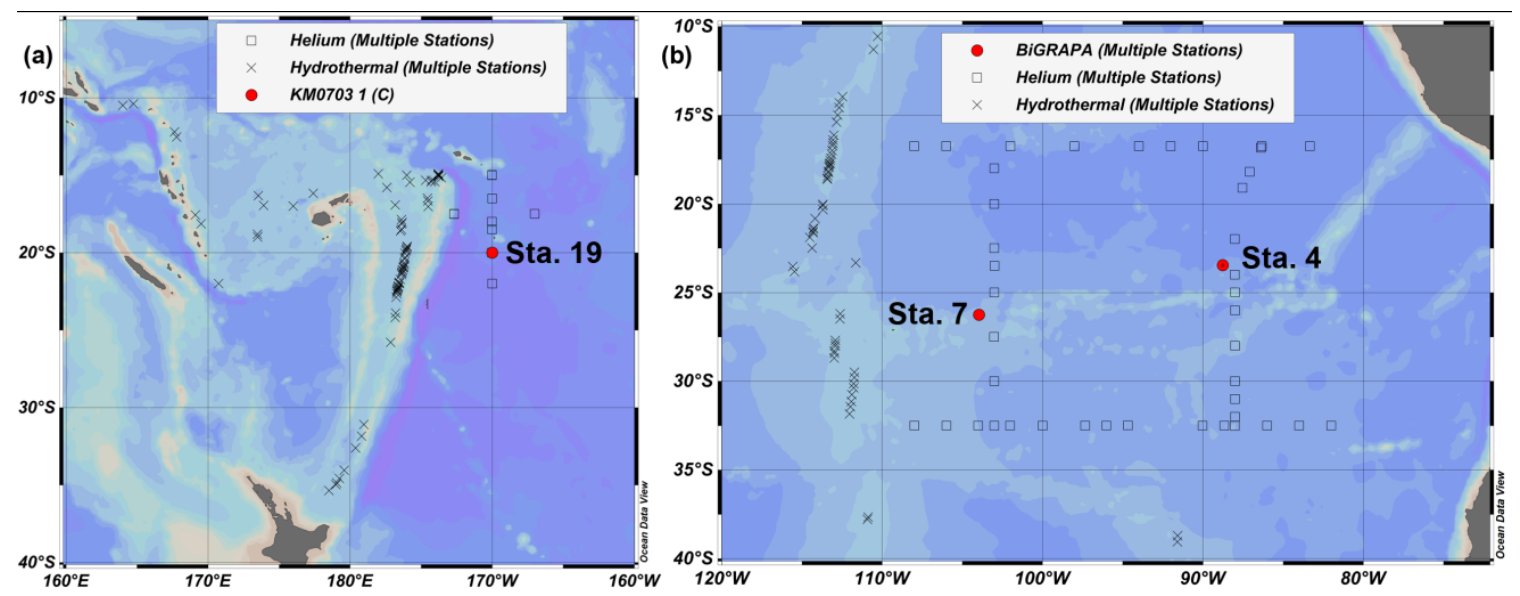

Figure S1: Map of study locations. (a) shows the Southwest Pacific where KM0703 SPEEDO Station $19\left(20^{\circ} \mathrm{S}, 170^{\circ} \mathrm{W}\right)$ is indicated in red, and the Kermadec/Tonga Arc is indicated as a topographic high along $175^{\circ} \mathrm{W}$. (b) shows the Southeast Pacific where Melville BiG RAPA Stations $7\left(26.25^{\circ} \mathrm{S}, 104^{\circ} \mathrm{W}\right)$ and $4\left(23.5^{\circ} \mathrm{S}, 88.75^{\circ} \mathrm{W}\right)$ are indicated in red, and the East Pacific Rise (EPR) is shown as the topographic high along $113^{\circ} \mathrm{W}$. Shown as squares are stations where historical ${ }^{3} \mathrm{He}$ data exists that was used to interpolate the average ${ }^{3} \mathrm{He}$ profiles onto this study's sampling locations $\left({ }^{3} \mathrm{He}\right.$ data from https://cchdo.ucsd.edu). Shown as crosses are sites of confirmed or inferred hydrothermal venting (deeper than $1000 \mathrm{~m})^{1}$. 


\section{Enhanced $\mathrm{dFe}$ at $2000 \mathrm{~m}$ is not a result of remineralization: Fe-AOU relationships}

The dFe maxima at the three sampling stations at $2000 \mathrm{~m}$ depth are not associated with maxima in AOU (Figure 1) and thus should not be attributed to remineralization. In fact, at all stations there is a ferricline at 400-500m depth that corresponds exactly with the depths of increasing AOU and phosphate concentrations, and $\mathrm{dFe}, \mathrm{AOU}$, and phosphate reach relative maxima by $1000 \mathrm{~m}$. This shallow ferricline depth also matches the ferricline depths recorded in prior studies of the Southeast ${ }^{2}$ and Equatorial Pacific ${ }^{3}$ and is attributed to remineralization of sinking organic matter. Remineralization $\mathrm{dFe}$ signals stabilize between $500-1000 \mathrm{~m}$ at concentrations of $0.3 \mathrm{nmol} / \mathrm{kg}$ at Stations 19 and 7 and $0.6 \mathrm{nmol} / \mathrm{kg}$ at Station 4. Along these depths, $\mathrm{dFe}$ and AOU have a linear relationship (Figure S2) that result in Fe:C ratios between $2.4-4.5 \mu \mathrm{mol} / \mathrm{mol}$, falling in the overall range of 1.4-4.7 found in the North and equatorial Pacific ${ }^{4}$.

At Stations 19 and 7, the anomalously enriched dFe data (shown as crosses in Figure S2) fall off a linear relationship of dFe:AOU, suggesting that the high Fe concentrations are not produced by remineralization. Accordingly if these enriched $\mathrm{dFe}$ data are included in the $\mathrm{Fe}: \mathrm{C}$ ratio estimates, not only do the linear correlations between $\mathrm{dFe}$ and AOU become less significant, but the resulting Fe:C ratios (designated as "Fe:C(all)" in Figure S2) also increase to 5.1-9.2 $\mu \mathrm{mol} / \mathrm{mol}$, which is higher than has ever been recorded in the open ocean Pacific. Both of these facts suggest that the deep dFe enrichment at $2000 \mathrm{~m}$ is not a result of remineralization. 


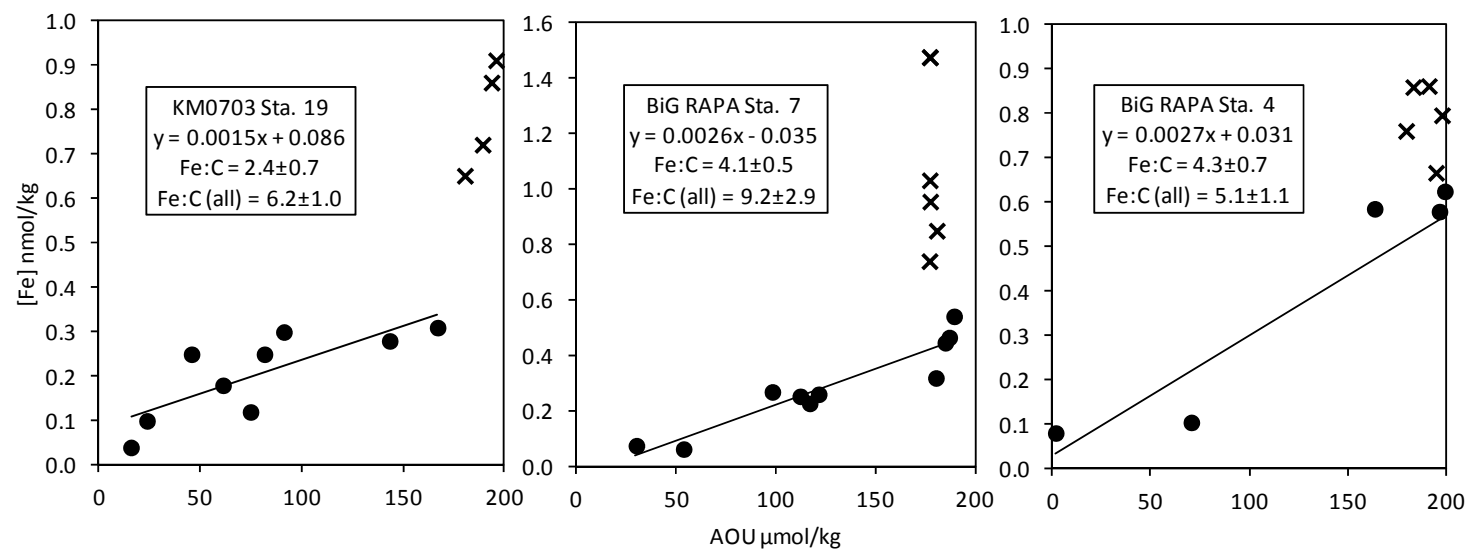

Figure S2: Fe-AOU relationships for each of the three stations. In circles are the stations included in the regression and the $\mathrm{Fe}: \mathrm{C}$ calculation, while the crosses show the sample depths that we suggest are affected by hydrothermal $\mathrm{Fe}$. When all points (circles and crosses) are included in the regression, the resulting Fe:C ratio is indicated as "Fe:C (all)." Fe:C ratios are calculated using an AOU:C ratio ${ }^{5}$ of 1.6 and are in units of $\mu \mathrm{mol} / \mathrm{mol}$.

\section{dMn data and $\mathrm{Fe} / \mathrm{Mn}$ ratios}

Hydrothermally-derived dissolved Mn maxima were detected at 2000m in our open ocean samples at all three stations, ranging from $0.32-1.18 \mathrm{nmol} / \mathrm{kg}$ in the profile peaks (compared to 0.1-0.2 nmol/kg dMn backgrounds in typical abyssal seawater). Station 7 in the eastern South Pacific had the highest dMn concentration, in accordance with highest $\mathrm{dFe}$ concentrations. Station $4\left(23.5^{\circ} \mathrm{S}, 88.75^{\circ} \mathrm{W}\right)$ had a peak $\mathrm{dMn}$ concentration of $0.40 \mathrm{nmol} / \mathrm{kg}$, which is much lower than the $1.77 \mathrm{nmol} / \mathrm{kg}$ total dissolved Mn (dissolved + particulate) measured in 1986 at a nearby station $\left(24.64^{\circ} \mathrm{S}\right.$, $94.04^{\circ} \mathrm{W}$ ) at $2579 \mathrm{~m} \mathrm{depth}^{6}$. Assuming similar hydrothermal Mn delivery at the two sampling stations today and in 1986, there must be a large particulate Mn component at these stations that was not monitored in this study, potentially suggesting that both particulate and dissolved $\mathrm{Mn}$ are transported hundreds-thousands of kilometers from the vent source in the hydrothermal plume. This particulate $\mathrm{Mn}$ inference requires further investigation to confirm.

Because of its slow scavenging kinetics ${ }^{7}$ and sluggish re-equilibration after temperature alteration in the buyoant plume ${ }^{8}$, dissolved $\mathrm{Mn}$ is believed to behave conservatively in vent fluids on the timescale of hours-days. Following this assumption 
of Mn conservation, $\mathrm{dFe} / \mathrm{dMn}$ ratios have been used in vent fluid samples to calculate the extent of plume dilution ${ }^{9,10}$ and the temperature of the hydrothermal reaction chamber ${ }^{11}$. Since our samples are taken from the distal hydrothermal plume at a very minimum of several days from the vent source, we believe that an analysis of vent fluid dilution using the dissolved Mn data is not appropriate because dissolved Mn no longer behaves conservatively, and ${ }^{3} \mathrm{He}$ is instead used as the conservative tracer of vent fluids in this paper.

However, there is still useful information to be gleaned from the Fe/Mn ratios with distance from the plume, although background deep-ocean concentrations must be subtracted from the hydrothermal concentration anomalies in order to compare the distal hydrothermal $\mathrm{Fe} / \mathrm{Mn}$ ratios to near-field hydrothermal ratios. We made these corrections by subtracting the non-hydrothermal, deep-ocean $\mathrm{dFe}$ and dMn concentrations of 0.4 $\mathrm{nmol} / \mathrm{kg}$ and $0.15 \mathrm{nmol} / \mathrm{kg}$, respectively ${ }^{12}$. The resulting Fe/ $\mathrm{Mn}$ ratios at the depths of maximum hydrothermal influence are Station 19: $2.65 \pm 0.5$, Station 7: $1.16 \pm 0.2$, and Station 4: $2.21 \pm 0.6$. Assuming both $\mathrm{Fe}$ and $\mathrm{Mn}$ behave non-conservatively in the far-field plume, these ratios inform us about the relative scavenging precipitation potential of $\mathrm{Fe}$ and $\mathrm{Mn}$ in the distal hydrothermal plume. If we assume a similar hydrothermal source for Stations 4 and 7, with Station 4 simply $\sim 1500 \mathrm{~km}$ farther along the distal plume, then the increase in $\mathrm{dFe} / \mathrm{dMn}$ ratio from 1.16 at Station 7 to 2.21 at Station 4 suggests that $\mathrm{dMn}$ is scavenged to a greater extent in the distal plume than $\mathrm{dFe}$, presumably because more of the "scavenge-able" dFe has already been removed in the near-field plume. While dFe removal pathways along the distal plume are abiotically-driven, including oxidation of remaining dissolved $\mathrm{Fe}^{2+}$ or pyrite nanoparticles and aggregation/scavenging of colloidal Fe to the particulate phase, dMn removal pathways include both an abiotic component (oxidation of dissolved $\mathrm{Mn}^{2+}$ to particulate $\mathrm{Mn}^{4+}$ ) as well as a biotic component that is microbially mediated ${ }^{13}$. This microbial Mn scavenging was the dominant Mn removal pathway in distal (15-20 km from vent) samples, compared to a larger abiotic scavenging component in proximal vent samples (0-3 km from vent) near the Juan de Fuca Ridge ${ }^{7}$. 


\section{Possible sources of hydrothermal vent input to the study locations}

With the data shown here, it is impossible to identify vent sources for the hydrothermally-derived dFe observed at the three study locations; it is also very probable, given that the study sites are situated far away from a large array of known hydrothermal vents, that multiple vents contribute to the cumulative hydrothermal $\mathrm{dFe}$ and ${ }^{3} \mathrm{He}$ anomalies measured at the three stations. We review here the hydrothermal vent fields that may have contributed to the observed $\mathrm{dFe}$ enrichment, in light of the recently assembled global hydrothermal vent database ${ }^{1}$ as well as published articles from the literature.

Southwest Pacific: KM0703 SPEEDO Station $19\left(20^{\circ} \mathrm{S}, 170^{\circ} \mathrm{W}\right)$

The hydrothermal dFe, dMn, and excess ${ }^{3} \mathrm{He}$ anomalies at Station 19 are both greatest over a depth range from 1000-3500m, with coincident maxima at $2000 \mathrm{~m}$. Although the nearest identified hydrothermal sources occur in the Tonga-Fiji region just to the west of this station ${ }^{14}$ the predominant flow pattern over this depth range is from the southeast, organized as a zonally elongated anticyclonic gyre extending perhaps as far eastward as the East Pacific Rise according to Reid ${ }^{15}$. This suggests that the fast spreading centers along the southern EPR described by Lupton and Craig ${ }^{16}$ may be the origin of the ${ }^{3} \mathrm{He}$ and $\mathrm{dFe}$ anomalies. Moreover, the direction of this circulation is consistent with the beta-plume dynamics earlier described by Stommel ${ }^{17}$ that arise from the mid-depth injection of buoyancy at these sites. However, we cannot completely rule out an additional contribution from the Tonga-Fiji venting sites, even though they occur "downstream" of Station 19 (a ${ }^{3}$ He plume has been observed ${ }^{14}$ north and west of Station 19 , centered at $1750 \mathrm{~m}$ near $15^{\circ} \mathrm{S}, 175^{\circ} \mathrm{W}$, emanating westward toward the Coral Sea). A detailed examination of the data from Lupton et al. ${ }^{14}$ shows that the zonal ${ }^{3} \mathrm{He}$ section is characterized by nearly vertical ${ }^{3} \mathrm{He}$ contours between $173^{\circ}$ and $176^{\circ} \mathrm{W}$, supporting the hypothesis of little influence of Tonga-Fiji vents on the $\mathrm{dFe}$ and ${ }^{3} \mathrm{He}$ profiles at Station 19. 
Southeast Pacific: Melville BiG RAPA Stations $4\left(23.5^{\circ} \mathrm{S}, 88.75^{\circ} \mathrm{W}\right)$ and $7\left(26.25^{\circ}\right.$, $\left.104^{\circ} \mathrm{W}\right)$

The hydrothermal ${ }^{3} \mathrm{He}$ and $\mathrm{dFe}$ anomalies at Stations 4 and 7 in the Southeast Pacific both have maxima at $2000 \mathrm{~m}$ depth, with Station 7 having $>50 \%$ more dFe than Station 4 at their maxima, although the ${ }^{3} \mathrm{He}$ anomalies are roughly comparable in magnitude at the two stations. The highly elevated $\mathrm{dFe}$ concentrations of $>1.5 \mathrm{nmol} / \mathrm{kg}$ at $2000 \mathrm{~m}$ at Station 7 might suggest the presence of a proximal Fe source. This station is also located on the topographic high of the Easter Seamount Chain, which might also support the premise of a nearby hydrothermal site. However, no venting has been confirmed or even inferred from CTD casts anywhere along the Easter Seamount Chain (as shown in Figure S1). The Sala y Gomez hotspot, which formed the Eastern Seamount Chain during the last 30 million years ${ }^{18,19}$, is currently believed to be somewhere between Easter Island (540 km away from Station 7) and Sala y Gomez Island (145 km away), likely nearer to Sala y Gomez Island. No modern seamount derived from this hotspot has been identified, and as a result no volcanic activity or associated venting has been inferred. If the Sala y Gomez hotspot is found to be the major dFe source to the Peru Basin at some later date, however, the elevated $\mathrm{dFe}$ at Station 4 still implies long range transport of dFe from distal hydrothermal sources because there are no known vents (or even topographic rises that might support vents) near Station 4.

The EPR is the most probable source of $\mathrm{dFe}$ and ${ }^{3} \mathrm{He}$ at Melville BiG RAPA Station 7. The well-known ${ }^{3} \mathrm{He}$ plume initially discovered at $\sim 15^{\circ} \mathrm{S}$ between $2000-3000 \mathrm{~m}$ is advected westward from the EPR, away from the Peru/Chile basins ${ }^{16}$, but there is still elevated $\delta^{3} \mathrm{He}(28-30 \%)$ at $15-30^{\circ} \mathrm{S}$ in the Peru Basin east of the EPR through and along $88^{\circ} \mathrm{W}^{20}$ (the longitude of Station 4). Despite being east of the EPR, Lupton ${ }^{20}$ attributed this $88^{\circ} \mathrm{W} \delta^{3} \mathrm{He}$ distribution to an EPR source, since steric height calculations infer eastward transport of water at $2500 \mathrm{~m}$ depth across the EPR and into the Peru/Chile basins ${ }^{21}$. In fact, the ${ }^{3} \mathrm{He}$ distribution along $32^{\circ} \mathrm{S}$ very clearly shows eastward transport of $a^{3} \mathrm{He}$ plume from the southern $\mathrm{EPR}^{22}$. This eastward aybssal flow south of $15^{\circ} \mathrm{S}$ has also been used to explain the enhanced Fe and Mn in surface sediments of the Peru/Chile 
Basins at $25^{\circ} \mathrm{S}^{23}$ and the enhanced total dissolved Mn concentrations (from unfiltered samples) collected at $18-25^{\circ} \mathrm{S}, 94^{\circ} \mathrm{W}$ near Station 4 of our study ${ }^{6}$. As shown in Figure S1, there are many hydrothermal vents between $20-32^{\circ} \mathrm{S}$, reported by Baker et al. ${ }^{24}$, that could source this enhanced $\mathrm{dFe}, \mathrm{dMn}$, and $3 \mathrm{He}$ along the Nazca Ridge, most of which vent at the appropriate depths of 2000-3000m to produce the observed signal. These EPR vents are a minimum of $860 \mathrm{~km}$ from Station 7 and thus indicate that $\mathrm{dFe}$ can be stably transported quite far from the vent source.

The geostrophic flow patterns proposed by Reid ${ }^{15}$ at Station 4 come from the north and northwest at 2000-2500m depth, instead of from due west, as at Station 7. Thus, although it is still likely that Station $4 \mathrm{dFe}$ is derived from the EPR, it may also receive hydrothermal influence from the northern EPR. As a hydrothermal plume extends away from its vent site, it typically shoals along isopycnal surfaces, and consequently ${ }^{3} \mathrm{He}$ plumes near $32^{\circ} \mathrm{S}, 80^{\circ} \mathrm{W}$ in the Chile Basin were hypothesized by Jenkins ${ }^{22}$ to have originated in the North Pacific and then shoaled during transport to the South Pacific, since the South Pacific enhanced ${ }^{3} \mathrm{He}$ was at a shallower isopycnal than southern EPRderived vent plumes. It is not clear whether a hydrothermal dFe signal from the North Pacific would survive long transit times to the South Pacific, but it is possible that North Pacific vents may contribute a portion of the accumulated hydrothermal signal observed in the Southeast Pacific. Station 4 is at a minimum of $2400 \mathrm{~km}$ from southern EPR vents, and hydrothermal signals would have had to transit even farther if derived from northernEPR vents. 
Table S1

\begin{tabular}{|c|c|c|c|c|c|c|c|c|}
\hline Station & $\begin{array}{l}\text { Depth } \\
\text { (m) }\end{array}$ & $\begin{array}{c}\text { Temp. } \\
\left({ }^{\circ} \mathrm{C}\right)\end{array}$ & Salinity & $\underset{(\mu \mathrm{mol} / \mathrm{kg})}{\text { AOU }}$ & $\begin{array}{c}\mathrm{dFe} \\
<0.4 \mu \mathrm{m} \\
(\mathrm{nmol} / \mathrm{kg})\end{array}$ & $\begin{array}{c}\mathrm{sFe} \\
<0.02 \mu \mathrm{m} \\
(\mathrm{nmol} / \mathrm{kg})\end{array}$ & $\begin{array}{c}\begin{array}{c}\text { dMn } \\
<0.4 \mu \mathrm{m} \\
(\mathrm{nmol} / \mathrm{kg})\end{array} \\
\end{array}$ & $\begin{array}{c}\text { Excess } \\
{ }^{3} \mathrm{He} \\
(\mathrm{fmol} / \mathrm{kg})\end{array}$ \\
\hline \multirow{10}{*}{$\begin{array}{c}\text { Melville } \\
\text { BiG } \\
\text { RAPA }\end{array}$} & 3 & 21.853 & 35.830 & & 0.073 & 0.080 & 0.676 & 0.0088 \\
\hline & 20 & 21.661 & 35.852 & & 0.202 & 0.087 & 0.644 & 0.0084 \\
\hline & 84 & 20.070 & 35.764 & & 0.090 & 0.026 & 0.686 & 0.0101 \\
\hline & 148 & 19.598 & 35.744 & & 0.081 & 0.062 & 0.672 & 0.0133 \\
\hline & 247 & 15.477 & 34.895 & 29.8 & 0.076 & 0.073 & 0.409 & 0.0336 \\
\hline & 331 & 11.802 & 34.469 & 53.46 & 0.063 & 0.079 & 0.233 & 0.0506 \\
\hline & 415 & 8.558 & 34.358 & 111.98 & 0.254 & 0.160 & 0.280 & 0.0665 \\
\hline & 543 & 6.714 & 34.338 & 116.73 & 0.228 & 0.115 & 0.219 & 0.0697 \\
\hline & 642 & 5.903 & 34.303 & 97.99 & 0.270 & 0.155 & 0.193 & 0.0717 \\
\hline & 790 & 4.952 & 34.306 & 121.25 & 0.261 & 0.125 & 0.227 & 0.1188 \\
\hline \multirow{10}{*}{$\begin{array}{c}\text { Station } 7 \\
\left(26.25^{\circ} \mathrm{S},\right. \\
\left.104^{\circ} \mathrm{W}\right)\end{array}$} & 987 & 4.192 & 34.411 & 180.04 & 0.320 & 0.169 & 0.270 & 0.2668 \\
\hline & 1030 & 4.033 & 34.432 & 184.75 & 0.447 & 0.242 & 0.214 & 0.3022 \\
\hline & 1170 & 3.629 & 34.478 & 189.21 & 0.542 & 0.357 & 0.225 & 0.4032 \\
\hline & 1311 & 3.158 & 34.524 & 186.76 & 0.466 & 0.247 & 0.342 & 0.5153 \\
\hline & 1451 & 2.767 & 34.554 & 180.96 & 0.848 & 0.298 & 0.394 & 0.5742 \\
\hline & 1685 & 2.296 & 34.605 & 177.3 & 0.738 & 0.355 & 0.655 & 0.6861 \\
\hline & 1966 & 2.053 & 34.635 & 177.37 & 1.475 & 0.364 & 1.176 & 0.7592 \\
\hline & 2087 & 1.979 & 34.645 & 177.56 & 1.473 & 0.350 & 0.995 & 0.7971 \\
\hline & 2247 & 1.931 & 34.652 & 177.47 & 1.030 & 0.288 & 1.030 & 0.8252 \\
\hline & 2387 & 1.905 & 34.657 & 177.68 & 0.953 & 0.297 & 0.927 & 0.8428 \\
\hline \multirow{10}{*}{$\begin{array}{c}\text { Melville } \\
\text { BiG } \\
\text { RAPA }\end{array}$} & 3 & 17.796 & 35.189 & & 0.130 & 0.145 & 1.031 & 0.0094 \\
\hline & 29 & 17.954 & 35.283 & & 0.030 & & 1.249 & 0.0094 \\
\hline & 59 & 12.495 & 34.358 & & 0.082 & & 0.976 & 0.0091 \\
\hline & 118 & 9.427 & 34.496 & & 0.041 & & 0.988 & 0.0091 \\
\hline & 172 & 7.281 & 34.433 & 1.41 & 0.081 & 0.084 & 0.918 & 0.0108 \\
\hline & 246 & 5.796 & 34.365 & 70.42 & 0.105 & & 0.360 & 0.0398 \\
\hline & 369 & 4.971 & 34.408 & 213.4 & 0.488 & 0.325 & 0.423 & 0.0947 \\
\hline & 492 & 4.138 & 34.477 & 199.42 & 0.625 & & 0.340 & 0.0880 \\
\hline & 639 & 3.588 & 34.52 & 163.74 & 0.586 & 0.321 & 0.289 & 0.1275 \\
\hline & 786 & 2.988 & 34.558 & 196.7 & 0.580 & 0.324 & 0.322 & 0.2307 \\
\hline \multirow{11}{*}{$\begin{array}{c}\text { Station } 4 \\
\left(23.5^{\circ} \mathrm{S}\right. \\
\left.88.75^{\circ} \mathrm{W}\right)\end{array}$} & 983 & 2.601 & 34.5972 & 212.21 & 0.622 & 0.396 & 0.291 & 0.3899 \\
\hline & 1182 & 2.302 & 34.6239 & 206.45 & 0.560 & 0.362 & 0.252 & 0.4841 \\
\hline & 1419 & 2.08 & 34.645 & 195.43 & 0.665 & 0.342 & 0.233 & 0.5897 \\
\hline & 1655 & 1.938 & 34.6593 & 198.46 & 0.795 & 0.418 & 0.329 & 0.6699 \\
\hline & 1892 & 1.847 & 34.6709 & 191.75 & 0.860 & 0.507 & 0.406 & 0.7296 \\
\hline & 2128 & 1.804 & 34.6776 & 183.83 & 0.858 & 0.371 & 0.324 & 0.7776 \\
\hline & 2364 & 1.771 & 34.6835 & 180.18 & 0.759 & 0.293 & 0.287 & 0.7904 \\
\hline & 2601 & 1.776 & 34.6872 & 178.71 & 0.511 & 0.290 & 0.236 & 0.7939 \\
\hline & 2837 & 17.796 & 35.189 & 178.86 & 0.329 & 0.251 & 0.187 & 0.7652 \\
\hline & 3216 & 17.954 & 35.283 & 183.05 & 0.371 & 0.305 & 0.160 & 0.7378 \\
\hline & 3594 & 12.495 & 34.358 & 184.45 & 0.405 & 0.291 & 0.151 & 0.7135 \\
\hline
\end{tabular}




\begin{tabular}{|c|c|c|c|c|c|c|c|c|}
\hline Station & $\begin{array}{l}\text { Depth } \\
\text { (m) }\end{array}$ & $\begin{array}{c}\text { Temp. } \\
\left({ }^{\circ} \mathrm{C}\right)\end{array}$ & Salinity & $\underset{(\mu \mathrm{mol} / \mathrm{kg})}{\text { AOU }}$ & $\begin{array}{c}\mathrm{dFe} \\
<0.4 \mu \mathrm{m} \\
(\mathrm{nmol} / \mathrm{kg})\end{array}$ & $\begin{array}{c}\mathrm{sFe} \\
<0.02 \mu \mathrm{m} \\
(\mathrm{nmol} / \mathbf{k g})\end{array}$ & $\begin{array}{c}\begin{array}{c}\mathrm{dMn} \\
<0.4 \mu \mathrm{m} \\
(\mathrm{nmol} / \mathrm{kg})\end{array} \\
\end{array}$ & $\begin{array}{c}\text { Excess } \\
{ }^{3} \mathrm{He} \\
(\mathrm{fmol} / \mathrm{kg})\end{array}$ \\
\hline \multirow{10}{*}{$\begin{array}{l}\text { KM0703 } \\
\text { SPEEDO }\end{array}$} & 35 & 27.8 & 35.26 & 15.67 & 0.04 & \multirow{4}{*}{0.2} & & 0.0220 \\
\hline & $90 *$ & 24.43 & 35.52 & 23.57 & 0.1 & & & 0.0257 \\
\hline & 150 & 22.46 & 35.61 & 45.54 & 0.25 & & & 0.0305 \\
\hline & $250^{*}$ & 19.24 & 35.58 & 61.09 & 0.18 & & & 0.0435 \\
\hline & 400 & 13.52 & 35.04 & 74.64 & 0.12 & \multirow[t]{2}{*}{0.11} & & 0.0821 \\
\hline & $546^{*}$ & 7.95 & 34.46 & 81.52 & 0.25 & & & 0.1458 \\
\hline & 700 & 5.98 & 34.33 & 91.11 & 0.3 & \multirow[t]{2}{*}{0.11} & & 0.2388 \\
\hline & $850 *$ & 4.97 & 34.37 & 143.3 & 0.28 & & & 0.3481 \\
\hline & 1000 & 4.22 & 34.44 & 166.94 & 0.31 & 0.22 & & 0.4673 \\
\hline & 1260 & 3.01 & 34.53 & 180.82 & 0.65 & 0.3 & 0.117 & 0.6713 \\
\hline \multirow{3}{*}{$\begin{array}{c}\text { Station } \\
19\end{array}$} & 1500 & 2.61 & 34.58 & 189.58 & 0.72 & \multirow[t]{3}{*}{0.36} & 0.209 & 0.8284 \\
\hline & $1747^{*}$ & 2.4 & 34.61 & 193.98 & 0.86 & & 0.299 & 0.9381 \\
\hline & $2000^{*}$ & 2.22 & 34.63 & 196.21 & 0.91 & & 0.393 & 0.9891 \\
\hline \multirow{10}{*}{$\begin{array}{c}\left(20^{\circ} \mathrm{S}\right. \\
\left.170^{\circ} \mathrm{W}\right)\end{array}$} & 2347 & 2.06 & 34.65 & & 0.87 & \multirow[t]{2}{*}{0.44} & 0.320 & 0.9696 \\
\hline & $2700^{*}$ & 1.9 & 34.66 & & 0.83 & & 0.314 & 0.8780 \\
\hline & 3000 & 1.77 & 34.67 & & 0.79 & \multirow[t]{2}{*}{0.3} & \multirow[t]{3}{*}{0.206} & 0.7741 \\
\hline & $3245^{*}$ & 1.67 & 34.68 & & 0.67 & & & 0.6855 \\
\hline & 3496 & 1.56 & 34.69 & & 0.49 & \multirow[t]{2}{*}{0.23} & & 0.5976 \\
\hline & $3743^{*}$ & 1.42 & 34.69 & & 0.5 & & & 0.5164 \\
\hline & 3993 & 1.27 & 34.70 & & 0.37 & \multirow[t]{2}{*}{0.2} & & 0.4416 \\
\hline & $4246^{*}$ & 1.16 & 34.71 & & 0.45 & & & 0.3779 \\
\hline & 4593 & 1.07 & 34.71 & & 0.4 & \multirow[t]{2}{*}{0.25} & & 0.3261 \\
\hline & $4997 *$ & 1.07 & 34.71 & & 0.41 & & & 0.3465 \\
\hline
\end{tabular}

*Designates where the MITESS bottles were composed of Teflon instead of polyethylene. 


\section{References for Chapter 4 Supplementary Information}

1 Beaulieu, S. E. InterRidge Global Database of Active Submarine Hydrothermal Vent Fields: prepared for InterRidge, Version 2.0, $<$ http://www.interridge.org/IRvents $>$ (2010).

Blain, S., Bonnet, S. \& Guieu, C. Dissolved iron distribution in the tropical and sub tropical South Eastern Pacific. Biogeosciences 5, 269-280 (2008).

Wu, J., Wells, M. L. \& Rember, R. Dissolved iron anomaly in the deep tropicalsubtropical Pacific: Evidence for long-range transport of hydrothermal iron. Geochimica et Cosmochimica Acta 75, 460-468 (2011).

Sunda, W. G. Control of dissolved iron concentrations in the world ocean, A comment. Marine Chemistry 57, 169-172 (1997).

Martin, J. H., Knauer, G. A., Karl, D. M. \& Broenkow, W. W. VERTEX: carbon cycling in the northeast Pacific. Deep Sea Research Part A. Oceanographic Research Papers 34, 267-285 (1987).

Klinkhammer, G. \& Hudson, A. Dispersal patterns for hydrothermal plumes in the South Pacific using manganese as a tracer. Earth and Planetary Science Letters 79, 241-249, doi:http://dx.doi.org/10.1016/0012-821X(86)90182-2 (1986).

Cowen, J. P., Massoth, G. J. \& Feely, R. A. Scavenging rates of dissolved manganese in a hydrothermal vent plume. Deep Sea Research Part A. Oceanographic Research Papers 37, 1619-1637, doi:http://dx.doi.org/10.1016/0198-0149(90)90065-4 (1990).

Seewald, J. S. \& Seyfried, W. E. The effect of temperature on metal mobility in subseafloor hydrothermal systems: constraints from basalt alteration experiments. Earth and Planetary Science Letters 101, 388-403 (1990).

Field, M. P. \& Sherrell, R. M. Dissolved and particulate Fe in a hydrothermal plume at $9^{\circ} 45^{\prime} \mathrm{N}$, East Pacific Rise: Slow Fe (II) oxidation kinetics in Pacific plumes. Geochimica et Cosmochimica Acta 64, 619-628 (2000).

James, R. H. \& Elderfield, H. Dissolved and particulate trace metals in hydrothermal plumes at the Mid-Atlantic Ridge. Geophysical Research Letters 23, 3499-3502, doi:10.1029/96g101588 (1996).

Pester, N. J., Rough, M., Ding, K. \& Seyfried, W. E. A new Fe/Mn geothermometer for hydrothermal systems: Implications for high-salinity fluids at $13^{\circ} \mathrm{N}$ on the East Pacific Rise. Geochimica et Cosmochimica Acta 75, 7881-7892 (2011).

Bruland, K. W., Orians, K. J. \& Cowen, J. P. Reactive trace metals in the stratified central North Pacific. Geochimica et Cosmochimica Acta 58, 3171-3182 (1994).

Cowen, J. P., Massoth, G. J. \& Baker, E. T. Bacterial scavenging of Mn and Fe in a midto far-field hydrothermal particle plume. Nature 322, 169-171 (1986).

Lupton, J. E., Pyle, D. G., Jenkins, W. J., Greene, R. \& Evans, L. Evidence for an 
extensive hydrothermal plume in the Tonga-Fiji region of the South Pacific. Geochemistry, Geophysics, Geosystems 5, Q01003, doi:10.1029/2003gc000607 (2004).

Reid, J. L. On the total geostrophic circulation of the south Pacific Ocean: Flow patterns, tracers and transports. Progress in Oceanography 39, 263-352 (1997).

Lupton, J. E. \& Craig, H. A major helium-3 source at 15S on the East Pacific Rise. Science 214, 13-18 (1981).

Stommel, H. Is the South Pacific helium-3 plume dynamically active? Earth and Planetary Science Letters 61, 63-67 (1982).

Ray, J. S. et al. Chronology and geochemistry of lavas from the Nazca Ridge and Easter Seamount Chain: an 30 Myr hostpot record. Journal of Petrology 53, 14171448 (2012).

Kingsley, R. H., Blichert-Toft, J., Fontignie, D. \& Schilling, J. G. Hafnium, neodymium, and strontium isotope and parent-daughter element systematics in basalts from the plume-ridge interaction system of the Salas y Gomez Seamount Chain and Easter Microplate. Geochem. Geophys. Geosyst. 8, 28, doi:Q04005 10.1029/2006gc001401 (2007).

Lupton, J. Hydrothermal helium plumes in the Pacific Ocean. J. Geophys. Res. 103, 15853-15868, doi:10.1029/98jc00146 (1998).

Reid, J. L. On the total geostrophic circulation of the South Pacific Ocean: Flow Patterns, tracers, and transports. Progress in Oceanography 16, 1-61 (1986).

Jenkins, W. J. in International WOCE Newsletter Vol. 23 6-11 (1996).

Boström, K., Peterson, M. N. A., Joensuu, O. \& Fisher, D. E. Aluminum-poor ferromanganoan sediments on active oceanic ridges. Journal of Geophysical Research 74, 3261-3270, doi:10.1029/JB074i012p03261 (1969).

Baker, E. T. et al. Hydrothermal venting along Earth's fastest spreading center: East Pacific Rise, $27.5^{\circ}-32.3^{\circ} \mathrm{S}$. Journal of Geophysical Research 107, doi:10.1029/2001JB000651 (2002). 


\title{
Chapter 5
}

\section{Assessment and comparison of Anopore ${ }^{\mathrm{TM}}$ and cross flow filtration methods for the determination of dissolved iron size fractionation into soluble/colloidal phases in seawater}

\author{
Submitted to Limnology \& Oceanography: Methods \\ Fitzsimmons, J.N. and Boyle, E.A. in review. Assessment and comparison of Anopore ${ }^{\mathrm{TM}}$ \\ and cross flow filtration methods for the determination of dissolved iron size \\ fractionation into soluble/colloidal phases in seawater. Limnology \& Oceanography: \\ Methods.
}

\begin{abstract}
The two most frequently used methods for determining the size fractionation of dissolved iron $(\mathrm{dFe})$ in seawater, $0.02 \mu \mathrm{m}$ Anopore membrane filtration and cross flow filtration using a $10 \mathrm{kDa}$ regenerated cellulose filter, were evaluated and compared. Anopore filtration was found to produce consistent soluble $\mathrm{Fe}(\mathrm{sFe})$ concentrations in the filtrate after $>1 \mathrm{~L}$ of unfiltered seawater was filtered, indicating that clogging is not an issue for typical open ocean filtration volumes. Cross flow filtration (CFF) only achieved a 70$75 \%$ mass balance regardless of flow rate and seawater pre-conditioning. However, Fe losses were determined to arise only from the colloidal (not soluble) size fraction, and $\mathrm{Fe}$ loss was constrained to Fe clogging in/on the CFF membrane. Both Anopore and cross flow filtration methods were found to be equally robust for the size fractionation of $\mathrm{dFe}$ in seawater samples. Additionally, sFe arising from these two filtration methods were compared for the first time using seawater samples across multiple depths from the North Pacific and Atlantic Oceans. sFe separated by CFF was almost always lower than sFe separated by Anopore filtration, with the $\mathrm{sFe}$ in $\mathrm{CFF} /$ Anopore filtration averaging $74 \pm 21 \%$. This $\mathrm{sFe}$ difference is attributed to a combination of the smaller effective pore size of the CFF system and the natural variability in the size distribution of dFe. Finally, the advantages and disadvantages of each method (pore size, filtration time, sample volume requirements, cost, experience necessary, etc.) are reviewed to offer users a suite of factors with which to choose their ideal filtration method.
\end{abstract}


Assessment and comparison of Anopore and cross flow filtration methods for the determination of dissolved iron size fractionation into soluble/colloidal phases in seawater

\author{
Jessica N. Fitzsimmons ${ }^{1 *}$ and Edward A. Boyle ${ }^{2}$
}

1. MIT/WHOI Joint Program in Chemical Oceanography, MIT E25-615, 45 Carleton St, Cambridge, Massachusetts 02142, USA; jessfitz@mit.edu; +1-617-324-0283

2. Massachusetts Institute of Technology; MIT E25-619; 45 Carleton St, Cambridge, Massachusetts 02142, USA; eaboyle@mit.edu; +1-617-253-3388

* Corresponding author

Keywords: iron, colloids, size fractionation, cross flow filtration, GEOTRACES

Running head: Anopore and CFF evaluation \& comparison

Submitted to Limnology \& Oceanography: Methods on 28 May 2013 


\section{Acknowledgements:}

We thank Susan Curless, Craig Nosse, and Dave Karl for the opportunity to sail on the HOT-231 cruise to Station ALOHA, as well as Simone Moos, Sam Wilson, and the rest of the HOE-DYLAN V team for help with the MITESS Vanes at sea. We also owe extreme gratitude to Gonzalo Carrasco for completing many of the filtrations on the GEOTRACES cruises. We also thank Pete Morton, Randie Bundy, Chris Measures, Mariko Hatta, and Ana Aguilar-Islas for their help collecting trace metal-clean seawater samples on the GEOTRACES cruises and Jingfeng Wu for demonstrating his CFF system. Finally, we thank Phoebe Lam and Carl Lamborg for useful discussions about marine colloidal Fe and especially Mark Wells for early comments and discussions on this manuscript. Excellent marine support was offered by the officers and crew of the R/V Knorr and R/V Kilo Moana. J.N. Fitzsimmons was funded by a National Science Foundation Graduate Research Fellowship (NSF Award \#0645960), and this work was funded by NSF grants OCE-0926204 and OCE-0926197 and the Center for Microbial Oceanography: Research and Education (NSF-OIA Award \#EF-0424599). 


\begin{abstract}
The two most frequently used methods for determining the size fractionation of dissolved iron $(\mathrm{dFe})$ in seawater, $0.02 \mu \mathrm{m}$ Anopore membrane filtration and cross flow filtration using a $10 \mathrm{kDa}$ regenerated cellulose filter, were evaluated and compared. Anopore filtration was found to produce consistent soluble $\mathrm{Fe}(\mathrm{sFe})$ concentrations in the filtrate after $>1 \mathrm{~L}$ of unfiltered seawater was filtered, indicating that clogging is not an issue for typical open ocean filtration volumes. Cross flow filtration (CFF) only achieved a $70-75 \%$ mass balance regardless of flow rate and seawater pre-conditioning. However, Fe losses were determined to arise only from the colloidal (not soluble) size fraction, and Fe loss was constrained to Fe clogging in/on the CFF membrane. Both Anopore and cross flow filtration methods were found to be equally robust for the size fractionation of $\mathrm{dFe}$ in seawater samples. Additionally, $\mathrm{sFe}$ arising from these two filtration methods were compared for the first time using seawater samples across multiple depths from the North Pacific and Atlantic Oceans. sFe separated by CFF was almost always lower than sFe separated by Anopore filtration, with the $\mathrm{sFe}$ in $\mathrm{CFF} /$ Anopore filtration averaging $74 \pm 21 \%$. This sFe difference is attributed to a combination of the smaller effective pore size of the CFF system and the natural variability in the size distribution of dFe. Finally, the advantages and disadvantages of each method (pore size, filtration time, sample volume requirements, cost, experience necessary, etc.) are reviewed to offer users a suite of factors with which to choose their ideal filtration method.
\end{abstract}




\subsection{Introduction}

Iron $(\mathrm{Fe})$ is an essential micronutrient for photosynthesis and nitrogen fixation in the ocean (MOREL et al., 2003), and because of its low seawater concentrations, Fe controls primary production in a large portion of the global ocean (MARTIN and FitzWATER, 1988; MoORE et al., 2009; MoORE et al., 2002). Fe(III) is the thermodynamically favored redox state in the modern oxic ocean, yet inorganic Fe(III) solubility is depressed to potentially biologically limiting concentrations of $<0.1 \mathrm{nM}$ in seawater (KUMA et al., 1996; LIU and MILLERO, 1999). In natural seawater, however, electrochemical methods indicate that $>99.9 \%$ of dissolved $\mathrm{Fe}(\mathrm{dFe})$ is bound to organic Fe-binding ligands that raise the solubility (RUE and BRULAND, 1995; VAN DEN BERG, 1995; WU and LUTHER, 1995). These organic ligands comprise a portion of the dissolved organic carbon (DOC) pool but have a high binding capacity for Fe. As for DOC, we know little about the chemical composition and structure of Fe-binding ligands (reviewed in GLEDHILL and BUCK, 2012b); therefore we rely mostly on electrochemical measurements of ligand concentration and binding strength to interpret how the organically-bound nature of dFe impacts its biogeochemical cycling.

Because Fe is bound to organic ligands, however, we can use clues about the characteristics of DOC to inform us about Fe. For instance, like marine DOC, oceanic $\mathrm{dFe}$ is partitioned between both truly dissolved and colloidal species (WU et al., 2001). In fact, it is thought that the organically-bound nature of $\mathrm{dFe}$ is what causes its observed size partitioning (as opposed to its potential for inorganic hydrolysis) because other hydrolyzable metals such as aluminum and titanium do not exhibit the same colloidal presence in the open ocean (DAMMSHAUSER and CROOT, 2012). The size fractionation of $\mathrm{dFe}$ has been investigated globally (Figure 1), and the colloidal contribution to dFe has been found to range from $0 \%$ in the shallow South Atlantic and Southern Oceans (BERGQUIST et al., 2007; BOYE et al., 2010) to 90\% in the surface ocean of the tropical North Atlantic (FITZSIMMONS and BOYLE, in prep). Like size fractionated DOC pools (GUO and SANTSCHI, 1997), the soluble, or low molecular weight, dFe fraction is thought to be the more biologically labile fraction (CHEN and WANG, 2001), while the colloidal 
(high molecular weight) dFe fraction is believed to be more easily removed to the particulate phase via aggregation and/or adsorption onto particles (HONEYMAN and SANTSCHI, 1989). Thus, the partitioning of dFe into these two size fractions may have a major influence on the biogeochemical fate of dFe across the global ocean.

In these $\mathrm{dFe}$ size fractionation studies, the sizes of the soluble and colloidal $\mathrm{Fe}$ define their "identity" in the ocean, and thus these size classifications drive our interpretation of how the marine compounds behave. Ideally, soluble compounds are those that are truly dissolved and cannot be differentiated from the surrounding solvent molecules. Ideal colloids can also be defined: their lower size limit is the molecular dimension at which the compound is large enough to establish a "surface" that separates it from the rest of the solution, while their upper size limit is the dimension at which the molecule is large enough for gravity to cause it to sink (WELLS, 2002). Thus, despite that colloids fall operationally in the dissolved phase, "classical" colloidal material is comprised of particles so small that they do not sink. Only when other compounds in solution interact with these colloids at their surface (sorption/aggregation) might they become large enough to sink, moving them into the particulate phase. This idealized framework defines what we might consider to be bioavailable (generally, the soluble phase), aggregating (the colloidal phase), and sinking (the particulate phase) fractions in seawater.

Ultimately, however, our measurement of these size fractions are operationally defined by the filtration techniques we use, and operational definitions don't necessarily match classical definitions. Historically, marine colloids have been counted using a combination of ultracentrifugation and transmission electron microscopy (WELLS and GOLDBERG, 1991; 1992; 1993) or atomic force microscopy (SANTSCHI et al., 1998), as well as light scattering methods including photon correlation spectroscopy (CHIN et al., 1998) and nanoparticle tracking analysis (TARTARKIEWICZ et al., 2012). Separations of the two size fractions for elemental quantification has been completed by a myriad of techniques including ultrafiltration methods such as cross flow filtration (BUESSELER et al., 1996; NISHIOKA et al., 2001) and Vivaspin ultracentrifugation (SCHLOSSER et al., in 
press), small-pore size membrane filtration (WU et al., 2001), flow field flow fractionation (BAALOUSHA et al., 2011; STOLPE et al., 2010), and various chromatography techniques (Burgess et al., 1996; CHIN and GSCHWEND, 1991). In the last decade, two methods have emerged as the dominant systems used for size partitioning studies of marine trace metals: cross flow filtration and small-pore sized membrane filtration using Anopore $^{\mathrm{TM}}$ filters. A growing number of studies have used one of these two methods to

quantify open ocean distributions of both soluble and colloidal Fe (Figure 1), yet the two methods have never been compared on the same samples. Because there is no reason to expect that the two systems should make the same operational separation of soluble and colloidal $\mathrm{dFe}$, it is difficult to make comparisons between literature studies using the two methods, and thus our global understanding of $\mathrm{dFe}$ size partitioning is limited to regions where only one operational definition has been used.

This study seeks to evaluate these two most common methods for collecting size fractionated dissolved Fe samples and outline the advantages and disadvantages of each, with the ultimate goal of offering a recommendation for when it might be ideal to use one method over the other. We will also compare these two methods in order to begin to resolve the literature divide between studies using the two methodologies.

\subsection{Methods}

5.2.1 Anopore $^{\mathrm{TM}}$ filtration - Anopore ${ }^{\mathrm{TM}}$ filter membranes (Whatman) are manufactured electrochemically by the anodic oxidation of aluminum and contain 0.02 $\mu \mathrm{m}$ pores composed of a single-layer honeycomb structure (FURNEAUX et al., 1989); operationally defined "soluble $\mathrm{Fe}$ ( $(\mathrm{sFe}<0.02 \mu \mathrm{m})$ passes through the pores, while colloidal $\mathrm{Fe}$ is retained on the filter $(0.02 \mu \mathrm{m}<\mathrm{cFe}<0.4 \mu \mathrm{m})$ and can be calculated as:

$$
\mathrm{cFe}=\mathrm{dFe}-\mathrm{sFe}
$$

where $\mathrm{dFe}$ is the iron passing through a $0.4 \mu \mathrm{m}$ (or sometimes $0.2 \mu \mathrm{m}$ ) filter. Anopore ${ }^{\mathrm{TM}}$ filters are available as individual membranes (called Anodisc ${ }^{\mathrm{TM}}$ membranes) to be used on a filtration rig, as in this study, or as syringe filters (called Anotop ${ }^{\mathrm{TM}}$ filters). In both 
of these cases, a traditional filtration geometry is employed where fluid is pushed parallel to (through) the membrane pores by differential pressure (Figure 2).

The methods we employed to collect soluble Fe samples through Anopore ${ }^{\mathrm{TM}}$ filtration are summarized in FITZSIMMONS and BOYLE (2012). Briefly, an untreated $47 \mathrm{~mm}$ Anodisc ${ }^{\mathrm{TM}} 0.02 \mu \mathrm{m}$ filter was loaded into a pre-cleaned PFA filter rig (Savillex) for cleaning immediately before sample filtration (filters were not cleaned in advance of the cruise because the acid treatment decomposes the alumina filter in the week after cleaning). Each filter was rinsed with $>50 \mathrm{~mL}$ of $\mathrm{pH} 1.5$ trace metal-grade hydrochloric acid $(\mathrm{HCl})$, followed by a rinse of $>50 \mathrm{~mL}$ of trace metal clean water. Finally, $>50 \mathrm{~mL}$ of seawater sample collected using trace metal clean techniques (see Sample Collection methods below) was used to pre-condition the filter, followed by the soluble Fe filtrate collection after a single sub-sample bottle rinse. Filtrates were collected in $30 \mathrm{~mL}$ HDPE bottles pre-cleaned using the bottle cleaning procedures outlined in FITZSIMMONS and BOYLE 2012, and typically two $30 \mathrm{~mL}$ bottles of sFe were filled for each seawater sample. In total, only about $150 \mathrm{~mL}$ of seawater was needed to collect two $30 \mathrm{~mL}$ soluble Fe samples.

\subsubsection{Cross flow filtration (ultrafiltration) - Cross flow filtration (or} ultrafiltration) was completed using a Millipore Pellicon XL (PLCGC) filter made of regenerated cellulose with a nominal molecular weight cutoff of $10 \mathrm{kDa}$ (surface area of $50 \mathrm{~cm}^{2}$ ) and was pumped using a Cole Parmer Masterflex peristaltic pump fed with FEP tubing. Feed solution flow rate was calibrated at $12 \mathrm{~mL} \mathrm{~min}^{-1}$, half of the maximum recommended flow rate of $25 \mathrm{~mL} \mathrm{~min}^{-1}$ through the Pellicon XL filter. The feed solution bottle, permeate bottle, and retentate bottle were held in an ISO 5 (formerly Class 100) flow bench and were fed by Teflon tubing that was rinsed in $\mathrm{pH} 2$ trace metal grade $\mathrm{HCl}$ before contacting any new solutions. Permeate and retentate flow rates were calibrated to be identical at $6 \mathrm{~mL} / \mathrm{min}$ each. New Pellicon filters arrive pre-loaded with glycerine and preservatives that were washed out in the lab before use at sea with several liters of trace metal-clean water, followed by $4 \mathrm{~L}$ of $0.25 \mathrm{~N}$ trace metal grade $\mathrm{HCl}$ to pre-clean the system of trace metals. The low blank of the system after initial cleaning was verified by 
ultrafiltering $\sim 800 \mathrm{~mL}$ of $0.4 \mu \mathrm{m}$-filtered seawater that had been acidified to $\mathrm{pH} 2$ through the system once, and then ultrafiltering the resulting permeate fraction again as a "new" sample (see methods for treatment of new samples below). The two resulting permeate solutions were then analyzed for their Fe concentration to ensure that the solution ultafiltered twice $([\mathrm{Fe}]=0.31 \pm 0.04 \mathrm{nmol} / \mathrm{kg}, \mathrm{n}=3)$ did not acquire additional contaminant Fe after its first ultrafiltration $([\mathrm{Fe}]=0.29 \pm 0.02 \mathrm{nmol} / \mathrm{kg}, \mathrm{n}=4)$; these two solutions did not have statistically different Fe concentrations ( $p=0.61$, Student's T-test, two-tailed), and thus the CFF system was assumed to be clean.

At sea, cross flow filtration (CFF) was completed on 0.2 or $0.4 \mu \mathrm{m}$ pre-filtered seawater samples as quickly as possible after sample collection (see Sample Collection methods below); previous experiments have shown that Fe sorbs to bottle walls on as short a timescale as 3 hours, depending on the surface area-to-volume ratio of the bottle (Fitzsimmons and Boyle, 2012). At the start of any day of CFF, $1 \mathrm{~L}$ of pH 1.5 trace metal grade $\mathrm{HCl}$ was flushed through the system as an initial rinse, and flow rates were calibrated. Before any new seawater was ultrafiltered (including between samples), 500 $\mathrm{mL}$ of $\mathrm{pH} 1.5$ trace metal grade $\mathrm{HCl}$ was used to rinse the system. Then $300-350 \mathrm{~mL}$ of pre-filtered sample seawater was used to condition the system before permeate and retentate solutions were collected in $30 \mathrm{~mL}$ HDPE bottles after a single rinse each. Relative permeate/retentate flow rates were also monitored after sample collection. The system was stored in $\mathrm{pH} 2.5$ trace metal grade $\mathrm{HCl}$ after flushing with the $\mathrm{pH} 1.5 \mathrm{HCl}$ rinse solution. About $500 \mathrm{~mL}$ of seawater is needed to collect two $30 \mathrm{~mL}$ soluble Fe samples through the CFF system.

After cross flow filtration, Fe concentrations can be measured in the permeate, retentate, and total dissolved (feed solution) fractions. In this system, soluble Fe is equal to the concentration of $\mathrm{Fe}$ in the permeate fraction $(\mathrm{sFe}<10 \mathrm{kDa})$. Colloidal $\mathrm{Fe}$ is operationally defined as the fraction between $10 \mathrm{kDa}$ and the 0.2 or $0.4 \mu \mathrm{m}$ filter used to pre-filter the seawater samples. In addition to the colloidal Fe, the retentate fraction also contains a portion of soluble Fe that is carried along in the aqueous carrier solution; this is monitored using the concentration factor (CF; BUESSELER et al., 1996): 


$$
\mathrm{CF}=\frac{\text { initial sample volume }}{\text { final retentate volume }}=\frac{\text { permeate volume }+ \text { retentate volume }}{\text { retentate volume }}
$$

Thus, in our static CFF system where permeate and retentate volumes are calibrated to be identical, the $\mathrm{CF}$ is equal to 2.0. Under ideal permeation conditions where the membrane does not preferentially retain any soluble compounds (permeation coefficient $=1$, SCHLOSSER and CROOT, 2008), the amount of Fe in both permeate and retentate solutions should be the same in a sample with no colloidal Fe. However, in solutions containing colloidal $\mathrm{Fe}$, the amount of $\mathrm{Fe}$ in the retentate solution must be corrected for the presence of soluble Fe and the degree of concentration in order to calculate the true colloidal Fe concentration:

$$
\mathrm{cFe}=\frac{[\mathrm{Fe}]_{\text {retentate }}-[\mathrm{Fe}]_{\text {permeate }}}{\mathrm{CF}}
$$

This method only involves Fe measurement in the permeate and retentate fractions (not the total dissolved feed solution). Alternatively, the total dissolved feed solution Fe concentration can be measured in place of the retentate fraction, and equation 1 can be used to calculate colloidal Fe. Under $100 \%$ mass balance in the CFF system and ideal membrane permeability, the colloidal Fe calculated using equations 1 and 3 should be identical, and both have been used in the literature to define cFe concentrations (see the Intercalibration section of the Assessment below for more information on choosing which colloidal Fe equation to use). The recovery of $\mathrm{Fe}$ in a measured mass balance can be calculated as:

$$
\text { Recovery }=\frac{\mathrm{sFe}+\mathrm{cFe}}{\mathrm{dFe}}(100 \%)
$$

where $\mathrm{sFe}$ is the concentration in the permeate solution, $\mathrm{cFe}$ is calculated using equation 3 , and $\mathrm{dFe}$ is the concentration of Fe in the sample fed into the CFF system.

5.2.3 Sample collection - Samples used in this methods assessment/intercalibration were collected and analyzed from four different cruises: the U.S. GEOTRACES North Atlantic cruise Leg 1 in late October-November 2010 (Station 8 at $20.59^{\circ} \mathrm{N}, 22.0^{\circ} \mathrm{W}$; Station 12 at the TENATSO time-series station at $17.0^{\circ} \mathrm{N}$, $\left.24.0^{\circ} \mathrm{W}\right)$, the HOT-231 cruise at Station ALOHA $\left(22.75^{\circ} \mathrm{N}, 158.0^{\circ} \mathrm{W}\right)$ in the North Pacific subtropical gyre in April 2011, the U.S. GEOTRACES North Atlantic cruise Leg 
2 in November 2011 (Station 24 at the TENATSO time-series station), and the HOEDYLAN cruise led by the Center for Microbial Oceanography: Research and Education program at Station ALOHA in July 2012. On both GEOTRACES cruises, trace metalclean seawater was collected using the U.S. GEOTRACES GO-FLO carousel (CUTTER and BRULAND, 2012) and was pre-filtered using $0.2 \mu \mathrm{m}$ Pall Acropak-200 ${ }^{\mathrm{TM}}$ Supor ${ }^{\circledR}$ capsule filters. Filtration protocols were identical to those described by FITZSIMMONS and BOYLE (2012), except that the Acropak filters were pre-cleaned by soaking overnight in filtered surface seawater that had been acidified to $\mathrm{pH} 2$ using trace metal grade $\mathrm{HCl}$, after which they were flushed with $5 \mathrm{~L}$ of unacidified surface seawater and stored empty in the refrigerator until use. On the Station ALOHA cruises, trace metal-clean seawater was collected using the MITESS Vanes system; MITESS stands for Moored In situ Trace Element Sampler System and is an autonomous sampler whose exterior is made entirely of metal-free ultra-high molecular weight polyethylene and contains an internal electronics board and motor that are used to open and close a sample bottle for clean seawater collection at a designated time at depth (BELL et al., 2002). The deployment of MITESS in the Vanes mode, as well as the subsequent pre-filtration of the seawater using $0.4 \mu \mathrm{m}$ Nuclepore $^{\mathrm{TM}}$ polycarbonate track-etched filters, are described in FITZSIMMONS and BOYLE (2012). It should be noted that in the Anopore Clog and Anopore Blank experiments from the Station ALOHA cruises, seawater was not pre-filtered so that potential clogging and contamination of the membrane was maximized. All samples were acidified at sea to $\mathrm{pH} 2$ with $6 \mathrm{~N}$ trace metal grade $\mathrm{HCl}$.

5.2.4 Fe analyses - At least one month after acidification, samples were analyzed in triplicate for their Fe concentration by isotope dilution inductively-coupled plasma mass spectrometry (ID-ICP-MS) with a hexapole collision cell IsoProbe multiple collector-ICP-MS. The ID-ICP-MS method employs an ${ }^{54} \mathrm{Fe}$-spike and batch preconcentration with nitrilotriacetate resin (LEE et al., 2011). Procedure blanks during the six analytical sessions ranged from $0.025-0.060 \mathrm{nmol} / \mathrm{kg}$, and the detection limit (three times the standard deviation of the procedure blanks for each analytical session) averaged $0.025 \mathrm{nmol} / \mathrm{kg}$. Comprehensive lab analyses of SAFe D2 standard for dFe during the 
period of these analyses averaged $0.99 \pm 0.03 \mathrm{nmol} / \mathrm{kg}$ (Bottle $242, \pm 1 \mathrm{SD}, \mathrm{n}=8$ ) and $0.92 \pm 0.01 \mathrm{nmol} / \mathrm{kg}$ (Bottle 446, $\pm 1 \mathrm{SD}, \mathrm{n}=8$ ), in close agreement with the current consensus value of $0.933 \pm 0.023 \mathrm{nmol} / \mathrm{kg}$ (updated May 2013; http://www.geotraces.org/science/intercalibration).

\subsection{Assessment}

The two most commonly used filtration methods for measuring the size fractionation of $\mathrm{dFe}$ in the open ocean were assessed in this study: traditional membrane filtration using Anopore ${ }^{\mathrm{TM}}$ filters with a pore size of $0.02 \mu \mathrm{m}$ and cross flow filtration using a regenerated cellulose membrane with a $10 \mathrm{kDa}$ molecular weight cutoff. These two filtration mechanisms have inherently different filtration geometries (Figure 2), where cross flow filtration is assumed to be a more "gentle" approach because of its tangential filtration geometry that is less likely to clog the filter membrane and create filtration artifacts in the resulting size distribution. Anopore ${ }^{\mathrm{TM}}$ filtration, in contrast, has a traditional direct-flow geometry that is more likely to suffer filter fouling but requires much lower sample volumes that can be filtered more rapidly. The experiments executed on each of these, as well as the comparison between them, are discussed below.

5.3.1 Anopore $^{\mathrm{TM}}$ filtration - Anopore ${ }^{\mathrm{TM}}$ filters were first used to examine the marine distribution of $\mathrm{dFe}$ size fractions by WU et al. (2001), who modified this microfiltration approach for open ocean $\mathrm{dFe}$ size partitioning after the Fe solubility studies of Kuma and Millero (Kuma et al., 1996; LiU and Millero, 1999). In open ocean studies, Anopore ${ }^{\mathrm{TM}}$ filtration has two significant advantages over other methods. First, it requires very little seawater volume for filtration and allows for fast filtration times when small volumes are filtered. Second, Anopore ${ }^{\mathrm{TM}}$ filters can be used on the same filter rig that is used for the $0.2-0.4 \mu \mathrm{m}$ pre-filtrations or in a small syringe and thus are less cumbersome to set up and manage at sea than CFF systems. These two benefits have allowed for sFe to be measured across several ocean basins in moderately high spatial resolution using Anopore ${ }^{\mathrm{TM}}$ filtration (Figure 1). 
However, because Anopore ${ }^{\mathrm{TM}}$ filtration employs a traditional filtration geometry where particles accumulate at the filter membrane, it potentially suffers from partitioning artifacts caused by membrane clogging. At the membrane surface, particles accumulate and form a "polarization layer" that changes the basic characteristics of the filter in several ways (BUFFLE et al., 1992). First, the effective pore size of the filter membrane can be decreased at high particle loadings, changing the particle size cut-off over time. Second, a "concentration polarization" builds up at the membrane surface when the particle concentration at the filter membrane is greater than that in solution, creating an osmotic barrier that results in a decreased flow rate through the membrane. Furthermore, aggregation and coagulation of colloids is a second-order reaction with respect to particle concentration (STUMM and MORGAN, 1996), and elevated particle concentrations at the membrane surface may induce the aggregation/coagulation of colloids, biasing the quantitative partitioning. Finally, in the presence of enhanced particle loading in the polarization layer, adsorption of soluble Fe to the accumulated colloids can be promoted that could also bias the partitioning.

Considering that these filtration artifacts amplify with decreasing pore size, we tested the effect of increasing sample volume on soluble Fe concentrations in the Anopore $^{\mathrm{TM}}$ filtrates in our Anopore ${ }^{\mathrm{TM}}$ Clog test. In the first experiment in April 2011, we fed $>1$ L of unfiltered seawater from $1000 \mathrm{~m}$ at Station ALOHA through an Anodisc ${ }^{\mathrm{TM}}$ filter over 2.5 hours; unfiltered water was strategically used to maximize potential clogging effects by the particulate load. It should be noted here that the internal pore walls of Anopore ${ }^{\mathrm{TM}}$ filters have been shown to be very smooth and uniform in comparison to polycarbonate track-etched pores using scanning electron microscopy and deuterium nuclear magnetic resonance (CRAWFORD et al., 1992), which might decrease the likelihood that compounds would sorb on or get caught in the filter cavities. The results (Figure 3, squares) show that the initial $30 \mathrm{~mL}$ sample (collected after $115 \mathrm{~mL}$ of seawater had passed through) had sFe of $0.67 \mathrm{nmol} / \mathrm{kg}$, somewhat higher than the $\sim 0.61$ $\mathrm{nmol} / \mathrm{kg} \mathrm{sFe}$ sampled after 712 and $1214 \mathrm{~mL}$ of seawater had been flushed. An initial high-sFe sample could be interpreted in one of two ways: either filter clogging changed 
the measured $\mathrm{dFe}$ size partitioning by decreasing the effective pore size, or the Anodisc ${ }^{\mathrm{TM}}$ filter was not sufficiently cleaned by the time the first sample was collected, resulting in an anomalously high $\mathrm{dFe}$ concentration in the first sample. Statistically, the first sFe sample collected was significantly higher in concentration $(p=0.025$ and 0.019 when the second and third sFe samples, respectively, were compared to the first sFe sample collected: Student's T-test, two-tailed), but practically an external reproducibility of at least $0.05 \mathrm{nmol} / \mathrm{kg}$ is common in marine Fe analyses (contributed by random sample handling/bottle contamination and analytical uncertainties) and thus we repeated this experiment to verify whether our initial enhanced $\mathrm{sFe}$ was a true filter artifact.

The Anopore Clog experiment was repeated at Station ALOHA in July 2012 with unfiltered seawater collected from $800 \mathrm{~m}$. A similar total volume was filtered over 2 hours, but sub-samples were collected over smaller volume steps to increase the resolution. In contrast to the initial experiment, the results (Figure 3, circles) showed no decreasing sFe trend with increasing volume filtered, despite the initial sample being collected earlier in the filtration process $(90 \mathrm{~mL}$ seawater filtered $)$ than in the April 2011 study (115 mL filtered). Thus, $>1$ L of unfiltered deep ocean seawater is insufficient to noticeably reduce flow rate through the filter or cause significant changes in the effective pore size of the Anodisc filter. This makes Anopore ${ }^{\mathrm{TM}}$ filtration a promising tool for quantitative estimates of dFe partitioning in unfiltered deep-water samples, since modern analytical techniques for trace metal concentration measurement require much less than 1 L volume for sample analysis (BILlER and BRULAND, 2012; LEE et al., 2011; MiLnE et al., 2010; OBATA et al., 1993). However, if larger volumes are required (for instance, for metal isotopes or metal-binding ligand measurements) or samples are collected with significantly higher particulate/colloidal loading (estuarine or coastal waters), this experiment should be repeated to prove that filtration artifacts are not biasing the measured partitioning. Pre-filtering the seawater samples with a coarse 0.2 or $0.4 \mu \mathrm{m}$ filter to first separate the dissolved from particulate phases is also recommended before Anopore $^{\mathrm{TM}}$ filtration to reduce particle loadings on the filter that could promote filtration artifacts. However, the decision to pre-filter must be weighed against total filtration time, 
which should be minimized because dFe sorbs significantly to bottle walls in as short a time as three hours (dependent on bottle surface area to volume ratio, FitzsimMONS and BOYLE, 2012), and Fe speciation/partitioning can change in the $<4$ hours before filtration (WeN et al., 1996).

Untreated Anopore ${ }^{\mathrm{TM}}$ membranes are a significant source of Fe to seawater filtrates, so we investigated the degree of acid cleaning required to yield uncontaminated samples in our Anopore Blank experiment. Replicate filters were rinsed with increasing volumes of $\mathrm{pH} 1.5 \mathrm{HCl}$ before processing unfiltered seawater from $800 \mathrm{~m}$ at Station ALOHA. The findings show that any contaminant $\mathrm{Fe}$ is fully removed with as little as a $20 \mathrm{~mL}$ rinse with $\mathrm{pH} 1.5 \mathrm{HCl}$ clean water (Figure 4), with rinse volumes up to $125 \mathrm{~mL}$ having no substantial effect on the filtrate Fe concentrations (800m Station ALOHA water sFe averaged $0.480 \pm 0.022 \mathrm{nmol} / \mathrm{kg}$ ). It must be noted, however, that this acid rinsing only removes potential contamination affecting the filtrate, and particulate $\mathrm{Fe}$ contamination (that no longer leaches Fe into the filtrate) may still be present. In fact, a closer inspection of Anopore filters by synchrotron Fe-XANES analysis (Brandy Toner, personal communication) showed that an acid-rinsed filter maintained the same particulate $\mathrm{Fe}$ inclusions as an unrinsed filter, resulting in a potentially significant $\mathrm{Fe}$ background in any analysis of the colloidal $\mathrm{Fe}$ on the Anopore filter.

From the Anopore Blank experiment, there was also no indication that the relatively strong $\mathrm{pH} 1.5 \mathrm{HCl}$ rinse sufficiently attacked the aluminum oxide filters to the point that they increased the pore size; no increases in sFe concentrations were observed with as much as $130 \mathrm{~mL}$ of acid rinse. However, longer storage under acidic conditions is not recommended as it may still significantly change the effective pore size of the filter. It is also important to note that the results of this blank evaluation highlight the excellent sFe reproducibility over the 10 individual Anodisc ${ }^{\mathrm{TM}}$ filters, with multiple membranes yielding very uniform $\mathrm{sFe}$ concentrations from the same seawater sample.

5.3.2 Cross flow filtration (ultrafiltration) - Cross flow filtration (CFF) has been used for years to separate high- and low-molecular weight DOC phases (reviewed in BUeSSELER et al., 1996; GuO and SANTSCHI, 1997; Wells, 2002). As shown in Figure 2, 
the sample stream of a CFF system flows tangentially to the membrane pores, so flow of soluble compounds through the pores into the permeate solution is driven by a pressure difference across the membrane, and the colloids are continually swept into the retentate solution. The major advantage of this filtration geometry is that concentration polarization effects at the membrane surface are reduced because fluid shear strips colloids away from the membrane surface, reducing the likelihood of clogging relative to filtration systems of normal geometry. Furthermore, extraction efficiencies of CFF systems are typically high, filtration of large volumes is relatively rapid compared to other filtration systems, and the colloidal phase is concentrated in the retentate solution of recirculating CFF systems for easy analysis (GUO and SANTSCHI, 1997), making this the most popular method for separating colloid-sized fractions for direct analysis.

However, an analysis of the integrity of these CFF systems was made during the "Colloid Cookout" in the mid-1990s (BUESSELER et al., 1996), where several groups used their own pre-treatment and sample processing methods to size fractionate identical seawater samples using identically rated CFF membranes ( $1 \mathrm{kDa}$ molecular weight size cutoff, polysulfone, although different manufacturers' membranes were allowed). The results showed two major patterns for DOC measurements. First, DOC blanks measured in Q-water were highly variable, indicating that membrane material, system cleaning, and sample handling protocols were critical. Second, the retention ratings used by various manufacturers is not uniform, and even membranes rated for the same molecular weight cutoff ( $1 \mathrm{kDa}$ in this case) do not have the same "effective pore sizes" (GUSTAFFSON et al., 1996). For example, Amicon membranes retained the most colloidal material while those manufactured by Membrex retained the least. A more rigorous discussion of "effective pore sizes" is found in the next section on Intercalibration.

REITMEYER et al. (1996) reported the results of the aluminum (Al) and $\mathrm{Fe}$ intercalibration from the Colloid Cookout and showed that most systems showed high contamination for $\mathrm{Al}$ and significant (up to $80 \%$ ) scavenging/loss of Fe by sorption to the CFF system. Although there have been very few analyses of the size partitioning of marine $\mathrm{Al}$ since, studies of Fe size partitioning using CFF have continued (as seen in 
Figure 1), many with surprisingly little consideration for establishing Fe mass balance. Notable exceptions to this are the Fe fertilization study by WELLS (2003), where mass balance $>90 \%$ was achieved (Filtron polysulfone membrane, $1 \mathrm{kDa}$ size cutoff), and the Fe solubility study by SCHLOSSER and CROOT (2008), where nearly $100 \%$ of the Fe was recovered after a dilute hydrochloric acid rinse (Vivaflow polyethersulfone membrane, $10 \mathrm{kDa}$ size cutoff).

For the cross flow filtration evaluation in this study, several steps were taken to optimize the mass balance for Fe. First, regenerated cellulose was chosen as an alternative membrane material to the typical polysulfone in hopes that it might be less likely to sorb Fe compounds, and a small membrane surface area was selected despite the slower flow rate in order to reduce the area to which Fe could sorb. The ultrafiltration system was also run in static mode (where retentate is collected immediately after filtration and is not sent back to the sample feed) instead of the more classical recirculation mode (where retentate is recycled through the CFF system multiple times) in order to avoid potential Fe contamination or sorptive losses as well as any potential size partitioning changes during recycling. Finally, the CFF system was conditioned by processing $\sim 350 \mathrm{~mL}$ of sample seawater before sample collection to minimize sorptive losses of Fe to the system during sample collection.

The mass balance results from the Station ALOHA test are shown in Figure 5 and indicate that, despite these efforts, only $75.0 \pm 2.5 \%$ of the Fe was recovered from the CFF system. The $25 \%$ Fe lost might reflect sorption to the walls of the CFF system (tubing or membrane walls), accumulation on the CFF membrane (i.e., concentration polarization), or retention of colloidal fragments within the pores of the CFF membrane. To determine which of these was the major Fe loss, we collected filtrate samples at multiple time points during the processing of a large sample volume. We hypothesized that if Fe sorption to the walls of the CFF system was responsible, then this effect would diminish with prolonged filtration as the active sites became saturated with $\mathrm{Fe}$, at which point the mass balance should improve. The mass balances, however, did not significantly improve with volume filtered (Figure 5a), indicating that the pre-conditioning of the system with $\sim 350$ 
$\mathrm{mL}$ of seawater was likely sufficient to saturate sorption sites with $\mathrm{Fe}$, and the $25 \% \mathrm{Fe}$ loss is instead occurring in or on the CFF membrane.

SCHLOSSER and CROOT (2008) used an acid rinse to liberate their retained Fe and achieve a $100 \%$ mass balance in their polysulfone CFF system. We used an identical $60 \mathrm{~mL} 0.06 \mathrm{M} \mathrm{HCl}$ rinse in clean water under our typical CFF operating methods to liberate membrane-associated Fe, but only $20 \%$ of the lost Fe was recovered, $\sim 75 \%$ of which appeared in the permeate solution. It is possible that we did not similarly achieve mass balance after acid rinsing because of the difference in our membrane materials: perhaps at this acid concentration, more acid must be cycled through the system to rinse out all of the sorbed/trapped Fe. In fact, we have noted that no Fe blank has built up upon continual use of our CFF system over the several years of use, and this result confirms that our $\mathrm{pH} 1.5$ acid washing between samples is sufficient to eliminate elutable Fe. However, with this acid rinse, we still could not constrain whether the missing Fe was lost inside or on top of the CFF membrane. If we assume that all Fe lost inside the membrane was solubilized into the permeate fraction, then the presence of any Fe in the retentate of the acid rinse indicates at least some Fe was lost onto the filter membrane (i.e. concentration polarization) or to the CFF walls.

In order to further differentiate the mechanism of Fe loss, we also varied flow rates through the CFF system (still balancing the relative permeate and retentate flow rates). We hypothesized that the decreased concentration polarization at higher flow rates would lead to less Fe loss to the membrane and increased recoveries. The results (shown in Figure 5b) indicate that at the three tested flow rates the Fe recovery did not change appreciably (average recovery of $71.1 \pm 2.7 \%$ ), producing the same $\sim 2.5 \%$ error in $\mathrm{Fe}$ recovery from variable flow rates that was found using a constant flow rate on the same sample (Figure 5a). This result suggests either that the Fe loss is not due to concentration polarization and instead is due to the trapping of Fe inside the membrane matrix or that the flow rates we used were too low to significantly diminish the concentration polarization. We are unable to distinguish between these possibilities with the data in 
hand. Regardless, the findings show that flow rates between $12-25 \mathrm{~mL} / \mathrm{min}$ are acceptable, but all result in a $25-30 \%$ Fe loss to the CFF membrane.

The most vexing aspect of this Fe loss is that it is not clear which Fe fraction is lost to the membrane. Although it would make sense for the lost Fe to be comprised of colloidal species (i.e., colloidal Fe becomes entwined in the membrane), the Fe loss may also reflect soluble Fe species sorbing strongly to a limited number of membrane surface sites or to the trapped colloidal species themselves. The identity of the lost Fe fraction is discussed further in the Intercalibration section.

5.3.3 Comparison of Anopore filtration with CFF - When interpreting the effect of soluble/colloidal Fe partitioning on the biogeochemistry of marine dFe, it is often assumed that the "classical" definitions of soluble and colloidal Fe phases apply (as discussed in the Introduction), yet the measured partitioning between the two size fractions is actually operationally defined by the filter type used, which can be very different from the "classical" description. As Figure 1 shows, marine studies of dFe size fractionation have used two filtration systems (CFF and Anopore ${ }^{\mathrm{TM}}$ filtration) with several nominal pore size cutoffs, and thus our definition of the "colloidal contribution" to $\mathrm{dFe}$ partitioning is actually quite fluid depending on which study you are reading. Additionally, a comparison of data among studies (e.g., to calculate scavenging rates along a water mass trajectory) is impossible unless the same filter types are used. Only one study has attempted a comparison between the two methodologies. An endnote in the WU et al. (2001) study reported a comparison of cFe separated by Anopore ${ }^{\mathrm{TM}}$ and CFF filtration and found them to be identical within error. It must be noted, however, that the cFe concentrations discussed were only $\sim 0.1 \mathrm{nM}$, too low a concentration to detect significant changes between filtration methods, especially given the reported $0.03 \mathrm{nM}$ external error, and thus this was not a very robust comparison effort.

A key issue for a comparison of colloid separation methods is the assessment of the accuracy, precision, and reproducibility of the nominal pore size cutoffs both within a given filter and among replicate filters. The anodizing voltage of the electrochemical fabrication method for Anopore ${ }^{\mathrm{TM}}$ membranes generates a very reproducible pore size, 
even at small dimensions, and a high pore density, both of which are desirable for synthetic filters. The pore size distribution of Anopore ${ }^{\mathrm{TM}}$ filters was measured by atomic force microscopy to cover a small range of only $0.0119-0.0278 \mu \mathrm{m}$, averaging $0.0188 \pm 0.0035 \mu \mathrm{m}$ over 108 replicates (BOWEN et al., 1996), demonstrating that the nominal $0.02 \mu \mathrm{m}$ pore size defined by Whatman is both accurate and precise. We did not confirm these dimensions in this study, but it is reasonable to expect similar specifications for the membranes used here.

Most CFF filters, in contrast, are depth filters that contain a wider range of effective pore sizes. As a consequence, in some cases retention of compounds smaller than the nominal molecular weight size cutoff occurs, while in other cases compounds larger than the size cutoff pass through to the permeate. The nominal molecular weight cutoff is defined by the manufacturers using standard compounds of a known molecular weight, and they report the percentage of those molecular weight standards that are retained by the filter (for example, a rating requirement might be that $90 \%$ of $10 \mathrm{kDa}$ compounds are retained by a $10 \mathrm{kDa}$ membrane). The variability in manufacturers' ratings, tested under different conditions with different standards, is what largely contributed to the variable permeation behavior of the filters used in the Colloid Cookout (BUESSELER et al., 1996). Moreover, the standard compounds chosen for the membrane ratings are optimized for biomedical or industrial water treatment applications (the most frequent users of CFF membranes) and thus are frequently proteins or polysaccharides; there are no equivalent standards for dilute solutions composed of natural compounds. In any filtration, molecular shape, electrostatics, and other physicochemical characteristics of the compounds in solution allow for intermolecular or membrane interactions that can change the retention characteristics of different molecules, so at best CFF can only be nominally defined, and individual filters (especially those from separate fabrication batches) may act differently than others that are identically rated.

Acknowledging the inherent differences in membranes, we compared the soluble Fe filtered through Anodisc ${ }^{\mathrm{TM}}$ membranes with the $\mathrm{sFe}$ filtered through our $10 \mathrm{kDa} C F F$ membrane (results shown in Figure 6). Assuming a common conversion of $1 \mathrm{kDa} \approx 1 \mathrm{~nm}$ 
and that molecular weight increases nonlinearly much faster than molecular size, the nominal molecular weight cutoff of an Anopore filter would be at least $20 \mathrm{kDa}$ (and perhaps much greater), overall larger than the nominal 10kDa size cutoff of our CFF. Thus, we expected the sFe collected through the Anodisc ${ }^{\mathrm{TM}}$ filter to be greater than that filtered through the $10 \mathrm{kDa}$ CFF membrane, and this was true at every location we intercalibrated. A study by CHEN et al. (2004) reported that the actual molecular weight cutoff of Anopore ${ }^{\mathrm{TM}}$ filters determined using standard molecules was approximately 3 $\mathrm{kDa}$. The results of our comparison, however, do not support this assessment; our results suggest instead that the pore size of Anopore ${ }^{\mathrm{TM}}$ filters are at least greater than the $10 \mathrm{kDa}$ nominal molecular weight cutoff of the CFF filter membrane with which we compared.

The initial comparison from Station ALOHA in the North Pacific Ocean and a North Atlantic station near the Cape Verde Islands indicated that CFF sFe concentrations were $68 \pm 15 \%$ of that measured in the Anodisc ${ }^{\mathrm{TM}}$ filtrate (Figure 6). Much of this difference in $\mathrm{sFe}$ concentrations can be attributed to a difference in the pore sizes of the two filtration systems. However, the $44-84 \%$ spread in sFe ratio between $\mathrm{CFF} /$ Anopore ${ }^{\mathrm{TM}}$ is also a function of the natural variations in the size distribution of $\mathrm{dFe}$ compounds, which allows the difference between the effective pore sizes of the two filter types to be more apparent at some locations than at others. Additionally, the composition of these colloids plays a role as well; for instance, if some of the colloids are comprised of loosely associated gels, they could fall apart during Anopore filtration and be observed as $\mathrm{sFe}$, while these same compounds may stay composed during the gentler CFF filtration and be measured as colloidal. So although a $68 \pm 15 \%$ correction factor may be a reasonable first order approximation for reconciling CFF and Anopore datasets, it is clear that more comparisons in different water masses are needed to refine this correction factor.

Two separate samplings at the TENATSO time-series station a year apart (Nov. 2010 and Dec. 2011) provided an opportunity to assess the reproducibility of these methods and the consistency of their differences (Figure 7). The CFF sFe was measured at six identical depths in both years, and the concentrations were statistically identical at 
all depths except $235 \mathrm{~m}$ ( $p$-values of the Student's t-test are mostly $>0.05$, Figure $7 \mathrm{a}$ ). This finding provided evidence that there were no significant natural changes in $\mathrm{Fe}$ concentration or partitioning at TENATSO during the two years, making it a good comparison site. Additionally, this proved that the (same) CFF membrane provides a stable platform for size fractioning colloidal materials, despite the inherent caveats mentioned above, and thus $\mathrm{CFF}$ produces $\mathrm{dFe}$ partitioning data of high integrity.

The sFe concentrations measured in Anopore filtrates were substantially higher at almost all depths than measured in CFF permeates in 2010 and 2011 (Figure 7b). The three exceptions were $185 \mathrm{~m}, 2750 \mathrm{~m}$, and $3200 \mathrm{~m}$ : $p$-values $=0.87,0.31$, and 0.23 respectively using a Student's T-test, two-tailed). A treatment of the implications of this data comparison on the natural size partitioning of $\mathrm{dFe}$ in the North Atlantic will be made elsewhere (Fitzsimmons et al. in prep). The average $\mathrm{CFF} /$ Anopore $^{\mathrm{TM}} \mathrm{sFe}$ ratio was $75 \pm 22 \%$ for the 23 TENATSO samples, bringing the total average CFF/Anopore ${ }^{\mathrm{TM}} \mathrm{SFe}$ ratio to $74 \pm 21 \%$ for all 28 samples analyzed in this intercalibration, similar to the $68 \pm 15 \%$ findings at Station ALOHA.

There was close agreement between the sFe concentrations from both filter types in the deepest 4 samples between $2750-3500 \mathrm{~m}$, and this indicates that there were negligible contributions of colloidal Fe in the $10 \mathrm{kDa}-0.02 \mu \mathrm{m}$ size fraction at these depths. This agreement in $\mathrm{sFe}$ would be impossible if there was a significant sorptive loss of soluble Fe to the CFF membrane. This finding then indicates that the $20-30 \% \mathrm{Fe}$ loss to the CFF system (described in the Cross Flow Filtration section above) is due to retention of colloidal $\mathrm{Fe}$, and accordingly it is reasonable to interpret permeate Fe from this CFF membrane as equivalent to $\mathrm{sFe}$ for our comparison with Anopore filtrates.

Ideally, CFF systems should attain $100 \%$ recovery of Fe in the permeate and retentate solutions; however, the results of this study and all other studies using CFF to measure $\mathrm{dFe}$ fractionation in seawater (Figure 1) have shown that this is nearly impossible without lengthy and aggressive treatments (such as post-filtration acid leaching that renders the remaining colloidal material useless for further characterization). To escape the consequences of poor mass balance, we proved in our 
CFF system that the Fe recovery was very reproducible for a single sample and that all of the retained Fe was colloidal. This has implications for the ideal equation to use to calculate true $\mathrm{cFe}$ concentrations by $\mathrm{CFF}$. As discussed in the methods section, the $\mathrm{cFe}$ can be calculated using the permeate and retentate concentrations (Equation 3) or using the permeate and total dissolved (feed solution) fractions (Equation 1). Any difference between the cFe calculated by these two methods depends entirely on the CFF recovery. An example of the resulting range in cFe concentrations using the two equations is shown in Table 1 as a function of recovery. We recommend the use of Equation 1 for our CFF system because it attributes all of the lost Fe to the colloidal fraction, which we confirmed for our system. Equation 3, in contrast, neglects any Fe that is lost to the CFF system, which can falsely bias the $\% \mathrm{sFe}$ high when recovery is low. For other CFF systems where it is not clear which fraction of $\mathrm{Fe}$ is being lost or where it is expected that permeation is non-ideal, Equation 3 might be a better estimate, although every effort should be made to constrain the phase of Fe loss or the permeation coefficient.

\subsection{Discussion}

Generally, it was found that both CFF and Anopore ${ }^{\mathrm{TM}}$ filtration methods reproducibly size fractionated dFe concentrations in open ocean seawaters, but the two methods produced different soluble Fe concentrations from the same seawater sample, likely due to differences in their effective pore sizes. However, the size separations defined here are valid only for the conditions outlined in this study, and we do not know whether the integrity of these methods for marine dFe persists for other metals.

Furthermore, the dFe separations by the two systems are quite arbitrary, since they cannot be verified by any independent method, and the use of standard compounds of known molecular weight is not appropriate because they do not match seawater compounds, characteristics, or conditions. Despite these overwhelming limitations, the operational size separations explored here provide a useful insight into the broader issues of trace metal biogeochemistry and are the state-of-the-art methods to this day. In this section, we will review the advantages and disadvantages for each method and offer a framework 
with which the best method for a given scientific question and sampling plan can be chosen.

First and foremost, as discussed in the Introduction, it would be ideal to match the "operational" definition of soluble/colloidal material to the "classical" definition that we use to interpret the oceanographic significance of the observed partitioning. In this case, CFF would be the better filtration method because it has a smaller pore size; very tiny colloids can pass through an Anopore ${ }^{\mathrm{TM}}$ filter and be measured as truly soluble, distorting oceanographic interpretations of the resulting partitioning data.

However, there are basic sampling restrictions that might preclude the use of CFF and favor Anopore filtration. For instance, if only small seawater volumes are available, Anopore $^{\mathrm{TM}}$ filtration is ideal because $\mathrm{CFF}$ requires at least $300 \mathrm{~mL}$ of seawater to condition the filter, increasing the seawater volume requirement to $\sim 500 \mathrm{~mL}$ to generate just $60 \mathrm{~mL}$ of sFe sample. In contrast, Anopore ${ }^{\mathrm{TM}}$ filters only require $\sim 150 \mathrm{~mL}$ of seawater to condition and collect the same sized sFe sample. If these small sFe samples are adequate (for concentration analyses, for example), Anopore ${ }^{\mathrm{TM}}$ filtration is also faster than CFF and thus better suited for high-throughput work, such as that undertaken by the GEOTRACES program. Alternatively, if larger sample volumes (1L or more) are required, $\mathrm{CFF}$ is the only practical method because it takes too long to filter a large volume sample through an Anopore ${ }^{\mathrm{TM}}$ filter, and it is not clear that the effective pore size would remain unchanged after a $>1 \mathrm{~L}$ sample was flushed through a single Anopore ${ }^{\mathrm{TM}}$ membrane. Additionally, unfiltered samples cannot be processed through CFF systems because the larger particles have the potential to clog the pumped system, raising the back-pressure and causing the pressure fittings to fail; thus, if pre-filtering the samples is inconvenient, Anopore ${ }^{\mathrm{TM}}$ filtration would be the better filtration choice.

There are also several advantages and disadvantages to each filtration system for applications of dissolved phase size partitioning studies beyond Fe. For instance, the recovery issues with $\mathrm{CFF}$ might become limiting for size partitioning of particle-reactive elements such as thorium and protactinium (as observed in, for example, DAI and BENITEZ-NELSON, 2001), and thus low-surface area Anopore ${ }^{\mathrm{TM}}$ filtration might be 
preferable in these cases. Furthermore, certain chemical characterization methods might require the colloidal material to be in the aqueous phase, in which a recirculating CFF system would be ideal, whereas others might require the colloidal material to be dried on a membrane, in which case Anopore ${ }^{\mathrm{TM}}$ filtration might be best.

Finally, several miscellaneous factors can influence the two filtration setups such that one technique might be favored over the other. The first of these factors is cost: CFF methods have a high initial cost but are reusable, reducing spending over the long term, while Anopore ${ }^{\mathrm{TM}}$ filters are individually less expensive but accumulate expense quickly when many samples need to be filtered because each filter can only be used once. Second, the physical footprint of these two methods can be quite different, depending on the extent of automation. Anopore ${ }^{\mathrm{TM}}$ filtration can be completed in a syringe filter that has no physical footprint and negligible weight, while cross flow filtration requires a peristaltic pump, clean tubing, and a clean working area. However, filtration through Anopore filters requires a high level of expertise, while CFF is semi-automated and thus is much more straightforward for a person trained in trace metal techniques. CFF can be run unattended for some periods of time while it cleans or conditions itself, which may be beneficial for multi-tasking users, while Anopore ${ }^{\mathrm{TM}}$ filtration largely requires constant attention.

In summary, there is no straightforward recommendation for a single filtration system, as there are many reasons why either filtration system might be preferable (summarized in Table 2). The major conclusion from this study, however, is that either filtration method produces reproducible data and is scientifically robust, and thus the choice between the two filtration methods is truly a matter of the question being asked, technical requirements in the field sampling, and/or convenience.

\subsection{Conclusions and Recommendations}

Our work aimed to evaluate the popular Anopore ${ }^{\mathrm{TM}}$ and cross flow filtration techniques for colloidal fractionation of seawater Fe samples. Anopore ${ }^{\mathrm{TM}}$ filtration has the advantage of small seawater volume requirements and rapid/convenient filtration for 
small volumes, but also has the potential for filtration artifacts as a result of filter fouling. The Anopore ${ }^{\mathrm{TM}}$ experiments showed, however, that even after $>1 \mathrm{~L}$ of unfiltered oligotophic seawater had been processed, the sFe collected in the filtrate was constant, indicating that there was not sufficient filter clogging to change the effective pore size of the filter over the volume studied. Our findings show that pre-cleaning the filter with $\geq 20 \mathrm{~mL}$ of $\mathrm{pH} 1.5 \mathrm{HCl}$ in clean water is sufficient to eliminate measurable filter-derived Fe blanks. We also recommend that when possible all samples be pre-filtered (0.2-0.4 $\mu \mathrm{m})$ to reduce the potential for filter fouling, as long as it does not unduly delay the Anopore filtration process, given that $\mathrm{Fe}$ loss to container walls and size partitioning/speciation changes can occur on short timescales.

Our cross flow filtration system was designed to minimize Fe sorption by having a low CFF filter surface area, running without recirculation, and conditioning with seawater before the size fractionated filtrate was collected. Nonetheless, $20-30 \%$ of the $\mathrm{Fe}$ was consistently lost to the CFF system, despite altering sample volumes and flow rates. A major portion of this $\mathrm{Fe}$ was not released from the membrane even with a small volume of $0.06 \mathrm{~N}$ hydrochloric acid. However, results from laboratory testing, and more importantly the close agreement between $\mathrm{sFe}$ concentrations in the permeate and Anopore filtrates in near-bottom waters, implies that the vast majority of the CFF loss is due to retention of colloidal matter rather than simple sorption of soluble Fe species. We therefore feel it is appropriate to assign the permeate $\mathrm{Fe}$ as equivalent to $\mathrm{sFe}$ with this CFF system. We recommend calculation of $\mathrm{cFe}$ concentration as the difference between the measured $\mathrm{dFe}$ and $\mathrm{sFe}$ concentrations, instead of using the retentate Fe concentration that neglects the lost Fe phase, although we can recommend this only for users of our same hardware and sample handling procedures. In any situation where sFe can be lost or permeation is non-ideal, an analysis of $\mathrm{Fe}$ in the retentate solution is required. In general, we note that low CFF system blanks and proper seawater conditioning of the filter before sample collection are critical to obtaining reproducible sFe samples by $\mathrm{CFF}$, and we recommend quantification of $\mathrm{Fe}$ recovery on any $\mathrm{CFF}$ used in trace metal oceanography. 
A comparison of sFe from 28 depths across the Atlantic and Pacific Oceans showed that sFe collected using CFF was $74 \pm 21 \%$ of that collected using Anopore ${ }^{\mathrm{TM}}$ filtration, a result reflecting the larger effective pore size of Anopore ${ }^{\mathrm{TM}}$ filters as well as the natural variability of the size distribution of dFe across the two oceans. This $\mathrm{CFF} /$ Anopore ${ }^{\mathrm{TM}} \mathrm{sFe}$ ratio can be used to preliminarily combine the bodies of literature on $\mathrm{dFe}$ size partitioning using the two methods that up until now have not been comparable because of the unknown differences in effective pore size between the two filter types.

Finally, we concluded that both filtration methods provide robust and reproducible size fractionation of $\mathrm{sFe}$ from $\mathrm{dFe}$ in seawater, each with distinct advantages and disadvantages. These were reviewed, and when deciding between the filtration systems each user should consider the full suite of factors that differentiate them including pore size, filtration time, sample volume requirements, cost, and user experience required. With this final note, we emphasize that careful trace metal clean techniques were used in the generation of all data in this study, and our results demonstrated that reliably low filter blanks and rapid filtration processing (FITZSIMMONS and BOYLE, 2012) were critical to the reproducibility of the data. 


\section{References for Chapter 5}

Baalousha, M., B. Stolpe, and J. R. Lead. 2011. Flow field-flow fractionation for the analysis and characterization of natural colloids and manufactured nanoparticles in environmental systems: A critical review. Journal of Chromatography A 1218: 4078-4103.

Bell, J., J. Betts, and E. Boyle. 2002. MITESS: a moored in situ trace element serial sampler for deep-sea moorings. Deep-Sea Research Part I-Oceanographic Research Papers 49: 2103-2118.

Bergquist, B. A., J. Wu, and E. A. Boyle. 2007. Variability in oceanic dissolved iron is dominated by the colloidal fraction. Geochimica et Cosmochimica Acta 71: 2960-2974.

Biller, D. V., and K. W. Bruland. 2012. Analysis of Mn, Fe, Co, Ni, Cu, Zn, Cd, and Pb in seawater using the Nobias-chelate PA1 resin and magnetic sector inductively coupled plasma mass spectrometry (ICP-MS). Marine Chemistry 130-131: 12-20.

Bowen, W. R., N. Hilal, R. W. Lovitt, and P. M. Williams. 1996. Atomic force microscope studies of membranes: Surface pore structures of Cyclopore and Anopore membranes. Journal of Membrane Science 110: 233-238.

Boye, M. and others 2010. Significant portion of dissolved organic Fe complexes in fact is $\mathrm{Fe}$ colloids. Marine Chemistry 122: 20-27.

Boye, M., J. Nishioka, P. L. Croot, P. Laan, K. R. Timmermans, and H. J. W. De Baar. 2005. Major deviations of iron complexation during 22 days of a mesoscale iron enrichment in the open Southern Ocean. Marine Chemistry 96: 257-271.

Buesseler, K. O. and others 1996. An intercomparison of cross-flow filtration techniques used for sampling marine colloids: Overview and organic carbon results. Marine Chemistry 55: 131.

Buffle, J., D. Perret, and M. Newman. 1992. The use of filtration and ultrafiltration for size fractionation of aquatic particles, colloids, and macromolecules, p. 171-230. In J. Buffle and H. P. van Leeuwen [eds.], Environmental Particles. IUPAC Series on Environmental Analytical and Physical Chemistry. Lewis Publishers.

Burgess, R. M., R. A. Mckinney, W. A. Brown, and J. G. Quinn. 1996. Isolation of marine sediment colloids and associated polychlorinated biphenyls: An evaluation of ultrafiltration and reverse-phase chromatography. Environmental Science and Technology 30: 1923-1932.

Chen, M., W.-X. Wang, and L. Guo. 2004. Phase partitioning and solubility of iron in natural seawater controlled by dissolved organic matter. Global Biogeochemical Cycles 18: GB4013.

Chen, M., and W. X. Wang. 2001. Bioavailability of natural colloid-bound iron to marine plankton: Influences of colloidal size and aging. Limnology and Oceanography 46: 19561967.

Chever, F. and others 2010. Physical speciation of iron in the Atlantic sector of the Southern Ocean along a transect from the subtropical domain to the Weddell Sea Gyre. J. Geophys. Res. 115: C10059.

Chin, W.-C., M. V. Orellana, and P. Verdugo. 1998. Spontaneous assembly of marine dissolved 
organic matter into polymer gels. Nature 391: 568-572.

Chin, Y.-P., and P. M. Gschwend. 1991. The abundance, distribution, and configuration of porewater organic colloids in recent sediments. Geochimica et Cosmochimica Acta 55: 1309-1317.

Crawford, G. P. and others 1992. Characterization of the cylindrical cavities of Anopore and Nuclepore membranes. The Journal of Chemical Physics 96: 7788-7796.

Cutter, G. A., and K. W. Bruland. 2012. Rapid and noncontaminating sampling system for trace elements in a global ocean surveys. Limnology \& Oceanography: Methods 10: 425-436.

Dai, M., and C. R. Benitez-Nelson. 2001. Colloidal organic carbon and ${ }^{234}$ Th in the Gulf of Maine. Marine Chemistry 74: 181-196.

Dammshauser, A., and P. L. Croot. 2012. Low colloidal associations of aluminium and titanium in surface waters of the tropical Atlantic. Geochimica et Cosmochimica Acta 96: 304318.

Fitzsimmons, J. N., and E. A. Boyle. 2012. An intercalibration between the GEOTRACES GOFLO and the MITESS/Vanes sampling systems for dissolved iron concentration analyses (and a closer look at adsorption effects). Limnology \& Oceanography: Methods 10: 437450.

---. in prep. Dynamic soluble and colloidal iron phases both control dissolved iron variability in the tropical North Atlantic Ocean. Geochimica et Cosmochimica Acta.

Furneaux, R. C., W. R. Rigby, and A. P. Davidson. 1989. The formation of controlled-porosity membranes from anodically oxidized aluminum. Nature 337: 147-149.

Gledhill, M., and K. N. Buck. 2012. The organic complexation of iron in the marine environment: a review. Frontiers in Microbiology 3: 69.

Guo, L., and P. H. Santschi. 1997. Composition and cycling of colloids in marine environments. Rev. Geophys. 35: 17-40.

Gustafsson, Ö., K. O. Buesseler, and P. M. Gschwend. 1996. On the integrity of cross-flow filtration for collecting marine organic colloids. Marine Chemistry 55: 93-111.

Honeyman, B. D., and P. H. Santschi. 1989. A Brownian-pumping model for oceanic trace metal scavenging: Evidence from Th isotopes. Journal of Marine Research 47: 951-992.

Kuma, K., J. Nishioka, and K. Matsunaga. 1996. Controls on iron(III) hydroxide solubility in seawater: The influence of $\mathrm{pH}$ and natural organic chelators. Limnology and Oceanography 41: 396-407.

Lee, J.-M., E. A. Boyle, Y. Echegoyen-Sanz, J. N. Fitzsimmons, R. Zhang, and R. A. Kayser. 2011. Analysis of trace metals $(\mathrm{Cu}, \mathrm{Cd}, \mathrm{Pb}$, and $\mathrm{Fe})$ in seawater using single batch Nitrilotriacetate resin extraction and isotope dilution inductively coupled plasma mass spectrometry. Analytica Chimica Acta 686: 93-101.

Liu, X., and F. J. Millero. 1999. The solubility of iron hydroxide in sodium chloride solutions. Geochimica et Cosmochimica Acta 63: 3487-3497.

Martin, J. H., and S. E. Fitzwater. 1988. Iron deficiency limits phytoplankton growth in the northeast Pacific subarctic. Nature 331: 341-343.

Milne, A., W. Landing, M. Bizimis, and P. Morton. 2010. Determination of Mn, Fe, Co, Ni, Cu, 
$\mathrm{Zn}, \mathrm{Cd}$ and $\mathrm{Pb}$ in seawater using high resolution magnetic sector inductively coupled mass spectrometry (HR-ICP-MS). Analytica Chimica Acta 665: 200-207.

Moore, C. M. and others 2009. Large-scale distribution of Atlantic nitrogen fixation controlled by iron availability. Nature Geosci 2: 867-871.

Moore, J. K., S. C. Doney, D. M. Glover, and I. Y. Fung. 2002. Iron cycling and nutrientlimitation patterns in surface waters of the World Ocean. Deep Sea Research Part II: Topical Studies in Oceanography 49: 463-507.

Morel, F. M. M., A. J. Milligan, and M. A. Saito. 2003. Marine Bioinorganic Chemistry: The Role of Trace Metals in the Oceanic Cycles of Major Nutrients, p. 113-143. In K. K. Turekian and H. D. Holland [eds.], Treatise On Geochemistry. Elsevier Science Ltd.

Nishioka, J., H. Obata, and D. Tsumune. 2013. Evidence of an extensive spread of hydrothermal dissolved iron in the Indian Ocean. Earth and Planetary Science Letters 361: 26-33.

Nishioka, J. and others 2005. Changes in the concentration of iron in different size fractions during an iron enrichment experiment in the open Southern Ocean. Marine Chemistry 95: 51-63.

---. 2003. Size-fractionated iron distributions and iron-limitation processes in the subarctic NW Pacific. Geophysical Research Letters 30.

Nishioka, J., S. Takeda, C. S. Wong, and W. K. Johnson. 2001. Size-fractionated iron concentrations in the northeast Pacific Ocean: distribution of soluble and small colloidal iron. Marine Chemistry 74: 157-179.

Obata, H., H. Karatani, and E. Nakayama. 1993. Automated determination of iron in seawater by chelating resin concentration and chemiluminescence. Analytical Chemistry 65: 15241528.

Reitmeyer, R., R. T. Powell, W. M. Landing, and C. I. Measures. 1996. Colloidal aluminum and iron in seawater: An intercomparison between various cross-flow ultrafiltration systems. Marine Chemistry 55: 75-91.

Rue, E. L., and K. W. Bruland. 1995. Complexation of iron(III) by natural organic ligands in the Central North Pacific as determined by a new competitive ligand equilibration/adsorptive cathodic stripping voltammetric method. Marine Chemistry 50: 117-138.

Santschi, P. H., E. Balnois, K. J. Wilkinson, J. Zhang, and J. Buffle. 1998. Fibrillar polysaccharides in marine macromolecular organic matter as imaged by atomic force microscopy and trasnission electron microscopy. Limnology and Oceanography 43: 896908.

Schlosser, C., and P. L. Croot. 2008. Application of cross-flow filtration for determining the solubility of iron species in open ocean seawater. Limnology and Oceanography-Methods 6: $630-642$.

Schlosser, C., P. Streu, and P. L. Croot. in press. Vivaspin ultrafiltration: A new approach for high resolution measurements of colloidal and soluble iron species. Limnology \& Oceanography: Methods.

Stolpe, B., L. Guo, A. M. Shiller, and M. Hassellöv. 2010. Size and composition of colloidal 
organic matter and trace elements in the Mississippi River, Pearl River and the northern Gulf of Mexico, as characterized by flow field-flow fractionation. Marine Chemistry 118: 119-128.

Stumm, W., and J. J. Morgan. 1996. Aquatic Chemistry: Chemical Equilibria and Rates in Natural Waters, 3rd ed. John Wiley \& Sons.

Tatarkiewicz, J., R. A. Reynolds, and D. Stramski. 2012. Counting and sizing of colloidal particles in the Arctic Ocean. Ocean Sciences Meeting.

Thuróczy, C. E. and others 2010. Speciation of Fe in the Eastern North Atlantic Ocean. Deep Sea Research Part I: Oceanographic Research Papers 57: 1444-1453.

Ussher, S. J., E. P. Achterberg, G. Sarthou, P. Laan, H. J. W. De Baar, and P. J. Worsfold. 2010. Distribution of size fractionated dissolved iron in the Canary Basin. Marine Environmental Research 70: 46-55.

Van Den Berg, C. M. G. 1995. Evidence for organic complexation of iron in seawater. Marine Chemistry 50: 139-157.

Wells, M. L. 2002. Marine Colloids and Trace Metals, p. 367-404. In A. H. Dennis and C. A. Carlson [eds.], Biogeochemistry of Marine Dissolved Organic Matter. Academic Press.

---. 2003. The level of iron enrichment required to initiate diatom blooms in HNLC waters. Marine Chemistry 82: 101-114.

Wells, M. L., and E. D. Goldberg. 1991. Occurrence of small colloids in sea water. Nature 353: 342-344.

---. 1992. Marine submicron particles. Marine Chemistry 40: 5-18.

---. 1993. Colloid aggregation in seawater. Marine Chemistry 41: 353-358.

Wen, L.-S., K.-T. Jiann, and P. H. Santschi. 2006. Physicochemical speciation of bioactive trace metals $(\mathrm{Cd}, \mathrm{Cu}, \mathrm{Fe}, \mathrm{Ni})$ in the oligotrophic South China Sea. Marine Chemistry 101: 104129.

Wen, L.-S., M. C. Stordal, D. Tang, G. A. Gill, and P. H. Santschi. 1996. An ultraclean crossflow ultrafiltration technique for the study of trace metal phase speciation in seawater. Marine Chemistry 55: 129-152.

Wu, J., E. A. Boyle, W. G. Sunda, and L. Wen. 2001. Soluble and colloidal iron in the oligotrophic North Atlantic and North Pacific. Science 293: 847-849.

$\mathrm{Wu}$, J., and G. W. Luther. 1995. Complexation of Fe(III) by natural organic ligands in the Northwest Atlantic Ocean by a competitive ligand equilibration method and a kinetic approach. Marine Chemistry 50: 159-177. 
Figure and Tables for Chapter 5:

\begin{tabular}{|c|c|c|c|c|c|c|c|c|c|c|}
\hline \multirow[b]{2}{*}{ Recovery } & \multirow[b]{2}{*}{$\begin{array}{c}\text { Depth } \\
\text { (m) }\end{array}$} & \multirow[b]{2}{*}{$\mathrm{dFe}$} & \multirow[b]{2}{*}{$\mathbf{s F e}$} & \multirow[b]{2}{*}{$\begin{array}{c}\text { Retentate } \\
\text { Fe } \\
\end{array}$} & \multicolumn{3}{|c|}{ Calculated using Eq (1) } & \multicolumn{3}{|c|}{ Calculated using Eq (3) } \\
\hline & & & & & cFe & $\%$ sFe & $\% \mathrm{cFe}$ & cFe & $\% \mathrm{sFe}$ & $\% \mathrm{cFe}$ \\
\hline $53 \%$ & 1099 & 1.022 & 0.356 & 0.704 & 0.666 & $34.8 \%$ & $65.2 \%$ & 0.182 & $66.2 \%$ & $33.8 \%$ \\
\hline $61 \%$ & 2998 & 0.466 & 0.231 & 0.329 & 0.234 & $49.7 \%$ & $50.3 \%$ & 0.051 & $81.9 \%$ & $18.1 \%$ \\
\hline $70 \%$ & 1999 & 0.728 & 0.331 & 0.656 & 0.396 & $45.6 \%$ & $54.4 \%$ & 0.170 & $66.2 \%$ & $33.8 \%$ \\
\hline $72 \%$ & 71 & 0.218 & 0.112 & 0.203 & 0.109 & $51.4 \%$ & $48.6 \%$ & 0.045 & $71.1 \%$ & $28.9 \%$ \\
\hline
\end{tabular}

Table 1: Comparison of cFe concentrations and dFe partitioning percentages calculated using two different calculations (Equation 1 and Equation 3). Recovery is calculated using Equation 4. All $\mathrm{Fe}$ concentrations are in nmol $/ \mathrm{kg}$. Data are taken from the 2012 U.S. GEOTRACES cruise at TENATSO (Station 24) using CFF. When recovery is low, the difference in $\%$ cFe between the two methods is significant.

Anopore ${ }^{\mathrm{TM}}$ filtration is recommended when:

- Only a small seawater volume is available

- Only unfiltered seawater is available

- Easy filtration setup is desired

- Rapid filtering times (for small volumes) is desired

- Colloidal material is desired in solid phase

- Highly sorptive elements are of interest
CFF is recommended when:

- $\quad$ "Ideal" soluble/colloidal definitions are desired (CFF has smallest pore size)

- Large sFe samples are required

- Colloidal material is desired in the aqueous phase/preconcentrated

- An automated filtration system is desired, or little attention can be paid to filtration

Table 2: Summarized recommendations for when to use Anopore ${ }^{\mathrm{TM}}$ or CFF to generate size fractionated samples of dissolved elements. 


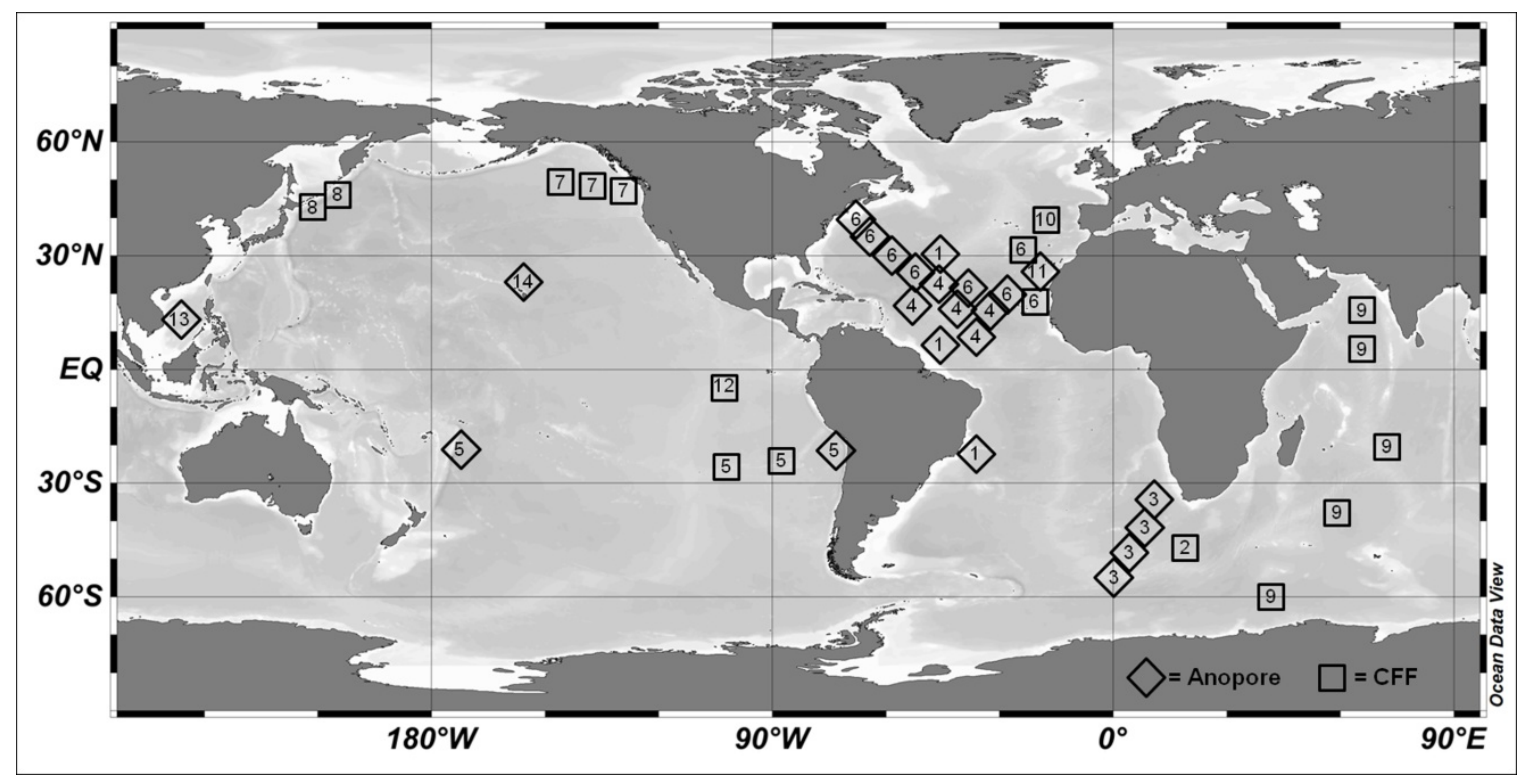

Figure 1: A map reviewing the locations of all of the studies of dFe size partitioning in the open ocean. Studies using Anopore ${ }^{\mathrm{TM}}$ filtration are shown as diamonds, while studies using cross flow filtration (CFF) are shown as squares. The numbers indicate the publications where discussions of these studies can be found: ${ }^{1}$ Bergquist et al. (2007) using Anotop ${ }^{\mathrm{TM}}$ filters; ${ }^{2}$ Boye et al. (2005), Boye et al. (2010), and Nishioka et al. (2005) using a $200 \mathrm{kDa}$ CFF membrane; ${ }^{3}$ Chever et al. (2010) using Anotop ${ }^{\mathrm{TM}}$ filters, ${ }^{4}$ Fitzsimmons and Boyle (in prep) using Anodisc ${ }^{\mathrm{TM}}$ filters; ${ }^{5}$ Fitzsimmons et al. (in prep) using $10 \mathrm{kDa}$ CFF membranes; ${ }^{6}$ Fitzsimmons et al. (in prep) using Anodisc ${ }^{\mathrm{TM}}$ and $10 \mathrm{kDa}$ CFF membranes (18 total stations); ${ }^{7}$ Nishioka et al. (2001) using a 200 kDa CFF membrane; ${ }^{8}$ Nishioka et al. (2003) using a $200 \mathrm{kDa}$ CFF membrane; ${ }^{9}$ Nishioka et al. (2013) using a $1000 \mathrm{kDa}$ CFF membrane; ${ }^{10}$ Thuróczy et al. (2010) using a $1000 \mathrm{kDa}$ CFF membrane; ${ }^{11}$ Ussher et al. (2010) using Anotop ${ }^{\text {TM }}$ filters (10 total stations); ${ }^{12}$ Wells (2003) using a $1 \mathrm{kDa}$ CFF membrane; ${ }^{13} \mathrm{Wen}$ et al. (2006) using a $1 \mathrm{kDa}$ CFF membrane; ${ }^{14} \mathrm{Wu}$ et al. (2001) using Anotop ${ }^{\mathrm{TM}}$ filters. 


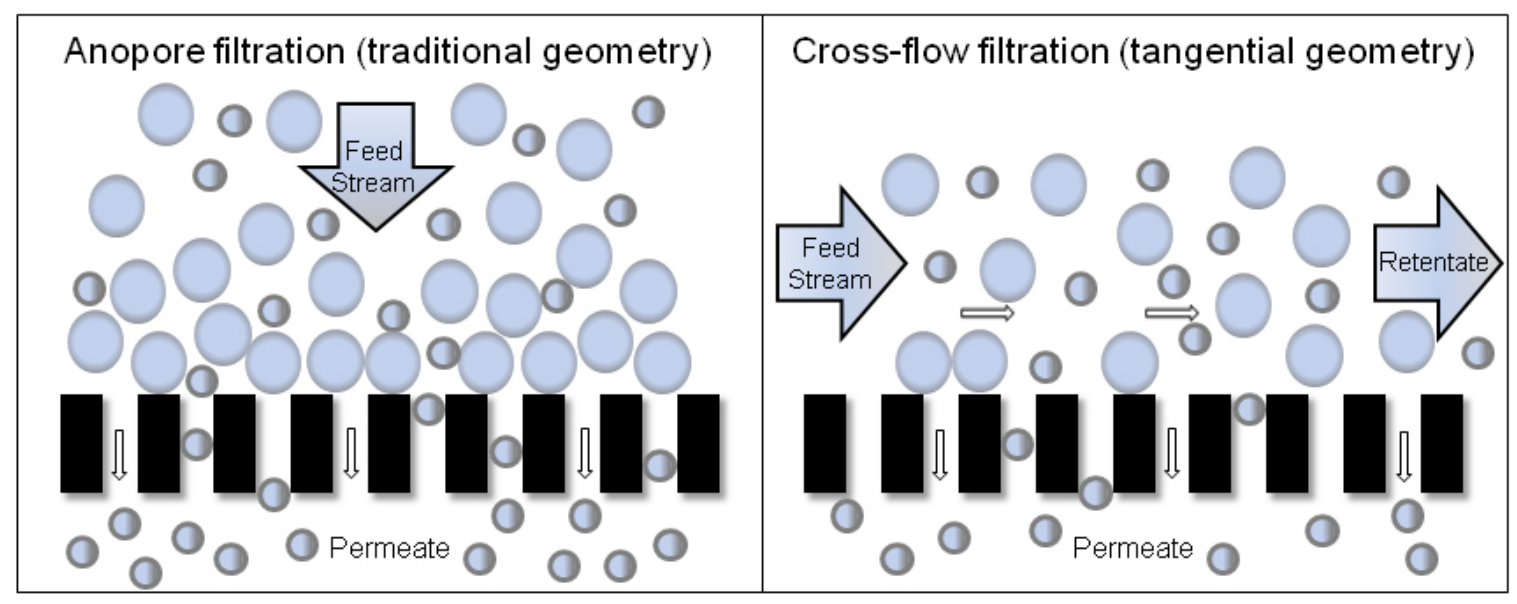

Figure 2: Anopore ${ }^{\mathrm{TM}}$ and cross flow filtration (CFF) geometries. The filter membrane is shown in black, assuming an equal pore size in the two filtration types (note that CFF actually has a smaller pore size than Anopore ${ }^{\mathrm{TM}}$ membranes in this comparison). Anopore ${ }^{\mathrm{TM}}$ filtration uses a traditional filtration geometry where the solution flows parallel (through) the membrane pores; particulate material accumulates at the membrane surface. CFF uses a tangential geometry where the solution enters perpendicular to the membrane pores; soluble material flows through the pores into the permeate, while both soluble and colloidal material exit perpendicular to the pores in the retentate solution. 


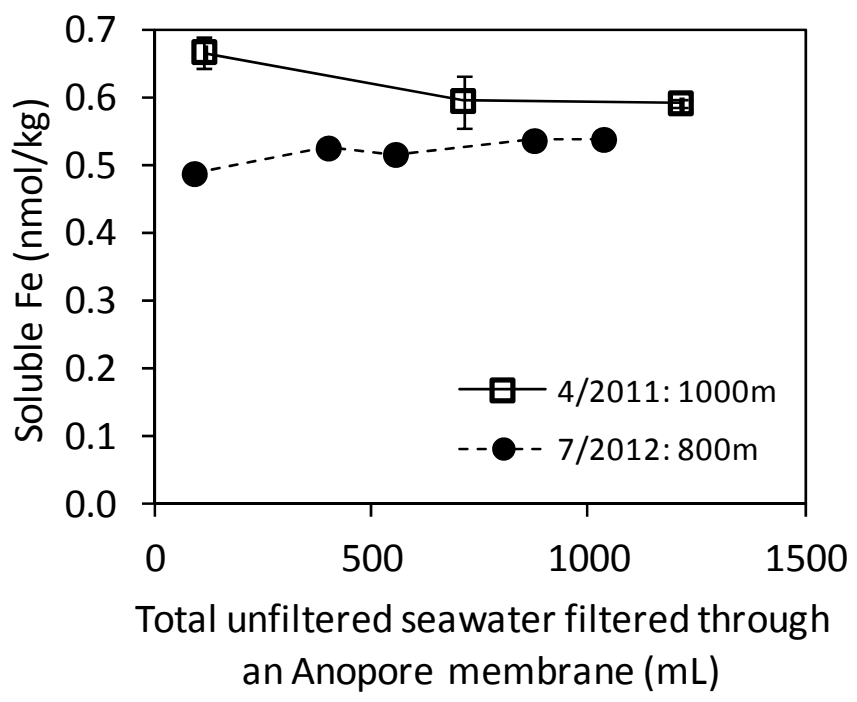

Figure 3: Results from the Anopore ${ }^{\mathrm{TM}}$ clog experiment, where soluble Fe that had passed through a single Anopore ${ }^{\mathrm{TM}}$ filter was measured as a function of the total volume of unfiltered seawater passed through the filter. Seawater is from Station ALOHA at 1000m (April 2011) and 800m (July 2012). Error bars represent one standard deviation of replicate analyses of the same sample.

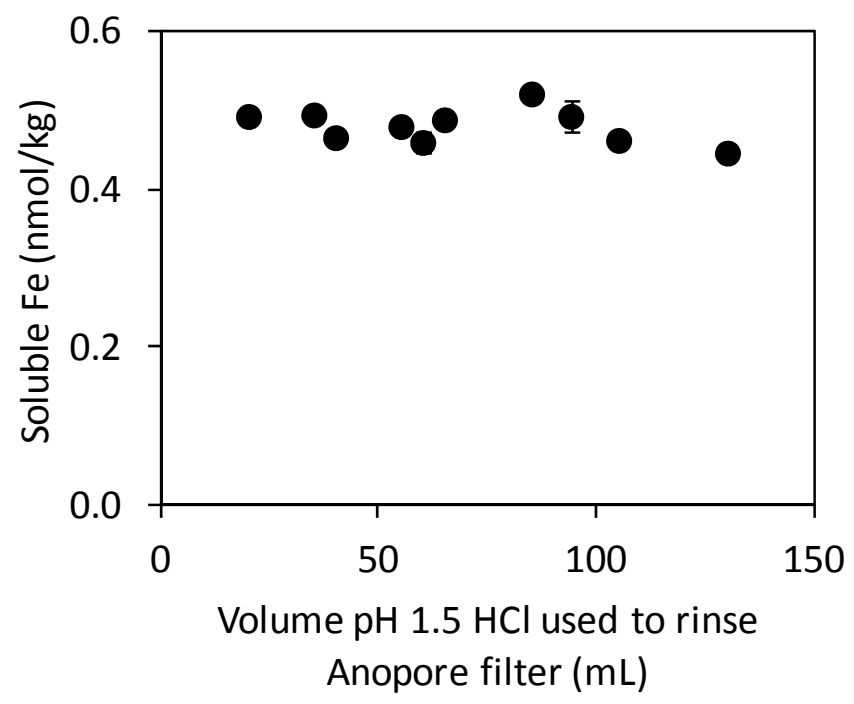

Figure 4: Results from the Anopore ${ }^{\mathrm{TM}}$ blank experiment, where soluble Fe was measured after being passed through a different Anopore ${ }^{\mathrm{TM}}$ filter, after the filter with variable acid $(\mathrm{pH} 1.5 \mathrm{HCl})$ rinse volumes. Seawater is from Station ALOHA at $800 \mathrm{~m}$ (July 2012). Error bars represent one standard deviation of replicate analyses of the same sample. 


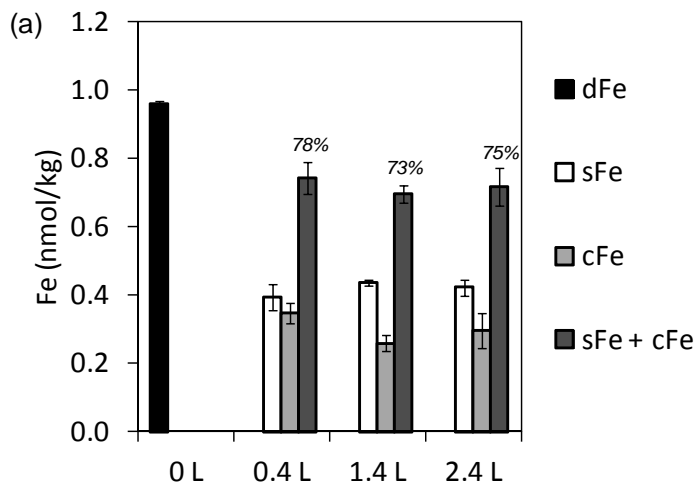

Total seawater volume flushed through CFF

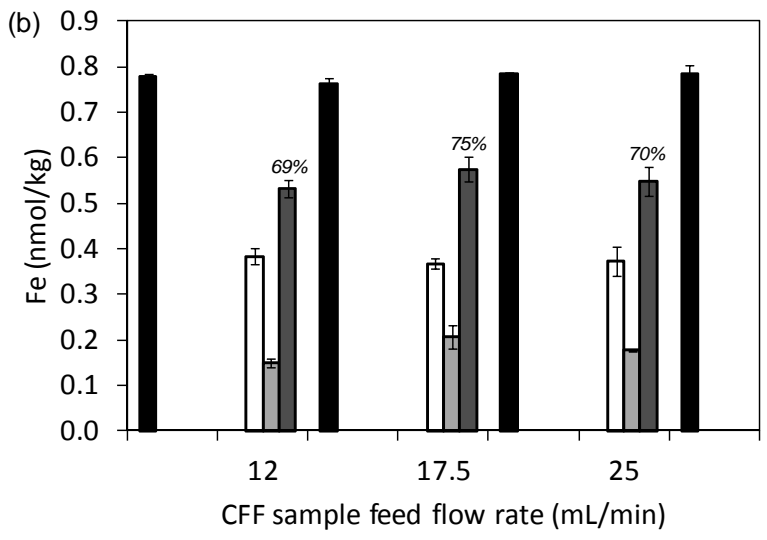

Figure 5: Cross flow filtration mass balance assessments made at Station ALOHA (a) at 1000m in $4 / 2011$ and (b) at $800 \mathrm{~m}$ in 7/2012. (a) Mass balance examined as a function of seawater volume flushed through the filter. (b) Mass balance examined as a function of CFF flow rate. Error bars represent $1 \sigma$ standard deviations on replicate analyses of the same sample. Colloidal Fe concentrations are calculated using Equation 3, and the italicized percentages shown indicate the Fe recovery calculated with Equation 4.

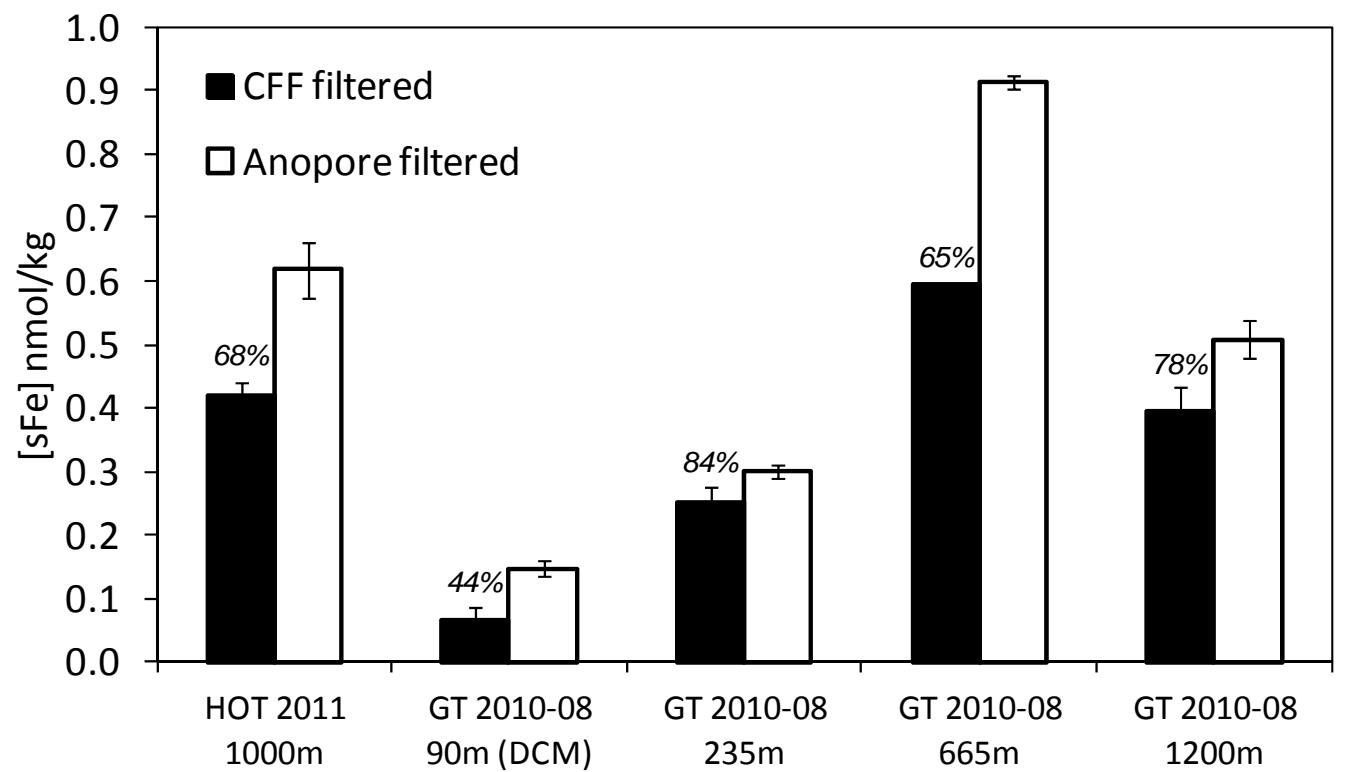

Figure 6: Comparison of the soluble Fe collected using cross flow filtration (CFF; black bars) and Anopore $^{\mathrm{TM}}$ filtration (white bars). Seawater samples were collected at Station ALOHA on the HOT-231 cruise (April 2011) and on the GEOTRACES (GT) cruise in 2010 at Station 8 at several depths. Error bars represent $1 \sigma$ standard deviations on replicate analyses of the same sample. The italicized percentages shown indicate the percent of sFe collected using Anopore ${ }^{\mathrm{TM}}$ filtration that is collected using CFF. 


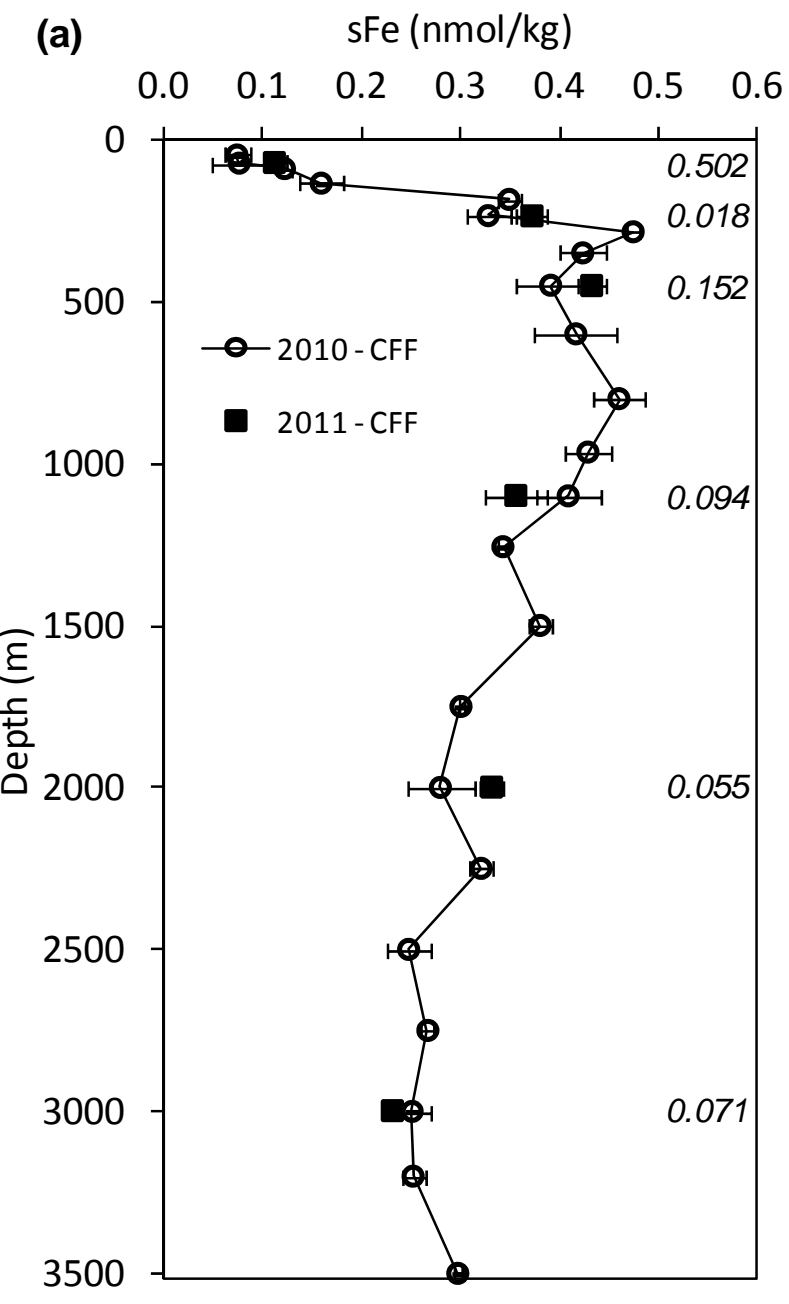
(b) $\quad \mathrm{sFe}(\mathrm{nmol} / \mathrm{kg})$
$\begin{array}{lllll}0.0 & 0.2 & 0.4 & 0.6 & 0.8\end{array}$

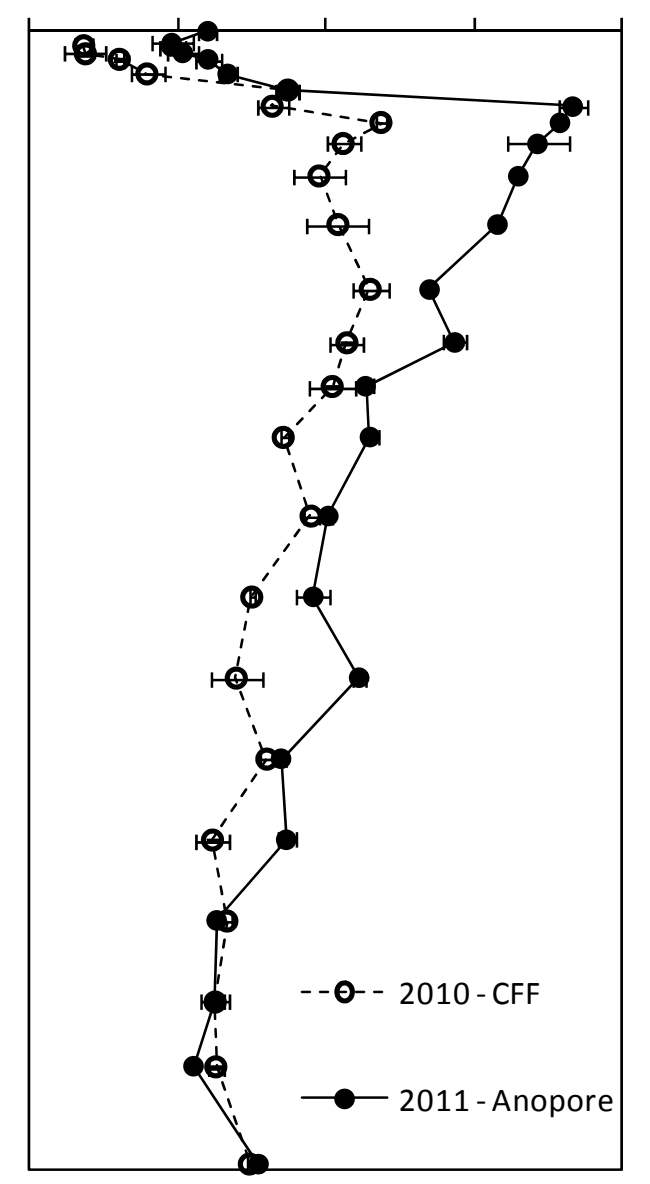

Figure 7: (a) Reproducibility of sFe concentrations generated using the same CFF systems at occupations of the TENATSO station near the Cape Verde Islands separated by 13 months. The italicized numbers show the p-value of a Student's T-test, two-tailed, completed on replicate analyses of samples from the two years, demonstrating that in all cases but at $235 \mathrm{~m}$ depth, the two values were identical within error at $95 \%$ confidence. (b) Comparison between sFe collected from CFF and Anopore ${ }^{\mathrm{TM}}$ filtrations at TENATSO during two years. Error bars represent $1 \sigma$ standard deviations on replicate analyses of the same sample. 


\title{
Chapter 6
}

\section{Both soluble and colloidal iron phases control dissolved iron variability in the tropical North Atlantic Ocean}

\author{
Submitted to Geochimica et Cosmochimica Acta \\ Fitzsimmons, J.N. and Boyle, E.A. in review. Both soluble and colloidal iron phases \\ control dissolved iron variability in the tropical North Atlantic Ocean. Geochimica et \\ Cosmochimica Acta.
}

\begin{abstract}
The size fractionation of dissolved iron $(\mathrm{dFe},<0.4 \mu \mathrm{m})$ between soluble $(\mathrm{sFe},<0.02 \mu \mathrm{m})$ and colloidal $(0.02 \mu \mathrm{m}<\mathrm{cFe}<0.4 \mu \mathrm{m})$ phases was investigated at seven stations in the tropical North Atlantic Ocean, and the results are compared to the dFe size partitioning study of Bergquist et al. (2007) in the same region. Downwind of the North African dust plumes, cFe comprised $80 \pm 7 \%$ of the surface $\mathrm{dFe}$ pool at six stations, supporting the hypothesis that atmospherically-derived $\mathrm{Fe}$ is maintained in the colloidal size fraction. In the deep chlorophyll maximum, colloidal Fe had minimum concentrations or was completely absent, suggesting that $\mathrm{cFe}$ was either preferentially taken up by microbes and/or scavenged/aggregrated at these depths. sFe was the dominant phase at remineralization depths both in the subtropical gyre-like stations $(76 \% \mathrm{sFe} ;[\mathrm{sFe}]=0.42 \pm 0.03 \mathrm{nmol} / \mathrm{kg})$ and in the oxygen minimum zone $(56 \% \mathrm{sFe} ;[\mathrm{sFe}]=0.65 \pm 0.03 \mathrm{nmol} / \mathrm{kg})$; only at remineralization depths of stations with intermediate oxygen concentrations $(100-110 \mu \mathrm{mol} / \mathrm{kg})$ did colloidal Fe dominate (contributing 58\% of dFe). North Atlantic Deep Water (NADW) had a sFe concentration of $0.34 \pm 0.05 \mathrm{nmol} / \mathrm{kg}$, and in the deepest samples composed of a NADW/Antarctic Bottom Water mixture where the bottom water may have attained a $\sim 0.1$ $\mathrm{nmol} / \mathrm{kg}$ hydrothermal Fe input during transit past the Mid-Atlantic Ridge, sFe did not increase coincidentally with $\mathrm{dFe}$, indicating that any potential hydrothermal contribution was comprised of colloidal Fe only. In general, the results of this study counter the previous hypothesis of BERGQUIST et al. (2007) that the colloidal Fe fraction predominately controls $\mathrm{dFe}$ variability and instead suggest that both soluble and colloidal Fe are variable and contribute to the observed $\mathrm{dFe}$ distribution throughout this region. To reconcile the results of both studies, we suggest one of two partitioning mechanisms persists: (1) the nearly constant sFe concentration with depth found in previous studies represents a "steady state" dFe partitioning pattern due to Fe exchange between the soluble and colloidal size fractions, over which regional Fe sources and unique Fe partitioning mechanisms are overlain, or (2), the partitioning of Fe-binding ligands between the two size fractions is variable in the open ocean and directly controls $\mathrm{dFe}$ partitioning.
\end{abstract}


Both soluble and colloidal iron phases control dissolved iron variability in the tropical North Atlantic Ocean

\author{
Jessica N. Fitzsimmons ${ }^{\mathrm{a} *}$ and Edward A. Boyle ${ }^{\mathrm{b}}$
}

a. MIT/WHOI Joint Program in Chemical Oceanography, MIT E25-615, 45 Carleton St, Cambridge, MA 02142, USA; jessfitz@mit.edu; +1-617-324-0283

b. Massachusetts Institute of Technology; MIT E25-619; 45 Carleton St, Cambridge, MA 02142,

USA; eaboyle@mit.edu; +1-617-253-3388

* Corresponding author 


\section{Abstract:}

The size fractionation of dissolved iron $(\mathrm{dFe},<0.4 \mu \mathrm{m})$ between soluble $(\mathrm{sFe}$, $<0.02 \mu \mathrm{m})$ and colloidal $(0.02 \mu \mathrm{m}<\mathrm{cFe}<0.4 \mu \mathrm{m})$ phases was investigated at seven stations in the tropical North Atlantic Ocean, and the results are compared to the dFe size partitioning study of Bergquist et al. (2007) in the same region. Downwind of the North African dust plumes, cFe comprised $80 \pm 7 \%$ of the surface $\mathrm{dFe}$ pool at six stations, supporting the hypothesis that atmospherically-derived Fe is maintained in the colloidal size fraction. In the deep chlorophyll maximum, colloidal Fe had minimum concentrations or was completely absent, suggesting that cFe was either preferentially taken up by microbes and/or scavenged/aggregrated at these depths. sFe was the dominant phase at remineralization depths both in the subtropical gyre-like stations $(76 \%$ $\mathrm{sFe} ;[\mathrm{sFe}]=0.42 \pm 0.03 \mathrm{nmol} / \mathrm{kg})$ and in the oxygen minimum zone $(56 \% \mathrm{sFe} ;[\mathrm{sFe}]=$ $0.65 \pm 0.03 \mathrm{nmol} / \mathrm{kg}$ ); only at remineralization depths of stations with intermediate oxygen concentrations $(100-110 \mu \mathrm{mol} / \mathrm{kg}$ ) did colloidal Fe dominate (contributing 58\% of $\mathrm{dFe}$ ). North Atlantic Deep Water (NADW) had a sFe concentration of $0.34 \pm 0.05 \mathrm{nmol} / \mathrm{kg}$, and in the deepest samples composed of a NADW/Antarctic Bottom Water mixture where the bottom water may have attained a $\sim 0.1 \mathrm{nmol} / \mathrm{kg}$ hydrothermal Fe input during transit past the Mid-Atlantic Ridge, sFe did not increase coincidentally with dFe, indicating that any potential hydrothermal contribution was comprised of colloidal Fe only. In general, the results of this study counter the previous hypothesis of BERGQUIST et al. (2007) that the colloidal Fe fraction predominately controls $\mathrm{dFe}$ variability and instead suggest that both soluble and colloidal Fe are variable and contribute to the observed dFe distribution throughout this region. To reconcile the results of both studies, we suggest one of two partitioning mechanisms persists: (1) the nearly constant sFe concentration with depth found in previous studies represents a "steady state" dFe partitioning pattern due to Fe exchange between the soluble and colloidal size fractions, over which regional Fe sources and unique Fe partitioning mechanisms are overlain, or (2), the partitioning of Fe-binding ligands between the two size fractions is variable in the open ocean and directly controls dFe partitioning. 


\section{Acknowledgements:}

We thank Ruifeng Zhang for his help with the dissolved iron measurements as well as Richard Kayser for his efforts maintaining and deploying the MITESS units. We would also like to thank Phoebe Lam, Mark Wells, and Carl Lamborg for useful discussions about marine colloidal Fe. Excellent marine support was offered by the officers and crew of the $R / V$ Oceanus. Finally, we thank Reiner Schlitzer and his group for sharing the Ocean Data View graphics program. J.N. Fitzsimmons was funded by a National Science Foundation Graduate Research Fellowship (NSF Award \#0645960), and this work was funded by NSF OCE-07020278 and the Center for Microbial Oceanography: Research and Education (NSF-OIA Award \#EF-0424599). 


\subsection{Introduction}

For decades our understanding of the limitation of marine primary productivity by the micronutrient iron (Fe, MARTIN and FitZWATER, 1988; MOREL et al., 2003) has been hampered by our scant knowledge of the global distribution of Fe. With the advent of the international GEOTRACES program, however, global transects of dissolved $\mathrm{Fe}(\mathrm{dFe})$ are being collected, and this information will improve our understanding of the sources and sinks of this trace element that has the potential regulate ocean productivity and climate. This maturation of our knowledge will shift our research focus from establishing the distribution of these metals throughout the oceans to determining the processes that lead to those distributions. The transfer of metals from the dissolved pool into the sinking particulate pool ("scavenging") is in particular need of illumination. Several metal loss mechanisms are encompassed by the term "scavenging," including adsorption/surface complexation, precipitation, and aggregation into successively larger particles, as well as microbiological uptake.

Colloids, the focus of this study, are an understudied physico-chemical group of materials defined as particles so small that they are operationally included in the dissolved size fraction, but they retain their status as particles since they are physically distinct from the fluid. Because of their diminutive size, colloids remain suspended until they aggregate to a size experiencing significant gravitational settling. Colloids thus serve the important role of transporting material between the dissolved and particulate phases, thereby coupling two of the aforementioned "scavenging" processes: a rapid initial adsorption of metal onto colloidal/particulate material in solution, followed by a slow aggregation of the colloids into particulate material of filterable size (the Brownianpumping model, HONEYMAN and SANTSCHI, 1989). Additionally, while suspended, colloidal material can mediate chemical processes that further alter the bulk seawater solution including sorption of solutes, ligand exchange, surface redox reactions, and photochemical reactions.

For Fe, a hybrid-type element demonstrating both nutrient-type profile shapes as well as scavenged-type surface maxima and concentration loss along global thermohaline 
circulation (BRULAND and LOHAN, 2003), scavenging plays an important role in its marine biogeochemical cycle. Under oxic conditions, Fe(III) has a very low inorganic solubility in seawater (MILLERO, 1998), and most of the dissolved Fe found in the ocean is complexed by natural organic ligands that sustain $\mathrm{dFe}$ concentrations above the $<0.1$ nM solubility observed in UV-irradiated seawater (KUMA et al., 1996; LIU and MiLLERO, 2002); excess Fe above ligand concentrations is quickly transformed into the particulate phase. Early studies of marine colloidal Fe distributions indicated that a large fraction, often $30-70 \%$ and as high as $80 \%$, of the dissolved $\mathrm{Fe}$ in the ocean exists in the colloidal size fraction (WU et al., 2001), which was operationally defined as the dFe between $0.02 \mu \mathrm{m}$ and $0.4 \mu \mathrm{m}$ (cFe, "colloidal Fe", and "Fe colloids" will be used interchangeably in this paper; soluble $\mathrm{Fe}, \mathrm{sFe}$, is the $\mathrm{Fe}$ passing through a $0.02 \mu \mathrm{m}$ filter; $\mathrm{sFe}+\mathrm{cFe}=\mathrm{dFe}$ ). Thus, a significant portion of the dissolved $\mathrm{Fe}$ that many imagine to be bound to siderophore-like organic ligands in seawater is actually composed of tiny particles that may have a different chemical composition and behavior than truly dissolved (soluble) Fe.

Using transmission electron microscopy imaging and energy dispersive spectroscopy composition analyses, it was concluded that colloidal Fe is organically bound in the open ocean (Wells and GoldBerg, 1991; Wells and GoldBerG, 1992). This is consistent with electrochemical measurements of Fe ligand concentration and binding strength indicating that $>99 \%$ of marine $\mathrm{dFe}$, which contains the colloidal fraction, is bound by organic Fe-binding ligands (GLEDHILL and BUCK, 2012; RUE and BRULAND, 1995). However, due to their differences in size and chemical composition, soluble and colloidal Fe have unique behaviors that affect the Fe biogeochemical cycle in two ways. First, because soluble and colloidal Fe undergo different chemical transformations (sFe experiencing sorption, while cFe experiences aggregation), the two phases may have an inherently different residence times. This size partitioning could impact, for instance, whether new $\mathrm{dFe}$ sources escape abiotic scavenging long enough to be taken up by microbes, and thus modelers must understand this size distribution of $\mathrm{dFe}$ in order to best predict downstream $\mathrm{dFe}$ concentrations. 
Second, and even more important to studies of micronutrient limitation, soluble and colloidal Fe may not be equally bioavailable. Laboratory experiments have conclusively shown that inorganic Fe colloids (here named nanoparticles) as small as 6$50 \mathrm{Fe}$ atoms per colloid are not directly bioavailable to diatoms (RICH and MoReL, 1990). Since most marine colloidal $\mathrm{Fe}$ is thought to be organically bound, however, incubations using natural, organic-dominated colloidal Fe assemblages were executed to reflect more realistic marine compounds, and the results indicated that natural colloidal Fe is only indirectly bioavailable, requiring first a dissociation from the colloid into the soluble phase before being taken into the cell; the smaller soluble Fe fraction, in contrast, was always taken up much faster and thus thought to be preferred (CHEN and WANG, 2001). An assessment of the bioavailability of natural colloidal $\mathrm{Fe}$ is essential in order to ensure that nutrient limitation models are not underestimating the geographic extent of $\mathrm{Fe}$ limitation simply because they parameterize the bioavailable Fe pool as dFe instead of sFe.

BERGQUIST et al. (2007) indicated that much of the dFe variability in the tropical and subtropical Atlantic Ocean is due to a dynamic colloidal fraction, while the soluble Fe concentration remained relatively constant with depth. This highlighted the importance of studying dFe size partitioning, as it suggested that the cycling of the two size fractions is distinct. Here, we have measured dFe size partitioning at several more stations across the tropical North Atlantic, reaching further along the southwestern boundary of the subtropical gyre and east into the heart of the oxygen minimum zone (OMZ). We find that both the soluble and colloidal fractions determine the dissolved $\mathrm{Fe}$ variability in this broader region, instead of just the colloidal fraction as in BERGQUIST et al.'s study. In this paper we will establish the similarities and differences between the BERGQUIST et al. study and the present one, and we will attempt to establish the major facets of dFe size partitioning and its contribution to Fe biogeochemistry in the tropical North Atlantic. 


\subsection{Sampling \& Analysis Methodology}

In August 2008, trace metal clean seawater samples were collected aboard the $R / V$ Oceanus (cruise OC449-2 sailing from Bridgetown, Barbados, to Mindelo, Cape Verde Islands) in the tropical North Atlantic (see cruise track in Figure 1). A review of the sample collection and Fe analysis protocols for this cruise can be found in FITZSIMMONS et al. (2013, Chapter 3), which discusses the major processes controlling the $\mathrm{dFe}$ distribution along this track. Briefly, the Moored In situ Trace Element Serial Samplers (MITESS, BELL et al., 2002) were used to collected profile seawater samples in the "Vane" mode using deployment procedures described in FITZSIMMONS and BOYLE (2012). Near-surface samples ( 5 m depth) were collected using the Automated Trace Element ("ATE") sampler, which is a single MITESS unit deployed manually off the side of the ship using a plastic-coated line. Seawater was vacuum-filtered ( $0.5 \mathrm{~atm}$.) through $0.4 \mu \mathrm{m}$ Nuclepore ${ }^{\mathrm{TM}}$ filters on a Savillex ${ }^{\mathrm{TM}}$ fluorocarbon filter rig directly into acidcleaned $30 \mathrm{~mL}$ HDPE sub-sampling bottles after two rinses. MITESS Vane sample collection produced dFe concentrations indistinguishable from those collected by the U.S. GEOTRACES GO-FLO carousel system (FITZSIMMONS and BOYLE, 2012).

To collect sFe samples, a $0.02 \mu \mathrm{m}$ Anodisc filter was pre-cleaned on a Teflon filter rig first with $>100 \mathrm{~mL} \mathrm{pH} 1.5 \mathrm{HCl}$ (distilled 4x in a Vycor still and tested for trace metal purity), followed by $>100 \mathrm{~mL}$ trace metal-clean distilled water, and finally $\sim 50 \mathrm{~mL}$ unfiltered seawater sample, after which unfiltered seawater was passed through the clean Anodisc filter and collected as sFe in acid-cleaned $30 \mathrm{~mL}$ HDPE sub-sampling bottles after one bottle rinse. Samples were acidified at sea to $\mathrm{pH} 2$, and at least six months after acidification they were analyzed in triplicate for their Fe content by isotope dilution inductively-coupled plasma mass spectrometry (ID-ICP-MS) on a hexapole collision cell

IsoProbe multiple collector-ICP-MS. The ID-ICP-MS method employs an ${ }^{54} \mathrm{Fe}-$ spike and batch pre-concentration with nitrilotriacetate resin (LEE et al., 2011). Comprehensive lab analyses of SAFe D2 standard for dFe during the period of these analyses averaged $0.95 \pm 0.05 \mathrm{nmol} / \mathrm{kg}$ (Bottle 33, $\pm 1 \mathrm{SD}, \mathrm{n}=38$ ) and $0.90 \pm 0.02 \mathrm{nmol} / \mathrm{kg}$ (Bottle 446, $\pm 1 \mathrm{SD}$, 
$\mathrm{n}=10$ ), which agree well with the current consensus value of $0.933 \pm 0.032 \mathrm{nmol} / \mathrm{kg}$ (consensus update: May 2013; www.geotraces.org/science/intercalibration).

\subsection{Results and Discussion}

6.3.1 Surface distribution - The surface ocean distributions of $\mathrm{dFe}$ and $\mathrm{sFe}$ as a function of longitude are shown in Figure 2. As discussed in Fitzsimmons et al. (2013, Chapter 3), dFe in the tropical North Atlantic exhibited concentration maxima at the surface, in accordance with expectations of high aerosol Fe deposition downwind of North African deserts along 10-20 $\mathrm{N}$ (MAHOWALD et al., 2005). dFe was highest in the west and lower in the east, despite closer proximity to the African dust source; this likely reflects a combination of spatially variable factors including dust source/solubility, dust deposition patterns (seasonal), biological uptake of metals in the surface ocean, and mixed layer depth. NOAA HYSPLIT backwards trajectories calculated using the GDAS Meteorological data indicate that the air masses over all of the stations in Figure 2 originated in NW Africa/Europe, except for Stations $9 \& 11\left(37-41^{\circ} \mathrm{W}\right)$, which had South American sources. It is reasonable to assume that over the 1.5-5 months residence time of dFe in surface waters of the tropical North Atlantic (BERGQUIST and BOYLE, 2006), most of the $\mathrm{dFe}$ is derived from North African desert sources.

What is most striking from Figure 2, however, is that soluble Fe concentrations remained low across the transect (at all but one station) despite a factor-of-two variability in $\mathrm{dFe}$, with $\mathrm{sFe} \leq 0.2 \mathrm{nmol} / \mathrm{kg}$ at most stations. Thus, most of the elevated surface $\mathrm{dFe}$ was partitioned into the colloidal Fe size fraction (\%cFe averaged $80 \pm 7 \%$, with Station 6 removed). This reinforces the hypothesis that atmospherically derived $\mathrm{Fe}$ is preferentially maintained in the colloidal pool, which was suggested by WU et al. (2001) using data near Bermuda and Hawaii and corroborated by BERGQUIST et al. (2007) in the tropical North Atlantic. It is possible that both soluble and colloidal Fe were released by dust and then only sFe was preferentially taken up by microorganisms, leaving the observed majority of aerosol $\mathrm{dFe}$ in the colloidal phase. However, the preferential release of dustderived Fe into the colloidal, not soluble, size fraction is supported experimentally by 
direct leaching of aerosols from diverse oceanic regions in filtered seawater with natural organic Fe-binding ligand assemblages (AGUILAR-IsLAS et al., 2010), although one can be concerned whether excess Fe binding ligands are saturated during these dust leaching experiments, which would generate colloidal Fe oxyhydroxides and bias the resulting size partitioning. Dust-derived Fe colloids could be composed of organically bound Fe-ligand complexes that fall in the colloidal size fraction, colloidal-sized dust particles, and/or inorganic Fe-colloids formed in situ during the dust solubilization process.

In contrast at the northernmost station of our transect (Station 6: $20^{\circ} \mathrm{N}, 45^{\circ} \mathrm{W}$ ), sFe had a much higher concentration of $0.48 \mathrm{nmol} / \mathrm{kg}$, which exceeded the $\mathrm{cFe}$ of 0.33 $\mathrm{nmol} / \mathrm{kg}$ ( $59 \%$ of the $\mathrm{dFe}$ was $\mathrm{sFe})$. If dust is assumed to partition into the colloidal fraction, then the decreased cFe contribution at Station 6 could indicate that dust deposition at this northernmost station was reduced. This hypothesis would be supported by a majority partitioning into the soluble phase in the surface ocean of other low-dust regions such as the South Atlantic (BERGQUIST et al., 2007), subarctic North Pacific (NishioKa et al., 2003), and the Southern Ocean (BOYE et al., 2010; Chever et al., 2010). However, the dFe concentration at Station 6 was relatively high $(0.8 \mathrm{nmol} / \mathrm{kg})$ and thus requires a recent $\mathrm{Fe}$ input. While we cannot exclude that the Station $6 \mathrm{sFe}$ sample might have been contaminated, we also know that dFe is stabilized by organic ligands, and thus the size partitioning of surface Fe-binding ligands at any individual location may be directly controlling the observed partitioning of surface dFe. Only one study has recorded the size partitioning of organic Fe-binding ligands in the tropical North Atlantic (CULLEN et al., 2006), with surface water samples taken at one station in the tropical North Atlantic $\left(3.5^{\circ} \mathrm{N}, 44.5^{\circ} \mathrm{W}\right)$ and one station in the North Atlantic subtropical gyre $\left(36.1^{\circ} \mathrm{N}, 65^{\circ} \mathrm{W}\right)$. At the tropical North Atlantic station, $50-62 \%$ of the dissolved ligands fell into the soluble fraction, while in the subtropical gyre station, $72-100 \%$ of the dissolved ligands were soluble. That study demonstrates that ligand partitioning is spatially variable and supports the premise that significant ligand partitioning into the soluble fraction might be predicted in the subtropical gyre at our Station 6, which lies closer to the gyre center (with a high surface salinity $>37.5$ and depressed mixed layer, 
chlorophyll max, and isopycnals) than any of the other stations sampled on our cruise track. More studies of the size partitioning of Fe-binding ligands across the global ocean would be useful for assessing the impact of the ligand size distribution on the solubility and size partitioning of $\mathrm{dFe}$, especially when comparing high- and low-dust regions. Nevertheless, the predominance of surface colloidal Fe only in regions of significant dust (inorganic Fe) input may imply that there is a contribution of inorganically bound $\mathrm{Fe}$ colloids (nanoparticles) to this dust-derived cFe that is not present in low-dust regions.

6.3.2 Water column profiles - Figures 3-6 show all of the subsurface dFe and sFe samples collected on OC449-2. Despite the fact that these samples were collected in a relatively narrow $12^{\circ}$ latitudinal band, the stations situated farther north and west in the subtropical gyre had very different $\mathrm{dFe}$ profiles than those stations farther south and east in the OMZ (FITZSIMMONS et al., 2013). BERGQUIST et al. (2007) made a similar designation of a subtropical gyre $\left(30^{\circ} \mathrm{N}, 45^{\circ} \mathrm{W}\right)$ and an $\mathrm{OMZ}\left(10^{\circ} \mathrm{N}, 45^{\circ} \mathrm{W}\right)$ station, and that same nomenclature will be applied to the stations in this study's cruise track. Subtropical gyre ( $3 \& 6$ ) and OMZ (9-22) stations were distinguished using salinity profiles (Figure 4) with subtropical gyre sites having a deeper pycnocline than OMZ stations. Notably, the stations formed the same groups when sorted by dFe distribution as by pycnocline depth (Figure $4 \mathrm{c} \& d$ ), indicating that the biogeochemical signature of each water mass was a determining factor for $\mathrm{dFe}$ size partitioning in the tropical North Atlantic.

Dissolved Fe generally displayed a nutrient-type profile with a dust-derived surface maximum, a minimum near the deep chlorophyll maximum (DCM), a maximum in the OMZ, and typical North Atlantic deep water values (FITZSIMMONS et al., 2013). The different pools of $\mathrm{dFe}$ ( $\mathrm{cFe}$ and $\mathrm{sFe}$ ), however, demonstrated unique features with depth. Throughout the open ocean, dFe partitioning can be interpreted as a function of two processes: unique Fe partitioning resulting from individual Fe transformations, inputs, or outputs occurring at the location of interest, and/or a unique Fe ligand partitioning (presumably regulated by microorganisms) that directly regulates the observed dFe partitioning. We will discuss the balance of these two partitioning 
mechanisms throughout the transect starting in the euphotic zone and extending down to the abyssal ocean.

6.3.2.1 Euphotic Zone - In the euphotic zone, $\mathrm{cFe}$ and sFe had very different profile structures (Figure 3), suggesting that $\mathrm{cFe}$ and $\mathrm{sFe}$ behave uniquely in the upper ocean. At all stations, the surface $\mathrm{dFe}$ maximum decreased with depth to a minimum near the DCM (Figure 3). In the subtropical gyre stations, dFe was relatively split between soluble and colloidal fractions (Figure 3a: Station 6 had $56 \% \mathrm{cFe}$ ), while at the OMZ stations 9 and 13, colloidal Fe disappeared completely in the DCM (Figure 3 b\&c). This lack of cFe in the DCM was also observed by BERGQUIST et al. (2007) at their OMZ station and by UsSHER et al. (2010) near the Canary Islands. CHEVER et al. (2010) also found a cFe minimum in Southern Ocean Antarctic Circumpolar Current (ACC) surface waters that persisted through the upper 100-200m.

The disappearance of $\mathrm{cFe}$ in the DCM can be interpreted as occurring either because of a unique Fe-ligand partitioning in the DCM that is different from that at other depths or as a result of unique Fe transformations occurring in the DCM. If size fractionation of Fe-binding ligands were to explain the observed pattern, the DCM must have had either higher soluble ligand concentrations than colloidal or substantially stronger soluble ligands that outcompeted colloidal ligands for Fe in the DCM. Very few studies have reported the size distribution of Fe-binding ligands at the DCM, but one study in the Southern Ocean ACC found that $92 \pm 3 \%$ (n=7) of Fe-binding ligands were soluble in the upper 100m of water (BoYE et al., 2010). This is in contrast to a study in the North Pacific near Hawaii that detected almost no soluble ligands in upper $100 \mathrm{~m}$ waters (WU et al., 2001). Regardless, it is generally believed that organic Fe-binding ligands, especially in the upper ocean, are biologically produced (HUNTER and BOYD, 2007), and several studies have shown that marine microbes produce "siderophore-like" ligands that would fall into the soluble size fraction (MARTINEZ et al., 2003; MARTinEZ et al., 2001; WILHELM and TRICK, 1994). Thus, it might make sense that strong, "siderophore-like" ligands in the soluble class might be produced at the DCM that outcompete any colloidal ligands present for Fe. 
However, without any data defining the Fe-ligand size partitioning in the DCM, an Fe transformation explanation for the observed pattern in Figure 3 is equally likely. Since the DCM is an upper ocean depth experiencing biological activity, it is possible that colloidal Fe is preferentially taken up by microbes, despite observations from incubation studies suggesting that microbes prefer sFe over $\mathrm{cFe}$ (CHEN and WANG, 2001). Alternatively, protozoan grazer ingestion of $\mathrm{cFe}$ could be depressing the $\mathrm{cFe}$ concentration at the DCM (BARBEAU and MofFETT, 2000; BARBEAU et al., 1996). Another possible explanation is that because of the particulate material maximum in the upper ocean, colloidal Fe may be scavenged onto particles more efficiently at the DCM, or cFe aggregation rates into large particles may be greater at the DCM.

It is worth mentioning that at all of the stations where soluble Fe was measured in the DCM, sFe was a measurable $0.10-0.15 \mathrm{nmol} / \mathrm{kg}$. While this region is not thought to be Fe-limited, it is not unreasonable to assume that microorganisms would use as much of the "highly bioavailable" sFe as possible. However, we find a persistent $0.13 \pm 0.01$ $\mathrm{nmol} / \mathrm{kg} \mathrm{sFe}$ concentration in the DCM at all stations examined. This pool of sFe may be a relatively refractory Fe pool that is unavailable to marine microorganisms and perhaps could be less bioavailable than colloidal Fe, assuming that biouptake is the reason for the depletion of $\mathrm{cFe}$ at the DCM some stations. Alternatively, a photochemically-produced Fe(II) pool (MOFFETT, 2001), either in a pseudo-steady state because of rapid turnover by photochemistry and/or biological utilization or a stabilization by organic ligands (ROY et al., 2008), may also comprise this nearly constant soluble Fe background in the upper ocean.

6.3.2.2 Upper 1000m - Below the euphotic zone, the distribution of the dFe size classes was very different in the subtropical gyre than in the OMZ (Figure $4 \mathrm{a} \& \mathrm{~b}$ ). In the subtropical gyre sites, sFe remained low down to $250 \mathrm{~m}(0.14-0.22 \mathrm{nmol} / \mathrm{kg})$, while in the OMZ stations, in contrast, sFe had already reached elevated concentrations of 0.4-0.5 $\mathrm{nmol} / \mathrm{kg}$ by $250 \mathrm{~m}$. This is consistent with a deeper peak in apparent oxygen utilization (AOU) in the subtropical gyre than in the OMZ. By 700m, maximum dFe was observed at all stations, and $\mathrm{dFe}$ was equally divided between $\mathrm{cFe}$ and $\mathrm{sFe}, 50 \pm 7 \%$. 
An intriguing pattern in $\mathrm{dFe}$ size partitioning was observed at 500m depth (Figure 5), which is the depth sampled at the core of the OMZ (also note that isopycnals were very flat near $500 \mathrm{~m}$ depth across the tropical North Atlantic, FITZSIMMONS et al. 2013). In the end-member subtropical gyre stations (squares in Figure 5) and OMZ stations (circles), $\mathrm{dFe}$ and $\mathrm{sFe}$ were relatively constant across all of the stations sampled: subtropical gyre stations had $\mathrm{dFe}=0.57 \pm 0.06 \mathrm{nmol} / \mathrm{kg}$ and $\mathrm{sFe}=0.42 \pm 0.03 \mathrm{nmol} / \mathrm{kg}$ $(1 \mathrm{SD}, \mathrm{n}=2)$; whereas $\mathrm{OMZ}$ stations had $\mathrm{dFe}=1.16 \pm 0.06 \mathrm{nmol} / \mathrm{kg}$ and $\mathrm{sFe}=0.65 \pm 0.03$ $(\mathrm{n}=4)$. The nearly constant $\mathrm{sFe}$ concentrations across each of the end-member regions imply a control on sFe in each region. Historically, the $0.02 \mu \mathrm{m}$ filters that operationally define the $\mathrm{sFe}-\mathrm{cFe}$ partition in this study have been used to define the Fe solubility of natural seawater (KuMA et al., 1996; LIU and MiLlero, 2002). In these Fe solubility experiments, excess $\mathrm{Fe}$ is added to a natural sample and equilibrated, after which the sample is filtered through a $0.02 \mu \mathrm{m}$ filter to measure the maximum "truly soluble" fraction of dissolved Fe. This Fe solubility is comprised of both an inorganic dFe fraction dominated by $\mathrm{Fe}(\mathrm{OH})_{\mathrm{x}}{ }^{3-\mathrm{x}}{ }_{\text {(aq) }}$ complexes and an organic fraction of "truly soluble" organic Fe-binding ligands. Given the near constancy of the sFe concentrations in the $\mathrm{OMZ}$ and subtropical gyre regions of this study, it is possible that the sFe concentrations may equal the Fe solubility in each end-member region, where all labile soluble ligands are saturated with Fe. Enhanced remineralization may be providing uncomplexed Fe to these lowoxygen depths that saturates the soluble ligands (although the low oxygen may also be an advected signal not designating enhanced remineralization). Remineralization may be providing uncomplexed Fe to these low-oxygen depths that saturates any unbound soluble ligands; however, an input of Fe-ligands from remineralization might also be expected and was in fact observed in the northeast Atlantic Ocean (THUROCZY et al., 2010) that would oppose the hypothesis that sFe is fully bound and equals Fe solubility. In the tropical North Atlantic, only euphotic zone measurements of Fe solubility have been made (SCHLOSSER and CROOT, 2009), so the hypothesis that sFe equals Fe solubility in this region cannot be confirmed, and thus a cause for the near constancy of sFe is not clear. 
Notably, however, only at intermediate oxygen concentrations (triangles in Figure 5), did colloidal Fe dominate $\mathrm{dFe}$ at 500m. The two "intermediate" samples were taken from OC449-2 station 9 and from the $\mathrm{OMZ}$ station $\left(10^{\circ} \mathrm{N}, 45^{\circ} \mathrm{W}\right)$ station of BERGQUIST et al. (2007), where dissolved oxygen concentrations were between 100-110 $\mu \mathrm{mol} / \mathrm{kg}$. At both stations, sFe was depressed to "gyre-like" concentrations, while dFe remained elevated to "OMZ" levels. What is driving this unique $\mathrm{dFe}$ size partitioning as $\mathrm{OMZ}$ waters meet subtropical gyre waters? We exclude a redox explanation, despite its clear link to oxygen concentrations, since at all stations of this study dissolved oxygen (minimum of $\sim 50 \mu \mathrm{mol} / \mathrm{kg}$ ) was high enough to favor Fe(III) over Fe(II). Alternatively, remineralization and ligand-partitioning may actually be the cause for this change in $\mathrm{dFe}$ size partitioning: if the population of microorganisms is unique at intermediate oxygen concentrations or in the surface waters above these regions, then the size partitioning of new, remineralization-produced Fe ligands may also be changing as a function of the biological population, perhaps driving the formation of enhanced organically-bound $\mathrm{dFe}$ into the colloidal size fraction. On the other hand, this pattern may be an abiotic function of the mixing of lower-oxygen OMZ waters with higher-oxygen subtropical gyre waters. It is clear that $\mathrm{sFe}$ concentrations remained depressed to subtropical gyre levels in these intermediate stations, and if sorption/aggregation rates transforming soluble Fe into colloidal Fe were higher than desoprtion/disaggregation in this mixing zone, then cFe would be favored. This could be motivated by an increase in particle concentrations or a change in particle composition at these mixing stations around the edge of the OMZ. Regardless of the cause, colloids may be serving as a conduit of dFe loss during mixing of high $\mathrm{dFe}$ waters of the $\mathrm{OMZ}$ with the low dFe waters of the gyre. If the colloidal phase is actively aggregating, as suggested by the model of HONEYMAN and SANTSCHI (1989), the partitioning of the remineralized fraction could affect the efficiency of Fe recycling, since if cFe aggregated to the particulate phase before it was upwelled to the surface ocean, it would result in a "leak" in the Fe recycling system that might not be present if the mixing zone comprised less $\mathrm{cFe}$. 
6.3.2.3 Deep ocean - We determined the deep water size partitioning of dFe at one station in the deepest part of the eastern tropical North Atlantic basin (Station 13: $12.8^{\circ} \mathrm{N}, 33.0^{\circ} \mathrm{W}$, Figure 6a). As described in Fitzsimmons et al. (2013), Antarctic Intermediate Water (AAIW) was the main water mass near 1000m, North Atlantic Deep Water (NADW) dominated from 1500-4000m, and Antarctic Bottom Water (AABW) was mixed with NADW below $4000 \mathrm{~m}$. In the deepest samples from $4000-5000 \mathrm{~m}$, FitZSIMMONS et al. (2013) observed a $0.1 \mathrm{nmol} / \mathrm{kg}$ increase in dFe compared to the shallower NADW-only depths, which they suggested might have been acquired from hydrothermal vent $\mathrm{Fe}$ inputs during deep water transit through the Vema Fracture Zone. As can be seen in Figure 6a, sFe concentrations at these AABW-influenced depths were not significantly different from those at the shallower, NADW-only depths, and thus the increase in $\mathrm{dFe}$ was contributed only by the colloidal Fe phase (composing $65 \pm 2 \%$ of the $\mathrm{dFe}$ in the deepest samples, $\mathrm{n}=2$ ). If this $0.1 \mathrm{nmol} / \mathrm{kg}$ excess $\mathrm{dFe}$ is hydrothermally derived, it is unknown whether it is composed of organically bound colloidal Fe, as would traditionally be assumed in deep ocean waters, or whether an inorganic $\mathrm{Fe}$ colloidal phase potentially precipitated during venting also contributes. Regardless, this cFe would have had to escape scavenging over the $>1200 \mathrm{~km}$ transit from the Vema Fracture Zone to Station 13.

In the mid-depth NADW at this site, sFe constituted $48 \pm 11 \%$ of the $\mathrm{dFe}$ pool, and $\mathrm{sFe}$ concentrations were $0.34 \pm 0.05 \mathrm{nmol} / \mathrm{kg}(\mathrm{n}=2)$, which compares well with the $0.35 \pm 0.05 \mathrm{nmol} / \mathrm{kg}$ values reported by BERGQUIST et al. (2007) in the North (Figure 6b) and South Atlantic as well as the $\sim 0.32 \mathrm{nmol} / \mathrm{kg}$ values reported by Wu et al. (2001) near Bermuda. Even in the Atlantic sector of the Southern Ocean, at depths where NADW is recognized by enhanced salinity, the same $\mathrm{sFe}$ values of $0.35 \pm 0.02 \mathrm{nmol} / \mathrm{kg}$ were observed (CHEVER et al., 2010). This is in contrast to measurements in the northeast Atlantic off Portugal where sFe was only measured to be $0.16-0.21 \mathrm{nmol} / \mathrm{kg}$ in NADW (THUROCZY et al., 2010). These samples, however, were collected using a different operational definition of the sFe size fraction, a $1000 \mathrm{kDa}$ membrane in a cross-flow filtration apparatus, and thus cannot be directly compared to the sFe concentrations in this 
study, which were collected using $0.02 \mu \mathrm{m}$ Anopore filtration (FITZSIMMONS and BOYLE, in review).

\subsubsection{Controls on dissolved Fe size partitioning in the tropical North Atlantic -}

In their study on dFe size partitioning in the Atlantic Ocean, BERGQUIST et al. (2007) suggested that it is the variability in colloidal Fe that determines $\mathrm{dFe}$ concentration variability in the open ocean, with soluble Fe remaining relatively invariant with depth. This pattern is clear in their data, which is reproduced in Figure 6b: sFe is relatively constant at $0.3-0.4 \mathrm{nmol} / \mathrm{kg}$ below the euphotic zone, while $\mathrm{dFe}$ is at high concentration and variable, with most of the variability contributed by changes in the colloidal phase. In contrast, however, the full-depth profile data from Station 13 of this study (Figure 6a) shows that where dissolved Fe is enhanced in the OMZ, soluble Fe is also enhanced, and as a result both soluble and colloidal fractions contribute to the variability in the $\mathrm{dFe}$ profile. In fact, the sFe concentrations from all stations of OC449-2 were generally more variable than in the two stations measured by BERGQUIST et al. (2007; Figure $4 \mathrm{c}-\mathrm{d}$ ), and at no stations in OC449-2 could sFe be considered to remain constant with depth. At the subtropical gyre site of BERGQUIST et al. (2007), sFe concentrations were nearly constant through the upper $1000 \mathrm{~m}$, averaging $0.34 \pm 0.04 \mathrm{nmol} / \mathrm{kg}(1 \mathrm{SD}, \mathrm{n}=12)$ over all depths sampled, while OC449-2 subtropical gyre stations reached lower minima in $\mathrm{sFe}$ in the upper ocean (0.12-0.22 nmol/kg) and higher maxima in the deeper waters (0.4-0.5 $\mathrm{nmol} / \mathrm{kg}$; Figure 4c). The same is true of the OMZ stations where OC449-2 stations reached a lower $\mathrm{sFe}$ near the chlorophyll maximum $(0.1-0.15 \mathrm{nmol} / \mathrm{kg})$ and higher $\mathrm{sFe}$ maxima in OMZ waters $(0.6-0.7 \mathrm{nmol} / \mathrm{kg})$ than the nearly constant $0.40 \pm 0.06 \mathrm{nmol} / \mathrm{kg}$ $(n=9)$ measured by BERGQUIST et al. (2007) at their OMZ site (Figure 4d).

Relatively invariant sFe below the euphotic zone was a major finding of the BERGQUIST et al. (2007) study, and combined with the dominance of cFe in the upper waters underlying dust deposition led them to conclude that colloidal Fe dominates $\mathrm{dFe}$ variability throughout the ocean (Figure 7a). The tropical North Atlantic OC449-2 stations, however, show a reliance of $\mathrm{dFe}$ variability on both $\mathrm{sFe}$ and $\mathrm{cFe}$ concentrations (Figure $7 b$ ). Why do these two studies show different patterns in dFe size partitioning? 
One possibility is that Station 13 is farther into the OMZ than BERGQUIST et al.'s OMZ station and thus might receive more of a "uniquely partitioned" OMZ Fe input that is enriched in more soluble Fe than colloidal Fe. Fitzsimmons et al. (2013) used several proxies to apportion the Fe sources to the $\mathrm{OMZ}$ and concluded that the most likely mechanism for the enriched $\mathrm{Fe}$ was enhanced remineralization of high Fe:C organic material formed in the dust-laden surface waters above rather than advection/mixing out of an African margin Fe source. If this is true, then for a remineralization-derived "source partitioning signature" to explain the difference between dFe partitioning in the Figure 6 profiles, there must be a difference in the microbial communities between Station 13 and BERGQUIST et al.'s OMZ station that would cause a change in the partitioning of remineralized Fe in the OMZ. Alternatively, the partitioning of free ligands that bind this newly remineralized material in the OMZ could be different between the two sites.

However, the dFe dependence on both $\mathrm{sFe}$ and cFe phases in OC449-2 is not isolated only to the $\mathrm{OMZ}$ stations in Figure $7 \mathrm{~b}$ : both size fractions are variable across the entire tropical North Atlantic Ocean. The data of BERGQUIST et al. (2007) shows a narrower range in $\mathrm{sFe}$ concentrations despite a wide range in $\mathrm{dFe}$ concentrations, and thus only a dFe-cFe relationship can be deduced from their data. Across a wider span of oceanographic conditions in the tropical North Atlantic, however, $\mathrm{sFe}$ also contributes to $\mathrm{dFe}$ variability where it did not in the more restricted sampling of BERGQUIST et al. We believe that the $\mathrm{dFe}$ partitioning pattern where both $\mathrm{sFe}$ and $\mathrm{cFe}$ contributions to $\mathrm{dFe}$ variability is more representative of the general tropical North Atlantic Ocean (as shown by the numerous stations emcompassed by this study's data). We hypothesize that this more equivalent partitioning is attributed to an equal partitioning of Fe-binding ligands in the two size fractions that controls $\mathrm{dFe}$ size distributions, or that following remineralization the exchange rates between soluble and colloidal Fe (aggregation/disaggregation, sorption/desorption, or ligand exchange) set a "steady state" $\mathrm{dFe}$ partitioning that is more equivalent between the two size fractions. We further explore the processes controlling this "steady state" partitioning in Chapter 7. We believe that the $>0.8 \mathrm{nmol} / \mathrm{kg} \mathrm{dFe}$ data of Bergquist et al. data in Figure $7 \mathrm{a}$ fall off the linear dFe- 
$\mathrm{sFe}$ trend because they do not reach a steady state between aggregation/disaggregation due to their location in waters of "intermediate" oxygen concentration after mixing of OMZ and gyre waters (as discussed in section 6.3.2.2).

The slopes of the dFe-cFe $(1.261 \pm 0.156, \pm 1 \mathrm{SE})$ and dFe-sFe $(1.235 \pm 0.140)$ relationships in Figure 7 are statistically identical, indicating that within the scatter of the regressions, soluble and colloidal Fe contribute equally to dissolved Fe variability. These slopes are also not significantly different from the dFe-cFe slopes cited by BERGQUIST et al. (2007) for their Atlantic Ocean data (1.18) or THUROCZY et al. (2010) for their Northeast Atlantic data (1.16). Notably, neither of these studies produced statistically significant regressions between $\mathrm{dFe}$-sFe, and there was also no significant $\mathrm{dFe}$-sFe correlation in the Southern Ocean study of CHEVER et al. (2010). This reinforces the conclusion that soluble $\mathrm{Fe}$ is playing a greater role in $\mathrm{dFe}$ variability in the tropical North Atlantic than previously thought.

The near-equal slopes between $\mathrm{dFe}$-sFe and $\mathrm{dFe}$-cFe also suggest that the average partitioning of marine $\mathrm{dFe}$ is $50-50 \%$ to the soluble and colloidal pools (when using a $0.02 \mu \mathrm{m}$ filter), driven either by control of the dFe size distribution by equally partitioned Fe-binding ligands or by a constant exchange rate between soluble-colloidal Fe pools. Regional Fe inputs or processes may impart additional Fe sources of one of the phases on top of this "steady state" partitioning, while scavenging/output processes may detract from it, to produce the observed variable partitioning. We believe that the data of Bergquist et al. (2007) is, in fact, out of steady state because of unique processes occurring in the OMZ-gyre mixing zone. Whether it is the partitioning of organic ligands that controls this background dFe partitioning, and if so which Fe-ligands are most important and where do they come from, remains to be determined. The "steady state partitioning" model is supported by near equal contributions of soluble and colloidal Fe to deep ocean dFe partitioning in the Atlantic, Pacific, and Southern Oceans (BERGQUIST et al., 2007; BOYE et al., 2010; CHEver et al., 2010; Wu et al., 2001).

It is clear from this and similar studies that the partitioning of $\mathrm{dFe}$ between soluble and colloidal phases is variable, even within the tropical North Atlantic alone, yet 
this partitioning has a major impact on Fe biogeochemical cycling, potentially affecting $\mathrm{dFe}$ bioavailability, solubility, and residence times. Unfortunately, we know very little about the chemical composition of $\mathrm{dFe}$ in the ocean, but it is clear from this and other size fractionation studies that soluble and colloidal Fe species cycle independently to some extent and warrant further study, both in exploration of their distribution as well as in experimental constraint of their bioavailability and scavenging potential. We rely heavily on the assumption that the partitioning of organic Fe-binding ligands drives the observed dFe partitioning, yet of the three published studies that have measured the size fractionation of ligands using electrochemical techniques (BOYE et al., 2010; CULLEN et al., 2006; THUROCZY et al., 2010), none have found that ligand partitioning actually predicts the observed $\mathrm{dFe}$ partitioning. This either indicates that electrochemical measurements are missing a fraction of Fe-binding ligands that are active in the open ocean, or that there is a missing link between our kinetically-limited measurements of Febinding ligand concentration and binding strength and our thermodynamic understand of organic ligand-binding of $\mathrm{Fe}$ in the open ocean. We still have much to learn about the chemical environment of $\mathrm{dFe}$ in the open ocean that will help us predict how Fe is solubilized and made available to marine microbes yet also is eventually scavenged to the particulate phase.

\subsection{Conclusions}

In this study, we investigated the partitioning of $\mathrm{dFe}$ between soluble and colloidal size fractions in the tropical North Atlantic and compared the distributions to the study of dFe size partitioning completed previously in the western portion of this region (BERGQUIST et al., 2007). We found that in the surface ocean underlying the Saharan dust plume that $\mathrm{dFe}$ was composed predominately of colloidal Fe, supporting the hypothesis that dust-derived Fe may be preferentially retained in the colloidal size fraction (AgUILAR-ISLAS et al., 2010; Wu et al., 2001). At the chlorophyll maximum, 
colloidal Fe was minimized or disappeared completely, which is likely due to a combination of biological uptake of colloidal Fe and/or the scavenging/aggregation of cFe at this depth. In the deep ocean, $\mathrm{dFe}$ size partitioning averaged $50-50 \%$ between the soluble and colloidal phases. Typical NADW sFe concentrations were observed, and in deeper waters including an $\mathrm{AABW}$ component that appear to have acquired Fe from hydrothermal activity or some other source during passage through the Vema Fracture Zone (FITZSIMMONS et al., 2013), soluble Fe did not increase coincidently, indicating that any new Fe source was contributed by the colloidal phase.

Most significantly, the results of this study oppose the premise that colloidal Fe alone controls the dissolved Fe variability in the open ocean. We instead propose that both soluble and colloidal Fe control dFe concentration variability and that the nearconstancy of sFe with depth found in previous studies either represents a "steady state" open ocean $\mathrm{dFe}$ partitioning pattern over which regional Fe sources with unique $\mathrm{dFe}$ partitioning are overlain to explain the observed partitioning, or that Fe-binding ligand partitioning between the two size fractions is variable in the open ocean and directly controls dFe partitioning. This distinction warrants future exploration in studies where the size fractionation of both the Fe-binding ligands and $\mathrm{dFe}$ are measured together throughout the water column. In general, this study confirms that soluble and colloidal Fe have unique patterns of cycling in different ocean regions and depths, and the two size classes cycle independently to some extent. These global dFe partitioning distributions impact both the bioavailability and scavenging residence time of $\mathrm{dFe}$ in the open ocean. 


\section{References for Chapter 6}

Aguilar-Islas, A. M., Wu, J., Rember, R., Johansen, A. M., and Shank, L. M., 2010. Dissolution of aerosol-derived iron in seawater: Leach solution chemistry, aerosol type, and colloidal iron fraction. Marine Chemistry 120, 25-33.

Barbeau, K. and Moffett, J. W., 2000. Laboratory and field studies of colloidal iron oxide dissolution as mediated by phagotrophy and photolysis. Limnology \& Oceanography $\mathbf{4 5}$, 827-835.

Barbeau, K., Moffett, J. W., Caron, D. A., Croot, P. L., and Erdner, D. L., 1996. Role of protozoan grazing in relieving iron limitation of phytoplankton. Nature Geosci 380, 6164.

Bell, J., Betts, J., and Boyle, E., 2002. MITESS: a moored in situ trace element serial sampler for deep-sea moorings. Deep-Sea Research Part I-Oceanographic Research Papers 49, 2103-2118.

Bergquist, B. A. and Boyle, E. A., 2006. Dissolved iron in the tropical and subtropical Atlantic Ocean. Global Biogeochemical Cycles 20, 14.

Bergquist, B. A., Wu, J., and Boyle, E. A., 2007. Variability in oceanic dissolved iron is dominated by the colloidal fraction. Geochimica et Cosmochimica Acta 71, 2960-2974.

Boye, M., Nishioka, J., Croot, P., Laan, P., Timmermans, K. R., Strass, V. H., Takeda, S., and de Baar, H. J. W., 2010. Significant portion of dissolved organic Fe complexes in fact is Fe colloids. Marine Chemistry 122, 20-27.

Bruland, K. W. and Lohan, M. C., 2003. Controls of Trace Metals in Seawater. In: Turekian, K. K. and Holland, H. D. Eds.), Treatise On Geochemistry. Elsevier Science Ltd., Cambridge, United Kingdom.

Chen, M. and Wang, W. X., 2001. Bioavailability of natural colloid-bound iron to marine plankton: Influences of colloidal size and aging. Limnology and Oceanography 46, 19561967.

Chever, F., Bucciarelli, E., Sarthou, G., Speich, S., Arhan, M., Penven, P., and Tagliabue, A., 2010. Physical speciation of iron in the Atlantic sector of the Southern Ocean along a transect from the subtropical domain to the Weddell Sea Gyre. J. Geophys. Res. 115, C10059.

Cullen, J. T., Bergquist, B. A., and Moffett, J. W., 2006. Thermodynamic characterization of the partitioning of iron between soluble and colloidal species in the Atlantic Ocean. Marine Chemistry 98, 295-303.

Fitzsimmons, J. N. and Boyle, E. A., 2012. An intercalibration between the GEOTRACES GOFLO and the MITESS/Vanes sampling systems for dissolved iron concentration analyses (and a closer look at adsorption effects). Limnology \& Oceanography: Methods 10, 437 450.

Fitzsimmons, J. N. and Boyle, E. A., in review. The assessment and intercalibration of 
Anopore $^{\mathrm{TM}}$ and cross flow filtration methods for the determination of dissolved iron size fractionation into soluble/colloidal phases in seawater. Limnology \& Oceanography: Methods.

Fitzsimmons, J. N., Zhang, R., and Boyle, E. A., 2013. Dissolved iron in the tropical North Atlantic oxygen minimum zone. Marine Chemistry 154, 87-99.

Gledhill, M. and Buck, K. N., 2012. The organic complexation of iron in the marine environment: A review. Frontiers in Microbiology: Microbiological Chemistry 3, Article 69.

Honeyman, B. D. and Santschi, P. H., 1989. A Brownian-pumping model for oceanic trace metal scavenging: Evidence from Th isotopes. Journal of Marine Research 47, 951-992.

Hunter, K. A. and Boyd, P. W., 2007. Iron-binding ligands and their role in the ocean biogeochemistry of iron. Environmental Chemistry 4, 221-232.

Kuma, K., Nishioka, J., and Matsunaga, K., 1996. Controls on iron(III) hydroxide solubility in seawater: The influence of $\mathrm{pH}$ and natural organic chelators. Limnology and Oceanography 41, 396-407.

Lee, J.-M., Boyle, E. A., Echegoyen-Sanz, Y., Fitzsimmons, J. N., Zhang, R., and Kayser, R. A., 2011. Analysis of trace metals $(\mathrm{Cu}, \mathrm{Cd}, \mathrm{Pb}$, and $\mathrm{Fe})$ in seawater using single batch

Nitrilotriacetate resin extraction and isotope dilution inductively coupled plasma mass spectrometry. Analytica Chimica Acta 686, 93-101.

Liu, X. and Millero, F. J., 2002. The solubility of iron in seawater. Marine Chemistry 77, 43-54.

Mahowald, N., Baker, A. R., Bergametti, G., Brooks, N., Duce, R. A., Jickells, T., Kubilay, N., Prospero, J. M., and Tegen, I., 2005. Atmospheric global dust cycle and iron inputs to the ocean. Global Biogeochemical Cycles 19, GB4025.

Martin, J. H. and Fitzwater, S. E., 1988. Iron deficiency limits phytoplankton growth in the northeast Pacific subarctic. Nature 331, 341-343.

Martinez, J. S., Carter-Franklin, J. N., Mann, E. L., Martin, J. D., Haygood, M. G., and Butler, A., 2003. Structure and membrane affinity of a suite of amphiphilic siderophores produced by a marine bacterium. Proceedings of the National Academy of Sciences 2003, 37543759 .

Martinez, J. S., Haygood, M. G., and Butler, A., 2001. Identification of a natural desferrioxamine siderophore produced by a marine bacterium. Limnology \& Oceanography 46, 420-424.

Millero, F. J., 1998. Solubility of Fe(III) in seawater. Earth and Planetary Science Letters 154, 323-329.

Moffett, J. W., 2001. Transformations among different forms of iron in the ocean. In: Turner, D. R. and Hunter, K. A. Eds.), The Biogeochemistry of Iron in Seawater. John Wiley \& Sons, West Sussex, England.

Morel, F. M. M., Milligan, A. J., and Saito, M. A., 2003. Marine Bioinorganic Chemistry: The Role of Trace Metals in the Oceanic Cycles of Major Nutrients. In: Turekian, K. K. and Holland, H. D. Eds.), Treatise On Geochemistry. Elsevier Science Ltd., Cambridge, United Kingdom.

Nishioka, J., Takeda, S., Kudo, I., Tsumune, D., Yoshimura, T., Kuma, K., and Tsuda, A., 2003. Size-fractionated iron distributions and iron-limitation processes in the subarctic NW Pacific. Geophysical Research Letters 30. 
Rich, H. W. and Morel, F. M. M., 1990. Availability of well-defined iron colloids to the marine diatom Thalassiosira weissflogii. Limnology and Oceanography 35, 652-662.

Roy, E. G., Wells, M. L., and King, D. W., 2008. Persistence of iron(II) in surface waters of the western subarctic Pacific. Limnology and Oceanography 53, 89-98.

Rue, E. L. and Bruland, K. W., 1995. Complexation of iron(III) by natural organic ligands in the Central North Pacific as determined by a new competitive ligand equilibration/adsorptive cathodic stripping voltammetric method. Marine Chemistry 50, 117-138.

Schlosser, C. and Croot, P. L., 2009. Controls on seawater Fe(III) solubility in the Mauritanian upwelling zone. Geophysical Research Letters 36, L18606.

Thuróczy, C. E., Gerringa, L. J. A., Klunder, M. B., Middag, R., Laan, P., Timmermans, K. R., and de Baar, H. J. W., 2010. Speciation of Fe in the Eastern North Atlantic Ocean. Deep Sea Research Part I: Oceanographic Research Papers 57, 1444-1453.

Ussher, S. J., Achterberg, E. P., Sarthou, G., Laan, P., de Baar, H. J. W., and Worsfold, P. J., 2010. Distribution of size fractionated dissolved iron in the Canary Basin. Marine Environmental Research 70, 46-55.

Wells, M. L. and Goldberg, E. D., 1991. Occurrence of small colloids in sea water. Nature 353, 342-344.

Wells, M. L. and Goldberg, E. D., 1992. Marine submicron particles. Marine Chemistry 40, 5-18.

Wells, M. L. and Goldberg, E. D., 1993. Colloid aggregation in seawater. Marine Chemistry 41, 353-358.

Wilhelm, S. W. and Trick, C. G., 1994. Iron-limited growth of cyanobacteria - Multiple siderophore production is a common response. Limnology and Oceanography 39, 19791984.

Wu, J., Boyle, E. A., Sunda, W. G., and Wen, L., 2001. Soluble and colloidal iron in the oligotrophic North Atlantic and North Pacific. Science 293, 847-849. 


\section{Figures for Chapter 6}

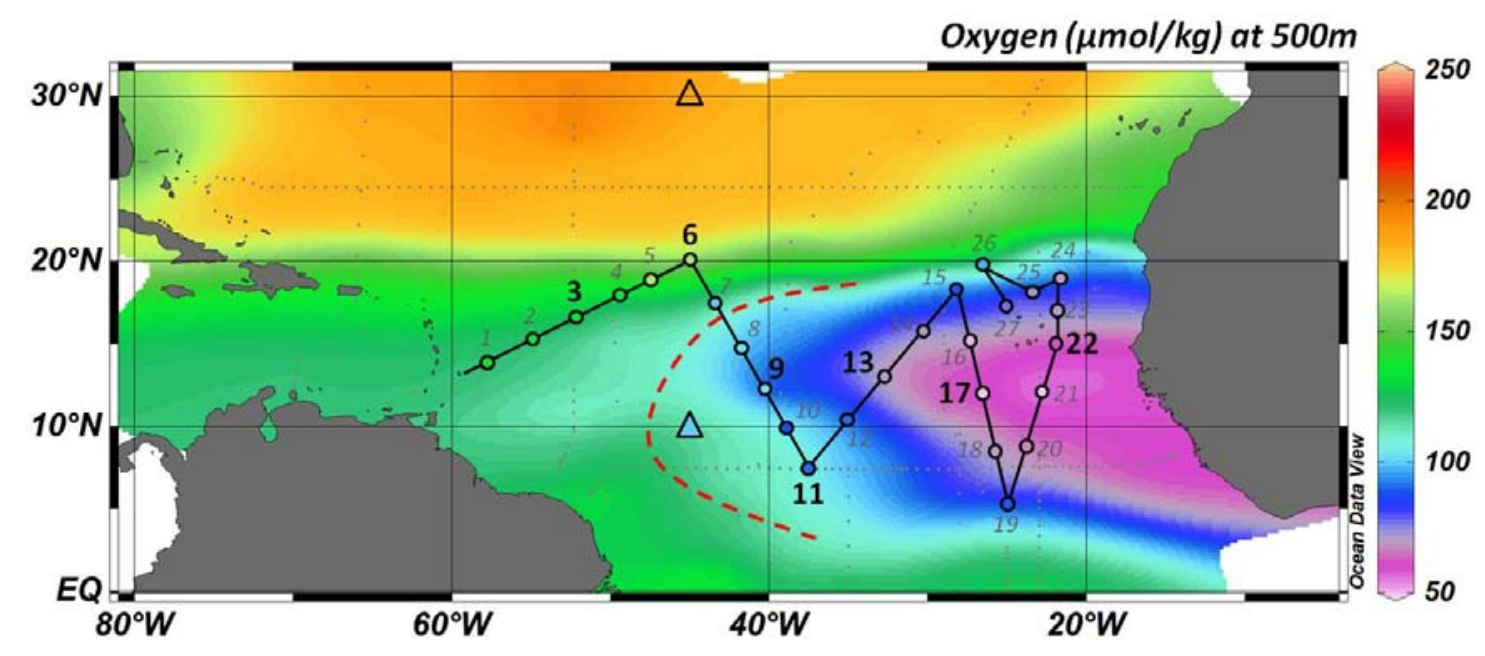

Figure 1: OC449-2 cruise track with the six stations sampled for dFe size partitioning indicated in bolded black. Color contours indicate the distribution of dissolved oxygen at $500 \mathrm{~m}$ taken from the eWOCE dataset (small dots). Colors inside the station dots indicate the dissolved oxygen concentrations at $500 \mathrm{~m}$ measured on OC449-2. The two triangles designate the subtropical gyre station $\left(30^{\circ} \mathrm{N}, 45^{\circ} \mathrm{W}\right)$ and the $\mathrm{OMZ}$ station $\left(10^{\circ} \mathrm{N}, 35^{\circ} \mathrm{W}\right)$ from Bergquist et al. (2007). The dashed red line designates the cut-off used in this study between the assigned "subtropical gyre stations" (3 \& 6) and "OMZ stations" (9, 11, 13, 17, \& 22). 


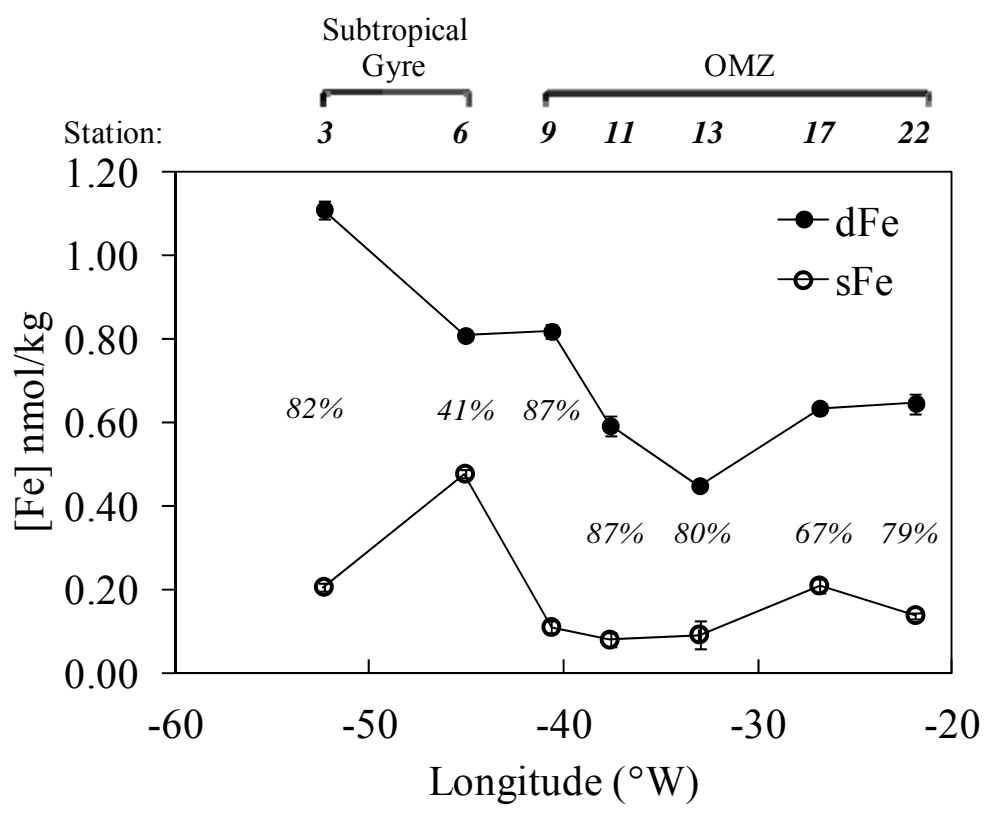

Figure 2: $\mathrm{dFe}$ and $\mathrm{sFe}$ in the surface ocean as a function of longitude, with station numbers and biogeochemical province indicated at the top. Station locations are indicated in Figure 1.

Italicized percentages indicate the $\% \mathrm{cFe}$ contribution to dFe. Error bars are shown for all points and represent $1 \sigma$ standard deviation of analytical replicates.
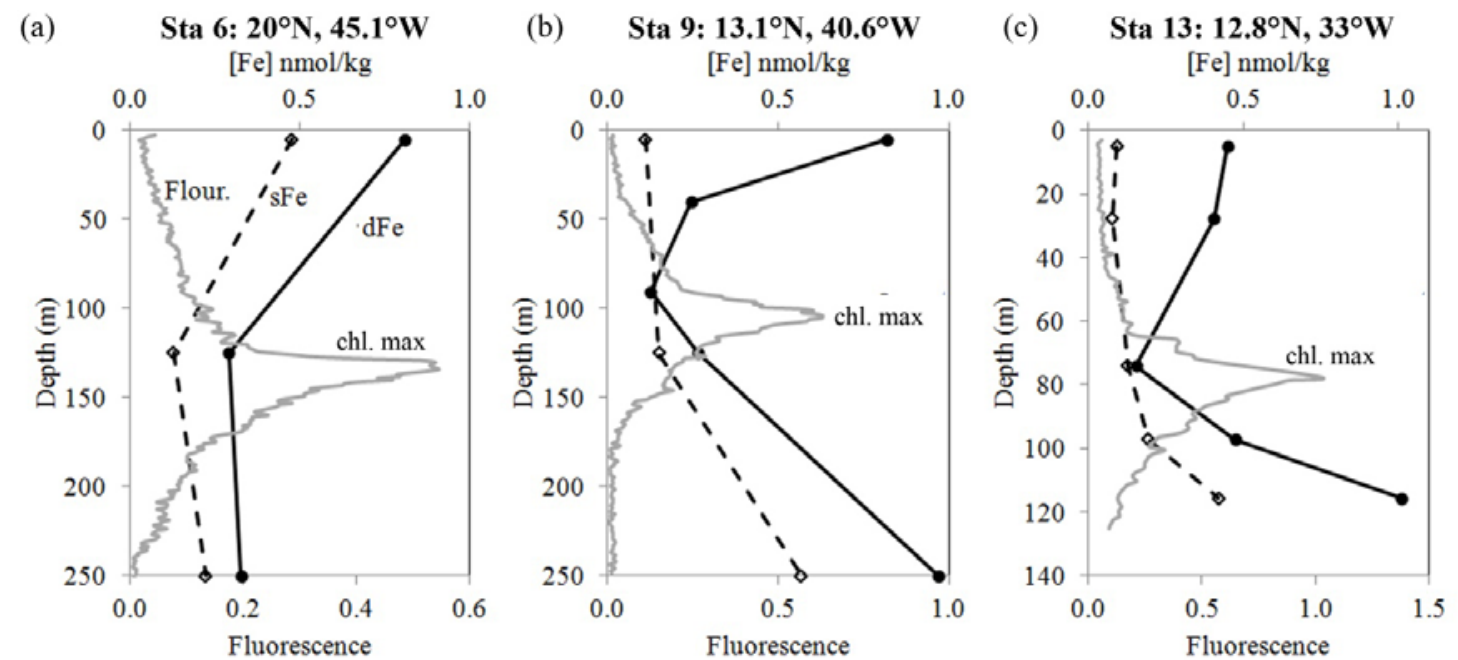

Figure 3: Euphotic zone dissolved Fe partitioning in the subtropical gyre at (a) Station 6 and in the OMZ at (b) Station 9 and (c) Station 13. dFe is shown in the filled circles (solid line), while $\mathrm{sFe}$ is shown in the open circles (dotted line). CTD fluorescence (V) is shown as the gray line to indicate the location of the deep chlorophyll maximum. At the $\mathrm{OMZ}$ stations, $\mathrm{cFe}(=\mathrm{dFe}-\mathrm{sFe})$ goes to zero at the chlorophyll maximum. 

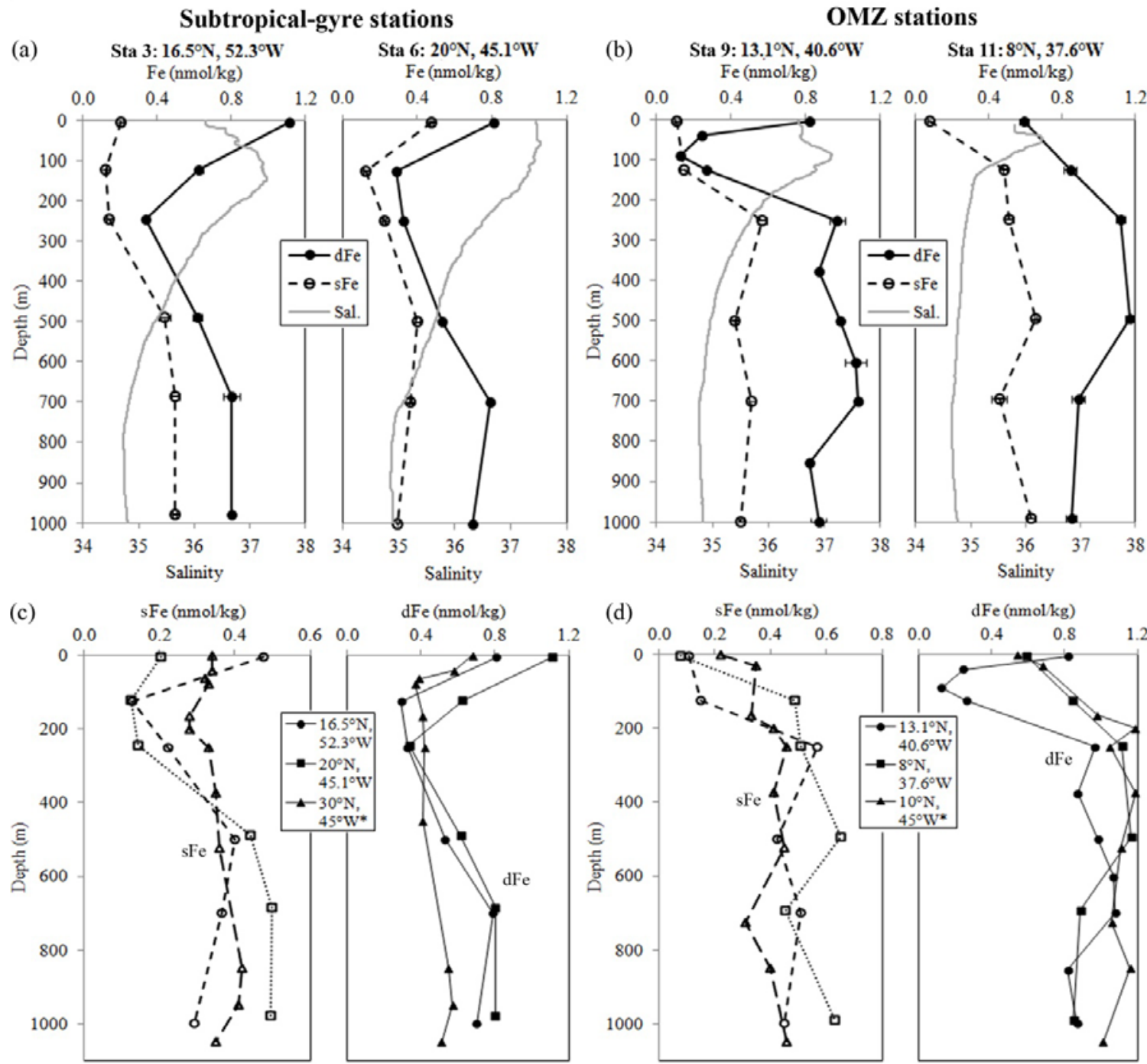

Figure 4: Dissolved Fe size partitioning to $1000 \mathrm{~m}$ in the subtropical gyre (a, c) and the OMZ (b, d). Data is shown for individual stations in (a) and (b) with salinity indicated in gray. In (c) and (d) $\mathrm{sFe}$ and $\mathrm{dFe}$ profiles from multiple stations are shown together for comparison. Error bars in (a) and (b) show $1 \sigma$ standard deviations of replicates analyzed. *Data taken from Bergquist et al. (2007). 


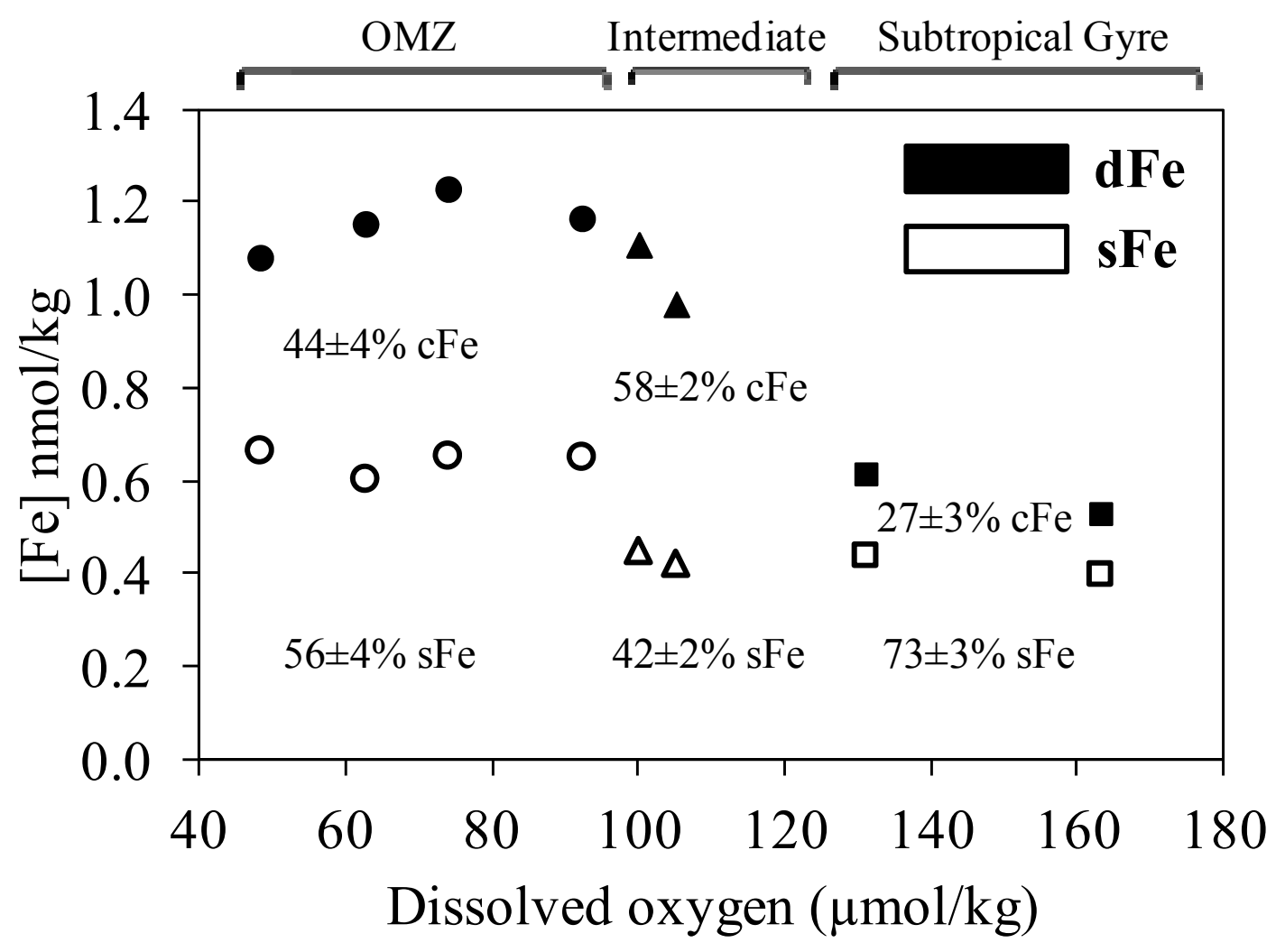

Figure 5: Dissolved and soluble Fe concentrations at 500m depth as a function of oxygen concentration. OMZ stations are designated as circles, subtropical gyre stations are designated as squares, and stations with intermediate oxygen concentration are shown as triangles. Note that the datapoints at $100 \mu \mathrm{mol} / \mathrm{kg}$ are taken from Bergquist et al. (2007) at $10^{\circ} \mathrm{N}, 45^{\circ} \mathrm{W}$. The percentage of $\mathrm{dFe}$ composed of soluble or colloidal Fe for each of the three regions is also designated. 

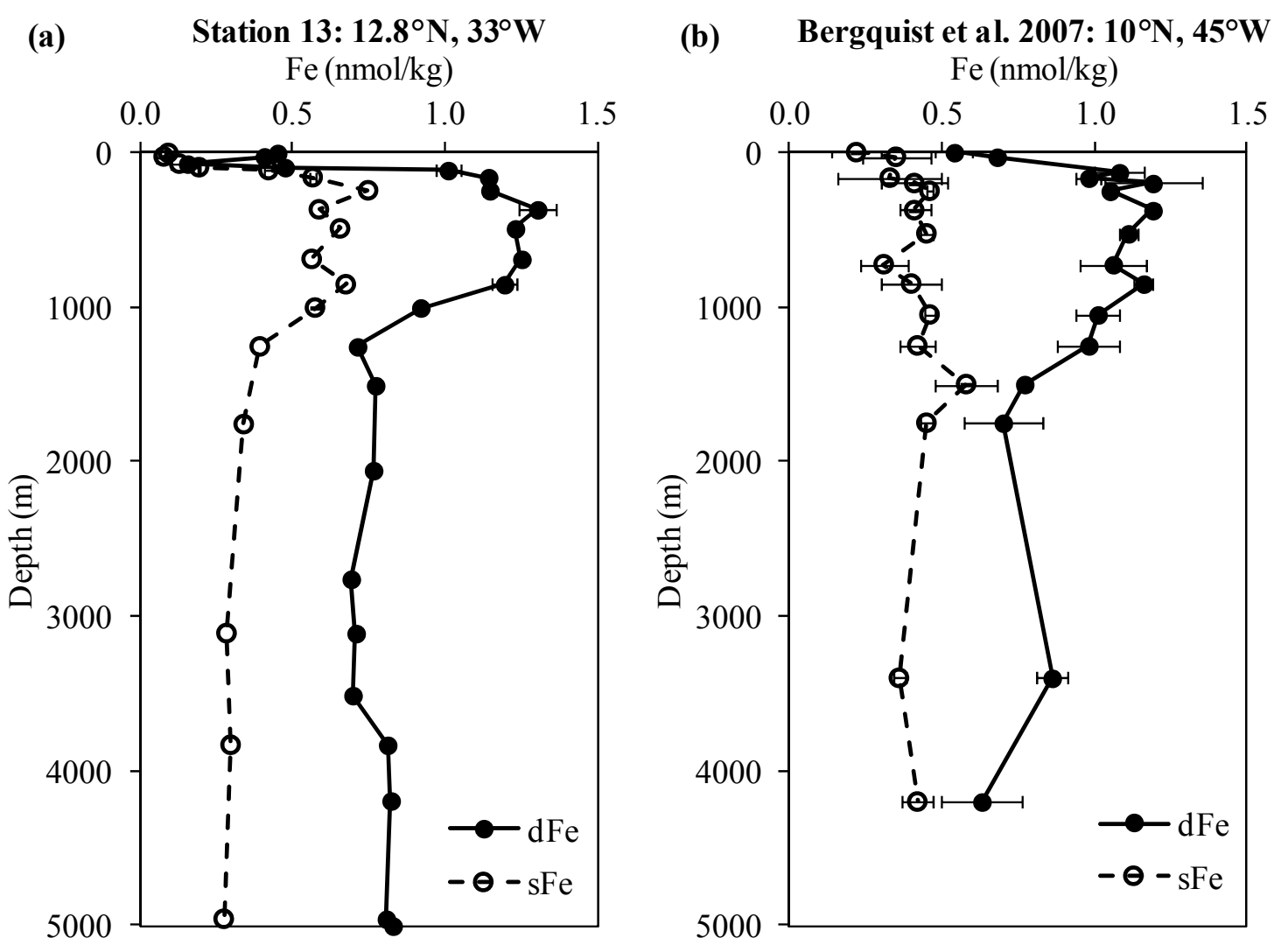

Figure 6: (a) Full-depth profile of dissolved Fe partitioning at Station 13 in the deepest part of the eastern tropical North Atlantic basin. (b) Full-depth profile of dissolved Fe partitioning in the OMZ station from Bergquist et al. (2007), shown for comparison. In both cases, error bars designate \pm 1 standard deviation. 
(a) Tropical $\left(10^{\circ} \mathrm{N}\right)$ and subtropical $\left(30^{\circ} \mathrm{N}\right)$ North Atlantic stations of Bergquist et al. (2007)
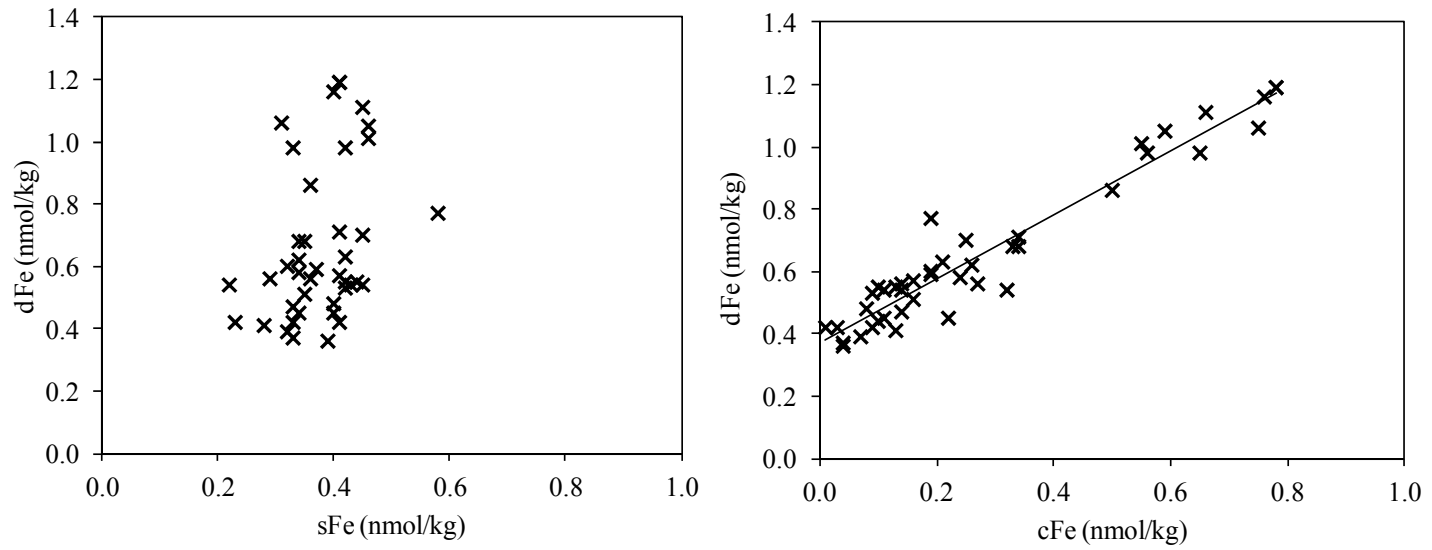

(b) All data from this study's OC449-2 stations
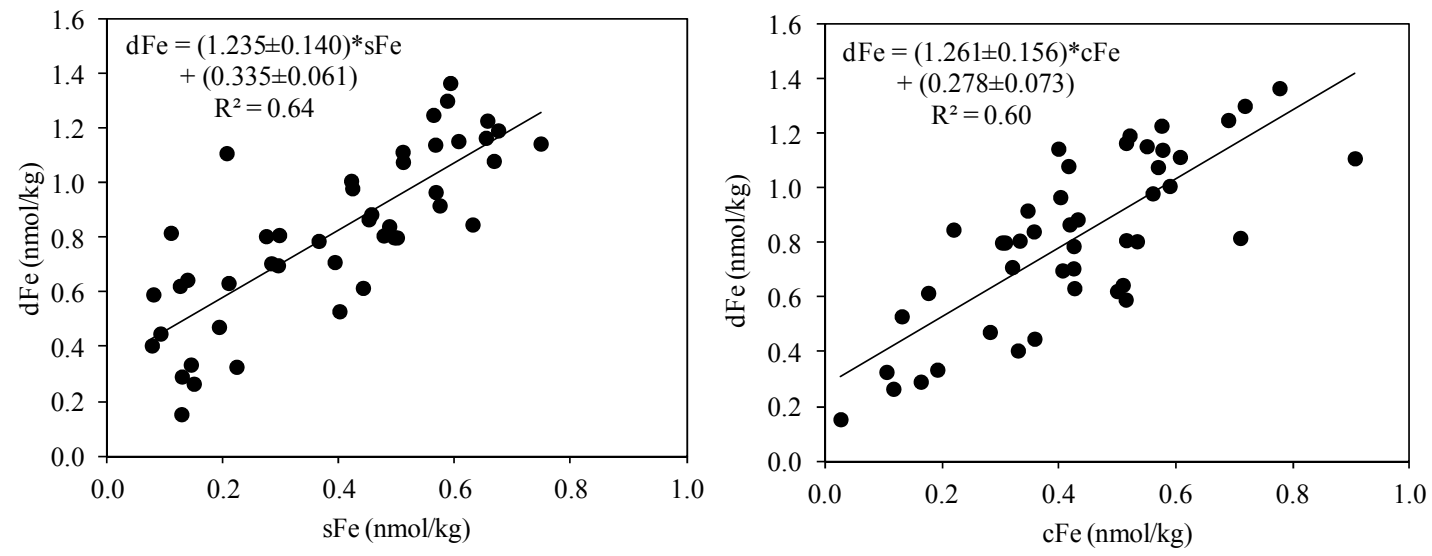

Figure 7: Dissolved Fe as a function of soluble Fe (left) and colloidal Fe (right) in the North Atlantic stations of Bergquist et al. (2007) in (a) and this study (b). The error in the slopes and intercepts from this study's data are $\pm \mathrm{SE}$. There is no relationship between $\mathrm{dFe}$ and $\mathrm{sFe}$ in the data of Bergquist et al. (2007), while there is a dFe-sFe relationship in the stations of this study. 


\section{Supplementary Data Table}

\begin{tabular}{|c|c|c|c|c|c|c|c|c|c|c|c|c|}
\hline Sta. & $\begin{array}{l}\text { Lat. } \\
\left({ }^{\circ} \mathrm{N}\right)\end{array}$ & $\begin{array}{l}\text { Long. } \\
\left({ }^{\circ} \mathrm{W}\right)\end{array}$ & $\begin{array}{l}\text { Depth } \\
\text { (m) }\end{array}$ & $\begin{array}{c}\mathrm{dFe} \\
\mathrm{nmol} / \mathrm{kg}\end{array}$ & $\begin{array}{c}1 \\
\text { SD }\end{array}$ & $\mathrm{n}$ & $\begin{array}{c}\mathrm{sFe} \\
\mathrm{nmol} / \mathrm{kg}\end{array}$ & $\begin{array}{c}1 \\
\text { SD }\end{array}$ & $\mathrm{n}$ & $\begin{array}{c}\mathrm{cFe} \\
(\mathrm{nmol} / \mathrm{kg})\end{array}$ & $\begin{array}{c}\mathrm{sFe} / \mathrm{dFe} \\
(\%)\end{array}$ & $\begin{array}{c}\mathrm{cFe} / \mathrm{dFe} \\
(\%)\end{array}$ \\
\hline 3 & 16.49 & 52.35 & 5 & 1.11 & 0.02 & 2 & 0.21 & 0.01 & 2 & 0.91 & 19 & 81 \\
\hline 3 & 16.49 & 52.35 & 122 & 0.62 & 0.02 & 2 & 0.12 & 0.00 & 2 & 0.50 & 20 & 80 \\
\hline 3 & 16.49 & 52.35 & 245 & 0.34 & 0.01 & 4 & 0.14 & 0.01 & 3 & 0.19 & 43 & 57 \\
\hline 3 & 16.49 & 52.35 & 489 & 0.62 & 0.02 & 2 & 0.44 & 0.03 & 2 & 0.18 & 71 & 29 \\
\hline 3 & 16.49 & 52.35 & 685 & 0.80 & 0.04 & 2 & 0.50 & 0.02 & 2 & 0.30 & 62 & 38 \\
\hline 3 & 16.49 & 52.35 & 978 & 0.80 & 0.01 & 2 & 0.49 & 0.01 & 2 & 0.31 & 62 & 38 \\
\hline 6 & 19.96 & 45.08 & 5 & 0.81 & 0.01 & 4 & 0.48 & 0.01 & 2 & 0.33 & 59 & 41 \\
\hline 6 & 19.96 & 45.08 & 126 & 0.29 & 0.01 & 2 & 0.13 & 0.01 & 2 & 0.16 & 44 & 56 \\
\hline 6 & 19.96 & 45.08 & 251 & 0.33 & 0.01 & 3 & 0.22 & 0.01 & 3 & 0.10 & 68 & 32 \\
\hline 6 & 19.96 & 45.08 & 503 & 0.53 & 0.01 & 2 & 0.40 & 0.01 & 2 & 0.13 & 75 & 25 \\
\hline 6 & 19.96 & 45.08 & 703 & 0.79 & 0.01 & 3 & 0.36 & 0.01 & 2 & 0.42 & 46 & 54 \\
\hline 6 & 19.96 & 45.08 & 1005 & 0.70 & 0.00 & 2 & 0.29 & 0.01 & 2 & 0.41 & 42 & 58 \\
\hline 9 & 13.07 & 40.63 & 5 & 0.82 & 0.02 & 4 & 0.11 & 0.01 & 3 & 0.71 & 13 & 87 \\
\hline 9 & 13.07 & 40.63 & 125 & 0.27 & 0.00 & 3 & 0.15 & 0.02 & 3 & 0.12 & 56 & 44 \\
\hline 9 & 13.07 & 40.63 & 250 & 0.97 & 0.04 & 2 & 0.57 & 0.03 & 2 & 0.40 & 59 & 41 \\
\hline 9 & 13.07 & 40.63 & 500 & 0.98 & 0.02 & 2 & 0.42 & 0.00 & 2 & 0.56 & 43 & 57 \\
\hline 9 & 13.07 & 40.63 & 700 & 1.08 & 0.02 & 6 & 0.51 & 0.02 & 3 & 0.57 & 47 & 53 \\
\hline 9 & 13.07 & 40.63 & 1000 & 0.87 & 0.04 & 4 & 0.45 & 0.01 & 2 & 0.42 & 52 & 48 \\
\hline 11 & 8.04 & 37.63 & 5 & 0.59 & 0.02 & 2 & 0.08 & 0.02 & 3 & 0.51 & 13 & 87 \\
\hline 11 & 8.04 & 37.63 & 124 & 0.84 & 0.03 & 2 & 0.49 & 0.01 & 3 & 0.36 & 58 & 42 \\
\hline 11 & 8.04 & 37.63 & 248 & 1.12 & 0.03 & 4 & 0.51 & 0.02 & 3 & 0.61 & 46 & 54 \\
\hline 11 & 8.04 & 37.63 & 496 & 1.17 & 0.02 & 2 & 0.65 & 0.01 & 2 & 0.51 & 56 & 44 \\
\hline 11 & 8.04 & 37.63 & 694 & 0.89 & 0.03 & 3 & 0.46 & 0.04 & 5 & 0.43 & 51 & 49 \\
\hline 11 & 8.04 & 37.63 & 991 & 0.85 & 0.03 & 4 & 0.63 & 0.02 & 5 & 0.22 & 74 & 26 \\
\hline 13 & 12.81 & 33.02 & 5 & 0.45 & 0.01 & 4 & 0.09 & 0.03 & 2 & 0.36 & 20 & 80 \\
\hline 13 & 12.81 & 33.02 & 28 & 0.41 & 0.00 & 2 & 0.08 & 0.02 & 2 & 0.33 & 19 & 81 \\
\hline 13 & 12.81 & 33.02 & 74 & 0.15 & 0.03 & 3 & 0.13 & 0.02 & 3 & 0.03 & 83 & 17 \\
\hline 13 & 12.81 & 33.02 & 97 & 0.47 & 0.00 & 2 & 0.19 & 0.03 & 3 & 0.28 & 41 & 59 \\
\hline 13 & 12.81 & 33.02 & 116 & 1.01 & 0.00 & 3 & 0.42 & 0.02 & 4 & 0.59 & 42 & 58 \\
\hline 13 & 12.81 & 33.02 & 162 & 1.14 & 0.03 & 2 & 0.57 & 0.03 & 2 & 0.58 & 50 & 50 \\
\hline 13 & 12.81 & 33.02 & 247 & 1.15 & 0.03 & 2 & 0.75 & 0.03 & 7 & 0.40 & 65 & 35 \\
\hline 13 & 12.81 & 33.02 & 370 & 1.30 & 0.03 & 4 & 0.59 & 0.01 & 2 & 0.72 & 45 & 55 \\
\hline 13 & 12.81 & 33.02 & 493 & 1.23 & 0.02 & 3 & 0.66 & 0.02 & 6 & 0.57 & 53 & 47 \\
\hline 13 & 12.81 & 33.02 & 690 & 1.25 & 0.03 & 3 & 0.56 & 0.02 & 3 & 0.69 & 45 & 55 \\
\hline 13 & 12.81 & 33.02 & 854 & 1.19 & 0.01 & 5 & 0.67 & 0.01 & 2 & 0.52 & 56 & 44 \\
\hline 13 & 12.81 & 33.02 & 1005 & 0.92 & 0.02 & 3 & 0.57 & 0.01 & 2 & 0.35 & 62 & 38 \\
\hline 13 & 12.81 & 33.02 & 1256 & 0.71 & 0.05 & 3 & 0.39 & 0.00 & 2 & 0.32 & 55 & 45 \\
\hline 13 & 12.81 & 33.02 & 1759 & ?1.19 & 0.01 & 3 & 0.34 & 0.01 & 3 & $? 0.85$ & & \\
\hline 13 & 12.81 & 33.02 & 2408 & ?1.52 & 0.06 & 3 & $? 0.44$ & 0.02 & 4 & $? 1.08$ & & \\
\hline 13 & 12.81 & 33.02 & 3111 & 0.71 & 0.03 & 3 & 0.28 & 0.01 & 2 & 0.42 & 40 & 60 \\
\hline 13 & 12.81 & 33.02 & 3833 & 0.81 & 0.02 & 2 & 0.30 & 0.02 & 2 & 0.51 & 37 & 63 \\
\hline 13 & 12.81 & 33.02 & 4958 & 0.81 & 0.04 & 3 & 0.27 & 0.01 & 3 & 0.53 & 34 & 66 \\
\hline
\end{tabular}




\begin{tabular}{ccccccccccccc}
\hline Sta. & $\begin{array}{c}\text { Lat. } \\
\left({ }^{\circ} \mathrm{N}\right)\end{array}$ & $\begin{array}{c}\text { Long. } \\
\left({ }^{\circ} \mathrm{W}\right)\end{array}$ & $\begin{array}{c}\text { Depth } \\
(\mathrm{m})\end{array}$ & $\begin{array}{c}\mathrm{dFe} \\
\mathrm{nmol} / \mathrm{kg}\end{array}$ & $\begin{array}{c}1 \\
\mathrm{SD}\end{array}$ & $\mathrm{n}$ & $\begin{array}{c}\mathrm{sFe} \\
\mathrm{nmol} / \mathrm{kg}\end{array}$ & $\begin{array}{c}1 \\
\mathrm{SD}\end{array}$ & $\begin{array}{c}\mathrm{n} \\
(\mathrm{nmol} / \mathrm{kg})\end{array}$ & $\begin{array}{c}\mathrm{sFe} / \mathrm{dFe} \\
(\%)\end{array}$ & $\begin{array}{c}\mathrm{cFe} / \mathrm{dFe} \\
(\%)\end{array}$ \\
\hline 17 & 11.71 & 26.84 & 5 & 0.63 & 0.01 & 2 & 0.21 & 0.02 & 2 & 0.43 & 33 & 67 \\
17 & 11.71 & 26.84 & 496 & 1.08 & 0.03 & 6 & 0.67 & 0.02 & 3 & 0.42 & 62 & 38 \\
& & & & & & & & & & & & \\
22 & 14.57 & 21.88 & 5 & 0.65 & 0.02 & 3 & 0.14 & 0.01 & 3 & 0.51 & 21 & 79 \\
22 & 14.57 & 21.88 & 126 & 1.37 & 0.02 & 3 & 0.59 & 0.02 & 3 & 0.78 & 43 & 57 \\
22 & 14.57 & 21.88 & 503 & 1.16 & 0.05 & 6 & 0.61 & 0.01 & 2 & 0.55 & 52 & 48 \\
\hline
\end{tabular}




\section{Chapter 7}

\section{Partitioning of dissolved iron into soluble and colloidal phases along the U.S. GEOTRACES North Atlantic Zonal transect}

In prep for the GEOTRACES North Atlantic special issue of Deep-Sea Research II.

Jessica N. Fitzsimmons* ${ }^{* 1,2}$, Gonzalo G. Carrasco ${ }^{2}$, Jingfeng $\mathrm{Wu}^{3}$, Mariko Hatta ${ }^{4}$, Christopher I. Measures ${ }^{4}$, and Edward A. Boyle ${ }^{2}$

\footnotetext{
${ }^{1}$ MIT/WHOI Joint Program in Chemical Oceanography, MIT E25-615, 45 Carleton St., Cambridge, MA 02142; 1-617-324-0283; jessfitz@mit.edu

${ }^{2}$ Department of Earth Atmospheric and Planetary Sciences, MIT, 45 Carleton St., Cambridge, MA 02142; gcarrasc@mit.edu; eaboyle@mit.edu; 1-617-253-3388

${ }^{3}$ Rosenstiel School for Marine and Atmospheric Sciences, University of Miami, 4600 Rickenbacker Causeway, Miami, FL 33149; 1-305-421-4714; jwu@rsmas.miami.edu

${ }^{4}$ School of Ocean and Earth Science and Technology, University of Hawai'i at Manoa, 1000 Pope Road, Honolulu, HI 96822; mhatta@hawaii.edu; chrism@soest.hawaii.edu; 1808-956-8693
}

* designates the corresponding author 


\subsection{Introduction}

The international GEOTRACES program endeavors to determine the global distribution of trace elements and their isotopes while also constraining the fluxes and processes controlling these distributions. One of the highest priority metals investigated by GEOTRACES is dissolved iron ( $\mathrm{dFe})$, which is known to be an essential micronutrient for photosynthesis and nitrogen fixation (Morel et al., 2003). However, the thermodynamically favored redox state of $\mathrm{dFe}$ in the oxic open ocean, $\mathrm{Fe}(\mathrm{III})$, is largely insoluble, causing $\mathrm{dFe}$ concentrations to fall to levels that limit phytoplankton growth in nearly $40 \%$ of the surface ocean (Moore et al., 2002). Based on electrochemical data, strong organic Fe-binding ligands are thought to bind $>99.9 \%$ of marine dFe, buffering its concentration above biologically limiting levels in many regions of the global ocean (Rue and Bruland, 1995). However, the identity of these ligands is largely unknown (Gledhill and Buck, 2012). One of our greatest motivators for studying Fe is to link external Fe fluxes to biological uptake of Fe as a micronutrient, and our ambiguous understanding of Fe speciation limits our ability to understand these chemical transformations.

One tool we can use to explore the form, composition, and cycling of $\mathrm{dFe}$ in the ocean is the size partitioning of dissolved Fe species. We know that $\mathrm{dFe}$ (here defined as $<0.2 \mu \mathrm{m})$ is composed of both soluble $(\mathrm{sFe}<0.02 \mu \mathrm{m})$ and colloidal $(0.02 \mu \mathrm{m}<\mathrm{cFe}<$ $0.2 \mu \mathrm{m}$ ) size fractions, and the partitioning across both geographic locations and depths is highly variable, with colloids contributing 0-90\% of the dFe phase (Bergquist et al., 2007; Fitzsimmons and Boyle, in review-b; Wu et al., 2001). Colloidal Fe comprises particles so small that they do not sink yet pass through the $0.2 \mu \mathrm{m}$ filter separating dissolved from particulate Fe, while soluble Fe largely comprises truly dissolved Fe species. Resolving this physical description of dFe size partitioning with the chemical composition of $\mathrm{dFe}$ composition is, however, a greater challenge. Since nearly all $\mathrm{dFe}$ is assumed to be organically bound in the open ocean (Rue and Bruland, 1995), as a first assumption we can assume this holds for sFe and cFe as well. This assessment is our best guess of the speciation of the two dFe size fractions, as not many studies actually 
measuring the chemical binding environment of Fe have been completed; some energy dispersive spectroscopy measurements on colloids imaged by electron microscopy supported the hypothesis that marine colloidal $\mathrm{Fe}$ is organically bound, while estuarine and coastal colloidal Fe had an inorganic Fe oxyhydroxide component not observed in the open ocean (Wells and Goldberg, 1992). However, recent studies have found exceptions to the general assumption that $\mathrm{dFe}$ is organically bound. Using synchrotron technology, von der Heyden et al. (2013) found that colloidal and particulate Fe in the surface Southern Ocean had an inorganic magnetite component. We will return to the idea of an inorganic colloidal Fe component (here termed "nanoparticulate") later in the discussion. For the purposes of this paper, unless otherwise indicated or discussed we will assume that both $\mathrm{sFe}$ and $\mathrm{cFe}$ are organically-bound in the open ocean, since most evidence supports this conclusion (Rue and Bruland, 1995; Wells and Goldberg, 1992).

The size partitioning of dFe affects marine Fe biogeochemistry in two important ways. First, colloidal Fe has been shown to be composed of discrete bits of material that have aggregated into or been trapped by a particle of colloidal size (Wells and Goldberg, 1992); thus, colloidal $\mathrm{Fe}$ has been hypothesized to be an actively aggregating pool that links the soluble and particulate phases of Fe via initial sorption followed by successive aggregation (Honeyman and Santschi, 1989). Not only does this size partitioning have implications for the chemical composition of the $\mathrm{dFe}$ pool, but it also can impact the fate and lifetime of $\mathrm{dFe}$ in any given location, depending on the relative rates of sorption/desoprtion and aggregation/disaggregation between the various $\mathrm{Fe}$ fractions. Secondly, the speciation of Fe has a direct impact on the bioavailability of Fe, with different species preferring different forms of dFe (Hassler and Schoemann, 2009; Hutchins et al., 1999). While very few studies have assessed the bioavailability of $\mathrm{dFe}$ from various size fractions, preliminary results indicate that soluble $\mathrm{Fe}$ is preferred, and colloidal $\mathrm{Fe}$ is only indirectly bioavailable after equilibration through the sFe pool (Chen and Wang, 2001; Wang and Dei, 2003); inorganic Fe colloids as small as 6-50 Fe atoms were not bioavailable to diatoms (Rich and Morel, 1990). If these studies are taken as representative of total $\mathrm{dFe}$ bioavailability in the open ocean, then an understanding of the 
$\mathrm{dFe}$ partitioning between soluble and colloidal phases is required in order to best assess dFe bioavailability.

In this paper, we describe the size partitioning of dFe between soluble and colloidal species across the U.S. GEOTRACES North Atlantic Transect. While several studies have investigated the size fractionation of dFe in the North Atlantic (see summary in Fitzsimmons and Boyle, in review-a), there is no consensus on the $\mathrm{dFe}$ partitioning pattern. Bergquist et al. (2007) reported that sFe concentrations in the central Atlantic were relatively constant with depth near $0.35 \mathrm{nmol} / \mathrm{kg}$, while cFe concentrations were highly variable, concluding that a dynamic colloidal phase controls dFe variability alongside relatively invariant $\mathrm{sFe}$. With better spatial coverage in the tropical North Atlantic, Fitzsimmons and Boyle (in review-b) found sFe to be more variable than seen by Bergquist et al. and concluded that both $\mathrm{sFe}$ and $\mathrm{cFe}$ play an active role in controlling $\mathrm{dFe}$ distributions. The new data presented here is the first full ocean-basin transect of $\mathrm{dFe}$ size partitioning ever obtained, with higher spatial and depth resolution than any prior study. This transect also encompasses several unique Fe inputs and biogeochemical regimes that highlight changes in $\mathrm{dFe}$ size partitioning, including the North African dust flux to the surface ocean, the TAG hydrothermal plume, and the Mauritanian oxygen minimum zone (OMZ). We will assess the influence of each of these sources on the observed dFe size partitioning, as well as offer a consensus of the general partitioning pattern of $\mathrm{dFe}$ in the North Atlantic Ocean.

\subsection{Methods}

$\mathrm{dFe}$ size partitioning was measured at 28 stations in the North Atlantic Ocean aboard the R/V Knorr on the U.S. GEOTRACES North Atlantic Zonal Transect (NAZT; station locations in Figure 1). Sampling took place on two cruise legs: the 2010 cruise (USGT10) sailed from Lisbon, Portugal, to Mindelo, Cape Verde Islands, from 14 October to 4 November, 2010, and the 2011 cruise (USGT11) sailed from Woods Hole, MA, to Praia, Cape Verde Islands, from 6 November to 11 December, 2011. 
Uncontaminated seawater was collected using the U.S. GEOTRACES GO-FLO rosette by the methods described in Cutter and Bruland (2012). After successful rosette deployment, GO-FLO bottles were carried individually into an ISO 5-rated clean van, where the seawater was filtered through $0.2 \mu \mathrm{m}$ Pall Acropak-200 ${ }^{\mathrm{TM}}$ Supor ${ }^{\circledR}$ capsule filters under $\sim 0.4 \mathrm{~atm}$ of HEPA-filtered air. Filtration protocols were identical to those described by Fitzsimmons and Boyle (2012), except that the Acropak filters were precleaned by soaking overnight in filtered surface seawater acidified to $\mathrm{pH} 2$, after which they were flushed with $5 \mathrm{~L}$ of unacidified $0.2 \mu \mathrm{m}$-filtered surface seawater and stored empty in the refrigerator until use. Surface samples were collected using the GeoFish system of the Bruland lab, which employs all PFA tubing attached to a vane that coasts at $\sim 3 \mathrm{~m}$ depth suspended from a boom off the starboard side of the ship during forward motion at up to 12 knot ship speeds. An all-PFA diaphragm pump sips clean seawater at $\sim 8$ psi pressure first through a $0.45 \mu \mathrm{m}$ Osmonics (PFA) filter and then through a $0.2 \mu \mathrm{m}$ PCTE filter mesh held in a polyproylene housing. The filtrates for sFe analyses were filtered into $500 \mathrm{~mL}$ HDPE bottles after three bottle rinses; the secondary sFe filtration is described below. The filtrates for dFe analyses $(<0.2 \mu \mathrm{m})$ were taken into 1L LDPE bottles and were analyzed in the laboratory of Jingfeng $\mathrm{Wu}$ at the RSMAS at the University of Miami by the methods described in Wu and Boyle (1998). Fe procedure blanks and reported detection limits for the RSMAS method are shown in Table 1, along with comprehensive lab analyses of SAFe standard reference materials.

A different sFe filtration method was used on each of the two cruises, and these two methods are described, summarized, and intercalibrated in Fitzsimmons and Boyle (in review-a). In 2010, a cross flow filtration (CFF) technique using a Millipore Pellicon XL (PLCGC) regenerated cellulose membrane with a 10kDa nominal molecular weight cutoff (Pellicon) was used in static mode to collect $\mathrm{sFe}$ samples after the system was conditioned with $300-350 \mathrm{~mL}$ of sample seawater. In 2011, we instead used $47 \mathrm{~mm}$ Anopore membrane filters made of alumina with $0.02 \mu \mathrm{m}$ pores on an offline, all-Teflon filter rig (Savillex) to collect sFe samples after the filters were rinsed with acid, clean water, and sample seawater. While the amount of sFe passing through both filter types is 
impacted by the natural variability in the $\mathrm{dFe}$ size distribution as a function of sampling location, the average sFe through the CFF system was only $74 \pm 21 \%$ of that passing through the Anopore filters on this cruise, indicating that CFF has a smaller nominal pore size ( $n=23$ depths from the North Atlantic, Fitzsimmons and Boyle, in review-a). These operational size definitions influence the interpretation of the results of this paper, since the use of Anopore filters includes the $10 \mathrm{kDa}-0.02 \mu \mathrm{m} \mathrm{dFe} \mathrm{compounds} \mathrm{in} \mathrm{the} \mathrm{soluble} \mathrm{Fe}$ fraction (USGT11 samples), while the $10 \mathrm{kDa}-0.02 \mu \mathrm{m}$ size fraction is interpreted as colloidal Fe using CFF (USGT10 samples). Thus, the sFe collected using CFF is closer to the ideal "truly dissolved" fraction because of its smaller pore size.

sFe samples were analyzed in triplicate for their Fe concentration at MIT by isotope dilution inductively-coupled plasma mass spectrometry (ID-ICP-MS) on a hexapole collision cell IsoProbe ICP-MS. The ID-ICP-MS method employs a ${ }^{54} \mathrm{Fe}-$-spike and batch pre-concentration with nitrilotriacetate resin (Lee et al., 2011). Fe procedure blanks and reported detection limits are shown in Table 1, along with comprehensive lab analyses of SAFe standard reference materials. The measured Fe concentrations in the SAFe reference samples are shown to be identical to consensus values, indicating the high integrity of the sFe analyses reported here.

\subsection{Results and Discussion}

The distribution of $\mathrm{dFe}$ and the measured partitioning into soluble and colloidal phases across the transect are shown in Figure 2, and all $\mathrm{dFe}$ and sFe data is tabulated online at the Biological and Chemical Oceanography Data Management Office under the project "U.S. GEOTRACES North Atlantic Transect." An assessment of North Atlantic $\mathrm{dFe}$ biogeochemistry in light of previous studies and general North Atlantic hydrography, are the subject of another paper (Hatta et al., in prep). The major Fe sources to the subtropical North Atlantic, however, are summarized here and can be inferred from Figure 2a. The most obvious $\mathrm{dFe}$ feature is the hotspot of $\mathrm{dFe}$ up to $66.4 \mathrm{nmol} / \mathrm{kg}$ that is observed at $3000-3500 \mathrm{~m}$ at USGT11-16, which is attributable to Fe inputs from the TAG hydrothermal system. In the surface ocean (more clearly seen in Figure 3), dFe 
enrichments often in excess of $1 \mathrm{nmol} / \mathrm{kg}$ are attributed to the solubilization of aerosol $\mathrm{Fe}$ blown in from continental sources, including the North African continent and industrialized North America and Europe. Finally, there appear to be sources of dFe emanating from both margins. The western $\mathrm{dFe}$ maximum from 1000-2500m in excess of $1 \mathrm{nmol} / \mathrm{kg}$ corresponds to the depth range of Labrador Sea Water (LSW), extending across the western boundary to the Bermuda Atlantic Time Series (BATS) station (USGT11-10). The eastern dFe maximum also in excess of $1 \mathrm{nmol} / \mathrm{kg}$ is coincident with the Mauritanian $\mathrm{OMZ}$ and is not thought to derive from a margin Fe source but rather to remineralization of high Fe:C organic material (Fitzsimmons et al., 2013).

In this paper, we will focus on the size partitioning of $\mathrm{dFe}$ into soluble and colloidal phases across the GEOTRACES NAZT, and we oganize our discussion as follows. In section 3.1, we discuss dFe partitioning in each of the major Fe source regions, and then in Section 3.2, we describe how internal oceanic cycling of dFe impacts the observed dFe size fractionation. Finally, in Section 3.3 we propose a new model of the patterns and mechanisms determining the dFe size fractionation that synthesizes all existing data on $\mathrm{dFe}$ size partitioning in the North Atlantic Ocean.

\subsection{1 dFe size partitioning from the major Fe sources}

7.3.1.1 Aerosol deposition: the surface ocean - The North Atlantic Ocean is directly downwind of North African dust sources and is thus predicted to receive the highest dust loadings on the planet (Jickells et al., 2005). As 3.5\% of dust by weight is composed of Fe (Taylor and McLennan, 1985), high dust loadings should result in high Fe inputs to the surface ocean, and accordingly the literature includes several reports of elevated surface dFe concentrations in the North Atlantic (Bergquist and Boyle, 2006; Croot et al., 2004; Fitzsimmons et al., 2013; Measures et al., 2008; Rijkenberg et al., 2008; Rijkenberg et al., 2012). On the GEOTRACES NAZT, aerosol measurements (Shelley and Landing, 2013) recorded a range of Fe loadings from 1-5000 ng of Fe per $\mathrm{m}^{3}$ of air, and the Fe solubility also varied across the four aerosol end-members (North Africa, North America, Europe, and "marine"). Thus, high surface dFe concentrations over much of the GEOTRACES transect were expected, and elevated surface ocean $\mathrm{dFe}$ 
concentrations $\geq 1.0 \mathrm{nmol} / \mathrm{kg}$ during the NAZT confirmed these expectations (Hatta et al., in prep).

The size partitioning of surface dFe is shown in Figure 3. Despite the surface enrichment of $\mathrm{dFe}$, soluble Fe occurred at low concentrations averaging $0.16 \pm 0.05$ $\mathrm{nmol} / \mathrm{kg}$ during USGT11, and the colloidal contribution to $\mathrm{dFe}$ (hereafter referred to as $\% \mathrm{cFe}$ ) was $79 \pm 6 \%$. This high colloidal contribution is identical to the $\% \mathrm{cFe}$ of $80 \pm 7 \%$ determined from six stations in the tropical North Atlantic (Fitzsimmons and Boyle, in review-b, station locations in Figure 1) and thus appears to be representative of dFe size partitioning in the surface tropical and subtropical Atlantic underlying the North African dust plume. It seems, then, that aerosol Fe is preferentially maintained in the colloidal size fraction, which has been observed previously by others (Bergquist et al., 2007; Fitzsimmons and Boyle, in review-b; Wu et al., 2001). It is possible that aerosols directly release $\mathrm{Fe}$ into both soluble and colloidal size fractions, after which most of the $\mathrm{sFe}$ is taken up rapidly by microorganisms so that it is nearly absent in the mixed layer. However, perhaps surprisingly given the variability in surface primary production from the gyre to the upwelling region along Mauritania, we do not find $\mathrm{sFe}>0.22 \mathrm{nmol} / \mathrm{kg}$ in the surface at any stations except USGT10-07, in which case it might be simpler to assume that aerosol $\mathrm{Fe}$ is deposited directly into the colloidal size fraction. Lab-based aerosol leaching experiments are also consistent with preferential aerosol Fe deposition directly into the colloidal-sized dFe pool (Aguilar-Islas et al., 2010), although one can be concerned whether excess Fe binding ligands are saturated during these dust leaching experiments, which would generate colloidal Fe oxyhydroxides and bias the resulting size partitioning. Our data cannot resolve these two mechanisms but only indicate that following dust input colloidal Fe often composes much of the resulting dFe surface maximum, while lower dust regions such as the Subarctic Pacific (Nishioka et al., 2001b) and Southern Ocean (Boye et al., 2010) do not have these cFe surface maxima. Finally, it is also noteworthy that dFe size partitioning at station USGT11-03, which is influenced by (presumably anthropogenic) North American aerosol sources (as determined by 
Shelley and Landing, 2013), shows the same surface dFe partitioning into the colloidal phase as locations receiving $\mathrm{dFe}$ inputs from North African aerosols.

The surface colloidal Fe maximum could be composed of any of three possible forms: Fe bound by colloidal-sized organic ligands after solubilization from dust, colloidal-sized bits of dust that physically separated from the dust particles upon impacting the surface ocean (resulting in an inorganic, nanoparticulate cFe composition), or Fe that was initially solubilized from dust in the surface ocean but then re-precipitated in situ (also resulting in a nanoparticulate cFe composition, likely amorphous $\mathrm{Fe}$ oxyhydroxides). An exploration of which of these processes might be dominant along this North Atlantic transect is the subject of another study (Fitzsimmons et al., in prep-a).

Nonetheless, which of these $\mathrm{cFe}$ forms comprises the surface $\mathrm{cFe}$ pool has important implications for its availability to phytoplankton. Early experiments suggested that natural orgnically-bound colloidal Fe is less bioavailable than soluble Fe (Chen et al., 2003; Chen and Wang, 2001; Wang and Dei, 2003). However, recent studies have suggested that certain organically-bound colloidal Fe compounds might be highly bioavailable, for instance colloidal-sized Fe bound to saccharides and biologicallyproduced exopolysaccharides (Hassler et al., 2011a; Hassler et al., 2011b). Inorganic colloidal Fe (nanoparticles) as small as 6-50 Fe atoms, in contrast, is not available to diatoms (Rich and Morel, 1990). There is some evidence of an inorganic component to the colloidal Fe pool in the surface ocean: von der Heyden et al. (2012) found that in the Southern Ocean Subantarctic Front underlying Patagonian dust plumes, particulate and colloidal Fe speciation was dominated by inorganic magnetite. A large inorganic component to surface colloidal Fe would significantly impact our understanding of $\mathrm{dFe}$ bioavailability and warrants further study. We will return to the question of the composition of the surface cFe pool in section 7.3.3.

It is noteworthy that soluble $\mathrm{Fe}$, while always at low concentrations of $0.1-0.2$ $\mathrm{nmol} / \mathrm{kg}$, was never depleted to zero (Figure 3), which is somewhat unexpected in the mixed layer if we are correct in assuming that $\mathrm{sFe}$ is the more bioavailable fraction. Fitzsimmons and Boyle (in review-b: Chapter 6) hypothesized that this sFe might be 
relatively refractory, potentially bound by ligands so strongly that the Fe is not accessible. Alternatively, this sFe could be so available that we are measuring a pseudo"steady state" sFe concentration that is rapidly biologically cycled such that it is always measurable. However, an equally likely explanation is that the sFe pool is composed of $\mathrm{Fe}(\mathrm{II})$ produced photochemically in the surface ocean. Sunlight can reduce Fe(III) to $\mathrm{Fe}(\mathrm{II})$ (Moffett, 2001), and because marine Fe(II) has never been shown to be bound by organic ligands, our primary hypothesis is that Fe(II) would fall into the smaller soluble Fe size fraction. While organically-bound cFe could also undergo photoreduction, perhaps with the $\mathrm{Fe}(\mathrm{II})$ remaining trapped inside the colloidal organic matrix to result in a colloidal Fe(II) species, we suggest that much of the non-zero soluble Fe in the surface ocean of the North Atlantic might be composed of photochemically-sustained Fe(II). Up to $50 \%$ of the $\mathrm{dFe}$ in the western subarctic Pacific was found to be composed of Fe(II) at mid-day (Roy et al., 2008), and similarly we might expect that a significant portion of the smallest Fe size fraction, sFe, may be composed of Fe(II) in the North Atlantic.

7.3.1.2 Eastern margin: Mauritanian oxygen minimum zone (OMZ) - Nearest the African coast, a dFe maximum within the oxygen minimum zone (OMZ) reached concentrations of 1.0-1.85 nmol/kg and extended westward past the TENATSO timeseries station (station USGT10-12, reoccupied as USGT11-24) to station USGT11-22 (Figure 2a, Figure 4). This dFe maximum was centered between 350-500m depth, coincident with the $\mathrm{OMZ}$ that had oxygen concentrations as low as $40 \mu \mathrm{mol} / \mathrm{kg}$ near Mauritania (Hatta et al., in prep), but extended to $1500 \mathrm{~m}$ depth. dFe enrichments in the tropical North Atlantic OMZ have been reported previously (Bergquist and Boyle, 2006; Fitzsimmons et al., 2013; Measures et al., 2008; Rijkenberg et al., 2012). While it might appear as if this $\mathrm{OMZ} \mathrm{dFe}$ plume emanates from the African margin, we do not see evidence of $\mathrm{Fe}(\mathrm{II})$, dissolved manganese, or ${ }^{228} \mathrm{Ra}$ reaching far beyond station USGT1010, all of which would be expected from a reducing sediments source (Hatta et al., in prep). Linear Fe:AOU correlations instead indicate that this $\mathrm{dFe}$ enrichment is caused by remineralization of high Fe:C organic material (Fitzsimmons et al., 2013, Hatta et al., in prep). 
Thus, the observed dFe size fractionation along the Mauritanian transect (stations USGT10-09 through USGT10-12) reveals the effects of OMZ remineralization on $\mathrm{dFe}$ size partitioning (Figure 4). Both soluble and colloidal Fe have maxima coincident with the dFe maximum, suggesting that remineralization partitions regenerated Fe into both soluble and colloidal size fractions. The partitioning pattern is clearest in the distribution of $\% \mathrm{cFe}$ in Figure $4 \mathrm{~d}$ : the $\% \mathrm{cFe}$ is nearly constant at $50-70 \%$ across this transect, and thus remineralization drives a nearly constant $\mathrm{dFe}$ partitioning in this region. The $50-70 \%$ cFe along the Mauritanian transect is higher than the 40-60\% cFe at stations USGT11-22 and USGT11-24 (Figure 2d), despite being in the same region, because of the change in methodology used to collect sFe samples on the two cruises; the $0.02 \mu \mathrm{m}$ Anodisc membranes used on USGT11 have a larger pore size than the $10 \mathrm{kDa}$ CFF filter used on USGT10 (Fitzsimmons and Boyle, in review-a), resulting in a higher \%cFe on the 2010 sections than on the 2011 sections. The effects of remineralization on $\mathrm{dFe}$ partitioning will be further discussed in sections 7.3.2.2 and 7.3.3.

Fitzsimmons and Boyle (in review-b, Chapter 6) suggested that along the edges of the North Atlantic OMZ, where oxygen concentrations are 100-110 $\mu \mathrm{mol} / \mathrm{kg}$ at their minimum, that a unique $\mathrm{dFe}$ partitioning favors the formation of excess colloids (compared to the end-members) when subtropical gyre waters mix with OMZ waters. We only sampled one station that satisfied this intermediate oxygen concentration, USGT1122. In the OMZ depths of this station, however, the $\mathrm{sFe}$ was $0.375 \pm 0.014 \mathrm{nmol} / \mathrm{kg}(\mathrm{n}=3)$, identical to the $\sim 0.4 \mathrm{nmol} / \mathrm{kg}$ reported by Fitzsimmons and Boyle, and cFe composed 55$60 \%$ of $\mathrm{dFe}$, identical to the $58 \pm 2 \%$ in Fitzsimmons and Boyle. Thus, our GEOTRACES data on the more northern edge of the OMZ than sampled by Fitzsimmons and Boyle captures the same excess of colloidal Fe. While only an assessment of the Fe content in sediments along the edge of the OMZ could confirm this, the excess cFe could be serving as an output pathway for $\mathrm{dFe}$ from the $\mathrm{OMZ}$. This has been shown in sediments surrounding the Peruvian OMZ where Fe redox chemistry plays a role in driving precipitation and loss of OMZ Fe(II) (Scholz et al. 2013). A non-redox mechanism would 
need to be implicated in the North Atlantic, though the colloidal Fe excess implies a role of increased aggregation.

Also, the occupation of the TENATSO time series station on both cruise legs (stations 2010-12 and 2011-24) afforded us an opportunity to compare the two filtration methods used in this project over a full-depth profile. dFe concentrations were relatively constant over the two sampling years (Figure 5a), so natural variability in dFe was not an issue during this comparison (see more on the TENATSO time-series in Hatta et al., in prep). At the 24 depths sampled at TENATSO, sFe collected using CFF (USGT10) was on average $75 \pm 21 \%$ of that collected by Anopore filtration (USGT11; Figure 5b), and the majority of this difference is attributed to a change in the effective pore sizes of the two filters used (Fitzsimmons and Boyle, in review-a).

However, the $21 \%$ standard deviation in this ratio of sFe concentrations results from the natural variability in the size distribution and/or composition of dFe (variability in the $10 \mathrm{kDa}-0.02 \mu \mathrm{m}$ size fraction), which is currently unknown, providing an oceanographic application to this comparison effort. There are two main depth ranges where the $\mathrm{CFF} /$ Anopore filtration $\mathrm{sFe}$ ratio falls below $50 \%$ (Figure $5 \mathrm{c}$ ), indicating where there was a large component of $10 \mathrm{kDa}-0.02 \mu \mathrm{m}$ (smallest colloidal Fe) material: the deep chlorophyll maximum (DCM) at $70 \mathrm{~m}$ and the upper portion of the oxygen minimum zone $(235 \mathrm{~m})$. Three processes could result in an enhanced abundance of small colloids at these depths: (1) a direct input of small colloids, (2) increased aggregation/disaggregation into the small colloid fraction, or (3) a unique ligand partitioning that forced $\mathrm{dFe}$ to favor the smallest colloid sizes. The low dFe concentrations at the DCM make the likelihood of an analytical artifact quite high, so we will not consider the DCM partitioning comparison further. At $235 \mathrm{~m}$, however, $\mathrm{dFe}$ concentrations have begun to increase (Hatta et al., in prep) and also the suspended particulate $\mathrm{Ba}, \mathrm{Fe}$, and $\mathrm{Al}$ reach their maxima (Ohnemus and Lam, 2013), indicating the depths at which disaggregation of large particles is occurring. Thus, the enrichment in small-colloidal Fe at $235 \mathrm{~m}$ is likely a result of particle disaggregation, all the way to the smallest $10 \mathrm{kDa}-0.02 \mu \mathrm{m}$ size. In contrast, small colloids in the $10 \mathrm{kDa}-0.02 \mu \mathrm{m}$ size fraction are negligible in the abyssal ocean $(2500-3500 \mathrm{~m})$, 
despite the abundance of larger colloids $(0.02-0.2 \mu \mathrm{m})$ at concentrations of $0.35-0.55$ $\mathrm{nmol} / \mathrm{kg}$.

7.3.1.3 Western boundary (Line W) - A dFe maximum of $0.8-1.2 \mathrm{nmol} / \mathrm{kg}$ is apparent in the western region of the transect (USGT11-02 through -10), extending throughout the Line W transect at 400-2500m depth, reaching even the BATS station from 900-2000m depth (Figure 2a). As described in Hatta et al. (in prep), this dFe feature is coincident with enhanced CFCs present in Labrador Sea Water (LSW, Smethie et al., 2013); LSW has been found to circulate along the deep western boundary current at the continental slope (Talley and McCartney, 1982) as well as into the subtropics via an interior pathway east of the Grand Banks (Bower et al., 2011; Bower et al., 2009). This Line $\mathrm{W}$ dFe enrichment could be a pre-formed Fe signal advected from the surface of the Labrador Sea; however, the observation of enhanced ${ }^{228} \mathrm{Ra}$ in these waters indicates that this water mass has been in contact with sediments during the last $\sim 30$ years (Charette et al., 2013), and LSW may also have acquired excess dFe during transport along slope sediments.

This western basin $\mathrm{dFe}$ enrichment is largely partitioned into the colloidal size fraction, with only $20-40 \%$ contributed by the soluble phase (Figure $2 b-d$ ). As a first approximation, the cFe concentration input by external sources (excluding remineralization) to LSW can be calculated by assuming a $40-60 \% \mathrm{sFe}-\mathrm{cFe} \%$ remineralization ratio (see Section 7.3.2.2) and that all of the sFe measured in LSW was remineralized: the resulting excess of cFe is $0.05-0.30 \mathrm{nmol} / \mathrm{kg}$ in LSW. This excess is either pre-formed $\mathrm{cFe}$ from the surface ocean of the Labrador Sea or $\mathrm{cFe}$ acquired from margin sediments during LSW transit. The $\mathrm{SF}_{6}$ age of this LSW is approximately 25 years since contact with the surface ocean (Smethie et al., 2013), which is shorter than estimates of cFe scavenging residence times in North Atlantic Deep Water (NADW) of $140 \pm 100$ years (Bergquist et al., 2007). This indicates that a pre-formed Labrador Sea cFe could escape scavenging during transit to the subtropics so long as the scavenging residence times in LSW and tropical NADW are the same (debatable since the chemical compositions of high-Fe LSW and abyssal ocean Fe could be very different). When 
considering the possibility of a pre-formed Labrador Sea cFe signal, it is important to note that models of dust input to the global ocean do not predict large dust loadings in the Labrador Sea (Jickells et al., 2005; Mahowald et al., 2005), although surface Labrador Sea waters could acquire Fe enrichments from other sources such as sea ice or glacial meltwaters (Bhatia et al., 2013; Lannuzel et al., 2007). Unfortunately, there are no published $\mathrm{dFe}$ measurements in the surface of the Labrador Sea to confirm or deny these hypotheses. Following the ${ }^{228} \mathrm{Ra}$ data (Charette et al., 2013), we instead hypothesize that LSW cFe was acquired during passage along continental shelf and slope sediments.

In addition to LSW, however, the entire Line W water column (USGT11-01 to USGT11-10) has an enhanced \%cFe of $60-70 \%$ (Figure $2 \mathrm{~d}$ ), which is in contrast to the rest of the GEOTRACES transect that has a \%cFe of $40-60 \%$. The upper $500 \mathrm{~m}$ of Line $\mathrm{W}$ is composed of Shelf/Slope Waters (USGT11-01 through USGT11-06), which flow southward along the continental margin, and Gulf Stream Waters (USGT11-08), which flow northward farther offshore (Joyce et al., 2005). Only the most nearshore stations USGT11-01 and USGT11-02 carried significantly elevated dFe concentrations greater than $0.4 \mathrm{nmol} / \mathrm{kg}$ (Figure $2 \mathrm{a}$ ), but waters from both regions contained a $\geq 60 \%$ colloidal Fe composition. We hypothesize that, similar to LSW, this colloidal Fe may be lithogenic (nanoparticulate) Fe acquired from the continental margin during transport. This is not difficult to believe for the Shelf/Slope Waters, which are in contact with margin sediments and could easily obtain continental Fe, as shown by lithogenic contribution of ${ }^{232}$ Th in Shelf/Slope Waters at USGT11-02 through USGT11-06 (Anderson et al., 2013). The Gulf Stream \%cFe maximum, however, is more difficult to explain since it is not in contact with margin sediments at Line W latitudes, and Gulf Stream waters are not thought to mix freely with cFe-rich Slope Waters (only mild interweaving observed; Bower et al., 1985). The Gulf Stream may carry continental cFe from the Florida Straits, where it was last in contact with margin sediments, or there could have been increased aerosol Fe deposition near USGT11-08 that was preferentially maintained in the colloidal Fe phase (see section 7.3.1.1) to produce the high \%cFe observed. 
Finally, there was an enhancement of $\% \mathrm{cFe}$ to $60-70 \%$ below the LSW layer from 2500-5000m along Line W. dFe concentrations were somewhat lower in these depths ( $\sim 0.6 \mathrm{nmol} / \mathrm{kg})$ compared to LSW waters, and sFe remained consistently low (0.2-0.3 $\mathrm{nmol} / \mathrm{kg}$ ), so it would not have taken much of a cFe input to increase the $\% \mathrm{cFe}$. There is no clear $\mathrm{dFe}$ enrichment associated with the particulate Fe nepheloid layers at stations USGT11-04, -08, and -10 (Lam and Ohnemus, 2013) relative to shallower depths, although there may be a subtle effect on Fe concentrations that contributes to the enhanced \%cFe observed in the deep ocean along Line W. Wells and Goldberg (1994) found evidence for increased colloid volume in deep waters off the Scotian shelf, very near the Line W stations, which they hypothesized was a result of episodic high-flow "storm" events that pushed sediments containing colloidal material into the deep water column (Gross et al., 1988).

In summary, continental $\mathrm{dFe}$ sources appear to dominate $\mathrm{dFe}$ partitioning along Line $\mathrm{W}$ and create an enrichment in colloidal Fe throughout much of the water column in the Western North Atlantic, reaching far beyond the continental slope. Since this enrichment is largely colloidal and presumably derived from contact with margin sediments, there is a possibility that this $\mathrm{cFe}$ is inorganic (nanoparticulate) in composition, perhaps colloidal-sized Fe oxyhydroxides swept up during the flow of waters along the continental margin and slope. Previous studies have also suggested that in coastal and nearshore environments, a portion of the colloidal Fe phase is inorganic (Wells and Goldberg, 1992, 1994), so while these results are not surprising, they must be considered when interpreting the distribution of North Atlantic $\mathrm{dFe}$. The proposition that a portion of dissolved $\mathrm{Fe}$ is comprised of inorganic colloids strays from the prevailing consensus, which posits that organic ligands bind the vast majority of dissolved Fe in the open ocean (Rue and Bruland, 1995). An inorganic portion of dissolved Fe would also have considerable implications for $\mathrm{dFe}$ bioavailability, since even very small inorganic $\mathrm{Fe}$ colloids are not thought to be bioavailable (Rich and Morel, 1990).

7.3.1.4 TAG hydrothermal system - Station USGT11-16 targeted the location of the TAG hydrothermal field in order to sample the proximal impacts of hydrothermal 
venting on the geochemistry of the deep North Atlantic water column. The TAG hydrothermal field is located on the eastern wall of the slow-spreading $(<2 \mathrm{~cm} / \mathrm{y})$ MidAtlantic Ridge rift valley in 3650m water depth (Rona et al., 1986). TAG black smoker vents have been found to release fluids with high $\mathrm{dFe}$ concentrations of $\sim 5.0-5.5 \mathrm{mM}$ (Chiba et al., 2001). A decrease in light transmission at USGT11-16 indicates that we encountered the particle-rich TAG plume, capturing a dFe maximum of $66.4 \mathrm{nmol} / \mathrm{kg}$ at USGT11-16 that appears to be composed almost entirely of colloidal Fe(II); details of the Fe chemistry and speciation in the near-field non-buoyant TAG plume are described in another paper (Appendix 2: Fitzsimmons et al., in prep-b) However, we also sampled two stations (Stations USGT11-14 and USGT11-18) that were each approximately $500 \mathrm{~km}$ away from TAG (to the northwest and southeast, Figure 1), which afforded us the opportunity to determine whether hydrothermal-derived dFe is transported away from the MAR vent system in the dissolved phase, and if so which size fraction of dFe persists. The distal hydrothermal dFe partitioning is the focus of this section.

While no hydrothermal dFe excess was recorded at USGT11-18 to the southeast of TAG, Hatta et al. (in prep) did record a hydrothermal signal of $\sim 1 \mathrm{nmol} / \mathrm{kg} \mathrm{dFe}$ at USGT11-14 (500 km northwest of TAG) at a slightly shallower depth of $2500 \mathrm{~m}$ compared to the $\sim 66.4 \mathrm{nmol} / \mathrm{kg}$ signal at TAG USGT11-16 at 3250m depth (Figure 6). This demonstrates distal transport of dFe and confirms the "leaky vent" hypothesis (Toner et al., 2012) in the North Atlantic that $\mathrm{Fe}$ is transported beyond the immediate MAR vent sites, contributing to broad scale deep ocean dFe. Subtracting background NADW dFe concentrations of $\sim 0.6 \mathrm{nmol} / \mathrm{kg}$, there is an excess of $\sim 0.4 \mathrm{nmol} / \mathrm{kg}$ hydrothermally-derived dFe at Station USGT11-14.

Of this $\sim 0.4 \mathrm{nmol} / \mathrm{kg}$ dFe excess between $2100-3000 \mathrm{~m}$ at the distal USGT11-14 site, soluble Fe contributed $9-18 \%$ (subtracting background $\mathrm{sFe}$ of $0.265 \mathrm{nmol} / \mathrm{kg}$ ). This sFe contribution is higher than the $4-11 \%$ soluble Fe proximal to the TAG site at USGT11-16 (Appendix II: Fitzsimmons et al., in prep-b). Thus, while both soluble and colloidal hydrothermal Fe are lower at USGT11-14 than at USGT11-16 because of precipitation/scavenging, the percent of $\mathrm{dFe}$ that is truly soluble is higher with increasing 
distance from vent fields. This has also been observed in the eastern South Pacific for $\mathrm{dFe}$ released from East Pacific Rise hydrothermal vents (Fitzsimmons et al., in review). This pattern may imply that the soluble fraction "leaks" more from hydrothermal vents, providing a clue about the mechanism of hydrothermal dFe preservation. However, we cannot tell whether the dFe maximum observed at USGT11-14 is derived from TAG or represents distal hydrothermal impacts from other hydrothermal vents along the MAR (vent distributions in Beaulieu, 2010), as a different vent source could partition dFe differently than at TAG and produce the observed USGT11-14 Fe size distribution without preferable persistence of $\mathrm{sFe}$.

\subsection{2 dFe size partitioning due to internal ocean $\mathrm{dFe}$ cycling}

As can be seen in the colloidal Fe distribution in Figure 2c, the dFe size partitioning in the North Atlantic are cannot be due solely to uniquely partitioned $\mathrm{Fe}$ sources because $\mathrm{cFe}$ concentrations in the ocean interior are also quite variable; thus, marine $\mathrm{dFe}$ partitioning must also be impacted by internal ocean processes that transform dFe between different size fractions. As described in section 3.3, aggregation/disaggregation (or sorption/desorption) between soluble and colloidal phases can explain a portion of this variability in size partitioning, potentially driven abiotically by the physical circulation and mixing of the oceans or by the interaction of marine particles. Alternatively, the internal ocean dFe partitioning could be driven by the biological pump. There are two places where biological aggregation/disaggregation might be most likely to occur: in the mixed layer/deep chlorophyll maximum (DCM) regions of the upper ocean where abundant microorganisms are active and at depths where oxygen minima (or apparent oxygen utilization, AOU, maxima) indicate that remineralization is occurring. We discuss each of these below, as well as the abyssal ocean dFe partitioning pattern.

7.3.2.1 Deep chlorophyll maximum (DCM) - Several studies of dFe size partitioning in the North Atlantic have shown colloidal Fe minima in the deep chlorophyll maxima (DCM; Bergquist et al., 2007; Fitzsimmons and Boyle, in review-b; Ussher et al., 2010). Similarly, along the US GEOTRACES North Atlantic Transect we 
found that colloidal Fe concentrations at most stations were at an absolute minimum in the DCM, and at many stations colloidal Fe disappeared completely (Figure 7). An exception to this was the Line $\mathrm{W}$ section (Figure 7a), where $\mathrm{cFe}$ was high throughout the upper ocean, presumably reflecting an external margin source of colloidal Fe (see Section 3.1.3). However, at most open ocean stations colloidal Fe disappeared altogether (Figure 7b-e), even along the more northern stations of USGT10 nearer to Europe (Figure 7e, USGT10-05 example shown).

Notably, however, despite the structure in the upper ocean cFe profile (surface maximum, DCM minimum, increasing $\mathrm{cFe}$ below DCM), soluble Fe was relatively invariant from the surface through the DCM at concentrations of $0.05-0.20 \mathrm{nmol} / \mathrm{kg}$ (Figure 7). The measurable sFe despite biological uptake was discussed in the surface dFe partitioning section 7.3.1.1, however, the data through the DCM shows that the nonzero $\mathrm{sFe}$ concentrations are also nearly constant in concentration until below the DCM. This could be either a relatively refractory sFe phase that is biologically inaccessible and thus persists in the upper ocean at relatively constant concentrations, a "steady state" sFe concentration persisting via rapid biological recycling, or an $\mathrm{Fe}(\mathrm{II})$ phase produced photochemically in the upper ocean.

We suggest several possible explanations for the absence of colloidalFe in the DCM:

(1) Colloidal Fe is bioavailable and is taken up by microorganisms in the DCM. Experimental studies have shown that natural soluble Fe is biologically preferred over colloidal Fe (Chen et al., 2003; Chen and Wang, 2001; Wang and Dei, 2003). However, some colloidal Fe may actually be utilized by microorganisms, either directly or indirectly after conversion through the sFe pool. A controlled ecosystem enclosure experiment by Nishioka et al. (2001a) showed that colloidal Fe decreased the most out of all $\mathrm{dFe}$ size fractions during a simulated phytoplankton bloom, some of which was attributed to biological uptake of colloidal Fe species (although also to cFe aggregation). Studies of Fe bound to colloidal-sized exopolymeric saccharides (EPS) have found this Fe-EPS to be highly bioavailable (Hassler et al., 2011a; Hassler et al., 2011b), supporting 
the hypothesis that some colloidal Fe may be biologically utilized by organisms in the DCM. In addition, phytoplankton living in the light-limited DCM may have higher cellular Fe requirements (Sunda and Huntsman, 1997), and this could encourage their aggressive utilization of any $\mathrm{dFe}$ phase available, including $\mathrm{cFe}$.

(2) Colloidal Fe scavenging and/or aggregation rates are increased in the DCM. Because colloidal aggregation rates have been modeled as a second order reaction with respect to particle concentration (Stumm and Morgan, 1996), then if the number of particles increases in the DCM, aggregation rates in the DCM should increase as well and could aggregate colloidal Fe into the particulate Fe phase. This might be especially likely considering the diverse character of the DCM particle maximum (cells, biological extracts, etc), which could also physically trap colloids in addition to simple cFe sorption/aggregation. We know that the fluorescence maximum designated as the DCM does not necessarily indicate a biomass maximum (Taguchi et al., 1988), since microbes deeper in the euphotic zone can adapt to lower light levels by increasing the stores of chlorophyll in each cell. In order to assess whether our DCM depths were in fact also particle maxima, we compared the fluorescence trace used to derive the DCM depth to the light transmission trace, which would illuminate depths with higher particulate loadings. As the example shown in Figure $7 \mathrm{f}$ indicates, at many stations the DCM depth did show a drop in light transmission, indicating a relative particle maximum that would be expected to promote increased $\mathrm{cFe}$ scavenging rates.

(3) A unique Fe-ligand partitioning where the DCM contains no colloidal ligands favors the formation of soluble-sized Fe-ligand compounds. The current consensus based on electrochemical measurements of seawater is that nearly all marine dissolved Fe is organically bound by strong Fe-binding ligands (Gledhill and Buck, 2012; Rue and Bruland, 1995). Since both soluble and colloidal Fe are encompassed by dFe, both size fractions should be organically complexed, and an equilibrium between ligands and $\mathrm{Fe}$ in the soluble and colloidal size fractions might determine the size partitioning of $\mathrm{dFe}$. If the DCM had no colloidal ligands or soluble ligands were significantly stronger there, we might not expect organically bound $\mathrm{dFe}$ to be colloidal at the DCM. However, there is 
very little data on the size partitioning of Fe ligands, especially with sufficient depth resolution to capture the DCM. The few size-fractionated Fe-ligand samples collected on the GEOTRACES NAZT cruise show a predominance of soluble Fe ligands throughout the entire upper ocean, with no particular change in ligand partitioning at the DCM (Appendix III: Fitzsimmons et al., in prep-a). Thus, the existing data do not support the hypothesis that ligand partitioning produces a unique dFe size partitioning at the DCM.

(4) Similar to a mechanism proposed for suspended particulate Fe (Ohnemus and Lam, 2013), colloidal Fe "short-circuits" the DCM via transport in large sinking aggregates. Suspended particulate $\mathrm{Fe}(\mathrm{pFe})$ also reaches a minimum in the DCM. This might not be expected to occur if the absence of $\mathrm{cFe}$ was explained by biological uptake or scavenging into the particulate phase (although the $\mathrm{pFe}$ minimum is non-zero and thus may include scavenged or biologically utilized $\mathrm{cFe}$, and thus we retain hypotheses 12).Ohnemus and Lam (2013) proposed that a DCM pFe minimum results when dustderived $\mathrm{pFe}$ is incorporated into large aggregates in the mixed layer that sink through the DCM to disaggregate below, resulting in low $\mathrm{pFe}$ in the DCM; importantly, this pattern only results when the DCM is located below the mixed layer depth (excluding Line $\mathrm{W}$ stations). Since the difference between colloidal $(0.02-0.2 \mu \mathrm{m})$ and suspended particulate $(0.8-0.51 \mu \mathrm{m}) \mathrm{Fe}$ is operational (they are near each other in the Fe size spectrum), it is possible that suspended particulate and colloidal Fe cycle similarly in the upper ocean and that the lack of $\mathrm{cFe}$ is simply related to $\mathrm{cFe}$ aggregation into sinking particulates above the DCM and disaggregation below it.

7.3.2.2 Remineralization - In order to assess the impact of remineralization on $\mathrm{dFe}$ partitioning, we examined the relationship between $\mathrm{dFe}$ species and the apparent oxygen utilization (AOU), which is a measure of the integrated oxygen loss due to remineralization in a water parcel since it was last in contact with the atmosphere. We show the correlation between $\mathrm{dFe}, \mathrm{cFe}$, and $\mathrm{sFe}$ with AOU in Figure 8 (Type-I regressions) for Central Waters (potential density 25.8-27.1) and Intermediate Waters (potential density 27.1-27.5) across the three North Atlantic sections: Line W (a), the subtropical gyre (b), and the 2010 stations including the Mauritanian transect (c). We 
then converted the resulting Fe:AOU slopes to Fe:C slopes using an AOU:C ratio of 1.6 (Martin et al., 1987), as in previous studies of dFe biogeochemistry in the North Atlantic (Bergquist and Boyle, 2006; Fitzsimmons et al., 2013). The Fe:C (slope) and pre-formed $\mathrm{Fe}(\mathrm{y}$-intercept) for both $\mathrm{dFe}$ and $\mathrm{sFe}$ are tabulated in Table 2.

Hatta et al. (in prep) showed that the $\mathrm{dFe}$ : C ratio was $7-8.5 \mu \mathrm{mol} / \mathrm{mol}$ in Central Waters (mostly North Atlantic Central Water) and Intermediate Waters (Antarctic Intermediate Water and Mediterranean Outflow Water) of the North Atlantic subtropical gyre using data from the 2011 cruise (Figure $8 \mathrm{a}-\mathrm{b}$, Table 2). In contrast, the $\mathrm{dFe}$ : $\mathrm{C}$ ratio increased to $>10 \mu \mathrm{mol} / \mathrm{mol}$ in the 2010 cruise samples along the eastern North Atlantic and Mauritanian upwelling zone (Figure 8c, Table 2). By analogy to $\mathrm{dFe}: \mathrm{C}$, we might have expected to observe a similar increase in sFe:C in the 2010 Mauritanian section stations compared to the 2011 subtropical gyre, assuming the partitioning was similar in the two regions. However, the results show that the $\mathrm{sFe}$ C ratio was not significantly different in the 2010 and 2011 subtropical gyre sections (Figure 8 b-c, Table 2). While we cannot exclude the possibility that $\mathrm{dFe}$ size partitioning is truly different in the Mauritanian section than in the gyre, we established previously (Section 7.3.1.2; Fitzsimmons et al., 2013; Hatta et al., in prep) that in both regions dFe distributions are controlled by remineralization, and thus the partitioning should be similar. Instead, we attribute the similarity in $\mathrm{sFe}: \mathrm{C}$ ratios to the smaller $\mathrm{sFe}$ pore size used to distinguish $\mathrm{sFe}$ in 2010, which likely obscured the higher sFe:C near Mauritania (less sFe is observed using the $2010<10 \mathrm{kDa}$ size cutoff than in the same water using the $2011<0.02 \mu \mathrm{m}$ cutoff, Figure 5b). Nonetheless, we see a higher (though not significantly different) sFe:C ratio of $4.72 \pm 0.53$ in the Mauritanian transect (USGT10-09 through USGT10-12) compared to the rest of the 2010 stations ( $\mathrm{sFe}: \mathrm{C} 4.27 \pm 0.35)$ in the Central Waters, consistent with a similar increase in the $\mathrm{dFe}$ : $\mathrm{C}$ ratio (Table 2).

The ratio of $\mathrm{sFe}: \mathrm{C}$ to $\mathrm{dFe}: \mathrm{C}$, however, provides useful information about the $\mathrm{dFe}$ partitioning resulting from remineralization (tabulated in Table 2). While this ratio might be interpreted as simply an average $\% \mathrm{sFe}$, it is actually a $\% \mathrm{sFe}_{\mathrm{REMIN}}$ resulting from remineralization, since any "pre-formed" sFe or dFe (the y-intercept of the Fe:AOU plot) 
is not included in the slope-calculated percentage. Across the broadest swath of the North Atlantic (2011 cruise, Figure 8b), the slope of the sFe-AOU plot produced a sFe:C ratio of $4.13 \pm 0.27 \mu \mathrm{mol} / \mathrm{mol}$ that was almost exactly $50 \%$ of the $\mathrm{dFe}$ :C ratio of $8.18 \pm 0.42$ $\mu \mathrm{mol} / \mathrm{mol}$. Thus, the $\% \mathrm{SFe}_{\text {REMIN }}$ of $\sim 50 \%$ indicates that the partitioning resulting from remineralization and the subsequent scavenging, ligand exchange and sorption/desorption with the colloidal pool is is half of the $\mathrm{dFe}$ in the soluble phase and half in the colloidal phase. Along the Line $\mathrm{W}$ section (Figure $8 \mathrm{a}$ ), the $\% \mathrm{SFe}_{\text {REMIN }}$ was $41 \%$, indicating that remineralization and the summed re-partitioning afterward partitioned more $\mathrm{dFe}$ into the colloidal size fraction than in the subtropical gyre. Finally, in the eastern North Atlantic 2010 cruise samples where the smaller 10kDa sFe-cFe size cutoff was used (Figure 8b), the slope of the sFe-AOU plot produced a sFe:C ratio of $4.27 \pm 0.35 \mu \mathrm{mol} / \mathrm{mol}$ that was $\sim 35 \%$ the $\mathrm{dFe}: \mathrm{C}$ ratio, some of which is likely related to the smaller $10 \mathrm{kDa}$ sFe size cutoff used on the 2010 cruise. These $\% \mathrm{SFe}_{\text {REMIN }}$ values in the Central and Intermediate Waters fall within the total sub-DCM deep ocean dFe size partitioning distributions of $40-60 \% \mathrm{cFe}$ in the 2011 abyssal ocean (Figure 2d) and 50-70\% cFe in the Mauritanian section (Figure 4d), indicating that remineralization and the re-partitioning processes occurring immediately thereafter likely control the dFe partitioning in the abyssal ocean away from new dFe inputs. We return to this idea in section 7.3.3.

The difference between $\% \mathrm{sFe}_{\text {REMIN }}$ and total $\% \mathrm{sFe}$ in a given water mass is the $\% \mathrm{sFe}$ in the pre-formed fraction, which can be explored using the y-intercepts of the FeAOU relationships. As can be seen in Table 2, the 2011 cruise Central Water was the only water mass to have a statistically significant pre-formed $\mathrm{dFe}$ of $0.16 \mathrm{nmol} / \mathrm{kg}$ and $\mathrm{sFe}$ of $0.07 \mathrm{nmol} / \mathrm{kg}$. Central Waters along this transect are composed of Madeira Mode Waters, which form southwest of Madeira, and $18^{\circ}$ Mode Waters, which subduct in the Sargasso Sea (Talley et al., 2011), and both regions receive Fe inputs from North African dust plumes that could generate pre-formed $\mathrm{dFe}$. NACW pre-formed Fe derived from the upper portion of the water mass (upper-NACW: potential density $25.8-26.6 \mathrm{~kg} / \mathrm{m}^{3}$ ), with statistically insignificant pre-formed dFe below (lower-NACW: potential density range 
26.6-27.1). It is noteworthy than the $\% \mathrm{sFe}_{\mathrm{PF}}$ pre-formed matched the $\% \mathrm{sFe} \mathrm{REMIN}_{\mathrm{R}}$ within error when pre-formed Fe was detectable (Table 2).

7.3.2.3 Deep ocean - The deep ocean circulation is described in Hatta et al. (in prep) using the neutral density limits of LeBel et al. (2008), showing that the core of NADW is in the depth range of $1000-4000 \mathrm{~m}$ and is composed of four water masses: Upper Labrador Sea Waters and Classical Labrador Sea Waters (1000-2000m), IcelandScotland Overflow Waters (2000-3000m in the western basin, to the bottom in the eastern basin), and Denmark Strait Overflow Waters (3000-4500m in the western basin only). Typical NADW dFe concentrations were $\sim 0.6 \mathrm{nmol} / \mathrm{kg}$ over these depths, with the western margin CLSW, the TAG plume, and a portion of the Mauritanian OMZ carrying higher $\mathrm{dFe}$ concentrations (Hatta et al., in prep). Soluble Fe along NADW was consistently between $0.25-0.35 \mathrm{nmol} / \mathrm{kg}$, agreeing well with the nearly-constant, $\sim 0.30$ $\mathrm{nmol} / \mathrm{kg}$ sFe concentrations previously reported for NADW in the North Atlantic (Fitzsimmons and Boyle, in review-b; Wu et al., 2001) through the South Atlantic (Bergquist et al., 2007) and into the Southern Ocean (Chever et al., 2010). Similar to dFe, enhanced sFe concentrations in NADW are attributed to the TAG plume at Stations USGT11-14 and USGT11-16, CLSW along Line W, and the OMZ along the Mauritanian section. As can be seen in Figure 2d, NADW dFe was on average 50\% cFe (in white), except along Line W in the CLSW trace eastward to USGT11-12 and at the TAG station where colloidal Fe dominated.

At station USGT11-12 (Figure 9b), an AABW influence below 5000m depth is evident by a drop in potential temperature below $1.8^{\circ} \mathrm{C}$ (McCartney, 1992) and elevated concentrations of dissolved silica $(53 \mu \mathrm{mol} / \mathrm{kg})$. The relative contribution of DSOW and AABW at these deepest depths is unclear, as some authors indicate a dominance of AABW below $\sim 4500 \mathrm{~m}$ depth in the subtropics (LeBel et al., 2008; Tomczak and Godfrey, 2003) and others estimate a much lower AABW contribution of only $\sim 10 \%$ (Johnson, 2008). Using a [Si] of $\sim 120 \mu \mathrm{mol} / \mathrm{kg}$ in AABW and $\sim 20 \mu \mathrm{mol} / \mathrm{kg}$ in NADW, we calculate that the 5000+ $m$ depths of USGT11-12 are comprised of $\sim 33 \%$ AABW. In these AABW-influenced waters, dFe dropped from $\sim 0.52 \mathrm{nmol} / \mathrm{kg}$ in DSOW to $\sim 0.43$ 
$\mathrm{nmol} / \mathrm{kg}$, with the colloidal Fe component always staying constant at $\sim 50 \%$ (52\% in DSOW, 46\% in AABW depths). sFe concentrations below 5000m were 0.20-0.25 $\mathrm{nmol} / \mathrm{kg}$, which is lower than the $0.33 \mathrm{nmol} / \mathrm{kg} \mathrm{sFe}$ found upstream in AABW-influenced waters near $25^{\circ} \mathrm{S}$ (Bergquist et al., 2007), which are thought to have much less diluted AABW according to their higher dissolved silicate concentration $(118 \mu \mathrm{mol} / \mathrm{kg})$ than the USGT11-12 AABW samples $(53 \mu \mathrm{mol} / \mathrm{kg})$. The drop in $\mathrm{sFe}$ of $0.1 \mathrm{nmol} / \mathrm{kg}$ from $25^{\circ} \mathrm{S}$ to $30^{\circ} \mathrm{N}$ cannot be attributed solely to increasing dilution with DSOW because DSOW has a higher $\mathrm{sFe}(0.25 \mathrm{nmol} / \mathrm{kg})$ than the most dilute $30^{\circ} \mathrm{N}$ data deeper than $5000 \mathrm{~m}(0.23$ $\mathrm{nmol} / \mathrm{kg}$ ). This $\mathrm{sFe}$ decrease must also be attributed to scavenging or aggregation. Note that $\mathrm{cFe}$ increased by the same $\sim 0.10 \mathrm{nmol} / \mathrm{kg}$ that $\mathrm{sFe}$ decreased, from $0.10 \mathrm{nmol} / \mathrm{kg}$ at $25^{\circ} \mathrm{S}$ to $\sim 0.20 \mathrm{nmol} / \mathrm{kg}$ at USGT11-12; this pattern points to a mechanism of sorption/aggregation. In summary, in abyssal waters we find rather consistent \%cFe along NADW flow paths and decreasing cFe concentrations along AABW flow paths. These patterns imply that transformations between soluble, colloidal, and particulate Fe pools are dynamic in the deep ocean, involving active exchange between soluble and colloidal pools via both aggregation and disaggregation, and thus calculations of the scavenging residence times of individual Fe size fractions along these abyssal water masses may be misleading.

\subsubsection{Consensus on dFe size partitioning in the North Atlantic}

The North Atlantic Ocean has been sampled more extensively for the size fractionation of $\mathrm{dFe}$ into soluble and colloidal phases than any other ocean basin (see global map of previous studies in Fitzsimmons and Boyle, in review-a), yet a consensus on the factors controlling $\mathrm{dFe}$ size partitioning has not emerged. We believe that the U.S. GEOTRACES NAZT captures most of the major dFe inputs into the North Atlantic that might impact $\mathrm{dFe}$ partitioning and also provides the highest spatial and depth resolution yet sampled for size fractionated dFe in the Atlantic. Thus, this GEOTRACES dataset is optimally suited for updating conclusions about the processes controlling the size partitioning of marine $\mathrm{dFe}$ in the Atlantic Ocean. 
First, we review the findings of previous North Atlantic dFe size partitioning studies (cruise locations indicated on the Figure 1 map). Bergquist et al. (2007) posited that variability in the colloidal Fe phase was responsible for most of the variability in North Atlantic dFe, while sFe remained relatively constant with depth at $\sim 0.3 \mathrm{nmol} / \mathrm{kg}$; this partitioning pattern is apparent in a reproduction of their size fractionated $\mathrm{dFe}$ data in Figure 10a (crosses), where dFe was well correlated with cFe but was not correlated with invariant sFe. In contrast, over a larger swath of stations in the tropical North Atlantic, Fitzsimmons and Boyle (in review-b) found that both $\mathrm{sFe}$ and $\mathrm{cFe}$ contributed $\mathrm{dFe}$ variability (Figure 10b, open circles). They concluded that either the size partitioning of organic Fe-binding ligands controlled the overall partitioning of dFe in the North Atlantic or that North Atlantic dFe had a "steady state" dFe partitioning pattern overlain by a series of Fe inputs with uniquely size-fractionated Fe.

To discriminate between these alternatives, we focused on correlations between different dFe size fractions from the GEOTRACES transect for the 2011 (c-d) and 2010 (e) cruises (Figure 10, closed circles). Since both $\mathrm{sFe}$ and cFe increase as dFe increases, both size fractions contribute to $\mathrm{dFe}$ variability, and thus we conclude that Bergquist et al.'s hypothesis does not apply broadly across the North Atlantic. We also discount the suggestion of Fitzsimmons and Boyle (in review-b) that the size partitioning of organic Fe-binding ligands directly controls the size partitioning of $\mathrm{dFe}$, since the excess ligand partitioning at stations USGT11-10 and USGT11-23 did not match the observed partitioning of dFe (Appendix III: Fitzsimmons et al., in prep-a). In fact, in those samples the partitioning of excess Fe-binding ligands predicted a predominance of sFe at depths where $\mathrm{cFe}$ clearly dominated $\mathrm{dFe}$ partitioning. Similar data from the North Atlantic by Cullen et al. (2006) were interpreted as being caused by a missing "inert" colloidal Febinding ligand fraction not detected electrochemically. Since the ligand partitioning studies have been largely in the upper ocean where unique $\mathrm{dFe}$ partitioning exists separate from the subsurface ocean, we must leave open the possibility that in the intermediate and deep ocean ligand size partitioning does control dFe size partitioning. 
However, the data reported thus far does not support this view (Boye et al., 2010; Cullen et al., 2006; Thuróczy et al., 2010).

We propose a dFe partitioning model for all depths below the DCM (Figure 11a) based on the hypothesis of Fitzsimmons and Boyle (in review-b) that there is a "steady state" dFe partitioning into soluble and colloidal phases that is constant for a given region. New $\mathrm{dFe}$ inputs cannot impart the constant $\mathrm{dFe}$ partitioning observed in the subsurface ocean because most of the Fe inputs to the North Atlantic are heavily colloidal (section 7.3.1), while the deep ocean has a near 50-50\% sFe-cFe partitioning. Instead, we know that deep water attains elevated $\mathrm{dFe}$ concentrations via remineralization. Thus, we must consider whether remineralization directly partitions $\mathrm{dFe}$ equally into $\mathrm{sFe}$ and $\mathrm{cFe}$ pools in the subtropical North Atlantic gyre. While we have no direct evidence against this, any subsequent scavenging or exchange of Fe between size fractions would change the observed dFe size partitioning, and the results in Figure 10b-e instead indicate a constant subsurface partitioning in each region of the North Atlantic. Thus, we suggest that the constant partitioning is driven by a "steady state" of the sum of dFe exchange processes potentially following remineralization (including ligand exchange, sorption/desorption, and aggregation/disaggregation, indicated with solid black arrows in Figure 11a); in other words, the rates of these processes are constant and result in constant partitioning. Thus, rather than $\mathrm{dFe}$ in a given seawater parcel having a fixed concentration of $\mathrm{sFe}$ and a variable concentration of $\mathrm{cFe}$ that determines the magnitude of $\mathrm{dFe}$, the $\mathrm{dFe}$ in a given water parcel will have a fixed percentage of sFe and cFe set by the relative rates of exchange between $\mathrm{sFe}$ and $\mathrm{cFe}$ fractions. This explains the near constancy of the relative partitioning along water mass trajectories (as discussed in section 7.3.2.3).

This "steady state" model of dFe partitioning is supported by the fact that the $\% \mathrm{SFe}_{\text {REMIN }}$ derived from the Fe-AOU relationships (section 7.3.2.2) is very similar to the total \%sFe inferred from Figure 2d, and partitioning patterns and mechanisms in each of the North Atlantic regions can be derived. Total \%sFe below the DCM in the subtropical gyre is $\sim 50 \%$ (white in Figure $2 \mathrm{~d}$ ), which is the same as the $\sim 50 \% \mathrm{sFe}$ REMIN derived in 
section 7.3.2.2 for the subtropical gyre (Table 2), even with a significant pre-formed dFe concentration. In fact, even the gyre pre-formed dFe appears to be partitioned $\sim 50-50 \%$ sFe-cFe (Table 2), suggesting that upstream remineralization and subsequent "steady state" exchange sets these ratios in the subtropical gyre. In contrast, along Line $\mathrm{W}$, the $\% \mathrm{SFe}_{\text {REMIN }}$ was lower at only $41 \%$, suggesting that aggregation rates were slightly greater than disaggregation rates, but again the $\% \mathrm{SFe}_{\text {REMIN }}$ matched the $30-40 \%$ total $\% \mathrm{sFe}$ inferred from Figure 2d. Similarly, the pre-formed dFe in these waters was partitioned $\sim 75 \%$ into the colloidal size fraction (Table 2), nearly matching the total \%cFe of 60 $70 \%$.. We must note that these "remineralization" dFe partitioning patterns are dependent on the operational definitions of sFe utilized: using the $0.02 \mu \mathrm{m}$ sFe size cutoff, typical "remineralization" dFe partitioning was $50 \%$, but using a smaller $10 \mathrm{kDa}$ sFe pore size in the 2010 cruise, "remineralization" partitioning was only $~ 35 \% \mathrm{sFe}$, as shown by the $35 \%$ $\mathrm{sFe}_{\text {REMIN }}$ and total $\% \mathrm{sFe}$ (Figure $4 \mathrm{~d}$ ).

Nevertheless, unique Fe sources/sinks can overwhelm the "steady state" partitioning when either the new Fe sources have much higher concentrations than typical open ocean $\mathrm{dFe}$ or the source is fresher than or inert to the kinetics of the $\mathrm{dFe}$ exchange processes. Examples of inputs that overwhelm the "steady state" partitioning include aerosol inputs of $\mathrm{Fe}$ to the surface ocean (section 7.3.1.1) and the TAG hydrothermal $\mathrm{Fe}$ inputs (section 7.3.1.4); both of these contained an excess of (potentially inert) colloidal $\mathrm{Fe}$ and were excluded from the partitioning plots of Figure 10. Additionally, increased scavenging rates or the biological uptake of one $\mathrm{dFe}$ fraction over another can alter the observed dFe partitioning, as we hypothesized might occur in the DCM (section 7.3.2.1), indicating that the kinetics of $\mathrm{dFe}$ transformations also play a role. To highlight how this changes our understanding of dFe partitioning, we offer a revised model of dFe exchange processes in Figure 11b for the euphotic zone (surface through DCM) of the subtropical gyre. At these depths, dust inputs, aggregation/disaggregation with the particulate pool, biological uptake, and photochemistry (not shown) inform the upper ocean $\mathrm{dFe}$ partitioning (as discussed in 7.3.1.1 and 7.3.2). Downstream of the TAG hydrothermal plume, a third framework of dFe partitioning could be evolved (model not shown), likely 
invoking hydrothermal Fe inputs and sorption to the particulate phase (Appendix III). These new Fe inputs and transformations are unique from the constant aggregation and disaggregation of the subsurface ocean in kinetics and/or absolute concentration, and they result in altered partitioning pattern in these regions.It may even be possible for preformed dFe to have a unique size partitioning that alters the overall observed $\mathrm{dFe}$ partitioning, assuming the kinetics of ligand exchange between pre-formed and remineralized $\mathrm{dFe}$ is slow. This, or the influence of some of the uniquely partitioned $\mathrm{Fe}$ inputs discussed above, may explain why there is more scatter in the subtropical gyre size partitioning plots (Figure $10 \mathrm{~b}$ and d). A significant correlation in these plots will only arise when a single process or group of processes controls the $\mathrm{dFe}$ partitioning in a given region and those processes have reached a "steady state." The influence of multiple partitioning mechanisms (margin Fe inputs, aerosol Fe inputs, etc.) or non-steady state exchange processes (potentially related to the $\mathrm{OMZ}$ edge, section 7.3.1.2) may also explain the poor relationship between dFe-sFe in the data of Bergquist et al. (2007, Figure 10a).

A summary of the dFe partitioning in the subsurface of the GEOTRACES NAZT can be seen in the sFe-cFe regressions on the right panel of Figure 10 (c-e), where it is shown that $\mathrm{sFe}$ and $\mathrm{cFe}$ cycle synchronously in the North Atlantic. In general, where sFe was low, cFe was also low, and vice-versa. The relation of the sFe-cFe trend to the 1:1 line also gives an indication of the general partitioning of the $\mathrm{dFe}$ in water from a given region: in "typical" North Atlantic gyre waters, half of the dFe was colloidal and half was soluble, while in Line $\mathrm{W}$ waters, more than half of the dFe was colloidal. We again note that the data in Figure 10 do not include the upper water column at or above the DCM or the hydrothermally-affected depths; in all of these regions sFe and cFe cycle asynchronously.

We conclude with a comment on resolving the physical size partitioning of $\mathrm{dFe}$ with the chemical composition of dFe. Gledhill and Buck (2012) define these as:

$\begin{array}{ll}\text { Physical partitioning: } & \mathrm{dFe}=\mathrm{sFe}+\mathrm{cFe} \\ \text { Chemical partitioning: } & \mathrm{dFe}=\mathrm{Fe}^{\prime}+\mathrm{FeL}+\mathrm{Fe}_{\text {inert }}\end{array}$ 
where $\mathrm{dFe}$ is categorized by size into soluble and colloidal phases (as in this study) and by chemical composition as labile inorganic Fe complexes ( $\left.\mathrm{Fe}^{\prime}\right)$, complexes of $\mathrm{Fe}$ to organic ligands labile on the order of $<1$ day (FeL), and relatively refractory $\mathrm{Fe}$ complexes $\left(\mathrm{Fe}_{\text {inert }}\right)$. Because different analytical methods are used to distinguish these two $\mathrm{dFe}$ descriptions, it is difficult to reconcile them. However, it is reasonable to assume that Fe' falls entirely into the soluble phase, $\mathrm{FeL}$ is found in both soluble and colloidal fractions, and $\mathrm{Fe}_{\text {inert }}$ might encompass both size fractions as well, with very stronglybound FeL complexes of soluble size appearing inert and also inorganically-bound colloidal Fe (Fe nanoparticles) appearing refractory by electrochemical speciation techniques.

We raise this distinction because our data in the surface ocean and downstream of TAG revealed an excess cFe pool that did not exchange with our "remineralization" $\mathrm{dFe}$ partitioning, and we also found an excess of $\mathrm{cFe}$ along Line $\mathrm{W}$ that was different from the subtropical gyre partitioning. While we know nothing about the chemical composition of this $\mathrm{cFe}$ from the observed size partitioning alone, we do know that $\mathrm{dFe}$ in these locations was derived from continental sources (see sections 7.3.1.1, 7.3.1.3, and 7.3.1.4), and thus our data is consistent with a hypothesis that this additional colloidal Fe fraction may be inorganic (nanoparticulate) Fe that is so small that it remains suspended in the $\mathrm{dFe}$ (colloidal) phase. This nanoparticulate cFe might also be "inert" to biological processes and even have separate exchange rates between the Fe size fractions than typical marine $d F e$. Others have previously suggested that nanoparticulate $d F e$ could be stabilized/trapped inside colloidal-sized organics such as transparent exopolymer compounds (Stolpe and Hassellov, 2010). While a nanoparticulate component to dFe would be no surprise in hydrothermal plumes where nanoparticulate pyrite has already been posited to exist in the dFe size fraction (Yucel et al., 2011), a significant nanoparticulate component of $\mathrm{dFe}$ in the surface ocean or along Line $\mathrm{W}$ would contradict the prevailing view that $>99.9 \%$ of marine $\mathrm{dFe}$ is bound by organic ligands. However, our hypothesis is consistent with Fe-ligand size partitioning studies in the surface North Atlantic Ocean that report nearly no excess colloidal Fe ligands, despite there being a 
surface excess of cFe over sFe (Cullen et al., 2006): potentially much of this "inert" cFe is nanoparticulate Fe that does not have an "unbound" ligand pool capable of being analyzed electrochemically (Appendix III: Fitzsimmons et al., in prep-a). With the size partitioning data reported here, we cannot confirm a nanoparticulate $\mathrm{dFe}$ composition. For confirmation, we look toward future analyses of the colloidal Fe phase by synchrotron (similar to von der Heyden et al., 2012) and flow-field flow fractionation methods (Stolpe et al., 2010) to resolve the physical and chemical classifications of dFe.

\subsection{Conclusions}

We sampled 28 stations across the North Atlantic Ocean for the size partitioning of dFe into soluble and colloidal phases with the highest depth resolution explored to date, and assisted by the multidimensional range of U.S. GEOTRACES tracers, we have reached a new view of dFe partitioning in the North Atlantic Ocean. Previously dFe was thought to have a constant soluble Fe concentration, while colloidal Fe was variable and controlled the magnitude of the measured $\mathrm{dFe}$ concentration (Bergquist et al., 2007). sFe was believed to be the more "nutrient-like" phase, while cFe had a more dynamic distribution related to new Fe inputs. Following this, we expected to find a relatively uniform sFe concentration in the intermediate and deep North Atlantic Ocean. Instead, we found that both soluble and colloidal Fe were variable in the North Atlantic Ocean, and both contributed to dFe variability, which we hypothesize occurs via a "steady state" partitioning driven by constant exchange between the Fe pools following remineralization. We observe a near $50-50 \% \mathrm{dFe}$ partitioning into soluble $(<0.02 \mu \mathrm{m})$ and colloidal $(0.02-0.2 \mu \mathrm{m})$ fractions in the subtropical gyre below the deep chlorophyll maximum and a partitioning favoring $60 \%$ colloidal Fe along Line $\mathrm{W}$. Using a smaller definition of $\mathrm{sFe}(<10 \mathrm{kDa})$, we found a $65 \%$ partitioning into colloidal $\mathrm{Fe}$ along the eastern North Atlantic (2010 stations). 
Several regions had clear exceptions to this "remineralization" dFe partitioning, however, either because of a uniquely partitioned $\mathrm{dFe}$ source that overwhelmed the "steady state" partitioning or because of the presence of a unique Fe partitioning process or one with with unique kinetics. Examples of these exceptions include colloidal Fe dominance in the surface ocean underlying the North African dust plume and in waters downstream of the TAG hydrothermal plume. We suggest that there may be a significant nanoparticulate (inorganic) $\mathrm{cFe}$ component in these continentally-derived Fe sources. In contrast, colloidal Fe disappears in the deep chlorophyll maximum as a result of increased cFe biological uptake and/or scavenging/aggregation to the particulate Fe phase in upper ocean waters. Thus, we have found that $\mathrm{sFe}$ and $\mathrm{cFe}$ cycle synchronously through much of the North Atlantic open ocean, except in the upper ocean and in regions experiencing significant continental $\mathrm{cFe}$ inputs, where cFe cycles independently of sFe to a large extent. This size partitioning should be incorporated into future models of $\mathrm{dFe}$ biogeochemistry in order to better predict Fe limitation and downstream $\mathrm{dFe}$ concentrations, since the two size fractions potentially behave uniquely during biouptake and scavenging. We also look forward to future studies that better combine size partitioning perspectives with analyses resolving the chemical composition of the $\mathrm{dFe}$ pool in order to better constrain the composition and chemistry of the soluble and colloidal Fe fractions. 


\section{References for Chapter 7}

Aguilar-Islas, A.M., Wu, J., Rember, R., Johansen, A.M., Shank, L.M., 2010. Dissolution of aerosol-derived iron in seawater: Leach solution chemistry, aerosol type, and colloidal iron fraction. Marine Chemistry 120 (1-4), 25-33.

Anderson, R.F., Fleisher, M., Hayers, C., Robinson, L., Huang, K.-F., Edwards, L., Cheng, H., Lu, Y., Moran, B., 2013. GA03: Dissolved and particulate 232Th, 230Th, and 231Pa: Tracers of TEI supply, removal, and internal cycling. U.S. GEOTRACES post-cruise data workshop, Old Dominion Unversity, Norfolk, VA.

Beaulieu, S.E., 2010. InterRidge Global Database of Active Submarine Hydrothermal Vent Fields: prepared for InterRidge, Version 2.0. http://www.interridge.org/IRvents.

Bergquist, B.A., Boyle, E.A., 2006. Dissolved iron in the tropical and subtropical Atlantic Ocean. Global Biogeochemical Cycles 20 (1), 14.

Bergquist, B.A., Wu, J., Boyle, E.A., 2007. Variability in oceanic dissolved iron is dominated by the colloidal fraction. Geochimica et Cosmochimica Acta 71 (12), 2960-2974.

Bhatia, M.P., Kujawinski, E.B., Das, S.B., Breier, C.F., Henderson, P.B., Charette, M.A., 2013. Greenland meltwater as a significant and potentially bioavailable source of iron to the ocean. Nature Geosci 6 (4), 274-278.

Bower, A., Lozier, S., Gary, S., 2011. Export of Labrador Sea Water from the subpolar North Atlantic: A Lagrangian perspective. Deep Sea Research Part II: Topical Studies in Oceanography 58 (17-18), 1798-1818.

Bower, A.S., Lozier, M.S., Gary, S.F., Boning, C.W., 2009. Interior pathways of the North Atlantic meridional overturning circulation. Nature 459 (7244), 243-247.

Bower, A.S., Rossby, H.T., Lillibridge, J.L., 1985. The Gulf Stream: Barrier or Blender? Journal of Physical Oceanography 15 (1), 24-32.

Boye, M., Nishioka, J., Croot, P., Laan, P., Timmermans, K.R., Strass, V.H., Takeda, S., de Baar, H.J.W., 2010. Significant portion of dissolved organic Fe complexes in fact is $\mathrm{Fe}$ colloids. Marine Chemistry 122 (1-4), 20-27.

Charette, M.A., Henderson, P., Morris, P., Moore, W.S., 2013. Radium isotope distributions: GEOTRACES NAT Legs $1 \& 2$ and historical data. U.S. GEOTRACES post-cruise data workshop, Old Dominion University, Norfolk, VA.

Chen, M., Dei, R.C.H., Wang, W.-X., Guo, L., 2003. Marine diatom uptake of iron bound with natural colloids of different origins. Marine Chemistry 81 (3-4), 177-189.

Chen, M., Wang, W.X., 2001. Bioavailability of natural colloid-bound iron to marine plankton: Influences of colloidal size and aging. Limnology and Oceanography 46 (8), 1956-1967.

Chever, F., Bucciarelli, E., Sarthou, G., Speich, S., Arhan, M., Penven, P., Tagliabue, A., 2010. Physical speciation of iron in the Atlantic sector of the Southern Ocean along a transect from the subtropical domain to the Weddell Sea Gyre. J. Geophys. Res. 115 (C10), C10059.

Chiba, H., Masuda, H., Lee, S., Y, Fujioka, K., 2001. Chemistry of hydrothermal fluids at the 
TAG Active Mound, MAR 26N, in 1998. Geophysical Research Letters 28 (15), 29192922.

Croot, P.L., Streu, P., Baker, A.R., 2004. Short residence time for iron in surface seawater impacted by atmospheric dry deposition from Saharan dust events. Geophysical Research Letters 31 (23), L23S08.

Cullen, J.T., Bergquist, B.A., Moffett, J.W., 2006. Thermodynamic characterization of the partitioning of iron between soluble and colloidal species in the Atlantic Ocean. Marine Chemistry 98 (2-4), 295-303.

Cutter, G.A., Bruland, K.W., 2012. Rapid and noncontaminating sampling system for trace elements in a global ocean surveys. Limnology \& Oceanography: Methods 10, 425-436.

Fitzsimmons, J.N., Boyle, E.A., 2012. An intercalibration between the GEOTRACES GO-FLO and the MITESS/Vanes sampling systems for dissolved iron concentration analyses (and a closer look at adsorption effects). Limnology \& Oceanography: Methods 10, 437-450.

Fitzsimmons, J.N., Boyle, E.A., in review-a. The assessment and intercalibration of Anopore ${ }^{\mathrm{TM}}$ and cross flow filtration methods for the determination of dissolved iron size fractionation into soluble/colloidal phases in seawater. Limnology \& Oceanography: Methods.

Fitzsimmons, J.N., Boyle, E.A., in review-b. Both soluble and colloidal iron phases control dissolved iron variability in the tropical North Atlantic Ocean. Geochimica et Cosmochimica Acta.

Fitzsimmons, J.N., Bundy, R.M., Conway, T.M., John, S.G., Boyle, E.A., and others, in prep-a. The composition of dissolved iron in the dusty surface ocean: an exploration using sizefractionated iron-binding ligands and iron isotopes.

Fitzsimmons, J.N., Hatta, M., Measures, C.I., Sedwick, P.N., Boyle, E.A., and others, in prep-b. Iron chemistry near the TAG hydrothermal field. Geophysical Research Letters.

Fitzsimmons, J.N., Jenkins, W.J., Boyle, E.A., in review. Distal transport of dissolved hydrothermal iron in the deep South Pacific Ocean. Nature Geoscience.

Fitzsimmons, J.N., Zhang, R., Boyle, E.A., 2013. Dissolved iron in the tropical North Atlantic oxygen minimum zone. Marine Chemistry 154, 87-99.

Gledhill, M., Buck, K.N., 2012. The organic complexation of iron in the marine environment: a review. Frontiers in Microbiology 3, 69.

Gross, T.F., Williams, A.J., Newell, A.R.M., 1988. A deep-sea sediment transport storm. Nature 331 (6156), 518-521.

Hassler, C.S., Alasonati, E., Mancuso Nichols, C.A., Slaveykova, V.I., 2011 a. Exopolysaccharides produced by bacteria isolated from the pelagic Southern Ocean: Role in Fe binding, chemical reactivity, and bioavailability. Marine Chemistry 123, 88-98.

Hassler, C.S., Schoemann, V., 2009. Bioavailability of organically bound Fe to model phytoplankton of the Southern Ocean. Biogeosciences 6 (10), 2281-2296.

Hassler, C.S., Schoemann, V., Nichols, C.M., Butler, E.C.V., Boyd, P.W., 2011b. Saccharides enhance iron bioavailability to Southern Ocean phytoplankton. Proceedings of the National Academy of Sciences 108 (3), 1076-1081.

Hatta, M., Measures, C.I., Wu, J., Fitzsimmons, J.N., and others, in prep. Dissolved Fe and Mn 
concentrations in the North Atlantic Ocean during the U.S. GEOTRACES 2010-2011 cruises. Deep-Sea Research II.

Honeyman, B.D., Santschi, P.H., 1989. A Brownian-pumping model for oceanic trace metal scavenging: Evidence from Th isotopes. Journal of Marine Research 47, 951-992.

Hutchins, D.A., Witter, A.E., Butler, A., Luther III., G.W., 1999. Competition among marine phytoplankton for different chelated iron species. Nature 400, 858-861.

Jickells, T.D., An, Z.S., Andersen, K.K., Baker, A.R., Bergametti, G., Brooks, N., Cao, J.J., Boyd, P.W., Duce, R.A., Hunter, K.A., Kawahata, H., Kubilay, N., laRoche, J., Liss, P.S., Mahowald, N., Prospero, J.M., Ridgwell, A.J., Tegen, I., Torres, R., 2005. Global iron connections between desert dust, ocean biogeochemistry, and climate. Science 308 (5718), 67-71.

Johnson, G.C., 2008. Quantifying Antarctic Bottom Water and North Atlantic Deep Water volumes. Journal of Geophysical Research: Oceans 113 (C5), C05027.

Joyce, T.M., Dunworth-Baker, J., Pickart, R.S., Torres, D., Waterman, S., 2005. On the Deep Western Boundary Current south of Cape Cod. Deep-Sea Research II 52, 615-625.

Lam, P.J., Ohnemus, D.C., 2013. Size-fractionated particle mass and composition during the U.S. GEOTRACES North Atlantic Zonal Transect. U.S. GEOTRACES post-cruise data workshop, Old Dominion University, Norfolk, VA.

Lannuzel, D., Schoemann, V.r., de Jong, J., Tison, J.-L., Chou, L., 2007. Distribution and biogeochemical behaviour of iron in the East Antarctic sea ice. Marine Chemistry 106 (12), 18-32.

LeBel, D.A., Smethie Jr, W.M., Rhein, M., Kieke, D., Fine, R.A., Bullister, J.L., Min, D.-H., Roether, W., Weiss, R.F., Andrie, C., Smythe-Wright, D., Peter Jones, E., 2008. The formation rate of North Atlantic Deep Water and Eighteen Degree Water calculated from CFC-11 inventories observed during WOCE. Deep Sea Research Part I: Oceanographic Research Papers 55 (8), 891-910.

Lee, J.-M., Boyle, E.A., Echegoyen-Sanz, Y., Fitzsimmons, J.N., Zhang, R., Kayser, R.A., 2011. Analysis of trace metals $(\mathrm{Cu}, \mathrm{Cd}, \mathrm{Pb}$, and $\mathrm{Fe})$ in seawater using single batch Nitrilotriacetate resin extraction and isotope dilution inductively coupled plasma mass spectrometry. Analytica Chimica Acta 686, 93-101.

Mahowald, N., Baker, A.R., Bergametti, G., Brooks, N., Duce, R.A., Jickells, T., Kubilay, N., Prospero, J.M., Tegen, I., 2005. Atmospheric global dust cycle and iron inputs to the ocean. Global Biogeochemical Cycles 19, GB4025.

Martin, J.H., Knauer, G.A., Karl, D.M., Broenkow, W.W., 1987. VERTEX: carbon cycling in the northeast Pacific. Deep Sea Research Part A. Oceanographic Research Papers 34 (2), 267-285.

McCartney, M.S., 1992. Recirculating components to the deep boundary current of the northern North Atlantic. Progress in Oceanography 29, 283-383.

Measures, C.I., Landing, W.M., Brown, M.T., Buck, C.S., 2008. High-resolution Al and Fe data from the Atlantic Ocean CLIVAR-CO2 Repeat Hydrography A16N transect: Extensive linkages between atmospheric dust and upper ocean geochemistry. Global Biogeochem. Cycles 22, GB1005. 
Moffett, J.W., 2001. Transformations among different forms of iron in the ocean. In: Turner, D.R., Hunter, K.A. (Eds.), The Biogeochemistry of Iron in Seawater. John Wiley \& Sons, West Sussex, England, pp. 343-372.

Moore, J.K., Doney, S.C., Glover, D.M., Fung, I.Y., 2002. Iron cycling and nutrient-limitation patterns in surface waters of the World Ocean. Deep Sea Research Part II: Topical Studies in Oceanography 49 (1-3), 463-507.

Morel, F.M.M., Milligan, A.J., Saito, M.A., 2003. Marine Bioinorganic Chemistry: The Role of Trace Metals in the Oceanic Cycles of Major Nutrients. In: Turekian, K.K., Holland, H.D. (Eds.), Treatise On Geochemistry. Elsevier Science Ltd., Cambridge, United Kingdom, pp. 113-143.

Nishioka, J., Takeda, S., Wong, C.S., 2001a. Change in the concentrations of iron in different size fractions during a phytoplankton bloom in controlled ecosystem enclosures. Journal of Experimental Marine Biology and Ecology 258 (2), 237-255.

Nishioka, J., Takeda, S., Wong, C.S., Johnson, W.K., 2001b. Size-fractionated iron concentrations in the northeast Pacific Ocean: distribution of soluble and small colloidal iron. Marine Chemistry 74 (2-3), 157-179.

Ohnemus, D.C., Lam, P.J., 2013. Particulate metals in the North Atlantic GEOTRACES section. U.S. GEOTRACES post-cruise data workshop, Old Dominion University, Norfolk, VA.

Rich, H.W., Morel, F.M.M., 1990. Availability of well-defined iron colloids to the marine diatom Thalassiosira weissflogii. Limnology and Oceanography 35 (3), 652-662.

Rijkenberg, M.J.A., Powell, C.F., Dall'Osto, M., Nielsdottir, M.C., Patey, M.D., Hill, P.G., Baker, A.R., Jickells, T.D., Harrison, R.M., Achterberg, E.P., 2008. Changes in iron speciation following a Saharan dust event in the tropical North Atlantic Ocean. Marine Chemistry $110(1-2), 56-67$.

Rijkenberg, M.J.A., Steigenberger, S., Powell, C.F., Haren, H.v., Patey, M.D., Baker, A.R., Achterberg, E.P., 2012. Fluxes and distribution of dissolved iron in the eastern (sub-) tropical North Atlantic. Global Biogeochemical Cycles 26, GB3004.

Rona, P.A., Klinkhammer, G., Nelsen, T.A., Trefry, J.H., Elderfield, H., 1986. Black smokers, massive sulphides and vent biota at the Mid-Atlantic Ridge. Nature 321 (6065), 33-37.

Roy, E.G., Wells, M.L., King, D.W., 2008. Persistence of iron(II) in surface waters of the western subarctic Pacific. Limnology and Oceanography 53 (1), 89-98.

Rue, E.L., Bruland, K.W., 1995. Complexation of iron(III) by natural organic ligands in the Central North Pacific as determined by a new competitive ligand equilibration/adsorptive cathodic stripping voltammetric method. Marine Chemistry 50 (1-4), 117-138.

Scholz, F., Hensen, C., Severmann, S., Noffke, A., Haley, B., McManus, J., Schneider, R., Wallmann, K., 2012. Spatial and temporal trends of iron and iron isotope cycling in the Peruvian Oxygen Minimum Zone. Mineralogical Magazine 76 (6), 2343.

Sedwick, P.N., Sohst, B., Bowie, A., 2013. U.S. GEOTRACES North Atlantic section: Dissolved Fe and Fe(II). U.S. GEOTRACES post-cruise data workshop, Old Dominion University, Norfolk, VA.

Shelley, R.U., Landing, W., 2013. North Atlantic aerosol TEIs. U.S. GEOTRACES post-cruise data workshop, Old Dominion University, Norfolk, VA. 
Smethie, W., Gorman, E., Lee, H., 2013. SF6 and CFC measurements on the U.S. North Atlantic GEOTRACES cruises. U.S. GEOTRACES post-cruise data workshop, Old Dominion University, Nofolk, VA.

Stolpe, B., Guo, L., Shiller, A.M., Hassellöv, M., 2010. Size and composition of colloidal organic matter and trace elements in the Mississippi River, Pearl River and the northern Gulf of Mexico, as characterized by flow field-flow fractionation. Marine Chemistry 118 (3-4), 119-128.

Stolpe, B., Hassellov, M., 2010. Nanofibrils and other colloidal biopolymers binding trace elements in coastal seawater: Significance for variations in element size distributions. Limnology \& Oceanography 55 (1), 187-202.

Stumm, W., Morgan, J.J., 1996. Aquatic Chemistry: Chemical Equilibria and Rates in Natural Waters. John Wiley \& Sons, New York.

Sunda, W.G., Huntsman, S.A., 1997. Interrelated influence of iron, light and cell size on marine phytoplankton growth. Nature 390, 389-392.

Taguchi, S., DiTullio, G.R., Laws, E.A., 1988. Physiological characteristics and production of mixed layer and chlorophyll maximum phytoplankton populations in the Caribbean Sea and western Atlantic Ocean. Deep Sea Research Part A. Oceanographic Research Papers 35 (8), 1363-1377.

Talley, L.D., McCartney, M.S., 1982. Distribution and circulation of Labrador Sea Water. Journal of Physical Oceanography 12, 1189-1205.

Talley, L.D., Pickard, G.L., Emery, W.J., Swift, J.H., 2011. Descriptive Physical Oceanography. Elsevier Ltd.

Taylor, S.R., McLennan, S.M., 1985. The Continental Crust: Its Composition and Evolution. Blackwell, Malden, MA.

Thuróczy, C.E., Gerringa, L.J.A., Klunder, M.B., Middag, R., Laan, P., Timmermans, K.R., de Baar, H.J.W., 2010. Speciation of Fe in the Eastern North Atlantic Ocean. Deep Sea Research Part I: Oceanographic Research Papers 57 (11), 1444-1453.

Tomczak, M., Godfrey, J.S., 2003. Regional Oceanography: An Introduction. Published online. Toner, B.M., Fakra, S.C., Manganini, S.J., Santelli, C.M., Marcus, M.A., Moffett, J., Rouxel, O., German, C.R., Edwards, K.J., 2009. Preservation of iron(II) by carbon-rich matrices in a hydrothermal plume. Nature Geoscience 2 (3), 197-201.

Toner, B.M., Marcus, M.A., Edwards, K.J., Rouxel, O., German, C.R., 2012. Measuring the form of iron in hydrothermal plume particles. Oceanography 25 (1), 209-212.

Ussher, S.J., Achterberg, E.P., Sarthou, G., Laan, P., de Baar, H.J.W., Worsfold, P.J., 2010. Distribution of size fractionated dissolved iron in the Canary Basin. Marine Environmental Research 70 (1), 46-55.

Ussher, S.J., Yaqoob, M., Achterberg, E.P., Nabi, A., Worsfold, P.J., 2005. Effect of Model Ligands on Iron Redox Speciation in Natural Waters Using Flow Injection with Luminol Chemiluminescence Detection. Analytical Chemistry 77 (7), 1971-1978.

von der Heyden, B.P., Roychoudhury, A.N., Mtshali, T.N., Tyliszczak, T., Myneni, S.C.B., 2012. Chemically and Geographically Distinct Solid-Phase Iron Pools in the Southern Ocean. Science 338 (6111), 1199-1201. 
Wang, W.X., Dei, R.C.H., 2003. Bioavailability of iron complexed with organic colloids to the cyanobacteria Synechococcus and Trichodesmium. Aquatic Microbial Ecology 33, 247259.

Wells, M.L., Goldberg, E.D., 1992. Marine submicron particles. Marine Chemistry 40, 5-18.

Wells, M.L., Goldberg, E.D., 1994. The distribution of colloids in the North Atlantic and Southern Oceans. Limnology and Oceanography 39 (2), 286-302.

$\mathrm{Wu}$, J., Boyle, E.A., 1998. Determination of iron in seawater by high-resolution isotope dilution inductively coupled plasma mass spectrometry after $\mathrm{Mg}(\mathrm{OH})_{2}$ coprecipitation. Analytica Chimica Acta 367 (1-3), 183-191.

Wu, J., Boyle, E.A., Sunda, W.G., Wen, L., 2001. Soluble and colloidal iron in the oligotrophic North Atlantic and North Pacific. Science 293, 847-849.

Yucel, M., Gartman, A., Chan, C.S., Luther, G.W., 2011. Hydrothermal vents as a kinetically stable source of iron-sulphide-bearing nanoparticles to the ocean. Nature Geoscience 4, 367-371. 


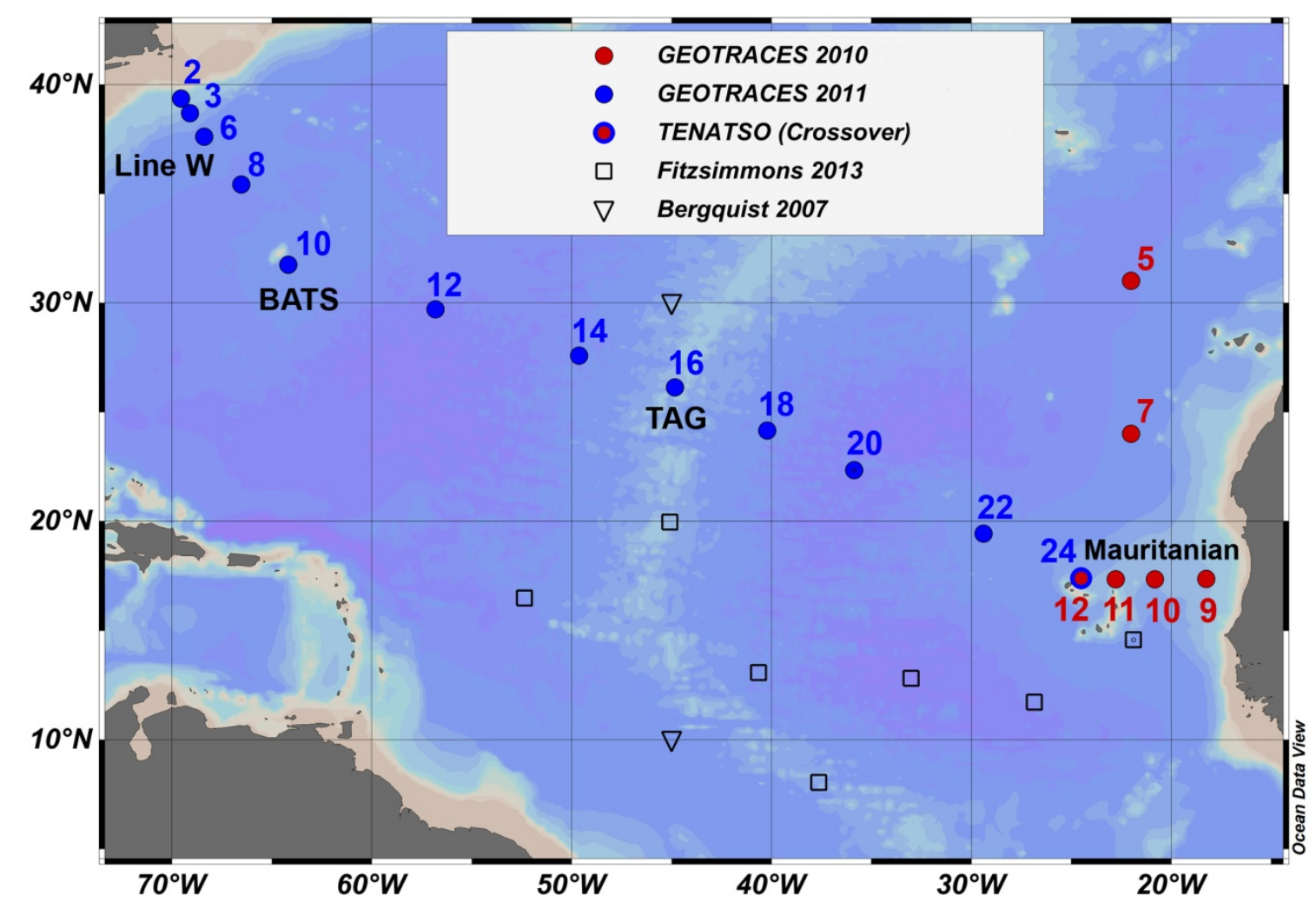

Figure 1: Station map. Stations from the 2010 cruise are shown in red, and stations from the 2011 cruise are in blue. The TENATSO crossover station was occupied on both cruises (station USGT10-12 and station USGT11-24). The locations of the Line W stations (USGT11-2 through USGT11-8), BATS station (USGT11-10), TAG hydrothermal station (USGT11-16), and the Mauritanian transect (USGT10-09 through USGT10-12) are also indicated. Stations from the literature that are referenced in this paper are also indicated as open symbols (Bergquist et al., 2007; Fitzsimmons and Boyle, in review-b). 


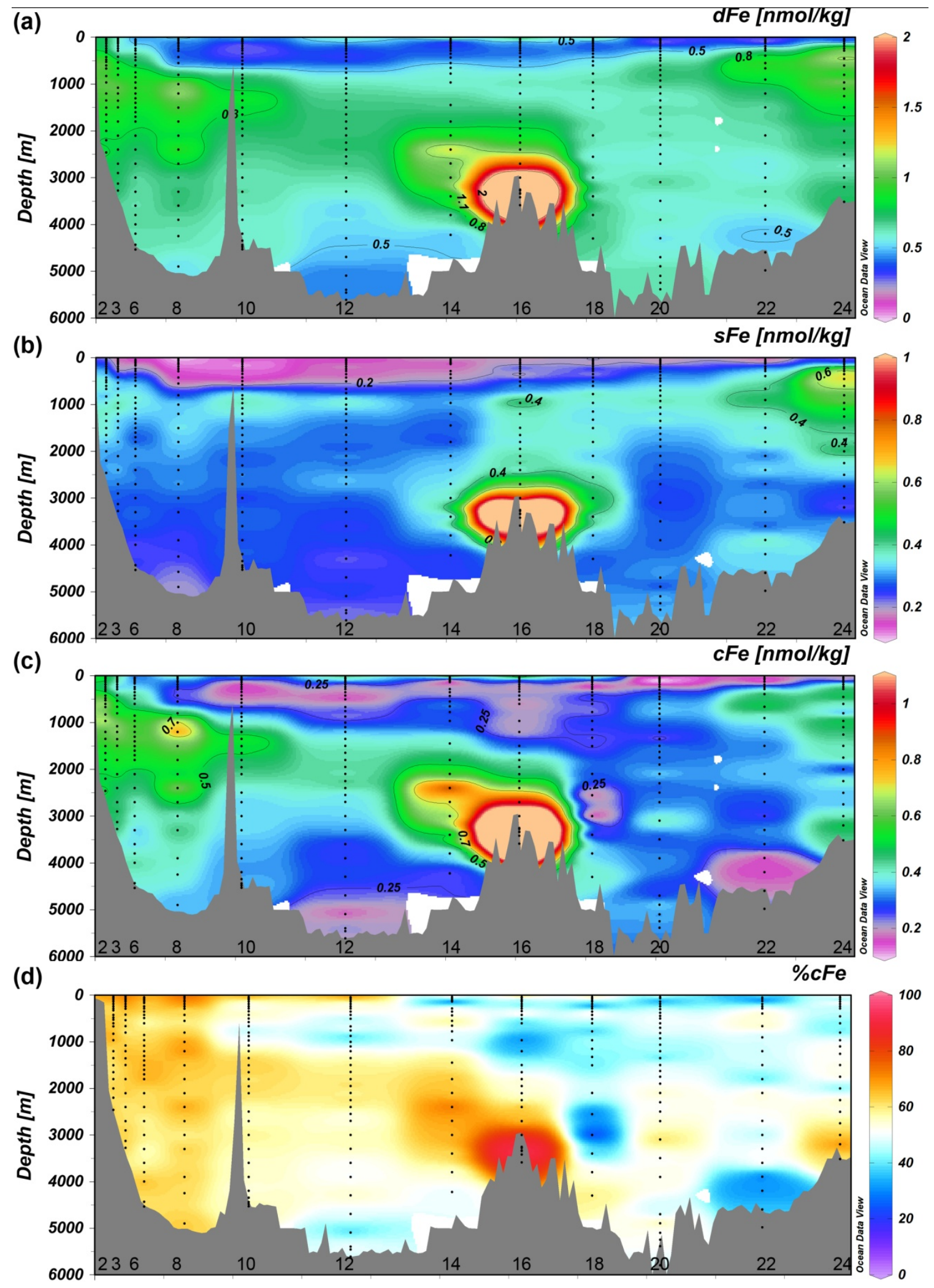


Figure 2: Sections from the 2011 cruise of (a) dissolved $\mathrm{Fe}<0.2 \mu \mathrm{m}$ analyzed by the $\mathrm{Mg}$ coprecipitation method of $\mathrm{Wu}$ and Boyle (1998), (b) soluble $\mathrm{Fe}<0.02 \mu \mathrm{m}$ analyzed by the NTA method of Lee et al. (2011), (c) colloidal Fe calculated as dFe-sFe, and (d) \%cFe calculated as $\mathrm{cFe} / \mathrm{dFe}$. Station numbers are shown at the bottom of each panel.
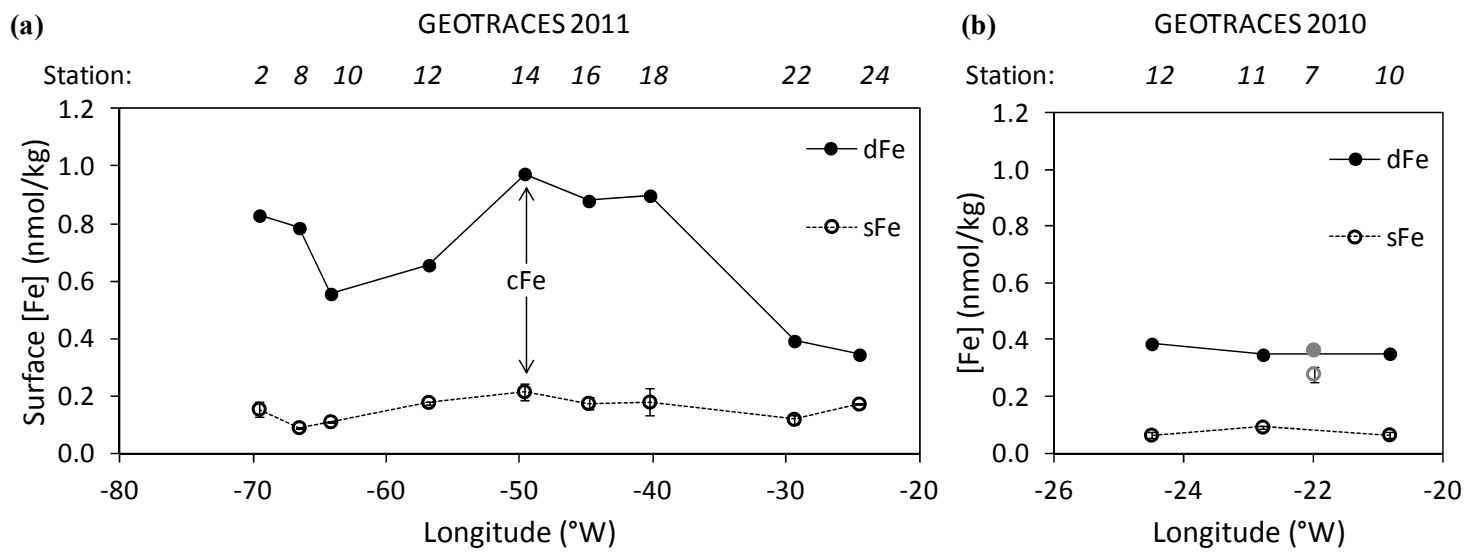

Figure 3: Surface dFe partitioning and $\mathrm{Fe}(\mathrm{II})$ concentrations as a function of longitude from (a) the 2011 cruise and (b) the 2010 cruise. Colloidal Fe can be calculated as dFe - sFe; recall that sFe is defined as $<0.02 \mu \mathrm{m}$ in (a) and $<10 \mathrm{kDa}$ in (b). In (b), the gray points at $-22^{\circ} \mathrm{W}$ are from USGT10-07, which lies somewhat north of the other three stations indicated (Mauritanian transect USGT10-10 through USGT10-12). Error bars show \pm 1 standard deviation error on analytical replicates. 

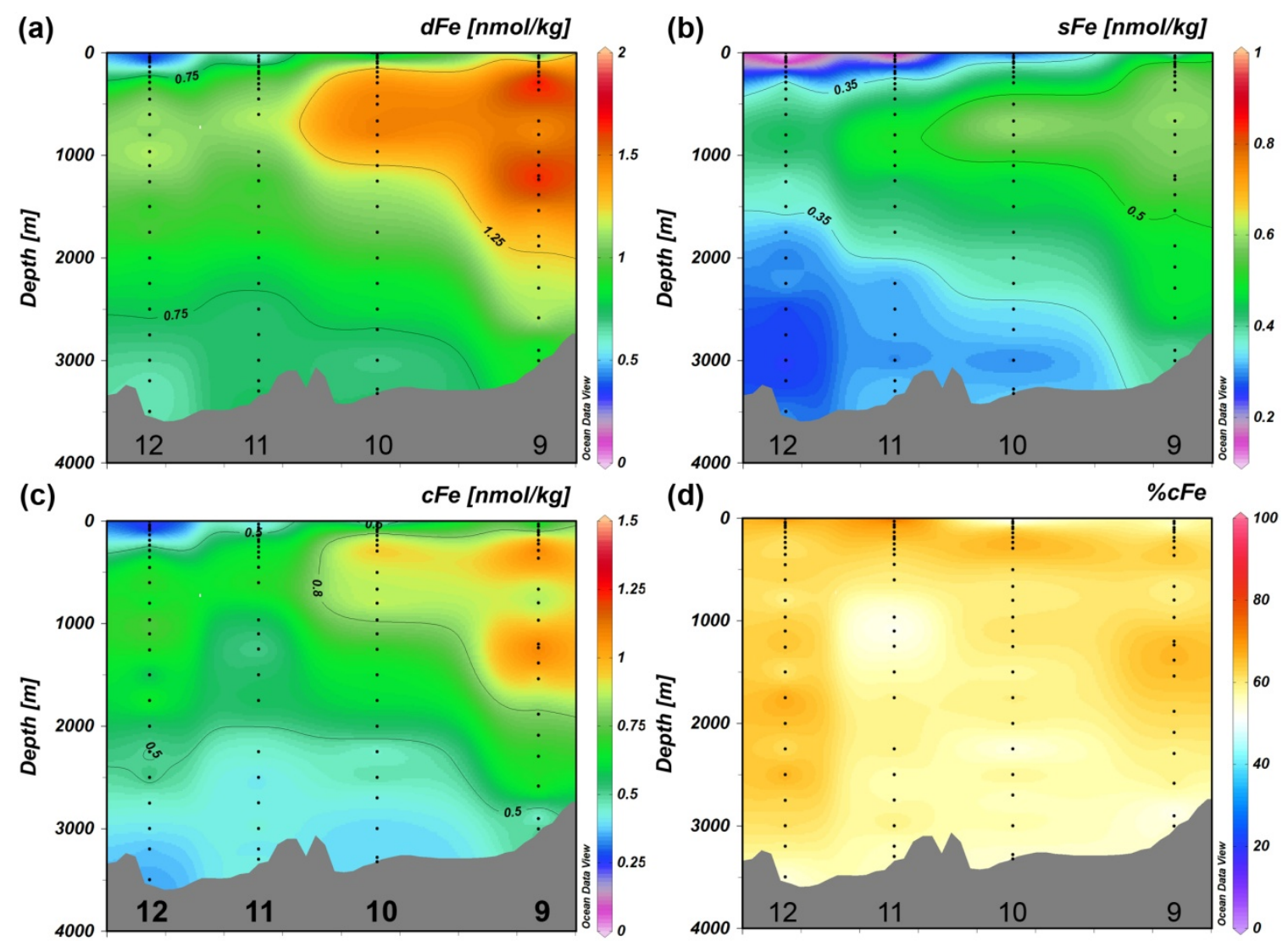

Figure 4: Sections from the 2010 cruise along the Mauritanian transect of (a) dissolved Fe $<0.2 \mu \mathrm{m}$, (b) soluble $\mathrm{Fe}<0.02 \mu \mathrm{m}$, (c) colloidal Fe calculated as dFe-sFe, and (d) $\% \mathrm{cFe}$ calculated as $\mathrm{cFe} / \mathrm{dFe}$. Station numbers are shown at the bottom of each panel. 


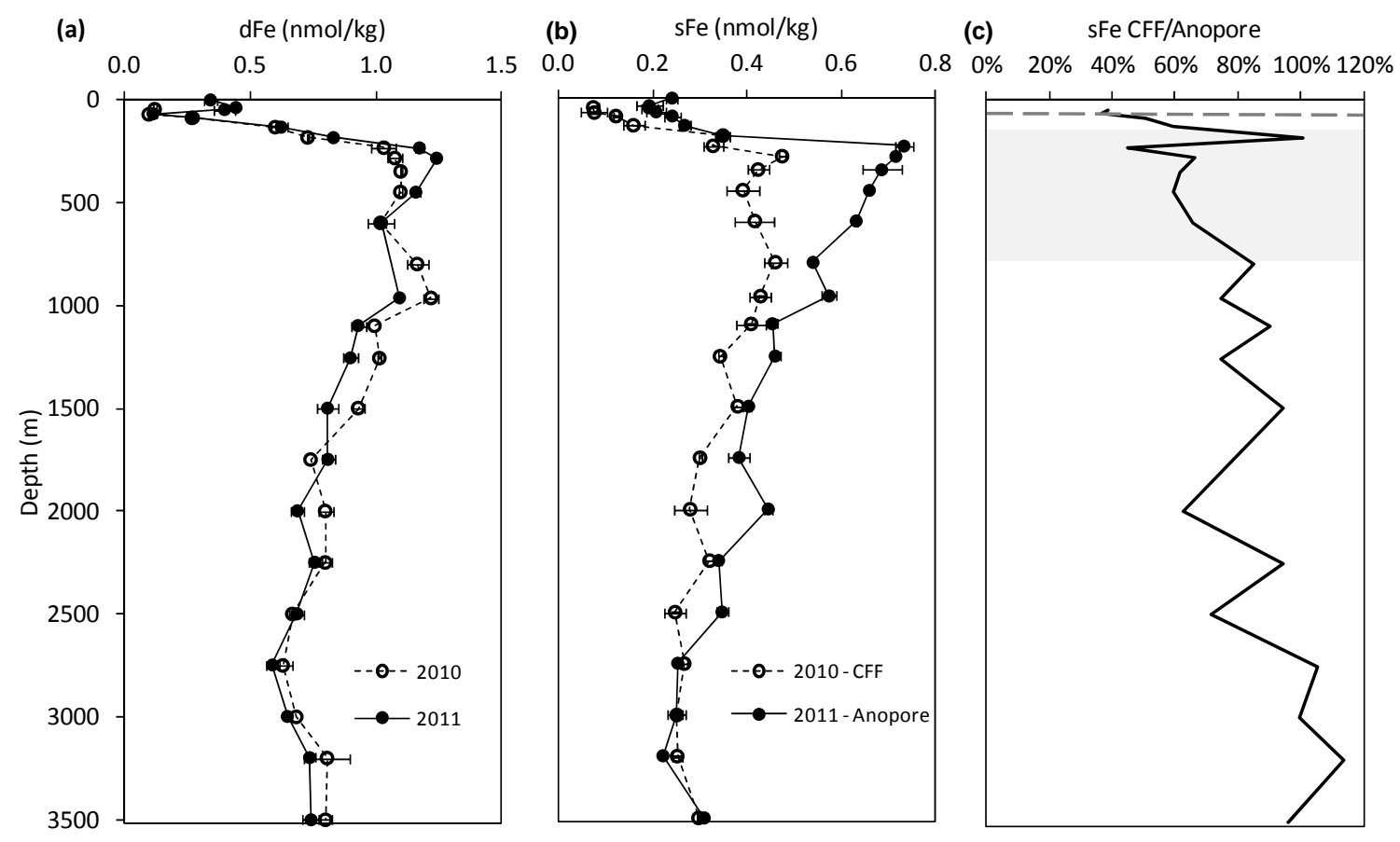

Figure 5: A comparison of dFe size partitioning during the two years of cruises at TENATSO. (a) $\mathrm{dFe}(<0.2 \mu \mathrm{m})$ over the two years. (b) sFe over the two years, with the 2010 sampling occurring by $\mathrm{CFF}(<10 \mathrm{kDa})$ and the 2011 sampling occurring by Anopore filtration $(<0.02 \mu \mathrm{m})$. (c) A ratio of the $2010 \mathrm{sFe}$ collected by CFF divided by the $2011 \mathrm{sFe}$ collected by Anopore filtration. Depths where this ratio is particularly low indicate depths where there is a significant component of $\mathrm{dFe}$ in the $10 \mathrm{kDa}-0.02 \mu \mathrm{m}$ size fraction. The dotted line at $70 \mathrm{~m}$ is the deep chlorophyll maximum as recorded by the CTD fluorometer, and the shaded region includes depths where the dissolved oxygen concentration is $<100 \mu \mathrm{mol} / \mathrm{kg}$ (the OMZ). Error bars indicate \pm 1 standard deviation in replicate analyses of the same sample. 


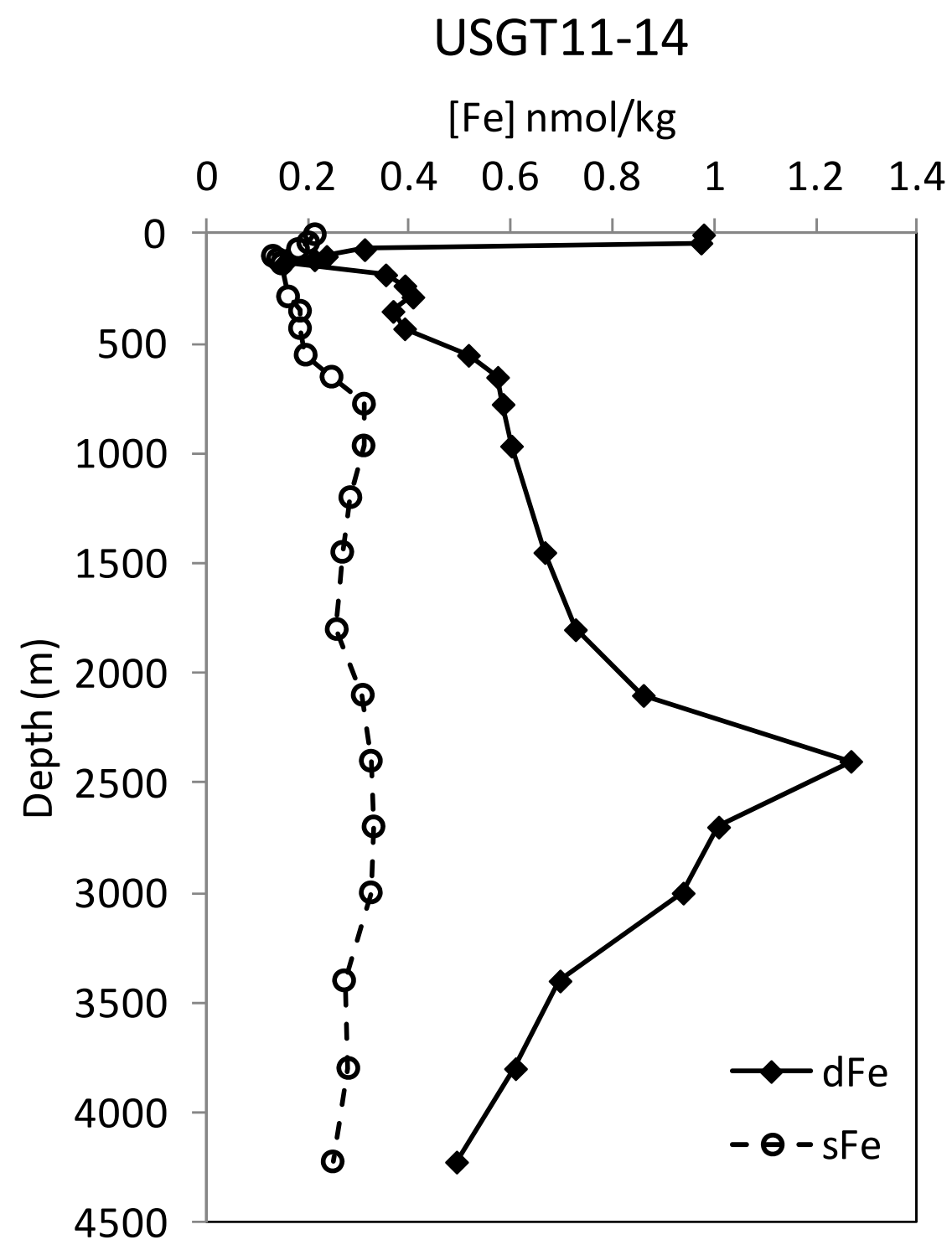

Figure 6: dFe speciation and size partitioning at station USGT11-14, which is $\sim 500 \mathrm{~km}$ to the northwest of the TAG site. The USGT11-16 hydrothermal maximum dFe partitioning data is discussed separately in Fitzsimmons et al. (in prep-b). Colloidal Fe (cFe) can be taken as the difference between $\mathrm{dFe}$ and $\mathrm{sFe}$ points at any depth. sFe comprises $9-18 \%$ of the dFe at USGT1114, compared to only $4-11 \%$ of the dFe at TAG USGT11-16. 

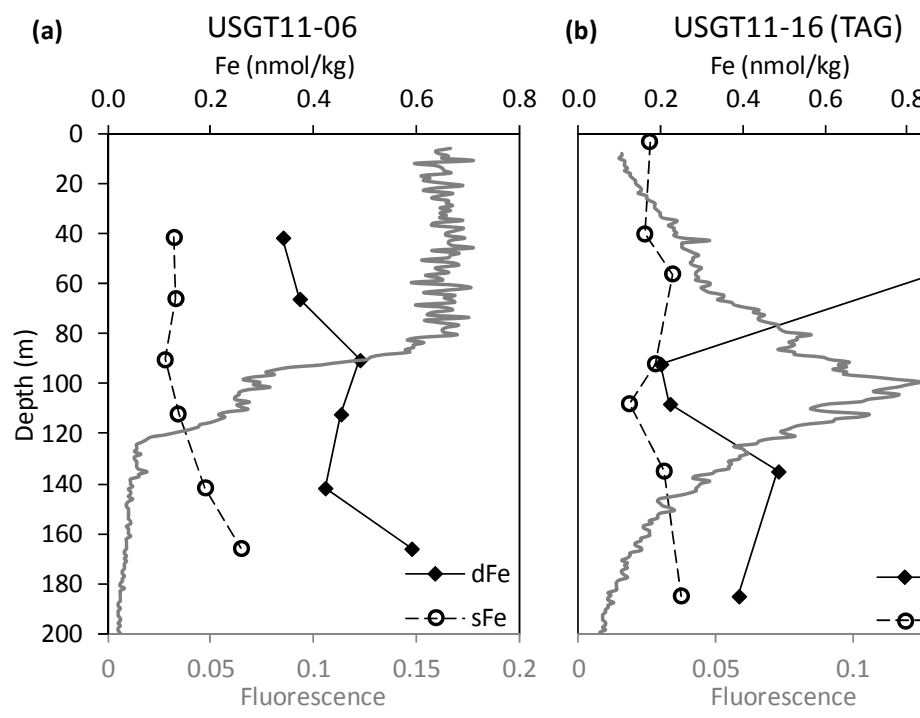

$\begin{array}{ll}\text { (c) } & \text { USGT11-20 } \\ & \mathrm{Fe}(\mathrm{nmol} / \mathrm{kg}) \\ 0.0 & 0.2\end{array}$
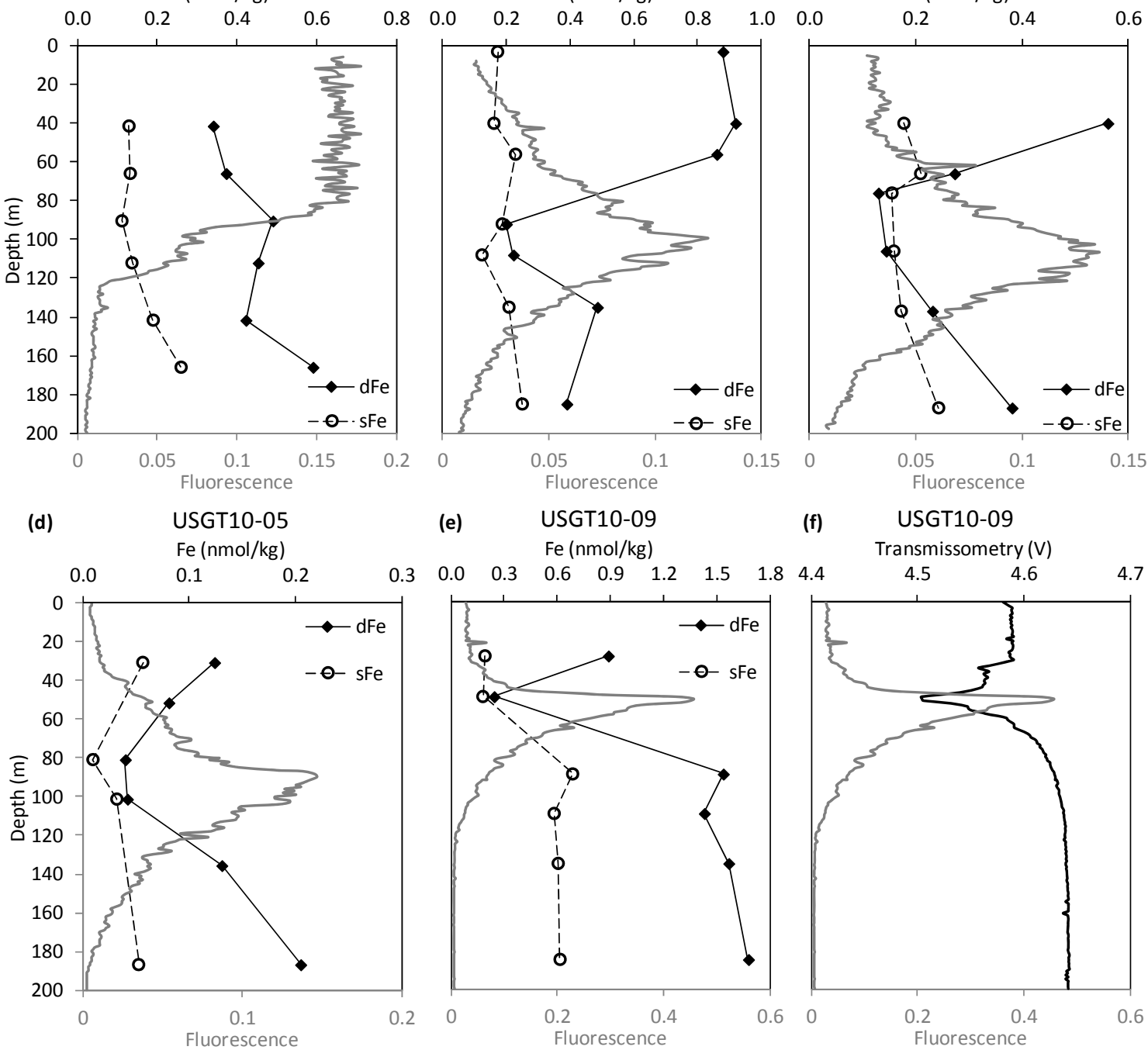

(e) $\quad \begin{aligned} & \text { USGT10-09 } \\ & \mathrm{Fe}(\mathrm{nmol} / \mathrm{kg})\end{aligned}$

(f)
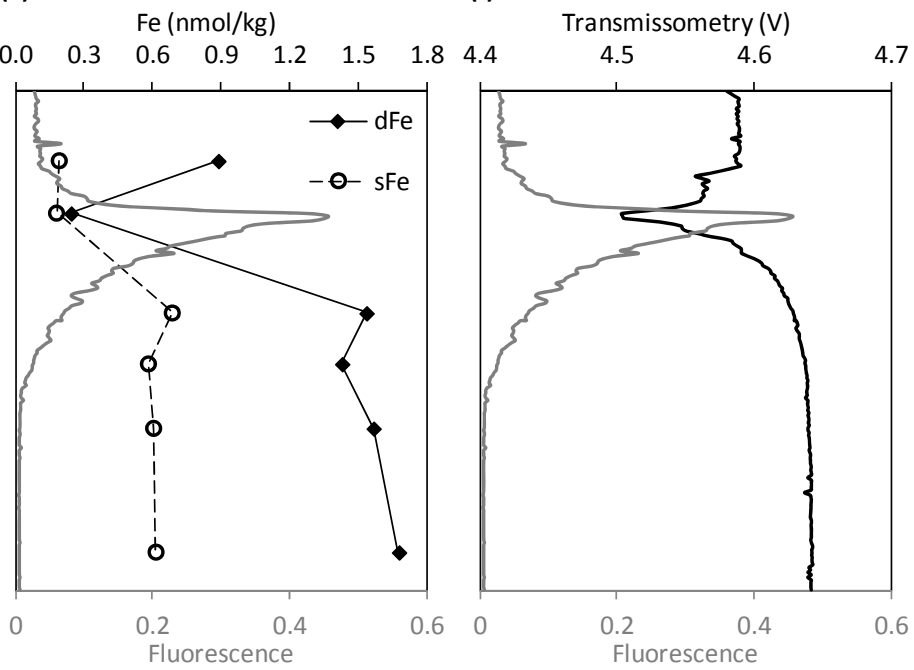

Figure 7: The speciation and size distribution of dissolved Fe in the upper $200 \mathrm{~m}$ on (a-c) the 2011 cruise where $\mathrm{sFe}$ is defined as $<0.02 \mu \mathrm{m}$ and on (d-e) the 2010 cruise where $\mathrm{sFe}$ is defined as $<10 \mathrm{kDa}$. The deep chlorophyll maximum (DCM) is designated as the fluorescence maximum in grey. Note that colloidal Fe (dFe - sFe) goes to zero at the DCM, except along the western North Atlantic margin (a, USGT11-06). Not surprisingly, the DCM also appears to be a depth of maximum particle loading, as the light transmission shows a coincident minimum with the DCM at many stations (f). 

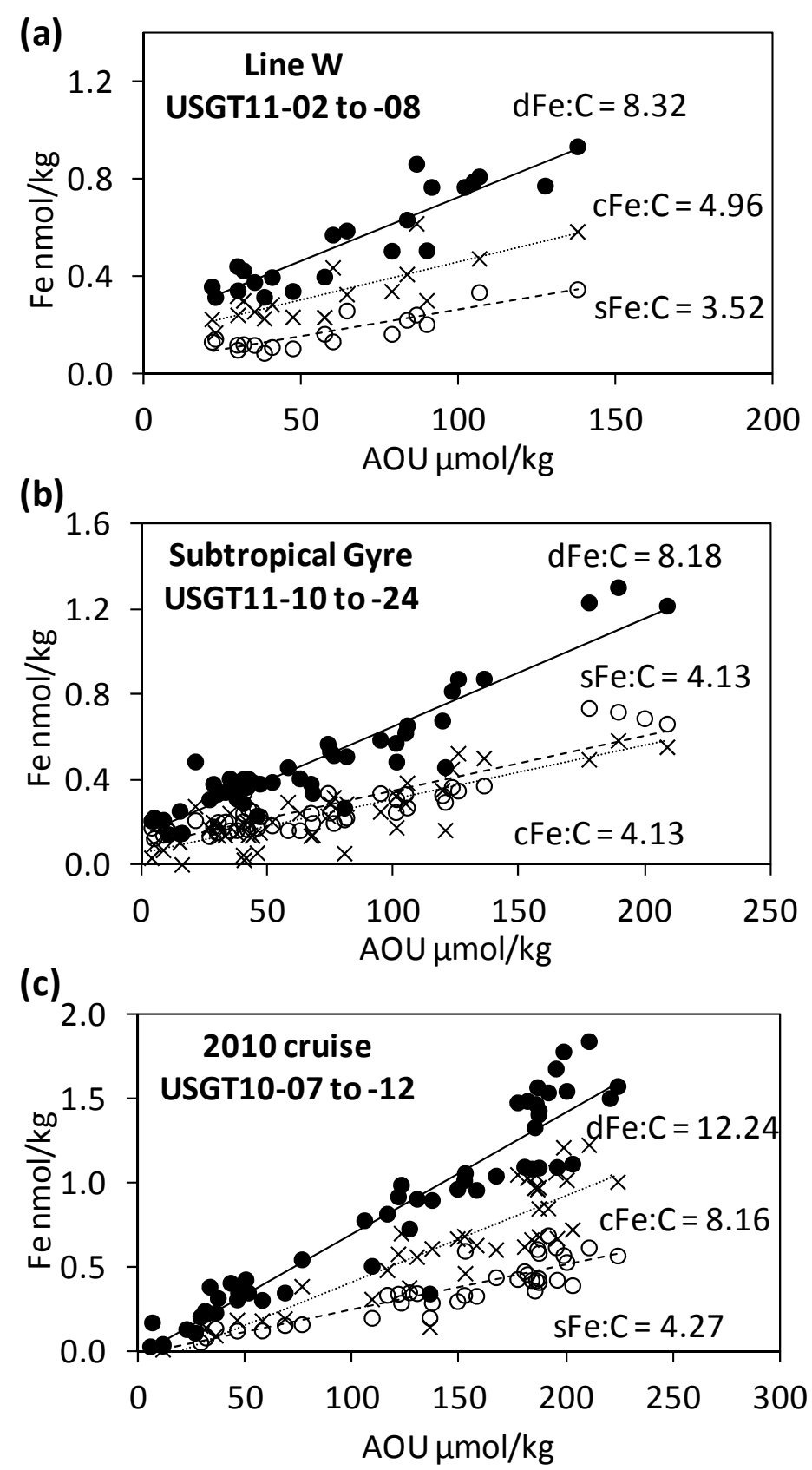

Figure 8: dFe partitioning resulting from remineralization in the Central Water layer (potential density layer $25.8-27.1 \mathrm{~kg} / \mathrm{m} 3$ ), shown as a function of AOU for (a) Line W USGT11-02 to -08 where the sFe size cutoff is $0.02 \mu \mathrm{m}$, (b) the subtropical gyre stations USGT11-10 to -24 where the sFe size cutoff is $0.02 \mu \mathrm{m}$, and (c) the 2010 cruise stations USGT10-07 to -12 where the sFe size cutoff is $10 \mathrm{kDa}$. Filled circles show dFe $(<0.2 \mu \mathrm{m})$, open circles show sFe $(<0.02 \mu \mathrm{m}$ in (ab), $<10 \mathrm{kDa}$ in (b)), and crosses show $\mathrm{cFe}(\mathrm{dFe}-\mathrm{sFe}$ ). sFe and $\mathrm{cFe}$ each contribute $\sim 50 \%$ to the $\mathrm{dFe}$ :AOU ratio in the subtropical gyre, while sFe contributes only $\sim 35-40 \%$ in the 2010 cruise and Line $\mathrm{W}$ sections. 


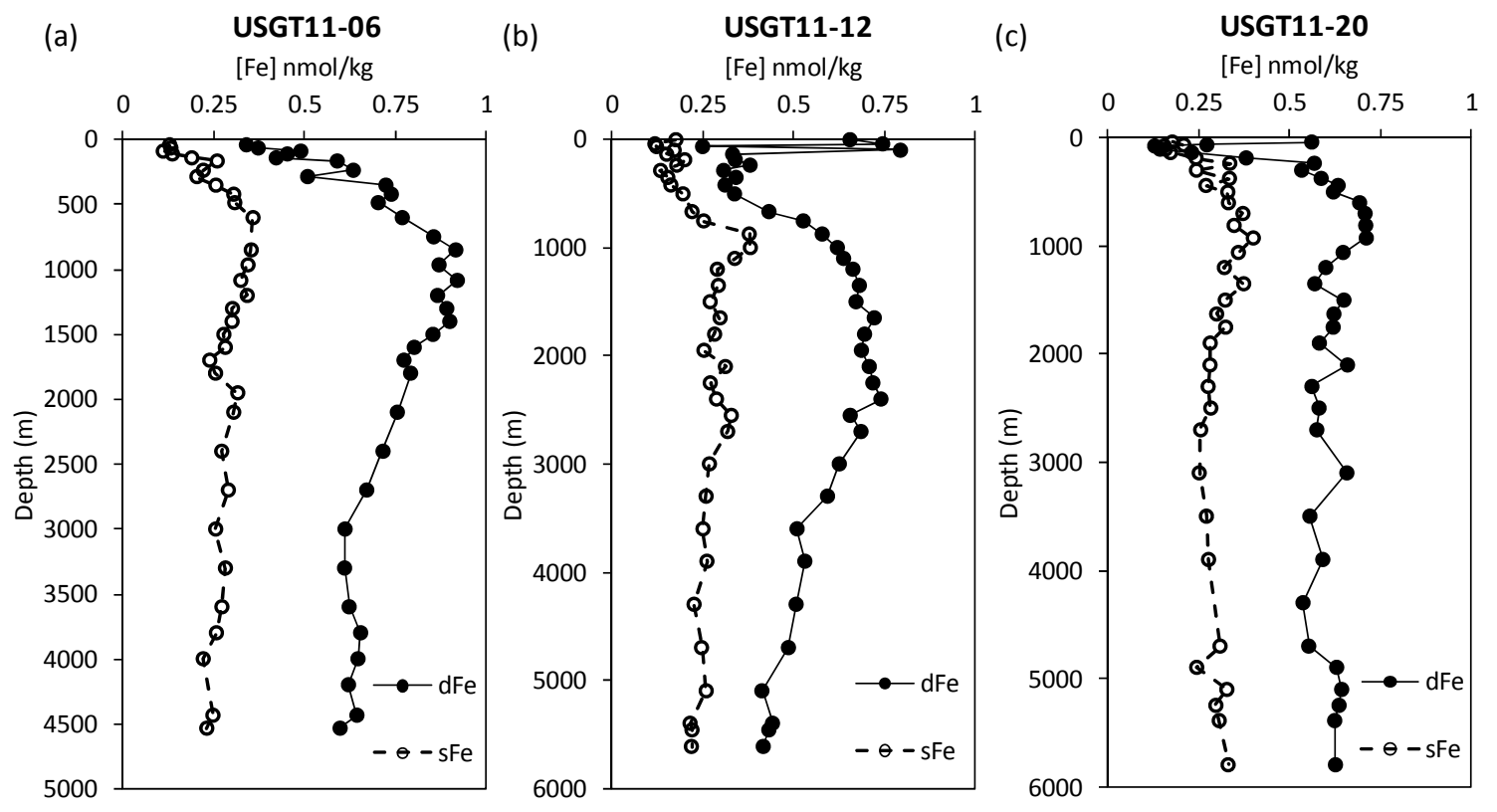

Figure 9: Full-depth ocean profiles of dissolved $\mathrm{Fe}(<0.2 \mu \mathrm{m}$, closed circles $)$ and soluble Fe $(<0.02 \mu \mathrm{m})$. Station locations are (a) USGT11-06, (b) USGT11-10 (BATS), and (c) USGT11-20. Note that the depth range in (c) is different than in (a-b). 

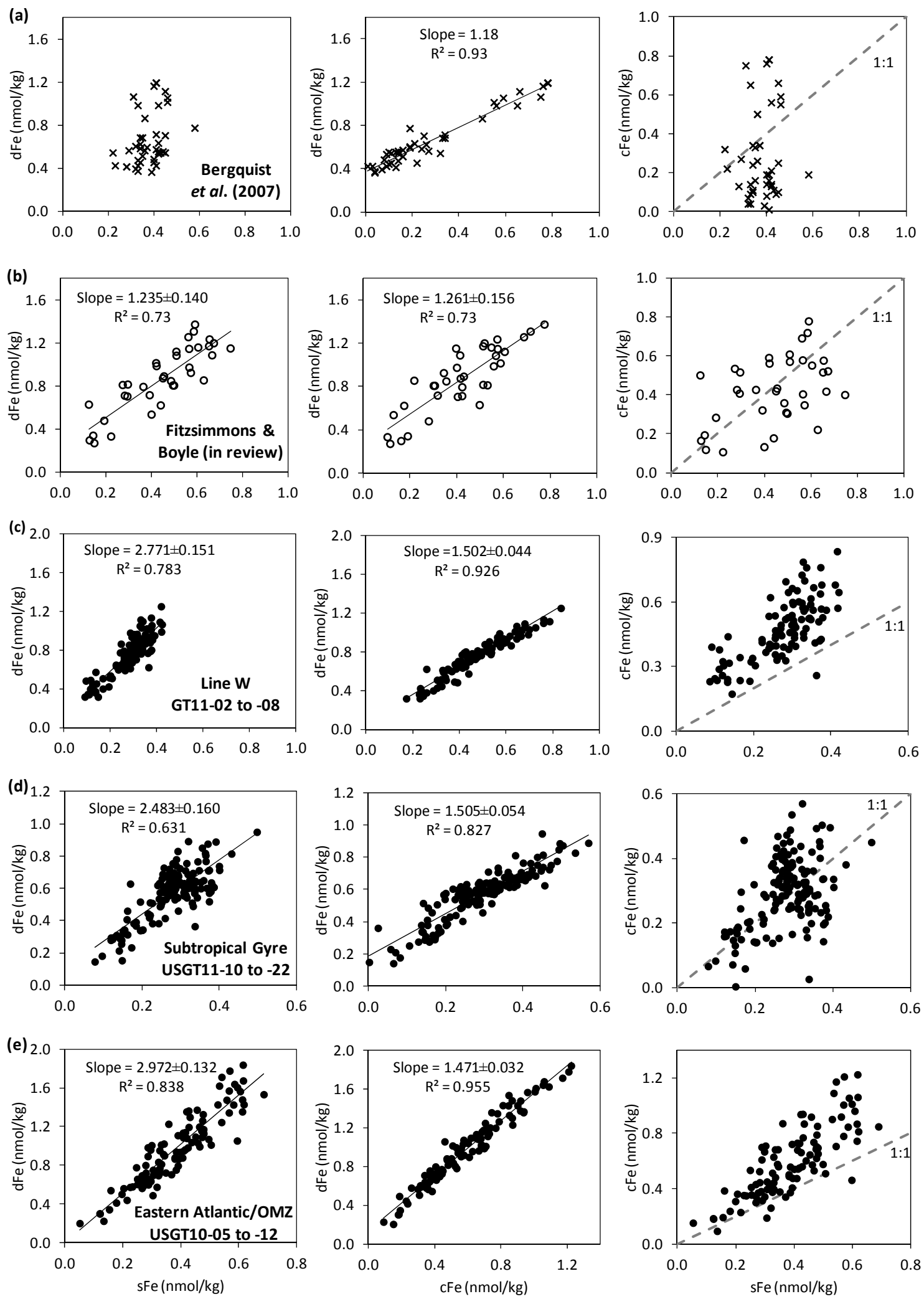
Figure 10: Relationships between dFe, sFe, and cFe in (a) Bergquist et al. (2007), (b)

Fitzsimmons and Boyle (in review-b), (c) Line W stations USGT11-02 through USGT11-08, (d) North Atlantic subtropical gyre stations USGT11-10 through USGT11-22, and (e) stations USGT10-05 through USGT10-12 from the 2010 eastern North Atlantic cruise including the Mauritanian/OMZ section. Only depths below the deep chlorophyll maximum are included, station USGT11-16 is excluded altogether, as well as the TAG-influenced depths at Station USGT11-14. Regressions are Type-II regressions, and in (a) the regressions are taken from Bergquist et al. (2007). The dashed line on the right panels shows the 1:1 sFe:cFe line. 
(a) Fe exchange model for the subsurface ocean: sFe and cFe cycle synchronously

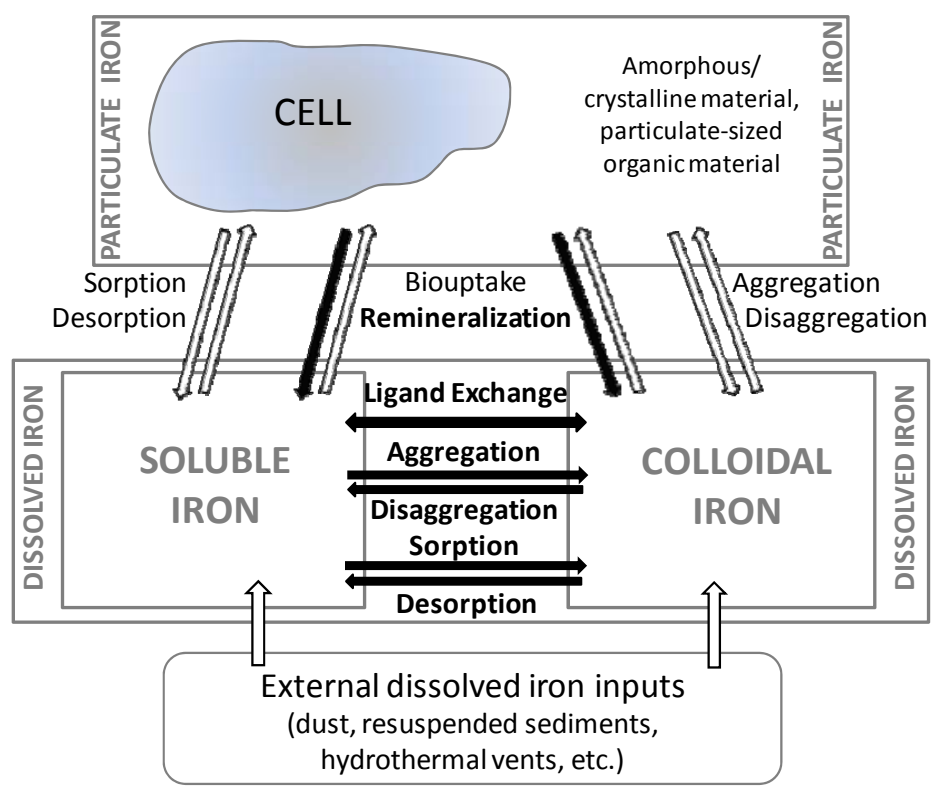

(b) Fe exchange model for the upper ocean: sFe and cFe cycle independently

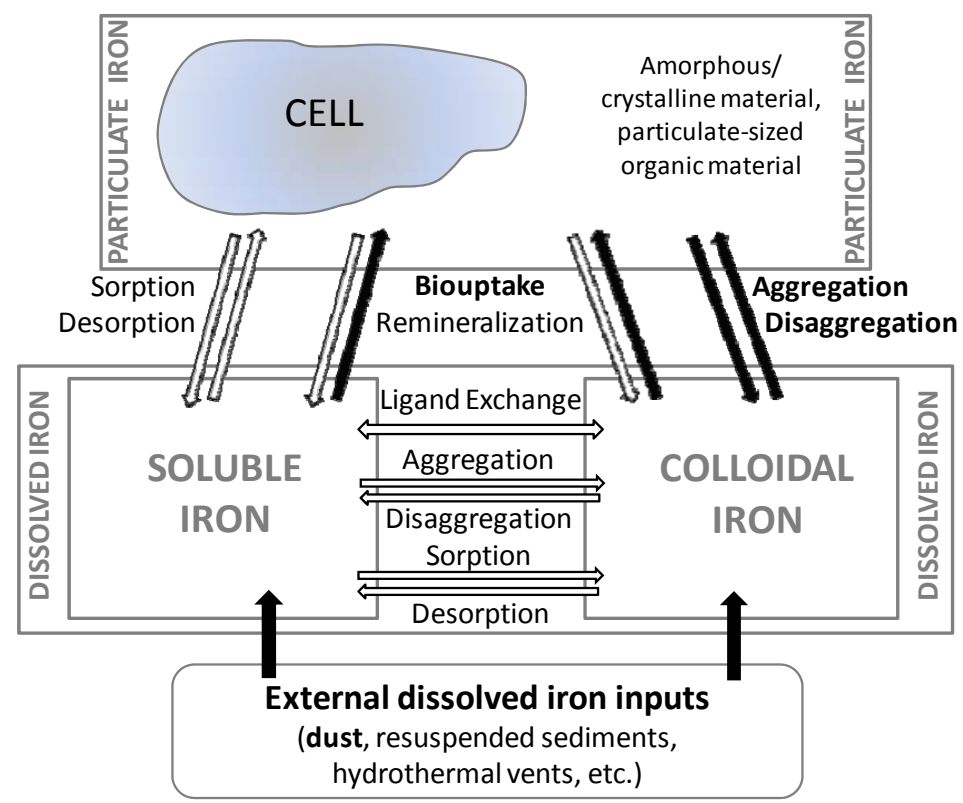

Figure 11: Model of Fe size partitioning, focused on the processes controlling dFe partitioning into soluble and colloidal fractions (box size has no relation to relative Fe pool size in this figure) for (a) the subsurface ocean (below the deep chlorophyll maximum) and (b) the upper ocean (surface through the deep chlorophyll maximum). Measurable quantities are shown in the gray rectangles ( $\mathrm{sFe}, \mathrm{cFe}$, $\mathrm{dFe}, \mathrm{pFe}$ ), and exchange rates are shown as arrows. The black arrows and bolded processes indicate the mechanism(s) driving the dominant partitioning pattern expressed in the partitioning plots of Figure 10 for each depth range. 


\begin{tabular}{|c|c|c|c|c|}
\hline Parameter or SRM & Consensus [Fe] & [dFe] & 2010 [sFe] & $2011[\mathrm{sFe}]$ \\
\hline $\begin{array}{l}\text { Procedure blank } \\
\text { range }\end{array}$ & -- & $\begin{array}{c}0.078 \pm 0.008 \\
(\mathrm{n}=11 \text { sessions })\end{array}$ & $\begin{array}{c}0.009-0.019 \\
(\mathrm{n}=11 \text { sessions })\end{array}$ & $\begin{array}{c}0.006-0.026 \\
(\mathrm{n}=18 \text { sessions })\end{array}$ \\
\hline Detection limit $(3 \sigma)$ & -- & $0.03-0.05$ & 0.027 & 0.030 \\
\hline SAFe D2 & $0.90 \pm 0.02$ & $0.950 \pm 0.035$ & $\begin{array}{c}0.931 \pm 0.046 \\
\quad(n=28)\end{array}$ & $\begin{array}{l}0.930 \pm 0.042 \\
\quad(n=43)\end{array}$ \\
\hline $\begin{array}{c}\text { SAFe surface } \\
\text { underway (Boyle-lab } \\
\text { internal standard) }\end{array}$ & $\begin{array}{c}0.093 \pm 0.008 \\
\text { (assume SAFe S) }\end{array}$ & -- & $\begin{array}{c}0.083 \pm 0.035 \\
\quad(n=39)\end{array}$ & $\begin{array}{l}0.079 \pm 0.050 \\
\quad(n=73)\end{array}$ \\
\hline SAFe S & $0.093 \pm 0.008$ & $0.103 \pm 0.010$ & -- & $\begin{array}{c}0.094 \pm 0.007 \\
(\mathrm{n}=3) \\
0.108 \pm 0.002 \\
(\mathrm{n}=3)\end{array}$ \\
\hline
\end{tabular}

Table 1: Reported procedure blanks, detection limits, and comprehensive lab analyses of the SAFe standard reference materials over the analytical sessions. dFe concentrations were analyzed in the Wu laboratory at RSMAS by the method described in Wu and Boyle (1998). sFe concentrations were analyzed in the Boyle laboratory at MIT by the methods described in Lee et al. (2011). All Fe concentrations are in units of nmol $/ \mathrm{kg}$, and consensus values are taken from http://www.geotraces.org/science/intercalibration as of May 2013. The detection limit is calculated as three times the standard deviation of the procedure blank for each analytical session. 


\begin{tabular}{|c|c|c|c|c|c|c|c|}
\hline \multirow[b]{2}{*}{$\begin{array}{c}\text { Water } \\
\text { mass: } \sigma_{\theta} \\
\left(\mathbf{k g} / \mathbf{m}^{3}\right)\end{array}$} & \multirow[b]{2}{*}{ Year } & \multirow[b]{2}{*}{ Sta. } & \multicolumn{2}{|c|}{ Dissolved Fe } & \multicolumn{2}{|c|}{ Soluble Fe } & \multirow{2}{*}{$\begin{array}{c}\text { \%sFe }_{\text {REN }} \\
\text { sFe:C / } \\
\text { dFe:C }\end{array}$} \\
\hline & & & $\begin{array}{c}\text { dFe:C } \\
(\mu \mathrm{mol} / \mathrm{mol})\end{array}$ & $\begin{array}{c}\text { Pre-formed } \\
\text { dFe } \\
(\mathrm{nmol} / \mathrm{kg})\end{array}$ & $\begin{array}{c}\text { sFe:C } \\
(\mu \mathrm{mol} / \mathrm{mol})\end{array}$ & $\begin{array}{c}\text { Pre-formed } \\
\text { sFe } \\
(\mathrm{nmol} / \mathrm{kg})\end{array}$ & \\
\hline \multirow{5}{*}{$\begin{array}{c}\text { Central } \\
\text { Water: } \\
25.8-27.1\end{array}$} & \multirow{2}{*}{2010} & $5-12$ & $12.24 \pm 0.78$ & 0 & $4.27 \pm 0.35$ & 0 & $34.9 \%$ \\
\hline & & $9-12$ & $13.50 \pm 1.40$ & 0 & $4.72 \pm 0.53$ & 0 & $35.0 \%$ \\
\hline & \multirow{3}{*}{2011} & $1-24$ & $8.18 \pm 0.42$ & $0.16 \pm 0.02$ & $4.13 \pm 0.27$ & $0.07 \pm 0.01$ & $50.5 \%$ \\
\hline & & $1-8$ & $8.38 \pm 0.87$ & $0.20 \pm 0.04$ & $3.46 \pm 0.46$ & $0.05 \pm 0.02$ & $41.3 \%$ \\
\hline & & $10-24$ & $8.04 \pm 0.46$ & $0.14 \pm 0.02$ & $4.17 \pm 0.28$ & $0.08 \pm 0.01$ & $51.9 \%$ \\
\hline \multirow{5}{*}{$\begin{array}{l}\text { Intermed } \\
\text { Waters: } \\
27.1-27.5\end{array}$} & \multirow{2}{*}{2010} & $5-12$ & $12.68 \pm 2.86$ & 0 & $4.99 \pm 1.12$ & 0 & $39.4 \%$ \\
\hline & & $9-12$ & - & 0 & - & 0 & \\
\hline & \multirow{3}{*}{2011} & $1-24$ & $6.78 \pm 1.44$ & 0 & $4.82 \pm 0.78$ & 0 & $71.1 \%$ \\
\hline & & $1-8$ & - & 0 & - & 0 & \\
\hline & & $10-24$ & $8.57 \pm 1.05$ & 0 & $4.52 \pm 0.84$ & 0 & $52.7 \%$ \\
\hline
\end{tabular}

Table 2: $\mathrm{dFe}: \mathrm{C}$ and sFe:C relationships (in $\mu \mathrm{mol} / \mathrm{mol}$ ) and pre-formed $\mathrm{dFe}$ and $\mathrm{sFe}$ (in $\mathrm{nmol} / \mathrm{kg}$ ) for various water masses. The $\% \mathrm{SFe}_{\text {REMIN }}$ attributed to remineralization is calculated as the ratio of $\mathrm{sFe}: \mathrm{C}$ to $\mathrm{dFe}: \mathrm{C}$. The cruise year and stations used are designated. Fe: $\mathrm{C}$ values are calculated from a Type-I regression of $\mathrm{Fe}$ and $\mathrm{AOU}$, and the Fe:AOU slope was converted to an $\mathrm{Fe}: \mathrm{C}$ using the AOU:C ratio of 1.6 (Martin et al., 1987). Error values are \pm 1 standard error from the calculated regression. 


\section{Appendix I}

\section{Dissolved iron distribution, size partitioning, and stable isotopes in the Southeast Pacific Ocean}

Collaborators: Jong-Mi Lee, Rick Kayser, Edward Boyle, Timothy Conway, Seth John

The Southeast Pacific Ocean is one of the most understudied regions of the global ocean, yet it encompasses enormous biogeochemical diversity (CLAUSTRE et al., 2008). Two opposing biogeochemical regimes share this region: the Southeast Pacific subtropical gyre and the permanent upwelling and oxygen minimum zone (OMZ) occurring along the Chilean cost. The Southeast Pacific subtropical gyre is the largest of the world's gyres and also the most oligotrophic, with the lowest marine chlorophyll-a

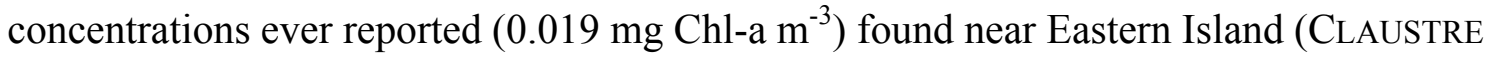
et al., 2008). In contrast, the wind-driven upwelling along the Chilean coast fuels some of the highest rates of primary production in the ocean (CARR, 2001). This organic material sinks and is remineralized at high rates, depleting the oxygen inventory, which combined with poor ventilation produces an OMZ reaching nearly complete anoxia (FUENZALIDA et al., 2009). Thus, across the Southeast Pacific, chlorophyll-a concentrations range over two orders of magnitude, and the redox gradient spans from complete to extinct oxygenation, providing an impressive gradient in biogeochemical features ripe for study.

In addition, the Southeast Pacific Ocean is one of the most understudied regions in the global ocean for trace metals, with no reported dissolved iron ( $\mathrm{dFe}$ ) measurements below 500m depth (MOORE and BRAUCHER, 2008). This dearth in dFe data exists despite that microorganisms in the Southeast Pacific subtropical gyre have been modeled to be limited by Fe (MOORE et al., 2002). Only one study has produced dFe data in this region and only above $400 \mathrm{~m}$ depth (BLAIN et al., 2008), but their data showed, as expected, high $\mathrm{dFe}$ concentrations $(>2 \mathrm{nmol} / \mathrm{kg})$ in the $\mathrm{OMZ}$ and very low dFe concentrations $(0.05-0.10$ $\mathrm{nmol} / \mathrm{kg}$ ) in the subtropical gyre. Incubation studies also completed on this cruise confirmed Fe limitation in the Southeast Pacific but surprisingly not in the heart of the gyre; only the edges of the gyre were found to be Fe limited, while in the heart of the gyre nitrogen concentrations controlled primary production (BONNET et al., 2008). Despite these studies, many questions remain about dFe biogeochemistry in the Southeast Pacific including controls of oxygen on $\mathrm{dFe}$ distributions, the influence of the $\mathrm{OMZ}$ on Fe distributions throughout the region, and of course the biogeochemistry of dFe in the abyssal Southeast Pacific. 
As a part of the Center for Microbial Oceanography: Research and Educate (CMORE), we collected trace metal-uncontaminated seawater samples from seven stations in the Southeast Pacific Ocean on the BiG RAPA cruise (Biogeochemical Gradients: Role in Arranging Planktonic Assemblages) in Nov-Dec 2010. The cruise track (Figure 1) was sampled using both the MITESS/Vanes system described in Chapter 2 (BELL et al., 2002; FitzSimmONS and BoyLE, 2012) and also the Saito-lab Niskin-X rosette deployed on a Kevlar hydrowire (NOBLE et al., 2012). Stations 1, 4, and 7 were sampled to the ocean bottom, while stations 2-3 and 5-6 were sampled to $1200 \mathrm{~m}$ only. Samples were filtered through $0.4 \mu \mathrm{m}$ Nuclepore filters using an offline, all-Teflon filter rig and were acidified to $\mathrm{pH} 2$ for a year before analysis. Fe analyses were made using the isotope dilution ICP-MS method of LEE et al. (2011). Replicate analyses of the SAFe D2 standard reference material, $0.925 \pm 0.041 \mathrm{nmol} / \mathrm{kg}(\mathrm{n}=23)$, were in good agreement with the consensus value of $0.933 \pm 0.023 \mathrm{nmol} / \mathrm{kg}$ (www.geotraces.org/science/intercalibration).

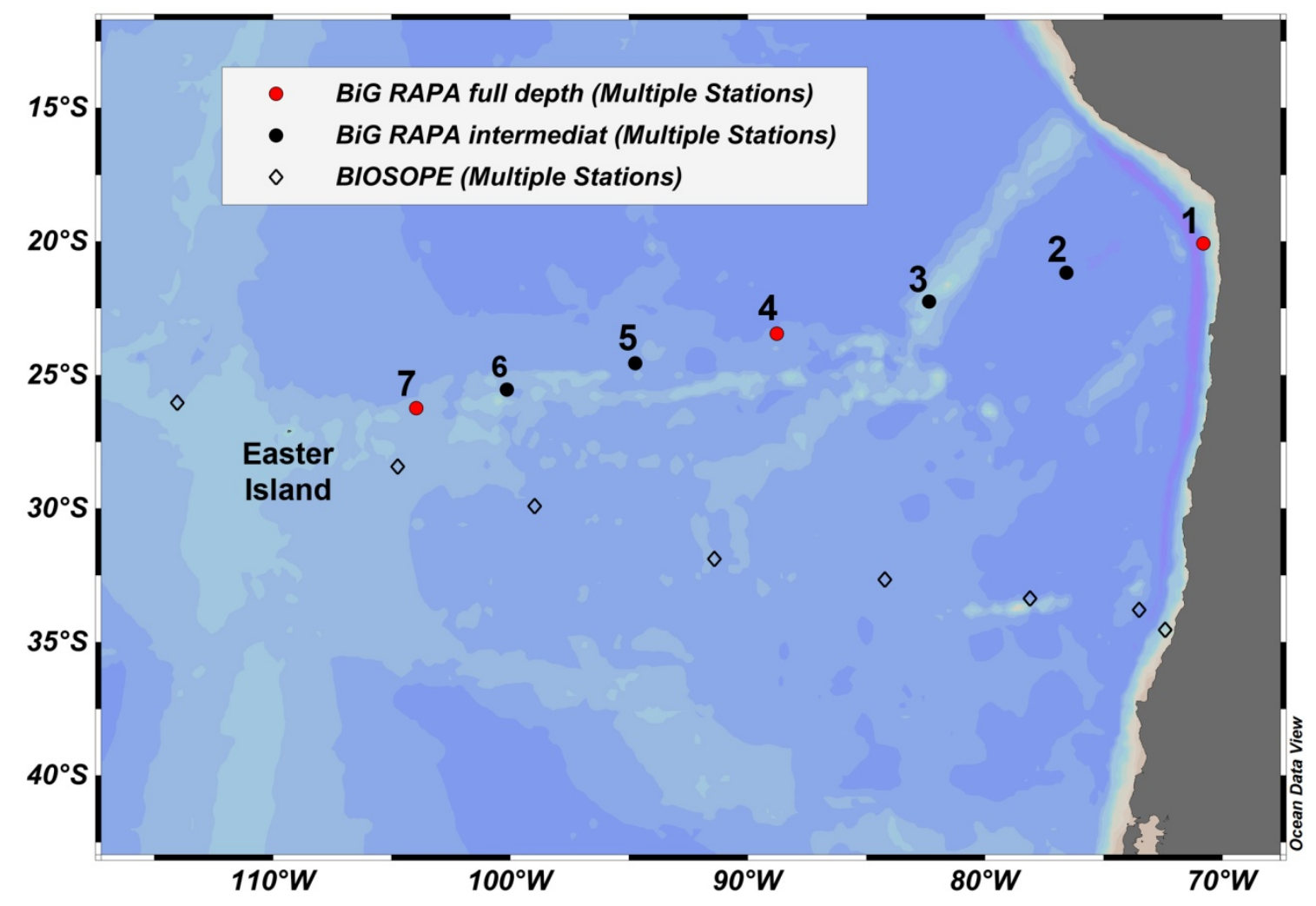

Figure 1: Map of the BiG RAPA stations sampled for trace metals. Red dots show the stations sampled to the ocean bottom, while the black dots show intermediate stations sampled to depths of $1200 \mathrm{~m}$. The BIOSOPE stations of BLAIN et al. (2008) are indicated as open diamonds. 


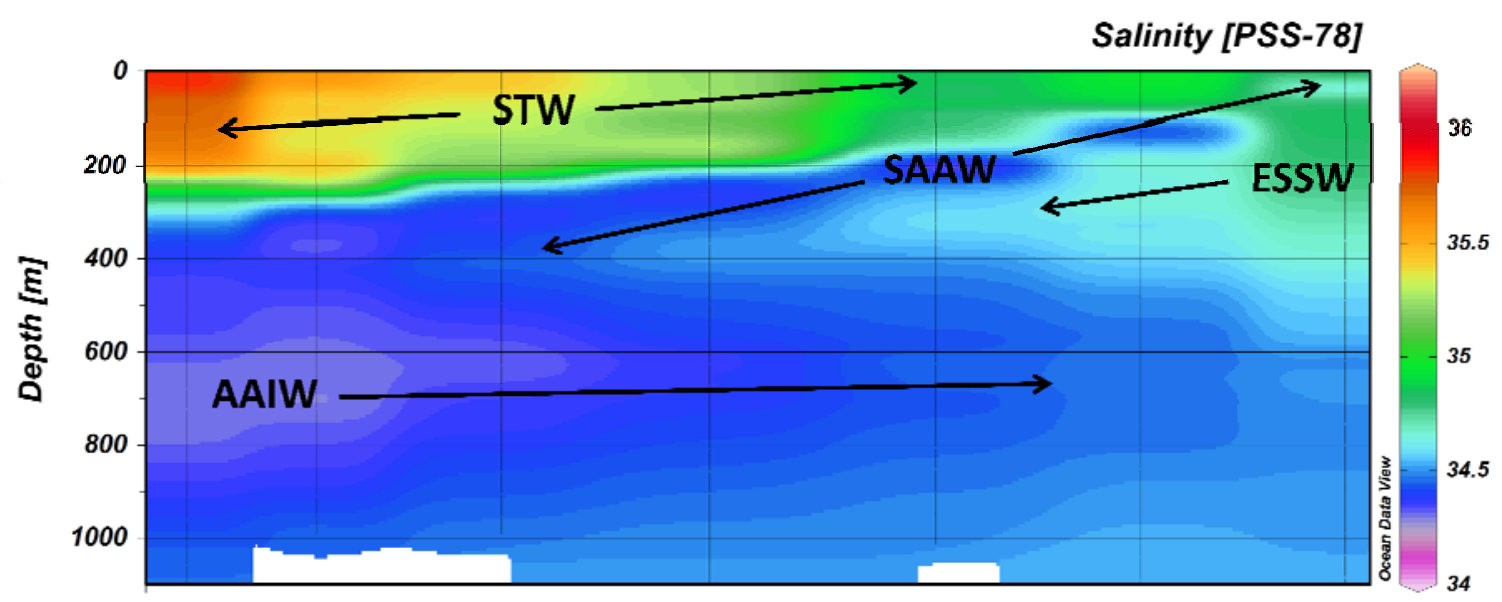

Figure 2: The salinity distribution along the BiG RAPA transect and the representative water masses (taken from SILVA et al., 2009). The subtropical gyre is composed of the high salinity and high temperature Subtropical Water (STW) and the Eastern South Pacific Central Waters. The OMZ is composed of the Equatorial Subsurface Water (ESSW), which is a high salinity feature that is advected southward with the Peru-Chile Undercurrent. In between these is the Subantarctic Water (SAAW), which is a low salinity feature that forms in the subtropical convergence $\sim 35^{\circ} \mathrm{S}$ that flows northward with the Humboldt current. Finally, Antarctic Intermediate Water (AAIW) is a low salinity, high oxygen water mass that flows northward. Both AAIW from below and SAAW from above ventilate the OMZ. 


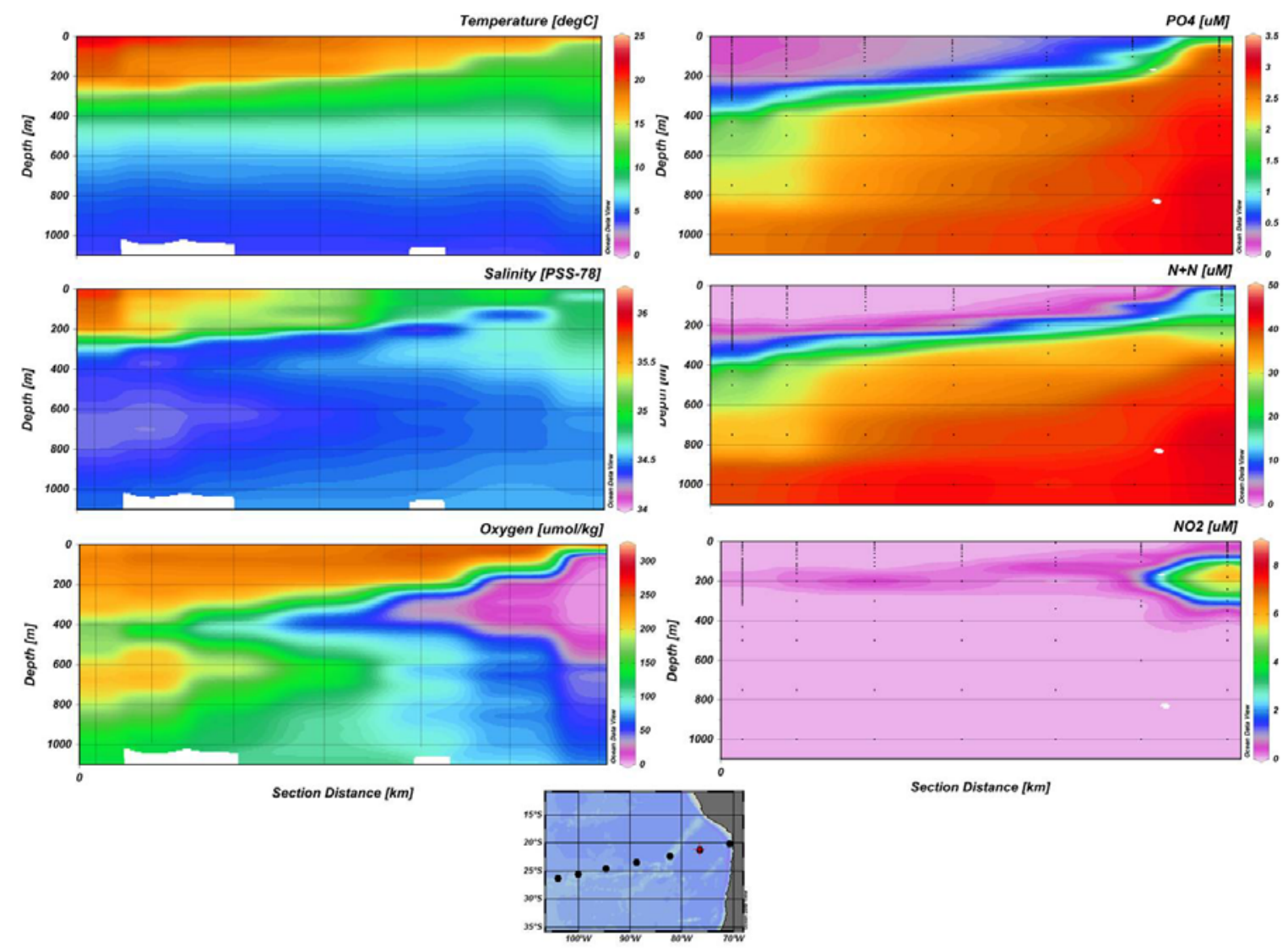

Figure 3: The hydrography and nutrient distribution of the BiG RAPA cruise transect. The oxygen minimum zone at Station 1 reaches from $100-400 \mathrm{~m}$ and is well represented in the oxygen distribution, with concentrations as low as $2 \mu \mathrm{mol} / \mathrm{kg}$. This OMZ is ventilated from above by SAAW and below by AAIW (both fully oxygenated). The $\mathrm{OMZ}$ also presents a clear nitrite maximum, with concentrations $>6 \mu \mathrm{M}$, indicating the severity of the oxygen depletion and corresponding change in redox state of the water column. The nitrate + nitrite and phosphate concentrations demonstrate the upwelling at Station 1 near the Chilean coast as well as the severe nutrient depletion in the upper 200$300 \mathrm{~m}$ of the subtropical gyre. 


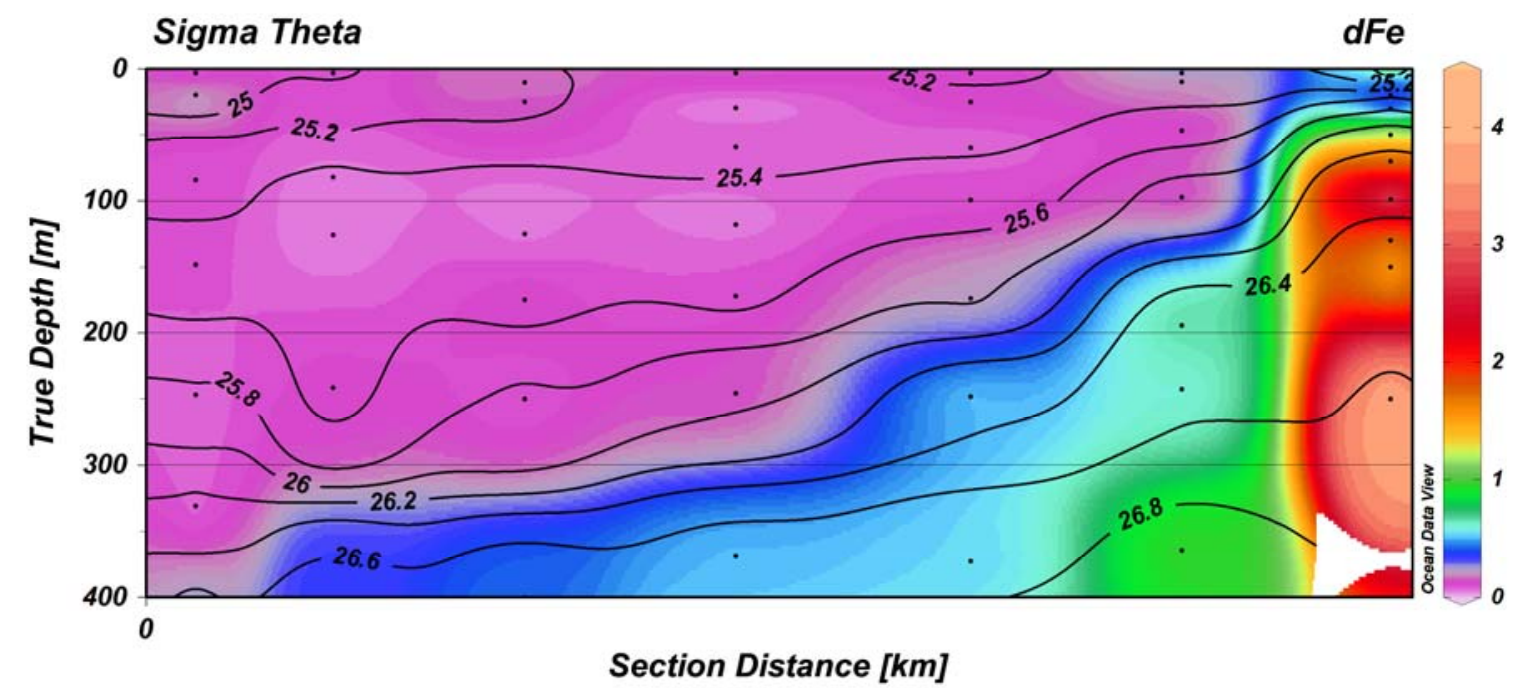

Figure 4: The dFe distribution (colors, in $\mathrm{nM}$ ) in the upper $400 \mathrm{~m}$ of the BiG RAPA transect, with potential density contour lines. dFe concentrations were highest in the OMZ $(\sim 3.5 \mathrm{nM})$ and lowest in the subtropical gyre $(<0.1 \mathrm{nM})$. This distribution was nearly identical to that reported by BLAIN et al. (2008). They reported maximum concentrations of $3.4 \mathrm{nM}$ dFe in the $\mathrm{OMZ}$ and subtropical gyre concentrations of 0.05 $0.10 \mathrm{nM}$. They also found the ferricline of the subtropical gyre to lie in the 26.4-26.6 $\mathrm{kg} / \mathrm{m}^{3}$ potential density layer, which was exactly the same on the BiG RAPA transect. This indicates that the dFe dynamics are very similar up and down the Chilean coast (20$35^{\circ} \mathrm{S}$ ). 


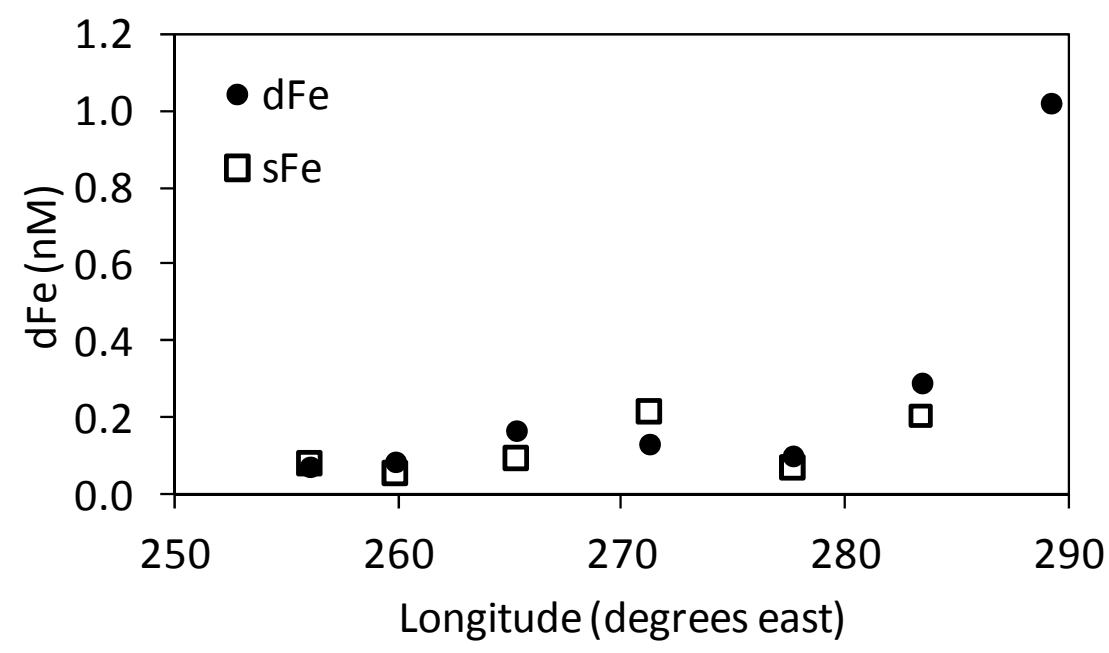

Figure 5: Surface dFe concentrations at the seven stations (where $\mathrm{dFe}<0.4 \mu \mathrm{m}$ and $\mathrm{sFe}<$ $10 \mathrm{kDa}$ ) were $\leq 0.25 \mathrm{nM}$ except for Station 1. Station 1 likely had high Fe concentrations from a combination of upwelling and $\mathrm{dFe}$ transport from reducing sediments along the margin. $\sim 1 \mathrm{nM} \mathrm{dFe}$ was observed at the surface along the narrow continental margin off of Peru (BRULAND et al., 2005), which is similar to the narrow continental margin near Station 1, indicating that advection and mixing of Fe(II) from margin sediments (as off Peru) may be sufficient to generate the Chilean Station 1 surface dFe concentration. If there was atmospheric deposition along the transect anywhere it would have been at Station 1 (HYSPLIT back trajectory shows transport from the South American continent), although the presence of coastal mountain ranges makes this questionable. Otherwise, atmospheric deposition to the Southeast Pacific Ocean is minimal, with measured Fe deposition rates from aerosols on the BIOSOPE cruise of only 0.11 $\mathrm{nmol} / \mathrm{m}^{2} /$ day (WAGENER et al., 2008); this is contrast to the high rates of deposition in the North Atlantic near Bermuda of 0.45-27.8 nmol $/ \mathrm{m}^{2} /$ day (SEDwICK et al., 2007). The minimal aerosol deposition is reflected in the very low concentrations of $\mathrm{dFe}$ measured in the surface waters. Much of this Fe was associated with the soluble Fe phase $(<10 \mathrm{kDa})$, instead of the colloidal phase as in high-dust regions (Chapter 6 and 7). This sFe is likely Fe that is rapidly recycled by biology in the surface ocean of the subtropical gyre. 

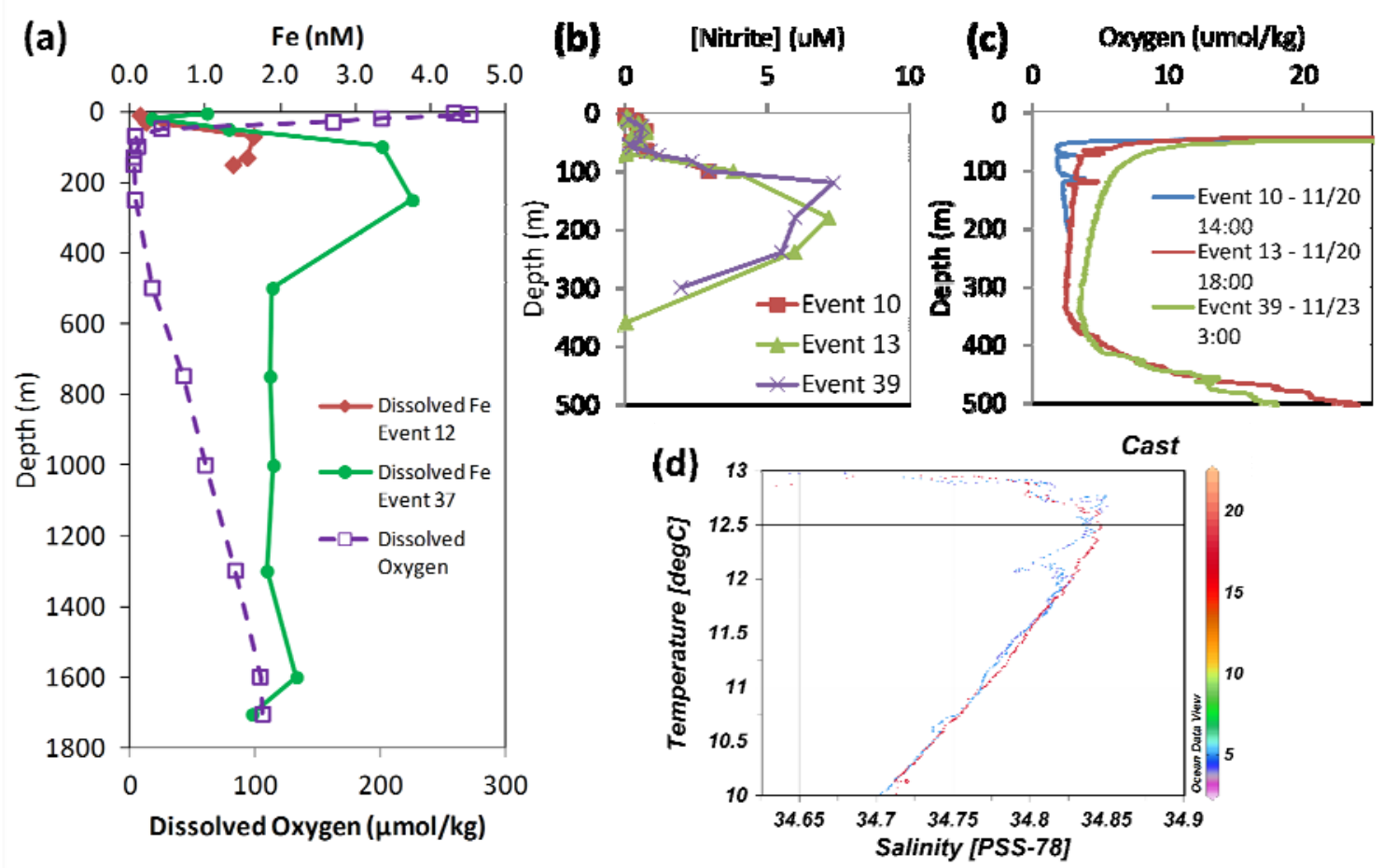

Figure 6: Station 1 chemistry and hydrography. (a) dFe concentrations were highly elevated $(3.5 \mathrm{nmol} / \mathrm{kg}$ ) from $100-300 \mathrm{~m}$, coincident with the OMZ. This is identical to that found in Blain et al. (2008) and also very typical of dFe concentrations found in lowoxygen marine environments such as the 1.5-2 $\mathrm{nM}$ dFe found in the Arabian Sea OMZ (MOFFETT et al., 2007). This OMZ dFe is likely comprised mostly of Fe(II) that is stabilized by the low oxygen concentrations. However, it was very surprising to find the concentration of dFe nearly double between Event 12 and Event 37, which were 2 days apart in time. This was not noticeably true of the nitrite concentrations (another redoxsensitive compound) over the same time period (b). Oxygen concentrations (c) did change over that time period, but the high oxygen concentrations, which would be expected to be associated with lower $\mathrm{dFe}$, were associated with the higher $\mathrm{dFe}$, and thus redox chemistry (more oxidation of $\mathrm{Fe}^{2+}$ in Event 12) cannot explain the observed $\mathrm{dFe}$. Instead, the temperature and salinity diagram (d) shows that a different water mass moved into the region of Station 1 between these two days, with a clear anomaly in T-S at $\sim 120 \mathrm{~m}$ very clear in the T-S diagram. Thus, there must be some advected component to the $\mathrm{dFe}$ measured at Station 1, although some of it may also be generated in situ. 


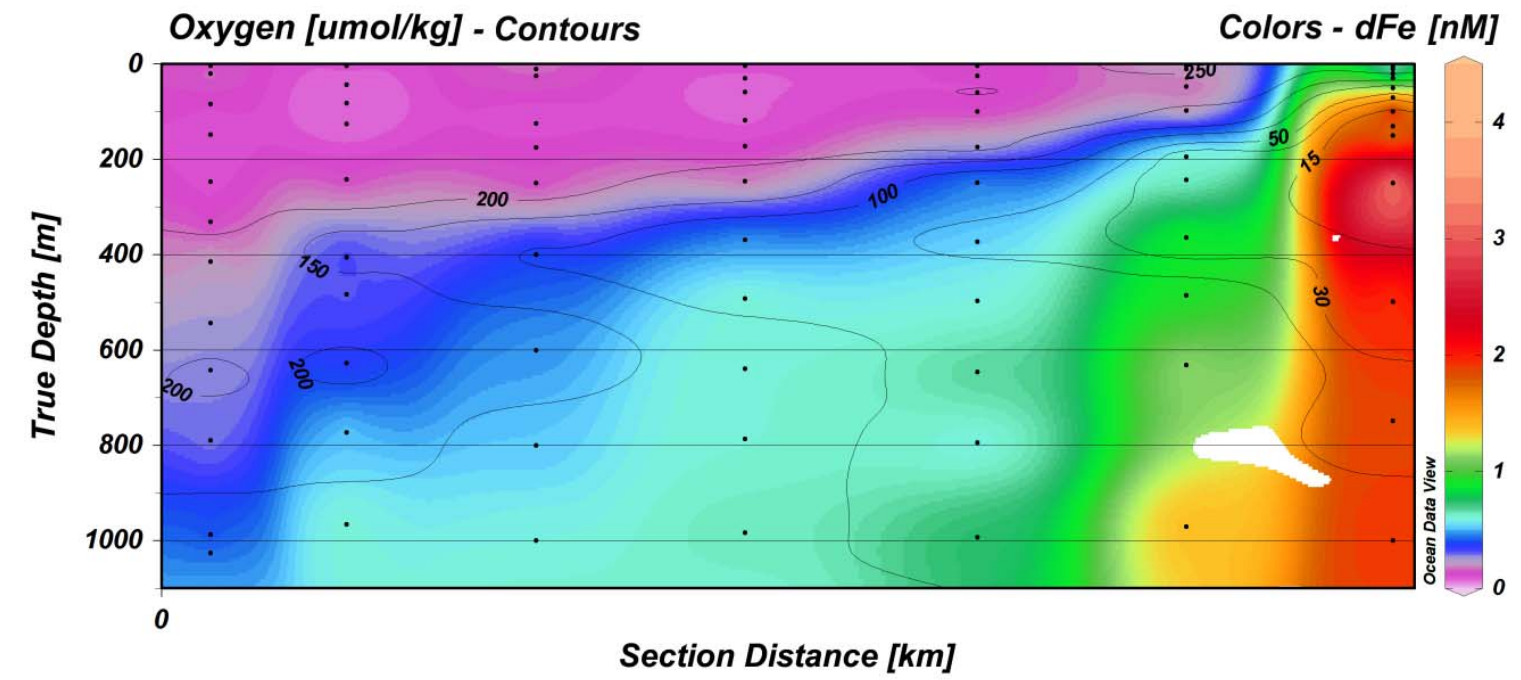

Figure 7: $\mathrm{dFe}$ distribution in the upper $1000 \mathrm{~m}$ (colors) with dissolved oxygen contours (lines). Oxygen is clearly a determining factor in the dFe distribution, as the contour lines largely match the color contours. This distribution clearly shows that the elevated $\mathrm{dFe}$ in the OMZ does not make it very far offshore, indicating that scavenging is significant.
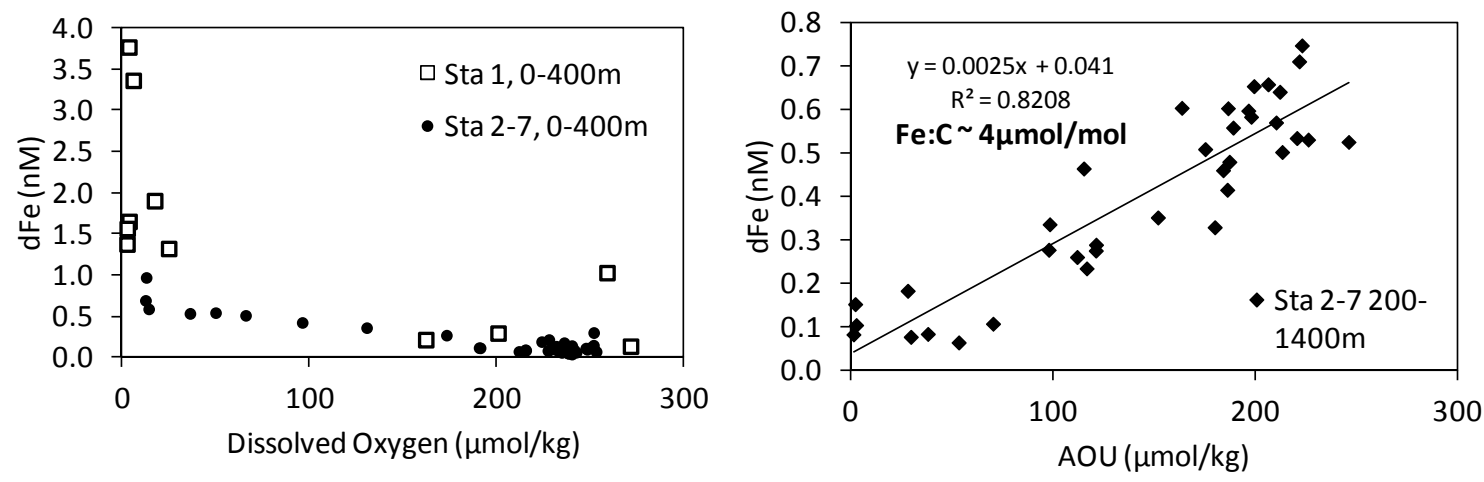

Figure 8: dFe is controlled by dissolved oxygen (a) and AOU (b). The relationship with oxygen in (a) clearly shows that when dissolved oxygen concentrations are low enough, $\mathrm{dFe}$ can be elevated as a result of the stabilization of Fe(II) species. In (b), the strong relationship between $\mathrm{dFe}$ and $\mathrm{AOU}$ shows that subsurface Fe concentrations are largely biologically controlled by uptake and remineralization, and the dFe:AOU slope can be converted to an $\mathrm{Fe}: \mathrm{C}$ ratio using the AOU:C ratio of 1.6 (MARTIN et al., 1987). The resulting Fe:C ratio of $\sim 4 \mu \mathrm{mol} / \mathrm{mol}$ is a bit lower than the 1.6-2.4 $\mu \mathrm{mol} / \mathrm{mol}$ ratios found in the Equatorial Pacific Fe-limited region (SUNDA, 1997) but is within the range of 2.6$6.1 \mu \mathrm{mol} / \mathrm{mol}$ measured in the subarctic North Pacific Fe-limited region (MARTIN et al., 1993; MARTIN et al., 1989). These Fe:C ratios are much lower than those measured in the tropical North Atlantic $(\sim 9-11 \mu \mathrm{mol} / \mathrm{mol}$, Chapter 3, FitzsimmONS et al., 2013). 

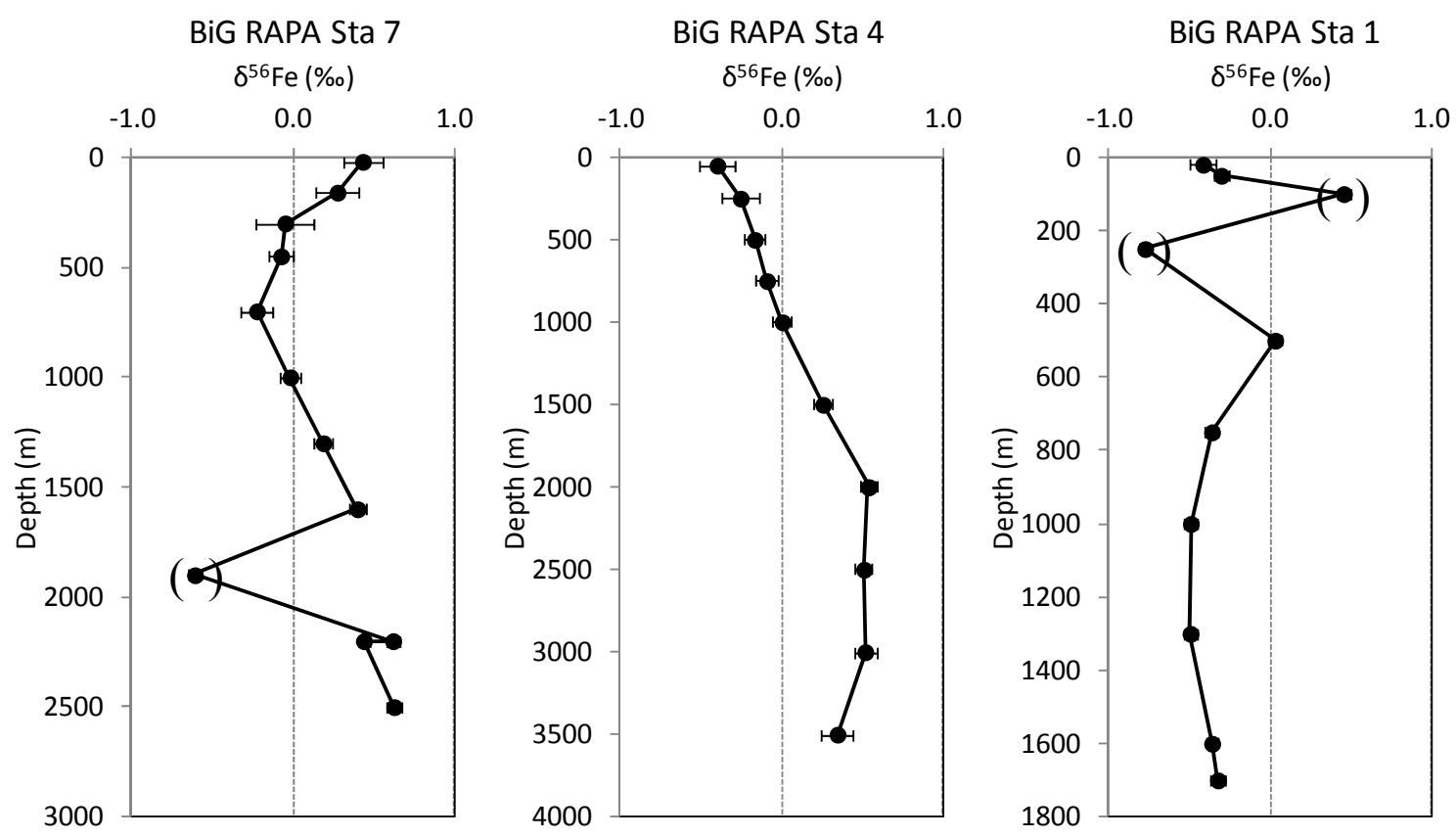

Figure 9: Fe stable isotopes, referenced to the IRMM-014 standard in \%o, at the three fulldepth stations on the BiG RAPA cruise (note that the depth range changes in each profile). Error bars show the $2 \sigma$ standard error on the isotope measurement. The parentheses indicate questionable Fe isotope values, and we will not interpret these data until they are re-analyzed. These measurements were made in the John laboratory at University of South Carolina by a ${ }^{57-58} \mathrm{Fe}$ double spike method (CONWAY et al., in press).

The main purpose of these analyses was to detect the Fe isotope signature associated with hydrothermal Fe (Chapter 5) near 2000m at Stations 4 and 7 and the enriched Fe in the OMZ of Station 1. We will not comment on the OMZ Fe isotopes because the values were so variable, which is not oceanographically consistent, and thus the data is potentially untrustworthy. However, the hydrothermally-influenced samples were undeniably enriched at $\sim+0.5 \%$. This was surprising given that hydrothermal vent fluids have always been found to have a depleted Fe isotope signature (-0.69 to $-0.21 \%$ ) both along the Mid-Atlantic Ridge and the East Pacific Rise (RouXEL et al., 2004; SEVERMANN et al., 2004). Even with a contribution of a third to half of the dFe measured at these stations as "background" $\mathrm{dFe}$ advected along the water mass or remineralized at depth, which in the Atlantic has an Fe isotopic composition of between 0 and $+0.5 \%$ o (JOHN and ADKINS, 2012; RADIC et al., 2011), we would not have expected such an enriched $\mathrm{Fe}$ isotope composition unless the hydrothermal vent $\mathrm{Fe}$ had undergone further fractionation since venting.

Four processes fractionate Fe isotopes during and after hydrothermal venting. First, basalt alteration results in isotopically enriched altered basalts and isotopically 
depleted fluids, indicating that the production of high-metal hydrothermal fluids itself is a fractionating process (ROUXEL et al., 2003; ROUXEL et al., 2004; SEVERMANN et al., 2004). Second, the precipitation of Fe sulfides has a kinetic isotope effect $\Delta \Delta^{56} \mathrm{Fe}$ Fe(II)-Fes of $+0.60 \%$, where the sulfide is depleted and the remaining Fe(II) becomes enriched (BENNETT et al., 2009; RouXEL et al., 2008). Third, during Fe(II) oxidation, the Fe(III) becomes enriched and the Fe(II) is depleted (BULLEN et al., 2001; WELCH et al., 2003). Finally, during ligand binding of free $\mathrm{Fe}(\mathrm{III})$ in seawater, the heavier the Fe-ligand complex, the more enriched the Fe becomes, presumably by an equilibrium isotope effect (MORGAN et al., 2010). All of these processes would result in the conversion of an initially depleted hyrdothermal fluid to a more enriched hydrothermally-derived dissolved Fe phase.

The hydrothermal portion of $\mathrm{dFe}$ at stations 4 and 7 is at minimum several hundred kilometers from the vent source (Chapter 5), indicating that it has undergone extensive chemical reactions before reaching the sampling location. If the southern-EPR vent fluid originally had depleted Fe, it would have first undergone sulfide precipitation at the vent site, which would have left the vent fluid relatively enriched. Then with increasing distance from the vents, the remaining Fe(II) should have been oxidized to Fe(III), which according to the oxidation kinetics predicted for the Pacific should have happened within hours of venting (FIELD and SHERRELL, 2000), well before reaching the sampling location years after venting; this oxidation would have further enriched the hydrothermal dissolved Fe. With all of these effects, plus the further enriching effect of ligand binding and the mixing with "background" dFe that is enriched, it might no longer be surprising that the distal hydrothermal $\mathrm{dFe}$ was isotopically enriched.

These profiles also show non-anomalous $\mathrm{dFe}$ isotope features that are valuable given the relative dearth of marine $\mathrm{dFe}$ isotope data in the Pacific Ocean. The surface $\mathrm{dFe}$ are depleted to $-0.4 \%$ at the more nearshore stations 1 and 4 , indicating that the $\mathrm{Fe}$ at these stations may have been derived from the reducing sediments along the coast, which have depleted Fe isotopic signatures (SEVERMANn et al., 2006; SEVERMAnN et al., 2010). This is no surprise at Station 1 but is potentially surprising at Station 4, which is $\sim 2000$ $\mathrm{km}$ offshore. At station 7, however, the surface $\delta^{56} \mathrm{Fe}$ was enriched to $+0.43 \%$, which is more typical of the surface ocean (JOHN and ADKINS, 2012; RADIC et al., 2011).

Furthermore, AAIW at both Stations 4 and 7 had a $\delta^{56} \mathrm{Fe}$ near -0.1 to $-0.2 \%$, which is likely a preformed Fe isotope signature since POC stocks ripe for remineralization in the subtropical gyre are so lean. 


\section{References for Appendix I}

Bell, J., Betts, J., and Boyle, E., 2002. MITESS: a moored in situ trace element serial sampler for deep-sea moorings. Deep-Sea Research Part I-Oceanographic Research Papers 49, 2103-2118.

Bennett, S. A., Rouxel, O., Schmidt, K., Garbe-Schonberg, D., Statham, P. J., and German, C. R., 2009. Iron isotope fractionation in a buoyant hydrothermal plume, 5S Mid-Atlantic Ridge. Geochimica et Cosmochimica Acta 73, 5619-5634.

Blain, S., Bonnet, S., and Guieu, C., 2008. Dissolved iron distribution in the tropical and sub tropical South Eastern Pacific. Biogeosciences 5, 269-280.

Bonnet, S., Guieu, C., Bruyant, F., Prasil, O., Van Wambeke, F., Raimbault, P., Moutin, T., Grob, C., Gorbunov, M. Y., Zehr, J. P., Masquelier, S. M., Garczarek, L., and Claustre, H., 2008. Nutrient limitation of primary productivity in the Southeast Pacific (BIOSOPE cruise). Biogeosciences 5, 215-225.

Bruland, K. W., Rue, E. L., Smith, G. J., and DiTullio, G. R., 2005. Iron, macronutrients and diatom blooms in the Peru upwelling regime: brown and blue waters of Peru. Marine Chemistry 93, 81-103.

Bullen, T. D., White, A. F., Childs, C. W., Vivit, D. V., and Schulz, M. S., 2001. Demonstration of significant abiotic iron isotope fractionation in nature. Geology 29, 699-702.

Carr, M.-E., 2001. Estimation of potential productivity in Eastern Boundary Currents using remote sensing. Deep Sea Research Part II: Topical Studies in Oceanography 49, 59-80.

Claustre, H., Sciandra, A., and Vaulot, D., 2008. Introduction to the special section biooptical and biogeochemical conditions in the South East Pacific in late 2004: the BIOSOPE program. Biogeosciences 5, 679-691.

Conway, T. M., Rosenberg, A. D., Adkins, J. F., and John, S. G., in press. A new method for precise determination of iron, zinc, and cadmium stable isotope ratios in seawater by double-spike mass spectrometry. Analytica Chimica Acta.

Field, M. P. and Sherrell, R. M., 2000. Dissolved and particulate Fe in a hydrothermal plume at $9^{\circ} 45^{\prime} \mathrm{N}$, East Pacific Rise: Slow Fe (II) oxidation kinetics in Pacific plumes. Geochimica et Cosmochimica Acta 64, 619-628.

Fitzsimmons, J. N. and Boyle, E. A., 2012. An intercalibration between the GEOTRACES GO-FLO and the MITESS/Vanes sampling systems for dissolved iron concentration analyses (and a closer look at adsorption effects). Limnology \& Oceanography: Methods 10, 437-450.

Fitzsimmons, J. N., Zhang, R., and Boyle, E. A., 2013. Dissolved iron in the tropical North Atlantic oxygen minimum zone. Marine Chemistry 154, 87-99.

Fuenzalida, R., Schneider, W., Garces-Vargas, J., Bravo, L., and Lange, C., 2009. Vertical and horizontal extension of the oxygen minimum zone in the eastern South Pacific Ocean. Deep-Sea Research II 56, 992-1003.

John, S. G. and Adkins, J., 2012. The vertical distribution of iron stable isotopes in the 
North Atlantic near Bermuda. Global Biogeochem. Cycles 26, GB2034.

Lee, J.-M., Boyle, E. A., Echegoyen-Sanz, Y., Fitzsimmons, J. N., Zhang, R., and Kayser, R. A., 2011. Analysis of trace metals $(\mathrm{Cu}, \mathrm{Cd}, \mathrm{Pb}$, and $\mathrm{Fe})$ in seawater using single batch Nitrilotriacetate resin extraction and isotope dilution inductively coupled plasma mass spectrometry. Analytica Chimica Acta 686, 93-101.

Martin, J. H., Fitzwater, S. E., Michael Gordon, R., Hunter, C. N., and Tanner, S. J., 1993. Iron, primary production and carbon-nitrogen flux studies during the JGOFS North Atlantic bloom experiment. Deep Sea Research Part II: Topical Studies in Oceanography 40, 115-134.

Martin, J. H., Goron, R. M., Fitzwater, S., and Broenkow, W. W., 1989. VERTEX: phytoplankton/iron studies in the Gulf of Alaska. Deep-Sea Research 36, 649-680.

Martin, J. H., Knauer, G. A., Karl, D. M., and Broenkow, W. W., 1987. VERTEX: carbon cycling in the northeast Pacific. Deep Sea Research Part A. Oceanographic Research Papers 34, 267-285.

Moffett, J. W., Goepfert, T. J., and Naqvi, S. W. A., 2007. Reduced iron associated with secondary nitrite maxima in the Arabian Sea. Deep Sea Research Part I: Oceanographic Research Papers 54, 1341-1349.

Moore, J. K. and Braucher, O., 2008. Sedimentary and mineral dust sources of dissolved iron to the world ocean. Biogeosciences 5, 631-656.

Moore, J. K., Doney, S. C., Glover, D. M., and Fung, I. Y., 2002. Iron cycling and nutrient-limitation patterns in surface waters of the World Ocean. Deep Sea Research Part II: Topical Studies in Oceanography 49, 463-507.

Morgan, J. L. L., Wasylenki, L. E., Nuester, J., and Anbar, A. D., 2010. Fe isotope fractionation during equilibration of Fe-organic complexes. Environmental Science \& Technology 44, 6095-6101.

Noble, A. E., Lamborg, C. H., Ohnemus, D. C., Lam, P. J., Goepfert, T. J., Measures, C. I., Frame, C. H., Casciotti, K. L., DiTullio, G. R., Jennings, J., and Saito, M. A., 2012. Basin-scale inputs of cobalt, iron, and manganese from the Benguela-Angola front to the South Atlantic Ocean. Limnology \& Oceanography 57, 989-1010.

Radic, A., Lacan, F., and Murray, J. W., 2011. Iron isotopes in the seawater of the equatorial Pacific Ocean: New constraints for the oceanic iron cycle. Earth and Planetary Science Letters 306, 1-10.

Rouxel, O., Dobbek, N., Ludden, J. N., and Fouquet, Y., 2003. Iron isotope fractionation during oceanic crust alteration. Chemical Geology 202, 155-182.

Rouxel, O., Fouquet, Y., and Ludden, J. N., 2004. Subsurface processes at the lucky strike hydrothermal field, Mid-Atlantic ridge: evidence from sulfur, selenium, and iron isotopes. Geochimica et Cosmochimica Acta 68, 2295-2311.

Rouxel, O., Shanks Iii, W. C., Bach, W., and Edwards, K. J., 2008. Integrated Fe- and S-isotope study of seafloor hydrothermal vents at East Pacific Rise 9-10 N. Chemical Geology 252, 214-227.

Sedwick, P. N., Sholkovitz, E. R., and Church, T. M., 2007. Impact of anthropogenic combustion 
emissions on the fractional solubility of aerosol iron: Evidence from the Sargasso Sea. Geochem. Geophys. Geosyst. 8, 21.

Severmann, S., Johnson, C. M., Beard, B. L., German, C. R., Edmonds, H. N., Chiba, H., and Green, D. R. H., 2004. The effect of plume processes on the Fe isotope composition of hydrothermally derived $\mathrm{Fe}$ in the deep ocean as inferred from the Rainbow vent site, Mid-Atlantic Ridge, 36 degrees 14' N. Earth and Planetary Science Letters 225, 63-76.

Severmann, S., Johnson, C. M., Beard, B. L., and McManus, J., 2006. The effect of early diagenesis on the Fe isotope compositions of porewaters and authigenic minerals in continental margin sediments. Geochimica et Cosmochimica Acta 70, 2006-2022.

Severmann, S., McManus, J., Berelson, W. M., and Hammond, D. E., 2010. The continental shelf benthic iron flux and its isotope composition. Geochimica et Cosmochimica Acta 74, 3984-4004.

Silva, N., Rojas, N., and Fedele, A., 2009. Water masses in the Humboldt Current System: Properties, distribution, and the nitrate deficit as a chemical water mass tracer for Equatorial Subsurface Water off Chile. Deep-Sea Research II 56, 1004-1020.

Sunda, W. G., 1997. Control of dissolved iron concentrations in the world ocean, A comment. Marine Chemistry 57, 169-172.

Wagener, T., Guieu, C., Losno, R., Bonnet, S., and Mahowald, N., 2008. Revisiting atmospheric dust export to the Southern Hemisphere ocean: Biogeochemical implications. Global Biogeochem. Cycles 22, GB2006.

Welch, S. A., Beard, B. L., Johnson, C. M., and Braterman, P. S., 2003. Kinetic and equilibrium $\mathrm{Fe}$ isotopic fractionation between aqueous $\mathrm{Fe}(\mathrm{II})$ and $\mathrm{Fe}(\mathrm{III})$. Geochimica et Cosmochimica Acta 67, 4231-4250. 


\section{Appendix II}

\section{Iron chemistry at the TAG hydrothermal field}

Collaborators: Mariko Hatta, Christopher Measures, Gonzalo Carrasco, Peter Sedwick, Edward Boyle (and soon to join: Sara Rauschenberg and Benjamin Twining)

The Trans-Atlantic Geotraverse (TAG) hydrothermal field is a well-studied hydrothermal vent system in the Atlantic Ocean around $26^{\circ} \mathrm{N}$. TAG is located on the eastern wall of the slow-spreading $(<2 \mathrm{~cm} / \mathrm{y}$ ) Mid-Atlantic Ridge (MAR) rift valley in $3650 \mathrm{~m}$ water depth (RoNA et al., 1986) and is comprised of a large mound that contains multiple black and white smoker vents (TIVEY et al., 1995). The vent fluids have been studied since 1985 over several Alvin dives (CAMPBELL et al., 1988) that explored the temporal and spatial variability of TAG hydrothermal venting (GAMO et al., 1996). These studies demonstrated that the TAG system vents fluid with very high dFe concentrations of $\sim 5.0-5.5 \mathrm{mM}$ that were stable in Fe concentration over the 12 years of study (CHIBA et al., 2001), despite Ocean Drilling Program (ODP) drilling nearby in the early 1990s (EDMONDS et al., 1996). This stability in vent-fluid Fe chemistry, along with the thorough characterization of both the physics of TAG plume dynamics (RUDNICKI and ELDERFIELD, 1992; SPEER and RoNA, 1989) and North Atlantic Fe chemistry (BERGQUIST and BOyLe, 2006; FITZSIMMONS et al., 2013; MEASURES et al., 2008), makes TAG an ideal model system for an exploration of Fe chemistry in MAR hydrothermal vents.

The Fe chemistry in the TAG buoyant plume has been modeled as a two-stage process where in the initial 15 seconds of venting ( $\sim 8 \mathrm{~m}$ plume rise) half of the Fe precipitates as sulfides, followed by precipitation of the rest of the Fe as oxyhydroxides (by $\sim 150 \mathrm{~m}$ plume rise) with an oxidation half-life of $\sim 2.1$ minutes (RUDNICKI and ELDERFIELD, 1993). However, JAMES AND ELDERFIELD (1996) found that up to 50\% of the Fe in TAG plume was still dissolved $(<0.4 \mu \mathrm{m})$ upon reaching plume neutral buoyancy, opposing the hypothesis of quantitative precipitation in the buoyant plume. Instead they hypothesized that much of their "dissolved Fe" was not actually composed of reduced $\mathrm{Fe}^{2+}$ but was instead composed of the Fe precipitates proposed by RUDNICKI AND ELDERFIELD that simply fell into the colloidal (instead of particulate) size fraction.

On the GEOTRACES North Atlantic Zonal Transect 2011 cruise (described in Chapter 7), we sampled in the region of the TAG hydrothermal vent field (Station GT1116) using CTD/GO-FLO rosette operations. We were able to capture a portion of the proximal TAG non-buoyant plume, which we confirmed with the measurement of a drop in light transmission as well as an increase in helium $(\mathrm{He})$ concentrations associated with 
an enriched $\delta^{3} \mathrm{He}$ signature vented from the Earth's mantle at TAG. In this paper, we aim to re-evaluate the Fe chemistry occurring in and around the TAG hydrothermal vent field using the combined measurements of dissolved $(\mathrm{dFe}<0.2 \mu \mathrm{m})$, particulate $(\mathrm{pFe}>0.4$ $\mu \mathrm{m}$ ), and soluble ( $\mathrm{sFe}<0.02 \mu \mathrm{m}$, which derives a colloidal component as $\mathrm{cFe}=\mathrm{dFe}$ $\mathrm{sFe}$ ) Fe size fractions, as well as an assessment of the Fe(II) concentration in the dissolved phase, and we compare our results with those of JAMES AND ELDERFIELD (1996) to derive an updated description of Fe chemistry in the TAG plume. The proximal hydrothermal TAG Fe chemistry is explored here, while the distal effects of TAG hydrothermal venting on the $\mathrm{dFe}$ distribution of the North Atlantic Ocean are explored in Hatta et al. (in prep) and Chapter 7.

\section{Methods}

Three casts at TAG $\left(26.137^{\circ} \mathrm{N}, 44.826^{\circ} \mathrm{W}\right)$ were completed on the GEOTRACES NAZT cruise. Cast 1 (28 Nov, 20:00-midnight) used the custom-built US GEOTRACES trace metal clean rosette (GTC) consisting of an epoxy-painted aluminum rosette frame containing 24 x 12 L GO-FLO bottles (CUTTER and BRULAND, 2012); this cast was used to collect trace metal-uncontaminated seawater samples, as all zinc anodes were replaced on the rosette, the GO-FLO bottles were all-Teflon and contained no metal springs, and filtration was completed under ISO5-rated clean air (see Chapter 7 for more sampling details). Casts 2 (29 Nov, midnight-3:00) and 4 (29 Nov, 12:30-15:00) used a Niskin rosette and CTD provided by the Oceanographic Data Facility (ODF) at Scripps. This rosette contained 12 x 30L Niskin bottles with Nylon-coated internal stainless steel springs and Viton o-rings mounted on a powder-coated aluminum frame; this package was not designed for trace metal sample collection and thus likely contributed some contamination to the seawater samples collected from it. It is important to note that dissolved Fe from the ODF rosette was filtered using an AcroPak-500 filter with a paired $0.8 / 0.45 \mu \mathrm{m}$ membrane filtration; this is different than the GTC seawater samples, which were filtered using AcroPak-200 filters with a $0.2 \mu \mathrm{m}$ pore size. The ODF samples were also collected at the end of the filtration process after all other samples had been collected, while the GTC dFe samples were collected early in the filtration process.

To estimate the mixing ratio between the high-temperature vent fluid and the abyssal seawater surrounding it, we followed JAMES and ELDERFIELD (1996) and used the concentration of dMn as dilution index:

$$
\text { Dilution factor }=\frac{[\mathrm{Mn}]_{\mathrm{vent}}-[\mathrm{Mn}]_{\mathrm{sw}}}{[\mathrm{Mn}]_{\text {sample }}-[\mathrm{Mn}]_{\mathrm{sw}}}
$$

where $[\mathrm{Mn}]_{\text {vent }}$ is the concentration of dMn in the black smoker TAG vent fluids (680 $\mu \mathrm{M}$, EDMOND et al., 1995), [Mn $]_{\mathrm{Sw}}$ is the concentration of dMn in abyssal North Atlantic seawater $(0.1 \mathrm{nM} \text {, STATHAM et al., 1998), and [Mn }]_{\text {sample }}$ is the concentration of dMn in the sample of interest. This dilution factor estimate assumes that $\mathrm{Mn}$ is a conservative 
tracer of plume dilution, which is contingent on the slow oxidation kinetics of $\mathrm{Mn}$ in the TAG plume relative to Fe, and is valid on the timescale of hours to days; after this, $\mathrm{Mn}$ is also non-conservatively precipitated/scavenged. Minimal dilution factors for GTC and ODF casts were 3.7-4.0 $\times 10^{4}$, which are greater than the calculated $1.2 \pm 0.2 \times 10^{4}$ dilution factors at the top of the TAG buoyant plume (based on simple plume theory: JAMES and ELDERFIELD, 1996; RUDNICKI and ELDERFIELD, 1992), suggesting that the plume samples collected on GEOTRACES were located some distance away from the main axis of the non-buoyant plume.

$\mathrm{dFe}$ and dissolved manganese $(\mathrm{dMn})$ were measured at sea by the Measures lab using the Flow Injection Analysis methods of MEASURES et al. (1995) and RESING and MotTL (1992), respectively. sFe was measured in the Boyle laboratory at MIT using the methods of LEE et al. (2011). cFe is calculated as dFe - sFe. Fe(II) was measured at sea by the Sedwick lab (SEDWICK et al. 2013). Particulate Fe will be analyzed in the laboratory of Benjamin Twining at Bigelow Laboratory for Ocean Sciences, and the data is soon to come.

\section{Results and Discussion}

High concentrations of $\mathrm{dFe}(35.7-66.4 \mathrm{nmol} / \mathrm{kg})$ and $\mathrm{dMn}(11.2 \mathrm{nM}-18.1$ $\mathrm{nmol} / \mathrm{kg}$ ) were observed between 3200-3600m, coincident with a decrease in light transmission associated with large particulate loadings from metal precipitation at TAG, indicating that these elevated $\mathrm{dFe}$ and $\mathrm{dMn}$ concentrations were derived from the TAG hydrothermal plumes (Figure 1). The variable depth range and intensity of the light transmission feature over the three casts indicate that either the ship and/or the plume itself drifted over the 19 hours of plume sampling; either mechanism requires the nonbuoyant plume to have significant heterogeneity. dMn was nearly constant in the hydrothermal maximum over the three casts, which supports our assumption that $\mathrm{dMn}$ is an appropriate conservative tracer of plume dilution. dFe concentration, in contrast, varied by a factor of three in the hydrothermal maximum between casts. While we might expect Fe contamination in the ODF rosette casts because the Niskin bottles contain stainless steel springs (at 3000m, the ODF samples' dFe concentrations are 1.5-2.0 $\mathrm{nmol} / \mathrm{kg}$ higher in concentration than the GTC sample), the ODF dFe concentrations were actually lower than the GTC dFe concentrations in the hydrothermal maximum. This pattern also occurred despite a larger $\mathrm{dFe}$ pore size cutoff in the ODF cast $(<0.45 \mu \mathrm{m})$ than in the GTC cast $(<0.2 \mu \mathrm{m})$. The higher dFe concentration during the GTC casts casts may reflect the fact that the wire time and timing of filtration were critical for the observed Fe partitioning. For instance, Fe may have precipitated into the particulate phase in the ODF Niskin bottles during rosette ascent (multiple additional depths tripped upon ascent) and filtration of all other chemical parameters (Fe was one of the last 
filtrates sampled), while the GTC cast was recovered immediately after the hydrothermal samples were taken, and dFe was one of the first chemicals sampled during filtration, perhaps allowing for the maintenance of higher Fe concentrations in the dissolved phase.

We observed the same pattern when we examined dFe as a function of $\mathrm{dMn}$, a proxy for plume dilution with ambient seawater (Figure 2). There was a positive relationship between these two metals, as expected since pure vent fluid contains high concentrations of both $\mathrm{Mn}$ and Fe. However, the fact that all of the GETORACES dFe regression lines fell below the conservative mixing line between black smoker vent fluids and ambient seawater means that Fe precipitated or was scavenged to a greater extent than $\mathrm{Mn}$ in these hydrothermally-influenced waters. The seawater samples from the two ODF casts had even lower slopes than the GTC samples, indicating that they experienced further Fe precipitation/scavenging before sample collection.

Using the GTC samples only, we took a closer look at the composition of the Fe pool near the TAG vent (Figure 3) in an attempt to confirm the hypothesis of JAMES and ELDERFIELD (1996) that the dFe in the non-buoyant plume was composed of colloidal Fe as opposed to $\mathrm{Fe}^{2+}$. We found two major results. First, we confirmed that $89-96 \%$ of the $\mathrm{dFe}$ fell in the colloidal size fraction ( $\mathrm{sFe}$ concentrations only reached as high as 7.4 $\mathrm{nmol} / \mathrm{kg}$ ). This confirms the hypothesis of JAMES and ELDERFIELD (1996) that a large fraction of total $\mathrm{Fe}$ in the non-buoyant plume is dissolved instead of particulate because the $\mathrm{dFe}$ fraction includes small particles (colloids).

Most surprising, however, was that $\sim 75-100 \%$ of the dFe was composed of $\mathrm{Fe}(\mathrm{II})$. This was primarily unexpected because of the short oxidation half-life of $\mathrm{Fe}(\mathrm{II})$, measured to be as short as 2.1 minutes in the TAG buoyant plume (RUDNICKI and ELDERFIELD, 1993) or estimated to be as long as 27 minutes near TAG using the $\mathrm{pH}$ and oxygen concentrations of abyssal North Atlantic waters (FIELD and SHERRELL, 2000). Either half-life estimate would predict that most of the $\mathrm{Fe}^{2+}$ should be oxidized in the $\sim 40$ minutes it takes for the TAG plume to reach neutral buoyancy (RUDNICKI and ELDERFIELD, 1992).

Secondarily, however, the Fe(II) dominance of non-buoyant plume TAG dissolved $\mathrm{Fe}$ is surprising because $\mathrm{Fe}(\mathrm{II})$ is typically thought to be truly dissolved. While we did not take strides to preserve deep water conditions before the colloidal $0.02 \mu \mathrm{m}$ filtration, and thus our observed colloidal composition may contain some Fe aggregation during the 1-2 hours it took to filter our samples, we instead propose that the $\mathrm{Fe}(\mathrm{II})$ is indeed truly colloidal and that this colloidal composition is actually what stabilizes the Fe(II) beyond its predicted oxidation half-life. Pyrite nanoparticles as small as $4 \mathrm{~nm}$ have been observed in hydrothermal vent fluids along the East Pacific Rise, near Lau Basin, and also at TAG (GARTMAN et al., 2012; YUCEL et al., 2011), an d this nano-pyrite aggregates into colloidal-sized nanoframboids of 50-350 nm diameter that could 
dominate the dissolved Fe pool in the proximity of TAG. YUCEL et al. (2011) suggest that it is the nanoparticulate nature of this Fe(II) that allows it to escape oxidation longer than truly dissolved Fe(II). Alternatively, the colloidal Fe in the diluted hydrothermal samples we sampled could have an organically-bound component. TONER et al. (2009)have shown that colloidal and particulate Fe(II) near the East Pacific Rise at $9^{\circ} \mathrm{N}$ is stabilized by organic carbon-rich material thought to be of biological origin from near the vent site. Additionally, a non-hydrothermal study in the mixed layer of the Southern Ocean has also shown that colloidal and particulate $\mathrm{Fe}(\mathrm{II})$ is associated with organic matrices (VON DER HEYDEN et al., 2012) and thus may indicate a pattern of Fe(II) "protection" against oxidation through organic colloid stabilization. Notably, the $>1 \mu \mathrm{m}$ particulate Fe at our TAG site was found by synchrotron analysis to be comprised of ferrihydrite, and no particulate $\mathrm{Fe}(\mathrm{II})$ component was observed (LAM and OHNEMUS, 2013). 


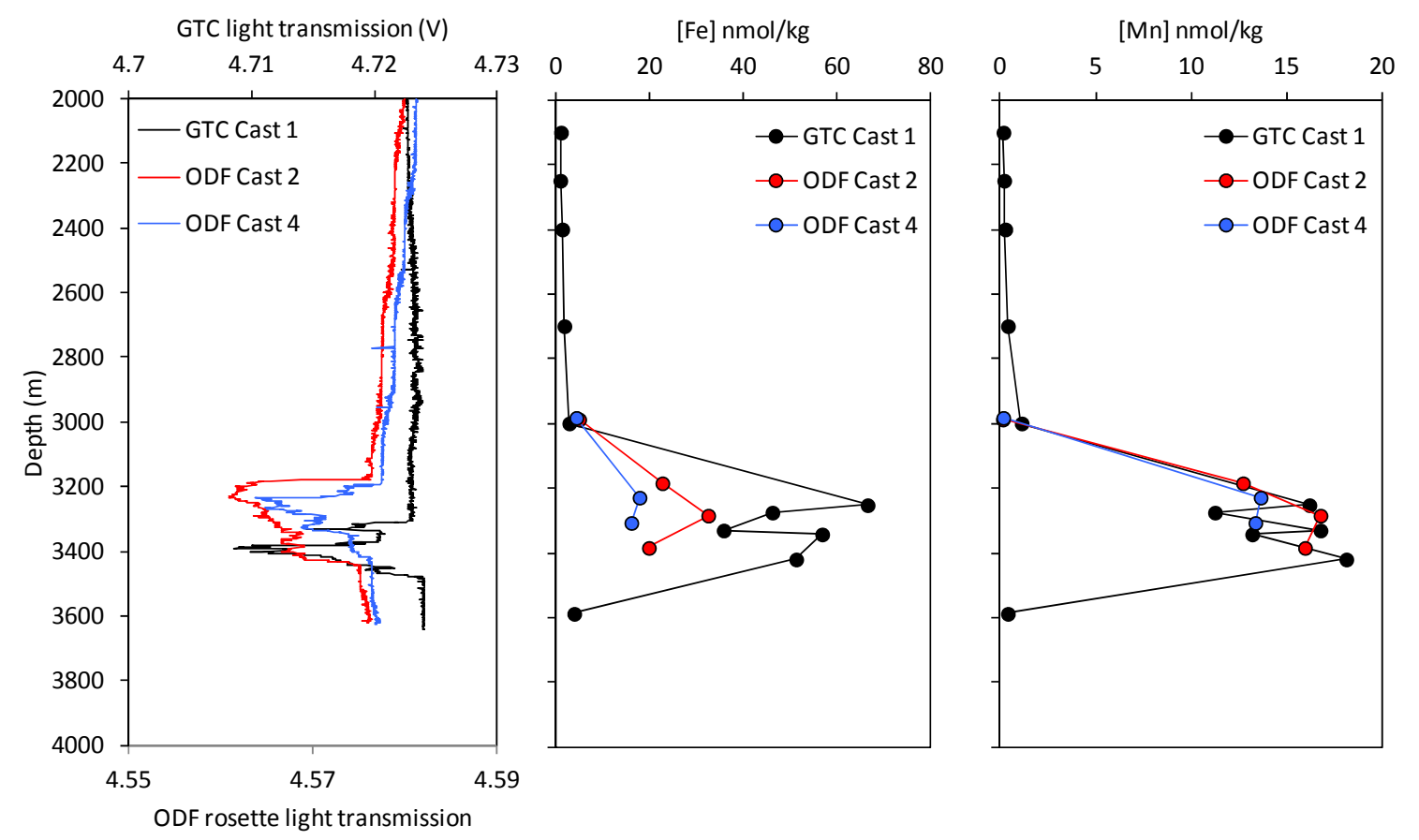

Figure 1: Data from the TAG station (GT11-16) on the 2011 GEOTRACES North Atlantic Zonal Transect cruise $\left(26.137^{\circ} \mathrm{N}, 44.826^{\circ} \mathrm{W}\right)$ on GTC rosette cast (black) and the two ODF rosette casts (cast 2: red, cast 4: blue). Light transmission is shown on the left, $\mathrm{dFe}$ in the middle, and $\mathrm{dMn}$ on the right. The dissolved fraction is defined as $<0.2 \mu \mathrm{m}$ in the GTC cast (black) and $<0.45 \mu \mathrm{m}$ in the ODF cast (red and blue). 


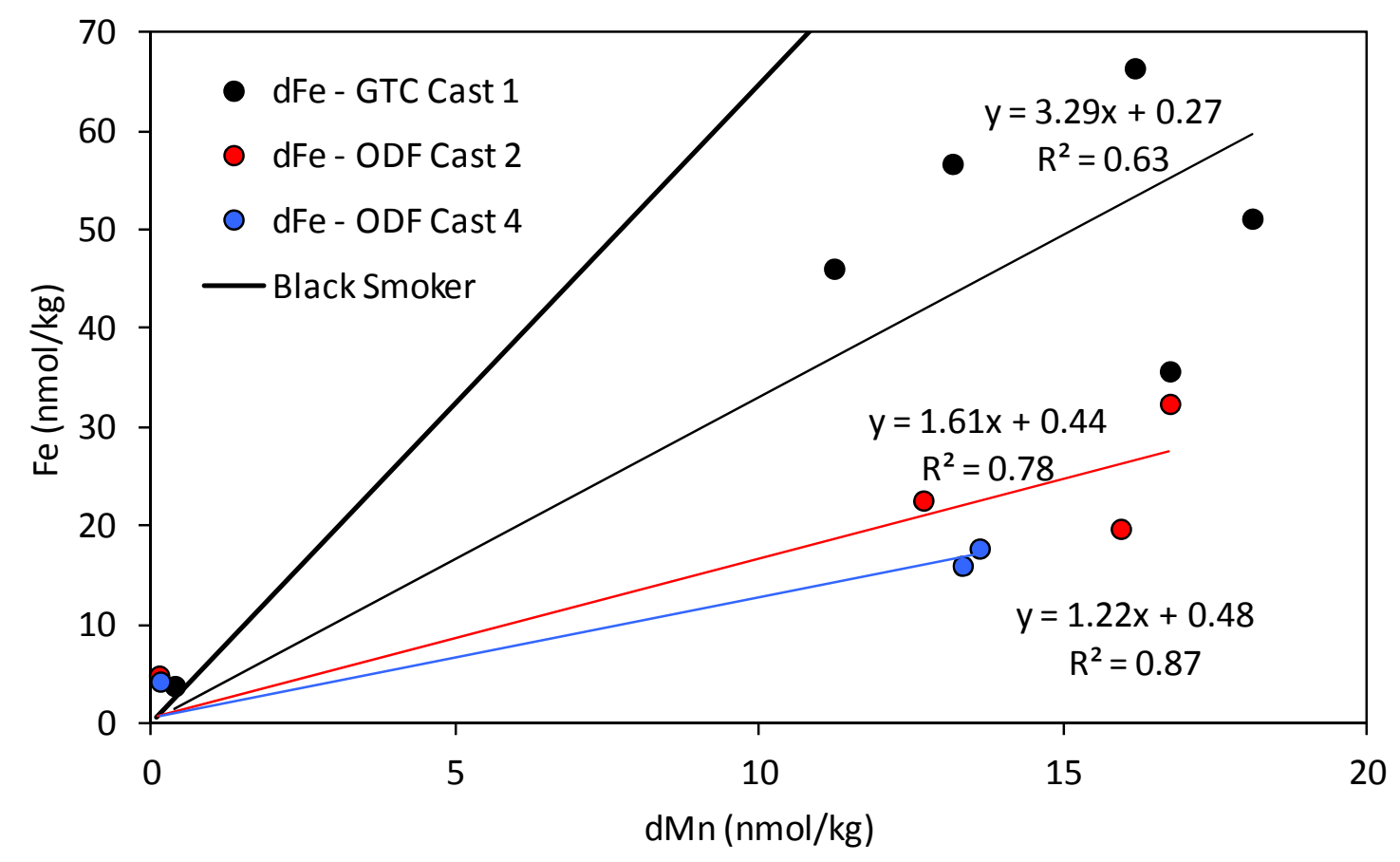

Figure 2: Fe chemistry as a function of dMn (plume dilution) at TAG. The Black Smoker line depicts conservative mixing between abyssal North Atlantic seawater ( $\mathrm{dMn}$ of 0.1 $\mathrm{nmol} / \mathrm{kg}$, dFe of $0.6 \mathrm{nmol} / \mathrm{kg}$ ) and TAG black smoker vent fluids (dMn of $680 \mu \mathrm{mol} / \mathrm{kg}$, $\mathrm{dFe}$ of $5590 \mu \mathrm{mol} / \mathrm{kg}$; EDMOND et al., 1995). The thin black, red, and blue lines are the regressions of the dFe data for the GTC Cast 1 (black), ODF Cast 2 (red), and ODF Cast 4 (blue) deployments, fit to go through the abyssal North Atlantic seawater data. 


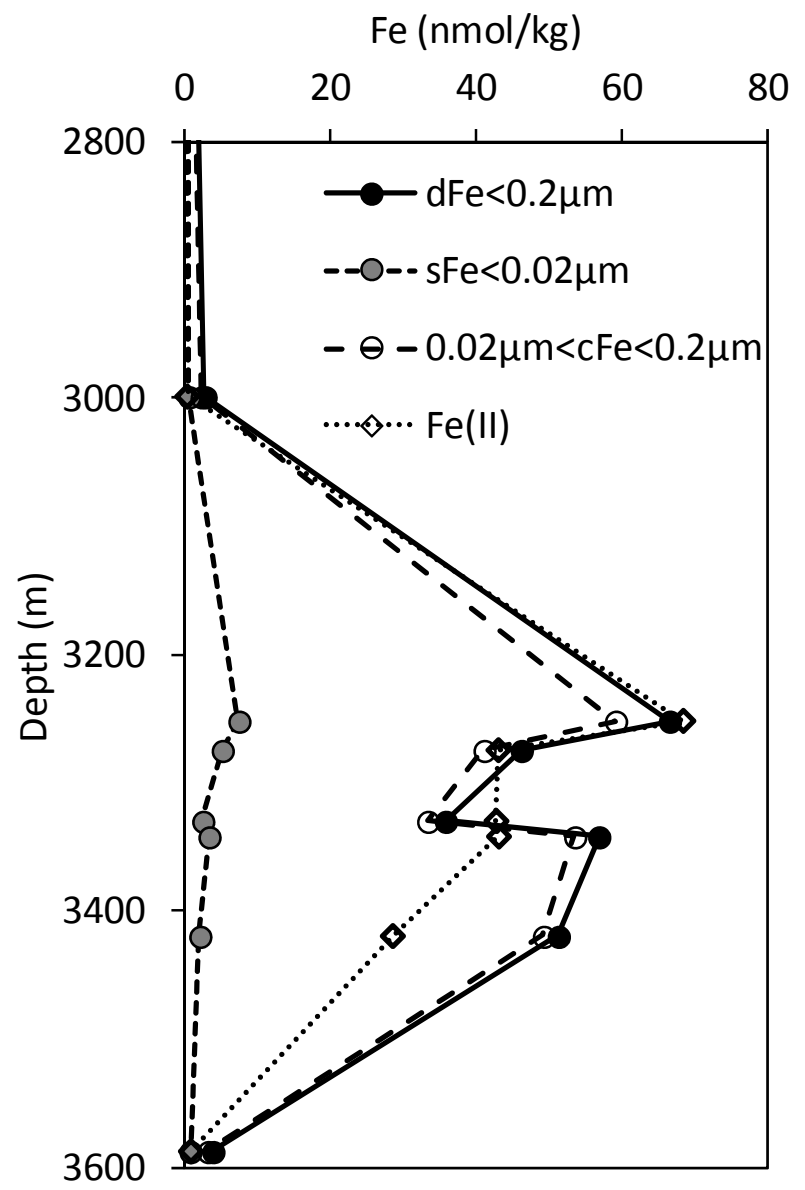

Figure 3: Fe physico-chemical speciation in the TAG hydrothermal non-buoyant plume (diluted 26000-60000 times with ambient seawater, according to equation 1). 


\section{References for Appendix II}

Bergquist, B. A. and Boyle, E. A., 2006. Dissolved iron in the tropical and subtropical Atlantic Ocean. Global Biogeochemical Cycles 20, 14.

Campbell, A. C., Palmer, M. R., Klinkhammer, G. P., Bowers, T. S., Edmond, J. M., Lawrence, J. R., Casey, J. F., Thompson, G., Humphris, S., Rona, P., and Karson, J. A., 1988. Chemistry of hot springs on the Mid-Atlantic Ridge. Nature 335, 514-519.

Chiba, H., Masuda, H., Lee, S., Y, and Fujioka, K., 2001. Chemistry of hydrothermal fluids at the TAG Active Mound, MAR 26² N, in 1998. Geophysical Research Letters 28, 2919-2922.

Cutter, G. A. and Bruland, K. W., 2012. Rapid and noncontaminating sampling system for trace elements in a global ocean surveys. Limnology \& Oceanography: Methods 10, 425-436.

Edmond, J. M., Campbell, A. C., Palmer, M. R., Klinkhammer, G. P., German, C. R., Edmonds, H. N., Elderfield, H., Thompson, G., and Rona, P., 1995. Time series of vent fluids from the TAG and MARK sites (1986-1990) Mid-Atlantic Ridge: a new solution chemistry model and a mechanism for $\mathrm{Cu} / \mathrm{Zn}$ zonation in massive sulfide orebodies. In: Parson, $\mathrm{L}$. M., Walker, C. L., and Dixon, D. R. Eds.), Hydrothermal Vents and Processes. Geological Society Special Publication No. 87.

Edmonds, H. N., German, C. R., Green, D. R. H., Huh, Y., Gamo, T., and Edmond, J. M., 1996. Continuation of the hydrothermal fluid chemistry time series at TAG, and the effects of ODP drilling. Geophysical Research Letters 23, 3487-3489.

Field, M. P. and Sherrell, R. M., 2000. Dissolved and particulate Fe in a hydrothermal plume at $9^{\circ} 45^{\prime} \mathrm{N}$, East Pacific Rise: Slow Fe (II) oxidation kinetics in Pacific plumes. Geochimica et Cosmochimica Acta 64, 619-628.

Fitzsimmons, J. N., Zhang, R., and Boyle, E. A., 2013. Dissolved iron in the tropical North Atlantic oxygen minimum zone. Marine Chemistry 154, 87-99.

Gamo, T., Chiba, H., Masuda, H., Edmonds, H. N., Fujioka, K., Kodama, Y., Nanba, H., and Sano, Y., 1996. Chemical characteristics of hydrothermal fluids from the TAG Mound of the Mid-Atlantic Ridge in August 1994: Implications for spatial and temporal variability of hydrothermal activity. Geophysical Research Letters 23, 3483-3486.

Gartman, A., Yucel, M., and Luther, G. W., 2012. Hydrothermal vents as a source of pyrite and trace metal-containing mineral nanoparticles to the ocean. AGU Fall Meeting, San Francisco, California.

James, R. H. and Elderfield, H., 1996. Dissolved and particulate trace metals in hydrothermal plumes at the Mid-Atlantic Ridge. Geophysical Research Letters 23, 3499-3502.

Lam, P. J. and Ohnemus, D. C. 2013. Size-fractionated particle mass and composition during the U.S. GEOTRACES North Atlantic Zonal Transect. U.S. GEOTRACES post-cruise data workshop, Old Dominion University, Norfolk, VA.

Lee, J.-M., Boyle, E. A., Echegoyen-Sanz, Y., Fitzsimmons, J. N., Zhang, R., and Kayser, R. A., 2011. Analysis of trace metals $(\mathrm{Cu}, \mathrm{Cd}, \mathrm{Pb}$, and $\mathrm{Fe})$ in seawater using single batch Nitrilotriacetate resin extraction and isotope dilution inductively coupled plasma mass spectrometry. Analytica Chimica Acta 686, 93-101.

Measures, C. I., Landing, W. M., Brown, M. T., and Buck, C. S., 2008. High-resolution Al and 
Fe data from the Atlantic Ocean CLIVAR-CO2 Repeat Hydrography A16N transect: Extensive linkages between atmospheric dust and upper ocean geochemistry. Global Biogeochem. Cycles 22, GB1005.

Measures, C. I., Yuan, J., and Resing, J. A., 1995. Determination of iron in seawater by flow injection-analysis using in-line preconcentration and spectrophotometric detection. Marine Chemistry 50, 3-12.

Resing, J. A. and Mottl, M. J., 1992. Determination of manganese in seawater using flow injection analysis with on-line preconcentration and spectrophotometric detection. Analytical Chemistry 64, 2682-2687.

Rona, P. A., Klinkhammer, G., Nelsen, T. A., Trefry, J. H., and Elderfield, H., 1986. Black smokers, massive sulphides and vent biota at the Mid-Atlantic Ridge. Nature 321, 33-37.

Rudnicki, M. D. and Elderfield, H., 1992. Theory applid to the Mid-Atlantic Ridge hydrothermal plumes: The finite difference approach. Journal of Volcanology and Geothermal Research 50, 161-172.

Rudnicki, M. D. and Elderfield, H., 1993. A chemical model of the buoyant and neutrally buoyant plume above the TAG vent field, 26 degrees N, Mid-Atlantic Ridge. Geochimica et Cosmochimica Acta 57, 2939-2957.

Sedwick, P.N., Sohst, B., Bowie, A., 2013. U.S. GEOTRACES North Atlantic section: Dissolved $\mathrm{Fe}$ and Fe(II). U.S. GEOTRACES post-cruise data workshop, Old Dominion University, Norfolk, VA.

Speer, K. G. and Rona, P. A., 1989. A model of an Atlantic and Pacific hydrothermal plume. Journal of Geophysical Research 94, 6213-6220.

Statham, P. J., Yeats, P. A., and Landing, W. M., 1998. Manganese in the eastern Atlantic Ocean: processes influencing deep and surface water distributions. Marine Chemistry 61, 55-68.

Tivey, M. K., Humphris, S. E., Thompson, G., Hannington, M. D., and Rona, P. A., 1995. Deducing patterns of fluid flow and mixing within the TAG active hydrothermal mound using mineralogical and geochemical data. Journal of Geophysical Research: Solid Earth 100, 12527-12555.

Toner, B. M., Fakra, S. C., Manganini, S. J., Santelli, C. M., Marcus, M. A., Moffett, J., Rouxel, O., German, C. R., and Edwards, K. J., 2009. Preservation of iron(II) by carbon-rich matrices in a hydrothermal plume. Nature Geoscience 2, 197-201.

von der Heyden, B. P., Roychoudhury, A. N., Mtshali, T. N., Tyliszczak, T., and Myneni, S. C. B., 2012. Chemically and Geographically Distinct Solid-Phase Iron Pools in the Southern Ocean. Science 338, 1199-1201.

Yucel, M., Gartman, A., Chan, C. S., and Luther, G. W., 2011. Hydrothermal vents as a kinetically stable source of iron-sulphide-bearing nanoparticles to the ocean. Nature Geoscience 4, 367-371. 


\section{Appendix III}

\section{The composition of dissolved iron in the dusty surface ocean: an exploration using size-fractionated iron- binding ligands and iron isotopes}

Collaborators: Randelle Bundy, Gonzalo Carrasco, Edward Boyle, Timothy Conway, and Seth John

Since iron (Fe) is estimated to be the limiting nutrient in up to $40 \%$ of the surface ocean (MoorE et al., 2002), linking Fe fluxes in the surface ocean to the biological uptake of dissolved $\mathrm{Fe}(\mathrm{dFe})$ by microorganisms is a major motivation of much of the exploration of marine $\mathrm{dFe}$ biogeochemistry. The biological utilization of dFe during photosynthesis, nitrogen fixation, and remineralization (MOREL et al., 2003) is what ties $\mathrm{dFe}$ biogeochemistry to the global carbon cycle and ultimately climate. However the transformation of "new" dFe from its input flux to its potential biological utilization is ultimately controlled by its chemical composition: both the scavenging residence time and the bioavailability of these new $\mathrm{dFe}$ species are impacted by their various chemical forms $\mathrm{dFe}$ assumes.

We have learned quite a bit about the composition of dFe over the last several decades. We know that $\mathrm{dFe}$ (here defined as $<0.2 \mu \mathrm{m}$ ) has a broad size distribution comprised of both "truly dissolved" soluble Fe $(\mathrm{sFe}<10 \mathrm{kDa})$ and "small particulate" colloidal Fe $(10 \mathrm{kDa}<\mathrm{cFe}<0.2 \mu \mathrm{m})$ size fractions (BERGQUIST et al., 2007; CHEVER et al., 2010; FitZSIMMONS and BOYLE, in review-b; NisHiOKA et al., 2001; UsSHER et al., 2010; WU et al., 2001). Incubation studies have shown that while both size fractions can be biologically utilized, soluble Fe is much preferred over colloidal Fe (CHEN et al., 2003; CHEN and WANG, 2001; WANG and DEI, 2003), and inorganic colloidal Fe (nanoparticles) is not biologically available at all (RICH and MOREL, 1990). In addition, studies using competitive ligand exchange electrochemical measurements have suggested that $>99.9 \%$ of marine dFe is bound by organic ligands (RUE and BRULAND, 1995; VAN DEN BERG, 1995; WU and LUTHER, 1995) that maintain marine dFe above its $\sim 0.1 \mathrm{nM}$ inorganic solubility in pH 8 seawater (LIU and MiLlero, 2002; MiLlero, 1998). While a few of these organic ligands have been identified as hydroxamate siderophores (MAWJI et al., 2011; VELASQUEZ et al., 2011; VRASPIR and BUTLER, 2009), chemically characterized ligands only comprise a small percentage of the total $\mathrm{dFe}$ pool, as the identity of marine Fe-binding ligands is largely unknown (GLEDHILL and BUCK, 2012). 
However, the hypothesis that nearly all marine $\mathrm{dFe}$ is organically bound relies on an assumption of thermodynamic equilibrium between $\mathrm{dFe}$ and dissolved $\mathrm{Fe}$-binding ligands in the open ocean. Additionally, electrochemical characterization of Fe-binding ligands is somewhat limiting, as only the Fe-binding ligands kinetically labile over the period of equilibrium with added ligand can be detected, and thus a relatively refractory portion of free Fe-binding ligands would not be detected by these methods. Despite these points, hardly any studies explicitly measuring the chemical composition of $\mathrm{dFe}$ species have been completed, largely because of analytical hurdles. One analysis of colloidal $\mathrm{Fe}$ composition by energy dispersive spectroscopy showed that open ocean cFe is organically bound (WELLS and GOLDBERG, 1992), while a recent study using synchrotron technology demonstrated that a portion of the surface colloidal $\mathrm{Fe}$ underlying dust plumes in the Southern Ocean is nanoparticulate, composed of tiny bits of magnetite (VON DER HEYDEN et al., 2012). Thus, while our best guess of the chemical composition of dFe is that the overwhelming majority is bound by strong organic Fe-binding ligands, there is a possibility that some $\mathrm{dFe}$, especially in the colloidal phase, is inorganically bound (nanoparticulate in nature). This might be especially true in regions where continental $\mathrm{Fe}$ sources are known to be significant (underlying dust plumes, downstream of hydrothermal vents, near the continental margin, in regions with abundant glacial meltwater, etc).

The chemical composition of dFe has the greatest impact on biological uptake in the upper ocean where phytoplankton are most active, and the surface ocean is also the location where atmospheric dust deposition, arguably the most significant Fe input to the ocean (JICKELLS et al., 2005; MAHOWALD et al., 2005), occurs. The solubility of aerosol $\mathrm{Fe}$ is variable and depends on a suite of factors including aerosol composition, source (anthropogenic or crustal), and size, as well as seawater $\mathrm{pH}$ and Fe-binding ligand concentration (BAKER and CROOT, 2010). One pattern, however, is reproducible in all studies: in the surface ocean underlying dust plumes, $\mathrm{dFe}$ is preferentially maintained in the colloidal size fraction (Chapter 7; BERGQUIST et al., 2007; FITZSIMMONS and BOYLE, in review-b; UsSHER et al., 2010; WU et al., 2001), while in low-dust surface ocean regions, the smaller soluble size fraction dominates the dFe pool (BOYE et al., 2010; CHEVER et al., 2010; NishiOKA et al., 2003; WeLLS, 2003). Colloidal Fe has also been shown to be the dominant Fe size fraction yielded in leaches of natural dust (AGUILARIslas and MeHALEK, 2013; AgUilar-IsLAS et al., 2010).

This raises two important questions: what is the binding environment of $\mathrm{dFe}$ in the surface ocean after recent dust deposition, and is this dust-derived dFe bioavailable? We envision that dust-derived colloidal Fe could assume any of three possible compositions: Fe bound by colloidal-sized organic ligands after Fe solubilization from dust, colloidal-sized bits of dust that physically separated from the dust particles upon 
impacting the surface ocean (resulting in a nanoparticulate cFe composition of the same composition as the dust), or Fe that was initially solubilized from dust in the surface ocean but then re-precipitated in situ in and aggregated into colloidal size (also resulting in a nanoparticulate cFe composition, likely amorphous Fe oxyhydroxides). Which of these comprises the majority of surface $\mathrm{dFe}$ underlying dust plumes has a significant impact on surface dFe residence time and bioavailability, and thus the distinction between these is at the crux of the problem linking dust deposition to biological uptake of dFe.

In this paper, we explore the binding environment of $\mathrm{dFe}$ in the surface of the high-dust North Atlantic Ocean using an analysis of the Fe-binding ligand concentration and strength, as well as the Fe isotope signature, of both the soluble and dissolved Fe pools. We aimed to consider whether there could be a natural nanoparticulate component to the dissolved Fe pool of the surface ocean, which would contradict the prevailing view that $>99.9 \%$ of $\mathrm{dFe}$ is believed to be bound by organic ligands. We based our research on two hypotheses:

1. If the size partitioning of surface Fe-binding ligands into soluble and colloidal fractions predicts the observed surface $\mathrm{dFe}$ size partitioning, then surface $\mathrm{dFe}$ is likely bound by organic ligands.

2. If the Fe isotope signature of colloidal Fe is significantly different from crustal isotopic values, then a dust-derived nanoparticulate component of $\mathrm{dFe}$ is unlikely without the implication of significant fractionation processes yet to be discovered.

\section{Site Selection and Methodology}

Seawater samples were collected from four stations on the US North Atlantic Zonal Transect 2011 cruise (Nov-Dec 2011): USGT11-10 at $31.933^{\circ} \mathrm{N},-64.733^{\circ} \mathrm{W}$ (the Bermuda Atlantic Time Series, BATS, station), USGT11-11 at $30.817^{\circ} \mathrm{N},-60.775^{\circ} \mathrm{W}$ ( $\sim 400 \mathrm{~km}$ to the southeast of BATS), USGT11-21 at $20.83^{\circ} \mathrm{N},-32.625^{\circ} \mathrm{W}$ (surface sample only), and USGT11-23 at $18.39^{\circ} \mathrm{N},-26.765^{\circ} \mathrm{W}$ (near the Cape Verde Islands). These locations were chosen for two reasons. First, we wanted to sample variable dust loading/composition in the surface ocean. USGT11-10 and -11 near Bermuda had 1-2 $\mathrm{ng} / \mathrm{m}^{3} \mathrm{Fe}$ loadings with a "marine" back-trajectory (HYSPLIT) and an Fe solubility of $\sim 7 \%$, while USGT11-21 and -23 near Cape Verde had much higher total aerosol Fe loadings $>1000 \mathrm{ng} / \mathrm{m}^{3} \mathrm{Fe}$ with a "North African" back-trajectory and a lower Fe solubility of $\sim 0.4 \%$ (SHELLEY and LANDING, 2013). Second, we wanted to sample variable biogeochemistries in the upper 1000m (Figure 3). USGT11-11 was situated more in the subtropical gyre and thus experienced a deeper pycnocline $(500-900 \mathrm{~m}$ based on the salinity trace) and an oxygen minimum of only $150 \mu \mathrm{mol} / \mathrm{kg}$ near $800 \mathrm{~m} \mathrm{depth}$, while USGT11-23 was situated south of the gyre with a much shallower pycnocline (beginning 
as shallow as $100 \mathrm{~m}$ ) and much lower minimum oxygen concentrations of $\sim 80 \mu \mathrm{mol} / \mathrm{kg}$ from 300-500m near the Mauritanian oxygen minimum zone (OMZ).

Trace metal uncontaminated seawater was collected using the U.S. GEOTRACES GO-FLO rosette by the methods described in CUTTER and BRULAND (2012). GO-FLO bottles were carried individually into an ISO 5-rated clean van, where the seawater was filtered through pre-cleaned $0.2 \mu \mathrm{m}$ Pall Acropak-200 ${ }^{\mathrm{TM}}$ Supor ${ }^{\circledR}$ capsule filters under $\sim 0.4 \mathrm{~atm}$ of HEPA-filtered air. Surface samples were collected using the GeoFish system of the Bruland lab, which employs all-PFA tubing attached to a vane that coasts at $\sim 3 \mathrm{~m}$ depth suspended from a boom off the starboard side of the ship during forward ship motion at up to 12 knots. An all-PFA diaphragm pump sipped clean seawater through this system at $\sim 8$ psi pressure, and filtration was completed first through a $0.45 \mu \mathrm{m}$ Osmonics (PFA) filter and then through a $0.2 \mu \mathrm{m}$ PCTE filter mesh held in a polypropylene housing. Filtrates were taken into acid cleaned 4L LDPE bottles after three bottle rinses. Sub-samples of this 4L were taken into 1L HDPE bottles for dFe isotope analysis and $500 \mathrm{~mL}$ fluorinated polyethylene (FLPE) bottles for the dFe-binding ligand sample; FLPE bottles had been conditioned with trace ultra-clean MilliQ for more than a month before sample collection to remove all acid residue. To collect the soluble Fe fraction, the rest of the 4L filtrates were immediately filtered again through an all-Teflon cross-flow filtration (CFF) system in static mode (FITZSIMMONS and BOYLE, in review-a). A Millipore Pellicon XL (PLCGC) $10 \mathrm{kDa}$ regenerated cellulose CFF membrane was employed, and 300-350mL of sample seawater was first flushed through the system to condition the membrane and CFF tubing against Fe sorption. After filtration, Fe-binding ligand samples were frozen unacidified, and $1 \mathrm{~L} \mathrm{Fe}$ isotope samples were acidified to $\mathrm{pH}$ 2 with trace metal grade hydrochloric acid.

$\mathrm{dFe}$ and sFe samples were analyzed in triplicate for their Fe concentration at MIT by isotope dilution inductively-coupled plasma mass spectrometry (ID-ICP-MS) on a hexapole collision cell IsoProbe ICP-MS. The ID-ICP-MS method employs a ${ }^{54} \mathrm{Fe}-$-spike and batch pre-concentration with nitrilotriacetate resin (LEE et al., 2011). Procedure blanks averaged $0.044 \mathrm{nmol} / \mathrm{kg}$ with a typical standard deviation over a single day's analysis of $0.009 \mathrm{nmol} / \mathrm{kg}$; thus, the reported detection limit was $0.027 \mathrm{nmol} / \mathrm{kg}$. Comprehensive lab analyses of the $\mathrm{SAFe} S$ seawater for $\mathrm{dFe}$ during the period of these analyses averaged $0.101 \pm 0.009 \mathrm{nmol} / \mathrm{kg}$ (Bottles 17 and 318, $\mathrm{n}=6$ ), which agrees well with the consensus value of $0.093 \pm 0.008 \mathrm{nmol} / \mathrm{kg}$. Similarly, SAFe D2 standard for dFe during the period of these analyses averaged $0.911 \pm 0.018 \mathrm{nmol} / \mathrm{kg}$ (Bottle 446, $\pm 1 \mathrm{SD}$, $\mathrm{n}=15$ ), which also agree well with the consensus value of $0.933 \pm 0.032 \mathrm{nmol} / \mathrm{kg}$. Consensus values were updated in May 2013 (www.geotraces.org/science/intercalibration). 
Measurements of Fe-binding ligand concentration and binding strength were made by competitive ligand exchange-adsorptive cathodic stripping voltammetry (CLEACSV) on a BioAnalytical Systems (BASi) Controlled Growth Mercury Electrode coupled to a BASi Epsilon $\varepsilon 2$ voltammetric analyzer in the Barbeau lab at Scripps by the methods described in BuCK et al. (2007). Briefly, $10 \mathrm{~mL}$ sample aliquots were buffered to $\mathrm{pH} 8.2$ with a borate-ammonium buffer in PFA Savillex vials that had been previously conditioned to the anticipated Fe addition. Titration Fe additions were made at concentrations ranging from 0-7.5 $\mathrm{nM}$ and were allowed to equilibrate for 2 hours before the addition of the added ligand, salicylaldoxime (SA), at concentrations of $25 \mu \mathrm{M}$ $\left(\alpha_{\mathrm{Fe}(\mathrm{SA}) 2}=60\right)$. After a 15 minute equilibration with SA, samples were adsorbed to the mercury drop at zero potential for 2-5 minutes and then stripped at $0.03 \mathrm{~V} / \mathrm{s}$ using differential pulse mode to a final potential of $-0.85 \mathrm{~V}$. Raw titration data were interpreted for their Fe-binding ligand concentration ([L]) and ligand conditional stability constants ( $K_{\text {Fel/Fe') }}^{\text {cond }}$ using the van den Berg/Ružić (RUžIĆ, 1982; VAN DEN BERG, 1982) and the Scatchard (MANTOURA and RILEY, 1975; SCATCHARD, 1949) linearization techniques, the results of which were averaged to obtain the reported values and error estimates. Sesnitivities were determined by internal calibration at the end of the titration, where all ligands are titrated. An $\alpha_{\mathrm{Fe}^{\prime}}$ of $10^{10}$ was assumed in the Fe speciation calculations.

Measurement of $\mathrm{Fe}$ isotopes in the marine dissolved $\mathrm{Fe}$ was measured in the John laboratory at the University of South Carolina by the methods of ConwAY et al. (in press), employing a ${ }^{57-58} \mathrm{Fe}$ double spike. Samples were preconcentrated at $\mathrm{pH} 2$ (unbuffered), and $\delta^{56} \mathrm{Fe}$ values are referenced to the IRMM-014 standard.

\section{Results and Discussion}

We collected large volume seawater samples containing the dissolved $(<0.2 \mu \mathrm{m})$ and soluble $(<10 \mathrm{kDa}) \mathrm{Fe}$ size fractions in two regions of the North Atlantic Ocean: the high North African dust flux OMZ region near the Cape Verde Islands (USGT11-21 and -23) and the low marine dust flux subtropical gyre region near Bermuda (USGT11-10 and -11) in order to explore the composition of the dissolved Fe pools in different biogeochemical regimes, as well as to assess whether $\mathrm{sFe}$ and $\mathrm{cFe}$ might be differentially fractionated as a result of various Fe transformations. A complete discussion of North Atlantic dFe biogeochemistry along the GEOTRACES NAZT can be found in the relevant papers for dFe distribution (HATTA et al., in prep), the distribution of dFe size partitioning (Chapter 7), aerosol Fe composition, fluxes, and solubility (SHELLEY and LANDING, 2013), organic Fe-binding ligand concentration and strength distribution (BuCK et al., 2013), and dissolved Fe isotope distribution (CoNWAY et al., 2013).

We must note that in the analysis thus far, we assume that CFF does not fractionate $\mathrm{sFe}$ isotopes, since we showed previously that $\mathrm{sFe}$ is $100 \%$ recovered using 
this CFF system (Chapter 5: FitzSiMMONS and BOYLE, in review-a). We also assume that soluble Fe-binding ligands are similarly $100 \%$ recovered; both of these assumptions will be tested in an upcoming Station ALOHA cruise (HOE-PhoR-2).

Size partitioning of Fe-binding ligands

We evaluated the size-partitioning of Fe-binding ligands in the upper $150 \mathrm{~m}$ of USGT11-10 and USGT11-23 in order to explore whether dust-derived dFe might be bound to organic ligands or have a nanoparticulate form. As shown in Figure 1, dFe concentrations were elevated $<0.4 \mathrm{nM}$ in the surface ocean of both stations and were $\sim 80 \%$ partitioned into the colloidal size fraction $(10 \mathrm{kDa}<\mathrm{cFe}<0.2 \mu \mathrm{m})$. This is consistent with other studies in the North Atlantic demonstrating that in regions where atmospheric dust input is significant, surface $\mathrm{dFe}$ is largely maintained in the cFe pool (BERGQuist et al., 2007; FITZSIMMONS and BOYLE, in review-b; Wu et al., 2001); this surface partitioning pattern favoring cFe was certainly relevant over the GEOTRACES NAZT (Chapter 7). Below, at the 70-90m deep chlorophyll maximum (DCM), cFe decreased to a minimum concentration, another feature typical of North Atlantic dFe size partitioning (Chapter 7).

Organic Fe-binding ligands, however, were overwhelmingly partitioned into the soluble size fraction. Fe ligand concentrations in both pools exceeded the Fe concentrations in each pool, and thus most of the Fe ligand concentrations reported are free ligands. Two ligand pools were detected at each of the depths measured $\left(\mathrm{L}_{1}\right.$ is the stronger ligand class, and $\mathrm{L}_{2}$ is weaker), and both ligand classes were preferentially partitioned into the soluble phase: soluble $\mathrm{L}_{1}$ ligands averaged $77 \pm 17 \%$ of the $\mathrm{L}_{1}$ ligands at USGT11-10 and $75 \pm 13 \%$ of the $\mathrm{L}_{1}$ ligands at USGT11-23, and total soluble ligands averaged $78 \pm 7 \%$ of the total ligands at USGT11-10 and $86 \pm 5 \%$ of the total ligands at USGT11-23. Colloidal ligands comprised the greatest portion of total dissolved ligands at the DCM of USGT11-10, but this pattern was not reproducible at the DCM of USGT1123. To a first degree, this data demonstrates that the size partitioning of Fe ligands into soluble and colloidal fractions is variable with depth and location, but to a second degree, this data shows the dominance of soluble ligands in the excess ligand pool, a result also observed in the upper $200 \mathrm{~m}$ by BOYE et al. (2010) in the Southern Ocean (200kDa filter used), by THUROCZY et al. (2010) in the Northeast Atlantic Ocean (1000 kDa filter used), and by CULLEN et al. (2006) in the Atlantic Oceans ( $0.02 \mu \mathrm{m}$ filter used). The $K^{\mathrm{cond}}{ }_{\mathrm{FeL} / \mathrm{Fe}}$ values for the two ligand classes had variable size partitioning patterns both within each station and across the two stations (Figure 1). At USGT11-10, $\log K$ values were not significantly different between the two size fractions, except near the DCM where $\log K_{1}$ was greater at $\sim 13$ for the soluble size fraction and nearer to $\sim 12$ for the total dissolved size fraction, indicating that colloidal ligands were much weaker. At USGT11-23, $\log K_{2}$ values were identical between the two size fractions, while $\log K_{1}$ 
values were slightly higher in the colloidal fraction than in the soluble fraction at most depths.

Using this size partitioned Fe-ligand binding strength and concentration data together, we determined the capacity for the free Fe-binding ligands in each size fraction to bind Fe, $\alpha_{\mathrm{FeL}}$ :

$$
\alpha_{\mathrm{FeL}^{\prime}}=\left(\left[\mathrm{xsL}_{1}\right] * K_{1}\right)+\left(\left[\mathrm{L}_{2}\right] * K_{2}\right)
$$

where the concentration of excess $\left[\mathrm{L}_{1}\right]\left(\left[\mathrm{xsL}_{1}\right]\right)$ is the $\mathrm{L}_{1}$ that is not bound to Fe:

$$
\left[\mathrm{xsL}_{1}\right]=\left[\mathrm{L}_{1}\right]-[\mathrm{Fe}]
$$

This $\alpha_{\mathrm{FeL}}$ ' was calculated for each size fraction and is shown in Figure 1. The total dissolved $\alpha_{\mathrm{FeL}}$ was greater at most depths across both stations than the soluble $\alpha_{\mathrm{FeL}}$, indicating that the colloidal ligands had at least some capacity to bind Fe. The first exception to this pattern was the surface of USGT11-10 and the deepest (140m) depth of USGT11-23, where the dissolved $\alpha_{\mathrm{Fe} \mathrm{L}^{\prime}}$ was the same as the soluble $\alpha_{\mathrm{FeL}}$; indicating that the colloidal ligands had no capacity to bind new Fe. The second exception was the DCM of USGT11-10, where the soluble $\alpha_{\mathrm{FeL}}$ was greater than the dissolved $\alpha_{\mathrm{FeL}}$; this was related to the greater $\log K$ values calculated for the soluble ligands than the total dissolved ligands at these depths.

The purpose of this study, however, was to determine whether the size partitioning of organic Fe-binding ligands in the upper ocean could predict the observed size partitioning of dFe. Thus, following CULLEN et al. (2006), we modeled the fraction of total $\mathrm{dFe}$ expected to exist in the soluble phase as:

$$
\frac{\mathrm{Fe}_{\mathrm{sol}}}{\mathrm{Fe}_{\mathrm{diss}}}=\frac{\left(\alpha_{\mathrm{FeL}^{\prime}}\right)_{\mathrm{sol}}}{\left(\alpha_{\mathrm{FeL}}\right)_{\mathrm{diss}}}=\frac{\left[\left(K_{1} *\left[\mathrm{xs} L_{1}\right]\right)+\left(K_{2} *\left[L_{2}\right]\right)\right]_{\mathrm{sol}}}{\left[\left(K_{1} *\left[\mathrm{xs} L_{1}\right]\right)+\left(K_{2} *\left[L_{2}\right]\right)\right]_{\mathrm{diss}}}
$$

If $\mathrm{dFe}$ is organically bound to ligands with the same concentration and strength as calculated using the $\alpha_{\mathrm{FeL}}$ value of the free ligands, then the modeled partitioning should match the observed dFe partitioning (in this case, the left-most and the right-most panels of Figure 1 should match). We also compare the model and observed soluble Fe partitioning fractions in Figure 2, and the observed sFe fractions all fall below the modeled-observed 1:1 line, indicating that the size partitioning of organic ligands as measured by electrochemistry, do not predict the observed dFe size partitioning in the upper ocean of either station.

What are the implications of these results for the influence of Fe-binding ligands on $\mathrm{dFe}$ in the upper ocean and the chemical composition of surface $\mathrm{dFe}$ ? To evaluate these questions, we must return to the assumptions involved in the electrochemical measurements of Fe binding ligands. First, CLE-ACSV can only detect the fraction of ligands that can exchange with Fe on the timescale of analytical equilibrium (in this case, 2 hours with added Fe and 15 minutes with SA). Thus, any kinetically inhibited ligands would not be detected in this method, and the CLE-ACSV equilibrium may not reflect 
natural seawater conditions (should equilibrium be reached or not). Second, and perhaps more important, all $\mathrm{dFe}$ is assumed to be organically bound, and the strength of the "bound" $\mathrm{dFe}$ is reflected in the $\log K_{1}$. Using these assumptions, we conclude that the size partitioning of labile organic Fe-binding ligands does not predict the size partitioning of $\mathrm{dFe}$ in the surface ocean or in the DCM of the North Atlantic Ocean.

But what results would we expect to see if a portion of colloidal Fe was nanoparticulate? As we mentioned, dust-derived surface dFe tends to be colloidal, and while it could be bound by organic ligands of colloidal size, it could also be composed of nanoparticulate bits of dust physically eroded away or nanoparticulate $\mathrm{Fe}$ oxyhydroxides precipitated and/or aggregated in situ after aerosol Fe dissolves. This nanoparticulate cFe would not be expected to adsorb to the electrochemical mercury drop or exchange Fe with the added ligand, and thus electrochemistry interprets this cFe as organically bound by a strong ligand. In this paper we modeled the predicted size partitioning of dFe using the size partitioning of the "excess" Fe-binding ligands; however, nanoparticulate Fe does not have an "excess" or "free" ligand pool. In other words, electrochemistry cannot capture the " potential" to form nanoparticulate cFe that an unbound colloidal-sized ligand would present. Thus, we would expect that if a significant portion of $\mathrm{cFe}$ was nanoparticulate, then we might see the same results that are observed in Figure 2, where ligand partitioning predicts that the surface $\mathrm{dFe}$ should be mostly soluble, while much of the dFe is actually colloidal. CULLEN et al. (2006) observed the same pattern (but to a lesser extent) in surface waters of the tropical North Atlantic, and they concluded that electrochemistry was missing an "inert" pool of colloidal Fe ligands.

However, our data cannot distinguish whether this inert pool is nanoparticulate or organic in nature. If it is bound to $\mathrm{Fe}$, electrochemistry will see it as a strong $\mathrm{L}_{1}$ ligand, whether the $\mathrm{cFe}$ is nanoparticulate or organically-bound. Yet, unbound ligands can only be detected if they are kinetically labile. Thus while our Figure 2 results indicating a missing "inert" fraction of colloidal ligands that could be interpreted as nanoparticulate $\mathrm{cFe}$, the same Figure 2 results are also consistent with an interpretation that $\mathrm{cFe}$ is bound by relatively inert organic ligands of colloidal size that are also not detected electrochemically. These ligands would have to be 1) unbound in the sample (or CLEACSV would detect them), 2) have the potential to bind Fe in nature (presumably composing a portion of the existing $\mathrm{dFe}$ ), but 3) bind Fe slower than the timescale of CLE-ACSV equilibration (which is why they were not detected). In addition to a chemical lability hindrance, a steric hindrance may also prevent these cFe ligands from being detected. In (1994), Mackey and Zirino presented their "onion model" in which trace metals in the ocean are bound by concentric layers of organic compounds held together by hydrogen and other coordination bonds. Thus, Fe may become sterically "trapped" inside a colloidal-sized organic matrix (which it does not even have to bound 
particularly strongly to) that passes through our $0.2 \mu \mathrm{m}$ filters and so is detected as $\mathrm{dFe}$ but is physically prevented from exchanging with the added ligand. While they might bind $\mathrm{Fe}$ in nature given time and the physical mixing of the surface ocean, these same "onion" organic compounds in their unbound form in our samples might not bind $\mathrm{Fe}$ strongly enough during electrochemical analysis to reveal their true binding "potential" in nature.

Thus, our size partitioning Fe ligand results showed that in surface locations underlying the North African dust plume, the labile organic Fe-binding ligands detected by CLE-ACSV were overwhelmingly partitioned into the soluble size fraction and do not predict the colloidal Fe composition of $\mathrm{dFe}$ observed. This suggests that the "binding potential" of a significant colloidal Fe fraction is missed by current electrochemical techniques. We hypothesize that this "missing cFe" is composed either of nanoparticulate $\mathrm{cFe}$ (eroded dust fragments or in situ precipitated Fe oxyhydroxide aggregates) that has no way to demonstrate an "excess ligand"-like binding potential via electrochemistry or a kinetically-slow or sterically-hindered organic ligand of colloidal size. In short, attempting to anticipate the chemical composition of new Fe upon external Fe inputs (such as dust fluxes) is challenging using electrochemical techniques because several colloidal Fe forms cannot demonstrate their natural "binding potential" by CLEACSV.

Size-fractionated dissolved Fe isotopes

We also evaluated the Fe isotope signatures of the size partitioned dissolved $(<$ $0.2 \mu \mathrm{m})$ and soluble $(<10 \mathrm{kDa}) \mathrm{Fe}$ pools in the upper $1000 \mathrm{~m}$ of three stations: USGT11-11 in the subtropical gyre near Bermuda and USGT11-21 and -23 (which we present together) near the Cape Verde Islands (Figure 3). USGT11-11 is situated in the subtropical gyre with a deep pycnocline and a relatively standard open ocean oxygen depletion to $\sim 150 \mu \mathrm{mol} / \mathrm{kg}$ near $\sim 800 \mathrm{~m}$, while USGT11-21 and -23 are situated near the Mauritanian OMZ(Chapter 7; HATTA et al., in prep) with much more significant oxygen depletion to $\sim 80 \mu \mathrm{mol} / \mathrm{kg}$ at $300-500 \mathrm{~m}$ depth.

Our primary goal was to determine whether the Fe isotope signature of surface colloidal $\mathrm{Fe}$ is consistent with a hypothesis of a significant nanoparticulate component of surface cFe in regions of high dust loadings. Thus, we calculated by mass balance the surface colloidal Fe concentration and isotope ratio by the following mass balance equations:

$$
\begin{aligned}
& \mathrm{dFe}=\mathrm{sFe}+\mathrm{cFe} \\
& {[\mathrm{dFe}]^{*} \delta^{56} \mathrm{Fe}_{\mathrm{dFe}}=[\mathrm{sFe}]^{*} \delta^{56} \mathrm{Fe}_{\mathrm{sFe}}+[\mathrm{cFe}]^{*} \delta^{56} \mathrm{Fe}_{\mathrm{cFe}}}
\end{aligned}
$$

The surface $\mathrm{dFe}$ and $\mathrm{sFe}$ concentrations and isotope ratios, as well as the mass balance colloidal Fe results, are tabulated in Table 1 below. The surface $\mathrm{dFe}$ had an $85 \%$ colloidal Fe composition at USGT11-11 and a 56\% colloidal Fe composition at USGT11- 
21, which fits the pattern of surface dFe partitioning into the colloidal phase in regions of high dust inputs (Chapter 7; BERGQUIST et al., 2007; FITZSIMMONS and BOYLE, in review-b; WU et al., 2001). The calculated Fe isotope signatures of the surface water colloidal Fe pools were $+0.38 \pm 0.12 \%$ at USGT11-11 and $-0.36 \pm 0.24 \%$ at USGT11-21, both of which are near the crustal Fe isotopic composition of aerosols of 0 to $+0.1 \%$ (BEARD et al., 2003; WAELES et al., 2007). Our community has not constrained the magnitude of any isotopic fractionation that Fe might undergo during $\mathrm{dFe}$ solubilization from aerosols; however, if a portion of the cFe is physically eroded bits of dust, we would imagine that this $\mathrm{cFe}$ would have a crustal $\mathrm{Fe}$ isotopic signature $(0$ to +0.1$)$. We must also consider, though, that the surface $\mathrm{cFe}$ pool is likely quite heterogeneous, both in composition and in isotopic signature. Thus the $\mathrm{cFe}$ ratios we calculate likely include some solubilized $\mathrm{Fe}$ of colloidal size (either ligand-bound $\mathrm{cFe}$, potentialy advected, or reprecipitated cFe nanoparticulate aggregates), which would likely have somewhat fractionated, non-crustal isotopic compositions. Thus, our data does not preclude the hypothesis that a portion of surface $\mathrm{cFe}$ is nanoparticulate, and much more information on the isotopic processes controlling aerosol Fe solubilization is required.

\begin{tabular}{ccccccc}
\hline Station & $\begin{array}{c}{[\mathbf{d F e}]} \\
(\mathbf{n m o l} / \mathbf{k g})\end{array}$ & $\begin{array}{c}\boldsymbol{\delta}^{\mathbf{5 6}} \mathbf{F e} \\
\mathbf{( \% )}\end{array}$ & $\begin{array}{c}{[\mathbf{s F e}]} \\
(\mathbf{n m o l} / \mathbf{k g})\end{array}$ & $\begin{array}{c}\boldsymbol{\delta}^{\mathbf{5 6}} \mathbf{F e} \\
\mathbf{( \% )}\end{array}$ & $\begin{array}{c}{[\mathbf{c F e}]} \\
(\mathbf{n m o l} / \mathbf{k g})\end{array}$ & $\begin{array}{c}\boldsymbol{\delta}^{\mathbf{5 6}} \mathbf{F e}_{\text {cFe }} \\
\mathbf{( \% o )}\end{array}$ \\
\hline USGT11-11 & $0.699 \pm 0.007$ & $+0.52 \pm 0.06$ & $0.105 \pm 0.041$ & $+1.33 \pm 0.11$ & $0.594 \pm 0.042$ & $+0.38 \pm 0.12$ \\
USGT11-21 & $0.412 \pm 0.003$ & $+0.45 \pm 0.07$ & $0.181 \pm 0.022$ & $+1.49 \pm 0.18$ & $0.231 \pm 0.022$ & $-0.36 \pm 0.24$ \\
\hline
\end{tabular}

Table 1: The concentration and Fe isotopic composition of surface dFe pools at USGT11-11 and USGT11-21. Concentration errors are $\pm 1 \mathrm{SD}$, and isotope errors are $\pm 2 \sigma$ standard errors.

Unexpectedly, surface soluble Fe, while low in concentration (only $15-45 \%$ of total surface $\mathrm{dFe}$ ), was quite enriched isotopically, with $\delta^{56} \mathrm{Fe}$ values $>+1.0 \%$. These values are higher than ever recorded in dissolved $\mathrm{Fe}$ in seawater. So why might $\mathrm{sFe}$ have such an enriched Fe isotope composition? Binding of Fe by organic ligands has been shown to produce an enriched FeL pool (DIDERIKSON et al., 2008), and preliminary laboratory experiments with known ligands have indicated that the stronger the ligand binds, the more enriched the Fe isotopic composition of the FeL (MORGAN et al., 2010). Thus, if surface $\mathrm{sFe}$ is bound by very strong Fe-binding ligands, the sFe isotopic composition might be expected to be quite enhanced. Additionally, there may be an isotope effect associated with the (abiotic) solubilization of Fe from dust. This is supported by the fact that typical surface $\mathrm{dFe}$ (including both soluble and colloidal size fractions) from the North Atlantic Ocean has an isotopic composition of +0.3 to +0.7 (CONWAY et al., 2013; JOHN and ADKINS, 2012), and thus solubilization from dust with an isotopic composition of 0 to $+0.1 \%$ must have an isotope effect enhancing $\mathrm{dFe}$ isotopic values. In contrast, surface dFe from the lower-dust Pacific and Southern Oceans 
have a wider range from -0.4 to $+0.56 \%$ (Appendix II; JOHN et al., 2012; LACAN et al., 2008), implicating the presence of other fractionation processes on potentially advected Fe sources. Finally, other Fe transformations occurring in the surface ocean may impart an isotope effect for $\mathrm{Fe}$ in the North Atlantic Ocean, including biological Fe utilization and photoreduction processes; the potential isotope effects associated with both of these processes have yet to be constrained.

While the subsurface $\mathrm{dFe}$ isotopic composition is used to quantify $\mathrm{dFe}$ provenance in CONWAY et al. (2013), we compared the subsurface sFe and dFe isotopic compositions in order to discriminate whether variable Fe transformations impact the soluble and colloidal fractions in the subsurface open ocean. As Figure 3 shows, the subsurface $\mathrm{sFe}$ and $\mathrm{dFe}$ isotopic compositions were very similar at all depths measured at both stations. This consistency occurred despite water mass changes, potentially with different advected or pre-formed dFe contributions, and despite the two biogeochemical regimes occurring at the two stations sampled. Hatta et al. (in prep) showed that the elevated dFe in the OMZ near the Cape Verde Islands (here at USGT11-23 of 1.05 $\mathrm{nmol} / \mathrm{kg}$ ) was due to remineralization of high-Fe:C organic material instead of a horizontally advected reduced Fe source from the African margin. Thus, remineralization presumably controls the subsurface $\mathrm{dFe}$ size partitioning at both USGT11-11 and USGT11-23 (as discussed in Chapter 7), and appropriately the isotopic compositions of both $\mathrm{dFe}$ size fractions are identical. This would be expected if similar isotope effects (in this case related to remineralization or ligand exchange following remineralization) influence both $\mathrm{dFe}$ size fractions.

Thus, the Fe isotopic compositions of the soluble and dissolved Fe pools collected during the GEOTRACES NAZT support our previously proposed model of dFe size partitioning in the North Atlantic (Chapter 7). The different isotope ratios in the soluble and colloidal fractions of surface seawater indicate that sFe and cFe cycle uniquely underneath the North African dust plume, with each size fraction receiving different $\mathrm{Fe}$ sources and/or undergoing differentially fractionating processes. Our results do not eliminate the possibility that the surface $\mathrm{cFe}$ pool contains a nanoparticulate component, but they do not prove this either, due to lack of knowledge on surface ocean $\mathrm{Fe}$ fractionating processes. Surface soluble Fe, additionally, must undergo a strong positively fractionating process in the surface ocean, possibly via abiotic dust solubilization and/or binding by organic ligands. In the subsurface, in contrast, the identical isotope ratios in the soluble and colloidal fractions support the "remineralization-driven" partitioning model (of Chapter 7), as the identical isotope compositions suggest that $\mathrm{sFe}$ and cFe cycle synchronously below the deep chlorophyll maximum. 


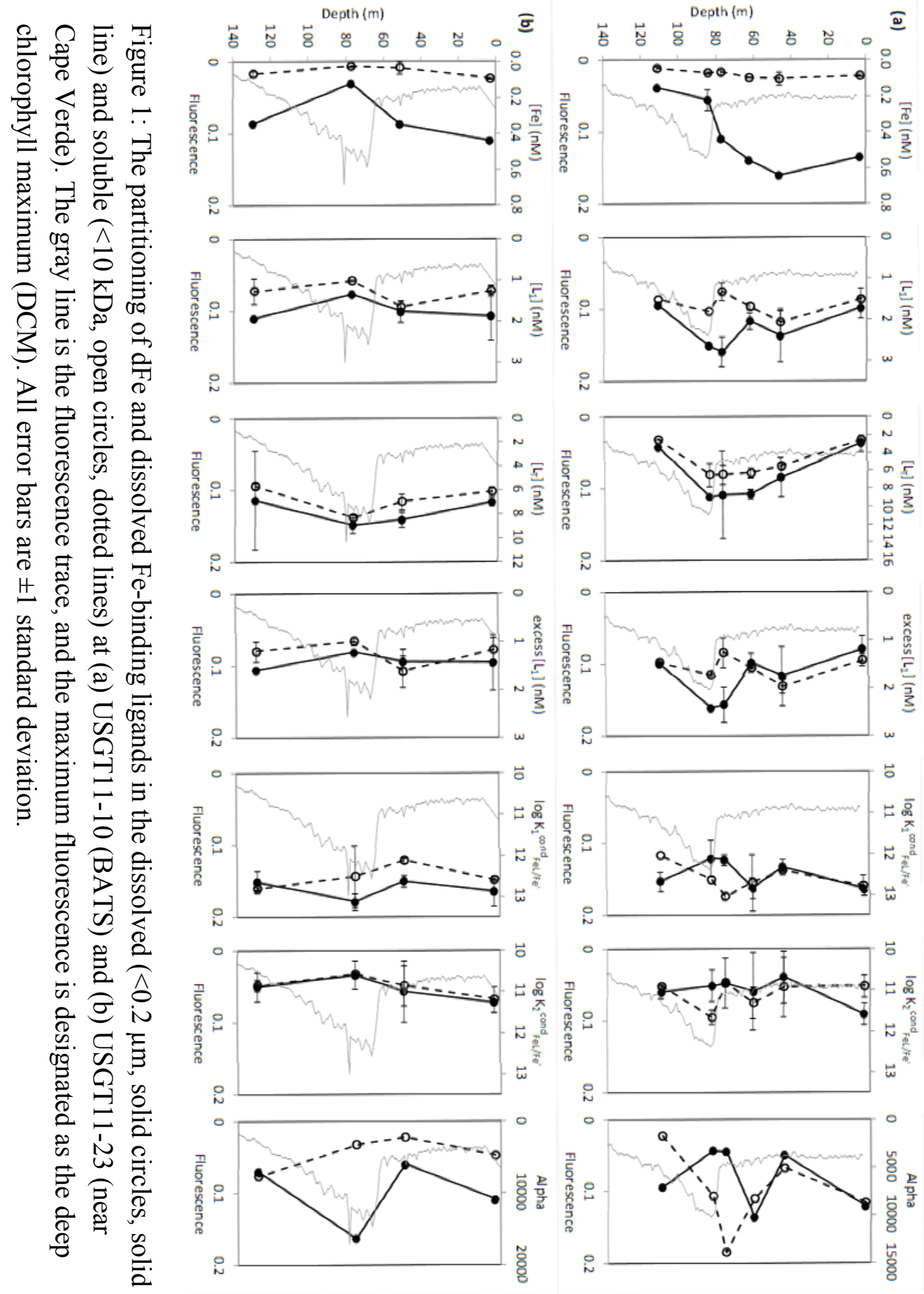




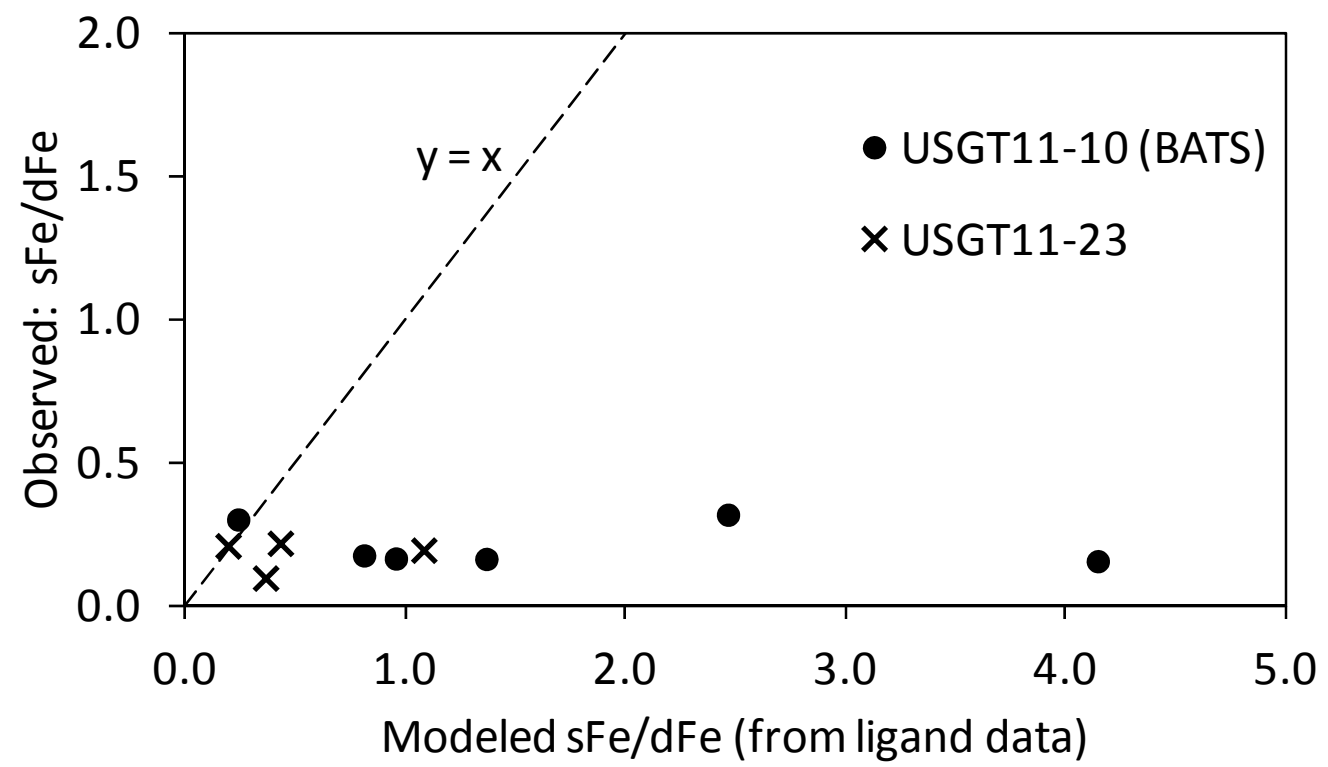

Figure 2: Measured sFe/dFe vs. modeled sFe/dFe at USGT11-10 (BATS, filled circles) and UST11-23 (crosses). Modeled sFe/dFe was derived by dividing $\alpha_{\text {soluble }} / \alpha_{\text {dissolved }}$. 

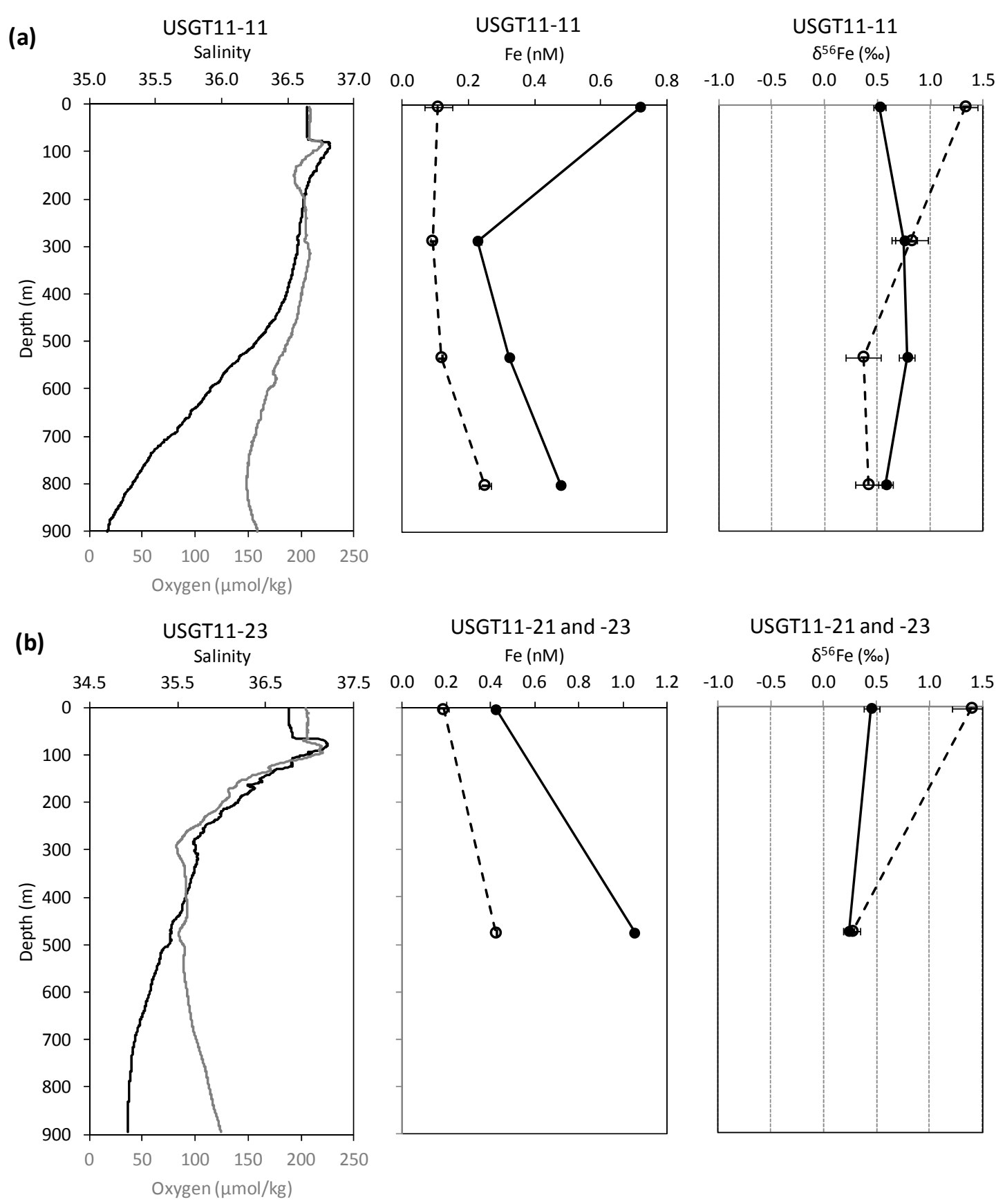

Figure 3: The hydrography (left), $\mathrm{dFe}$ and $\mathrm{sFe}$ concentrations (middle) and $\mathrm{dFe}$ and sFe isotopic composition (right) at USGT11-11 near Bermuda (a) and USGT11-23 near the Cape Verde Islands (b). In the hydrographic panels, salinity is shown in black, and oxygen is shown in gray. In the Fe panels, $\mathrm{dFe}(<0.2 \mu \mathrm{m})$ is shown as filled black dots and solid lines, while $\mathrm{sFe}(<10$ $\mathrm{kDa}$ ) is shown as open black dots and dashed lines. Errors on the Fe concentrations are \pm 1 standard deviation during replicate analyses, and errors on the $\delta^{56} \mathrm{Fe}$ values are $\pm 2 \sigma$ standard error. 


\section{References for Appendix III}

Aguilar-Islas, A.M., Mehalek, A., 2013. Aerosol Fe solubility from field and lab-based leaching protocols. U.S. GEOTRACES post-cruise data workshop, Old Dominion University, Norfolk, VA.

Aguilar-Islas, A.M., Wu, J., Rember, R., Johansen, A.M., Shank, L.M., 2010. Dissolution of aerosol-derived iron in seawater: Leach solution chemistry, aerosol type, and colloidal iron fraction. Marine Chemistry 120 (1-4), 25-33.

Baker, A.R., Croot, P.L., 2010. Atmospheric and marine controls on aerosol iron solubility in seawater. Marine Chemistry 120, 4-13.

Beard, B.L., Johnson, C.M., Von Damm, K.L., Poulson, R.L., 2003. Iron isotope constraints on Fe cycling and mass balance in oxygenated Earth oceans. Geology 31 (7), 629-632.

Bergquist, B.A., Wu, J., Boyle, E.A., 2007. Variability in oceanic dissolved iron is dominated by the colloidal fraction. Geochimica et Cosmochimica Acta 71 (12), 2960-2974.

Boye, M., Nishioka, J., Croot, P., Laan, P., Timmermans, K.R., Strass, V.H., Takeda, S., de Baar, H.J.W., 2010. Significant portion of dissolved organic Fe complexes in fact is Fe colloids. Marine Chemistry 122 (1-4), 20-27.

Buck, K.N., Lohan, M.C., Berger, C.J.M., Bruland, K.W., 2007. Dissolved iron speciation in two distinct river plumes and an estuary: Implications for riverine iron supply. Limnology and Oceanography 52 (2), 843-855.

Buck, K.N., Sedwick, P., Sohst, B., 2013. U.S. GEOTRACES North Atlantic: Organic complexation of dissolved Fe. U.S. GEOTRACES post-cruise data workshop, Old Dominion University, Norfolk, VA.

Chen, M., Dei, R.C.H., Wang, W.-X., Guo, L., 2003. Marine diatom uptake of iron bound with natural colloids of different origins. Marine Chemistry 81 (3-4), 177-189.

Chen, M., Wang, W.X., 2001. Bioavailability of natural colloid-bound iron to marine plankton: Influences of colloidal size and aging. Limnology and Oceanography 46 (8), 1956-1967.

Chever, F., Bucciarelli, E., Sarthou, G., Speich, S., Arhan, M., Penven, P., Tagliabue, A., 2010. Physical speciation of iron in the Atlantic sector of the Southern Ocean along a transect from the subtropical domain to the Weddell Sea Gyre. J. Geophys. Res. 115 (C10), C10059.

Conway, T.C., John, S.G., Rosenberg, A., 2013. Iron isotopes from the NAZT. U.S. GEOTRACES post-cruise data workshop, Old Dominion University, Norfolk, VA.

Conway, T.M., Rosenberg, A.D., Adkins, J.F., John, S.G., in press. A new method for precise determination of iron, zinc, and cadmium stable isotope ratios in seawater by doublespike mass spectrometry. Analytica Chimica Acta.

Cullen, J.T., Bergquist, B.A., Moffett, J.W., 2006. Thermodynamic characterization of the partitioning of iron between soluble and colloidal species in the Atlantic Ocean. Marine Chemistry 98 (2-4), 295-303.

Cutter, G.A., Bruland, K.W., 2012. Rapid and noncontaminating sampling system for trace elements in a global ocean surveys. Limnology \& Oceanography: Methods 10, 425-436.

Dideriksen, K., Baker, J.A., Stipp, S.L.S., 2008. Equilibrium Fe isotope fractionation between 
inorganic aqueous Fe(III) and the siderophore complex, Fe(III)-desferrioxamine B. Earth and Planetary Science Letters 269, 280-290.

Fitzsimmons, J.N., Boyle, E.A., in review-a. The assessment and intercalibration of Anopore ${ }^{\mathrm{TM}}$ and cross flow filtration methods for the determination of dissolved iron size fractionation into soluble/colloidal phases in seawater. Limnology \& Oceanography: Methods.

Fitzsimmons, J.N., Boyle, E.A., in review-b. Both soluble and colloidal iron phases control dissolved iron variability in the tropical North Atlantic Ocean. Geochimica et Cosmochimica Acta.

Gledhill, M., Buck, K.N., 2012. The organic complexation of iron in the marine environment: a review. Frontiers in Microbiology 3, 69.

Hatta, M., Measures, C.I., Wu, J., Fitzsimmons, J.N., others, a., in prep. Dissolved Fe and Mn concentrations in the North Atlantic Ocean during the U.S. GEOTRACES 2010-2011 cruises. Deep-Sea Research II.

Jickells, T.D., An, Z.S., Andersen, K.K., Baker, A.R., Bergametti, G., Brooks, N., Cao, J.J., Boyd, P.W., Duce, R.A., Hunter, K.A., Kawahata, H., Kubilay, N., laRoche, J., Liss, P.S., Mahowald, N., Prospero, J.M., Ridgwell, A.J., Tegen, I., Torres, R., 2005. Global iron connections between desert dust, ocean biogeochemistry, and climate. Science $\mathbf{3 0 8}$ (5718), 67-71.

John, S.G., Adkins, J., 2012. The vertical distribution of iron stable isotopes in the North Atlantic near Bermuda. Global Biogeochem. Cycles 26 (2), GB2034.

John, S.G., Mendez, J., Moffett, J., Adkins, J., 2012. The flux of iron and iron isotopes from San Pedro Basin sediments. Geochimica et Cosmochimica Acta 93, 14-29.

Lacan, F., Radic, A., Jeandel, C., Poitrasson, F., Sarthou, G., Pradoux, C., Freydier, R., 2008. Measurement of the isotopic composition of dissolved iron in the open ocean. Geophysical Research Letters 35 (24), 5.

Lee, J.-M., Boyle, E.A., Echegoyen-Sanz, Y., Fitzsimmons, J.N., Zhang, R., Kayser, R.A., 2011. Analysis of trace metals $(\mathrm{Cu}, \mathrm{Cd}, \mathrm{Pb}$, and $\mathrm{Fe})$ in seawater using single batch Nitrilotriacetate resin extraction and isotope dilution inductively coupled plasma mass spectrometry. Analytica Chimica Acta 686, 93-101.

Liu, X., Millero, F.J., 2002. The solubility of iron in seawater. Marine Chemistry 77, 43-54.

Mackey, D.J., Zirino, A., 1994. Comments on trace metal speciation in seawater or do "onions" grow in the sea? Analytica Chimica Acta 284, 635-647.

Mahowald, N., Baker, A.R., Bergametti, G., Brooks, N., Duce, R.A., Jickells, T., Kubilay, N., Prospero, J.M., Tegen, I., 2005. Atmospheric global dust cycle and iron inputs to the ocean. Global Biogeochemical Cycles 19, GB4025.

Mantoura, R.F.C., Riley, J.P., 1975. The use of gel filtration in the study of metal binding by humic acids and related compounds. Analytica Chimica Acta 78, 193-200.

Mawji, E., Gledhill, M., Milton, J.A., Zubkov, M.V., Thompson, A., Wolff, G.A., Achterberg, E.P., 2011. Production of siderophore type chelates in Atlantic Ocean water enriched with different carbon and nitrogen sources. Marine Chemistry 124, 90-99.

Millero, F.J., 1998. Solubility of Fe(III) in seawater. Earth and Planetary Science Letters 154, 
323-329.

Moore, J.K., Doney, S.C., Glover, D.M., Fung, I.Y., 2002. Iron cycling and nutrient-limitation patterns in surface waters of the World Ocean. Deep Sea Research Part II: Topical Studies in Oceanography 49 (1-3), 463-507.

Morel, F.M.M., Milligan, A.J., Saito, M.A., 2003. Marine Bioinorganic Chemistry: The Role of Trace Metals in the Oceanic Cycles of Major Nutrients. In: Turekian, K.K., Holland, H.D. (Eds.), Treatise On Geochemistry. Elsevier Science Ltd., Cambridge, United Kingdom, pp. 113-143.

Morgan, J.L.L., Wasylenki, L.E., Nuester, J., Anbar, A.D., 2010. Fe isotope fractionation during equilibration of Fe-organic complexes. Environmental Science \& Technology 44 (16), 6095-6101.

Nishioka, J., Takeda, S., Kudo, I., Tsumune, D., Yoshimura, T., Kuma, K., Tsuda, A., 2003. Sizefractionated iron distributions and iron-limitation processes in the subarctic NW Pacific. Geophysical Research Letters 30 (14).

Nishioka, J., Takeda, S., Wong, C.S., Johnson, W.K., 2001. Size-fractionated iron concentrations in the northeast Pacific Ocean: distribution of soluble and small colloidal iron. Marine Chemistry 74 (2-3), 157-179.

Rich, H.W., Morel, F.M.M., 1990. Availability of well-defined iron colloids to the marine diatom Thalassiosira weissflogii. Limnology and Oceanography 35 (3), 652-662.

Rue, E.L., Bruland, K.W., 1995. Complexation of iron(III) by natural organic ligands in the Central North Pacific as determined by a new competitive ligand equilibration/adsorptive cathodic stripping voltammetric method. Marine Chemistry 50 (1-4), 117-138.

Ružić, I., 1982. Theoretical aspects of the direct titration of natural waters and its information yield for trace metal speciation. Analytica Chimica Acta 140, 99-113.

Scatchard, G., 1949. The attractions of proteins for small molecules and ions. Annals of the New York Academy of Sciences 51, 660-672.

Shelley, R.U., Landing, W., 2013. North Atlantic aerosol TEIs. U.S. GEOTRACES post-cruise data workshop, Old Dominion University, Norfolk, VA.

Thuróczy, C.E., Gerringa, L.J.A., Klunder, M.B., Middag, R., Laan, P., Timmermans, K.R., de Baar, H.J.W., 2010. Speciation of Fe in the Eastern North Atlantic Ocean. Deep Sea Research Part I: Oceanographic Research Papers 57 (11), 1444-1453.

Ussher, S.J., Achterberg, E.P., Sarthou, G., Laan, P., de Baar, H.J.W., Worsfold, P.J., 2010. Distribution of size fractionated dissolved iron in the Canary Basin. Marine Environmental Research 70 (1), 46-55.

van den Berg, C.M.G., 1982. Determination of copper complexation with natural organic ligands in sea water by equilibrium with $\mathrm{MnO}_{2}$ : I. Theory. Analytica Chimica Acta 11, 307-312.

van den Berg, C.M.G., 1995. Evidence for organic complexation of iron in seawater. Marine Chemistry 50 (1-4), 139-157.

Velasquez, I., Nunn, B.L., Ibisanmi, E., Goodlet, D.R., Hunter, K.A., Sander, S.G., 2011.

Detection of hydroxamate siderophores in coastal and sub-Antarctic waters off the South Eastern coast of New Zealand. Marine Chemistry 126, 97-107.

von der Heyden, B.P., Roychoudhury, A.N., Mtshali, T.N., Tyliszczak, T., Myneni, S.C.B., 2012. 
Chemically and Geographically Distinct Solid-Phase Iron Pools in the Southern Ocean. Science 338 (6111), 1199-1201.

Vraspir, J., Butler, A., 2009. Chemistry of marine ligands and siderophores. Annual Review of Marine Science 1, 43-63.

Waeles, M., Baker, A.R., Jickells, T., Hoogewerff, J., 2007. Global dust teleconnections: aerosol iron solubility and stable isotope composition. Environmental Chemistry 4 (4), 233-237.

Wang, W.X., Dei, R.C.H., 2003. Bioavailability of iron complexed with organic colloids to the cyanobacteria Synechococcus and Trichodesmium. Aquatic Microbial Ecology 33, 247259.

Wells, M.L., 2003. The level of iron enrichment required to initiate diatom blooms in HNLC waters. Marine Chemistry 82 (1-2), 101-114.

Wells, M.L., Goldberg, E.D., 1992. Marine submicron particles. Marine Chemistry 40, 5-18.

Wu, J., Boyle, E.A., Sunda, W.G., Wen, L., 2001. Soluble and colloidal iron in the oligotrophic North Atlantic and North Pacific. Science 293, 847-849.

Wu, J., Luther, G.W., 1995. Complexation of Fe(III) by natural organic ligands in the Northwest Atlantic Ocean by a competitive ligand equilibration method and a kinetic approach. Marine Chemistry 50 (1-4), 159-177. 


\section{Appendix IV}

\section{Temporal variability of dissolved iron at Station ALOHA}

Collaborators: Gonzalo Carrasco, Abigail Noble, Simone Moos, Rick Kayser, Edward Boyle, Timothy Conway, and Seth John

In summer 2012, we participated in the HOE-DYLAN project (Hawaii Ocean Experiment - Dynamics of Light and Nutrients) in association with the Center for Microbial Oceanography: Research and Education (C-MORE). HOE-DYLAN aimed to occupy Station ALOHA consistently from May to September 2012 over $\sim 9 \mathrm{HOE}$ and Hawaii Ocean Time Series (HOT) cruises. Our goal was to use this project to follow up on the study of BOYLE et al. (2005), which described the dissolved iron (dFe) biogeochemistry at Station ALOHA, with an investigation of the temporal variability of their observed $\mathrm{dFe}$ features. We had three primary goals:

1. Record the temporal variability of $\mathrm{dFe}$ in the surface on a daily timescale to investigate both the short-scale variability in a single location (never before shown for $\mathrm{dFe}$ ) as well as the impact of sporadic dust events on the $\mathrm{dFe}$ distribution at ALOHA.

2. Record the temporal variability of $\mathrm{dFe}$ profiles in the euphotic zone of Station ALOHA, in response to changes in both hydrography and microbial populations.

3. Explore the potential distal contribution of the Loihi hydrothermal plume on the $\mathrm{dFe}$ distribution at $1100 \mathrm{~m}$ at Station ALOHA through the use of Fe isotopes and the $\mathrm{dFe}$ variability over several months.

We used the MITESS/Vanes system and the surface ATE (described in detail for HOE-DYLAN in Chapter 5; Bell et al., 2002; FitzSIMMONS and BOYLE, 2012) to sample seawater for $\mathrm{dFe}$ profiles and the surface time-series, respectively. The primary filtration defining $\mathrm{dFe}$ was a $0.4 \mu \mathrm{m}$ filtration using Nuclepore filter membranes on an offline, all-Teflon filter rig. A subset of these samples were analyzed for their $\mathrm{dFe}$ concentration using the isotope dilution ICP-MS method of LEE et al. (2011) over a single analytical session. The SAFe D2 standard was found to have a dFe concentration of $0.914 \pm 0.020 \mathrm{nmol} / \mathrm{kg}(\mathrm{n}=5)$, which is in good agreement with the consensus value of $0.933 \pm 0.023 \mathrm{nmol} / \mathrm{kg}$ (www.geotraces.org/science/intercalibration). Fe stable isotope measurements were analyzed in the laboratory of Seth John at the University of South Carolina by the double spike ICP-MS method of CONWAY et al. (in press). 


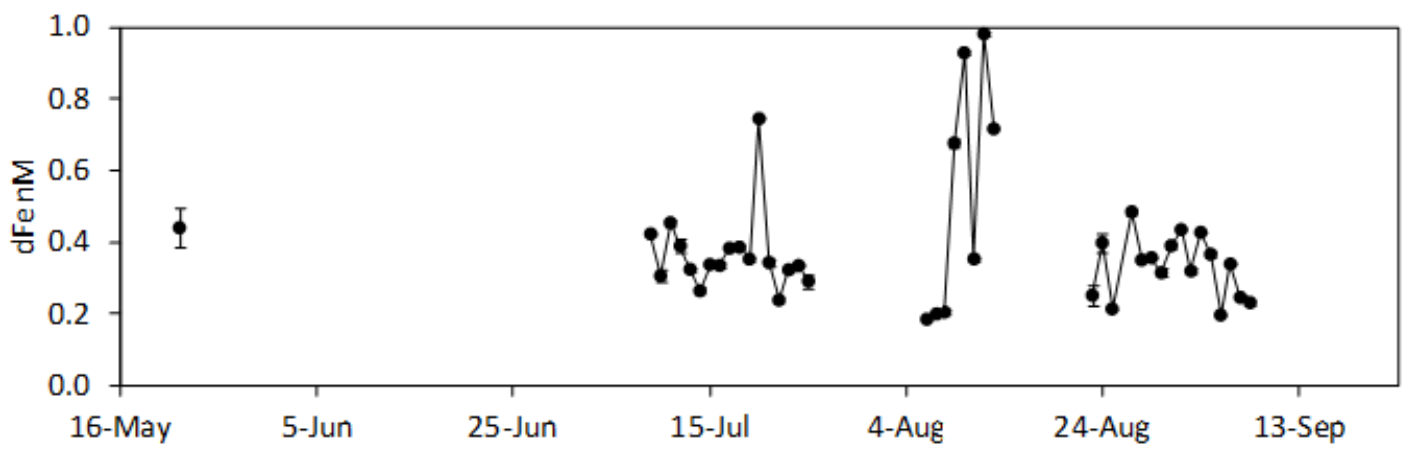

Figure 1: Surface dFe timeseries at Station ALOHA in the $<0.4 \mu \mathrm{m}$ fraction. Error bars show the $1 \sigma$ standard deviation of replicate analyses. The datapoint in parenthesis is questionable. $\mathrm{dFe}$ concentrations were typically between $0.2-0.4 \mathrm{nM}$. While we might have expected surface dFe concentrations to be quite high in May, which is the tail end of the high-Asian dust season for the Hawaiian region (BOYLE et al., 2005 and references therein), the single May dFe concentration did not have significantly higher concentrations that the rest of the data. BOYLE et al. (2005) also found surface dFe concentrations near Hawaii ranging from $0.3-0.7 \mathrm{nM}$ in May, so this low concentration was not unprecedented.

The elevated dFe concentrations to $0.7-1.0 \mathrm{nM}$ in early-mid August, however, were surprising. Reanalysis of this data is required to ensure these values truly represent the concentration of the collected seawater, and even if the data quality is high there is a chance that there was random contamination during this period of the cruise; however, at this stage we consider this pattern to represent true variability, given the reproducibility of these concentrations over four days. While we cannot exclude a sporadic dust input at this time (this will be explored in the future using ${ }^{232} \mathrm{Th}$, CHRIS HAYES, personal communication), dust input is predicted to be low in August near Hawaii (BOYLE et al., 2005), and there was no qualitative record of a dust storm at this time of the cruise.

Coincident with this high-surface $\mathrm{dFe}$ period, however, was the passing of an anticyclonic eddy (as detected by satellite sea-height anomaly) that has been identified as a mode-water eddy (SAM WILSON, personal communication). Eddies have previously been reported to impact trace metal distributions (JOHNSON et al., 2005; NOBLE et al., 2008). More investigation will be required to resolve the cause of the August enrichment in surface $\mathrm{dFe}$. 


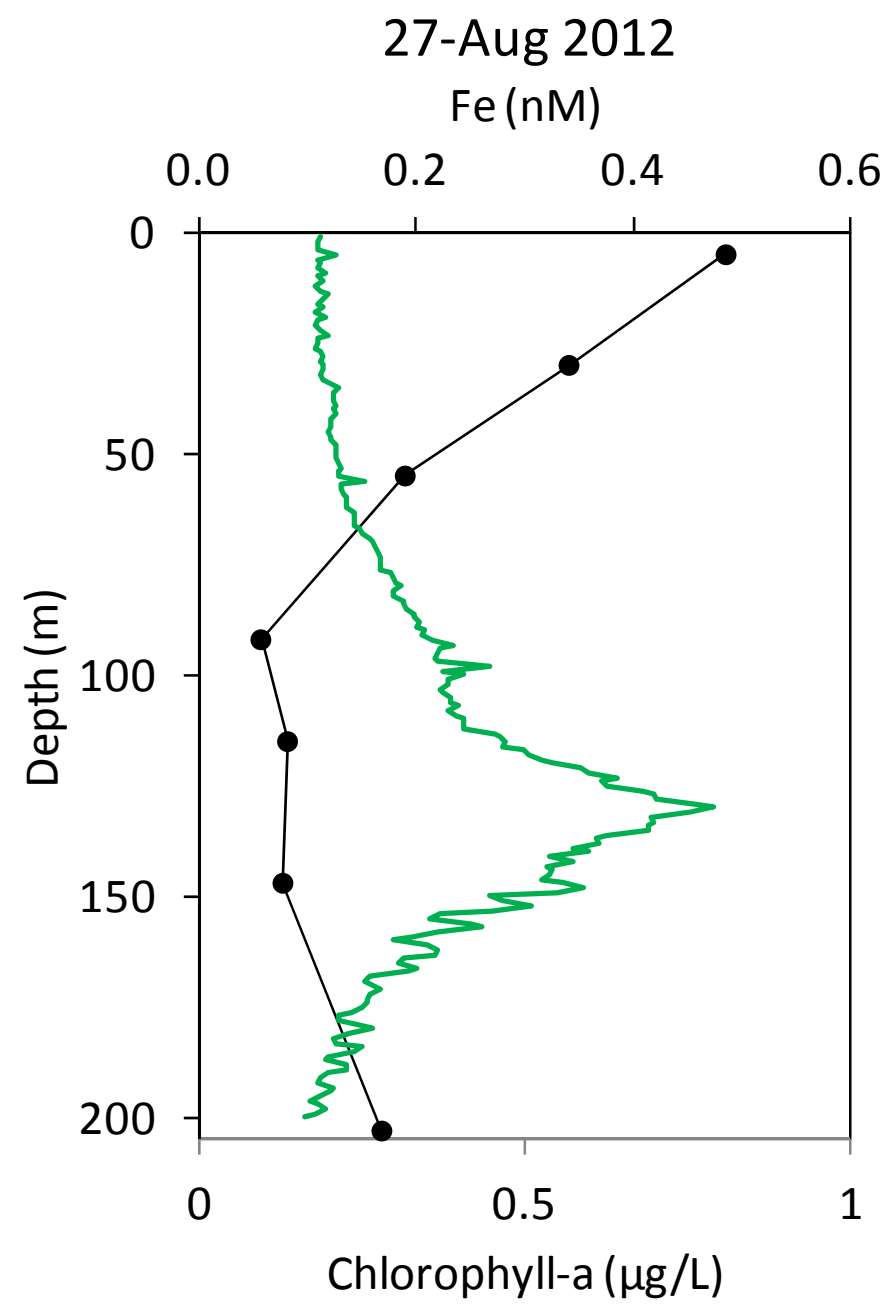

Figure 2: Euphotic zone profile of $\mathrm{dFe}(<0.4 \mu \mathrm{m})$ sampled on 27 August 2012 at Station ALOHA. This is one of six euphotic zone profiles collected over the summer to record the temporal variability of euphotic zone $\mathrm{dFe}$ at this station. A similar short-timescale sampling study was conducted near Bermuda by SEDWICK et al. (2005) along the track of a single eddy. They recorded variability in the dFe concentrations in the surface ocean, $150 \mathrm{~m}$, and $300 \mathrm{~m}$ depths, which they hypothesize are related to variability in wet deposition, spatial variability in $\mathrm{dFe}$ (below the eddy depths), and/or temporal changes in biological dFe uptake. Similar to SEDWICK et al. (2005) and BOYLE et al. (2005), we detect a minimum in $\mathrm{dFe}$ at extremely low concentrations of $0.06 \mathrm{nM}$ dFe coincident with the deep chlorophyll maximum (DCM). Presumably this is related to increased biological uptake/scavenging in the DCM. SEDWICK et al. hypothesized that Fe limitation may exist in the DCM in the late summer near Bermuda; similar limitation may exist at ALOHA in late summer. 


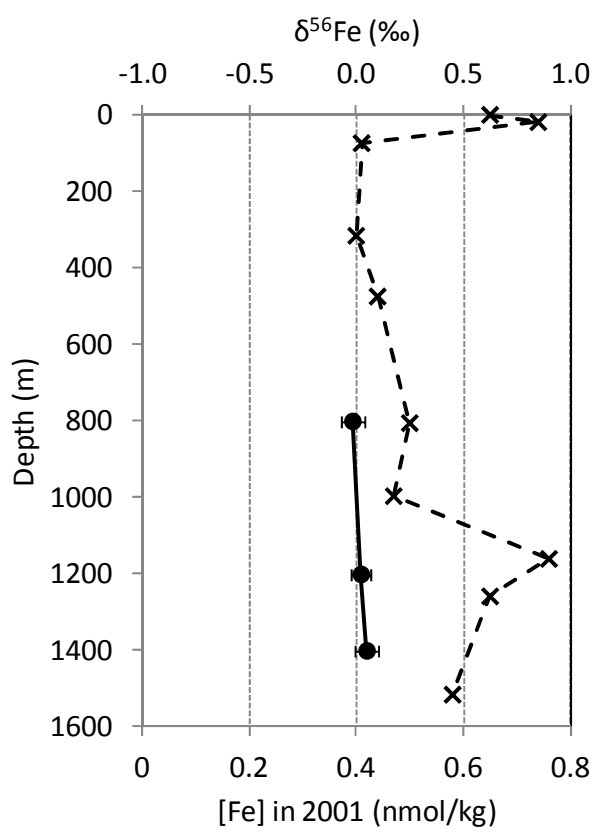

Figure 3: The $\delta^{56} \mathrm{Fe}$ of the dissolved $\mathrm{Fe}$ (with respect to the standard IRMM-014) at Station ALOHA (filled circles); $2 \sigma$ standard errors in replicate measurements are indicated. These measurements were designed to detect a potential distal hydrothermal Fe influence from Loihi vents, and so the $\mathrm{dFe}$ concentration data used to propose a Loihi influence at Station ALOHA (from 2001, MP2 cruise: BOYLE et al., 2005) are also shown (crosses).

A hydrothermal influence was expected at $1200 \mathrm{~m}$ but not at $800 \mathrm{~m}$, based on the $\mathrm{dFe}$ concentration data. However, there was no significant difference in the $\delta^{56} \mathrm{Fe}$ at those two depths. Three explanations for this pattern exist. The Loihi hydrothermal vents could influence the entire depth range $800-1400$ m equally with a composition of $\sim 0 \%$ so no anomaly is observed, yet we believe this to be unlikely based on the dFe concentration data (dFe concentration data from 27-Aug on HOE-DYLAN is still to be analyzed). Alternatively the Fe isotope signature of distal Loihi hydrothermal Fe could be insignificantly different from Pacific Fe in this depth range (both $\sim 0 \%$ ), making Fe isotopes a poor proxy for distinguishing hydrothermal influence in this region. Finally, there may be no influence of Loihi hydrothermal Fe at Station ALOHA during HOEDYLAN. As discussed in Appendix I, we would expect hydrothermal fluids to have a depleted Fe isotope signature; however, during distal Fe processing, the remaining $\mathrm{dFe}$ would be expected to become enriched, so a value of $0 \%$ does not exclude a hydrothermal influence. There is also not significant Fe isotope data in the literature to determine what signature might be expected in background $\mathrm{dFe}$ of the $1000 \mathrm{~m}$ water mass at Station ALOHA. Thus, a final conclusion cannot be reached thus far with the data in hand. 


\section{References for Appendix IV}

Bell, J., Betts, J., and Boyle, E., 2002. MITESS: a moored in situ trace element serial sampler for deep-sea moorings. Deep-Sea Research Part I-Oceanographic Research Papers 49, 2103-2118.

Boyle, E. A., Bergquist, B. A., Kayser, R. A., and Mahowald, N., 2005. Iron, manganese, and lead at Hawaii Ocean Time-series station ALOHA: Temporal variability and an intermediate water hydrothermal plume. Geochimica et Cosmochimica Acta 69, 5165 5166.

Conway, T. M., Rosenberg, A. D., Adkins, J. F., and John, S. G., in press. A new method for precise determination of iron, zinc, and cadmium stable isotope ratios in seawater by double-spike mass spectrometry. Analytica Chimica Acta.

Fitzsimmons, J. N. and Boyle, E. A., 2012. An intercalibration between the GEOTRACES GO-FLO and the MITESS/Vanes sampling systems for dissolved iron concentration analyses (and a closer look at adsorption effects). Limnology \& Oceanography: Methods 10, 437-450.

Johnson, W. K., Miller, L. A., Sutherland, N. E., and Wong, C. S., 2005. Iron transport by mesoscale Haida eddies in the Gulf of Alaska. Deep Sea Research Part II: Topical Studies in Oceanography 52, 933-953.

Lee, J.-M., Boyle, E. A., Echegoyen-Sanz, Y., Fitzsimmons, J. N., Zhang, R., and Kayser, R. A., 2011. Analysis of trace metals $(\mathrm{Cu}, \mathrm{Cd}, \mathrm{Pb}$, and $\mathrm{Fe})$ in seawater using single batch Nitrilotriacetate resin extraction and isotope dilution inductively coupled plasma mass spectrometry. Analytica Chimica Acta 686, 93-101.

Noble, A. E., Saito, M. A., Maiti, K., and Benitez-Nelson, C. R., 2008. Cobalt, manganese, and iron near the Hawaiian Islands: A potential concentrating mechanism for cobalt within a cyclonic eddy and implications for the hybrid-type trace metals. Deep-Sea Research II 55, 1473-1490.

Sedwick, P. N., Church, T. M., Bowie, A. R., Marsay, C. M., Ussher, S. J., Achilles, K. M., Lethaby, P. J., Johnson, R. J., Sarin, M. M., and McGillicuddy, D. J., 2005. Iron in the Sargasso Sea (Bermuda Atlantic Time-series Study region) during summer: Eolian imprint, spatiotemporal variability, and ecological implications. Global Biogeochem. Cycles 19, GB4006. 